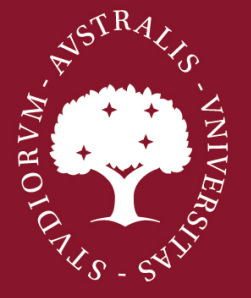

\title{
Revista Jurídica Austral
}

Publicación científica de la Facultad de Derecho de la Universidad Austral

Volumen 2. Número 2. Diciembre de 2021 Buenos Aires

Argentina 


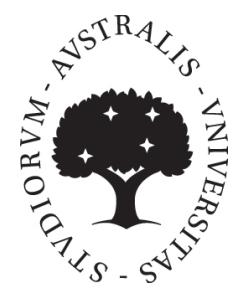

\section{Revista Jurídica Austral}

Publicación científica de la Facultad de Derecho de la Universidad Austral

Volumen 2. Número 2. Diciembre de 2021

Buenos Aires

Argentina 


\section{Equipo editorial \\ Director}

Alfonso Santiago (Universidad Austral, Argentina)

\section{Director ejecutivo}

Andrés A. Arla (Universidad Austral, Argentina)

\section{Consejo editorial}

Manuel José García-Mansilla (Universidad Austral, Argentina)

Juan B. Etcheverry (Universidad Austral, Argentina)

Ignacio E. Alterini (Universidad Austral, Argentina)

Pedro Rivas Palá (Universidad de La Coruña, España/Universidad Austral, Argentina)

\section{Comité científico}

John Finnis (Oxford University, Reino Unido)

Lawrence Solum (Georgetown University, Estados Unidos)

Alberto B. Bianchi (Universidad Católica Argentina/Universidad Austral, Argentina)

Rodolfo L. Vigo (Universidad Austral, Argentina)

Rafael Navarro Valls (Universidad Complutense de Madrid, España)

Verónica Rodríguez Blanco (Surrey University, Reino Unido)

Guillermo J. Yacobucci (Universidad Austral, Argentina)

Jesús María Silva Sánchez (Universidad Pompeu Fabra, España)

Pedro Serna (Universidad de La Coruña, España)

Andrés Ollero Tassara (Universidad Rey Juan Carlos, España)

Juan Carlos Cassagne (Pontificia Universidad Católica Argentina/Universidad de Buenos Aires, Argentina)

Isabel Trujillo (Universitá Degli Studi di Palermo, Italia)

Juan Cianciardo (Universidad de Navarra, España)

Alfonso F. Miranda Campoamor (Universidad Complutense de Madrid, España)

María Carmelina Londoño (Universidad de La Sabana, Colombia)

Jaime Rodríguez Arana Muñoz (Universidad de La Coruña, España)

Raúl Madrid Ramírez (Pontificia Universidad Católica de Chile, Chile)

Frida M. Armas Pfirter (Universidad de Buenos Aires/Universidad Austral, Argentina)

Sergio Díaz Ricci (Universidad Nacional de Tucumán, Argentina)

Encarnación Fernández Ruíz Gálvez (Universidad de Valencia, España)

Néstor P. Sagüés (Universidad de Buenos Aires/Universidad Católica Argentina/Universidad Austral, Argentina)

Carlos I. Massini-Correas (Universidad de Mendoza, Argentina)

Armando S. Andruet (Universidad Católica de Córdoba, Argentina)

Eduardo Sodero (Universidad del Litoral, Argentina)

Renato Rabbi-Baldi Cabanillas (Universidad de Buenos Aires/Universidad Católica de Salta, Argentina)

Pablo Luis Manili (Universidad de Buenos Aires, Argentina)

\section{Equipo técnico}

Lucila Scibona (edición, corrección, diagramación)

Ángeles A. Boris (coordinación y gestión de contenidos digitales)

Asistentes editoriales

María Isabel Negre y Claudia Saleme

\section{Revista Jurídica Austral}

ISSN 2684-0537

https://ojs.austral.edu.ar/index.php/juridicaaustral revistajuridicaaustral@austral.edu.ar

Tel.: 011-5239-8000

\section{Universidad Austral}

Facultad de Derecho

Sede Bs. As.: Cerrito 1250 (C1010AAZ), CABA

Sede Pilar: M. Acosta 1611 (B1629WWA), Pilar

Buenos Aires, Argentina 


\section{PresentaCIÓN}

A casi dos años de su creación, les presentamos en esta oportunidad un nuevo número de la Revista Jurídica Austral (Vol. 2, N² 2, diciembre de 2021), el cual nos enorgullece y nos llena de satisfacción.

Tanto las autoridades de la Revista como los miembros del Consejo Editorial, del Comité Científico y del Equipo Técnico procuramos en todo este tiempo brindarles a nuestros lectores los mejores contenidos académicos, que se definen por un alto nivel de exigencia, generado en el marco de un proceso de gestión editorial que se caracteriza por las notas de transparencia, control y calidad. Al mismo tiempo, hemos logrado obtener una mayor visibilidad para que dichos contenidos y los autores que nos confían sus manuscritos puedan ser consultados en la mayor cantidad de portales digitales, bibliotecas, bases de datos, índices, catálogos y repositorios institucionales. De esta manera, durante el corriente año hemos obtenido diversas inclusiones e indexaciones en espacios de prestigio iberoamericano e internacional, y en especial en el European Reference Index for the Humanities and Social Sciences (ERIHPLUS); Citas Latinoamericanas en Ciencias Sociales y Humanidades de la Universidad Autónoma de México (CLASE, UNAM); Directory of Open Access Journal (DOAJ); Dialnet (Universidad de La Rioja, España) y en el Catálogo 2.0 de Latindex (Sistema Regional de Información en Línea para Revistas Científicas de América Latina, el Caribe, España y Portugal), cuyo centro de acopio funciona bajo la órbita del CAYCYT-CONICET de la República Argentina. Este último organismo, además, ha calificado a la Revista Jurídica Austral con la máxima puntuación que se les asigna a las revistas científicas digitales, a partir del cumplimiento de ciertos criterios de calidad editorial previamente establecidos $(38 / 38)$.

En este número que nos toca presentar, destacamos en la primera sección la erudita investigación del reconocido profesor argentino de Derecho Constitucional, académico Dr. Alberto B. Bianchi, sobre la historia del Congreso de los Estados Unidos (una primera parte que abarca desde su creación hasta la crisis de 1930). También les recomendamos a los lectores el trabajo de investigación y análisis acerca de la evolución de los derechos humanos en la jurisprudencia del TEDH, realizado por Lawrence R. Helfer (Professor of Law, Duke University School of Law) y Erik Voeten (Professor of Geopolitics and Justice in World Affairs, Edmund A. Walsh School of Foreign Service, Georgetown University, USA): "Walking Back Human Rightsin Europe?". Creemos importante subrayar también los artículos de los profesores Ignacio Cofone (Mac Gill University): "Los límites de la causalidad probabilística en derecho", Fernando D. Álvarez Álvarez (Universidad Católica Argentina y Universidad Austral, Argentina): "El problema de la dificultad contramayoritaria de la justicia constitucional desde la 
perspectiva de la legitimidad de reflexividad en Pierre Rosanvallon”, y las valiosas contribuciones académicas del Mag. Adriel Fernández Santander (Universidad Austral, Argentina): "Asociaciones civiles, tutela individual homogénea y las facultades reglamentarias de la Corte Suprema de Justicia de la Nación" y del profesor Leonardo J. Ambesi (titular del Departamento de Derecho del Trabajo de la Facultad de Derecho de la Universidad Austral, Argentina): "La discriminación por razones gremiales como diferencia funcional y su impacto en el sistema jurídico sindical argentino".

En la segunda sección, el entrañable profesor y titular del Departamento de Magistratura y Derecho Judicial de nuestra casa, académico Dr. Rodolfo Luis Vigo, nos ilumina una vez más con un análisis comparativo entre las propuestas de Ronald Dworkin y John Finnis, bajo el título "¿Hay una respuesta correcta para cada caso jurídico? Dworkin versus Finnis”. Luego, en un estudio acerca de la necesidad de revalorizar o pensar el derecho a la educación desde lugares que exceden la dimensión jurídica, Noelia Gutiérrez Herrera y María Laura Barbado formulan una propuesta atractiva en su trabajo "La educación es el camino". Por último, Agustín López Olocco (Universidad de Córdoba) realiza un análisis particular sobre la autonomía municipal -tema muy en boga en estos tiempos- a partir del fallo de la Corte Suprema de Justicia de Santa Fe Municipalidad de Esperanza c/Provincia de Santa Fe.

En la tercera sección, Florencia Ratti Mendaña y Sofía Caderone (Universidad Católica Argentina) efectúan una minuciosa recensión del libro del profesor académico Dr. Alfonso Santiago Principio de subsidiariedad y margen nacional de apreciación. Articulación del sistema interamericano de protección de derechos humanos con los regímenes nacionales (Buenos Aires, Astrea, 2020).

En el mismo espacio editorial, nos acompaña también con una reseña de lujo el querido y destacado profesor y filósofo del derecho argentino, Dr. Carlos Ignacio Massini-Correas, con un trabajo realizado a partir de la obra de Francisco José Contreras, titulado Una defensa del liberalismo conservador (Madrid, Unión Editorial/Centro Diego de Covarrubias, 2018).

Por último, se destaca también la recensión de la obra de Jeremy Waldron Contra el gobierno de los jueces (Buenos Aires, Siglo XXI, 2018), elaborada por Angello Javier Peña Barrios (Universidad de Los Andes, Venezuela).

Buenos Aires, diciembre de 2021

Académico Dr. Alfonso Santiago

Director
Mg. Andrés Arla

Director ejecutivo 


\section{AgRADECIMIENTO ESPECIAL A LOS REVISORES EXTERNOS}

Desde la edición del primer volumen, hemos adoptado como norma expresar un agradecimiento especial a todos los revisores externos que nos prestan una generosa y desinteresada colaboración, de forma tal que esas contribuciones, tan necesarias y particularmente valiosas, no queden sin el reconocimiento que se merecen.

Por su participación en los números 1 y 2 del Volumen 2, año 2021, les agradecemos a:

Carola Bottini

Carlos Aldao Zapiola

Claudio Aquino

Esteban Carcavallo

Estela Sacristán

Gastón González

Jerónimo Lau Alberdi

Jorge Nicolás Lafferriere

Jorge Aquino

José María Orelle

Marcela S. Molina

\author{
María Carlota Ucín \\ Mario Laporta \\ Miguel Araya \\ Miriam Ivanega \\ Oscar Ramos Rivera \\ Ricardo Ramírez Calvo \\ Santiago Finn \\ Sebastián Balbín \\ Sebastián J. Cosola \\ Sergio Díaz Ricci
}





\section{Artículos de investigación}

323 El Congreso de los Estados Unidos. Desde sus inicios hasta la crisis de 1930 Alberto B. Bianchi

$445 \quad$ ¿El retroceso de los derechos humanos en Europa? Laurence R. Helfer - Erik Voeten

491 El problema de la dificultad contramayoritaria de la justicia constitucional desde la perspectiva de la legitimidad de reflexividad en Pierre Rosanvallon Fernando D. Álvarez Álvarez

515 Los límites de la causalidad probabilística en derecho Ignacio N. Cofone

551 Asociaciones civiles, tutela individual homogénea y las facultades reglamentarias de la Corte Suprema de Justicia de la Nación Adriel Fernández Santander

603 La discriminación por razones gremiales como diferencia funcional y su impacto en el sistema jurídico sindical argentino

Leonardo J. Ambesi

\section{Análisis, crónicas y comentarios}

629 ¿Hay una respuesta correcta para cada caso jurídico? Dworkin versus Finnis Rodolfo L. Vigo

639 La educación es el camino

Noelia Gutiérrez Herrera - María Laura Barbado

659 Autonomía municipal en el fallo: Municipalidad de Esperanza c/Provincia de Santa Fe. Corte Suprema de Justicia de Santa Fe

Agustín López Olocco

\section{Recensiones}

677 Una defensa del liberalismo conservador de Francisco José Contreras

Carlos I. Massini-Correas

681 Principio de subsidiariedad y margen nacional de apreciación. Articulación del sistema interamericano de protección de derechos humanos con los regímenes nacionales de Alfonso Santiago Florencia Ratti - Sofía Calderone

689 Contra el gobierno de los jueces de Jeremy Waldron

Angello Javier Peña Barrios 
Sobre los autores

695

Normas editoriales

701 
ArtículOS de INVESTIGACIÓN 



\title{
El Congreso de los Estados Unidos. DESDE SUS INIIIOS HASTA LA CRISIS DE 1930
}

\section{Alberto B. Bianchi}

\author{
Universidad Austral. Universidad Católica Argentina \\ ab@bgcv.com.ar
}

Recibido: 02/08/2021

Aprobado: 24/10/2021

\section{Resumen}

Este trabajo resume la historia del Congreso de los Estados Unidos desde sus orígenes coloniales hasta la crisis económica de 1930. Se analiza en primer lugar cómo se diseñó el Congreso en la Convención Constituyente, las luchas internas que se produjeron en esta que dieron origen a un Congreso bicameral y cómo fue interpretado inicialmente el texto constitucional en El Federalista. Luego, la historia propiamente dicha del Congreso -desde su instalación en 1789 hasta la crisis de 1930- está dividida en cinco capítulos que intentan poner de manifiesto la impronta política existente en el Congreso en cada uno de ellos. Se muestra, así, la manera en la que cada partido ha influido en el Congreso según las mayorías que cada uno de ellos ha tenido alternativamente. Se destaca también la sanción de algunas leyes fundamentales, las enmiendas constitucionales que han influido en el diseño o formación del Congreso y se mencionan las figuras de los principales líderes políticos que han predominado en ambas cámaras en cada época. Asimismo, se muestra la evolución, conformación y crecimiento de cada cámara a lo largo del siglo y medio que abarca este estudio, a partir de las circunstancias políticas y económicas que se han presentado en cada época.

Palabras clave: Constitución, Convención Constitucional, Congreso, Speaker, Cámara de Representantes, Senado, partidos políticos, líderes políticos, comisiones, reglamentos, distribución distrital, legislador, elección, filibuster.

\section{The United States Congress. From the Beginnings to the 1930's Crisis}

\author{
Abstract \\ This paper contains a summarized history of the U.S. Congress, from its colonial inception \\ until the economic crisis of 1930. It analyses first how Congress was designed at the Constitu-
}


tional Convention, the internal disagreements within the Convention that eventually gave rise to a bicameral Congress, and the manner how the Constitution was initially interpreted at The Federalist. Then, the history of Congress itself, from its creation in 1789 until the economic crisis of 1930, has been divided into five chapters designed to reflect the political influences prevailing in Congress at each such stage. This structure shows the manner how Congress has been influenced by each political party, depending on the majorities held by each at different times. Additionally, reference is made to some fundamental laws, the constitutional amendments that have influenced the design or structure of Congress, as well as some prominent political leaders from both Chambers of Congress at different times in history. This paper also includes a description of the evolution, structure and growth of each Chamber in the 150-year period covered here, in line with the political and economic circumstances prevailing at different times.

Key words: Constitution, Constitutional Convention, Congress, Speaker, House Senate, political parties, political leaders, committee, rules, apportionment, legislator, election, filibuster.

Well, Doctor, what have we got - a Republic or a Monarchy? Benjamin Franklin: A Republic, if you can keep it.

\section{Índice}

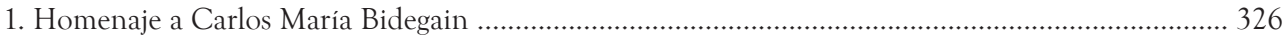

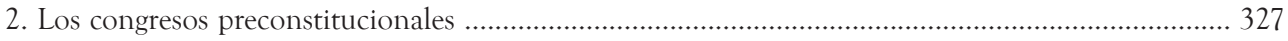

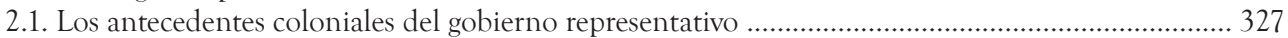

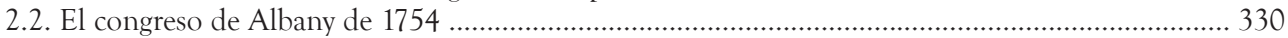

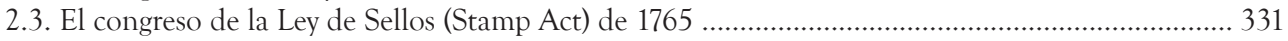

2.4. El primer Congreso Continental ............................................................................................. 332

2.5. El Segundo Congreso Continental, los Artículos de la Confederación y el Congreso

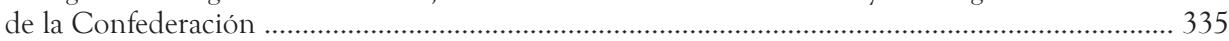

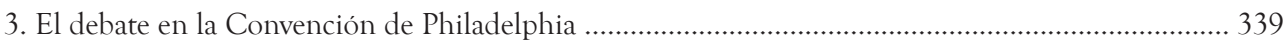

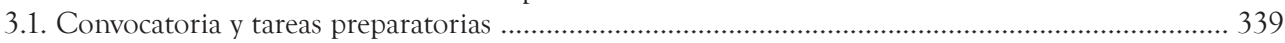

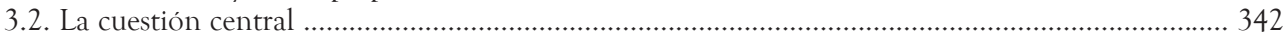

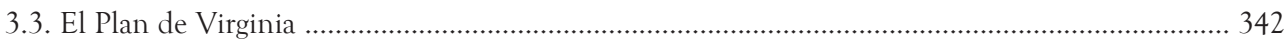

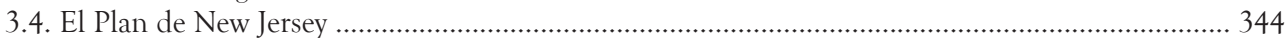

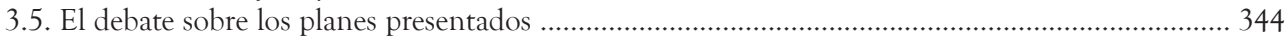

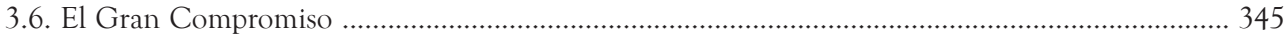

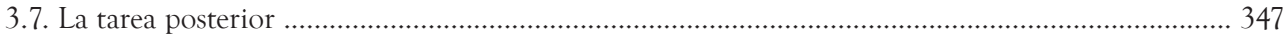

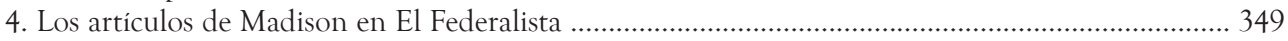

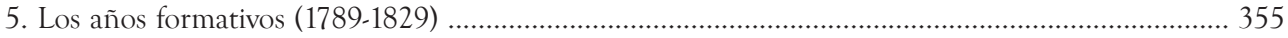

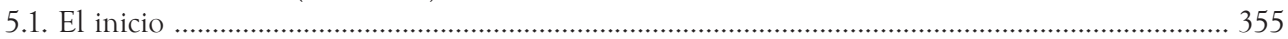

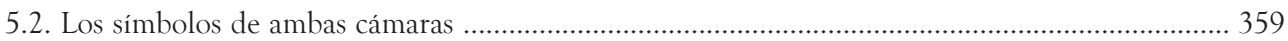

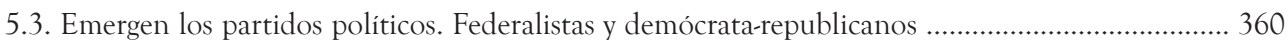

5.4. El reparto del poder entre el Ejecutivo y el Congreso ..................................................................... 361 


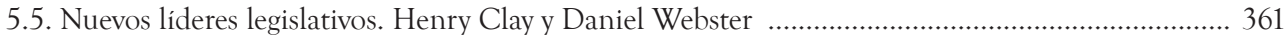

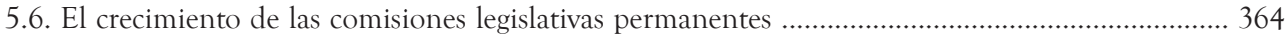

5.7. La Corte Suprema colabora para fortalecer al Congreso ............................................................ 365

5.8. La elección de 1824 y el nacimiento del Partido Demócrata ............................................................. 366

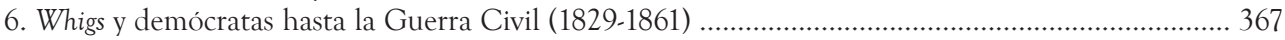

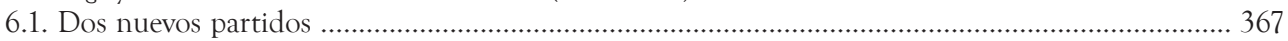

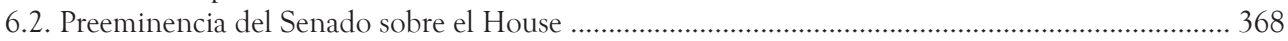

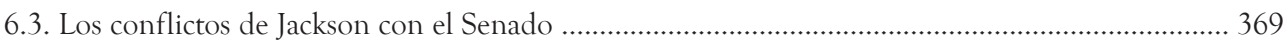

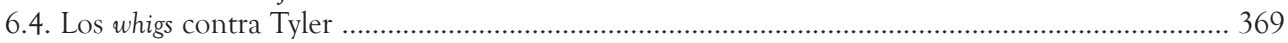

6.5. Los acuerdos legislativos sobre la distribución geográfica de la esclavitud ...................................... 370

6.6. Las contiendas en el House por la designación del Speaker .......................................................... 372

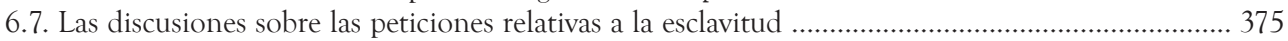

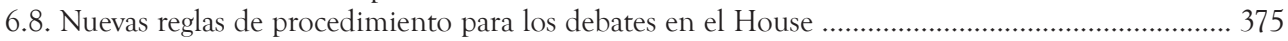

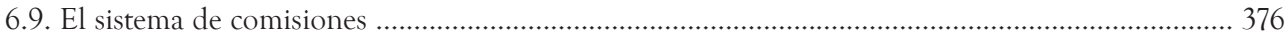

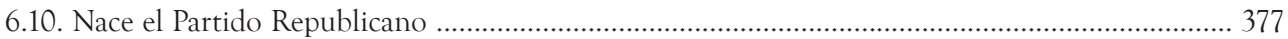

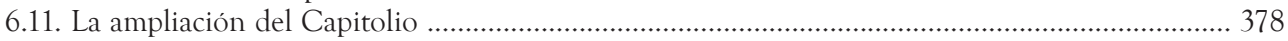

7. La Guerra Civil y la Reconstrucción (1861-1877) .................................................................................. 379

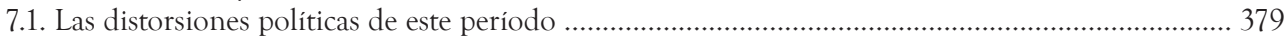

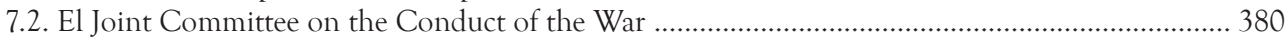

7.3. Los republicanos radicales y sus conflictos con Andrew Johnson ............................................... 381

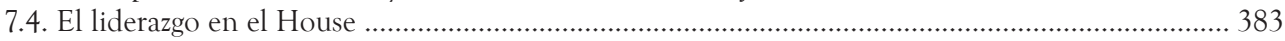

7.5. El Joint Committee on Reconstruction y la legislación derivada de la Guerra Civil ..................... 383

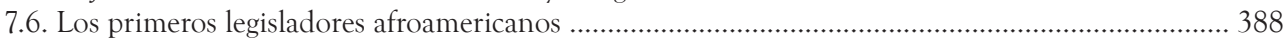

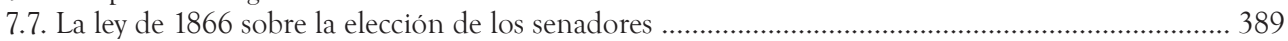

7.8. La elección presidencial de 1876, el Compromiso de 1877 y el fin de la Reconstrucción .............. 390

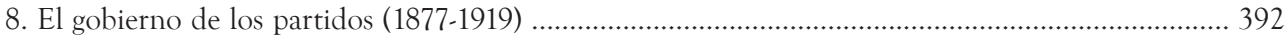

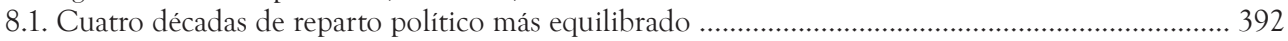

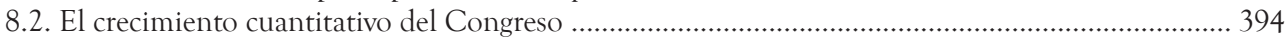

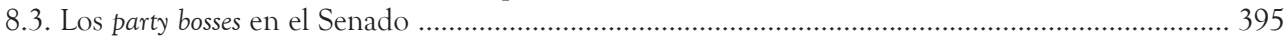

8.4. La práctica del filibuster en el Senado y el Cloture Rule ............................................................... 397

8.5. El caso Kilbourn v. Thompson y la revisión de las investigaciones del Congreso ............................... 399

8.6. La centralización del poder del Speaker. Thomas B. Reed y Joseph G. Cannon ............................. 400

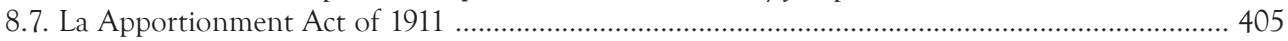

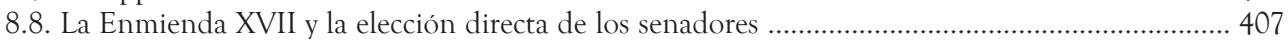

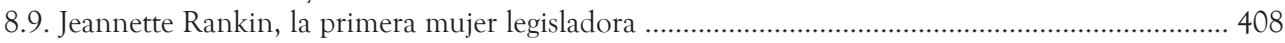

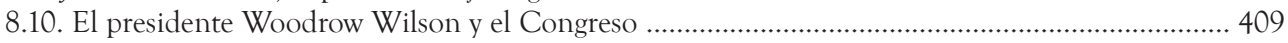

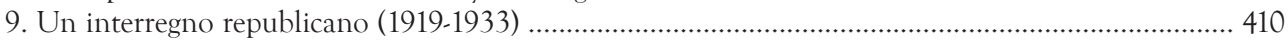

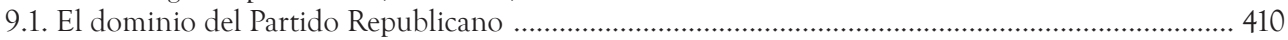

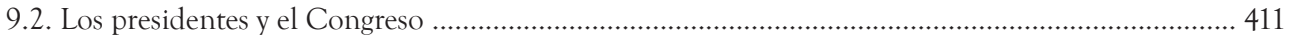

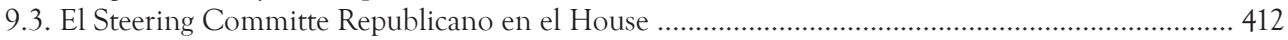

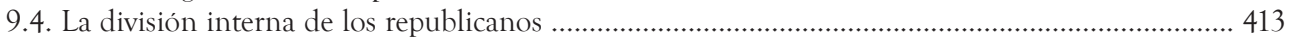

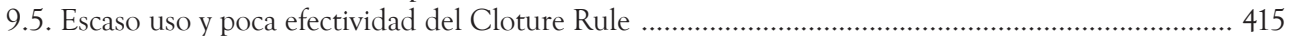

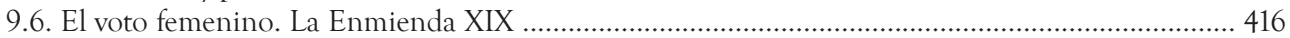

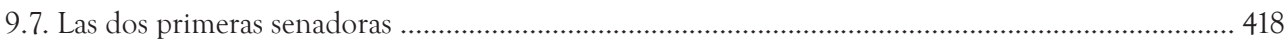

9.8. La Corte Suprema fortifica el poder de las comisiones legislativas de investigación ..................... 419

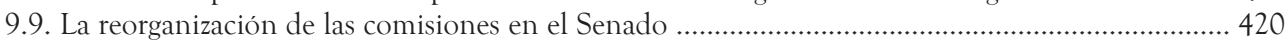

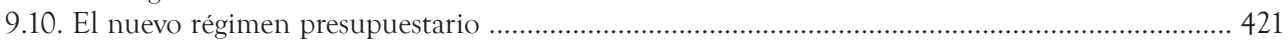

9.11. El debate sobre el aumento y redistribución de las bancas en el House. La Permanent

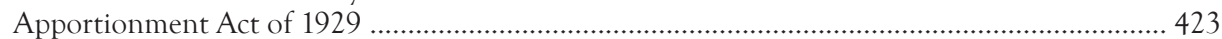

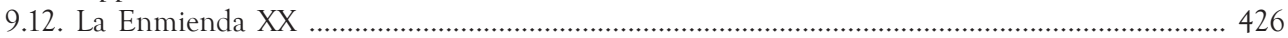

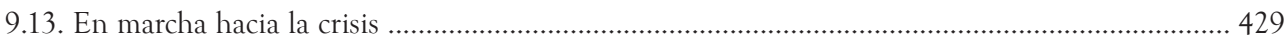

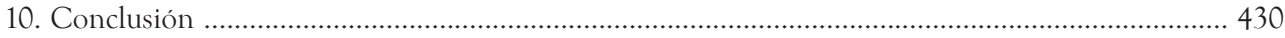




\section{Homenaje a Carlos María Bidegain}

En 1950, Carlos María Bidegain publicó una obra extraordinaria sobre el Congreso de los Estados Unidos. Fue su tesis doctoral, un trabajo de juventud que daba testimonio de la temprana madurez intelectual de su autor. Su extensión y profundidad excedía en mucho los alcances de una investigación de ese tipo, tal como señaló con razón Linares Quintana al prologarla. Laureada con el premio Montes de Oca a la mejor tesis de derecho constitucional y recomendada al Premio Facultad, desde entonces no se ha vuelto a escribir sobre este tema en nuestro país, al menos en forma orgánica y con tal intensidad.

Me ha parecido por ello de toda justicia, al comenzar este estudio, rendir un breve, pero muy sincero y sentido, homenaje al trabajo y a su autor, que ha sido uno de los grandes constitucionalistas argentinos. ${ }^{1}$ En sus Palabras Preliminares, Bidegain dice que "los propósitos y el esfuerzo han sido considerablemente superiores al resultado que queda expuesto", pero ello no es más que una muestra de su proverbial humildad y sencillez, dos notas que lo caracterizaban. Si bien tuve pocas oportunidades de tratarlo personalmente, lo que lamento, no me quedan dudas de que era una auténtica persona de bien y un jurista eximio.

Pasadas siete décadas de su publicación, la tesis de Bidegain -un verdadero tratado, como lo calificó su prologuista- sigue siendo una obra sin dudas relevante por su erudición y claridad, cuya consulta al estudiar el Congreso de los Estados Unidos es indispensable todavía para el mundo de habla hispana. Es por ello que con ese trabajo deseo cumplir -dentro de mis posibilidades y limitaciones- con la exhortación que Bidegain formuló en sus Palabras Preliminares: "Estimular la realización de estudios de derecho parlamentario en nuestro país”.

1 Nacido en Buenos Aires en 1916, se graduó de abogado en la Facultad de Derecho y Ciencias Sociales de la Universidad de Buenos Aires en 1938 y de doctor en Jurisprudencia en la misma Universidad en 1950. Fue también Master of Laws in Comparative Law, graduado "Magna cum Lauda" en el Law Institute of The Americas, SMU, Dallas, Texas (1954-1955). Fue procurador del Tesoro de la Nación (1960-1962) y profesor titular de Derecho Constitucional en la Universidad Católica Argentina (1964-1984). Fue miembro de número de la Academia Nacional de Ciencias Morales y Políticas y de la Academia Nacional de Derecho y Ciencias Sociales y miembro correspondiente de la Real Academia de Ciencias Morales y Políticas de España y de la Academia Chilena de Ciencias Sociales, Políticas y Morales. En 2006 recibió el Premio Konex. Su obra es extensa, señalo tan solo, además de su estudio sobre el Congreso de los Estados Unidos, el Curso de Derecho Constitucional en cinco volúmenes, cuya última edición (2001) fue preparada en colaboración con los profesores Eugenio L. Palazzo, Orlando Gallo, Roberto Punte y Guillermo C. Schinelli. Falleció en septiembre de 2016, cuando ya había cumplido 101 años. 


\section{Los congresos preconstitucionales}

\subsection{Los antecedentes coloniales del gobierno representativo}

A diferencia de la América española, donde la organización colonial era rígida, uniforme y muy estructurada, ${ }^{2}$ la Corona británica no tenía un sistema de gobierno uniforme para sus colonias y muchas de ellas nacieron, a lo largo del siglo XVII, como una iniciativa privada de naturaleza comercial, como Virginia, o bien tuvieron como origen la llegada de emigrados religiosos, como Massachusetts. Cada una de ellas tuvo, como acta de nacimiento formal, una carta real otorgada en diferentes momentos, pero en modo alguno este conglomerado colonial constituyó una unidad política, sino más bien un grupo de emprendimientos independientes, de variado tipo, desarrollados inicialmente por particulares bajo reglas propias. Algunas de ellas, hacia fines del siglo XVII y comienzos del XVIII, se convirtieron formalmente en colonias reales, otras permanecieron como colonias particulares hasta la Independencia. ${ }^{3}$

No entraré en los detalles históricos de la fundación y desarrollo de cada colonia, pues ello es ajeno a este trabajo. Por lo demás, la literatura sobre este tema es muy abundante. Uno de los primeros en exponerlo fue Joseph Story en sus Commentaries... ${ }^{4}$ Sin embargo, es importante tener presente que en todas las colonias existía alguna forma, aunque rudimentaria, de gobierno representativo. ${ }^{5}$

Story -siguiendo a Blackstone (1 Bl Comm 108)- clasifica a las colonias en tres grupos: (a) Gobiernos o establecimientos provinciales; (b) Gobiernos de propietarios (propietary governments); y (c) Gobiernos de la carta real (charter governments). En las primeras, el rey designaba como autoridad ejecutiva a un gobernador, denominado "capitán general”, quien recibía una comisión real y era el representante del soberano en la colonia. La comisión real incluía, entre otras previsiones, la de convocar a una asamblea compuesta de dos estamentos: el del gobernador y su consejo y el de los representantes de los propietarios de

2 Basta pensar que la Corona española tenía órganos de gobierno específico para todo el Gobierno colonial, como el Consejo de Indias o la Casa de Contratación de Sevilla, creados a comienzos del siglo XVI para asesorar políticamente al rey y controlar el comercio, respectivamente. Sumado a ello, toda la legislación indiana estaba recopilada y ordenada en verdaderos códigos, como fueron la Recopilación de 1680 y la Novísima Recopilación de 1805.

3 En el Anexo I (p. 433) explico brevemente el origen histórico de algunas de ellas.

4 Vid. Story (1858, caps. I-XVII).

5 Coincido con Bidegain (1950) en que "[l]a herencia política inglesa y las tempranas prácticas del régimen representativo contenían en potencia los elementos básicos sobre los que habría de edificarse la actual democracia norteamericana" (p. 20, nota al pie 1), aunque también tiene razón este autor en señalar que lejos estaba por entonces la existencia de un régimen democrático con los estándares de hoy día, pues la esclavitud era una institución legal y el derecho de voto era un privilegio de muy pocos. 
tierras y granjeros. Estas asambleas tenían poder para legislar en asuntos locales, sus leyes u ordenanzas no podían contradecir las leyes inglesas y estaban sujetas a la aprobación de la Corona. ${ }^{6}$ Dentro de esta categoría, al momento de producirse la revolución, existían 7 colonias: New Hampshire, New York, New Jersey, Virginia, North Carolina, South Carolina y Georgia. En el segundo grupo, el de los Gobiernos de propietarios (propietary goverments), un individuo particular recibía de la Corona una concesión para administrar la colonia. Este designaba al gobernador de la colonia y convocaba a las asambleas legislativas. Las colonias organizadas bajo esta modalidad fueron Maryland, Pennsylvania y Delaware. ${ }^{7}$ Por último, en los charter governments, la organización era bastante similar a la de los Gobiernos provinciales. Había tres colonias organizadas de esta manera: Massachusetts, Rhode Island y Connecticut. ${ }^{8}$ Story (1858) aclara que en los Gobiernos de propietarios y en los de la carta real, el derecho a ser gobernado por las leyes de la legislatura local fue reconocido como un principio fundamental. En los Gobiernos provinciales, en cambio, la cuestión estaba en debate. En opinión de los colonos, este era un derecho propio, en cambio, según la Corona, se trataba de un privilegio otorgado discrecionalmente. ${ }^{9}$

Sin perjuicio de la clasificación mencionada, existían diferencias específicas que ponen de manifiesto el mosaico legal del sistema colonial inglés y la ausencia de conexión entre las diferentes colonias, pese a que todas estaban sometidas a la misma autoridad central. ${ }^{10}$ Así, en Maryland, Connecticut y Rhode Island, las leyes locales no requerían la aprobación real; en Rhode Island y Connecticut, el gobernador no tenía poder de veto sobre las leyes locales; en Pennsylvania, el consejo del gobernador no vetaba las leyes locales, pues ejercía una función meramente consultiva del gobernador; y en Massachusetts, el consejo era elegido por la legislatura, pero el gobernador podía vetar a los candidatos. ${ }^{11}$

6 Story (1858, vol. I, § 159, p. 107).

7 Story $(1858, \S 160$, p. 108).

8 Story $(1858, \S 161$, p. 109).

9 Story $(1858, \S 167$, p. 113).

10 Según explica Story (1858): "Though the colonies had a common origin, and owed a common allegiance, and the inhabitants of each were British subjects, they had no direct political connexion with each other. Each was independent of all the others; each, in a limited sense, was sovereign within its own territory. There was neither alliance nor confederacy between them. The assembly of one province could not make laws for another; nor confer privileges, which were to be enjoyed or exercised in another, farther than they could be in any independent foreign state. As colonies, they were also excluded from all connexions with foreign states. They were known only as dependencies; and they followed the fate of the parent country both in peace and war, without having assigned to them, in the intercourse or diplomacy of nations, any distinct or independent existence” (§ 177, p. 122).

11 Story $(1858, \S 171$, pp. 118-119). 
Estas diferencias en la estructura legal de cada colonia y la independencia y separación entre ellas con el tiempo se convirtieron en una gran desventaja, pues les impedían o dificultaban formar lazos comunes o confederarse de manera estable, con miras a presentar un frente común para formular reclamos al Gobierno de Londres. ${ }^{12}$ Todo ello fue gestando gradualmente en las colonias la idea de que debían unirse como medio para proteger sus derechos frente a los abusos de la Corona, de la política mercantilista ${ }^{13} \mathrm{y}$, en particular, de la presión tributaria, que fue finalmente la que desencadenó la Revolución, aunque sus causas no fueron puramente económicas. ${ }^{14}$ Fue así que, desde mediados de la década de 1750 y por espacio de poco más de veinte años, los colonos norteamericanos se reunieron formalmente en cuatro oportunidades: el congreso de

12 Señala Story (1858) que "[t]hey did not possess the power of forming any league or treaty among themselves, which should acquire an obligatory force without the assent of the parent state. And though their mutual wants and necessities often induced them to associate for common purposes of defence, these confederacies were of a casual and temporary nature, and were allowed as an indulgence, rather than as a right. They made several efforts to procure the establishment of some general superintending government over them all; but their own differences of opinion, as well as the jealousy of the crown, made these efforts abortive" (§ 177, p. 122).

13 El mercantilismo fue el arma económica de los Estados nacionales en los siglos XVII y XVIII. Perseguía como objetivo principal la autosuficiencia económica y la prosperidad para el Estado, el cual, a los efectos comerciales, era concebido como un individuo, por lo que resultaba particularmente importante la obtención de un balance favorable de intercambio comercial, ya que si se exportaban más mercaderías de las que eran importadas, más aumentaba el poder económico de la nación. Al igual que Inglaterra, las otras potencias europeas también deseaban un balance favorable en el intercambio con sus colonias, de modo que estas eran empleadas por las metrópolis para producir las materias primas esenciales a bajo costo y proporcionar un mercado ilimitado que absorbiese el sobrante de productos manufacturados, ofreciendo nula competencia económica. Véase Schumpeter (1971, cap. 7).

14 En paralelo con el levantamiento económico en contra de Gran Bretaña, las colonias comenzaron a desarrollar un movimiento de protesta de tono religioso. Hacia 1750, tuvo lugar el llamado Gran Despertar (The Great Awakening), caracterizado por el resurgimiento de las corrientes calvinistas y de su énfasis evangelizador, que tuvo una marcada influencia en el desencadenamiento de la Revolución norteamericana. Tal como explica Paul Johnson (1997, p. 110), en su momento este movimiento no tuvo conciencia de sí mismo ni puede establecerse una fecha para su comienzo o su fin. De hecho, el nombre que recibe le fue dado por Joseph Tracey en un best seller llamado The Great Awakening: a History of the Revival of Religion in the Times of Edwards and Whitefield, publicado en 1842. Sin perjuicio de ello, durante los años previos a la Revolución, estas posturas desembocaron en una encendida defensa de la necesidad de la rebelión y la prédica de los clérigos llegó a ser una punta de lanza del movimiento general de oposición a Gran Bretaña. El reverendo John J. Zubly, en su obra The Law of Liberty, señalaba que si el Evangelio era una ley de libertad, oponerse a este principio era contravenir la voluntad de Dios. Entonces, aquellos que menospreciaban las libertades de los colonos, aquellos que negaban sus derechos -es decir, Inglaterra- atacaban la ley fundamental de Dios. De ese modo, la resistencia a la política inglesa se concebía como la única vía para apartarse de la cólera divina. El parlamento inglés, con su política de opresión económica, había ofendido al Señor y la transgresión de los pactos y cartas originales eran crímenes en contra de Dios. Incluso se llegó a afirmar que el propio rey Jorge III estaba instigado por el demonio. Sobre este tema puede verse Gaustad (1968). 
Albany, el congreso de la Ley de Sellos y los dos Congresos Continentales. De estos, el más importante fue el segundo, pues durante sus sesiones se aprobó la Declaración de la Independencia y fueron sancionados los Artículos de la Confederación, que dieron origen al Congress of the Confederation, el primer órgano legislativo estable que tuvieron los Estados Unidos.

\subsection{El congreso de Albany de 1754}

En 1754, por inspiración de Benjamin Franklin, las colonias decidieron reunirse en una asamblea general para discutir, entre otros asuntos, la defensa de la frontera norte contra los franceses y sus aliados los indígenas. No estaba todavía en la agenda de este congreso la lucha en contra de Inglaterra ni menos aún la independencia, pero no hay dudas de que esta asamblea es uno de los hitos de ese camino.

Se reunió en la ciudad de Albany, en los meses de junio y julio de 1754, donde se congregaron delegados de siete colonias: Connecticut, Maryland, Massachusetts, New Hampshire, New York, Pennsylvania y Rhode Island. De este congreso surgió el llamado Albany Plan of Union, ${ }^{15}$ redactado por Franklin y Thomas Hutchinson, ${ }^{16}$ en el cual sustancialmente se le proponía al Parlamento inglés el dictado de una ley que creara autoridades centrales, dando forma a una suerte de confederación colonial. ${ }^{17}$ La idea era que existiera un presidente general elegido por un Gran Consejo, elegido a su vez por representantes del pueblo de las colonias ${ }^{18}$ y en el cual cada una de ellas tendría un número proporcional de representantes, que se reuniría por primera vez en Philadelphia y se renovaría cada tres años. ${ }^{19}$ El Consejo tenía autoridad legislativa para regular

15 Su texto puede verse en: https://avalon.law.yale.edu/18th_century/albany.asp.

16 Vid. Morison et al. (1980, p. 114).

17 "It is proposed that humble application be made for an act of Parliament of Great Britain, by virtue of which one general government may be formed in America, including all the said colonies, within and under which government each colony may retain its present constitution, except in the particulars wherein a change may be directed by the said act, as hereafter follows".

18 "That the said general government be administered by a President-General, to be appointed and supported by the crown; and a Grand Council, to be chosen by the representatives of the people of the several Colonies met in their respective assemblies".

19 "That within - months after the passing such act, the House of Representatives that happen to be sitting within that time, or that shall especially for that purpose convened, may and shall choose members for the Grand Council, in the following proportion [...] who shall meet for the first time at the city of Philadelphia, being called by the President-General as soon as conveniently may be after his appointment". 
el comercio con los indígenas y establecer nuevos asentamientos. Sus leyes, que no podían contradecir la legislación inglesa, debían ser aprobadas por el rey y su consejo y quedaban tácitamente aprobadas luego de tres años de requerida su aprobación. ${ }^{20}$

\subsection{El congreso de la Ley de Sellos (Stamp Act) de 1765}

Diez años después del congreso de Albany, las colonias se reunieron nuevamente en una asamblea similar convocada en New York, ${ }^{21}$ pero esta vez con motivo de la protesta general levantada contra el impuesto de sellos creado por la Stamp Act de 1765 para sufragar los gastos ocasionados por la llamada French and Indian War. La asamblea tuvo lugar en octubre de 1765 con la participación de 27 delegados de 9 colonias, ${ }^{22}$ bajo la presidencia de Timothy Ruggles de Massachusetts. El congreso aprobó una Declaración de Derechos y Agravios (Declaration of Rights and Grievances), reclamando para sí, en primer lugar, las mismas libertades que las que gozaban los súbditos ingleses que vivían en Inglaterra. ${ }^{23}$ Reafirmaron luego el principio de legalidad en materia tributaria ${ }^{24}$ y la necesidad de regularse a sí mismos en materia impositiva. ${ }^{25}$ Criticaron específicamente el impuesto de sellos creado, ${ }^{26}$ reclamaron la aplicación del juicio

20 "That the laws made by them for the purposes aforesaid shall not be repugnant, but, as near as may be, agreeable to the laws of England, and shall be transmitted to the King in Council for approbation, as soon as may be after their passing; and if not disapproved within three years after presentation, to remain in force".

21 Se reunieron en el llamado Federal Hall, al sur de Manhattan en la zona de Wall Street.

22 No estuvieron presentes Georgia, North Carolina, New Hampshire y Virginia.

23 "That His Majesty's liege subjects in these colonies, are entitled to all the inherent rights and liberties of his natural born subjects within the kingdom of Great-Britain".

24 "That it is inseparably essential to the freedom of a people, and the undoubted right of Englishmen, that no taxes be imposed on them, but with their own consent, given personally, or by their representatives".

25 "That the only representatives of the people of these colonies, are persons chosen therein by themselves, and that no taxes ever have been, or can be constitutionally imposed on them, but by their respective legislatures".

26 "That the late Act of Parliament, entitled, An Act for granting and applying certain Stamp Duties, and other Duties, in the British colonies and plantations in America, etc., by imposing taxes on the inhabitants of these colonies, and the said Act, and several other Acts, by extending the jurisdiction of the courts of Admiralty beyond its ancient limits, have a manifest tendency to subvert the rights and liberties of the colonists". 
por jurados,${ }^{27}$ el ejercicio del derecho de petición ${ }^{28}$ y señalaron que la situación económica creada con la carga impositiva que debían soportar no les permitiría seguir comprando mercaderías en Gran Bretaña. ${ }^{29}$

\subsection{El primer Congreso Continental}

A pesar de estos reclamos, la política británica hacia sus colonias no cambió en absoluto. La Corona y el Parlamento hicieron oídos sordos a estos reclamos y continuaron con la creciente imposición de gravámenes hasta que, en diciembre de 1773, se produjo el famoso Boston Tea Party, que terminó con un cargamento de té arrojado a las aguas del puerto de Boston como repudio contra la llamada Ley del Té (Tea Act 1773) que le otorgaba a la East India Company un monopolio para vender té en las colonias como medio de auxiliar financieramente a la compañía y reducir el contrabando de té holandés. ${ }^{30}$ La respuesta inmediata del Gobierno británico fue la sanción de las llamadas Leyes Intolerables (Intolerable Acts), entre las cuales se dispuso clausurar el puerto hasta que los bostonianos pagaran el té que habían destruido, ${ }^{31}$ se eliminó el derecho de los colonos de Massachusetts a elegir representantes en la asamblea, se le otorgaron amplios poderes al gobernador ${ }^{32}$ y se dispuso que los funcionarios británicos que reprimieran las protestas o se encargaran del cobro de los im-

27 "That trial by jury is the inherent and invaluable right of every British subject in these colonies".

28 "That it is the right of the British subjects in these colonies, to petition the King, Or either House of Parliament. Lastly, That it is the indispensable duty of these colonies, to the best of sovereigns, to the mother country, and to themselves, to endeavour by a loyal and dutiful address to his Majesty, and humble applications to both HoU.S.es of Parliament, to procure the repeal of the Act for granting and applying certain stamp duties, of all clauses of any other Acts of Parliament, whereby the jurisdiction of the Admiralty is extended as aforesaid, and of the other late Acts for the restriction of American commerce".

29 "That the duties imposed by several late Acts of Parliament, from the peculiar circumstances of these colonies, will be extremely burthensome and grievous; and from the scarcity of specie, the payment of them absolutely impracticable. That as the profits of the trade of these colonies ultimately center in Great-Britain, to pay for the manufactures which they are obliged to take from thence, they eventually contribute very largely to all supplies granted there to the Crown".

30 La protesta no estaba directamente relacionada con el monopolio, sino con el impuesto con el cual el té estaba gravado como consecuencia de las Townshend Acts, un conjunto de leyes impositivas impulsadas por Charles Townshend, ministro de economía (Chancellor of the Exchequer) del rey Jorge III. Los colonos sostenían que el pago del impuesto violaba el principio de legalidad tributaria.

31 The Boston Port Act (marzo de 1774).

32 The Massachusetts Government Act (mayo de 1774). 
puestos no serían juzgados por los tribunales de Massachusetts, sino por los de otra colonia o bien por los tribunales ingleses. ${ }^{33}$

Comenzó entonces a organizarse la resistencia a estas leyes y se propuso reunir una convención similar a las dos anteriores. Esta tuvo lugar en el Carpenter's Hall de Philadelphia entre el 5 de septiembre y el 26 de octubre de 1774 y fue luego conocida como el Primer Congreso Continental. Asistieron representantes de todas las colonias, con excepción de Georgia. Lo presidió Peyton Randolph de Virginia y entre sus miembros se encontraban algunos de los que serían luego los padres fundadores de los Estados Unidos, tales como Samuel y John Adams, de Massachusetts, y George Washington y Patrick Henry, de Virginia.

El Congreso aprobó dos documentos importantes. El primero de ellos, suscripto el 14 de octubre, constituye una típica declaración de derechos. ${ }^{34} \mathrm{Co}$ mienza con una exposición de motivos sobre los agravios provocados por las recientes leyes ${ }^{35}$ y luego declara una serie de derechos fundamentales, basados en la teoría política de que los habitantes de las colonias, por las inmutables leyes de la naturaleza (the immutable laws of nature), gozaban de las mismas libertades y garantías que los súbditos ingleses en el Reino Unido, pues sus antepasados,

33 The Administration of Justice Act (mayo de 1774). El artículo 1 de esta ley decía: "[...] it is of the utmost. importance to the general welfare thereof [...] That if any inquisition or indictment shall be found, or if any appeal shall be sued or preferred against any person, for murder, or other capital offence, in the province Of the Massachuset's Bay [...] either in the execution of his duty as a magistrate, for the suppression of riots, or in the support of the laws of revenue, or in acting in his duty as an officer of revenue, or in acting under the direction and order of any magistrate, for the suppression of riots, or for the carrying into effect the laws of revenue, or in aiding and assisting in any of the cases aforesaid [...] it shall and may be lawful for the governor, or lieutenant-governor, to direct, with the advice and consent of the council, that the inquisition, indictment, or appeal, shall be tried in some other of his Majesty's colonies, or in Great Britain [...]".

34 Ver: https://avalon.law.yale.edu/18th_century/resolves.asp.

35 "Whereas, since the close of the last war, the British parliament, claiming a power, of right, to bind the people of America by statutes in all cases whatsoever, hath, in some acts, expressly imposed taxes on them, and in others, under various presences, but in fact for the purpose of raising a revenue, hath imposed rates and duties payable in these colonies, established a board of commissioners, with unconstitutional powers, and extended the jurisdiction of courts of admiralty, not only for collecting the said duties, but for the trial of caU.S.es merely arising within the body of a county: And whereas, in consequence of other statutes, judges, who before held only estates at will in their offices, have been made dependant on the crown alone for their salaries, and standing armies kept in times of peace: And whereas it has lately been resolved in parliament, that by force of a statute, made in the thirty-fifth year of the reign of King Henry the Eighth, colonists may be transported to England, and tried there upon accusations for treasons and misprisions, or concealments of treasons committed in the colonies, and by a late statute, such trials have been directed in cases therein mentioned [...]". 
al salir de Inglaterra hacia América, no se habían despojado de ninguno de los derechos que entonces poseían. ${ }^{36}$ Entre esos derechos figura el de estar representados y participar en una legislatura en cuestiones impositivas y de política interna ${ }^{37}$ el de ser juzgados por sus pares y vecinos ${ }^{38}$ y de ejercer el derecho de reunión y petición. ${ }^{39}$ Sostuvieron también la ilegalidad de que Gran Bretaña tuviera un ejército en las colonias en tiempos de paz sin el consentimiento de aquellas. ${ }^{40}$ Peticionaron finalmente la derogación de una serie de leyes que consideraban violatorias de sus derechos.

El segundo documento, denominado The Articles of Association, ${ }^{41}$ fue suscripto el 20 de octubre. Tenía un contenido económico-comercial, pues pretendía presionar al Parlamento británico para que derogara las llamadas "Leyes Intolerables", estableciendo a tal fin la suspensión de toda exportación, importación y consumo de mercaderías, bienes o productos ingleses. Acusaba directamente al Gobierno británico de las penurias económicas que atravesaban las colonias debido al ruinoso sistema de administración impuesto ${ }^{42}$ y planteaba básicamente la necesidad de llevar adelante una independencia económica completa de Gran Bretaña, prometiendo incluso mejorar la ganadería ${ }^{43}$ y la

36 "That our ancestors, who first settled these colonies, were at the time of their emigration from the mother country, entitled to all the rights, liberties, and immunities of free and natural- born subjects, within the realm of England. That by such emigration they by no means forfeited, surrendered, or lost any of those rights, but that they were, and their descendants now are, entitled to the exercise and enjoyment of all such of them, as their local and other circumstances enable them to exercise and enjoy".

37 "That the foundation of English liberty, and of all free government, is a right in the people to participate in their legislative council: and as the English colonists are not represented, and from their local and other circumstances, cannot properly be represented in the British parliament, they are entitled to a free and exclusive power of legislation in their several provincial legislatures, where their right of representation can alone be preserved, in all cases of taxation and internal polity, subject only to the negative of their sovereign, in such manner as has been heretofore used and accustomed [...]".

38 "That the respective colonies are entitled to the common law of England, and more especially to the great and inestimable privilege of being tried by their peers of the vicinage, according to the course of that law".

39 "That they have a right peaceably to assemble, consider of their grievances, and petition the king; and that all prosecutions, prohibitory proclamations, and commitments for the same, are illegal".

40 "That the keeping a standing army in these colonies, in times of peace, without the consent of the legislature of that colony, in which such army is kept, is against law".

41 Ver: https://www.archivesfoundation.org/documents/1774-articles-association/.

42 "... the present unhappy situation of our affairs is occasioned by a ruinous system of colony administration, adopted by the British ministry about the year 1763, evidently calculated for enslaving these colonies [...]".

43 "We will use our utmost endeavours to improve the breed of sheep, and increase their number to the greatest extent [...]". 
agricultura, así como ciertas industrias -como la de la lana- para lograr un autoabastecimiento. ${ }^{44}$ Se preveía, además, la creación de una comisión que vigilara el cumplimiento de este acuerdo. ${ }^{45}$

\subsection{El Segundo Congreso Continental, los Artículos de la Confederación y el Congreso de la Confederación}

Al finalizar el Primer Congreso Continental, los delegados se comprometieron a reunirse nuevamente en mayo de 1775 . Cumpliendo con este acuerdo, se congregaron el 10 de mayo de ese año en Philadelphia, lo que dio inicio al Segundo Congreso Continental cuando ya habían comenzado las primeras hostilidades con el ejército inglés en las ciudades de Lexington y Concord. Acudieron a esta reunión delegados de las trece colonias y entre ellos se hallaban figuras como Samuel y John Adams, Benjamin Franklin, John Hancock, Patrick Henry, Thomas Jefferson y George Washington.

En la práctica, el Congreso comenzó a actuar inmediatamente como un Gobierno independiente, pese a que no se había producido todavía una declaración formal en tal sentido. Se decidió la formación del Ejército Continental y, en junio, George Washington fue designado comandante en jefe. Fue suscripto también, el 6 de julio, un documento titulado Declaration of Causes of Taking up Arms (Declaración de las Causas para Tomar las Armas), ${ }^{46}$ en el cual Inglaterra fue considerada potencia agresora y se les dio a las colonias el derecho para armarse en contra de los británicos.

Aun así, en el Congreso existían dos posturas. La más radical pretendía declarar inmediatamente la independencia de Gran Bretaña, ${ }^{47}$ mientras que la otra, más conservadora, prefería darle una última chance a la metrópoli inglesa

44 "We will, in our several stations, encourage frugality, economy, and industry, and promote agriculture, arts and the manufactures of this country, especially that of wool [...]".

45 "That a committee be chosen in every county, city, and town, by those who are qualified to vote for representatives in the legislature, whose business it shall be attentively to observe the conduct of all persons touching this association; and when it shall be made to appear, to the satisfaction of a majority of any such committee, that any person within the limits of their appointment has violated this association, that such majority do forthwith cause the truth of the case to be published in the gazette; to the end, that all such foes to the rights of British-America may be publicly known, and universally contemned as the enemies of American liberty [...]".

46 "A Declaration by the Representatives of the United Colonies of North-America, Now Met in Congress at Philadelphia, Setting Forth the Causes and Necessity of Their Taking Up Arms".

Ver: https://avalon.law.yale.edu/18th_century/arms.asp.

47 Representaban esta postura John Adams, de Massachusetts, y Thomas Jefferson, de Virginia. 
intentando llegar a un acuerdo pacífico. ${ }^{48}$ Esta última prevaleció inicialmente y, en julio de 1775, se formuló ante Jorge III la llamada "Petición de la Rama de Olivo" (Olive Branch Petition), redactada por John Dickinson, la cual fue rechazada, ${ }^{49}$ desencadenando con ello los hechos posteriores, entre ellos, la Declaración de la Independencia, aprobada por el Congreso el 4 de julio de 1776, su fecha oficial, aunque el documento fue firmado un mes más tarde. ${ }^{50}$

Este Congreso, en los hechos, se extendió a lo largo de toda la Guerra de la Independencia y concluyó recién en marzo de 1789, para dar paso ya al Congreso de los Estados Unidos una vez que entró en vigencia la Constitución, sancionada en 1787. Antes de ello, fueron sancionados los Artículos de la Confederación y Unión Perpetua (Articles of Confederation and Perpetual Union), el documento constitucional más importante sancionado por el Segundo Congreso Continental, ${ }^{51}$ que rigió desde marzo de 1781 , luego de ser ratificado por los 13 estados, hasta marzo de 1789, cuando entró formalmente en vigencia la Constitución sancionada en septiembre de $1787 . .^{52}$

Los Artículos de la Confederación habían sido aprobados en noviembre de 1777, pero las disputas internas entre los estados -que se repetirían luego en la Convención de Philadelphia- demoraron su ratificación hasta $1781 .{ }^{53} \mathrm{El}$ resultado fue la creación de una Confederación híbrida y débil, denominada

48 Lideraban esta posición John Jay y John Dickinson.

49 Jorge III no solo se negó a recibir la petición, sino que en agosto emitió la Proclamation of Rebellion. Más tarde, en diciembre, el Parlamento sancionó la American Prohibitory Act, que prohibió el comercio inglés con las colonias.

50 He relatado los pormenores del nacimiento y concreción de Declaración de la Independencia en Bianchi (2008, pp. 63-68).

51 En los hechos, fue la primera constitución de los Estados Unidos.

52 La ratificación de la Constitución había tenido lugar en junio de 1788, cuando New Hapmshire otorgó la novena aprobación necesaria para que pudiera entrar en vigencia.

53 Los Artículos fueron preparados por una comisión presidida por John Dickinson, quien en julio de 1776 le presentó un informe al Congreso en el cual proponía establecer un Gobierno central fuerte, donde los estados tuvieran igual representación, dotado de poderes impositivos y que ejerciera control sobre los territorios del oeste. Los delegados al Congreso, no obstante, temían crear un Gobierno federal con amplias facultades, pues veían reflejado en ello el poder ejercido otrora por la Corona británica. El Congreso entonces cambió drásticamente la propuesta de Dickinson y, luego de muchas demoras, el 15 noviembre de 1777 sometió su propuesta a los estados, cuidando de limitar lo menos posible su autonomía. Los estados, por su lado, tenían intereses muy diferentes. Los más pequeños pretendían igual representación que los más grandes, quienes, a su vez, temían tener que sufragar en mayor medida los costos de un Gobierno central. También generaba un conflicto el control sobre los territorios del oeste, ya que los estados linderos con estos pretendían ejercer sobre ellos un control mayor que los restantes. Finalmente, se acordó que el Gobierno central tendría el control de estos territorios, lo que permitió la ratificación final del documento en marzo de 1781. La descripción del conflicto que desató su ratificación puede verse en Story (1858, vol. I, §§ 223-227, pp. 157-160). 
"Los Estados Unidos de América. ${ }^{54}$ Tal como señala Bidegain (1950), "[l]as funciones del poder central eran tan reducidas como podía esperarse en una confederación integrada por Estados que durante el curso de toda su historia, apenas habían mantenido relaciones ente sí, y que, en cambio, habían ejercido el gobierno propio" (p. 27).

El documento constaba de trece cláusulas. ${ }^{55}$ Luego de indicar el nombre de la Confederación, "The United States of America", establecía que cada estado retenía su soberanía y todos los poderes no expresamente delegados, ${ }^{56} \sin$ perjuicio de prometerse mutuamente constituir una unión firme y de ayuda mutua $^{57}$ que conservara la libertad individual de los habitantes de cada estado, quienes podrían circular libremente por el territorio de los demás ejerciendo el comercio. Se aseguraba además que los procedimientos llevados a cabo en un estado tendrían plena validez (full faith and credit) en los restantes. ${ }^{58}$

Estaba previsto un órgano legislativo denominado United States in Congress Assembled, ${ }^{59}$ que, en la práctica, resultó ser una continuación del Segundo Congreso continental, bien que bajo un nombre diferente. Estaba constituido por delegados de todos los estados elegidos según el método que cada uno de ellos hubiera establecido. Debía reunirse anualmente en noviembre y cada estado retenía la facultad de revocar el mandato de sus delegados en cualquier momento y designar otros. Cada estado podía nombrar entre 2 y 7 representantes, que tenían un mandato de hasta 3 años en un período de 6 años. Sin perjuicio de la cantidad de representantes elegidos, cada estado tenía un solo voto al momento de decidir alguna cuestión. Se les garantizaba a los delegados la libertad de expresión en el recinto legislativo y de arresto mientras

54 En la práctica, el Gobierno central creado por los Artículos fue altamente inefectivo, dependía de la discrecionalidad de los estados miembros para su financiamiento económico, no pudo pagar las deudas contraídas durante la Guerra de la Independencia y ni siquiera tuvo fuerza para imponerles a los estados que firmaran el Tratado de París de 1783, por medio del cual se dio por finalizado el conflicto revolucionario con Gran Bretaña. Consecuentemente, fue muy criticado por los líderes federalistas, como Alexander Hamilton y George Washington.

55 Su análisis detallado puede verse en Story (1858, vol. I, §§ 229-241, pp. 161-165).

56 "II. Each state retains its sovereignty, freedom, and independence, and every power, jurisdiction, and right, which is not by this Confederation expressly delegated to the United States, in Congress assembled".

57 "III. The said States hereby severally enter into a firm league of friendship with each other, for their common defense, the security of their liberties, and their mutual and general welfare, binding themselves to assist each other, against all force offered to, or attacks made upon them, or any of them, on account of religion, sovereignty, trade, or any other pretense whatever".

58 Ello constituye un antecedente del artículo IV § 1 de la Constitución de 1787.

59 También se lo ha llamado Congress of the Confederation o Confederation Congress. 
ejercían sus funciones. ${ }^{60} \mathrm{El}$ Congreso ejercía, en forma exclusiva, las relaciones exteriores, celebraba tratados y declaraba la guerra. ${ }^{61}$ Tenía también el poder de resolver conflictos territoriales entre estados. ${ }^{62}$

El órgano ejecutivo era colegiado, temporal y dependía del Congreso. Cuando este entraba en receso, se elegía una comisión integrada por un delegado por cada estado, que actuaría en su reemplazo. ${ }^{63}$ Las decisiones de este cuerpo ejecutivo podían ser adoptadas por nueve de sus miembros. ${ }^{64}$ No estaba prevista la existencia de un poder judicial en la Confederación.

60 "V. For the most convenient management of the general interests of the United States, delegates shall be annually appointed in such manner as the legislatures of each State shall direct, to meet in Congress on the first Monday in November, in every year, with a power reserved to each State to recall its delegates, or any of them, at any time within the year, and to send others in their stead for the remainder of the year.

No State shall be represented in Congress by less than two, nor more than seven members; and no person shall be capable of being a delegate for more than three years in any term of six years; nor shall any person, being a delegate, be capable of holding any office under the United States, for which he, or another for his benefit, receives any salary, fees or emolument of any kind.

Each State shall maintain its own delegates in a meeting of the States, and while they act as members of the committee of the States.

In determining questions in the United States in Congress assembled, each State shall have one vote. Freedom of speech and debate in Congress shall not be impeached or questioned in any court or place out of Congress, and the members of Congress shall be protected in their persons from arrests or imprisonments, during the time of their going to and from, and attendance on Congress, except for treason, felony, or breach of the peace".

61 "VI. No State, without the consent of the United States in Congress assembled, shall send any embassy to, or receive any embassy from, or enter into any conference, agreement, alliance or treaty with any King, Prince or State [...] No two or more States shall enter into any treaty, confederation or alliance whatever between them, without the consent of the United States in Congress assembled [...] No State shall lay any imposts or duties, which may interfere with any stipulations in treaties, entered into by the United States in Congress assembled, with any King, Prince or State, in pursuance of any treaties already proposed by Congress, to the courts of France and Spain [...] No State shall engage in any war without the consent of the United States in Congress assembled, unless such State be actually invaded by enemies [...]".

62 "IX [...] The United States in Congress assembled shall also be the last resort on appeal in all disputes and differences now subsisting or that hereafter may arise between two or more States concerning boundary, jurisdiction or any other caU.S.es whatever; which authority shall always be exercised in the manner following".

63 "IX. [...] The United States in Congress assembled shall have authority to appoint a committee, to sit in the recess of Congress, to be denominated 'A Committee of the States', and to consist of one delegate from each State; and to appoint such other committees and civil officers as may be necessary for managing the general affairs of the United States under their direction - to appoint one of their members to preside, provided that no person be allowed to serve in the office of president more than one year in any term of three years [...]".

64 "X. The Committee of the States, or any nine of them, shall be authorized to execute, in the recess of Congress, such of the powers of Congress as the United States in Congress assembled, by the consent of the nine States [...]". 


\section{El debate en la Convención de Philadelphia 3.1. Convocatoria y tareas preparatorias}

Bajo este esquema, el Gobierno de la Confederación fue un fracaso. En palabras de Washington, citadas por Story (1858), la Confederación no era más que una "sombra sin sustancia y el Congreso un cuerpo ineficaz" (nugatory). ${ }^{65}$ Fue por ello que el 21 de febrero de 1787, el Congreso Continental dispuso que en mayo se reuniera una convención en Philadelphia. ${ }^{66} \mathrm{Su}$ objeto era revisar los Artículos de la Confederación, pero el resultado fue la sanción de una Constitución enteramente diferente, mucho más vigorosa, que está vigente todavía y ha sido el modelo de muchas otras.

Sin perjuicio del valioso trabajo institucional llevado a cabo por la Convención de Philadelphia, algunos autores han puesto de manifiesto los intereses económicos que impulsaron a los constituyentes. En 1913, Charles A. Beard publicó una interesante y polémica obra, destinada a demostrar el trasfondo de los intereses económicos que animaban a los convencionales. Sus conclusiones generaron una fuerte reacción en sus contemporáneos y en autores posteriores, ya que bajo su interpretación la Constitución no parecía ser más que el resultado de una transacción sobre intereses patrimoniales entre comerciantes, propietarios, poderosos terratenientes y tenedores de bonos públicos, lo que obviamente restaba buena parte de patriotismo e interés institucional a la gesta constituyente. ${ }^{67}$

La reunión estaba programada para el 14, pero recién obtuvo quorum para sesionar el 25. La Convención trabajó formalmente desde esa fecha por espacio de cuatro meses, hasta el 17 de septiembre, fecha en que la Constitución fue

65 "[t]he confederation appears to me to be little more, than a shadow without the substance; and congress a nugatory body, their ordinances being little attended to” (Story, 1858, vole I, § 247, p. 169).

66 El año anterior, en septiembre, ya había intentado reunirse una Convención en la ciudad de Annapolis, pero la convocatoria fracasó ya que solo acudieron representantes de cinco estados.

67 Según Beard (1956), “... es enteramente falso el concepto de que la Constitución es una pieza de legislación abstracta, que no refleja grupos de interés y no reconoce antagonismos económicos. Fue un documento económico escrito con extraordinaria destreza por hombres cuyos intereses como propietarios estaban en juego de modo tal que apelaron directamente y sin equivocaciones a idénticos intereses para todo el país" (p. 188). En el Capítulo V, uno de los centrales en el libro, Beard (1956) pasa revista a la condición económica de cada uno de los constituyentes con el objeto de determinar cuáles eran los intereses que cada uno estaba dispuesto a defender. Concluye señalando que la mayoría de ellos eran abogados y provenían de ciudades situadas en o cerca de la costa, es decir, en aquellas zonas donde más personalidades se hallaban congregadas. Nadie representaba directamente a las clases de pequeños agricultores. La abrumadora mayoría -por lo menos cinco sextos- estaban personal y directamente interesados en el resultado de su labor en Philadelphia y se beneficiaron, en mayor o menor medida, con la Constitución. 
aprobada. ${ }^{68}$ De los trece estados, concurrieron a la Convención todos menos Rhode Island, que no mandó delegados. ${ }^{69}$ No hubo una representación igualitaria, ya que algunos estados tuvieron más delegados que otros. ${ }^{70}$ En total fueron designados 74 , de los cuales asistieron $55 ;^{71}$ el promedio de asistencia a las sesiones fue de $33^{72}$ y estuvieron ausentes por diferentes motivos figuras destacadas. ${ }^{73}$

Reunida la Convención, se desarrollaron los trabajos preliminares propios de todo cuerpo legislativo recién constituido. George Washington fue elegido presidente por unanimidad y William Jackson fue designado secretario; se examinaron las credenciales de cada diputado y se designó una comisión para

68 Se inició luego el proceso de ratificación, que concluyó el 21 de junio de 1788 con la aprobación dada por New Hampshire. En marzo del año siguiente, como dije antes, entró en vigencia la Constitución.

69 New Hampshire se unió casi al final, y cuando la Constitución fue firmada, de los tres delegados enviados por New York solo quedaba Alexander Hamilton.

70 La delegación de Virginia estaba liderada por su ciudadano más destacado, George Washington, que fue elegido presidente de la Convención, secundado por Edmund Randolph y James Madison. También fueron delegados de Virginia John Blair, George Wythe y George Mason, redactor este último del Bill of Rights de su estado. New Jersey estuvo representada, entre otros, por David Brearly, William Paterson, Jonathan Dayton y William Livingston. Benjamin Franklin fue el más popular de la nutrida delegación de Pennsylvania. Además de Franklin, actuaron Thomas Mifflin, Robert Morris, Jared Ingersoll, James Wilson, George Clymer y Thomas Fitzsimons. North Carolina envió a Alexander Martin, William R. Davie y Richard Spaigth; South Carolina, a Charles Pinckney y Pierce Butler; Delaware, a George Read y John Dickinson; New York envió a Alexander Hamilton, Robert Yates y John Lansing; Georgia fue representada, entre otros, por William Pierce y Abraham Baldwin; Roger Sherman y Oliver Ellsworth representaron a Connecticut y Elbribge Gerry y Nathaniel Gorham a Massachusetts. También fueron delegados de este estado Nathaniel Gordman y Rufus King. Sus edades oscilaban en un rango que va desde la ancianidad de Franklin, que contaba con 81 años, a la juventud de Dayton, de apenas 27, bien que otros muchos estaban cerca de los 30 años. Madison tenía 36; Baldwin, 33; Hamilton, 30 y Davie, Pinckney y Spaight no llegaban a 30. En total concurrieron 55 convencionales -sobre un total de 72 que fueron nominados-, de los cuales 39 firmaron la Constitución.

71 Todos ellos eran figuras prominentes de su época: 8 habían firmado la Declaración de la Independencia, 7 habían sido gobernadores de sus estados y 39 habían sido miembros del Congreso de la Confederación.

72 Los convencionales más influyentes fueron: Gouverner Morris y James Wilson, de Pennsylvania; James Madison, de Virginia, y Roger Sherman, de Connecticut, con más de 100 intervenciones cada uno. También se destacaron George Mason y Edmund Randolph de Virginia, Oliver Ellsworth de Connecticut, Rufus King y Elbridge Gerry de Massachusetts, John Rutledge y Charles Pickney de South Carolina, Alexander Hamilton de New York, John Dickinson de Delaware y William Paterson de New Jersey.

73 No asistieron John Jay, que era secretario de asuntos exteriores, Thomas Jefferson, embajador en Francia, y John Adams, embajador en Inglaterra. También estuvieron ausentes personalidades destacadas de la Independencia, como Samuel Adams, Patrick Henry, John Hancock, Christopher Gadsen y Richard Henry Lee. 
redactar el reglamento y otras disposiciones. Asimismo, luego de cierto debate, se decidió que cada estado tendría un voto, ${ }^{74}$ que 7 estados formarían quorum, que las decisiones se tomarían por mayoría ${ }^{75}$ y que los debates serían secretos.

Tan escrupulosa fue esta regla que los debates de la Convención no se conocieron sino luego de varios años, cuando el Congreso ordenó imprimirlos luego de la Guerra de 1812 contra Inglaterra. El resultado parece haber sido desalentador, pues el trabajo del secretario no reflejaba adecuadamente los debates. Este déficit fue luego suplido por las notas que tomaron algunos miembros de la Convención, que ayudaron a esclarecer puntos que no suplía el texto oficial. De todos ellos, la contribución más importante fue la de James Madison. Elegido como delegado por Virginia, fue uno de los primeros en instalarse en Philadelphia. Había llegado allí munido de dos estudios que había preparado, titulados "Study of Ancient and Modern Confederacies" y "Vices of the Political System of the United States", lo que le permitió presentar inmediatamente ante la asamblea constituyente su plan de gobierno, consistente en la creación de poderes nacionales fuertes como modo de obtener uniformidad en la regulación de ciertas materias. Este plan (Virginia Plan) fue presentado luego ante la Convención por el gobernador y convencional Edmund Randolph. Además de su contribución en la preparación de este plan y de su labor como principal redactor de la Constitución, aporte incrementado luego con sus artículos en El Federalista, Madison tuvo el cuidado de escribir notas detalladas sobre los procedimientos llevados a cabo por la Convención, que se convirtieron en un documento indispensable para conocer la labor de la asamblea constituyente. Este trabajo se publicó inicialmente en 1840, luego de la muerte de Madison, bajo el título Journal of the Federal Convention, que ha tenido numerosas ediciones. ${ }^{76}$

74 Se siguió en esto la regla aplicada en los Artículos de la Confederación.

75 No obstante, esta regla fue modificada luego, permitiéndose reconsiderar los votos emitidos, algo que sucedió con frecuencia a lo largo de la convención.

76 Más tarde, en 1911, Max Farrand publicó una obra en tres volúmenes llamada The Records of the Federal Convention of 1787, que se convirtió desde entonces en la fuente principal para el análisis de los debates de la Convención. Farrand recopiló ordenadamente los debates tomando como base, por un lado, el registro llevado por William Johnson, secretario de la Convención, enviados al Departamento de Estado por Washington en 1796 e impresos en 1819 por disposición del Congreso, bajo la supervisión de John Quincy Adams, entonces secretario de Estado, y, por el otro, el trabajo de James Madison. La obra fue publicada originalmente por Yale University Press y actualmente se la puede consultar online en: https://oll.libertyfund.org/title/farrand-the-records-of-the-federal-convention-of-1787-3vols. También puede verse Farrand (1913). 


\subsection{La cuestión central}

Tal como veremos en los párrafos siguientes, la cuestión central de los debates estuvo enfocada en el diseño del Congreso, en particular, el problema más arduo fue la proporcionalidad de la representación en las cámaras legislativas, una cuestión que ya se había presentado al redactar los Artículos de la Confederación y que rebrotó vivamente en la Convención de Philadelphia, al punto que estuvo al borde de hacerla fracasar. Esta disputa enfrentaba a los estados grandes y económicamente poderosos -tales como Virginia, Pennsylvania y Massachusetts- con los estados pequeños. Los primeros pretendían que ambas cámaras legislativas se integraran mediante una regla de estricta proporcionalidad poblacional. A los segundos esto los perjudicaba, pues disminuía enormemente la cantidad de sus representantes y temían, con fundada razón, que el Congreso fuera dominado por los estados grandes. La cuestión fue zanjada en el "Gran Compromiso" del 16 de julio, en el cual se acordó que la Cámara de Representantes se integraría sobre la base proporcional de la población y que en el Senado cada estado tendría igualdad de votos.

\subsection{El Plan de Virginia}

El 29 de mayo, una vez finalizadas las tareas de organización, comenzaron los debates. Hasta ese momento, la convocatoria tenía el modesto propósito de revisar los Artículos de la Confederación, sin embargo, la convención tomó un giro de más alto vuelo cuando Edmund Randolph, gobernador y representante de Virginia, abrió el fuego presentando un plan integral de reformas, elaborado por James Madison, que preveía la creación de un Gobierno nacional mucho más fuerte y enteramente diferente al de la Confederación. ${ }^{77}$ Conocido como el "Plan de Virginia", fue finalmente la base de la Constitución, bien que con algunas modificaciones importantes.

Desarrollado en quince propuestas, ${ }^{78}$ el Plan de Virginia preveía un Gobierno separado en tres ramas: legislativa, ejecutiva y judicial. La legislatura estaría dividida en dos cámaras, una elegida por el pueblo de los estados y la otra por los miembros de la primera. ${ }^{79}$ El ejecutivo sería elegido por la legislatura nacio-

77 Ese mismo día, Charles Pinckney, de South Carolina, presentó también una propuesta, pero no fue considerada.

78 Ver las partes relevantes de su texto en el Anexo II (p. 434).

79 Nunca fue objetado en el curso de la Convención que el Congreso fuera bicameral, pues ello venía de la tradición inglesa y colonial, aunque no estaba reflejado en los Artículos de la Confederación. 
nal, sin posibilidad de acceder a un segundo período. Los jueces, divididos en dos instancias (una Corte Suprema y cortes inferiores), también serían elegidos por la legislatura. El plan preveía también que el ejecutivo y un "conveniente número de la judicatura nacional" conformarían un consejo con facultades para vetar las leyes, decisión que podía quedar sin efecto mediante la insistencia de las dos cámaras legislativas. Se establecía asimismo la posibilidad de incorporar nuevos estados y de reformar la Constitución, para lo cual, una vez aprobada la enmienda por el Congreso, este debía someterla a la aprobación de convenciones especialmente convocadas al efecto por los estados.

A partir de allí, y por espacio de dos semanas, la Convención se constituyó en comisión para analizar el Plan de Virginia, el cual enfrentó la oposición de algunos estados, como Maryland, New Jersey y Delaware. No era para menos. El Plan de Virginia, más que reformar los Artículos de la Confederación, los alteraba completamente en dos aspectos fundamentales.

En primer lugar, proponía la creación de un Gobierno federal fuerte por encima de los estados. Se establecía de este modo una doble soberanía: la del Gobierno federal y la de los Gobiernos estaduales, algo que hasta 1787 jamás había sido pensado. Aunque en la sesión del 30 de mayo Randolph se esforzó en explicar que los poderes otorgados al Gobierno federal, tomados de los estados, solo tenían el propósito de dotarlo de la capacidad de defenderse a sí mismo, ${ }^{80}$ era evidente que los estados debían resignar una amplia porción de las facultades ejercidas hasta ese momento.

En segundo lugar, se pretendía imponer la representación proporcional en ambas cámaras legislativas. ${ }^{81}$ Esto permitía el dominio de los estados grandes sobre los más pequeños, pues le otorgaba a Virginia, Pennsylvania y Massachusetts la posibilidad de elegir 13 miembros sobre un total de 28 en el Senado y una porción similar en la Cámara de Representantes. Luther Martin, de

Parecería ser que uno de los que objetó la composición bicameral fue Jefferson, luego de sancionada la Constitución. Una anécdota - no comprobada- cuenta que al regresar de Francia, donde había sido embajador mientras se sancionaba la Constitución, Jefferson desayunaba con Washington y se quejaba de que la existencia de dos cámaras dilataría el proceso legislativo. Mientras hablaba, volcó el café en un plato y Washington le preguntó por qué lo hacía. Jefferson le respondió que era para enfriar el café. Washington le dijo entonces que era conveniente volcar las leyes en el plato del Senado para enfriarlas (Vid. Farrand, 1913, p. 74).

80 "It is only meant to give the national government a power to defend and protect itself. To take therefore from the respective legislatures or States, no more sovereignty than is competent to this end" (Farrand, 1911a, p. 42).

81 En la Cámara de Representantes era directa y en el Senado era indirecta, pues sus miembros eran elegidos por los integrantes de la primera. 
Maryland, en la sesión del 20 de junio dijo que el Plan sometía a los estados chicos a la esclavitud de los grandes; ${ }^{82}$ Dickinson, de Delaware, en la sesión del 15 de junio reconoció que prefería someterse a un poder extranjero que ser privado del voto igualitario para todos los estados en ambas cámaras; ${ }^{83}$ y Paterson, de New Jersey, en la sesión del 9 de junio había dicho que su estado jamás aprobaría la propuesta, pues sería "tragado" por los estados grandes y que prefería someterse a un monarca o a un déspota antes que tener tal destino. ${ }^{84}$

\subsection{El Plan de New Jersey}

En la sesión del 11 de junio fueron votadas las propuestas del Plan de Virginia. La referida al modo de elección de los senadores fue aprobada por 6 votos contra 5. Si bien el resultado era ajustado, era indudable que los estados grandes estaban ganando la partida. A fin de contrarrestar esta tendencia que ya se insinuaba como definitiva, en la sesión del 15 de junio William Paterson, de New Jersey, presentó un plan alternativo, el Plan de New Jersey, que fue apoyado por Connecticut, New York y Delaware. Consistía en nueve resoluciones que se limitaban a reformar los Artículos de la Confederación otorgándole poderes impositivos al Congreso, creando un ejecutivo pluripersonal y un tribunal superior elegido por el ejecutivo con jurisdicción originaria en casos de juicio político y jurisdicción apelada respecto a los tribunales estaduales. Preveía también una cláusula de supremacía de la Constitución. ${ }^{85}$ Sin decirlo expresamente, el Plan de New Jersey mantenía la regla de un voto por cada estado establecida en los Artículos de la Confederación.

\subsection{El debate sobre los planes presentados}

Luego de sometido el Plan de New Jersey, la Convención nuevamente se cons-

82 "[T]he propositions on the table were a system of slavery for 10 States: that as Va. Masts. \& Pa. have 42/90 of the votes they can do as they please without a miraculous Union of the other ten: that they will have nothing to do, but to gain over one of the ten to make them complete masters of the rest, that they can then appoint an Execute: \& Judiciary \& legislate for them as they please" (Farrand, 1911a, p. 347).

83 "We would sooner submit to a foreign power, than submit to be deprived of an equality of suffrage, in both branches of the legislature, and thereby be thrown under the domination of the large States" (Farrand, 1911a, p. 242).

84 "New Jersey will never confederate on the plan before the Committee. She would be swallowed up. He had rather submit to a monarch, to a despot, than to such a fate" (Farrand, 1911a, p. 179).

85 Ver las partes relevantes de su texto en el Anexo III (p. 436). 
tituyó en comisión para analizarlo. Seis delegados llevaron en esa oportunidad la voz cantante: a favor del nuevo plan se pronunciaron Paterson, Ellsworth, de Connecticut, y Lansing, de New York; en contra se alinearon Madison, Wilson y Randolph. En el curso de este debate, hizo sentir su voz, por primera y prácticamente única vez en el curso de la Convención, Alexander Hamilton. Se había mantenido apartado de Lansing y Yates, los otros delegados de New York, y, con poco tacto político, aprovechó esta ocasión para exponer un plan de gobierno, muy elaborado, pero completamente diferente a los ya presentados, ${ }^{86}$ que luego sus detractores calificaron de monárquico, aun cuando no lo era en realidad. Propuso, en síntesis, un sistema fuertemente centralizado, ${ }^{87}$ que, al no tener en cuenta para nada el espíritu localista de la mayoría de los estados, estaba destinado al más rotundo rechazo, como efectivamente ocurrió. ${ }^{88}$

En la sesión del martes 19 de junio, luego de una extensa exposición de Madison -el último de los oradores-, en la que reconoció que el nudo del problema era la representación y que todas las otra cuestiones eran superables, ${ }^{89} \mathrm{se}$ sometió a votación si debía optarse por el Plan de Virginia o el de New Jersey. ${ }^{90}$ La elección se inclinó por el primero de ellos por 7 votos contra 3. El Plan de New Jersey solo obtuvo el voto de su estado y los de New York y Delaware. El voto de Maryland resultó dividido.

\subsection{El Gran Compromiso}

Con la opción a favor del Plan de Virginia, habían triunfado los estados grandes, pero faltaba todavía un largo camino para llegar a un acuerdo sobre el texto

86 El plan de Hamilton puede verse en Farrand (1911c, pp. 617 y ss.).

87 Hamilton propuso que el ejecutivo y los senadores fueran elegidos por electores por tiempo indeterminado mientras durara su buena conducta; que el ejecutivo tuviera amplios poderes, entre ellos, un veto absoluto; que los gobernadores estaduales fueran elegidos por el Gobierno central y pudieran vetar la legislación local.

88 William Johnson, de Connecticut, en la sesión del 21 de junio expresó: "El caballero de New York, con audacia y decisión, ha propuesto un plan totalmente diferente a los otros y a pesar de haber sido elogiado por todos, nadie lo ha apoyado" ("A gentleman from New-York, with boldness and decision, proposed a system totally different from both; and though he has been praised by everybody, he has been supported by none") (Farrand, 1911a, p. 363).

89 "The great difficulty lies in the affair of Representation; and if this could be adjusted, all others would be surmountable" (Farrand, 1911a, pp. 321).

90 " $[. .$.$] whether the Committee should rise and Mr. Randolph's propositions be re-reported without$ alteration, which was in fact a question whether Mr. Randolph's should be adhered to as preferable to those of Mr. Patterson" (Farrand, 1911a, p. 322). 
de cada cláusula y el punto clave para ello era la composición y elección de los miembros de cada cámara legislativa. Fue en este momento que la Convención alcanzó el clima de mayor tensión. A comienzos de julio, poco se había avanzado en la materia y, en algunos casos, los delegados de un mismo estado no se ponían de acuerdo, neutralizando el voto de ese estado. En medio de esta situación, el lunes 2 de julio se sometió a votación si en el Senado la representación sería igualitaria; la votación resultó empatada: 5 estados votaron por la afirmativa y 5 por la negativa, con un voto dividido.

Era indudable que, a esa altura, la Convención, estaba a punto de estancarse. Charles Pickney propuso entonces la formación de una comisión integrada por un representante de cada estado a fin de intentar un acuerdo. Pese a la oposición de los estados grandes, esta propuesta fue aprobada y resultaron electos Gerry, Elseworth, Yates, Paterson, Franklin, Bedford, Martin, Mason, Davy, Rutlidge y Baldwin. El 5 de julio, la Comisión presentó en la Convención una propuesta que contenía dos puntos, sujetos a la condición de que ambos fueran aprobados: 1) en la Cámara de Representantes la representación sería proporcional a la población tomando una base de 40000 habitantes; los estados que no tuvieran esa población tendrían un representante; las leyes de contenido económico debían originarse en la Cámara de Representantes sin posibilidad de ser enmendadas por el Senado; y 2) en el Senado, cada estado tendría igual cantidad de votos. ${ }^{91}$

Luego de arduas discusiones y reproches, el 16 de julio se acordaron finalmente, por muy escasa mayoría, ${ }^{92}$ las bases estructurales del Congreso de los Estados Unidos. Fue resuelto allí que en la Cámara de Representantes la representación sería proporcional a la población y en el Senado cada estado tendría igual cantidad de votos. Se estableció, asimismo, la composición de la primera legislatura,

91 "That the subsequent propositions be recommended to the Convention, on condition that both shall be generally adopted. 1st That in the first branch of the Legislature each of the States now in the Union be allowed one Member for every forty thousand inhabitants of the description reported in the seventh resolution of the Committee of the whole House. That each State not containing that number shall be allowed one Member - That all Bills for raising or appropriating money and for fixing the salaries of the Officers of the Government of the United States, shall originate in the first Branch of the Legislature, and shall not be altered or amended by the second Branch - and that no money shall be drawn from the public Treasury but in pursuance of appropriations to be originated by the first Branch. 2ndly That in the second Branch of the Legislature each State shall have an equal Vote" (Farrand, 1911a, p. 524).

92 En una decisión 5-4, votaron a favor: Connecticut, New Jersey, Delaware, Maryland y North Carolina y, en contra, Pennsylvania, Virginia, South Carolina y Georgia. El voto de Massachusetts quedó dividido y dos de los representantes de New York para ese entonces ya se habían retirado de la Convención. Quedaba solamente Hamilton. 
fijándose el número de representantes de cada estado; la obligación de hacer un censo poblacional cada diez años y de redistribuir los distritos electorales para reflejar los cambios poblacionales y territoriales -por adición o divisiónque pudiera experimentar cada estado. Se dispuso también que las leyes impositivas y las de aprobación de gastos públicos debían originarse en la Cámara de Representantes, sin que el Senado pudiera modificarlas. ${ }^{93}$

\subsection{La tarea posterior}

Desde el Gran Compromiso del 16 de julio hasta la aprobación definitiva de la Constitución, la Convención trabajó febrilmente en la redacción del texto. Fue designada una comisión redactora (Committee of Detail) integrada por cinco miembros -tres de los cuales representaban a los estados grandes-, ${ }^{94}$ que el 6 de agosto presentó un proyecto de Constitución en 23 artículos, 6 de los cuales (los artículos IV a IX) estaban dedicados al Congreso, tan solo uno al Poder Ejecutivo (artículo X) y otro al Poder Judicial (artículo XI). ${ }^{95}$ Durante el curso de los debates posteriores, este proyecto fue intensamente modificado hasta convertirse en la Constitución sancionada el lunes 17 de septiembre.

Dado que este no es un estudio específico sobre la Convención de Philadelphia, no me detendré con detalle en los debates específicos de cada cláusula. Me limitaré tan solo a mencionar algunos aspectos tratados por aquella relativos al Congreso que me parecen importantes. El análisis más detallado de las secciones y cláusulas del artículo I será materia de las siguientes partes de este trabajo.

Un dato a tener en cuenta es que hasta que fue elaborado el proyecto de constitución por el Committee of Detail, la Convención no había empleado la palabra "Congreso", que figuraba en los Artículos de la Confederación. Se refería, en cambio, a la "legislatura de los Estados Unidos" y las cámaras eran designadas como "primera rama" (first branch), en alusión a la Cámara de Representantes, y "segunda rama" (second branch), en alusión al Senado. Recién en el proyecto del Committee of Detail se emplearon las denominaciones Congress (artículo III), House of Representatives (artículo IV) y Senate (artículo V).

En cuanto a la cantidad de representantes y de senadores, el 8 de agosto se

93 Ver Anexo IV (p. 438).

94 Sus integrantes fueron: Rutledge (South Carolina), Randolph (Virginia), Gorham (Massachusetts), Ellsworth (Connecticut) y Wilson (Pennsylvania). Casi todos ocuparon luego cargos de importancia. Randolph fue el primer attorney general y Rutledge, Ellsworth y Wilson fueron jueces de la Corte Suprema.

95 El proyecto está transcripto en Farrand (1911b, pp. 177-189). 
decidió que los primeros serían 1 por cada 40000 habitantes, cantidad que se redujo a 30000 el último día de la convención, es decir, el 17 de septiembre. Así, hasta el primer censo, la cantidad de legisladores en el House fue de 65. A su vez, el 14 de julio, a propuesta de Elbridge Gerry, se decidió que cada senador votaría en forma individual y el 23 de julio se acordó que habría 2 senadores por cada estado.

Antes de ello, el 21 de junio, se había decidido que el término del mandato de los representantes sería de dos años y el 26 de junio se resolvió que el de los senadores sería de 6 años y se renovarían por tercios. Ese mismo día se votó también, por unanimidad, que los proyectos de ley podían originarse en cualquiera de las dos cámaras. El 14 de agosto se aprobó que los salarios de senadores y representantes serían pagados por el Tesoro Nacional. ${ }^{96}$

Estas y otras muchas decisiones fueron conformando lo que resultó ser el artículo I de la Constitución. Ciertamente, este artículo, al igual que todos los restantes, no fueron más que una obra imperfecta e incompleta, ${ }^{97}$ producida por un grupo de hombres a los que les costó mucho llegar a un acuerdo y por momentos estuvieron al borde de fracasar. ${ }^{98} \mathrm{Al}$ concluir la Convención, algunos manifestaron su disenso con ella y hubo quienes se negaron a firmarla, como Randolph, Mason y Gerry. De las palabras de todos ellos, las de Franklin, con la sabiduría que le daban los años vividos, fueron tal vez las más sensatas. Confesó no estar de acuerdo con muchos aspectos de la Constitución, pero reconoció que nadie podía esperar la perfección de una asamblea de personas en la que todos volcaban su sabiduría, sus errores, sus intereses personales y sus pasiones. Con todas sus limitaciones - dijo-, la Constitución era lo más parecido a la perfección que se podía lograr y con ese sentimiento la aprobaba, estando seguro de que no era la mejor. ${ }^{99}$ Tal vez, el reconocimiento de sus mu-

96 Antes de ello, Ellsworth había propuesto que los salarios fueran pagados por los estados, pero Randolph y Hamilton se opusieron, señalando que ello los haría dependientes de los estados, viciando su imparcialidad.

97 Faltaba una declaración de derechos, el Bill of Rights, que fue aprobado años más tarde en las Enmiendas I a X.

98 Mientras se firmaba la Constitución, Franklin comentó que, durante los debates, muchas veces miraba el sillón de la presidencia en cuyo respaldo está tallado un sol naciente, preguntándose si realmente representaba el amanecer o el crepúsculo.

99 "In these sentiments, Sir, I agree to this Constitution with all its faults, if they are such [...] when you assemble a number of men to have the advantage of their joint wisdom, you inevitably assemble with those men, all their prejudices, their passions, their errors of opinion, their local interests, and their selfish views. From such an Assembly can a perfect production be expected? It therefore astonishes me, Sir, to find this system approaching so near to perfection as it does [...] Thus I consent, Sir, to this Constitution because I expect no better, and because I am not sure, that it is not the best" (Farrand, 1611b, p. 642-643). 
chos defectos y debilidades sea una de las claves de la estabilidad del sistema político norteamericano.

\section{Los artículos de Madison en El Federalista}

Puestos a escribir en defensa de la Constitución contra los ataques de los antifederalistas, ${ }^{100}$ que arreciaban mientras se llevaba a cabo el proceso de ratificación por parte de los estados, ${ }^{101}$ le tocó a James Madison la tarea de explicar la organización y funciones del Congreso. Lo hizo en 15 artículos, publicados en The Independent Journal de New York, junto con los de Alexander Hamilton y John Jay, ${ }^{102}$ recopilados luego en El Federalista ${ }^{103}$ como capítulos 52 a 66, dedicados los 10 primeros a la Cámara de Representantes; y los 5 restantes, al Senado. ${ }^{104}$

En relación con la Cámara de Representantes, lo primero que analiza son las elecciones de los legisladores, señalando que el sufragio es esencial para el Gobierno republicano ${ }^{105}$ y preguntándose cada cuanto deberían tener lugar tales elecciones. ${ }^{106} \mathrm{Su}$ conclusión es que la elección debe tener lugar cada dos años, pues ello asegura, por un lado, que los legisladores tengan más tiempo para recabar información y conocimientos sobre la legislación que propongan y, por el otro, que en caso de producirse una elección irregular, la investigación

100 Entre los opositores se hallaban George Mason, de Virginia, Elbridge Gerry, James Winthrop y John Hancock, de Massachusetts, George Clinton, de New York, Patrick Henry y Richard H. Lee, de Virginia, convencidos de que el Gobierno federal creado por la Constitución ahogaría la libertad de los estados. Se temía que la presidencia fuera un paso hacia la monarquía, particularmente porque la Constitución permitía la reelección sin límites y que el Congreso, investido de una amplia autoridad, se convirtiera en el instrumento de un poder arbitrario. En el bando opuesto, los defensores más ardientes de la Constitución, además de Washington, Madison, Hamilton y Jay, fueron entre otros: Benjamin Franklin y Rufus King.

101 En el Anexo V (p. 438) menciono cómo se desarrolló el proceso de ratificación.

102 Todos ellos escribieron bajo el seudónimo de Publius.

103 Un estudio de los diferentes tópicos que abarca esta obra puede verse en Carey (1989).

104 A los fines de este análisis, he consultado la Gideon Edition de 1818, editada luego por George Carey y James McLean (2001). Una excelente versión en español es la de Fondo de Cultura Económica, que tiene numerosas ediciones con prólogo y revisión de Gustavo R. Velasco.

105 "The definition of the right of suffrage is very justly regarded as a fundamental article of republican government. It was incumbent on the convention, therefore, to define and establish this right in the constitution" (El Federalista, $\mathrm{N}^{\circ}$ 52).

106 "Frequent elections are unquestionably the only policy, by which this dependence and sympathy can be effectually secured. But what particular degree of frequency may be absolutely necessary for the purpose, does not appear to be susceptible of any precise calculation, and must depend on a variety of circumstances with which it may be connected" (El Federalista, №52). 
del hecho no consuma todo el período legislativo. ${ }^{107}$ Analiza luego qué parámetros deben tenerse en cuenta para calcular la cantidad de representantes por cada estado y se pregunta si debe tomarse como base la población, la riqueza o una combinación de ambas y sostiene que esta última es la fórmula más conveniente. ${ }^{108}$ Considera seguidamente cuántos miembros debe tener en total la Cámara de Representantes. Partiendo de que la Convención había establecido provisionalmente una cámara de 65 miembros hasta que se llevara a cabo el primer censo, Madison hace algunos cálculos -muy estimativos- sobre el crecimiento poblacional y concluye que, en medio siglo más, los legisladores llegarían a ser 400 , un número que le resulta satisfactorio. ${ }^{109}$ Sin dudas, su cálculo

107 "The second question stated is, whether biennial elections be necessary or useful? The propriety of answering this question in the affirmative, will appear from several very obvious considerations. No man can be a competent legislator, who does not add to an upright intention and a sound judgment, a certain degree of knowledge of the subjects on which he is to legislate. A part of this knowledge may be acquired by means of information, which lie within the compass of men in private, as well as public stations. Another part can only be attained, or at least thoroughly attained, by actual experience in the station which requires the use of it. The period of service ought, therefore, in all such cases, to bear some proportion to the extent of practical knowledge, requisite to the due performance of the service. The period of legislative service established in most of the states for the more numerous branch is, as we have seen, one year. The question then may be put into this simple form: does the period of two years bear no greater proportion to the knowledge requisite for federal legislation, than one year does to the knowledge requisite for state legislation? The very statement of the question, in this form, suggests the answer that ought to be given to it [...]It is an inconvenience mingled with the advantages of our frequent elections, even in single states, where they are large, and hold but one legislative session in the year, that spurious elections cannot be investigated and annulled in time for the decision to have its due effect [...] Each house is, as it necessarily must be, the judge of the elections, qualifications and returns of its members; and whatever improvements may be suggested by experience, for simplifying and accelerating the process in disputed cases, so great a portion of a year would unavoidably elapse before an illegitimate member could be dispossessed of his seat, that the prospect of such an event would be little check to unfair and illicit means of obtaining a seat" (El Federalista, $\mathrm{N}^{\circ} 53$ ).

108 "[...] the establishment of a common measure for representation and taxation, will have a very salutary effect. As the accuracy of the census to be obtained by the congress, will necessarily depend, in a considerable degree, on the disposition, if not the co-operation of the states, it is of great importance that the states should feel as little bias as possible, to swell or to reduce the amount of their numbers. Were their share of representation alone to be governed by this rule, they would have an interest in exaggerating their inhabitants. Were the rule to decide their share of taxation alone, a contrary temptation would prevail. By extending the rule to both objects, the states will have opposite interests, which will control and balance each other, and produce the requisite impartiality" (El Federalista, $\mathrm{N}^{\circ}$ 54).

109 "The number of which this branch of the legislature is to consist, at the outset of the government, will be sixty-five. Within three years a census is to be taken, when the number may be augmented to one for every thirty thousand inhabitants; and within every successive period of ten years, the census is to be renewed, and augmentations may continue to be made under the above limitation. It will not be thought an extravagant conjecture, that the first census will, at the rate of one for every thirty thousand, raise the number of representatives to at least one hundred. Estimating the negroes in 
fue premonitorio, pues en 1911 el número de representantes fue establecido, por ley, en $433 .{ }^{110}$ Este se incrementó a 435 cuando, de acuerdo con lo previsto por esa misma ley, se incorporaron como nuevos estados Arizona y New Mexico. Desde entonces, la cantidad de representantes no ha variado. ${ }^{111}$

Madison contesta luego algunas objeciones que se le formularon a la Cámara de Representantes. Sostiene, entonces, que: (a) la cantidad de legisladores establecida originalmente es suficiente para que el Congreso ejerza las competencias que le asigna la Constitución; ${ }^{112}$ (b) el modo de elección popular permitirá que se elijan a quienes mejor representan los intereses de todos; ${ }^{113}$ (c) la Cámara irá aumentando el número de sus miembros a medida que crezca la población, lo que será medido por cada censo; ${ }^{114}(\mathrm{~d})$ el Congreso debe regular las elecciones de sus miembros, pues si esta facultad quedara en manos de las legislaturas estatales, ello podría poner en crisis todo el sistema; ${ }^{115}$ (e) la diver-

the proportion of three-fifths, it can scarcely be doubted, that the population of the United States will, by that time, if it does not already, amount to three millions. At the expiration of twenty-five years, according to the computed rate of increase, the number of representatives will amount to two hundred; and of fifty years, to four hundred. This is a number, which I presume will put an end to all fears arising from the smallness of the body. I take for granted here, what I shall, in answering the fourth objection, hereafter show, that the number of representatives will be augmented, from time to time, in the manner provided by the constitution. On a contrary supposition, I should admit the objection to have very great weight indeed" (El Federalista, $\mathrm{N}^{\circ} 55$ ).

110 Apportionment Act of 1911, Public Law 62-5; 37 Stat. 13.

111 Cuando el 86 Congreso (1959-1961) incorporó como estados a Alaska y Hawaii, el número se incrementó temporalmente a 437, pero luego del censo de 1960 y de la elección de 1962, se redujo nuevamente a 435.

112 El Federalista ( $\left.\mathrm{N}^{\circ} 56\right)$.

113 "Who are to be the electors of the federal representatives? Not the rich, more than the poor; not the learned, more than the ignorant; not the haughty heirs of distinguished names, more than the humble sons of obscure and unpropitious fortune. The electors are to be the great body of the people of the United States. They are to be the same who exercise the right in every state of electing the correspondent branch of the legislature of the state. Who are to be the objects of popular choice? Every citizen whose merit may recommend him to the esteem and confidence of his country. No qualification of wealth, of birth, of religious faith, or of civil profession, is permitted to fetter the judgment, or disappoint the inclination of the people" (El Federalista, $\mathrm{N}^{\circ} 57$ ).

114 "Within every successive term of ten years, a census of inhabitants is to be repeated. The unequivocal objects of these regulations are, first, to re-adjust, from time to time, the apportionment of representatives to the number of inhabitants; under the single exception, that each state shall have one representative at least: secondly, to augment the number of representatives at the same periods; under the sole limitation, that the whole number shall not exceed one for every thirty thousand inhabitants. If we review the constitutions of the several states, we shall find that some of them contain no determinate regulations on this subject; that others correspond pretty much on this point with the federal constitution; and that the most effectual security in any of them is resolvable into a mere directory provision" (El Federalista, $\mathrm{N}^{\circ} 58$ ).

115 "Nothing can be more evident, than that an exclusive power of regulating elections for the national 


\section{sidad de intereses y opiniones existentes en el Gobierno federal evitará que cualquier estado pueda ser excluido de ella; ${ }^{116}$ (f) no era necesario establecer expresamente que las elecciones se llevaran a cabo en cada condado, ${ }^{117}$ del mis- mo modo que tampoco era necesario establecer en la Constitución que todas las elecciones deben llevarse a cabo el mismo día. ${ }^{118}$}

government, in the hands of the state legislatures, would leave the existence of the union entirely at their mercy $[. .$.$] with regard to the federal house of representatives, there is intended to be a general$ election of members once in two years. If the state legislatures were to be invested with an exclusive power of regulating these elections, every period of making them would be a delicate crisis in the national situation; which might issue in a dissolution of the union, if the leaders of a few of the most important states should have entered into a previous conspiracy to prevent an election" (El Federalista, $\mathrm{N}^{\circ} 59$ ).

116 "The dissimilarity in the ingredients, which will compose the national government, and still more in the manner in which they will be brought into action in its various branches, must form a powerful obstacle to a concert of views, in any partial scheme of elections. There is sufficient diversity in the state of property, in the genius, manners, and habits of the people of the different parts of the union, to occasion a material diversity of disposition in their representatives towards the different ranks and conditions in society. And though an intimate intercourse under the same government, will promote a gradual assimilation of temper and sentiment, yet there are causes, as well physical as moral, which may, in a greater or less degree, permanently nourish different propensities and inclinations in this particular. But the circumstance which will be likely to have the greatest influence in the matter, will be the dissimilar modes of constituting the several component parts of the government" (El Federalista, $\mathrm{N}^{\circ} 60$ ).

117 "The more candid opposers of the provision, contained in the plan of the convention, respecting elections, when pressed in argument, will sometimes concede the propriety of it; with this qualification, however, that it ought to have been accompanied with a declaration, that all elections should be held in the counties where the electors reside. This, say they, was a necessary precaution against an abuse of the power. A declaration of this nature would certainly have been harmless: so far as it would have had the effect of quieting apprehensions, it might not have been undesirable. But it would, in fact, have afforded little or no additional security against the danger apprehended; and the want of it will never be considered, by an impartial and judicious examiner, as a serious, still less as an insuperable objection to the plan. The different views taken of the subject in the two preceding papers, must be sufficient to satisfy all dispassionate and discerning men, that if the public liberty should ever be the victim of the ambition of the national rulers, the power under examination, at least, will be guiltless of the sacrifice" (El Federalista, $\mathrm{N}^{\circ} 61$ ).

118 "Uniformity, in the time of elections, seems not less requisite for executing the idea of a regular rotation in the senate; and for conveniently assembling the legislature at a stated period in each year. It may be asked, why then could not a time have been fixed in the constitution? As the most zealous adversaries of the plan of the convention in this state, are in general not less zealous admirers of the constitution of the state, the question may be retorted, and it may be asked, why was not a time for the like purpose fixed in the constitution of this state? No better answer can be given, than that it was a matter which might safely be intrusted to legislative discretion; and that, if a time had been appointed, it might, upon experiment, have been found less convenient than some other time. The same answer may be given to the question put on the other side. And it may be added, that the supposed danger of a gradual change being merely speculative, it would have been hardly advisable upon that speculation to establish, as a fundamental point, what would deprive several states of the convenience of having the elections for their own governments, and for the national government, at the same epoch" (El Federalista, №61). 
Al analizar el Senado, Madison se ocupa, en primer lugar, de justificar los requisitos para ser senador, más exigentes que los de los representantes, pues -según dice- en el Senado se requiere más experiencia y madurez. ${ }^{119}$ En segundo lugar, explica que la elección de los senadores por parte de las legislatura locales tiene la ventaja de que los estados intervienen en la formación de un órgano del Gobierno federal, generando un vínculo entre ambos sistemas. ${ }^{120}$ En tercer lugar, analiza la igualdad de senadores para todos los estados. Aquí se advierte su disgusto con el Gran Compromiso llevado a cabo en la Convención. En su opinión, cada distrito debería tener una representación proporcional, sin embargo, admite que una combinación de representación proporcional con representación igualitaria no está totalmente exenta de razón. ${ }^{121}$ En cuarto lugar, analiza la duración del mandato de los senadores, pero antes de ello se encarga de justificar la existencia misma del Senado. Sostiene básicamente que esta segunda cámara obra como un doble control, ${ }^{122}$ aquieta las pasiones, ${ }^{123}$ ofrece mayor continuidad en la tarea legislativa ${ }^{124}$ frente a la natural mutabilidad de opiniones que se producen en un

119 "The propriety of these distinctions, is explained by the nature of the senatorial trust; which, requiring greater extent of information and stability of character, requires, at the same time, that the senator should have reached a period of life most likely to supply these advantages; and which, participating immediately in transactions with foreign nations, ought to be exercised by none who are not thoroughly weaned from the prepossessions and habits incident to foreign birth and education" (El Federalista, $\mathrm{N}^{\circ} 62$ ).

120 "It is recommended by the double advantage of favouring a select appointment, and of giving to the state governments such an agency in the formation of the federal government, as must secure the authority of the former, and may form a convenient link between the two systems" (El Federalista, № 62).

121 "If indeed it be right, that among a people thoroughly incorporated into one nation, every district ought to have a proportional share in the government; and that among independent and sovereign states bound together by a simple league, the parties, however unequal in size, ought to have an equal share in the common councils, it does not appear to be without some reason, that in a compound republic, partaking both of the national and federal character, the government ought to be founded on a mixture of the principles of proportional and equal representation" (El Federalista, $\mathrm{N}^{\circ} 62$ ).

122 "[...] a senate, as a second branch of the legislative assembly, distinct from, and dividing the power with, a first, must be in all cases a salutary check on the government. It doubles the security to the people, by requiring the concurrence of two distinct bodies in schemes of usurpation or perfidy, where the ambition or corruption of one would otherwise be sufficient" (El Federalista, $\mathrm{N}^{\circ} 62$ ).

123 "The necessity of a senate is not less indicated by the propensity of all single and numerous assemblies, to yield to the impulse of sudden and violent passions, and to be seduced by factious leaders into intemperate and pernicious resolutions" (El Federalista, $\mathrm{N}^{\circ} 62$ ).

124 "It is not possible that an assembly of men, called, for the most part, from pursuits of a private nature, continued in appointment for a short time, and led by no permanent motive to devote the intervals of public occupation to a study of the laws, the affairs, and the comprehensive interests of their country, should, if left wholly to themselves, escape a variety of important errors in the exercise of their legislative trust (El Federalista, $\mathrm{N}^{\circ} 62$ ). 
cuerpo - como la Cámara de Representantes, que cambia sus miembros cada dos años- ${ }^{125}$ y otorga carácter nacional al Gobierno frente a las potencias extranjeras. ${ }^{126}$ Todas estas recomendaciones hacen recordar la conocida anécdota del desayuno entre Washington y Jefferson, a la que ya me he referido. ${ }^{127}$ Explica luego, en los $\mathrm{N}^{\circ}$ 64, 65 y 66, por qué se le ha encomendado al Senado que preste el acuerdo para la celebración de tratados y lleve a cabo el juicio político. En relación con lo primero, destaca la importancia de esta tarea, señalando que debe ofrecer las mayores seguridades y estar en manos de los más calificados. Todo ello se garantiza con el sistema de la Constitución, pues el presidente, que celebra el tratado, está elegido por el colegio electoral, compuesto por un grupo de notables, y el Senado, que da el acuerdo, es elegido por las legislaturas locales. ${ }^{128}$ Sobre el juicio político, dice que ningún otro órgano de Gobierno podría llevarlo a cabo. Descarta, incluso, a la Corte Suprema, en tanto no posee el "crédito y autoridad suficiente". ${ }^{29}$ Dice, asimismo, que el juicio político es discrecional y que la ausencia de un jurado exige que el tribunal sea numeroso. ${ }^{130}$ Por último, explica que esta función jurisdiccional encomendada

125 "The mutability in the public councils, arising from a rapid succession of new members, however qualified they may be, points out, in the strongest manner, the necessity of some stable institution in the government. Every new election in the states, is found to change one half of the representatives. From this change of men must proceed a change of opinions; and from a change of opinions, a change of measures. But a continual change even of good measures is inconsistent with every rule of prudence, and every prospect of success" (El Federalista, $\mathrm{N}^{\circ} 62$ ).

126 "[...] a sense of national character may be, it is evident that it can never be sufficiently possessed by a numerous and changeable body. It can only be found in a number so small, that a sensible degree of the praise and blame of public measures may be the portion of each individual; or in an assembly so durably invested with public trust, that the pride and consequence of its members may be sensibly incorporated with the reputation and prosperity of the community" (El Federalista, $\mathrm{N}^{\circ} 63$ ).

127 Ver nota 79.

128 "The power of making treaties is an important one, especially as it relates to war, peace, and commerce; and it should not be delegated but in such a mode, and with such precautions, as will afford the highest security, that it will be exercised by men the best qualified for the purpose, and in the manner most conducive to the public good. The convention appear to have been attentive to both these points: they have directed the president to be chosen by select bodies of electors, to be deputed by the people for that express purpose; and they have committed the appointment of senators to the state legislatures. This mode has, in such cases, vastly the advantage of elections by the people in their collective capacity, where the activity of party zeal, taking advantage of the supineness, the ignorance, the hopes, and fears of the unwary and interested, often places men in office by the votes of a small proportion of the electors" (El Federalista, $\mathrm{N}^{\circ}$ 64).

129 Se nota en esta opinión que la Corte Suprema no tenía todavía el peso institucional que fue adquiriendo luego.

130 "The convention, it appears, thought the senate the most fit depository of this important trust [...] Where else, than in the senate, could have been found a tribunal sufficiently dignified, or 
a un cuerpo legislativo no afecta la separación de poderes, en tanto es parte de los controles de la legislatura sobre el ejecutivo. Destaca también que los diferentes roles asignados a ambas cámaras establecen un equilibrio entre ellas y evitan la parcialidad en la decisión. ${ }^{131}$

\title{
5. Los años formativos (1789-1829) \\ 5.1. El inicio
}

\begin{abstract}
Ratificada la Constitución el 21 de junio de 1788 y elegido George Washington como presidente el 4 de febrero de $1789,{ }^{132}$ se convino que el Congreso
\end{abstract}

sufficiently independent? What other body would be likely to feel confidence enough in its own situation, to preserve, unawed and uninfluenced, the necessary impartiality between an individual accused, and the representatives of the people, his accusers? [...] Could the supreme court have been relied upon as answering this description? It is much to be doubted whether the members of that tribunal would, at all times, be endowed with so eminent a portion of fortitude, as would be called for in the execution of so difficult a task; and it is still more to be doubted, whether they would possess the degree of credit and authority, which might, on certain occasions, be indispensable towards reconciling the people to a decision that should happen to clash with an accusation brought by their immediate representatives. A deficiency in the first, would be fatal to the accused; in the last, dangerous to the public tranquillity. The hazard in both these respects could only be avoided, if at all, by rendering that tribunal more numerous than would consist with a reasonable attention to economy. The necessity of a numerous court for the trial of impeachments, is equally dictated by the nature of the proceeding. This can never be tied down by such strict rules, either in the delineation of the offence by the prosecutors, or in the construction of it by the judges, as in common cases serve to limit the discretion of courts in favour of personal security. There will be no jury to stand between the judges, who are to pronounce the sentence of the law, and the party who is to receive or suffer it. The awful discretion which a court of impeachments must necessarily have, to doom to honour or to infamy the most confidential and the most distinguished characters of the community, forbids the commitment of the trust to a small number of persons" (El Federalista, $\mathrm{N}^{\circ} 63$ ).

131 "This partial intermixture is even, in some cases, not only proper, but necessary to the mutual defence of the several members of the government, against each other. An absolute or qualified negative in the executive, upon the acts of the legislative body, is admitted by the ablest adepts in political science, to be an indispensable barrier against the encroachments of the latter upon the former. And it may, perhaps, with not less reason, be contended, that the powers relating to impeachments are, as before intimated, an essential check in the hands of that body, upon the encroachments of the executive. The division of them between the two branches of the legislature, assigning to one the right of accusing, to the other the right of judging, avoids the inconvenience of making the same persons both accusers and judges; and guards against the danger of persecution, from the prevalency of a factious spirit in either of those branches. As the concurrence of two-thirds of the senate will be requisite to a condemnation, the security to innocence, from this additional circumstance, will be as complete as itself can desire" (El Federalista, $\mathrm{N}^{\circ} 63$ ).

132 Washington fue electo por unanimidad, con el voto de 69 electores, y John Adams fue electo vicepresidente con 34 votos. Los resultados recién se conocieron el 6 de abril y Washington tomó posesión del cargo el 30 de ese mes. 
comenzaría sus sesiones un mes más tarde, el 4 de marzo, una vez concluidas las elecciones de senadores y representantes. El lugar de reunión fue el Federal Hall de la ciudad de New York, ${ }^{133}$ por entonces capital de la nación. ${ }^{134}$

El día previsto para el inicio solo habían llegado a New York 13 de los 30 representantes necesarios para el quorum, de modo que fue necesario esperar casi un mes para que pudiera comenzar la primera sesión del House of Representatives, que tuvo lugar el 1 de abril. ${ }^{135}$ Ese mismo día, Frederick A. C. Muhlenberg, de Pennsylvania, fue elegido Speaker of the House y al día siguiente fue designada una comisión de 11 miembros para redactar las reglas de procedimiento que fueron aprobadas el 7 de abril. La primera comisión permanente, el Committee on Elections, compuesta de 7 miembros, fue elegida el 13 de ese mes con el propósito de examinar las credenciales de los representantes. El día 18 fueron aceptadas 49 credenciales y el House pudo comenzar sus tareas debatiendo una ley aduanera.

Inicialmente, las reglas de procedimiento del House fueron tomadas de las prácticas parlamentarias inglesas. El Speaker dirigía el debate, estaba encargado de preservar el decoro y el orden de las exposiciones y anunciaba el resultado de las votaciones. Las comisiones de 3 miembros eran elegidas por el Speaker; y las de mayor número, por elección entre los representantes. Ningún miembro del House podía hablar más de dos veces en un mismo asunto, solo podían votar quienes estaban presentes -salvo causa justificada- y debían abstenerse los que tenían un interés personal en el asunto. Era usual también que en el tratamiento de las leyes más importantes el House se reuniera como una comisión del pleno (Committee of the Whole House), en cuyo caso la presidencia no la ejercía el Speaker. Se aprobaban allí los lineamientos generales de la ley, luego se designaba una comisión especial (select committee) para que redactara el proyecto $^{136} \mathrm{y}$, una vez cumplida esta tarea, se informaba el resultado a la comi-

133 En ese mismo lugar se había reunido el Congreso de la Ley de Sellos en 1765. Para esta ocasión, el edificio había sido renovado íntegramente por el arquitecto francés Pierre-Charles L’Enfant. Había peleado como voluntario en la Guerra de la Independencia y luego fue el encargado del diseño de Washington D.C. Ver Rimini (2006, p. 10).

134 En diciembre de 1790, la capital se mudó a Philadelphia, donde el Congreso sesionó en el llamado Congress Hall, hasta que, en noviembre de 1800, se instaló en la flamante Washington D.C., creada como distrito federal por la Residence Act de 1790. Las sesiones comenzaron en el Capitolio (U.S Capitol), cuya primera parte ya estaba terminada en esa época.

135 El mal tiempo y el peor estado de los caminos habían demorado a los representantes que venían de los estados más lejanos (Rimini, 2006, p. 12).

136 Del mismo modo que en el Parlamento británico, esta comisión no era permanente, sino que se disolvía una vez cumplida su tarea. 
sión del pleno, que debatía la ley cláusula por cláusula. Luego de ello, el House se reunía como tal, el Speaker retomaba la presidencia, se aprobaban o rechazan las enmiendas introducidas por la comisión del pleno, luego se hacía una tercera lectura de la ley y se votaba la aprobación del texto. ${ }^{137}$ La práctica de elegir una comisión especial para el tratamiento de cada proyecto de ley, que luego se disolvía una vez concluido el trámite legislativo de ese proyecto, fue abandonándose a medida que el House fue creciendo en número ${ }^{138}$ y los asuntos a tratar fueron aumentando. Las comisiones especiales (select committees) fueron remplazadas paulatinamente por comisiones permanentes (standing committees). ${ }^{139}$

Tampoco el Senado pudo reunirse el 4 de marzo. Ese día habían llegado a New York solamente 8 senadores de los 22 que por entonces lo integraban. ${ }^{140}$ La primera sesión tuvo lugar el 6 de abril, 5 días después de haberse reunido el House. Por aquel entonces, el rol del Senado estaba por definirse. Había nacido, como vimos, del Great Compromise, que permitió sancionar la Constitución y no se sabía si debía actuar como revisor de las leyes sancionadas por el House o bien como un consejo asesor del presidente en la celebración de tratados internacionales, una función que en la práctica nunca ejerció. ${ }^{141}$ Algunos lo veían, incluso, como una amenaza a los principios republicanos, considerándolo una suerte de House of Lords americana, un sentimiento que alimentaban algunos senadores pretendiendo tener superioridad institucional sobre los representantes.

Del mismo modo que el House, en su primera sesión el Senado aprobó sus reglas de procedimiento, en la cuales John Adams, como presidente del cuerpo, se aseguró una amplia discreción y un control total. Las primeras sesiones del Senado se celebraron a puertas cerradas. Recién se permitió el acceso del público en 1794. Tampoco existía por entonces un diario de sesiones ni un espacio especial para la prensa, que recién fue creado en 1802. De todos modos, en es-

137 Por aquel entonces no existían límites temporales para exponer, lo que alargaba extraordinariamente los debates.

138 Luego del censo de 1790, su número creció a 106 y aumentó a 142 en 1800.

139 En 1795 ya había cuatro comisiones permanentes y entre 1802 y 1809 se agregaron seis más. Las más importantes fueron las de Comercio e Industria (Commerce and Manufactures), Presupuesto y Gasto Público (Ways and Means) y Tierras Públicas (Public Lands), creada en 1805 a propósito de la compra de la Louisiana francesa.

140 En ese momento, la Constitución había sido ratificada por once estados. Faltaban North Carolina, que la ratificó en noviembre de 1789, y Rhode Island, que lo hizo en mayo de 1790.

141 De hecho, cuando el 22 de agosto de 1789 Washington quiso valerse del acuerdo del Senado para celebrar un tratado con tribus indígenas, su presencia en el recinto, junto con Henry Knox, el secretario de Guerra, no fue bien recibida. 
tos años iniciales, el Senado no tuvo una gran carga de tareas, pues la gran mayoría de las leyes se originaron en el House. ${ }^{142}$ Las leyes no eran analizadas por comisiones permanentes, sino por comisiones creadas específicamente para un caso determinado y, concluida su tarea, se disolvían.

Pese a la necesidad de organizarse desde lo más básico y elemental, durante la sesión del primer año (1789), el Congreso estuvo muy activo. El 15 de mayo fueron distribuidos, por primera vez, los senadores en las tres clases que establece la sección del artículo I de la Constitución. ${ }^{143}$ El 8 de junio, James Madison introdujo el proyecto del Bill of Rights en el House; ${ }^{144}$ en julio, el Congreso organizó el primer departamento ejecutivo (ministerio), que en septiembre fue denominado State Department; ${ }^{145}$ en agosto fue organizado el Ministerio de Guerra (War Department); en septiembre; el Ministerio de Economía (Treasury Department) ${ }^{146}$ y el 24 de ese mes fue sancionada la primera Judiciary Act, que organizó la justicia federal y creó la Corte Suprema. ${ }^{147}$

Con el paso del tiempo, cada cámara iría adquiriendo su propia fisonomía, marcada en buena medida por el modo en que se componían. Mientras el House aumentaba numéricamente muy rápido, a impulsos del crecimiento de la población, el Senado lo hacía en forma lenta y esporádica, con el ingreso de cada estado. El mayor número de representantes obligó a que en el House

142 Durante los veinte primeros años (1789-1809), el 78\% de las leyes se originó en el House (Conf. Guide to Congress, 2015, p. 104).

143 Según esta cláusula constitucional, "Tan pronto como se hayan reunido en virtud de la elección inicial, [los senadores] se dividirán en tres grupos tan iguales como sea posible. Las bancas de los senadores del primer grupo quedarán vacantes al terminar el segundo año; las del segundo grupo, al expirar el cuarto año y las del tercer grupo, al concluir el sexto año, de tal manera que se pueda elegir una tercera parte cada dos años, y si se producen vacantes, por renuncia u otra causa, durante el receso de la legislatura de algún Estado, el Poder Ejecutivo [de dicho estado] podrá hacer designaciones provisionales hasta el siguiente período de sesiones de la legislatura, la que cubrirá dichas vacantes" ("Immediately after they shall be assembled in Consequence of the first Election, they shall be divided as equally as may be into three Classes. The Seats of the Senators of the first Class shall be vacated at the Expiration of the second Year, of the second Class at the Expiration of the fourth Year, and of the third Class at the Expiration of the sixth Year, so that one third may be chosen every second Year; and if Vacancies hap pen by Resignation, or otherwise, during the Recess of the Legislature of any State, the Executive thereof may make temporary Appointments until the next Meeting of the Legislature, which shall then fill such Vacancies").

144 El 25 de septiembre fueron sancionadas doce enmiendas por el Congreso y 2 años después, el 15 de diciembre de 1791, entraron en vigencia las diez primeras enmiendas con la ratificación otorgada por Virginia.

145 Thomas Jefferson fue designado secretario de Estado el 26 de septiembre.

146 El 11 de septiembre, Alexander Hamilton fue designado secretario del Tesoro.

147 John Jay fue elegido Chief Justice el 26 de septiembre y la Corte Suprema se reunió, por primera vez, el 2 de febrero de 1790 . 
sus miembros se restringieran en el uso de la palabra, delegaran muchas de sus funciones en las comisiones y crearan diversas técnicas para mantener fluido el paso de la legislación. El Senado, en cambio, mucho más pequeño en número, en el que cada senador se sentía un embajador de su estado, estas limitaciones de tiempo no fueron acuciantes. En el House, el objetivo principal fue la decisión; en el Senado predominaba la deliberación.

\subsection{Los símbolos de ambas cámaras}

Siguiendo la tradición del Parlamento británico -tomada, a su vez, de los romanos-, ambas cámaras del Congreso eligieron inmediatamente los símbolos representativos de su autoridad.

El House, en su primera sesión, diseñó para ello un mazo (mace) cuyo portador sería el sergeant at arms, encargado de preservar el orden en el recinto. El mace es un haz de 13 varillas de ébano ${ }^{148}$ atadas con bandas de plata, que en su extremo superior tiene un globo terráqueo y encima de él un águila con las alas desplegadas, todo del mismo metal. Tiene una longitud de 46 pulgadas (117 centímetros). ${ }^{149}$ Cuando el House está en una sesión ordinaria, el mace está colocado en un pedestal a la derecha del escritorio del Speaker; en cambio, cuando se reúne como comisión de la Cámara en pleno, se lo ubica en un lugar más inferior. ${ }^{150}$

En el Senado no hay un mace, sino un gavel, que tiene una forma similar a la cabeza del martillo que emplean los jueces. Según la tradición, John Adams, para preservar el orden en el Senado, utilizó desde el comienzo un gavel de marfil de unas 2,5 pulgadas y existen registros de su uso desde 1831. El gavel original se desintegró, sin posibilidad de ser reparado, en $1954 .{ }^{151}$ Ese año, el Gobierno de la India, recientemente establecido luego de su independencia, le obsequió al Senado uno nuevo, que actualmente está en uso. ${ }^{152}$

148 Representan a los 13 estados originales.

149 El primer mace fue destruido por los británicos cuando en la Guerra de 1812 incendiaron el Capitolio. Hasta 1841 fue utilizado uno de madera y, ese año, William Adams, un platero de New York, hizo el que actualmente sigue en uso.

150 Ver: https://history.house.gov/Collection/Listing/2006/2006-162-000/.

151 Ya estaba muy deteriorado y parece ser que en una acalorada sesión en 1954, Richard Nixon, por entonces vicepresidente, lo usó con fuerza y lo terminó de romper.

152 Ver: https://www.senate.gov/artandhistory/history/minute/The_Senates_New_Gavel.htm. 


\subsection{Emergen los partidos políticos. Federalistas y demócrata-republicanos}

Si bien la Constitución no tenía -ni tiene- cláusula alguna sobre los partidos políticos, estos no tardaron en aparecer y cobrar forma a partir de las dos agrupaciones que habían antagonizado en torno a la sanción de la Constitución: los federalistas y los antifederalistas. Washington, como presidente, se mantuvo imparcial en este proceso, pero ambos partidos comenzaron a formarse dentro de su propio gabinete. Alexander Hamilton, un activo y eficiente secretario del Tesoro, se erigió rápidamente como líder de los federalistas y Thomas Jefferson, como secretario de Estado, encabezó la posición contraria, secundado por James Madison, quien lo sucedería en el cargo en 1801. Ambos ocuparían luego la presidencia durante dos períodos cada uno. ${ }^{153}$ Los federalistas, en cambio, perdieron a su líder tempranamente, cuando Hamilton falleció en 1804 a raíz de la herida fatal que tuvo en el duelo con Aaron Burr, por entonces vicepresidente de Jefferson. ${ }^{154}$ Esta separación entre los que favorecían a un Gobierno central fuerte de corte más elitista y quienes preferían una democracia agraria se hizo más evidente y profunda con motivo del antagonismo entre Inglaterra y Francia a raíz de la Revolución francesa. Hamilton y sus partidarios proponían una política de neutralidad, mientras que Jefferson sostenía el apoyo a los franceses.

Durante las presidencias de Washington (1789-1797) y de Adams (17971801), ambos partidos estuvieron equilibrados en el House, pero bajo las presidencias de Jefferson (1801-1809) y de Madison (1809-1817) los Jeffersonians ${ }^{155}$ superaron ampliamente en número a los federalistas. Algo similar ocurrió en el Senado, donde los federalistas tuvieron una ajustada mayoría hasta 1801. A partir de allí, esta declinó. De todos modos, la existencia de estos dos partidos iniciales sería breve. Madison fue sucedido por James Monroe (1817-1825), quien si bien pertenecía al mismo partido que sus predecesores, intentó borrar

153 Recordemos que si bien por aquel entonces la Constitución permitía la reelección presidencial sin límites, todos los presidentes siguieron la costumbre de Washington de retirarse luego de cumplido el segundo período. La limitación a dos períodos fue establecida recién por la Enmienda XII (sancionada en 1947 y ratificada en 1951), luego de que Franklin D. Roosevelt fuera reelegido tres veces (1936, 1940 y 1945).

154 El duelo fue con pistolas y, aparentemente, Hamilton disparó primero en dirección a un cedro, sin intentar herir a Burr. Este, en cambio, hirió mortalmente a Hamilton. La bala le penetró en el abdomen y se alojó cerca de la columna vertebral. Falleció al día siguiente. Un detallado relato del duelo y sus antecedentes puede verse en una de las principales biografías de Hamilton (Chernow, 2005, caps. 41 y 42).

155 En esta primera etapa, los partidos políticos no tuvieron una denominación uniforme u oficial. Los federalistas siempre fueron reconocidos por este nombre y los partidarios de Jefferson se llamaron demócrata-republicanos, aunque esta denominación nada tiene que ver con los actuales partidos Republicano y Demócrata. 
las diferencias partidarias mediante su política del good feeling, convencido de que el partisanismo era negativo. Sea como fuere, ambos partidos prácticamente dejaron de existir hacia 1825. Tal como veremos más adelante, los federalistas se extinguieron y los demócrata-republicanos se dividieron en "demócratas" y whigs, los dos partidos que se disputaron el poder desde 1829 hasta la fundación del Partido Republicano, en 1854.

\subsection{El reparto del poder entre el Ejecutivo y el Congreso}

Durante los primeros veinte años (1789-1809), el Ejecutivo dominó el Congreso. Las figuras de Jefferson y Hamilton ejercieron una influencia tal en sus partidos que no permitieron el nacimiento de liderazgos legislativos fuertes. ${ }^{156}$ A lo largo de este período, los diferentes Speakers se comportaron en el House como portavoces de sus partidos, y cuando alguna figura elegida por el propio presidente no seguía sus mandatos, era inmediatamente removida del cargo que se le había asignado. ${ }^{157}$ Por su lado, Albert Gallatin, quien bajo el Gobierno de Jefferson sucedió a Hamilton en la Secretaría del Tesoro, continuó con la costumbre de su predecesor de influir con su política en el House. De modo tal que si bien en estas dos primeras décadas se fue institucionalizando el trabajo de las comisiones legislativas y la elección de un líder de la mayoría, todo ello se hizo bajo un estricto control del Ejecutivo.

\subsection{Nuevos líderes legislativos. Henry Clay y Daniel Webster}

Con la llegada de Madison a la presidencia, en 1809, esta tendencia se revirtió. Pese a que había liderado intelectualmente la Convención constituyente y había ejercido luego ocho años como secretario de Estado bajo Jefferson, durante su mandato presidencial Madison perdió el control sobre el Congreso que habían ejercido sus antecesores. Una nueva generación de políticos más jóvenes, a quienes John Randolph llamaba war hawks (halcones de guerra), pues propiciaron la guerra de 1812 contra Gran Bretaña, tomaron el control de Partido De-

156 Como gesto formal para que esta influencia fuera menos notoria, Jefferson inauguró la costumbre de no asistir a la inauguración de la sesiones del Congreso, enviando en su reemplazo a un asistente que leía su mensaje. Esta tradición se mantuvo hasta que Woodrow Wilson (1913-1921) la abandonó.

157 Este fue el caso de John Randolph, a quien Jefferson había elegido como líder en el recinto y presidente de la comisión de presupuesto (Ways and Means Committee). Sin embargo, Randolph entró en conflicto con Jefferson sobre la adquisición de Florida y fue destituido de su cargo en la comisión de presupuesto. 
mócrata-Republicano a expensas de las debilidades de Madison. Esta ausencia de influencia ejecutiva sobre el Congreso se mantuvo durante las dos décadas siguientes, hasta la presidencia de Andrew Jackson. ${ }^{158}$ Dentro de esta segunda generación de políticos, que sucedió a los Founding Fathers, se destacaron, entre otros, Henry Clay y Daniel Webster. ${ }^{159}$

Henry Clay era, indudablemente, un hombre de acción. Nacido en Virginia, se estableció desde joven en Kentucky, estado al cual representó en el Congreso. En la política nacional comenzó su carrera como senador por su estado de adopción en $1810,{ }^{160}$ donde se hizo notar por su exhortación a formar una "nueva raza de héroes" y su propuesta de luchar contra Canadá. ${ }^{161}$ De hecho, fue uno de los que impulsó la declaración de guerra contra Inglaterra, que dio lugar a la Guerra de 1812, y luego fue el jefe de la delegación que negoció el tratado de paz (Treaty of Ghent) en 1814. Representaba con ello un nuevo nacionalismo encendido por la interferencia británica en el comercio de los Estados Unidos. Su actividad como senador en esta primera etapa de su vida fue breve. Su carrera política se desarrolló como miembro del House, donde ingresó como representante de Kentucky en 1811. Merced a su elocuencia y personalidad, fue rápidamente elegido Speaker, posición para la que fue reelegido 6 veces, ocupando el cargo por espacio de más de 10 años. ${ }^{162}$ Desde allí dominó la Cámara, poniendo en las comisiones legislativas a sus war hawks. Todo ello le permitió convertirse en el líder del Partido Demócrata-Republicano. Luego fue secretario de Estado entre 1825 y 1829 durante la presidencia de John Quincy Adams y, más tarde, retornó al Senado ocupando una banca en 1831-1842 y 1849-1852.

Una carrera similar fue la de Daniel Webster, aunque tal vez sea más recordado por su actividad como abogado y senador que como representante en el House. Había nacido en New Hampshire en 1782 y, a diferencia de Clay,

158 Los sucesores de Madison, James Monroe y John Quincy Adams, tampoco tuvieron el control de su partido. Este último, especialmente, le debía su cargo al acuerdo celebrado con Henry Clay, que era por entonces Speaker del House.

159 También pertenecen a esta generación otros políticos prominentes que ocuparon en este período bancas en el Senado, tales como Andrew Jackson, por Tennessee (1823-1825), Martin van Buren, por New York (1821-1828), William Henry Harrison, por Ohio (1825-1828) y John Tyler, que fue representante por Virginia (1816-1821) y luego senador por ese mismo estado (1827-1836). Todos ellos fueron luego presidentes de los Estados Unidos.

160 Antes, en 1807, había sido diputado y presidente de la Cámara de Representantes de Kentucky.

161 Decía que con la milicia de Kentucky era suficiente para poner Montreal y el Alto Canadá a los pies de los Estados Unidos ("the militia of Kentucky are alone competent to put Montreal and the Upper Canada at your feet”). Vid. Mayo (1937, pp. 346-347).

162 Tenía 34 años cuando fue elegido la primera vez y fue el Speaker más joven 
militaba en las filas federalistas, a las que representó en el House como diputado por su estado natal en 1813-1817. Luego volvería a ocupar una banca allí en 1823-1827, por Massachusetts. Durante este período, combinó su actividad legislativa con el intenso ejercicio de la abogacía, representando los intereses de su partido en casos clave ante la Corte Suprema, donde los federalistas conservaban un fuerte bastión defendido por el Chief Justice John Marshall. Son famosos sus éxitos en leading cases como McCulloch $v$. Maryland, ${ }^{163}$ en el que se declaró la constitucionalidad de la creación del segundo Banco de los Estados Unidos; Trustees of Dartmouth College v. Woodward, ${ }^{164}$ en el cual se hizo valer la cláusula contractual frente a la interferencia legislativa de New Hampshire en una institución educativa privada; y Gibbons v. Ogden, ${ }^{165}$ en el que fue establecido que el Congreso tiene competencia exclusiva para regular el comercio interestatal. En 1827, Webster fue electo senador por Massachusetts y tuvo que dejar su banca en el House con cierta reticencia, pues había sentado allí sus reales desempeñándose como presidente de la Comisión de Asuntos Judiciales (House Judiciary Committee). Fue reelecto como senador hasta 1841, cuando fue designado secretario de Estado por el presidente William Harrison. En 1845 volvió al Senado hasta 1850, año en el que fue nuevamente designado secretario de Estado por el presidente Millard Fillmore. Murió en 1852 en ejercicio del cargo. Estando en el Senado, fue famoso su debate con el senador Robert Y. Hayne de South Carolina. Lo que comenzó siendo una discusión sobre tierras fiscales federales concluyó en un análisis integral del sistema federal. Hayne sostenía el derecho de anulación (nullification) de los estados, una posición propia de una confederación, mientras que Webster defendía la tesis de la Unión como estado soberano. ${ }^{166}$

Hacia el final de este período, cobró notoriedad John Caldwell Calhoun, de South Carolina, que fue el segundo vicepresidente de John Quincy Adams en 1825-1829 y luego el primer vicepresidente de Andrew Jackson en 1829-1832, sucedido por Martin Van Buren. Sus antecesores inmediatos en el cargo no se habían lucido. George Clinton, vicepresidente de Madison, era anciano, estaba débil y murió durante su mandato, al igual que su sucesor, Elbridge Gerry. Daniel Tompkins, exgobernador de New York y vicepresidente de Monroe, casi

\footnotetext{
16317 U.S. 316 (1819).

16417 U.S. 518 (1819).

16522 U.S. 1 (1824).

166 El debate está reproducido en Belz (2000). Por mi parte, lo he analizado con más detalle en Bianchi (2008, pp. 210-214).
} 
no concurrió a las sesiones, aquejado por problemas financieros y de salud. ${ }^{167}$ Calhoun, por el contrario, merced a su hostilidad con Adams y sus ambiciones presidenciales, revitalizó el cargo con el apoyo del senador Hayne -rival de Webster en el debate antes mencionado-, quien fue el vocero de sus decisiones. Durante las dos décadas siguientes, hasta su muerte en 1850, Calhoun fue un influyente senador, liderando la facción esclavista de los sureños.

\subsection{El crecimiento de las comisiones legislativas permanentes}

El fortalecimiento de ambas cámaras en este período fue acompañado de un crecimiento sustancial de las comisiones legislativas permanentes (standing committees). De acuerdo con la tradición heredada del Parlamento inglés, en un comienzo las leyes eran analizadas por comisiones ad hoc (select committees), que se disolvían una vez concluida su tarea. Durante ese período, esta costumbre fue abandonándose paulatinamente y se crearon numerosas comisiones permanentes con competencia específica, que se convirtieron en el foro principal para el análisis de los proyectos de leyes.

Así, en el House, de las 350 comisiones ad hoc existentes en el $3^{\circ}$ Congreso (1793-1795), solo quedaban 70 en el 13० Congreso (1813-1815), y las comisiones permanentes, que eran 10 en 1809 , crecieron a 20 en 1825 . Asimismo, en 1822 , una regla dictada por el House le otorgó a estas comisiones la facultad de reportar sus conclusiones directamente al pleno de la Cámara. Entre las comisiones permanentes creadas en el House durante este período, la más importante fue la de presupuesto y asuntos financieros (Committee of Ways and Means), creada en 1789 como una comisión especial (select committee) y convertida en permanente en $1802 .{ }^{168}$ Esta comisión es particularmente importante para el

167 Además de las numerosas biografías individuales sobe cada vicepresidente, puede verse Purcell (2001).

168 La resolución que crea el Committee of Ways and Means como una comisión permanente establece su competencia en estos términos: "It shall be the duty of the said Committee on Ways and Means to take into consideration all such reports of the U.S. Department of the Treasury, and all such propositions relative to the revenue, as may be referred to them by the House; to inquire into the state of the public debt, of the revenue, and of the expenditures, and to report, from time to time, their opinion thereon; to examine into the state of the several public departments, and particularly into the laws making appropriations of moneys, and to report whether the moneys have been disbursed conformably with such laws; and also to report, from time to time, such provisions and arrangements, as may be necessary to add to the economy of the departments, and the accountability of their officers". Ver: https://waysandmeans.house.gov/about/committee-history. Ver también: https://waysandmeans.house.gov/about/committee-history/appendix-ii-historical-note-committee-ways-and-means. 
House, ya que por mandato constitucional (artículo I, sección 7) las leyes impositivas deben iniciarse allí. Fueron creadas también, en 1822, las comisiones de Asuntos Militares, Asuntos Navales y Relaciones Internacionales. Antes de ello, en 1816, a instancias de Clay, fueron creadas seis comisiones sobre gasto público, una por cada Secretaría de Estado (ministerios) existentes en ese momento. Todas estas comisiones llevaron a cabo numerosas investigaciones en la década de 1816-1826, entre ellas, la de la conducta del general Andrew Jackson en la Seminole War y las de William Crawford como secretario del Tesoro y John Calhoun como secretario de Guerra. ${ }^{169}$

Aunque con menor intensidad, las comisiones permanentes también comenzaron a proliferar en el Senado. La tarea de nombrar una comisión para el tratamiento de cada proyecto de ley resultó agotadora ${ }^{170} \mathrm{y}$, como resultado, comenzó a extenderse en el Senado también la práctica de designar comisiones permanentes con competencia específica. Las primeras fueron creadas en diciembre de 1816. Entre ellas, las de Relaciones Exteriores, Finanzas, Comercio y Manufacturas, Asuntos Militares, Asuntos Navales, Milicia, Tierras Públicas, Reclamos, Justicia, Correo, Caminos y Pensiones. Inicialmente, estas comisiones tenían cinco miembros, pero ese número se incrementó a siete a mediados del siglo XIX y a nueve en $1900 .{ }^{171}$

\subsection{La Corte Suprema colabora para fortalecer al Congreso}

El fortalecimiento del Congreso durante este período recibió la ayuda de la Corte Suprema en tres fallos, dos de ellos ya mencionados en párrafos anteriores. Me refiero a McCulloch v. Maryland, ${ }^{172}$ en el que se reconoció que el Congreso tenía facultades implícitas, dentro de las cuales estaba la de crear un banco

169 Vid. Guide to Congress (2015, p. 41).

170 En la sesión de 1815-1816 se nombraron casi cien comisiones.

171 El modo de elegir a los miembros de estas comisiones fue variando de acuerdo a las conveniencias políticas de cada momento. Hasta 1823, eran elegidos por votación mediante boleta (ballot). Ese año se dispuso que serían elegidos por el presidente pro tempore del Senado. Durante 1825-1827, John Calhoun reasumió personalmente esa tarea como vicepresidente para designar en ellas a los partidarios de Andrew Jackson, en una clara maniobra para fastidiar al presidente John Quincy Adams. En 1828 se delegó nuevamente la tara en el presidente pro tempore y en 1833 se volvió al sistema de la votación por boleta.

17217 U.S. 316 (1819). 
federal; ${ }^{173}$ Gibbons v. Ogden, ${ }^{174}$ que le otorgó al Congreso facultades exclusivas para regular el comercio interjurisdiccional; y Brown v. Maryland, ${ }^{175}$ que ratificó lo anterior al declarar inconstitucional una ley de Maryland que exigía una licencia para vender, dentro de su territorio, productos importados, sosteniendo que si bien los estados tienen el poder de gravar a sus ciudadanos, ese poder no puede obstruir el ejercicio de facultades propias del Congreso. ${ }^{176}$

\subsection{La elección de 1824 y el nacimiento del Partido Demócrata}

A partir de la elección de 1816, los demócrata-republicanos, que ya dominaban por completo la escena política, comenzaron a dividirse entre los antiguos terratenientes y los nuevos pequeños granjeros que se habían incorporado a la vida política con la extensión del sufragio. Estos últimos encontraron un líder en el general Andrew Jackson, de Tennessee. Aguerrido y controvertido militar de numerosas batallas, ${ }^{177}$ Jackson compitió por la presidencia con John Quincy

173 'Although, among the enumerated powers of government, we do not find the word 'bank,' or 'incorporation,' we find the great powers to lay and collect taxes; to borrow money; to regulate commerce; to declare and conduct a war; and to raise and support armies and navies. The sword and the purse, all the external relations, and no inconsiderable portion of the industry of the nation, are entrusted to its government. It can never be pretended that these vast powers draw after them others of inferior importance, merely because they are inferior. Such an idea can never be advanced. But it may with great reason be contended, that a government, entrusted with such ample powers, on the due execution of which the happiness and prosperity of the nation so vitally depends, must also be entrusted with ample means for their execution. The power being given, it is the interest of the nation to facilitate its execution. It can never be their interest, and cannot be presumed to have been their intention, to clog and embarrass its execution by withholding the most appropriate means [...] If, indeed, such be the mandate of the constitution, we have only to obey; but that instrument does not profess to enumerate the means by which the powers it confers may be executed; nor does it prohibit the creation of a corporation, if the existence of such a being be essential to the beneficial exercise of those powers. It is, then, the subject of fair inquiry, how far such means may be employed" (17 U.S., pp. 407-408).

17422 U.S. 1 (1824).

17525 U.S. 419 (1827).

176 "It has been contended, that this construction of the power to regulate commerce, as was contended in construing the prohibition to lay duties on imports, would abridge the acknowledged power of a state to tax its own citizens, or their property within its territory. We admit this power to be sacred; but cannot admit that it may be used so as to obstruct the free course of a power given to Congress. We cannot admit that it may be used so as to obstruct or defeat the power to regulate commerce. It has been observed, that the powers remaining with the states may be so exercised as to come in conflict with those vested in Congress. When this happens, that which is not supreme must yield to that which is supreme" (25 U.S., p. 448).

177 Siendo muy joven, fue prisionero de los ingleses durante la Guerra de la Independencia, intervino luego en la Guerra de 1812, también contra los ingleses y participó en la guerra de 1817-1818 contra los indígenas de la tribu seminola, excediendo en varias oportunidades las instrucciones que había 
Adams (hijo de John Adams, el segundo presidente) en la reñida elección de 1824, siendo por entonces senador por Tennessee. ${ }^{178}$ Si bien Jackson había obtenido la mayoría de los votos populares, ninguno de los cuatro candidatos que se presentaron (los otros fueron Henry Clay y William H. Crawford) obtuvo mayoría en el colegio electoral, de modo que, bajo lo establecido en la Enmienda XII (sancionada en 1803 y ratificada en 1804), el House tuvo que dirimir la elección. Allí, la balanza se inclinó a favor de Adams, merced a un acuerdo que este había celebrado con Henry Clay, de Kentucky, el entonces Speaker, un ferviente oponente de Jackson, que luego fue designado secretario de Estado por Adams. Los partidarios de Jackson se alzaron furiosos, denunciando la existencia de un acuerdo corrupto entre Adams y Clay y se separaron del partido gobernante, fundando el actual Democratic Party, ${ }^{179}$ que llevó a Jackson a la presidencia en 1828 con un triunfo aplastante sobre Adams. El resto del partido, bajo el liderazgo de Henry Clay y Daniel Webster, pasó a llamarse Whig Party, ${ }^{180}$ que disputó el poder con los demócratas jacksonianos hasta extinguirse luego del nacimiento del Republican Party, en 1854, surgido, como veremos, como reacción espontánea contra la llamada "Ley Kansas-Nebraska".

\section{Whigs y demócratas hasta la Guerra Civil (1829-1861) \\ 6.1. Dos nuevos partidos}

Whigs y demócratas sucedieron, respectivamente, a los antiguos federalistas y a los demócrata-republicanos de la primera época, pero, curiosamente, intercambiaron en parte la filosofía política que originariamente había inspirado a cada partido. Los demócratas jacksonianos tomaron de su jefe político el presidencialismo fuerte, que otrora predicaban los federalistas. A su vez, los whigs propiciaban la supremacía legislativa, una bandera inicialmente enarbolada por los seguidores de Jefferson. No obstante ello, de sus antiguas raíces los whigs conservaron el interés por la protección de la industria y el comercio, mientras que los demócratas defendían los derechos de los estados y, fundamentalmente, la economía agraria basada en la esclavitud. Con este telón de fondo, ambos partidos dominaron -y se repartieron- la escena política durante los 30 años

recibido del presidente James Monroe.

178 Antes de ello había sido juez del superior tribunal de ese estado entre 1798 y 1804.

179 Sobre los orígenes del Democratic Party puede verse Cheathem (2018).

180 Sobre la historia del Whig Party en los Estados Unidos puede verse Holt (1999). 
que precedieron a la Guerra Civil, cuyos hechos más salientes son: la disputa por la esclavitud, la preeminencia del Senado, la fractura interna del House en dos mitades prácticamente iguales, los conflictos entre el Senado y el Ejecutivo y el nacimiento del Partido Republicano en 1854.

\subsection{Preeminencia del Senado sobre el House}

A lo largo de las tres décadas previas a la Guerra Civil, el Senado vivió una edad dorada. Si bien sus causas pueden ser numerosas, lo cierto es que contribuyeron a ello factores tales como la mayor experiencia política de sus miembros, su prestigio y su estabilidad en el cargo, fruto de la más prolongada duración de sus mandatos. Asimismo, la constante expansión territorial y la creación sucesiva de nuevos estados, cada uno de los cuales aportaba dos nuevos senadores, fue transformando al Senado de un cenáculo íntimo y reducido en un cuerpo político de gran peso, nutrido con las personalidades políticamente más destacadas de entonces. De hecho, en 1829, al comienzo del primer mandato de Jackson, el Senado tenía 48 miembros, y hacia el final del gobierno de Buchanan, en 1861, había alcanzado los 66. Por el contrario, el House, luego de alcanzar los 242 representantes en 1833, no incrementó el número de representantes durante los cuarenta años siguientes. ${ }^{181}$

Además de Daniel Webster y Henry Clay, a los que ya hice mención, se destacaron en este período, entre otros, John C. Calhoun, de South Carolina (1832-1843 y 1845-1850), que había sido vicepresidente bajo John Quincy Adams (1825-1829) y Andrew Jackson (1829-1832) y fue luego secretario de Estado con John Tyler (1844-1845); Thomas Hart Benton, de Missouri, que representó allí a los demócratas durante treinta años (1821-1851); Lewis Cass, demócrata de Michigan (1849-1857); Samuel Houston, demócrata de Texas, uno de los dos primeros senadores de su estado (1846-1859), cuyo nombre lleva la conocida ciudad; Jefferson F. Davis y Henry S. Foote, demócratas de Mississippi que luego se volcaron a la causa de los confederados; William H. Seward, de New York (1849-1861), que fuera primero whig y luego republicano; Stephen Douglas, de Illinois (1847-1861), quien entre agosto y octubre de 1858 mantuvo con Lincoln los célebres debates sobre la esclavitud en siete ciudades de ese estado; y Charles Sumner, de Massachusetts (1851-1874), gran orador y ferviente antiesclavista. ${ }^{182}$

181 Recién alcanzó los 292 miembros en el 43 Congreso (1873-1875).

182 Su enérgica prédica antiesclavista lo convirtió en víctima de uno los hechos más deplorables y violentos que hayan tenido lugar en el Senado. En mayo de 1856 estaba ardiente la discusión acerca de si 


\subsection{Los conflictos de Jackson con el Senado}

La pérdida de poder político que había sufrido el Ejecutivo con Madison fue recobrada bajo el Gobierno de Jackson. Apoyado por mayorías populares y dotado de una fuerte personalidad, el nuevo presidente no tardó en ejercer una gran influencia sobre el House, pero encontró, paralelamente, una fuerte oposición en los senadores del joven Partido Whig, representantes de intereses industriales y comerciales y, sobre todo, sostenedores del principio de supremacía legislativa, que no tardaron en cuestionar el ejercicio de la prerrogativa presidencial. Entre otras controversias, una de las más notables tuvo lugar en 1834, cuando Jackson dispuso de fondos depositados en el Banco de los Estados Unidos y se negó a entregarle al Senado los documentos que sobre este asunto había intercambiado con miembros de su gabinete. Impulsada por Henry Clay, el Senado emitió entonces una resolución censurando la decisión presidencial, que no tardó en ser respondida por un mensaje de Jackson cuestionando la competencia del Senado para emitirla, en tanto -sostuvo- se trataba de cargos propios de un juicio político (impeachment), que solo podía ser promovido por el House. Todo ello dio lugar a una larga disputa, en la cual el senador Thomas Benton ejerció una fuerte influencia para derogar la resolución, lo que finalmente tuvo lugar hacia 1837, ya sobre el final del segundo mandato de Jackson, cuando los demócratas jacksonianos habían logrado el control del Senado.

\subsection{Los whigs contra Tyler}

Estas disputas entre los senadores whigs y el presidente continuaron bajo el Gobierno de John Tyler (1841-1845). A Jackson lo sucedió Martin Van Buren (1837-1841), demócrata también, y este fue sucedido, a su vez, por William Harrison, del Partido Whig, fuertemente apoyado por Daniel Webster y Henry Clay. Con Harrison, los whigs pensaron que tenían asegurado el control

Kansas debía ser admitido como un estado libre o esclavista. Durante un encendido discurso para que fuera declarado un estado libre, Sumner se dirigió en términos muy duros contra los senadores Stephen Douglas, de Illinois, y Andrew Butler, de South Carolina. Tres días después, el 22 de mayo, luego de concluida la sesión, entró en el recinto del Senado Preston S. Brooks, representante de South Carolina, y, sin decir palabra, comenzó a golpear a Sumner en la cabeza con un bastón con puntera de metal hasta dejarlo sangrando e inconsciente, sin que nadie fuera capaz de detener la agresión. Como todo castigo, Brooks fue removido de su banca, aunque luego fue reelegido. Dada la gravedad de sus heridas, Sumner tardó casi tres años en regresar al Senado. Tal como veremos luego, en 1867 Sumner fue uno de los artífices de la aprobación en el Senado de la compra de Alaska. Ver https://www.senate. gov/artandhistory/history/minute/The_Caning_of_Senator_Charles_Sumner.htm. 
político, ${ }^{183}$ pero, para su desgracia, Harrison falleció un mes después de haber asumido y fue sucedido por Tyler, su vicepresidente, otrora militante de las filas demócratas ${ }^{184}$ que había sido elegido para integrar la fórmula con Harrison con miras a que la candidatura de este tuviera mayor equilibrio geográfico. Clay, antiguo amigo de Tyler y líder de los senadores whigs, creyó que podría dominarlo, pero no resultó así. Tyler vetó numerosas iniciativas legislativas de los whigs y estos, a su vez, rechazaron muchas de sus propuestas de designaciones, cuatro de ellas en el gabinete. Como resultado de esta controversia, los whigs nunca lograron tener, durante este período, una mayoría que les permitiera consolidar la supremacía legislativa a la que aspiraban.

\subsection{Los acuerdos legislativos sobre la distribución geográfica de la esclavitud}

Como parte de su preeminencia sobre el House, el Senado se convirtió en el principal foro de discusión de uno los problemas nacionales más importantes y sensibles de ese momento: la esclavitud. El debate, por cierto, tenía un trasfondo humanitario, pero su móvil también era económico y amenazaba seriamente con dividir a la Unión, como efectivamente ocurrió al final de este período. Mientras los estados del norte hacían grandes esfuerzos por abolirla, los del sur se resistían con dureza, pues ello comprometía seriamente sus economías rurales, basadas en gran medida en la mano de obra gratuita que la esclavitud representaba.

Si bien un primer paso importante en el intento por limitarla había tenido lugar en marzo de 1807 cuando, a instancias de Jefferson, el Congreso aprobó una ley que declaró ilegal -en todo el territorio de los Estados Unidos- el ingreso de esclavos a partir del 1 de enero de 1808, a lo largo de los años siguientes la esclavitud se convirtió en un problema que dividiría, geográfica y políticamente, al país a medida que este se expandía territorialmente. Ello ocurrió en dos oleadas: la primera tuvo lugar con la expansión al oeste del río Mississippi luego de la compra de Louisiana al Gobierno francés en 1803, y la segunda se produjo con la anexión de nuevos territorios luego de la guerra con México. Esta cuestión era particularmente sensible en el Senado, pues había estados con esclavitud y otros libres de ella, de modo que cada vez que se reconocía uno nuevo, se discutía cuál sería su condición ante dicho fenómeno.

183 Webster fue designado secretario de Estado y numerosos partidarios de Clay ocuparon cargos en el gabinete.

184 Antes de ello, Tyler había sido gobernador de Virginia (1825-1827) y senador nacional por ese estado (1827-1836). 
Todo ello generó, entre 1820 y 1854, tres acuerdos legislativos por medio de los cuales se dividió el territorio de los Estados Unidos entre estados sin esclavitud y estados con esclavitud. La línea divisoria fue el paralelo 36: los estados que estaban al norte eran libres y en los que estaban al sur se mantenía la esclavitud. El primer acuerdo fue celebrado en 1820, como consecuencia de la incorporación de Missouri como estado. Esto produjo el llamado Missouri Compromise, instrumentado en un conjunto de leyes que, además de resolver que Missouri sería un estado esclavista y Maine no, generó un acuerdo mediante el cual la incorporación de cada nuevo estado se llevaría a cabo alternando un estado esclavista con un estado libre como medio para mantener el equilibrio en el Senado.

Treinta años después, en 1850, con motivo de la anexión de los territorios obtenidos en la Mexican War de 1846-1848, fue necesario celebrar un nuevo acuerdo. Este conflicto le dio a los Estados Unidos la oportunidad de incorporar un vasto territorio ${ }^{185} \mathrm{y}$ correr su frontera hacia el oeste. ${ }^{186} \mathrm{Al}$ mismo tiempo, California, uno de los mejores frutos de la expansión, había crecido exponencialmente con el gold rush de 1849 y pretendía convertirse en estado. Surgió así el Compromise of 1850, integrado por cinco leyes que negociaron los senadores Henry Clay y Daniel Webster, por el Partido Whig, y Stephen Arnold Douglas, por los demócratas. Por medio de este conjunto de leyes: (a) se solucionó una disputa territorial de Texas; (b) se dispuso que los territorios de New Mexico, Nevada, Arizona y Utah serían organizados sin mención expresa de la esclavitud, cuestión que sería luego resuelta por sus habitantes al momento en que requirieran el otorgamiento de la condición de estado; (c) en el distrito de Columbia, donde existían los mayores mercados de esclavos, estos se eliminarían, sin perjuicio de la subsistencia de la esclavitud; y (d) California sería admitida como estado libre de esclavitud. ${ }^{187}$

185 Es el que actualmente ocupan los estados de Arizona, California, Colorado, New Mexico, Nevada, Utah y parte de Wyoming.

186 Sobre la guerra entre los Estados Unidos y México puede verse Meed (2002).

187 Adicionalmente, y como medio para pacificar a los políticos esclavistas que cuestionaron la incorporación de California como estado libre, rompiendo con ello el equilibrio logrado luego del Compromiso de Missouri de 1820, fue sancionada la Ley de Esclavos Fugitivos (Fugitive Slave Act), una norma brutal, plagada de disposiciones en las cuales el esclavo seguía siendo nada más que una mercancía despojada de todo derecho. Se les requería a todos los ciudadanos asistencia para la recuperación de los esclavos fugitivos, y si estos eran capturados, no podían testificar y carecían de todo derecho a un juicio por jurados. En sustitución eran sometidos a comisionados especiales, designados por los tribunales federales, que cobraban cinco dólares si ordenaban la libertad del esclavo y diez dólares si disponían su devolución al dueño original. Estas disposiciones montaron un 
Bajo estas cláusulas, el Compromiso de 1850 logró mantener unida a la Nación, pero fue una solución meramente temporaria que dividió más aún las aguas entre esclavistas y abolicionistas. Tan es así que cuatro años después, en 1854, una nueva embestida esclavista logró derogar el Compromiso de Missouri. El hecho tuvo lugar con motivo de la creación de los territorios de Kansas y Nebraska, en el marco de una nueva expansión hacia el oeste impulsada por varios factores, entre ellos, la construcción del llamado "ferrocarril transcontinental", que llegaría hasta la frontera oeste. Debía decidirse entonces la situación de la esclavitud en estos nuevos territorios ubicados al norte del paralelo 36. A tal fin se habían llevado a cabo, sin éxito, cuatro intentos de organizar un solo territorio, los que fueron boicoteados por los sureños que se oponían al Compromiso de Missouri. Finalmente, se impuso el proyecto del senador Stephen Douglas, presidente de la Comisión de Territorios, que hizo una fuerte concesión a los intereses esclavistas. Como resultado transaccional, fue sancionada la Ley Kansas-Nebraska (Kansas-Nebraska Act) de mayo de 1854, ${ }^{188}$ apoyada por el presidente Pierce, por medio de la cual se crearon dos territorios diferentes, disponiéndose que la población de cada uno en su momento decidiría la cuestión de la esclavitud. Era lo que Douglas llamó "el principio de la soberanía popular". Adicionalmente fue derogado el Compromiso de Missouri, bajo el cual la esclavitud habría sido prohibida en ambos territorios. Tal como veremos más adelante, la sanción de esta ley dio nacimiento al Partido Republicano.

\subsection{Las contiendas en el House por la designación del Speaker}

Una muestra de la fractura política del House, en dos mitades casi iguales a lo largo de este período, son las contiendas internas que se produjeron en 1839, 1849, 1855 y 1859 por la designación del Speaker, bien que estas ya se habían producido también con anterioridad, aunque con menor intensidad. ${ }^{189}$ Estas

reino de terror en la población negra, pues muchos de sus integrantes, aun sin ser esclavos, fueron secuestrados y sometidos como tales sin poder ejercer defensa alguna. Si bien es anterior a esta ley, la situación de los afroamericanos libres secuestrados y vendidos como esclavos fue relatada por Solomon Northup, una víctima de este crimen, en la célebre obra Twelve Years a Slave, publicada originalmente en 1853, que dio lugar a una también aclamada película en 2013.

18810 Statutes at Large 277.

189 Antecedentes de estas dificultades fueron las elecciones de 1819 y 1821 . En la primera debieron llevarse a cabo 22 votaciones para poder elegir a John Tyler, de New York, un candidato antiesclavista, sobre William Lowndes, de South Carolina. En la segunda, Philip P. Barbour, de Virginia, derrotó a Taylor luego de 12 votaciones. Estos datos, así como los de las siguientes contiendas electorales, fueron consultados en: https://history.house.gov/People/Office/Speakers-Multiple-Ballots/. 
contiendas tienen, como contexto general, el profundo debate sobre la esclavitud entre whigs y demócratas, pero se explican, además, por el equilibrio en número de representantes de ambos partidos y porque, en aquella época, el Speaker designaba a los miembros de las comisiones y a los presidentes de estas, lo que le otorgaba un gran poder.

En diciembre de 1839, al iniciarse el 26 Congreso (1839-1841), la distribución de las bancas en el House estaba prácticamente empatada entre los partidos. Había 120 representantes demócratas, 118 whigs y 5 bancas que todavía se disputaban. Luego de 4 días de agrias disputas, fue electo en forma temporaria John Quincy Adams. Luego, el 14 de diciembre, se decidió llevar a cabo la elección sin contar las bancas en disputa, y dos días después, luego de 11 votaciones, Robert M. T. Hunter, de Virginia, venció a John W. Jones, virginiano también.

Mucho más reñida fue la contienda de 1849 , producida al comienzo del $31^{\circ}$ Congreso (1849-1851), cuando la elección de Howell Cobb, un demócrata de Georgia, exigió 63 votaciones. Durante los años anteriores, merced al virtual empate en la distribución de las bancas entre demócratas y whigs, el control del House fue alternándose de un partido a otro con escaso margen de diferencia. Los whigs tuvieron el control del $27^{\circ}$ Congreso (1841-1843), los demócratas lo recuperaron en el 28० (1843-1845) y 29० (1845-1847) y los whigs lo retomaron nuevamente en el 30॰ (1847-1849). En 1848 fue electo presidente de los Estados Unidos Zachary Taylor, un militar con poca experiencia política, pero que había liderado la guerra con México y, como tal, era considerado un héroe nacional. Si bien Taylor había ganado con el apoyo del Partido Whig, estos no consiguieron controlar el House durante el 31 ${ }^{\circ}$ Congreso, que se reunió en diciembre de 1849. Ningún partido tenía la mayoría en ese momento, en el cual la cuestión más crítica a resolver era si en los nuevos territorios conquistados a México se impondría la esclavitud o si estos quedarían libres de ella. La elección del Speaker se hizo más difícil aún, pues ninguno de los dos partidos decidió apoyar a quienes eran los principales candidatos: Robert C. Winthrop, de Massachusetts, por los whigs, y Howell Cobb, por los demócratas. Como resultado de ello, 8 candidatos compitieron en la elección que fue decidida, luego de 63 votaciones, a favor de Cobb, el candidato demócrata y proesclavista, por un margen de apenas 2 votos.

Luego, en el $32^{\circ}$ y $33^{\circ}$ Congresos (1851-1855), tuvieron el control del House los demócratas proesclavistas, siendo Speaker Linn Boyd, de Kentucky. Pero en 1854, como reacción contra la Kansas-Nebraska Act ya mencionada, se formó 
el Partido Republicano, fuerte opositor a la esclavitud que, finalmente, sería el continuador de los whigs. Los republicanos participaron, por primera vez, en las elecciones en las que se eligieron representantes para el $34^{\circ}$ Congreso, reunido en diciembre de 1855, en el cual republicanos y whigs tuvieron una mayoría de 108 representantes, contra 83 demócratas. A pesar de esta mayoría, los opositores a la Kansas Nebraska Act no lograron unirse detrás de un solo candidato. Como resultado de ello, durante 2 meses se llevaron a cabo 133 votaciones, con 21 postulantes compitiendo en ellas. Finalmente, sin haber obtenido la mayoría, en febrero de 1856 Nathaniel P. Banks, de Massachusetts, fue declarado Speaker. No pertenecía a ninguna de los partidos mayoritarios, sino que militaba en una agrupación llamada American Party o Know Nothings, ${ }^{190}$ que luego se disolvió pasando a formar parte de las filas republicanas.

También fue muy disputada la elección de William Pennington, de New Jersey, en 1859. Como en el caso anterior, la decisión terminó recayendo, por compromiso, en un individuo casi desconocido que no tenía una clara afiliación política. Los demócratas controlaron el House durante el $35^{\circ}$ Congreso (1857-1859), pero al reunirse el 36 Congreso, en diciembre de 1859, ningún partido tenía el control de la Cámara, compuesta entonces por 109 republicanos, 101 demócratas y 27 know nothings. En un primer momento, parecía que la elección recaería en John Sherman, republicano de Ohio, ${ }^{191}$ quien llegó a tener 101 votos, pero la fuerte oposición ejercida por los demócratas contra aquel les hizo comprender a los republicanos que nunca resultaría electo. Sherman retiró entonces su candidatura y los republicanos le dieron su apoyo a Pennington, que obtuvo 117 votos en la $44^{\text {a }}$ votación. ${ }^{192}$

Como saldo institucional, estas contiendas no favorecieron la elección de figuras de relevancia. Ninguno de los 14 Speakers que sucedieron a Henry Clay entre 1825 y 1860 tuvieron su estatura e influencia, y solamente tres de ellos -Stevenson, Polk y Boyd- fueron elegidos como representantes en más de un Congreso.

190 Formada en la década de 1850, sus integrantes eran protestantes que se oponían a la ola de católicos llegados en esa época, principalmente desde Irlanda, sosteniendo que eran antidemocráticos. Las luchas entre protestantes y católicos de ese momento se hizo más conocida cuando, en 2002, fue llevada al cine en la película Gangs of New York (Pandillas de Nueva York), dirigida por Martin Scorsese.

191 Muchos años después, siendo senador, John Sherman fue el redactor de la Sherman Antritust Act (Ley Sherman Antimonopolios), sancionada en 1890 por el 51 Congreso (1889-1891).

192 De tal forma, Pennington fue electo Speaker en su primer y único mandato como representante. Murió poco después, en 1862. 


\subsection{Las discusiones sobre las peticiones relativas a la esclavitud}

No solo las elecciones de los Speakers fueron reñidas. La fractura interna del House entre los dos partidos mayoritarios se hizo sentir en muchos otros aspectos. Uno de ellos fue el tratamiento que la Cámara debía darle a las peticiones relativas a la esclavitud, aunque la división en este caso no fue tan tajante entre whigs y demócratas.

Desde 1792 existía la costumbre de no recibir este tipo de peticiones y propuestas, pero, en 1836, John Quincy Adams quebró esta práctica presentando una petición de ciudadanos de Massachusetts para abolir la esclavitud en el distrito de Columbia. A raíz de ello, se desató una fuerte disputa que terminó con la emisión de una resolución, aprobada por una mayoría de 117-68 votos, según la cual las propuestas relativas a la esclavitud serían recibidas por el House, pero no se les daría tratamiento. No contento con ello, al año siguiente, Adams insistió en presentar una nueva petición formulada por 22 esclavos. Su propuesta fue nuevamente rechazada por una mayoría de 163-18, con fundamento en que los esclavos carecían del derecho de petición otorgado por la Constitución a las personas libres. ${ }^{193}$ Tres años después, en 1840, se reanudó esta discusión y, por mayoría de 114-108, se decidió que el House no recibiría ni le daría tratamiento a ninguna petición en favor de abolir la esclavitud. No obstante, en 1844, esta regla fue derogada por una mayoría de 108-80 votos.

\subsection{Nuevas reglas de procedimiento para los debates en el House}

A medida que se iban desarrollando las actividades del House, se advirtió la necesidad de cambiar algunas reglas de procedimiento aplicables a los debates. Así, por ejemplo, en 1837 se dispuso que tendría precedencia en los debates el tratamiento de los proyectos de ley referidos a cuestiones financieras e impositivas. También se dispuso, en 1841, que las intervenciones de los representantes no podrían tener una duración de más de una hora. Esta medida ya había sido propuesta en 1820, cuando John Randolph habló durante más de 4 horas oponiéndose al Compromiso de Missouri.

Una cuestión que debía resolverse también era la prolongación indefinida de los debates en la Comisión de la Cámara en Pleno (Committee of the Whole). A tal fin, en 1841 se decidió que el House podía, por simple mayoría y sin debate previo, relevar a la Comisión del tratamiento del proyecto una

193 Hecht (1972, p. 545). 
vez que las enmiendas pendientes de aprobación hubieran sido rechazadas. No obstante, para evitar una terminación abrupta de la tarea de la Comisión del Pleno, en 1847 se decidió que los representantes que habían propuesto enmiendas al proyecto tendrían cinco minutos para explicarlas y defenderlas. Como ocurre habitualmente en la vida parlamentaria, esta regla dio lugar a una práctica que tendía a invalidarla, ya que los representantes de una minoría, con el fin de alargar indefinidamente el tratamiento de un proyecto al cual se oponían, proponían numerosas enmiendas que luego eran retiradas. Fue por ello que, en 1850 , se dispuso que el retiro de una enmienda debía hacerse por unanimidad.

Toda esta acumulación de reglas, que hacia 1858 sumaban más de 150, motivó que se designara una comisión especial (select committee) para revisarlas y ordenarlas. La tarea se completó en marzo de 1860 y tuvo un carácter técnico, sin que se llevaran a cabo cambios sustanciales en las reglas existentes.

\subsection{El sistema de comisiones}

Durante este período no se produjeron en el House grandes cambios en el sistema de comisiones. Básicamente, los cambios fueron cuantitativos, ya que a las comisiones permanentes (standing committees) existentes en 1825 se añadieron 8 más, llegando a sumar 34. La más importante -y más antigua- de todas ellas era y sigue siendo la de presupuesto y finanzas (Committee of Ways and Means). En el Senado, por el contrario, se produjeron cambios importantes en 1833 y 1846. En el primer caso, fue establecido que los miembros de las comisiones ya no serían designados por el vicepresidente, sino por votación de todos los senadores por medio de listas previamente acordadas. En el segundo caso, este poder de designación recayó aún más en los partidos políticos, ya que esas listas eran elaboradas por cada uno de ellos. Por lo general, en la elección de los miembros de cada comisión, y en particular en la presidencia de cada una de ellas, se tomaba la antigüedad como criterio. Si bien el sistema parecía correcto, se prestaba a algunos abusos, ya que, en 1859, todos los presidentes de comisiones pertenecían a estados esclavistas. ${ }^{194}$

194 Vid. Guide to Congress (2015, p. 113). 


\subsection{Nace el Partido Republicano}

Sin lugar a dudas, la Ley Kansas-Nebraska había sido una victoria esclavista al permitir que dos nuevos territorios ubicados al norte del paralelo 36 pudieran ser esclavistas. Ello quebraba claramente la regla establecida en el Compromiso de Missouri de 1820, pues, al dejar librada la cuestión de la esclavitud al voto popular, abría las puertas de esta en territorios que debían quedar libres de ella. Como reacción en contra de esta ley, comenzó a formarse, de forma espontánea y sin un liderazgo claramente identificado, una agrupación que muy rápidamente daría lugar al Partido Republicano. Tan fuerte y veloz fue esta gestación que, en 1860, Abraham Lincoln fue electo como el primer presidente republicano. Concomitantemente, en las elecciones para el $37^{\circ} \mathrm{Con}$ greso (1861-183), los republicanos obtuvieron una victoria aplastante contra los demócratas. ${ }^{195}$

A diferencia de los demócratas, que se alinearon detrás de Jackson luego de la elección de 1824, a la cual consideraban fraudulenta, los republicanos no tuvieron inicialmente un líder con el cual identificarse. Lincoln, que emergería como jefe indiscutido del partido en 1858, estaba por entonces lejos de serlo. ${ }^{196}$ Los orígenes del futuro Grand Old Party (GOP), como también se lo ha llamado desde $1885,{ }^{197}$ son dos reuniones que llevaron a cabo los opositores a la Ley Kansas-Nebraska en 1854. La primera de ellas se realizó el 28 de febrero en Ripon, Wisconsin; la segunda se llevó a cabo "bajo los robles" (under the oaks) el 6 de julio en Jackson, Michigan. ${ }^{198}$ Dos años después, se produjo la creación formal del partido. El 22 de febrero de 1856, en Pittsburgh, Pennsylvania, se llevó a cabo una reunión para preparar la primera convención nacional del partido, que tuvo lugar en Philadelphia el 17 de junio de ese año. En ella fue aprobada la primera plataforma partidaria. También surgió en forma espontánea el nombre del partido. Podría decirse que se debe a un editorial publicado por Horace Greeley en el New-York Tribune, en junio de 1854, en el que decía

195 En el Senado, los republicanos ganaron el doble de bancas que los demócratas: 31 a 15 (ver: https:// www.senate.gov/history/partydiv.htm), y en el House el triunfo fue aún mayor: obtuvieron 108 bancas contra solo 44 de los demócratas (ver: https://history.house.gov/Institution/Party-Divisions/ Party-Divisions/).

196 Hasta ese momento, Lincoln era un poco conocido abogado de Springfield, Illinois, que había sido representante por el Partido Whig en el $29^{\circ}$ Congreso (1847-1849), pero su figura creció indisputablemente luego de los célebres debates que mantuvo en 1858 con Stephen Douglas con motivo de la esclavitud. Ver Angle (1991).

197 Ver Gould (2003).

198 Como resultado de ello, ambas ciudades se disputan la maternidad del Partido Republicano. Para asegurarlo, en Jackson hay una placa, colocada "bajo los robles", que se la atribuye. 
que la denominación que unía a todos los opositores a la esclavitud era "republicanos" ${ }^{199}$

\subsection{La ampliación del Capitolio}

Vale la pena recordar aquí que, en 1851, el Congreso encaró un importante plan de ampliación de su edificio, dado que el constante crecimiento de sus legisladores había tornado incómodas las instalaciones existentes. El nuevo recinto del Senado fue completado en 1859 y este se mudó de la antigua chamber -que había sido empleada desde 1810 (Old Senate Chamber) - a la que ocupa actualmente. ${ }^{200} \mathrm{La}$ antigua sala del Senado fue asignada entonces a la Corte Suprema, que sesionó allí hasta la construcción de su propio edificio en $1935 .{ }^{201}$ Por su lado, el 16 de diciembre de 1857 se reunió el House por primera vez en su recinto actual en la apertura de las sesiones del 35 Congreso (1857-1859). Faltaba tan solo terminar algunos trabajos en el sistema de calefacción y en la escalera central de acceso. Con este nuevo recinto, mucho más amplio y que formaba parte de un plan de reformas en ambas alas del edificio comenzado en 1851, se reemplazaba el antiguo salón ${ }^{202}$ empleado desde 1819. La nueva cámara, más cómoda, lujosa y espaciosa que la anterior, necesaria para albergar al creciente número de representantes y con una mejor acústica, fue objeto sin embargo de algunas críticas. El senador Jacob Collamer, de Vermont, antiguo miembro del House en la década de 1840 , sostuvo que el nuevo recinto era demasiado suntuoso y colorido. ${ }^{203}$ También fue emplazada la nueva cúpula del edificio, diseñada por Thomas Ustick Walter, cuarto arquitecto del Capitolio. Fue construida entre 1855 y 1866 y su estructura no es de piedra, sino de hierro fundido.

199 "We should not care much whether those thus united (against slavery) were designated 'Whig,' 'Free Democrat' or something else; though we think some simple name like 'Republican' would more fitly designate those who had united to restore the Union to its true mission of champion and promulgator of Liberty rather than propagandist of slavery" (como se citó en Bueno de Mesquita-Smith, 2016, p. 217).

200 Ver: https://www.senate.gov/art-artifacts/publications/pdf/room-old-senate-chamber.pdf.

201 Hasta que fue construido su propio edificio, la Corte Suprema fue ocupando las salas que iba dejando vacante el Senado. Así ocurrió en 1810 y luego en 1860. Ver: https://www.senate.gov/ art-artifacts/publications/pdf/room-old-supreme-court-chamber.pdf.

202 Donde actualmente está ubicado el Statuary Hall.

203 Ver:https://history.house.gov/HistoricalHighlight/Detail/37069?current_search_qs=\%3FTerm\%3Dnumber\%2Bof\%2Brepresentatives\%26PreviousSearch\%3D\%26CurrentPage\%3D1\%26SortOrder\%3DDate. 


\section{La Guerra Civil y la Reconstrucción (1861-1877) 7.1. Las distorsiones políticas de este período}

De todos los períodos en los que puede ser dividido el proceso histórico del Congreso de los Estados Unidos, el que corre desde la secesión de los estados del sur en 1860 -que da origen a la Guerra Civil- hasta el final de la Reconstrucción en 1877, es sin dudas uno de los más críticos y el de mayor distorsión política. ${ }^{204}$ Sin mencionar los horrores propios de la guerra, en el terreno estrictamente legislativo basta recordar que las bancas de los estados del sur, tanto en el Senado como en el House, estuvieron vacantes, casi en su totalidad, desde 1861 hasta 1869, y que el Partido Demócrata en la Unión, durante esos años, fue una fuerza política minoritaria y debilitada. De hecho, muchos demócratas norteños emigraron hacia las filas republicanas. Como resultado de ello, los republicanos retuvieron la presidencia hasta 1885, cuando Grover Cleveland sucedió a Chester Arthur, ${ }^{205}$ y controlaron el House desde el 36 Congreso (1859-1861) hasta el 44 Congreso (1875-1877); y el Senado, desde el 37 Congreso (1861-1863) hasta el 45 Congreso (1877-1879).

La hegemonía republicana, sin embargo, no estuvo exenta de conflictos entre Lincoln y el Congreso. Uno y otro intentaron ejercer, durante el conflicto, una gran porción de poder. Muchas decisiones del Ejecutivo, tales como la suspensión del hábeas corpus, el llamado de voluntarios para combatir, el aumento de tropas y los gastos que ello demandaba, así como la liberación de esclavos en los estados rebeldes, fueron tomadas sin previo consentimiento del Congreso. Este, a su vez, creó la Comisión Conjunta sobre la Conducción de la Guerra (Joint Committee on the Conduct of the War), integrada por tres senadores y cuatro representantes, cuya misión, como su nombre lo indica, era controlar la marcha de la guerra. Asimismo, cuando en 1863 Lincoln emitió una proclamación sobre la futura reconstrucción de los estados del sur, estableciendo nuevos Gobiernos en Louisiana y Arkansas, el Congreso le respondió sancionado un proyecto de ley (Wade-Davis Bill) que transfería esa tarea a la órbita legislativa. Lincoln, entonces, ejerció el pocket veto (veto de bolsillo) sobre la ley, lo que dio

204 En el Anexo VI (p. 439) menciono brevemente los hechos que dieron lugar al conflicto.

205 Durante 25 años, desde Lincoln (1861-1865) hasta Chester Arthur (1881-1885), la presidencia estuvo bajo el control de los republicanos. De todos modos, hay que hacer la salvedad de que Andrew Johnson, vicepresidente de Lincoln en la segunda presidencia y sucesor de este luego de su asesinato, era demócrata. Para la elección de 1864, Lincoln y Johnson habían formado una lista de coalición llamada National Union Party. No obstante, el control político del país lo tenían en ese momento los republicanos, que estuvieron a punto de destituir a Johnson en el Juicio Político de 1868. 
lugar, a su vez, al Wade-Davis Manifesto, un documento en el cual el Congreso se expresó en duros términos, reafirmado su autoridad en la materia y sosteniendo que el presidente debía limitarse a ejercer su función ejecutiva. ${ }^{206}$

\subsection{El Joint Committee on the Conduct of the War}

En los comienzos de la guerra, los norteños sufrieron varias derrotas inesperadas. La primera ocurrió en Bull Run Creek, en julio de 1861, conocida como la Batalla del Picnic (Picnic Battle) por sus tragicómicas características. ${ }^{207} \mathrm{~A}$ ella le siguieron otros reveses para los ejércitos de la Unión, tales como el de Ball's Bluff, en octubre de ese mismo año, en el que murió el senador Edward D. Baker, un amigo muy cercano de Lincoln. A raíz de ello, en el Congreso se levantaron voces en demanda de una investigación de estos reveses militares, que fueron respondidas inicialmente por el senador Zachariah T. Chandler, de Michigan, quien propició, en diciembre de 1861, la sanción de una resolución para investigar las derrotas de Bull Run y Ball's Bluff. Esta iniciativa, sin embargo, no fue considerada suficiente por quienes pretendían llevar a cabo una investigación aún más amplia. Fue así que el senador James W. Grimes, de Iowa, proyectó una resolución, aprobada el 10 de diciembre de 1861, mediante la cual fue creado la Joint Committee on the Conduct of the War, una comisión conjunta integrada por tres senadores y cuatro diputados, a la que se le otorgaron amplios poderes para "investigar la conducción de la presente guerra y ordenar la producción prueba testimonial y documental”. 208

Aunque sus propósitos eran correctos, estando dominada por republicanos

206 Entre otras consideraciones, el manifiesto dice: "The authority of Congress is paramount and must be respected; that the whole body of the Union men of Congress will not submit to be impeached by him of rash and unconstitutional legislation; and if he wishes our support, he must confine himself to his executive duties-to obey and execute, not make the laws-to suppress by arms armed Rebellion, and leave political reorganization to Congress".

207 En la mañana del domingo 21 de julio de 1861, legisladores, abogados, periodistas y otras personas de Washington se congregaron en Centreville, Virginia, para ver cómo combatían los ejércitos del norte y del sur. Ubicados en una colina sobre Bull Run Creek, habían llevado sándwiches y bebidas con el mismo espíritu que anima a quien se dispone a ver un espectáculo deportivo. Después de un buen comienzo para los norteños, la situación se tornó en su contra y, hacia las 16 horas, las tropas de la Unión comenzaron a desbandarse en una retirada apresurada y desordenada, atropellando a los civiles que había ido a observar la batalla. El senador Henry Wilson, de Massachusetts, tuvo que huir montado en una mula luego de que el carrito desde el cual repartía los sándwiches fuera destruido por un disparo de cañón. Ver: https://www.senate.gov/about/powers-procedures/investigations/joint-committee-conduct-of-war.htm.

208 "Inquire into the conduct of the present war and to send for persons and papers". 
radicales, la Comisión se tornó rápidamente en un órgano político enfrentado, en ocasiones, con el propio Lincoln, a quien acusaban de ser muy tolerante con el bando contrario y cuestionaban su estrategia en la conducción del conflicto, pese a que sus miembros no tenían experiencia militar alguna. Habían decidido, incluso, que sus deliberaciones serían secretas, pero varios de sus integrantes violaron esta regla pasando información a la prensa con la expectativa de que su tarea fuera apoyada por el público. Sin perjuicio de ello, la Comisión llevó a cabo una intensa tarea de escrutinio sobre la marcha de la Guerra, no solo en el plano de las operaciones militares, sino también en relación con el tratamiento de los prisioneros y de la corrupción en los contratos de provisión de armamentos y otros elementos. Sus tareas se desarrollaron durante los Congresos $37^{\circ}$ y $38^{\circ}$ a lo largo de los cuatros años que duró el conflicto (18611865). La Comisión se reunió en 272 oportunidades y recopiló gran cantidad de documentos y testimonios, algunos de ellos tomados en el lugar mismo de los hechos. Todo este material fue recopilado en cuatro informes anuales, publicados en 1863, 1864, 1865 y 1866.

\subsection{Los republicanos radicales y sus conflictos con Andrew Johnson}

Como ocurre habitualmente, en el joven Partido Republicano de aquel entonces anidaban varias tendencias. Los halcones, en este caso, eran los republicanos radicales, abolicionistas estrictos que no tardaron en lanzarse contra el vicepresidente Andrew Johnson cuando Lincoln fue asesinado en 1865. Nacido y criado en el sur, ${ }^{209}$ Johnson carecía de toda formación intelectual, ${ }^{210}$ aunque tenía bastante experiencia política. ${ }^{211}$ Sus talentos, sin embargo, eran muy escasos para manejar la difícil situación que le tocó vivir, agravado todo ello por su muy mala relación con el Congreso, dominado por los republicanos. Tanto era el encono en su contra que, a fin de evitar que pudiera cubrir las vacantes en la Corte Suprema con jueces que se opusieran a la Reconstrucción, fue reducido el número de los integrantes del Tribunal, el cual fue aumentado nuevamente en 1869 cuando Ulysses S. Grant ocupó la presidencia. ${ }^{212}$

209 Había nacido en North Carolina y desarrolló su vida política en Tennessee.

210 Jamás fue a la escuela y había trabajado como sastre antes de entrar a la política.

211 Fue gobernador de Tennessee en 1853-1857; luego, senador por dicho estado en 1857-1862; y durante la Guerra Lincoln lo designó gobernador militar también allí.

212 En 1865, la Corte tenía 10 jueces, como resultado de una ampliación producida en 1863. Johnson tuvo una primera oportunidad para nombrar un juez en la Corte con la vacante producida al morir 
Sin embargo, el pico de la colisión entre Johnson y el Congreso tuvo lugar en 1868, cuando se lo intentó destituir por juicio político. El detonante de este juicio fue la controversia suscitada en torno a la destitución de Edwin W. Stanton como secretario de Guerra, acto que, a juicio de los opositores de Johnson, violaba la ley que regulaba los nombramientos de los funcionarios ejecutivos (Tenure of Office Act). Stanton, que había sido designado por Lincoln, se oponía a la política de Johnson sobre la Reconstrucción y fue removido de su cargo, en agosto de 1867, durante el receso del Congreso, siendo reemplazado por Ulysses S. Grant, designado en forma interina. Al reunirse nuevamente el Senado, durante el otoño de ese año, repuso a Stanton en su cargo y Johnson lo destituyó nuevamente, designando al general Lorenzo Thomas como su reemplazo. Como respuesta, la Comisión Conjunta sobre la Reconstrucción (Joint Committee on Reconstruction), a la que me referiré en el punto siguiente, elaboró una resolución en la cual se promovió el juicio político contra Johnson, imputándole once cargos. Esta resolución fue aprobada en el House por una mayoría de 126-47 votos. En el Senado, el juicio comenzó en marzo de 1868 bajo la presidencia del Chief Justice Salmon P. Chase. Era la primera vez en la historia de los Estados Unidos que se promovía un juicio político contra un presidente y el caso, como era inevitable, atrajo toda la atención de la prensa y del público. Finalmente, dos meses después -en mayo de 1868-, el Senado emitió su veredicto, en el cual faltó un solo voto para alcanzar los dos tercios necesarios para obtener una sentencia de condena. Una mayoría de 35 senadores votó por la destitución y 19 -entre ellos siete republicanos- votaron por la absolución. ${ }^{213}$

John Catron, en 1865. Después de vacilar durante un año, eligió finalmente a Henry Stanbery, su Attorney General (ministro de Justicia) y respetado abogado. Pero la relación entre el Congreso y el presidente por aquel entonces era tan mala que, como dice Henry Abraham, ni Dios hubiera obtenido el acuerdo de haber sido nominado por Johnson. Se temía que Johnson designara jueces contrarios a la legislación de la Reconstrucción, protectora de los derechos de los esclavos recientemente liberados. De hecho, Johnson había vetado algunas de estas leyes No solo se rechazó la propuesta de Johnson, sino que el Congreso fue más lejos aún. Para evitar que se produjeran nuevas nominaciones, se redujo el número de jueces de diez a nueve y, además, se estableció que, de producirse una nueva vacante, el número de jueces se reduciría a ocho. Así, cuando en 1867 falleció el juez James Wayne, su sillón también fue eliminado. Terminada la presidencia de Johnson, su sucesor fue Ulysses S. Grant, héroe de la Guerra Civil. Con Grant en la presidencia y aventados los peligros que su predecesor representaba para la Reconstrucción, el Congreso, en 1869, elevó nuevamente a 9 los jueces de la Corte, número que se ha mantenido desde entonces. Vid. Abraham (1985, pp. 123-124).

213 Ver Wineapple (2020). 


\subsection{El liderazgo en el House}

A diferencia de lo que se verá en el período siguiente, con el fuerte liderazgo de Thomas B. Reed y Joseph G. Cannon, los Speakers en este período no fueron auténticos líderes del House. Schuyler Colfax, de Indiana, ocupó el cargo entre 1863 y 1869 y lo dejó para ser vicepresidente de Ulysses Grant durante su primer período. Calificado como un figurehead (figura decorativa), Colfax tuvo su momento más decisivo cuando ejerció el casting vote para desempatar la votación de lo que sería la Enmienda XIII de abolición de la esclavitud, quebrando con ello la costumbre de que el Speaker no ejercía tal poder. Sin embargo, el verdadero líder del House en esos años fue Thaddeus Stevens, de Pennsylvania, un republicano radical que había liderado el juicio político contra Johnson. Como presidente de la Comisión de Presupuesto (Ways and Means Committe) y de la Comisión de Ingresos Fiscales (Appropriations Committee), creada en 1865, Stevens era el verdadero conductor del House, función que ejercía -según algunos- en forma tiránica. ${ }^{214}$ Colfax fue sucedido en 1869 por James G. Blaine, de Maine, también republicano, quien presidió el House hasta 1875. Con mayor autoridad que su predecesor, Blaine manejó los nombramientos en las comisiones para lograr la sanción de las leyes que le interesaban. ${ }^{215}$

\subsection{El Joint Committee on Reconstruction y la legislación derivada de la Guerra Civil}

Terminada la Guerra Civil, comenzó la llamada Reconstrucción de los estados del sur, que tuvo importantes consecuencias en el orden constitucional y legislativo. Para analizar el problema de los estados vencidos y su organización, el 39 Congreso (1865-1867) estableció, el 13 de diciembre de 1865, la llamada Comisión Conjunta para la Reconstrucción (Joint Committee on Reconstruction), con el objeto de investigar e informar sobre la situación existente en los exestados confederados y proponer la legislación necesaria para reorganizarlos. Presidido por el senador William Pitt Fessenden, de Maine, un republicano moderado, la comisión se integró con quince miembros: seis senadores y nueve representantes. Todos ellos, salvo tres, eran republicanos. Entre los republicanos radicales se encontraba Thaddeus Stevens, representante de Pennsylvania,

214 Ver MacNeil (2011, p. 185).

215 Dentro de su partido, Blaine compitió sin éxito en dos oportunidades para la nominación como presidente de la República. Perdió en 1876 con Hayes y en 1880 con Garfield. Fue nominado, finalmente, en 1884, pero perdió la elección con Cleveland, con quien los demócratas retornaron a la Casa Blanca luego de largos años fuera de ella. 
y entre los republicanos moderados se destacó John A. Bingham, representante de Ohio, quien colaboró en la propuesta de las enmiendas constitucionales para proteger los derechos civiles, a las que me referiré enseguida. ${ }^{216}$ Entre febrero y mayo de 1866, cuatro subcomisiones reunieron pruebas y tomaron numerosos testimonios sobre la situación existente en el sur, entre ellos, al general Robert E. Lee y a Alexander H. Stephens, exvicepresidente de los estados confederados. Mientras los testimonios de los confederados afirmaban que en el sur la situación era pacífica y se estaba en condiciones de retornar a la normalidad, los testimonios de los norteños daban cuenta de una situación de fuerte violencia racial contra los negros y quienes los apoyaban. Como conclusión de su tarea, la comisión conjunta elaboró un informe -en el cual no constan los debates internos- que dio lugar a la legislación sobre la Reconstrucción, a la que me referiré seguidamente. ${ }^{217}$

En el terreno legislativo, se incorporaron a la Constitución las Enmiendas XIII, XIV y XV, ratificadas entre 1865 y 1870. Juntamente con ellas, el Congreso sancionó la Civil Rights Act of 1866 (Ley de Derechos Civiles) ${ }^{218}$ y las llamadas Reconstructions Acts of 1867 (Leyes de la Reconstrucción), un grupo de cuatro leyes sancionadas entre marzo de 1867 y marzo de 1868, que establecieron el Gobierno militar en los estados del sur con la intención de organizarlos y reintegrarlos a la Unión. ${ }^{219}$ Esta nueva legislación provocó fuertes resistencias, que acentuaron las diferencias ya existentes entre los estados beligerantes. Los sureños, aun vencidos y destrozados económicamente, ejercieron una fuerte oposición a la nueva legislación. Básicamente, se oponían a igualarse jurídicamente con sus otrora esclavos.

La primera Enmienda constitucional surgida después de la Guerra Civil eliminó la esclavitud. Era evidente que si esta había sido la causa principal del conflicto, su abolición figuraría entre las primeras medidas posteriores al cese del fuego. Ya con anterioridad a la rendición final de las fuerzas del sur,

216 Además de Stevens y Bingham, los otros representantes que integraron la comisión fueron: Elihu Washburne (republicano de Illinois), Justin Morrill (republicano de Vermont), Roscoe Conkling (republicano de New York), George Boutwell (republicano de Massachusetts), Henry T. Blow (republicano de Missouri), Henry Grider (demócrata de Kentucky) y Andrew Jackson Rogers (demócrata de New Jersey). Además de Fessenden, los otros senadores fueron: James W. Grimes (republicano de Iowa), Jacob Howard (republicano de Michigan), George Henry Williams (republicano de Oregon), Ira Harris (republicano de New York) y Reverdy Johnson (demócrata de Maryland).

217 Ver Kendrick (1969).

21814 Statutes at Large 27-30.

21914 Statutes at Large 428-430 (2 de marzo de 1867); 15 Statutes at Large 2-5 (23 de marzo de 1867); 15 Statutes at Large 14-16 (19 de julio de 1867); 15 Statutes at Large 41 (11 de marzo de 1868). 
la Enmienda había sido propuesta en el Congreso el 31 de enero de 1865. Por medio de ella, se declaró formalmente abolida la esclavitud, salvo la que fuera impuesta como pena por delitos debidamente juzgados. Luego de enunciado este principio, se le otorgaron al Congreso facultades para ponerlo en práctica por medio de legislación adecuada. ${ }^{220}$

Inmediatamente después de la Enmienda XIII, el Congreso sancionó -pese al veto del presidente Johnson- ${ }^{221}$ la Civil Rights Act of 1866, la primera de las ocho leyes de derechos civiles que ha tenido los Estados Unidos. ${ }^{222}$ Con ella se intentaba contrarrestar los llamados Black Codes (Código Negros) que habían empezado a sancionarse en los estados del sur, por medio de los cuales se privaba a los negros de los derechos de votar, de dar testimonio en juicio, de casarse con blancos, etc. Desde su primera sección, la ley marcaba los efectos de la Guerra Civil al reconocer una igualdad completa entre blancos y negros y extenderles la ciudadanía a estos últimos. ${ }^{223}$ Para reforzar este principio, se imponían penas de prisión y de multa a quienes ejercitaran actos contrarios a

220 Dice esta Enmienda: "1. Ni en los Estados Unidos ni en ningún lugar sujeto a su jurisdicción habrá esclavitud ni trabajo forzado, excepto como castigo de un delito del que el responsable haya quedado debidamente convicto. 2. El Congreso estará facultado para hacer cumplir este artículo por medio de leyes apropiadas" ("Section 1. Neither slavery nor involuntary servitude, except as a punishment for crime whereof the party shall have been duly convicted, shall exist within the United States, or any place subject to their jurisdiction. Section 2. Congress shall have power to enforce this article by appropriate legislation").

Su antecedente inmediato fue la Proclama de Emancipación (Emancipation Proclamation), ordenada por Abraham Lincoln en 1863. En plena guerra, invocando sus poderes de guerra, el presidente proclamó la emancipación de todos los esclavos existentes en los estados del sur que se hallaban en conflicto. De todos modos, y para evitar cualquier planteo de nulidad de esta Proclama, el Congreso creyó necesario darle rango constitucional a la abolición. Desde su propuesta a los estados hasta que se obtuvieron las ratificaciones necesarias para su entrada en vigencia transcurrió menos de un año. El 6 de diciembre de 1865 se obtuvo el voto de Georgia necesario para ello y el 18 de diciembre fue certificada formalmente por el secretario de Estado. Pero la reticencia de algunos de los estados del sur para dar su aprobación fue tal que Kentucky recién la ratificó más de un siglo después -en 1976- y Mississippi lo hizo en 1995, después de haberla rechazado ambos inicialmente.

221 Johnson llegó a ejercer el veto sobre las leyes de la Reconstrucción en 29 ocasiones, 15 de las cuales fueron rechazadas por el Congreso.

222 Le sucederían luego las de 1871 (17 Statutes at Large 13), 1875 (18 Statutes at Large 335), 1957 (71 Statutes at Large 634), 1960 (74 Statutes at Large 86), 1964 (78 Statutes at Large 241), 1968 (82 Statutes at Large 73) y 1991 (Public Law 102-166; § 109, 42 U.S.C. § 2000e et seq).

223 Decía esta Sección 1: "Be it enacted, That all persons born in the United States and not subject to any foreign power, excluding Indians not taxed, are hereby declared to be citizens of the United States; and such citizens, of every race and color, without regard to any previous condition of slavery or involuntary servitude, except as a punishment for a crime whereof the party shall have been duly convicted, shall have the same right, in every State and Territory in the United States, to make and enforce contracts, to sue, be parties, and give evidence, to inherit, purchase, lease, sell, hold, and convey real and personal property, and to full and equal benefit of the laws and proceedings for the 
los derechos reconocidos en la ley. ${ }^{224}$ Aun así, la lucha por imponer la igualdad completa entre blancos y negros no fue fácil y la Corte demoraría más de setenta años en admitirla plenamente. ${ }^{225}$

Sin perder tiempo, pocos meses después -en junio de 1866-, el Congreso propuso la Enmienda XIV, la que luego de un largo proceso de ratificación entró en vigencia en julio de 1868, luego de ser aprobada por 28 de los 37 estados entonces existentes. ${ }^{226}$ El propósito de esta Enmienda era erradicar toda duda que pudiera presentarse acerca de los derechos reconocidos por la Ley de Derechos Civiles. ${ }^{227}$ De las tres Enmiendas de la Reconstrucción, sin dudas esta es la que mayor aplicación judicial ha suscitado debido a las cláusulas del debi-

security of person and property, as is enjoyed by white citizens, and shall be subject to like punishment, pains, and penalties, and to none other, any law, statute, ordinance, regulation, or custom, to the contrary notwithstanding".

224 "Section. 2. And be it further enacted, That any person who, under color of any law, statute, ordinance, regulation, or custom, shall subject, or cause to be subjected, any inhabitant of any State or Territory to the deprivation of any right secured or protected by this act, or to different punishment, pains, or penalties on account of such person having at any time been held in a condition of slavery or involuntary servitude, except as a punishment for any crime whereof the party shall have been duly convicted, or by reason of his color or race, than is prescribed for the punishment of white persons, shall be deemed guilty of a misdemeanor, and, on conviction, shall be punished by fine not exceeding one thousand dollars, or imprisonment not exceeding one year, or both, in the discretion of the court".

225 Lo hizo recién en la década 1950, cuando resolvió los casos de segregación racial, en particular Brown v. Board of Education of Topeka, 347 U.S. 483 (1954).

226 La ratificación de la Enmienda XIV fue un proceso largo y complicado. Cuando se admitió a Nebraska en calidad de trigésimo séptimo estado, el 1 de marzo de 1867, el requisito de ratificación por las tres cuartas partes de los estados impuso la necesidad de que votaran por ella un total de veintiocho. En 1866 hubo seis ratificaciones y otros dieciséis estados ratificaron la enmienda en 1867. Iowa lo hizo en abril de 1868. Antes de aquella fecha, los exestados confederados ya habían advertido que, sometidos a las Leyes de Reconstrucción, tenían que ratificar dicha enmienda u obedecer a los Gobiernos militares instalados luego de la Guerra Civil. En abril de 1868 se decidió Arkansas; en junio ratificó Florida; en julio, Carolina del Norte, Louisiana, Carolina del Sur y, por fin, Alabama, el estado vigésimo noveno. Sin embargo, Ohio, en enero de 1868, y Nueva Jersey, en abril, habían manifestado su intención de retirar su respectiva ratificación. El 20 de julio, el secretario de Estado Seward dio una proclama condicional: la enmienda estaría en vigor si el retiro de Ohio y de Nueva Jersey quedaba sin efecto. El 21 de julio, el gobernador electo por Georgia telegrafió al presidente de la Cámara de Representantes que aquel estado acababa de ratificar la enmienda. Se tenían, pues, veintiocho estados, aun sin contar a Ohio y Nueva Jersey. Tras un breve debate acerca de la autenticidad del aviso telegráfico, la Cámara declaró ratificada la enmienda. El Senado había hecho lo mismo sin esperar a Georgia. El secretario de Estado promulgó entonces la enmienda incondicionalmente el 28 de julio de 1868. Oregon dio a entender su intención de retirar la ratificación en octubre de 1868, pero Virginia la ratificó en 1869 y Mississippi y Texas en 1870. La Enmienda XIV tenía, pues, a su favor tres cuartas partes de los estados.

227 Es por ello que su primera sección establece: "Todas las personas nacidas o naturalizadas en los Estados Unidos y sometidas a su jurisdicción son ciudadanos de los Estados Unidos y de los Estados 
do proceso y de la igualdad. ${ }^{228}$ La segunda sección regula y tutela los derechos electorales, la tercera limita los derechos políticos de quienes hayan incurrido en actos de rebelión contra los Estados Unidos, la cuarta se ocupa de la deuda pública y rechaza toda aquella que pudiera haberse generado como consecuencia de la liberación de esclavos y la quinta, por último, le reconoce al Congreso facultades suficientes para hacer cumplir lo establecido en la enmienda.

Aunque estaban devastados, los estados del sur se resistían férreamente a reconocer la autoridad que sobre ellos pretendían ejercer las autoridades nacionales. Se negaron a ratificar la Enmienda XIV y no acataban la Ley de Derechos Civiles. ${ }^{229}$ Para poner coto a esta situación, el Congreso sancionó las Leyes de la Reconstrucción, que establecieron - provisionalmente y hasta tanto pudiera reorganizarse debidamente la autoridad civil- Gobiernos militares en los estados de Virginia, North Carolina, South Carolina, Georgia, Mississippi, Alabama, Louisiana, Florida, Texas y Arkansas ${ }^{230}$ como medio de evitar el pillaje y el desorden propios de la anarquía. Se crearon entonces cinco distritos militares bajo la autoridad directa del Gobierno federal. ${ }^{231} \mathrm{Al}$ mando de cada uno de estos distritos se puso a un oficial de alto rango, dotado de autoridad administrativa y judicial, bien que no podía aplicar castigos crueles e inusuales.

No obstante todo ello, la resistencia en el sur a reconocer los derechos de los

en que residen. Ningún Estado podrá dictar ni dar efecto a cualquier ley que limite los privilegios o inmunidades de los ciudadanos de los Estados Unidos; tampoco podrá Estado alguno privar a cualquier persona de la vida, la libertad o la propiedad sin el debido proceso legal; ni negar a cualquier persona que se encuentre dentro de sus límites jurisdiccionales la protección de las leyes, igual para todos" ("All persons born or naturalized in the United States, and subject to the jurisdiction thereof, are citizens of the United States and of the state wherein they reside. No state shall make or enforce any law which shall abridge the privileges or immunities of citizens of the United States; nor shall any state deprive any person of life, liberty, or property, without due process of law; nor deny to any person within its jurisdiction the equal protection of the laws").

228 La primera de ellas, incluso, ha sido una de las principales claves en manos de la Corte para regular la constitucionalidad de las leyes estatales, bien que esa facultad ya había sido ejercida con anterioridad desde United States v. Peters, 9 U.S. 115 (1809) y Fletcher v. Peck, 10 U.S. 87 (1810). El primer caso en el que la constitucionalidad de una ley estatal fue escrutada bajo la Enmienda XIV fue el de los mataderos de Louisiana en 1873, Slaughterhouse Cases, 83 U.S. 36 (1873).

229 Incluso, en la mayoría de los estados vencidos comenzaron a organizarse asociaciones clandestinas que proclamaban la supremacía de la raza blanca. El más célebre de todos ellos ha sido el Ku Klux Klan, fundado en 1866 en la ciudad de Pulaski, Tennessee, que tomó su nombre de la palabra griega kuclos, que significa "círculo".

230 Curiosamente, Tennessee -la patria del Ku Klux Klan- no fue incluido en la ley, pues había ratificado la Enmienda XIV.

231 Virginia constituía el primer distrito; North Carolina y South Carolina, el segundo; Georgia, Alabama y Florida, el tercero; Mississippi y Arkansas, el cuarto; y finalmente Louisiana y Texas, el quinto. 
negros era tal que fue necesario incorporar una tercera enmienda constitucional, la Enmienda XV, por medio de la cual se reconocen en absoluta condición de igualdad para todos los ciudadanos los derechos electorales. ${ }^{232}$ Esta tercera Enmienda de la Reconstrucción parece redundante ante el texto de las dos anteriores, pero es evidente que en su época no lo fue. Fue propuesta por el Congreso en febrero de 1869 y obtuvo su ratificación un año después.

\subsection{Los primeros legisladores afroamericanos}

Como resultado de las reformas legislativas antes mencionadas, comenzaron a ingresar al Congreso los primeros legisladores afroamericanos. Ellos fueron: los senadores republicanos por Mississippi Hiram Revels, elegido en 1870, y Blanche K. Bruce, elegido en 1874. Entre los primeros representantes cabe mencionar a Joseph Rainey (South Carolina, 1870), Robert C. De Large y Robert B. Elliott (South Carolina, 1871), Josiah T. Walls (Florida, 1871), Jefferson F. Long (Georgia, 1871) y Benjamin S. Turner (Alabama, 1873). Es difícil imaginar actualmente la revolución que este hecho produjo en su momento, ya que escasos diez años antes esas mismas bancas estaban ocupadas por propietarios de esclavos. Desde entonces, un total de 173 afroamericanos han sido elegidos como senadores o representantes en el Congreso.

Aun así, esta corriente se vio rápidamente interrumpida a raíz de la finalización de la Reconstrucción, producida con el Compromiso de 1870 (al que me referiré más abajo), por medio del cual las tropas federales dejaron de ocupar los estados del sur, dejando a los afroamericanos librados a su suerte en manos de sus antiguos propietarios. Como consecuencia de ello, hacia 1890, la mayoría de aquellos ya habían sido excluidos de toda participación política. El último legislador negro de esa época fue George White, representante de North Carolina, que dejó su banca en marzo de 1901. Desde entonces, y por espacio de casi tres décadas, ningún otro afroamericano pudo ser legislador. ${ }^{233}$ Recién en 1928, Oscar De Priest fue electo como representante republicano

232 "Ni los Estados Unidos, ni ningún otro Estado, podrán desconocer ni menoscabar el derecho de sufragio de los ciudadanos de los Estados Unidos por motivo de raza, color o de su condición anterior de esclavos" ("The right of citizens of the United States to vote shall not be denied or abridged by the United States or by any State on account of race, color, or previous condition of servitude").

233 También se les vedó a los afroamericanos el derecho al voto. A tal fin, muchos estados crearon, como condición para conceder el franchise (derecho a registrarse como elector), los test de capacitación (literacy test), consistentes en rendir un examen de lectura y comprensión de la constitución local y las llamadas Grandfather Clause (Cláusula Abuelo), por medio de las cuales se eximía de rendir el 
por Illinois, llegando a ocupar su banca en tres períodos consecutivos (1929$1931,1931-1933$ y $1933-1935) .{ }^{234}$

\subsection{La ley de $\mathbf{1 8 6 6}$ sobre la elección de los senadores}

Hasta 1866, la elección de los senadores estaba regulada por las respectivas disposiciones de cada estado. De acuerdo con el artículo I, sección 3, el Senado se integraba con dos senadores por cada estado elegidos por la legislatura local por un término de seis años. Cuando la Constitución fue sancionada, se suponía que este sistema de elección indirecta promovería una mejor relación entre el Gobierno federal y los estados. Así lo explica Madison en el capítulo 62 de El Federalista. ${ }^{235}$ Jay, por su lado, en el capítulo 64 -no exento de ingenuidad-, afirmaba que con el método propuesto se elegiría a los hombres más probos y capaces. ${ }^{236}$ Pese a estas loables creencias, con el correr del tiempo quedó demostrado que el sistema favorecía la manipulación política de la elección, lo que fue suscitando crecientes protestas en procura de la elección directa de los senadores. Muchas bancas eran literalmente compradas por grupos de influencia, que llenaban los cargos con individuos ligados a sus intereses, poco estimulados para proteger los derechos de quienes no habían colaborado o contribuido en su elección. Además de ello, el sistema era inconveniente, pues ya sea que las legislaturas locales votaran separada o conjuntamente, conforme lo establecido

literacy test a los descendientes de quienes ya hubieran tenido derecho a votar con anterioridad al mes de enero de 1866. Naturalmente, esta fecha estaba cuidadosamente elegida, pues solo beneficiaba a los blancos, de manera tal que muchos de ellos quedaban exentos de rendir un examen que, tal vez, no hubieran aprobado. Una de estas cláusulas figuraba en la Constitución de Oklahoma, conforme una enmienda sancionada en 1910 y fue declarada inconstitucional en Guinn v. United States, 238 U.S. 347 (1915) por ser violatoria de la Enmienda XV. Por el contrario, los literacy test fueron declarados constitucionales en Lassiter v. Northampton County Board of Education, 360 U.S. 45 (1959).

234 Ver Swain (1993).

235 "Among the various modes which might have been devised for constituting this branch of the government, that which has been proposed by the convention is probably the most congenial with the public opinion. It is recommended by the double advantage of favouring a select appointment, and of giving to the state governments such an agency in the formation of the federal government, as must secure the authority of the former, and may form a convenient link between the two systems" (Carey y McLean, 2001, p. 320).

236 "As the select assemblies for choosing the president, as well as the state legislatures who appoint the senators, will, in general, be composed of the most enlightened and respectable citizens, there is reason to presume, that their attention and their votes will be directed to those men only who have become the most distinguished by their abilities and virtue, and in whom the people perceive just grounds for confidence" (Carey y McLean, 2001, p. 333). 
en las respectivas leyes estatales, la elección muchas veces quedaba trabada.

En vista de todo ello, en 1866 el Congreso decidió regular la elección de los senadores por medio de una legislación federal uniforme. Fue sancionada a este fin la Election Law of $1866,{ }^{237}$ mediante la cual se dispuso que la elección debía tener lugar el segundo martes del mes en cada cámara legislativa, por separado, donde sus miembros votaban en voz alta. Al día siguiente, las cámaras debían reunirse conjuntamente para verificar el resultado y, en caso de que la elección no hubiera recaído sobre el mismo candidato, debían reunirse todos los días sucesivos hasta elegir al senador. Esta ley estuvo vigente por espacio de casi medio siglo, hasta 1912, cuando fue sancionada la Enmienda XVII. No obstante, sus resultados fueron magros, tal como señaló en su momento Haynes (1938) en su clásica obra sobre el Senado de los Estados Unidos. ${ }^{238}$ Las elecciones con frecuencia eran obstaculizadas o paralizadas hasta que los grupos de interés lograban imponer a sus candidatos, todo lo cual distorsionaba el proceso electoral y comprometía la labor legislativa. ${ }^{239}$

\subsection{La elección presidencial de 1876, el Compromiso de 1877 y el fin de la Reconstrucción}

En 1876, al concluir el segundo mandato de Ulysses S. Grant, se produjo una contienda electoral que puso en jaque al sistema. Compitieron por la presidencia Rutherford B. Hayes, por el Partido Republicano, y Samuel J. Tilden, por el Partido Demócrata. Los demócratas estaban fuera de la presidencia desde el Gobierno de James Buchanan (1857-1861), pero tenían fuertes posibilidades de retornar a la Casa Blanca dada la oposición a la política republicana de la Reconstrucción y

23714 Statutes at Large 243.

238 "[N]ot a few, but nearly half the states of the Union suffered from serious deadlocks. These contests, the outcome of which was often as much a matter of chance as would be the throw of dice, aroused men's worst passions and gave rise now to insistent charges of bribery, now to riot, to assault and to threats of bloodshed, such that legislative sessions had to be held under protection of martial law. Fourteen contests lasted throughout an entire session of the legislature without affecting an election. Four states submitted to the heavy cost and inconvenience of special sessions to select Senators. Six states preferred to accept vacancies, thus losing their 'equal suffrage in the Senate,' while the country was deprived of a Senate constituted as the fathers had intended. At times legislative election led to positive and flagrant misrepresentation of the state in the Senate. To the individual state it brought a domination of state and local politics by the fierce fight for a single federal office, and interference with the work of lawmaking, ranging all the way from the exaction of a few hours of the legislators' time to the virtual annihilation of the legislature, which had been constituted to care for the interests of the state" (Haynes, 1938, p. 79-117, esp. p. 95).

239 Ver Schiller et al. (2013, pp. 835-847). 
a la depresión económica reinante. Si bien Tilden obtuvo la mayoría de los votos populares, se produjo una disputa con los emitidos en Louisiana, Florida y North Carolina, estados controlados por los republicanos. Ello comprometía el resultado del colegio electoral, en el que además se cuestionaba un voto proveniente de Oregon, ya que sin los votos objetados Tilden no llegaba a la mayoría necesaria para ser proclamado. ${ }^{240}$ Los resultados electorales fueron enviados al Congreso, que debía dirimir la cuestión. Allí, la situación política estaba dividida, pues en el 44 Congreso (1875-1877) los republicanos tenían mayoría en el Senado; y los demócratas, en el House. Para colmo, la Enmienda XII -que regula la elección presidencial- no decía exactamente a quién le correspondía decidir sobre la validez de los votos emitidos. Naturalmente, si la decisión recaía en el Senado, el ganador sería Hayes, en tanto que el House le daría el triunfo a Tilden.

Cada cámara designó entonces sendas comisiones para estudiar el problema, pero tampoco se avanzó mucho. La del Senado encontraba soluciones favorables a Hayes y los representantes propiciaban las que le daban el triunfo a Tilden. Alguien sugirió entonces que una comisión de jueces de la Corte Suprema resolviera la cuestión, simulando con ello que estos no obrarían motivados por preferencias partidarias, pero la propuesta fracasó porque cada partido pretendía tener una mayoría de jueces propios en la comisión. Finalmente, se sancionó una ley que creó una Comisión Electoral, ${ }^{241}$ integrada por quince miembros: cinco por el Senado, cinco por el House y cinco jueces de la Corte Suprema. La ley establecía, además, el método a ser empleado para contar los votos.

Era obvio que los integrantes del Senado tendrían mayoría republicana; y los del House, mayoría demócrata, de modo que el delicado equilibrio residía en la selección de los jueces de la Corte. Para evitar lo que en definitiva resultó inevitable, la ley dispuso que se elegirían cuatro jueces, quienes, a su vez, designarían al quinto. Si bien la elección de cada juez se hizo en función de los distritos judiciales que cada uno de ellos presidía - para dar con ello una apariencia de representación territorial-, lo cierto es que en la práctica ello aseguró la presencia de dos republicanos y dos demócratas: por los primeros fueron elegidos los jueces Samuel Miller y William Strong; y por los demócratas, los jueces Nathan Clifford y Stephen Field.

En síntesis, el acuerdo político plasmado permitía que la Comisión Electoral se constituyera con siete republicanos y siete demócratas. Si cada uno de ellos votaba

240 Tilden obtuvo 4301000 votos populares y Hayes solamente 4036000 , pero en el colegio electoral Hayes aventajaba a su oponente por un solo voto: tenía 185 votos contra 184 de Tilden.

241 Electoral Commission Act, 19 Statutes at Large 227. 
por el candidato de su partido, lo cual era esperable, la elección presidencial quedaba en definitiva en manos del juez de la Corte Suprema elegido por sus propios colegas. Parecía que la elección recaería en David Davis, ${ }^{242}$ cuyas vacilaciones políticas no permitían determinar exactamente cuál partido prefería, aunque era probable que se inclinara por Tilden. ${ }^{243}$ En el ínterin, Davis fue electo senador por Illinois y renunció a la Corte. Si bien su renuncia se haría efectiva recién en marzo de 1877, lo que le daba tiempo para cumplir la tarea en la Comisión, declinó el ofrecimiento de integrarla. ${ }^{244}$ La elección recayó entonces en Joseph Bradley, el menos partisano de los jueces -pero republicano al fin-, quien votó por el candidato de su partido dándole el triunfo a Hayes, que, naturalmente, llegó a la presidencia muy debilitado políticamente en medio de las fuertes críticas de los demócratas, dirigidas en especial contra Bradley. Estos, no obstante, decidieron acatar la decisión luego de celebrar el Compromiso de 1870, un acuerdo no escrito por medio del cual, en esencia, los republicanos se comprometieron a retirar las tropas federales de los estados del sur. Con ello concluyó la Reconstrucción y los afroamericanos quedaron a merced de los Gobiernos sureños, hostiles a sus libertades, sin ayuda del gobierno nacional. Desde entonces, y hasta la sanción de la Civil Rights Act de 1964, los demócratas controlaron férreamente lo que se denominó el Bloque del Sur (Southern Bloc), integrado por los dieciséis estados ubicados en el sudeste y en el centro sud del país, a los que se les sumó el Distrito de Columbia. ${ }^{245}$

\section{El gobierno de los partidos (1877- 1919) \\ 8.1. Cuatro décadas de reparto político más equilibrado}

Los 21 congresos que tuvieron lugar entre 1877 y 1919 muestran un panorama político mucho más equilibrado que el del período anterior. Si bien puede decirse que los republicanos tuvieron preponderancia, los demócratas, fortalecidos en el sur después de la Reconstrucción, equilibraron esa fuerza. En el

242 Designado por Abraham Lincoln en 1862, había hecho su carrera política en Illinois, donde había sido diputado, convencional constituyente y luego juez.

243 Era un republicano moderado, oriundo de Maryland y establecido en Illinois, que se convirtió en el director de la campaña presidencial de Lincoln, esfuerzo que luego fue premiado con una designación en la Corte Suprema en 1862. En 1872 había apoyado al Liberal Republican Party, que se oponía a la reelección de Ulysses Grant, cuya candidatura sostenían los republicanos radicales.

244 Parece ser, incluso, que los republicanos apoyaron su candidatura, pues la elección como senador desnudaba su partidismo y lo descalificaba como supuesto miembro independiente de la Comisión.

245 Esos estados son: Delaware, Florida, Georgia, Maryland, North Carolina, South Carolina, Virginia, West Virginia, Alabama, Kentucky, Mississippi, Tennessee, Arkansas, Louisiana, Oklahoma y Texas. 
cuadro siguiente se puede ver qué partido tuvo la mayoría en cada uno de los congresos que tuvieron lugar en el período aquí considerado. Esta muestra indica que en el Senado predominaron los republicanos, pues tuvieron mayoría en 16 de los 22 congresos, mientras que en el House las mayorías se repartieron por mitades, con 11 congresos para cada partido. ${ }^{246}$

\begin{tabular}{c|c|c}
\hline Congreso & Mayoría en el Senado & Mayoría en el House \\
\hline $45^{\circ}(1877-1879)$ & Republicana & Demócrata \\
\hline $46^{\circ}(1879-1881)$ & Demócrata & Demócrata \\
$47^{\circ}(1881-1883)$ & Dividida & Republicana \\
$48^{\circ}(1883-1885)$ & Republicana & Demócrata \\
$49^{\circ}(1885-1887)$ & Republicana & Demócrata \\
$50^{\circ}(1887-1889)$ & Republicana & Demócrata \\
$51^{\circ}(1889-1891)$ & Republicana & Republicana \\
$52^{\circ}(1891-1893)$ & Republicana & Demócrata \\
$53^{\circ}(1893-1895)$ & Demócrata & Demócrata \\
$54^{\circ}(1895-1897)$ & Republicana & Republicana \\
$55^{\circ}(1897-1899)$ & Republicana & Republicana \\
$56^{\circ}(1899-1901)$ & Republicana & Republicana \\
$57^{\circ}(1901-1903)$ & Republicana & Republicana \\
$58^{\circ}(1903-1905)$ & Republicana & Republicana \\
$59^{\circ}(1905-1907)$ & Republicana & Republicana \\
$60^{\circ}(1907-1909)$ & Republicana & Republicana \\
$61^{\circ}(1909-1911)$ & Republicana & Republicana \\
$62^{\circ}(1911-1913)$ & Republicana & Demócrata \\
$63^{\circ}(1913-1915)$ & Demócrata & Demócrata \\
$64^{\circ}(1915-1917)$ & Demócrata & Demócrata \\
$65^{\circ}(1917-1919)$ & Demócrata & Demócrata \\
\hline & & \\
\hline
\end{tabular}

246 Un dato de color de este período es que en el 47 Congreso (1881-1883) el Senado estuvo dividido en dos mitades iguales, con 37 senadores cada partido y dos independientes: David Davis, de Illinois, que votaba con los demócratas, y William Mahone, de Virginia, que se inclinaba por los republicanos. Este empate, en definitiva, favorecía a los republicanos, pues Chester Arthur, el vicepresidente republicano, ejercía el casting vote votando a favor de su partido. Esta situación produjo una ardua disputa por el reparto de las comisiones al comienzo de la primera sesión en marzo de 1881 . 
Un segundo dato a tener en cuenta sobre este período es que la Casa Blanca, ocupada mayoritariamente por presidentes republicanos, no tuvo grandes figuras, salvo las de Theodore Roosevelt (1901-1909) y Woodrow Wilson (19131921). ${ }^{247}$ Sin la influencia de líderes fuertes en el Ejecutivo, el Congreso y los partidos emergieron políticamente, ejerciendo un poder que coincidía con lo que el propio Wilson, en su temprana juventud, predicaba en su obra Congressional Government, publicada originalmente en $1885,{ }^{248}$ en la que sostenía que la tarea principal de gobierno le corresponde al Congreso. ${ }^{249}$ Es probable que Wilson haya tenido oportunidad de meditar sobre estas afirmaciones años después, en 1919, siendo presidente, cuando un Senado hostil rechazó la aprobación del Tratado de Versailles, frustrando su propósito de incorporar a los Estados Unidos a la Liga de Naciones, tratado que el propio Wilson había ido en persona a defender en el recinto, haciendo un gesto extravagante que, ya en 1789, había resultado insatisfactorio incluso para Washington. ${ }^{250}$

\subsection{El crecimiento cuantitativo del Congreso}

Durante este período, el Congreso tuvo un importante incremento cuantitativo de sus miembros. El House, que en 1877 comenzó con 293 representantes, alcanzó en 1913 los 435, como consecuencia del aumento de la población registrada en cada Censo, número este que, como veremos luego, se mantiene fijo hasta el presente por imposición de la Permanent Apportionment Act of 1929. El Senado, por su lado, creció de 76 a 96 senadores en virtud de la incorpora-

247 En el Anexo VII (p. 440) trazo una semblanza de estos presidentes

248 He consultado la edición publicada por Okitos Press (Wilson, 2017).

249 Ya desde el prefacio de la obra Wilson (2017) dice que el Congreso es el poder predominante y central del sistema, y al formular sus conclusiones sostiene que este rápidamente se está convirtiendo en el cuerpo gobernante de la nación que posee el poder de legislar que lubrica el Gobierno. ("Congress is fast becoming the governing body of the nation, and yet the only power which it possesses in perfection is the power which is but a part of government, the power of legislation. Legislation is but the oil of government. It is that which lubricates its channels and speeds its wheels; that which lessens the friction and so eases the movement").

250 El 22 de agosto de 1789, acompañado por Henry Knox, su secretario de Guerra, Washington concurrió personalmente al Senado para urgir la firma de un tratado con los indigenas de la tribu Creek en el sur. Según el relato del senador William McClay de Pennsylvania, no solo el ruido de los carruajes que circulaba por la calle impedía escuchar bien a Washington, sino que los senadores, en lugar de aprobar inmediatamente el tratado, como Washington esperaba, lo enviaron a comisión para estudiarlo, un gesto que irritó al presidente. Finalmente, lo aprobaron la semana siguiente. A partir de entonces, todas las comunicaciones entre Washington y el Senado se hicieron por escrito. Vid. Guide to Congress (2015, p. 77). 
ción de 10 nuevos estados. ${ }^{251}$ En el cuadro siguiente se muestra esta evolución en cada una de las cámaras.

\begin{tabular}{c|c|c}
\hline Congreso & Senadores & Representantes \\
\hline $45^{\circ}(1877-1879)$ & 76 & 293 \\
$46^{\circ}(1879-1881)$ & 76 & 293 \\
$47^{\circ}(1881-1883)$ & 76 & 325 \\
$48^{\circ}(1883-1885)$ & 76 & 325 \\
$49^{\circ}(1885-1887)$ & 76 & 325 \\
$50^{\circ}(1887-1889)$ & 76 & 325 \\
$51^{\circ}(1889-1891)$ & 88 & 332 \\
$52^{\circ}(1891-1893)$ & 88 & 332 \\
$53^{\circ}(1893-1895)$ & 88 & 356 \\
$54^{\circ}(1895-1897)$ & 90 & 357 \\
$55^{\circ}(1897-1899)$ & 90 & 357 \\
$56^{\circ}(1899-1901)$ & 90 & 357 \\
$57^{\circ}(1901-1903)$ & 90 & 357 \\
$58^{\circ}(1903-1905)$ & 90 & 386 \\
$59^{\circ}(1905-1907)$ & 90 & 386 \\
$60^{\circ}(1907-1909)$ & 92 & 391 \\
$61^{\circ}(1909-1911)$ & 92 & 391 \\
$62^{\circ}(1911-1913)$ & 96 & 394 \\
$63^{\circ}(1913-1915)$ & 96 & 435 \\
$64^{\circ}(1915-1917)$ & $95^{\circ}(1917-1919)$ & 96 \\
$66^{\circ}(1919-1921)$ & 96 & \\
\hline
\end{tabular}

\subsection{Los party bosses en el Senado}

Luego de la Guerra Civil, entró al Senado una nueva camada de legisladores. Ninguno de ellos tenía la brillantez oratoria de Daniel Webster o Henry Clay,

251 En orden cronológico, los estados incorporados fueron: Montana (1889), North Dakota (1889), South Dakota (1889), Washington (1889), Idaho (1890), Wyoming (1890), Utah (1896), Oklahoma (1907), Arizona (1912) y New Mexico (1912). 
sino que eran políticos profesionales que habían emergido de las filas de sus partidos en cada uno de los estados y que llegaron a Washington luego de haber consolidado su poder en las respectivas estructuras partidarias, cuya disciplina interna y armonía estaban bien dispuestos a mantener y controlar.

Para estos hombres, el Senado era un escalón en su carrera política y se los veía como resultado del crecimiento del poder de los partidos, atribuido, en buena medida, a los trusts, es decir, a las empresas económicamente monopólicas que los apoyaban y se valían de ellos para preservar sus intereses por medio de fuertes lobbies. ${ }^{252}$ Como resultado de ello, el Senado perdió estima popular y se lo calificó como el "Club de los Millonarios" (Millionaires Club), una denominación que fue acuñada hacia $1890 .{ }^{253}$ Con el control del Senado por parte de los "jefes del partido" (party boses), la discusión parlamentaria descendió en calidad, pues las cuestiones ya llegaban acordadas al recinto y las sesiones carecían de brillo, transformándose en actos formales de aprobación de lo ya decidido previamente. ${ }^{254}$ Todo ello generó el ambiente propicio para gestar una reforma en el procedimiento de elección de los senadores, que ya había tenido, como vimos, una primera modificación -no muy exitosa- en la ley de 1866 y que se concretó finalmente con la Enmienda XVII, a la que me referiré más abajo.

Representantes típicos de esta disciplina partidaria fueron los senadores republicanos Orville H. Platt, de Connecticut, John C. Spooner, de Wisconsin, Nelson W. Aldrich, de Rhode Island, James McMillan, de Michigan, y William B. Allison, de Iowa. Este último, a lo largo de tres décadas en la banca (18811911), encontró la forma de consolidar su poder por medio del empleo del caucus, ${ }^{255}$ lo que le permitió influir decisivamente en el nombramiento de quienes eran afines a sus intereses en las comisiones legislativas. ${ }^{256}$ En las filas demócratas, el senador más influyente, como contraparte de Allison, fue Arthur

\section{Ver Rothman (1966).}

253 Ver Patrick et al. (2001, p. 411).

254 El senador republicano George F. Hoar, de Massachusetts, decía que ser senador sería encantador si no hubiera que asistir a las sesiones (como se citó en Rothman, 1966, p. 146).

255 Se entiende por caucus, cuyo nombre oficial en la actualidad es Legislative Service Organization, a la reunión u organización de un cierto número de legisladores con un propósito determinado. Tanto su origen histórico como etimológico son imprecisos. La palabra caucus, entendida como "club político", aparece en el diario de John Adams en 1763 y se dice que proviene de caucauasu, que entre los indígenas algonquin era una reunión del consejo tribal. Vid. Dickson y Clancy (1993, pp. 49-50).

256 Allison también controlaba el llamado Steering Committe de los republicanos en el Senado, es decir, la "comisión de dirección", que se encargaba de controlar la marcha de los proyectos legislativos. En el Senado, los integrantes de esta comisión eran designados por períodos bianuales desde 
P. Gorman, de Maryland, que tuvo también una larga trayectoria (1881-1899 y 1903-1906), aunque su influencia fue menor, dada la mayoría republicana que dominó el Senado durante este período.

\subsection{La práctica del filibuster en el Senado y la Cloture Rule}

En la jerga parlamentaria, el filibuster (filibustero) es la antigua práctica de entorpecer y tratar de evitar el proceso de discusión y sanción de una ley por medio de largos e innecesarios discursos que dilatan extraordinariamente las sesiones. ${ }^{257}$ Usualmente, es el recurso empleado por los legisladores de la minoría para obstruir los proyectos de la mayoría. ${ }^{258}$ Con ello se asocia a quienes lo practican con los piratas o bandidos que atacaban las naves comerciales, que tuvieron su auge en el siglo XVIII. ${ }^{259}$ En lenguaje sencillo, quien hace un filibuster "piratea" la sesión.

Si bien esta táctica ya había sido empleada en el Senado antes y durante la Guerra Civil, ${ }^{260}$ a partir de 1880 su uso fue mucho más intenso, favorecido por la antigua regla de que los discursos no tenían un tiempo limitado de duración. Ya a finales de la década de 1870, los republicanos la emplearon para obstruir los proyectos demócratas de retiro de las tropas federales en el sur y, en 1881, los demócratas se valieron del filibuster para impedir que el Senado se organizara hasta que renunciaran los senadores republicanos de New York Roscoe Conckling y Thomas C. Platt. Por tal motivo, el Senado estuvo virtualmente paralizado desde el 24 de marzo hasta el 16 de mayo de ese año. Un caso curioso fue el de Henry W. Blair, senador republicano por New Hampshire, que en 1890 presentó un proyecto de ley de subsidios a la educación y, entre el 26 de febrero y el 20 de marzo, se ocupó de dilatar su tratamiento en aras de lograr la mayoría para su aprobación, la cual finalmente no obtuvo. ${ }^{261}$ Fue

mediados de 1880 .

257 Tan antigua es que, en Roma, Catón el Joven la empleó en el Senado, hablando días y días para oponerse a las leyes de Julio César.

258 En el Congreso de los Estados Unidos, el récord lo tiene el entonces senador demócrata por South Carolina Strom Thurmond, quien, para impedir la sanción de la Civil Rights Act of 1957, habló durante 24 horas y 27 minutos en la sesión del 30 de agosto de 1957.

259 La palabra viene del holandés (vrijbuiter), que podría traducirse al inglés como freebooter.

260 Fue empleada en 1863 para intentar que Lincoln no fuera sancionado por la suspensión del hábeas corpus, y en 1865 el senador Charles Sumner de Massachusetts hizo uso de ella para impedir que Louisiana fuera reincorporada a la Unión.

261 El proyecto fue rechazado por un voto de 37-31 y el propio Blair votó en contra para tener la 
célebre también el filibuster de los demócratas contra el llamado Force Bill, que autorizaba la supervisión de las autoridades nacionales en las elecciones de los estados sureños para impedir que los afroamericanos fueran excluidos de votar. Luego de siete semanas de dilación, transcurridas entre el 2 de diciembre de 1890 y el 26 de enero de 1891, los republicanos intentaron sin éxito imponer una regla de cierre o clausura a los debates (cloture rule), pero no les fue posible. Finalmente, abandonaron el proyecto porque la parálisis del Senado estaba impidiendo la aprobación de otras leyes antes de que terminaran las sesiones del 51 Congreso. Dos años después, en 1893, también fue objeto de un largo filibuster la derogación de la Silver Purchase Act of 1890, que se prolongó entre el 29 de agosto y el 24 de octubre, ${ }^{262}$ provocando una fuerte crítica del senador republicano Henry Cabot Lodge, de Massachusetts, quien señaló la necesidad de establecer un cambio en el reglamento que impidiera estas demoras, pues un Senado paralizado no puede gobernar. ${ }^{263}$ Los ejemplos históricos podrían seguir, pero mencionaré solamente dos más. El primero de ellos figura entre los filibusters más prolongados: el del senador republicano Robert M. La Follette, de Wisconsin, ${ }^{264}$ producido en 1908 , que se extendió por 18 horas para impedir la sanción de un proyecto presentado por su propio partido ${ }^{265}$ relativo al Money Trust (el monopolio de los bancos). ${ }^{266}$ El segundo tuvo lugar en 1917, cuando el Senado obstruyó un proyecto del presidente Wilson para armar buques mercantes en preparación para la próxima intervención de los Estados Unidos en la Primera Guerra Mundial, provocando la ira del presidente. ${ }^{267}$

posibilidad de pedir la reconsideración del proyecto, lo que tampoco logró.

262 En esta ocasión se emplearon todas las técnicas posibles de dilación en una asamblea legislativa, entre ellas, el llamado roll-call vote, o recorded vote, que consiste en que el voto de cada legislador queda registrado con su nombre, a diferencia del ballot vote, que es secreto, pues se vota por medio de una boleta depositada en una urna sin indicación de quién lo emite.

263 Citado por Haynes (1938, pp. 398-399).

264 Famoso por su energía, se lo conocía como Fighting Bob (Roberto el Luchador).

265 Sus impulsores fueron el senador Aldrich, ya mencionado, y Edward B. Vreeland, representante de New York.

266 Empleando el filibuster, La Follette logró introducir en la ley una enmienda que penaba el envío de información bancaria inexacta al Gobierno. Ver Thelen (1976a, pp. 64-66).

267 "The Senate of the United States -dijo Wilson- is the only legislative body in the world which cannot act when its majority is ready for action. A little group of willful men, representing no opinion but their own, have rendered the great government of the United States helpless and contemptible" (Haynes, 1938, pp. 402-403).

Una vez más, Wilson debe de haberse arrepentido de lo que escribiera años antes como profesor universitario en Congressional Government, elogiando la posibilidad de hablar en el Senado abierta e irrestrictamente. Ver Wilson (2017, p. 70). 
Fue precisamente a raíz de este último filibuster que el Senado incorporó la Regla XXII, llamada Cloture Rule (del francés clôture: cierre, clausura). Según esta, los debates podían ser concluidos si lo votaba una mayoría de dos tercios de los senadores presentes. ${ }^{268}$

A diferencia del Senado, en el House el filibuster no se ha extendido como práctica. Si bien los hubo antiguamente, antes incluso que en el Senado, el mayor tamaño de la cámara obligó a establecer varias reglas tendientes a evitarlos. Así, por ejemplo, desde 1798 fue establecido que cada representante puede hablar una sola vez en cada debate y, en 1847 , se dispuso que las intervenciones relativas a enmiendas en los proyectos solo pueden durar cinco minutos.

\subsection{El caso Kilbourn v. Thompson y la revisión de las investigaciones del Congreso}

En 1881, la Corte Suprema resolvió el caso Kilbourn v. Thompson, ${ }^{269}$ que delimitó los alcances de los poderes de investigación del Congreso. Con motivo de la investigación de la quiebra Jay Cooke \& Company -una de las compañías financieras más importantes de ese momento-, ${ }^{270}$ producida por la crisis económica de 1873 (Panic of 1873), ${ }^{271}$ Hallet Kilbourn, un agente inmobiliario vinculado comercialmente con la compañía en quiebra, fue citado a declarar como testigo por la comisión investigadora establecida por el House. ${ }^{272} \mathrm{Si}$ bien Kilbourn se presentó ante la comisión investigadora, se negó a declarar y a producir la prueba que se le requirió. A raíz de esta negativa, fue arrestado por desacato (contempt) y penado con 45 días de prisión por orden del House. Impugnada judicialmente esta decisión, la Corte Suprema -por medio del voto del Justice Miller- sostuvo que el Congreso no estaba conduciendo una investigación de naturaleza legislativa, sino judicial, y que por lo tanto no era competente para ello ni para ordenar tampoco, en ese contexto, el arresto de

268 En la actualidad, según una reforma introducida en 1975, la Regla XXII dispone que la petición deben formularla dieciséis senadores y la mayoría para votarla se reduce a tres quintos.

269103 U.S. 168 (1881).

270 Fundada en 1861 por Jay Cooke, había crecido extraordinariamente colocando bonos del Gobierno durante la Guerra Civil.

271 Jay Cooke \& Company había invertido fuertemente en la construcción de la Northern Pacific Railway, pero quebró cuando no pudo colocar los bonos de la compañía a causa de la crisis financiera de 1873, cuyas causas en los Estados Unidos son más profundas, pero fue desatada por la Coinage Act of 1873 (17 Statutes at Large 424), que eliminó el bimetalismo plata/dólar y puso a los Estados Unidos en el caminos del gold standard, que fue oficialmente adoptado en 1900.

272 Uno de los acreedores en la quiebra era el Gobierno de los Estados Unidos, lo que justificaba la promoción de la investigación en el Congreso. 
un testigo renuente a declarar. ${ }^{273}$ Asimismo, citando una sentencia de la Corte Suprema de Massachusetts, ${ }^{274}$ sostuvo que las decisiones emitidas en el curso de una investigación del Congreso eran revisables judicialmente. ${ }^{275}$

\subsection{La centralización del poder del Speaker. Thomas B. Reed y Joseph G. Cannon}

Por espacio de dos décadas, entre 1890 y 1910, dos figuras prominentes del Partido Republicano, Thomas Brackett Reed y Joseph Gurney Cannon, lideraron el House en forma autoritaria como Speakers y generaron una gran centralización de poder en torno a su persona.

Ya mencioné que, durante la Guerra Civil y el período de la Reconstrucción, los Speakers no dominaron el House. Schuyler Colfax (1863-1869) y quienes lo

273 "[...] we are of opinion that the House of Representatives not only exceeded the limit of its own authority, but assumed a power which could only be properly exercised by another branch of the government, because it was in its nature clearly judicial (103 U.S. en p. 192) [...] We are of opinion, for these reasons, that the resolution of the House of Representatives authorizing the investigation was in excess of the power conferred on that body by the Constitution; that the committee, therefore, had no lawful authority to require Kilbourn to testify as a witness beyond what he voluntarily chose to tell; that the orders and resolutions of the House, and the warrant of the speaker, under which Kilbourn was imprisoned, are, in like manner, void for want of jurisdiction in that body, and that his imprisonment was without any lawful authority (103 U.S. en p. 196) [...] we do not concede that the Houses of Congress possess this general power of punishing for contempt. The cases in which they can do this are very limited, as we have already attempted to show. If they are proceeding in a matter beyond their legitimate cognizance, we are of opinion that this can be shown, and we cannot give our assent to the principle that, by the mere act of asserting a person to be guilty of a contempt, they thereby establish their right to fine and imprison him, beyond the power of any court or any other tribunal whatever to inquire into the grounds on which the order was made. This necessarily grows out of the nature of an authority which can only exist in a limited class of cases, or under special circumstances; otherwise the limitation is unavailing and the power omnipotent" (103 U.S. en p. 197).

274 Burnham v. Morrissey, 14 Gray 226 (1859).

275 "The house of representatives is not the final judge of its own power and privileges in cases in which the rights and liberties of the subject are concerned, but the legality of its action may be examined and determined by this court. That house is not the legislature, but only a part of it, and is therefore subject in its action to the laws, in common with all other bodies, officers, and tribunals within the Commonwealth. Especially is it competent and proper for this court to consider whether its proceedings are in conformity with the Constitution and laws, because, living under a written constitution, no branch or department of the government is supreme; and it is the province and duty of the judicial department to determine in cases regularly brought before them, whether the powers of any branch of the government, and even those of the legislature in the enactment of laws, have been exercised in conformity to the Constitution; and if they have not, to treat their acts as null and void. The house of representatives has the power under the Constitution to imprison for contempt; but the power is limited to cases expressly provided for by the Constitution, or to cases where the power is necessarily implied from those constitutional functions and duties, to the proper performance of which it is essential" (103 U.S. en p. 199). 
sucedieron -Theodore Pommeroy (1869), ,276 James G. Blaine (1869-1875), $277 \mathrm{Mi}$ chael Kerr (1875-1876), ${ }^{278}$ Samuel J. Randall (1876-1881), ${ }^{279}$ Warren Kiefer (18811883), ${ }^{280}$ y John Carlisle (1883-1889) - no ejercieron el control de la Cámara. ${ }^{281}$ Esta situación tuvo un giro importante en el 51 Congreso (1889-1891), cuando los republicanos retomaron el control del House y eligieron como Speaker a Thomas Brackett Reed, de Maine, quien ocuparía el cargo en tres oportunidades: 1889-1891, 1895-1897 (54º Congreso) y 1897-1899 (55 Congreso). ${ }^{282}$

Reed era un individuo alto y fornido, vestido siempre de negro, que tenía un temperamento fuerte, con el que rápidamente se hizo del control del House. ${ }^{283}$ Para ello, impuso de inmediato, casi por la fuerza, las llamadas Reed Rules sobre el cómputo del quorum -luego incorporadas en forma permanente- para evitar que la minoría pudiera obstruir las sesiones no dando el quorum necesario para votar. La ocasión para ello se presentó en enero de 1890, cuando John Dalzell, de Pennsylvania, propuso como cuestión de privilegio que fuera tratado el caso de la elección de Charles Brooks Smith, republicano de West Virginia, que estaba en disputa. Esto provocó la reacción negativa de Charles F. Crisp, de Georgia, líder de la oposición. Sometida la cuestión a votación por medio del roll-call vote, es decir, registrando los nombres de los que votaban en uno y otro sentido, ${ }^{284}$ votaron 161 en sentido afirmativo, solo 2 votaron por el no y 166 se abstuvieron. Reed decidió, entonces, que el quorum debía computarse contando también a los presentes que no habían votado y que la votación se había llevado a cabo correctamente. Planteada la revisión de esta decisión, la moción fue rechazada por mayoría. ${ }^{285}$

\footnotetext{
276 Republicano de New York.

277 Republicano de Maine.

278 Demócrata de Indiana.

279 Demócrata de Pennsylvania.

280 Republicano de Ohio.

281 Demócrata de Kentucky.
}

282 Había ingresado al House en el 45 Congreso (1877-1879) y luego fue reelecto como representante

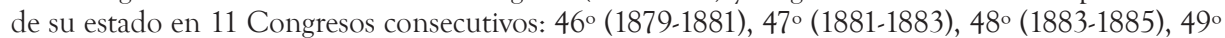
(1885-1887), 50॰ (1887-1889), 51。 (1889-1891), 52。 (1891-1893), 53。 (1893-1895), 54 (1895-1897), 55 (1897-1899) y 56 (1899-1901). Antes de ello, había sido miembro del House en Maine (18681869), senador estatal (1870) y Attorney General de Maine (1870-1872).

283 Desde Henry Clay, que dominó el House como Speaker en cinco Congresos (12 1811-1813; 13 1813-1814; 14 1815-1817; 15॰ 1817-1819 y 16 1819-1820), no se había visto a un líder semejante. La oposición rápidamente lo calificó de "tirano" y "zar".

284 Ver nota 262.

285 Justificó la decisión diciendo, en síntesis, que el objetivo del Congreso no era obstruir la legislación, 
Un mes más tarde, esta regla fue incorporada al reglamento del House por el Rules Committee y fue aprobada por el pleno por una mayoría de 161-144. Adicionalmente, en el nuevo reglamento se dispuso reducir el quorum para las sesiones de la Comisión del Pleno (Committee of the Whole House) de la mitad de los miembros a solo 100, lo que agilizó las sesiones, teniendo en cuenta el crecimiento constante del número de representantes. ${ }^{286}$ Se dispuso también que la presentación de un proyecto ya no requeriría la autorización del House (leave of the House), sino que era suficiente su presentación ante el Clerk. ${ }^{287}$ Bajo estas nuevas reglas, se le permitió al Speaker tener el control del House. Podía designar a todos los miembros de las comisiones, premiando con ello a sus adláteres y castigando a sus opositores, y presidía las dos comisiones más importantes: la de reglamento (Rules Committee) y la de presupuesto (Committee on Ways and Means and Appropiations).

Cuando en el 52॰ Congreso (1891-1893) los demócratas recobraron la mayoría en el House, derogaron las Reed Rules, pero, dándose cuenta de lo efectivas que eran para quien tuviera la mayoría, las restablecieron en el $53^{\circ}$ Congreso (1893-1895), en el que también fueron mayoría. En este período, Charles F. Crisp, como Speaker, hizo amplio uso de ellas, incluso en contra de Reed. Bajo estas reglas, durante este período, ambos partidos en el House actuaron con gran unidad interna. En el ala republicana, ello tuvo lugar, en parte, merced a que Reed, como Speaker en el 55 Congreso (1897-1899), designó como Whip (jefe de bloque) a James A. Tawney, de Minnesota, quien mantuvo el control en las votaciones, evitando que los caucus dentro del partido votaran divididos.

sino promoverla, y que la mayoría tenía el derecho de rechazar aquellas mociones, que aun estando permitidas por la práctica parlamentaria, eran dilatorias. "There is no possible way by which the orderly methods of parliamentary procedure can be used to stop legislation. The object of a parliamentary body is action, and not stoppage of action. Hence, if any member or set of members undertakes to oppose the orderly progress of business, even by the use of the ordinarily recognized parliamentary motions, it is the right of the majority to refuse to have those motions entertained, and to cause the public business to proceed" (como se citó en Guide to Congress, 2015, p. 53).

286 Ver Grant (2011).

287 Como resultado de ello, el número de proyectos presentados aumentó considerablemente. Hasta el 40॰ Congreso (1867-1869) esta cantidad nunca había excedido los 2000. En el 51 Congreso (1889-1891) fueron presentados 19000 proyectos, bien que, como anotaba Woodrow Wilson (2017), la mayoría de ellos era desechado. "The fate of bills committed is generally not uncertain. As a rule, a bill committed is a bill doomed. When it goes from the clerk's desk to a committee-room it crosses a parliamentary bridge of sighs to dim dungeons of silence whence it will never return. The means and time of its death are unknown, but its friends never see it again. Of course no Standing Committee is privileged to take upon itself the full powers of the House it represents, and formally and decisively reject a bill referred to it; its disapproval, if it disapproves, must be reported to the House in the form of a recommendation that the bill 'do no pass'” (p. 24). 
Además de la centralización del House en torno al Speaker, en los últimos años del siglo XIX tuvo lugar otro fenómeno -no tan visible- que también contribuyó a la unidad de las decisiones. Hasta la Guerra Civil, ser elegido representante no era considerado como una carrera política. La movilidad entre los legisladores era muy alta, al punto que, a fines de la década de 1870, más de la mitad de los entonces 293 representantes se renovaba en cada Congreso. Muchos de ellos solo eran elegidos por un término no mayor a dos períodos y no les interesaba demasiado su relación con el Speaker que los designaba en las comisiones, pues no tenían un alto interés en integrarlas. Hacia el final del siglo XIX, esta rotación fue moderándose, la reelección se hizo más frecuente y ocupar una banca en el House adquirió un carácter de mayor permanencia, convirtiéndose en una suerte de profesión. En 1899, por ejemplo, la cantidad de nuevos legisladores que ingresaron al 56 Congreso fue tan solo del 30\%, mientras que el promedio de duración en la banca se había incrementado a más de tres mandatos. Con ello, la actitud de los representantes hacia su puesto político cambió, la antigüedad cobró mayor importancia ${ }^{288}$ y adquirieron más interés en especializarse en ciertos temas y ocupar posiciones destacadas en las comisiones. Todo ello contribuyó, ciertamente, a cuestionar el centralismo del Speaker, quien ahora debía lidiar con políticos profesionales.

Reed renunció como Speaker en 1899 por sus desavenencias con el presidente McKinley sobre la guerra de Cuba y la anexión de Hawaii, y fue reemplazado en el 56 Congreso (1899-1901) por David Henderson, republicano de Iowa, que ejerció el cargo durante dos períodos sin mayor efectividad. En 1903, al comenzar el 58 Congreso (1903-1905), los republicanos eligieron Speaker a John G. Cannon (Uncle Joe), de Illinois, quien con sus 67 años era el mayor de todos los representantes y el más antiguo: ya tenía por entonces 28 años de servicio en el House. ${ }^{289}$ Siguiendo el ejemplo de Reed, Cannon se propuso manejar el House controlando de cerca la Comisión de Reglamento (Rules Committe) y la de Presupuesto (Ways and Means Committe). En esta última retuvo como chairman a Sereno E. Payne, de New York, que había sido designado por Henderson. Inicialmente le permitió a John Sharp Williams, líder de los demócratas, que hiciera las designaciones de sus partidarios en las comisiones, sujetas al veto el Speaker. Williams aprovechó esta oportunidad para unir a su partido y, en

288 La importancia de la antigüedad fue aumentando a medida que transcurría el siglo XX. En 1900, solamente 3 de los 391 representantes tenían acumulados más de 10 mandatos en el House; en 1971, ese número se había elevado a 87.

289 Había ingresado al House en 1873 y se había postulado sin éxito como Speaker en 1881, 1889 y 1899. 
1908, Cannon retomó la prerrogativa de hacer por sí mismo todas las designaciones, cuando James Beauchamp Clark (Champ Clark), de Missouri, sucedió a Williams como líder de la minoría.

Cannon era un conservador duro que se oponía y hacía todos los esfuerzos necesarios para bloquear la sanción de la legislación social y progresista que impulsaban, por entonces, Theodore Roosevelt desde la presidencia y la creciente ala liberal de su propio partido. Para mantener estrechas sus filas, el Speaker se encargaba de sancionar duramente a quienes no lo apoyaban en esta tarea. A raíz de ello, la palabra "canonismo" (cannonism) se convirtió en sinónimo de arbitrariedad en el uso del poder del Speaker para obstruir los proyectos de ley que no eran de su agrado. Comenzó entonces un foco de resistencia contra Cannon, que tuvo una primera asonada el 3 de marzo de 1909, a fines del 60 Congreso (1907-1909), cuando fue aprobada la llamada Calendar Wednesday Rule, según la cual todos los miércoles los presidentes de las comisiones, o quienes ellos designaran, podían informarle al pleno sobre los proyectos de ley que habían sido analizados en comisión, pero que no habían recibido aprobación del Rules Committee para ser debatidos. Días después, el 15 de marzo, al comienzo del 61 Congreso (1909-1911), un grupo de treinta representantes republicanos opositores a Cannon, liderados por George W. Norris, de Nebraska $^{290}$-aunque habían votado para reelegir al Speaker-, se aliaron con los demócratas para limitar su autoridad, bien que los resultados en esta primera oportunidad fueron magros. ${ }^{291}$ Una nueva embestida contra Cannon -esta vez exitosa- tuvo lugar al año siguiente, en marzo de 1910, cuando Norris insistió nuevamente en aprobar, con algunas reformas, la propuesta de Clark formulada el año anterior. ${ }^{292}$ Si bien Cannon se opuso férreamente a tratarla, esta vez fue derrotado por un voto decisivo y el House, finalmente, aprobó la propuesta

290 En ese momento, el House estaba compuesto por 219 republicanos y 172 demócratas.

291 La táctica para ello consistió en no continuar con la costumbre de aprobar el empleo de las reglas vigentes en el anterior Congreso, sino de establecer nuevas. A tal fin, Champ Clark, líder de los demócratas, propuso que el Speaker: (a) ya no hiciera las designaciones de los miembros de todas las comisiones, sino en solo cinco de ellas, de las cuales la única importante era la de Presupuesto; y (b) dejara de presidir la Comisión de Reglamento, cuyo tamaño debía ser triplicado, añadiéndose para ello 10 nuevos miembros. Esta propuesta dividió a los partidos, pues 28 republicanos votaron a favor y 22 demócratas -liderados por John J. Fitzgerald, de New York- en contra. Fue necesario entonces adoptar una solución intermedia, propuesta por Fitzgerald, que moderó muy tibiamente la autoridad del Speaker. La principal modificación consistió en establecer un calendario para el tratamiento de ciertas leyes de interés para algunos representantes, estableciendo dos días al mes designados específicamente a tal fin. Estas leyes podían ser tratadas sin requerirse para ello la aprobación del Speaker, pero debían ser sancionadas por unanimidad.

292 Ver nota 291. 
de Norris por una mayoría de 191-156. ${ }^{293}$ Despojado de su poder, Cannon ofreció su renuncia, pero no fue aceptada y continuó siendo Speaker hasta el final del 61 Congreso, en marzo de 1911. ${ }^{294}$ En el 62 Congreso (1911-1913), los demócratas recobraron la mayoría en el House y eligieron Speaker a Champ Clark, quien impulsó un nuevo reglamento que incorporó las reglas aprobadas en 1910. Entre ellas, se dispuso que los miembros de todas las comisiones ya no serían elegidos por el Speaker, sino por el House al comienzo de cada sesión.

Desde el 62 Congreso (1911-1913), hasta el 65 Congreso (1917-1919), los demócratas tuvieron mayoría en el House. Durante este período, el poder del Speaker declinó fuertemente. La figura dominante de los demócratas en el House, desde 1911 hasta 1915, no fue Champ Clark, el Speaker, sino Oscar W. Underwood, de Alabama, presidente de la Comisión de Presupuesto y líder de la mayoría. Las decisiones retornaron a los caucus de los partidos, y en el demócrata la autoridad de Underwood era indiscutible. ${ }^{295}$

\subsection{La Apportionment Act of 1911}

El 8 de agosto de 1911 fue sancionada la Apportionment Act of 1911, ${ }^{296}$ por medio de la cual se dispuso, siguiendo los resultados del 13 Censo llevado a cabo en 1910, que el número de representantes en el House aumentaría de 391 a 433, estableciéndose, asimismo, que ese número se incrementaría a 435 una vez que Arizona y New México fuera incorporados como estados. Dado que la

293 John M. Nelson, republicano de Wisconsin, expresó vivamente los sentimientos de sus colegas insurgentes denunciando la opresión y humillación que Cannon les había impuesto: "Have we not been punished by every means at the disposal of the powerful House organization? Members long chairmen of important committees, others holding high rank - all with records of faithful and efficient party service to their credit - have been ruthlessly removed, deposed, and humiliated before their constituents and the country because, forsooth, they would not cringe or crawl before the arbitrary power of the Speaker and his House machine [...]. We are fighting with our Democratic brethren for the common right of equal representation in this House, and for the right of way of progressive legislation in Congress" (Guide to Congress, 2015, p. 55).

294 Salvo durante el 63 Congreso (1913-1915), Cannon continuó siendo miembro del House hasta 1923.

295 George B. Galloway (1976) describió el poder de Underwood en estos términos: "As floor leader, Underwood was supreme, the Speaker a figurehead. The main cogs in the machine were the caucus, the floor leadership, the Rules Committee, the standing committees, and special rules. Oscar Underwood became the real leader of the House. He dominated the party caucus, influenced the rules and, as chairman of Ways and Means, chose the membership of the committees. Champ Clark was given the shadow, Underwood the substance, of power. As floor leader, he could ask and obtain recognition at any time to make motions, restrict debate or preclude amendments or both" (p. 136).

29637 Statutes at Large 13. 
ley se aplicaría a partir del 63 Congreso (1913-1915), el House ya contaba con 435 representantes cuando dicho Congreso fue inaugurado, en tanto Arizona y New México fueron convertidos en estados en 1912.

Conforme a esta ley, la distribución de representantes por cada estado era la siguiente:

\begin{tabular}{|c|c|c|}
\hline Alabama: 10 & Maryland: 6 & Oregon: 3 \\
\hline Arkansas: 7 & Massachusetts: 16 & Pennsylvania: 36 \\
\hline California: 11 & Michigan: 13 & Rhode Island: 3 \\
\hline Colorado: 4 & Minnesota: 10 & South Carolina: 7 \\
\hline Connecticut: 5 & Mississippi: 8 & South Dakota: 3 \\
\hline Delaware: 1 & Missouri: 16 & Tennessee: 10 \\
\hline Florida: 4 & Montana: 2 & Texas: 18 \\
\hline Georgia: 12 & Nebraska: 6 & Utah: 2 \\
\hline Idaho: 2 & Nevada: 1 & Vermont: 2 \\
\hline |llinois: 27 & New Hampshire: 2 & Virginia: 10 \\
\hline Indiana: 13 & New Jersey: 12 & Washington: 5 \\
\hline lowa: 11 & New York: 43 & West Virginia: 6 \\
\hline Kansas: 8 & North Carolina: 10 & Wisconsin: 11 \\
\hline Kentucky: 11 & North Dakota: 3 & Wyoming: 1 \\
\hline Louisiana: 8 & Ohio: 22 & \\
\hline Maine: 4 & Oklahoma: 8 & \\
\hline
\end{tabular}

A pesar de que una mayor cantidad de representantes parecería asegurar una mayor democracia, la sanción de esta ley produjo críticas basadas en que el aumento de representantes con cada censo debilitaba el sistema representativo establecido en la Constitución. Uno de los voceros de estas críticas fue Edgar 
D. Crumpacker, representante republicano de Indiana. ${ }^{297}$ Fue por ello que, como veremos más adelante, en 1929 se dictó la Permanent Apportionment Act, que fijó el número de representantes en 435, número que no ha variado hasta ahora, salvo por un breve período -entre 1959 y 1963 - en el que aumentó a 437 con la incorporación de Alaska y Hawaii como estados.

\subsection{La Enmienda XVII y la elección directa de los senadores}

Ya mencioné, al comentar la ley de 1866 sobre elección de los senadores, que el sistema de elección de estos, establecido en el artículo I, sección 3 de la Constitución, favorecía a los grupos de interés que controlaban las legislaturas estatales y producía, en ocasiones, un empate en la elección o bien una distorsión del proceso electoral. La ley de 1866 no fue efectiva para mejorar el sistema, de modo tal que, para cambiarlo sustancialmente eliminando la competencia de las legislaturas locales para elegir a los senadores, era necesaria una enmienda constitucional, que finalmente tuvo lugar en 1913 con la ratificación de la Enmienda XVII, que estableció la elección directa de los senadores. Antes de ella, en varios estados ya se habían sancionado leyes que, en forma indirecta, permitían la elección popular de los senadores. En 1912, sistemas de este tipo estaban vigentes en aproximadamente 29 estados. ${ }^{298}$

297 En su opinion: "Members are [...] supposed to reflect the opinion and to stand for the wishes of their constituents [...] If we make the ratio [of persons per Representative] too large the idea of representation becomes attenuated and less definite. The personal interest of the voter in his representative becomes less important to him, and we may lose something of the vital strength of our representative form of government". Ver: https://history.house.gov/HistoricalHighlight/Detail/35159? ret=True.

298 Hacia 1900, en los estados del sur empezó a hacerse la elección de senadores en las elecciones primarias. Por un lado, en Oregon, donde la manipulación política en la legislatura era muy grave, se sancionó en 1901 una ley por medio de la cual, al votar por los legisladores locales, los votantes podían indicar a los senadores de su preferencia. Si bien esta manifestación no era vinculante, ejercía una fuerte presión política, pues cada cámara, además, debía contar los votos populares y anunciar el nombre del candidato que había tenido el mayor número de sufragios. Luego se llevaba a cabo la elección de senador. No obstante, en la primera ocasión en la que la ley fue puesta en práctica, la legislatura eligió a un senador que no había obtenido un solo sufragio popular. Para evitar que ello volviera a ocurrir, en 1904 una nueva ley les permitió a los candidatos a cargos en la legislatura local que incluyeran en la presentación de sus candidaturas dos tipos de declaraciones. Por medio de la primera se obligaba a votar por el candidato a senador que recibiera mayor número de votos en la elección popular. Por medio de la segunda, declaraba que no estaba obligado por el voto popular. Obviamente, ningún legislador optaba por esta segunda declaración y ello favoreció en lo sucesivo una mayor transparencia, ya que en la siguiente elección la mayoría republicana tuvo que respetar la voluntad popular y designar a un senador demócrata que había obtenido el mayor número de sufragios populares. A partir de ese momento, otros estados adoptaron el sistema de Oregon, de modo que la elección indirecta prevista en 
Para resolver esta cuestión, en 1912 el Congreso sancionó la Enmienda XVII, que fue ratificada el 8 de abril de 1913 y entró en vigencia al mes siguiente. Su texto es el siguiente:

\begin{abstract}
El Senado de Estados Unidos estará compuesto por dos senadores de cada Estado, elegidos por el pueblo, por seis años; cada senador tendrá un voto. Los electores de cada Estado deberán tener las mismas calificaciones requeridas a los electores de la rama más numerosa de las Legislaturas estatales. Cuando se produzcan vacantes en la representación de cualquier Estado en el Senado, la autoridad ejecutiva de ese Estado convocará a elección para llenar las vacantes, sin perjuicio de que la Legislatura de cualquier Estado puede autorizar al Ejecutivo a hacer nombramientos temporarios hasta que el pueblo llene las vacantes por elección, en la forma dispuesta por la Legislatura. Esta enmienda no será interpretada de modo que afecte la elección o el mandato de un senador elegido antes de que entre en vigencia como parte válida de la Constitución. ${ }^{299}$
\end{abstract}

Poco después de haber sido ratificada la Enmienda XVII, un tribunal federal de Indiana estableció que si una persona posee las condiciones necesarias para votar por un senador, ese derecho no deriva solamente de la legislación local que regula la elección, sino de la Constitución federal misma. ${ }^{300}$

la Constitución fue perdiendo vigencia real. Como consecuencia de ello, el Senado empezó a nutrirse paulatinamente, con senadores surgidos de la elección popular, debilitando la posición de quienes pretendían mantener el sistema indirecto. Ver Haynes (1938, pp. 79-117).

299 "The Senate of the United States shall be composed of two Senators from each State, elected by the people thereof, for six years; and each Senator shall have one vote. The electors in each State shall have the qualifications requisite for electors of the most numerous branch of the State legislatures. When vacancies happen in the representation of any State in the Senate, the executive authority of each State shall issue writs of election to fill such vacancies: Provided that the legislature of any State may empower the executive thereof to make temporary appointments until the people fill the vacancies by election as the legislature may direct. This amendment shall not be so construed as to affect the election or term of any Senator chosen before it becomes valid as part of the Constitution".

300 "The right to vote for a member of Congress being a right secured by the Constitution, and laws of the United States, it is perfectly plain that the right to vote for a United States Senator, since the adoption of the seventeenth amendment to the United States Constitution and the passage by Congress of the act of June 4, 1914, is also a right secured by the Constitution and laws of the United States. If the right to vote for a Representative in Congress or a Senator of the United States is a right secured by the Constitution and laws of the United States, then it appears that the right and privilege to serve as a member of an election board where such Representative or Senator is to be elected is likewise a right or privilege secured by the Constitution and laws of the United States. If a man has a right to vote, he has a right to have his vote received and counted by the proper election officers; otherwise, the right to vote is but an empty right". United States v. Aczel, 219 F. 917 (U.S. District Court for the District of Indiana, 1915). 


\subsection{Jeannette Rankin, la primera mujer legisladora}

El 2 de abril de 1917 puede ser celebrado como una jornada de triunfo cívico para las mujeres. Ese día, Jeannette Rankin, republicana de Indiana, juró como representante en el House, convirtiéndose en la primera legisladora del Congreso de los Estados Unidos. ${ }^{301}$ Desde entonces y hasta el 117 ${ }^{\circ}$ Congreso (20212023), 378 mujeres han sido senadoras o representantes y, algunas de ellas, han ocupado bancas en ambas cámaras. ${ }^{302}$

\subsection{El presidente Woodrow Wilson y el Congreso}

Durante sus dos períodos como presidente (1913-1921), Woodrow Wilson revivió la antigua costumbre de Washington y Adams, luego abandonada por Jefferson y los mandatarios siguientes, de concurrir personalmente al Congreso con el objetivo de impulsar la legislación que le interesaba, trabajando en ello muy estrechamente con los líderes demócratas en ambas cámaras. Inicialmente, estos esfuerzos fueron exitosos en el orden interno, pues en el $63^{\circ}$ Congreso (1913-1915) Wilson logró que fueran sancionadas leyes importantes en materia impositiva, ${ }^{303}$ bancaria, ${ }^{304}$ antimonopólica ${ }^{305}$ y de regulación económica. ${ }^{306}$

En cambio, no tuvo igual suerte en materia internacional, en la que, ya desde el comienzo, enfrentó la oposición de su propio partido. Cham Clark, el Speaker, y Oscar W. Underwood, líder de la mayoría demócrata en el House, confrontaron con Wilson sobre su política respecto al peaje (toll) en el canal de Panamá, recién abierto por el propio Wilson, coronando de esa manera los

301 Nacida en 1880 y fallecida en 1973, Rankin fue toda su vida una activa trabajadora social, sufragista y pacifista. Se opuso tenazmente a la entrada de los Estados Unidos en ambas guerras mundiales y en la Guerra de Vietnam. Fue representante por su estado en el 65 Congreso (1917-1919) y en el 77 Congreso (1941-1943). Ver Lopach y Luckowski (2018).

302 De ese total, 337 (221 demócratas y 116 republicanas) han sido representantes, 41 (25 demócratas y 16 republicanas) han sido senadoras y 17 (11 demócratas y 6 republicanas) han estado en ambas cámaras. Si se suman las delegadas sin voto provenientes de los territorios (Guam, Samoa, Islas Vírgenes), del Distrito de Columbia y de Puerto Rico, el número llega a 395. Vid. Women in Congress: Statistics and Brief Overview (2021).

303 Revenue Act of 1913, 38 Statutes at Large 114, que impuso el income tax (impuesto a las ganancias) en el orden federal y redujo los derechos aduaneros.

304 Federal Reserve Act of 1913, 38 Statutes at Large 251, por medio de la cual se creó el banco central (Federal Reserve).

305 Clayton Antitrust Act of 1914, 38 Statutes at Large 730.

306 Federal Trade Commission Act of 1914, 15 USC §§ 41-58. 
esfuerzos comenzados por Theodore Roosevelt. ${ }^{307}$ También tuvo dificultades para declararle la guerra a Alemania en 1917 e imponer la conscripción obligatoria, en la que enfrentó la oposición de Claude Kitchin, de North Carolina, que había sucedido a Underwood como líder de la mayoría demócrata, bien que esta oposición fue luego superada por amplia mayoría. ${ }^{308}$ Pero su mayor derrota en política internacional tuvo lugar en noviembre de 1919 y en marzo de 1920, cuando el Senado, con mayoría republicana liderada por Henry Cabot Lodge, un antiguo rival de Wilson, ${ }^{309}$ rechazó la aprobación del Tratado de Versailles y el ingreso de los Estados Unidos a la Liga de Naciones, que el propio Wilson había impulsado con toda energía. Esta derrota, que afectó gravemente su salud, marcó el fin de su carrera política. ${ }^{310}$

\section{Un interregno republicano (1919-1933)}

\subsection{El dominio del Partido Republicano}

Desde 1919 hasta 1933, el dominio de la escena política por parte de los republicanos fue abrumador. No solo tuvieron mayoría en ambas cámaras en

307 Ver Baker (1966, pp. 279-293).

308 El único voto en el House en contra de que Estados Unidos entrara en la Primera Guerra Mundial fue el de Jeannette Rankin.

309 Por entonces, Henry Cabot Lodge tenía una larga trayectoria legislativa. Fue senador por Massachusetts por más de 30 años (1893-1924) y presidía la Comisión de Relaciones Exteriores del Senado.

310 Wilson había ido personalmente al Senado a entregar el Tratado y defenderlo en el mes de julio de 1919. Cuando entró al recinto, él mismo llevaba el documento bajo su brazo derecho. Pero, probablemente por su entusiasmo y sus ansias personales de liderar el nuevo orden mundial emergente de la "Gran Guerra", había cometido el error político de negociarlo y firmarlo sin consultar con los líderes republicanos, a quienes había ignorado abiertamente. Luego de su discurso, que duró unos 40 minutos, se encontró con una actitud hostil por parte de los senadores de la oposición. Entre sus opositores, además de Henry C. Lodge, estaban William Borah, de Idaho, Robert La Follette, de Wisconsin, y Hiram Johnson, de California, que integraban el grupo de los "Irreconciliables". Pero Wilson había jugado sus cartas a todo o nada, señalando la necesidad imperiosa de aprobar el Tratado ("The stage is set, the destiny disclosed. It has come about by no plan of our conceiving, but by the hand of God. We cannot turn back. The light streams on the path ahead, and nowhere else") y la respuesta que obtuvo en ese momento fue muy fría, apenas un aplauso de compromiso. Lodge y su grupo habían formulado 14 reservas al Tratado, que Wilson no estaba dispuesto a negociar. Entonces, inició en septiembre una campaña por casi todo el país en busca de apoyo, que lo agotó por completo. En octubre sufrió un derrame cerebral que lo dejó parcialmente paralizado y apenas pudo hacerse cargo del Gobierno. Las comunicaciones con sus asesores las hacía a través de su mujer, a quien se la empezó a llamar la "primera presidenta de los Estados Unidos". Con sus fuerzas muy debilitadas, Wilson no tuvo posibilidad alguna ya de continuar defendiendo el Tratado, que fue rechazado en las dos oportunidades que fue objeto de tratamiento: el 19 de noviembre de 1919 y el 19 de marzo de 1920. Ver Hazelgrove (2016). 
todos los congresos hasta $1931,{ }^{311}$ sino que los tres presidentes de este período, Warren G. Harding (1921-1923), Calvin Coolidge (1923-1929) y Herbert Hoover (1929-1933), fueron republicanos. La Corte Suprema, por su lado, estuvo integrada por una mayoría de jueces de tendencia netamente conservadora ${ }^{312}$ que se mantendría hasta 1937, cuando Franklin D. Roosevelt comenzó a rehacer la conformación del Tribunal, merced a las vacantes que se fueron produciendo. ${ }^{313}$ De todos modos, como veremos enseguida, los republicanos en el Congreso distaban mucho de constituir un bloque unificado; estaban divididos, entre otras cuestiones, por la política agraria, y si bien tenían formalmente la mayoría, esta era muy ajustada.

\subsection{Los presidentes y el Congreso}

Harding, Coolidge y Hoover tuvieron la posibilidad de gobernar con un Congreso mayoritariamente controlado por su partido, sin embargo, su relación con la rama legislativa no fue de las mejores, probablemente debido a que ninguno de ellos tenía gran talento ni tacto para la política y tampoco eran figuras influyentes dentro de su partido. Harding, oriundo de Ohio, había sido vicegobernador de su estado (1903-1905) y luego senador nacional (1915-1921), donde integró el grupo liderado por Henry C. Lodge, que rechazó el Tratado de Versailles. Inicialmente intentó establecer una buena relación con el Senado y, para ello, en 1921 concurrió personalmente para obtener el acuerdo para la designación de sus ministros. ${ }^{314}$ Ese mismo año también fue al Senado para urgir la sanción una ley de presupuesto equilibrada, pero este gesto provocó resultados adversos en ambas cámaras; los senadores le reprocharon haber querido interferir con el proceso legislativo y los representantes se queja-

311 Desde el 66 Congreso (1919-1921) hasta el 71 Congreso (1929-1931), los republicanos tuvieron mayoría en ambas cámaras. Recién en el 72 Congreso (1931-1933) los demócratas recuperaron la mayoría en el House.

312 El ala conservadora de la Corte estuvo integrada por Willis Van Devanter (1911-1937), James C. McReynolds (1914-1941); William H. Taft (1921-1930), George Sutherland (1922-1938), Pierce Butler (1923-1939) y Edward T. Sanford (1923-1930). En la minoría liberal se encontraban Oliver W. Holmes (1902-1932), Louis Brandeis (1916-1932) y Harlan Fiske Stone (1925-1946).

313 Durante sus cuatro mandatos, F. D. Roosevelt llegó a nombrar a ocho nuevos jueces en la Corte Suprema, todos ellos adherentes al New Deal: Hugo Lafayette Black (1937-1971), Stanley Reed (19381957), Felix Frankfurter (1939-1962), William O. Douglas (1939-1975), Frank Murphy (1940-1949), James F. Byrnes (1941-1942), Robert H. Jackson (1941-1954) y Wiley B. Rutledge (1943-1949).

314 Recordemos que en la Constitución de los Estados Unidos (artículo II, sección 2, cláusula 2), a diferencia de la nuestra, los ministros del Poder Ejecutivo se designan con acuerdo del Senado. 
ron porque los money bills (proyectos de leyes de contenido financiero) debían iniciarse en el House. Aquejado por los numerosos escándalos de corrupción de sus ministros, falleció de un paro cardíaco en 1923 antes de completar su período presidencial. ${ }^{315} \mathrm{Su}$ sucesor, Coolidge, ejerció un liderazgo aún menor. Era un individuo retraído y de pocas palabras, cuya mayor virtud -pasiva, por cierto- fue ser un moralista de costumbres austeras en medio de un período de gran prosperidad económica, en el cual el establishment no reparaba en lujos y gastos. ${ }^{316}$ Tampoco logró establecer una buena relación con el Senado, al punto que, en 1925, fue rechazado el acuerdo para la designación de Charles Beecher Warren como ministro de Justicia (Attorney General), ${ }^{317}$ algo que no ocurría desde 1868. Por último, Hoover, que había llegado a la Casa Blanca precedido de una distinguida actuación durante la Primera Guerra Mundial a cargo de la Food Administración (Administración de los Alimentos) fue golpeado inmediatamente por la crisis económica de 1929, que no supo ni pudo manejar e impidió su reelección. ${ }^{318}$

\subsection{El Steering Committe Republicano en el House}

Cuando los republicanos en el 66 Congreso (1919-1921) recobraron la mayoría en el House, el candidato para ser elegido Speaker era James R. Mann, de Illinois, que había sido líder de la minoría desde 1911. Pero Mann no gozaba de la simpatía de muchos de sus colegas, pues había objetado algunos de sus proyectos y además se temía que, considerando a Cannon su mentor político y amigo personal, pretendiera seguir los pasos de este y centralizara el poder del Speaker. Fue por ello que el partido decidió proponer a Frederick H. Gillett, de Massachusetts, para presidir el House. Molesto por ello, Mann se rehusó a ser el líder de la mayoría, función que asumió entonces Frank W. Mondell, de Wyoming.

315 Uno de los escándalos más conocidos fue el llamado Teapot Dome, protagonizado por Albert Fall, su secretario de Interior, quien entregó reservas petroleras nacionales percibiendo por ello fuertes sumas de dinero. Fall fue enjuiciado por ello y sentenciado a 10 años de prisión. También fue acusado de corrupción Harry Daugherty, su Attorney General (ministro de Justicia), pero el juicio político en su contra no prosperó. En similares escándalos se vieron envueltos Charles Forbes, director de la Oficina de Veteranos (Veterans Bureau), y su asistente, Charles Cramer. Ver Mee (2014).

316 Ver Sobel (2015).

317 Warren había sido embajador en Japón (1921-1923) y luego en México (1924).

318 Paradójicamente, Hoover había anunciado durante la campaña presidencial que los Estados Unidos estaban más cerca de triunfar sobre la pobreza de lo que cualquier otro país había estado alguna vez ("We in America today are nearer to the final triumph over poverty than ever before in the history of any land”). Ver Singer, 1976, p. 31). 
Asimismo, para descentralizar aún más el poder dentro del House, el líder de la mayoría dejó de presidir, por primera vez, la Comisión de Presupuesto (Ways and Means) y fue creado un Steering Committe, ${ }^{319}$ compuesto por cinco miembros, que no estaba integrado ni por el Speaker ni por el presidente de la Comisión de Reglamento (Rules Committee). Dado que esta composición reducida levantó críticas acerca de la falta de representatividad de la comisión en el 67 Congreso (1921-1923), la cantidad de sus integrantes fue ampliada a ocho y fueron invitados a participar de sus reuniones el Speaker y el presidente de la Comisión de reglamento. Durante estos años, el Steering Committee se reunió casi a diario y fue el principal órgano de conducción del partido desde 1919 hasta 1925.

\subsection{La división interna de los republicanos}

Pese a la prosperidad económica reinante en la década de 1920, el sector agrícola pasaba por serias dificultades. Ello trajo como consecuencia una crisis interna dentro del Partido Republicano, que se dividió en dos bloques regionales. Los del este disfrutaban de la bonanza y los del oeste (los republicanos insurgentes o progresistas), asentados en las grandes llanuras (Great Plains) y en las montañas (Rocky Mountains), menos favorecidos, presionaban por obtener la sanción de leyes que les otorgaran ayuda. Si bien los primeros tenían el upper hand (ventaja) en el Congreso, los insurgentes, apoyados por los demócratas, bloqueaban muchas de las iniciativas de los regular republicans, pero no tenían fuerza suficiente para impulsar sus propias iniciativas.

Mientras los republicanos tuvieron amplia mayoría, tal como ocurrió en el 67 ${ }^{\circ}$ Congreso (1921-1923), ${ }^{320}$ ello no presentó mayores problemas y les permitió a individuos como Philip P. Campbell, de Kansas, controlar con mano férrea la Comisión de Reglamento, de la que era presidente. ${ }^{321}$ Pero esta división se hizo crítica en el 68 Congreso (1923-1925), en el que los republicanos retuvieron la

319 Tal como mencioné antes (ver nota 256), el Steering Committee es una comisión creada por cada partido para dirigir y controlar la marcha de los proyectos de ley. En el Senado ya existía desde el siglo anterior.

320 En el House, los republicanos tenían 302 representantes contra solo 131 de los demócratas.

321 En una oportunidad en la que Campbell se opuso a un proyecto que había obtenido mayoría en la comisión, le dijo a sus colegas que se podían ir al infierno, que la comisión era él y que en él residía todo el poder de obstruir los proyectos ("You can go to [hell] [...] it makes no difference what a majority of you decide; if it meets with my disapproval, it shall not be done; I am the Committee; in me repose absolute obstructive powers") (como se citó en Riddick, 1949, p. 123). 
mayoría en ambas cámaras, pero con un muy escaso margen sobre los demócratas. ${ }^{322}$ Ello dio lugar a una batalla por la integración de las comisiones y por la designación del Speaker. Los republicanos insurgentes, liderados por Robert La Follette, de Wisconsin, junto con los dos senadores de Minnesota pertenecientes al Farmer-Labor Party, aceptaron integrar las comisiones, pero sin participar del caucus republicano. Munido de esta ventaja, La Follete intentó remover a Albert Cummins, de Iowa, de la Comisión de Comercio Interestatal (Interstate Commerce Commission), y luego de 32 votaciones empatadas los republicanos regulares apoyaron al demócrata Ellison C. Smith, de South Carolina, que resultó elegido pese a que pertenecía a la minoría. También fue ardua la elección del Speaker. En 1923 compitieron Frederick H. Gillett, por los republicanos regulares, ${ }^{323}$ Henry A. Cooper, de Wisconsin, por los republicanos progresistas, y Finis J. Garrett, de Tennessee, por los demócratas. Luego de ocho votaciones empatadas entre Gillett y Garrett, los republicanos progresistas fueron convencidos por Nicholas Longworth, de Ohio, para que votaran por Gillett con la promesa de flexibilizar las reglas de debate. ${ }^{324}$

Al año siguiente, en 1924, La Follette volvió a poner en crisis a los republicanos al presentarse como candidato presidencial independiente por el Progressive Party, un partido recién fundado con el apoyo de grupos sindicales y socialistas. ${ }^{325}$ Compitió con Calvin Coolidge y con el candidato demócrata, John W. Davis, pero obtuvo tan solo el 16\% de los votos. Coolidge triunfó ampliamente $^{326} \mathrm{y}$, en el 690 Congreso (1925-1927), en el que los republicanos recuperaron en el House 25 bancas, ${ }^{327}$ los insurgentes no fueron invitados a integrar ninguna comisión, ${ }^{328}$ especialmente porque se negaron a votar por $\mathrm{Ni}$ -

322 En el Senado, los republicanos contaban con el 54,2\%; y los demócratas, con el 43,8\%. El 2\% restante lo tenía el recientemente creado Farmer-Labor Party, que subsistió como partido independiente hasta la década de 1940, cuando fue absorbido por los demócratas. En el House, los republicanos tenían el 51,3\%; los demócratas, el 48\%; el Farmer-Labor, el 0,5\%; y los socialistas (Socialist Party of America), el 0,2\%.

323 Recordemos que había sido elegido Speaker en el 66 Congreso (1919-1921) y reelegido en el 67 Congreso (1921-1923).

324 En particular modificaron la llamada Rule of Discharge (regla de dispensa), aprobada inicialmente en 1910, reduciendo de 218 a 150 el número de votos necesarios para que la ley pudiera ser tratada en el recinto, aun habiendo sido rechazada en comisión.

325 Ver Thelen (1976b, en especial caps. viii y ix).

326 En votos populares obtuvo el 54\% y en el colegio electoral ganó en todos los estados del norte, menos en Wisconsin, donde triunfó La Follette.

327 De 222 bancas en el $68^{\circ}$ Congreso pasaron a tener 247 en el $69^{\circ}$ Congreso, con una mayoría del 57\%.

328 Asimismo, John M. Nelson y Florian Lampert, ambos de Wisconsin, fueron desplazados de la 
cholas Longworth como Speaker, apoyando en cambio a Henry A. Cooper, de Wisconsin. ${ }^{329}$ Siguiendo el ejemplo de Reed y Cannon, Longworth rápidamente inició la tarea de centralizar el poder del Speaker, lo que puso en práctica entre 1925 y 1931 con la ayuda de John Q. Tilson, de Connecticut, líder de la mayoría, y de Bertrand H. Snell, de New York, presidente de la Comisión de Reglamento (Rules Committe).

Hacia el final de este período, cuando los republicanos estaban más debilitados, la separación entre ambas líneas internas se hizo más crítica. En el 72。 Congreso (1931-1933), Herbert Hoover, sucesor de Coolidge, tuvo que lidiar con un House donde los republicanos insurgentes se aliaban con los demócratas, que habían recuperado la mayoría, ${ }^{330}$ y con un Senado casi empatado. ${ }^{331}$

\subsection{Escaso uso y poca efectividad de la Cloture Rule}

Durante este período, la Regla de Cierre o Clausura (Cloture Rule), adoptada por el Senado en 1917 para impedir el filibuster, fue poco utilizada y, cuando se la intentó emplear, tuvo poca efectividad. Fue invocada en once oportunidades (cinco de ellas en 1927) y solo resultó efectiva en cuatro de ellas. Pudo ser aplicada con éxito en 1919, cuando se votó el rechazo del Tratado de Versailles; en 1926, con motivo del tratamiento de un protocolo de la Corte Permanente de Justicia Internacional (World Court), creada por el Tratado de Versailles, a la que finalmente los Estados Unidos nunca adhirieron; y en dos oportunidades

presidencia de las comisiones de elecciones y de patentes, respectivamente.

329 Además de asegurarse su posición en las comisiones, los republicanos regulares se garantizaron que las leyes no aprobadas en comisión no pudieran ser llevadas fácilmente al recinto. Para ello, modificaron nuevamente la llamada Rule of Discharge, elevando otra vez de 150 a 218 el número de votos necesarios para poder tratar la ley en el recinto, luego de su rechazo en comisión.

330 Si bien los republicanos comenzaron este Congreso con una escasa mayoría de 217 representantes sobre 216 de los demócratas, ya en el final, merced a elecciones intermedias, la habían perdido. En 1933, al concluir el 72 Congreso, los demócratas tenían en el House 220 bancas, los republicanos 206, los Farmer-Labor 1 y había 8 bancas vacantes.

331 En el Senado, la mayoría republicana era ínfima. Sobre un total de 96 senadores, los republicanos tenían 48, los demócratas 46, los Farmer-Labor 1 y había 1 banca vacante. Con gran ingenuidad política, Hoover le pidió al senador republicano James Watson, de Indiana, líder de la mayoría republicana, que le permitiera a los demócratas tomar el control de las comisiones para concluir con todas las demoras y convertir ese sabotaje en un acto responsable (to convert their sabotage into responsibility) para poder trabajar más productivamente y no hacer demagogia con cada propuesta del presidente ("[to] deal more constructively with the Democratic leaders if they held full responsibility in both houses, than with an opposition in the Senate conspiring in the cloakrooms to use every proposal of mine for demagoguery"). Watson y sus colegas se negaron, por supuesto, pues no estaban dispuestos a entregarles el control de las comisiones a los demócratas. Ver Jones (1970, p. 144). 
en 1927, una de ellas con motivo de una ley que, entre otros aspectos, afectaba a los bancos que no eran miembros del sistema de la Reserva Federal ${ }^{332}$ y la otra sobre regulaciones de la llamada Prohibition (Ley Seca), establecida por la Enmienda XVIII.

Hubo también filibusters en casos tan sensibles y conflictivos por aquel entonces que se decidió no emplearla. En 1922, un grupo de senadores sureños montó un filibuster contra una ley que prohibía los linchamientos. Entre sus protagonistas se hallaba el poderoso senador demócrata Oscar Underwood, de Alabama, ${ }^{33}$ quien se encargó de dejar muy en claro que el Senado no volvería a sesionar hasta que el proyecto fuera retirado. ${ }^{334}$ La promesa se cumplió y el Senado estuvo paralizado hasta que el proyecto fue retirado sin haberse recurrido al Cloture Rule. ${ }^{335}$ Una actitud similar tuvo lugar en 1927, cuando se quiso poner fin al filibuster motivado por el proyecto de prolongar la tarea de la comisión presidida por el senador demócrata James A. Reed, de Missouri, que investigaba la presunta corrupción habida en la campaña de los senadores republicanos Frank L. Smith, de Illinois, y William S. Vare, de Pennsylvania. Si bien la iniciativa contaba con mayoría, un reducido grupo de senadores obstruyó el proyecto y la Cloture Rule no fue empleada. ${ }^{336}$

\subsection{El voto femenino. La Enmienda XIX}

Uno de los acontecimientos más importantes de este período tuvo lugar en marzo de 1919, cuando el Congreso sancionó la Enmienda XIX, ratificada poco

332 McFadden Act of 1927.

333 Recordemos que ya había liderado el House en años anteriores.

334 "It is perfectly apparent that you are not going to get an agreement to vote on [this bill] [...] I want to say right now to the Senate that if the majority party insist on this procedure they are not going to pass the bill, and they are not going to do any other business [...] [W] e are going to transact no other business until we have an understanding about this bill [...]We are willing to take the responsibility, and we are going to do it" Vid. Haynes (1938, p. 411).

335 Molesto con esta actitud, el senador Charles Curtis, de Kansas, jefe del bloque republicano, le pidió a Calvin Coolidge, por entonces presidente del Senado (era vicepresidente de Harding), que aplicara las Reed Rules, creadas por Thomas B. Reed como Speaker del House en el siglo anterior, pero Coolidge declinó hacerlo.

336 Cuando Calvin Coolidge fue electo presidente, en 1925, su vicepresidente, Charles G. Dawes, quien lejos de ser un aliado fue un opositor de Coolidge, denunció estas irregularidades y llevó a cabo una campaña nacional para imponer nuevas reglas que impidieran el filibuster. Sorpresivamente, se encontró con la oposición de la American Federation of Labor (AFL), en cuya opinión, la iniciativa de Dawes emanaba de las cámaras secretas de los intereses depredadores ("emanates fron the secret chambers of the predatory interests"). 
más de un año después, en agosto de 1920, por medio de la cual se les acordó el derecho de sufragio a las mujeres. ${ }^{337}$ La sanción de esta Enmienda fue la consagración de una prolongada lucha por extender el sufragio a todo el electorado y no solamente a unos pocos ciudadanos varones, que se inició prácticamente con la Independencia. ${ }^{338}$ En el ínterin, mujeres como Susan B. Anthony (18871922), coeditora de un extenso trabajo sobre la historia del sufragio femenino, fueron arrestadas y multadas por intentar ejercer su derecho. También fueron activas "sufragistas" Alice S. Paul, Lucy Burns ${ }^{339}$ y Carrie Chapman Catt. ${ }^{340}$

Antes de la Enmienda XIX, varias legislaturas estatales ya habían establecido el derecho al sufragio femenino. Wyoming les concedió a las mujeres el derecho de votar por funcionarios territoriales en 1869 y lo mantuvo en 1890, cuando el territorio fue convertido en estado. Colorado siguió este ejemplo en 1893, Utah en 1895 e Idaho en 1896. En 1914, once estados ya permitían el sufragio igualitario, y en 1917 las sufragistas triunfaron en New York, que era considerado un reducto opositor del este. Estas victorias fortificaron el movimiento nacional contra el cual se oponía, como argumento, que la legislación electoral debía ser decidida por cada estado sin interferencia del Gobierno federal. No obstante, en la elección de 1916 las plataformas de los dos partidos defendieron el sufragio femenino en contra de la opinión de Woodrow Wilson, cuya oposición desató una ola de violentas protestas, similares a las que estaban teniendo lugar también en el Reino Unido. A partir de allí, las cosas se precipitaron. En septiembre de 1917, la comisión del Senado para el sufragio femenino elevó un

337 El texto de la enmienda es el siguiente: "1. El derecho de sufragio de los ciudadanos de los Estados Unidos no será desconocido ni limitado por los Estados Unidos o por Estado alguno por razón de sexo. 2. El Congreso estará facultado para hacer cumplir este artículo por medio de leyes apropiadas" " 1 . The right of the citizens of the United States to vote shall not be denied or abridged by the United States or by any State on account of sex. 2. Congress shall have power to enforce this article by appropriate legislation").

338 Las condiciones religiosas para votar fueron abolidas gradualmente, al igual que las fundadas en el derecho de propiedad. Fueron eliminadas luego las de la raza y finalmente llegó el turno de las del sexo. Estas últimas podrían haber sido extirpadas cuando la Enmienda XV extendió el voto a los afroamericanos, pero no fue así. Los propagandistas del sufragio femenino intentaron en ese momento que el sexo fuera incluido entre los requisitos de raza y color, pero fracasaron. A partir de entonces comenzaron una campaña para incorporar tal requisito y lograron que la cuestión fuera introducida en el Senado en 1878 y reintroducida sesión por sesión hasta que fue ratificada la Enmienda XIX.

339 Juntas crearon, en 1916, el Partido Nacional de la Mujer (National Woman's Party), disuelto en 1930. Ambas integraron también el grupo de las llamadas Centinelas Silenciosas (Silent Sentinels), que acamparon frente a la Casa Blanca durante dos años -de 1917 a 1919- en demanda del voto femenino.

340 Fue presidenta de la National American Woman Suffrage Association y fundadora de la League of Women Voters y de la International Alliance of Women. 
informe favorable a la enmienda y, dos meses después, la comisión de justicia de la Cámara de Diputados emitió su auspicio. Wilson entendió que debía cambiar su posición y anunció su apoyo a la enmienda. Señaló que los ingleses estaban otorgando el voto femenino y que estaban reconociendo los patrióticos servicios de la mujer en la guerra, de modo que los Estados Unidos no podían hacer menos que seguir su ejemplo. Poco más tarde, en las elecciones de noviembre de 1918, tres estados más emanciparon por entero a la mujer y un número adicional de defensores del sufragio femenino fue elegido para el Senado y la Cámara de Representantes con el propósito de asegurar un exitoso final para la enmienda. Asimismo, en su mensaje anual al Congreso del 2 de diciembre de 1918, Wilson alegó que el mejor tributo que se les podía rendir a las mujeres era igualarlas a los hombres en cuanto a derechos políticos, ya que se habían mostrado iguales en todo cuanto habían encarado.

\subsection{Las dos primeras senadoras}

Acompañando la igualdad de hombres y mujeres ante el sufragio, se produjo en 1922 el ingreso de la primera senadora en el Congreso, aunque no creo que el caso de Rebecca Latimer Felton pueda computarse exactamente como un triunfo cabal de las sufragistas, pese a que era una antigua militante de ese movimiento. Su ingreso como senadora, cuando ya había cumplido 87 años -cargo que ocupó solo por un día- fue en, todo caso, parte de una estrategia electoral para beneficiar la candidatura de Thomas W. Hardwick.

En las elecciones para senadores de 1922, el candidato por Georgia era Hardwick, por entonces gobernador del estado, cuando el senador Thomas E. Watson, también de Georgia, murió inesperadamente. Para cubrir temporalmente esa vacante hasta el final del mandato de Watson, Hardwick eligió a Rebecca Felton, quien no competía en la elección y le permitía, además, granjearse el voto femenino. ${ }^{341}$ Asimismo, no se esperaba que el Congreso volviera a reunirse hasta después de las elecciones, de modo tal que era improbable que Felton prestara efectivamente juramento y ocupara la banca, siquiera por escasos días. La elección, sin embargo, no la ganó Hardwick, sino Walter F. George, quien, presionado por una campaña emprendida por las mujeres blancas de Georgia, en lugar de tomar posesión de su cargo en la siguiente reunión del Senado, permitió que Felton prestara juramento. De esta manera, ella se con-

341 Hardwick pretendía compensar con ello su oposición a la Enmienda XIX. 
virtió en la primera senadora -por un solo día- y la única mujer que ocuparía una banca en el Senado por Georgia por espacio de casi un siglo. ${ }^{342}$

La segunda senadora fue Hattie Ophelia Caraway, demócrata de Arkansas, elegida en 1932. También llegó al senado para ocupar temporalmente una vacante, en este caso, la de su marido, Thaddeus Horatius Caraway, fallecido en noviembre de 1931 durante el 72॰ Congreso (1931-1933). No obstante, a diferencia de su predecesora, no solo completó el mandato de su marido hasta 1933, sino que en 1932 fue electa para un período completo (1933-1939) y reelecta en 1938 para un segundo período (1939-1945). En la elección de 1944 compitió por un tercer período (1945-1951), pero fue vencida por J. William Fulbright. Caraway llevó adelante una intensa actividad apoyando el New Deal de Franklin D. Roosevelt y fue la primera mujer en presidir una comisión legislativa. ${ }^{343}$ Durante sus trece años como senadora, otras tres mujeres fueron senadoras también ${ }^{344}$

\subsection{La Corte Suprema fortifica el poder de las comisiones legislativas de investigación}

En 1922, bajo el Gobierno de Harding, estalló el llamado escándalo del Tea Pot Dome, producido como consecuencia de concesiones petroleras otorgadas por Albert B. Fall, secretario del Interior, a muy bajo precio y sin licitación pública en terrenos bajo jurisdicción de la Marina. ${ }^{345}$ Una de ellas estaba ubicada en la zona de Tea Pot Dome, Wyoming, y le fue otorgada a Mammoth Oil, una subsidiaria de la Sinclair Oil Corporation; las otras áreas, Elk Hills y Buena

342 Hasta 2020, el estado de Georgia no volvió a ser representado por una mujer senadora y nuevamente, en este caso, sucedió algo similar a lo ocurrido un siglo atrás. En 2020, durante el 116 ${ }^{\circ}$ Congreso (2019-2020), el senador republicano John Hardy Isakson renunció por razones de salud y el gobernador de Georgia, Brian Kemp, eligió para reemplazarlo a Kelly Lynn Loeffler, una ferviente republicana y católica, firme sostenedora de Donald Trump. Luego de completar el mandato, Loeffler intentó ser reelecta para el $117^{\circ}$ Congreso (2021-2023), pero fue vencida por el demócrata Raphael G. Warnock, afroamericano y pastor protestante.

343 Ver Hendricks (2013).

344 Ellas fueron: Rose McConnell Long, demócrata de Louisiana, Dixie Bibb Graves, demócrata de Alabama, y Gladys Pyle, republicana de South Dakota. La primera fue elegida en 1935 para completar el mandato de su marido, Huey Long, un político populista conocido como el Kingfish, que fue asesinado. La segunda fue elegida en 1937 por su propio marido, Bibb Graves, el gobernador de Alabama, para completar el mandato de Hugo Black, que había sido designado juez de la Corte Suprema. Y la tercera llegó al Senado por sus propios medios no para completar el mandato de otro senador, sino luego de ser electa en 1938 para ejercer un período completo (1939-1945), aunque renunció antes de haber cumplido el primer año.

345 Ver McCartney (2009). 
Vista Oil Fields, estaban en California y les fueron otorgadas a la Pan American Petroleum and Transport Company. La investigación del caso en el Senado, impulsada por el senador demócrata Thomas J. Walsh, de Montana, pudo probar finalmente, luego de varias dificultades, que Fall había recibido dinero a cambio del otorgamiento de las concesiones. ${ }^{346}$ En el curso de la investigación, Harry M. Daugherty, el Attorney General, intentó encubrir a Fall, y cuando su hermano, Mally Daugherty, se negó a testificar ante la comisión investigadora, fue ordenado su arresto. Daugherty interpuso un hábeas corpus que fue rechazado por la Corte Suprema en McGrain v. Daugherty, ${ }^{347}$ sosteniendo que el poder de investigar es una facultad implícita del Congreso, el cual debe contar con los medios necesarios para ser puesto en práctica. ${ }^{348}$ Dos años después, en Sinclair v. United States, ${ }^{349}$ otro caso vinculado también con el mismo escándalo, ${ }^{350}$ la Corte sostuvo que un testigo podía ser condenado por incurrir en falso testimonio (perjury) ante una comisión legislativa.

\subsection{La reorganización de las comisiones en el Senado}

Desde mediados del siglo XIX en adelante, la cantidad de comisiones permanentes (standing committees) en el Senado no había parado de crecer. Eran 25 en 1853, habían aumentado a 42 en 1889 y en el cuarto de siglo siguiente esa cifra continuó en ascenso. ${ }^{351}$ En 1884, 5 comisiones temporarias (select committees) se habían hecho permanentes, 3 más se habían agregado en 1896; en 1909 todas las comisiones temporarias fueron transformadas en permanentes y se crearon 9 más, a las que se les agregaron otras 3 en 1913. Como resultado de ello, hacia 1914 existían unas 74 comisiones permanentes, un número muy superior al de los senadores que integraban la mayoría. Prácticamente todos los senadores, aun

346 Fall fue penalmente enjuiciado y cumplió un año en prisión, convirtiéndose en el primer miembro del gabinete presidencial en correr esa suerte.

347273 U.S. 135 (1927).

348 " [...] the two houses of Congress, in their separate relations, possess not only such powers as are expressly granted to them by the Constitution, but such auxiliary powers as are necessary and appropriate to make the express powers effective, and the other that neither house is invested with "general" power to inquire into private affairs and compel disclosures [...] We are of opinion that the power of inquiry -with process to enforce it - is an essential and appropriate auxiliary to the legislative function" (273 U.S. en pp. 173 y 174).

349279 U.S. 263 (1929).

350 Harry Ford Sinclair, ejecutivo de la Sinclair Oil Corporation, era quien le había pagado a Fall por el otorgamiento de la concesión en California.

351 Ver Kravitz (1974, pp. 27-38). 
los recién incorporados, tenían la posibilidad de integrar una comisión y muchos de ellos podían aspirar a presidirlas, aun estando en la minoría. ${ }^{352}$ Una gran cantidad de ellas eran consideradas sinecure committees, es decir, no cumplían ninguna función legislativa específica, salvo la de proveer un espacio de trabajo y servicios a los senadores, ${ }^{353}$ en una época en la que el Senado no disponía todavía de espacio suficiente para sus oficinas administrativas. ${ }^{354}$ En 1920, cuando se tomó la decisión de reducir la cantidad de comisiones, el número de estas había llegado a 80 , algunas de las cuales era evidente que no tenía sentido alguno mantener. ${ }^{355} \mathrm{Se}$ decidió entonces eliminar 42 comisiones obsoletas, y en el 68 Congreso (19231925) el número total de comisiones permanentes ya estaba reducido a $34 .{ }^{356}$

\subsection{El nuevo régimen presupuestario}

Hasta 1920, el Gobierno federal no tenía un sistema centralizado para elaborar la ley de presupuesto. Cada departamento (ministerio) elaboraba su propio presupuesto y lo enviaba individualmente al House, como cámara de origen, donde intervenían unas ocho comisiones diferentes que analizaban estos proyectos de ley según su propia competencia. Algo similar ocurría en el Senado. El resultado era que no se sancionaba una ley de presupuesto unificada, sino muchas leyes diferentes y, en algunos casos, había más de una por cada departamento. Como

352 Al comenzar el 60 Congreso (1907-1909), el Partido Republicano, en mayoría, se asignó la presidencia de 61 comisiones y le otorgó 10 a los demócratas.

353 El senador La Follette recordaba que cuando fue designado presidente de la Comisión para Investigar el Estado la Rivera del río Potomac en Washington (Committee to Investigate the Condition of the Potomac River Front at Washington) descubrió que la comisión no se había reunido nunca ni se había presentado proyecto de ley alguno para ordenar la limpieza del río. Ver: https://www.senate. gov/artandhistory/history/minute/Senate_Eliminates_42_Committees.htm.

354 En 1908 fue construido el Russell Senate Office Building, primer edificio de oficinas del Senado. Luego fueron construidos dos más: el Dirksen Senate Office Building, en 1958, y el Hart Senate Office Building, en 1982.

355 Existía todavía la comisión de los reclamos de la Guerra de la Independencia (Revolutionary War), pese a que esta había concluido hacía ya 137 años.

356 En orden alfabético, estas comisiones eran las siguientes: Agriculture and Forestry; Appropriations; Audit and Control the Contingent Expenses of the Senate; Banking and Currency; Civil Service; Claims; Commerce; District of Columbia; Education and Labor; Enrolled Bills; Expenditures in Executive Departments; Finance; Foreign Relations; Immigration; Indian Affairs; Interoceanic Canals; Interstate Commerce; Irrigation and Reclamation; Judiciary; Library; Manufactures; Military Affairs; Mines and Mining; Naval Affairs; Patents; Pensions; Post Office and Post Roads; Printing; Privileges and Elections; Public Buildings and Grounds; Public Lands and Surveys; Rules y Territories and Insular Possessions. Había, a su vez, cinco select committees: Alien Property Custodian's Office; Internal Revenue Bureau; Senatorial Elections; Tariff Commission y War Finance Corporation Loans. 
tal, el sistema presupuestario existente era bastante caótico y generaba críticas. ${ }^{357}$ A fin de ordenar la cuestión, fue sancionada la Budget and Accounting Act of $1921,{ }^{358}$ que le ordenó al presidente centralizar la elaboración del presupuesto, especificando cómo y qué debía ser incluido en él disponiendo, asimismo, que el proyecto debía ser enviado al comienzo de cada sesión legislativas anual. ${ }^{359}$ La ley creó también la Oficina de Presupuesto en jurisdicción del Departamento el Tesoro (Ministerio de Economía) ${ }^{360}$ y la General Accounting Office, ${ }^{361}$ a cuyo cargo fue puesto el Comptroller General. ${ }^{362}$

357 Alvan T. Fuller, representante republicano de Massachusetts y luego gobernador de ese estado, decía en 1918 que no se les podia exigir a los empresarios que economizaran y fueran eficientes cuando el Congreso era costoso e ineficiente ("The President is asking our business men to economize and become more efficient while we continue to be the most inefficient and expensive barnacle that ever attached itself to the ship of state"). Ver Hasbrouck (1972, p. 15).

35842 Statutes at Large 20.

359 "Section 201. The President shall transmit to Congress on the first day of each regular session, the Budget, which shall set forth in summary and in detail : (a) Estimates of the expenditures and appropriations necessary in his judgment for the support of the Government for the ensuing fiscal year; except that the estimates for such year for the Legislative Branch of the Government and the Supreme Court of the United States shall be transmitted to the President on or before October 15th of each year, and shall be included by him in the Budget without revision; (b) His estimates of the receipts of the Government during the ensuing fiscal year, under (1) laws existing at the time the Budget is transmitted and also (2) under the revenue proposals, if any, contained in the Budget; (c) The expenditures and receipts of the Government during the last completed fiscal year; (d )Estimates of the expenditures and receipts of the Government during the fiscal year in progress; (e) The amount of annual, permanent, or other appropriations, including balances of appropriations for prior fiscal years, available for expenditure during the fiscal year in progress, as of November 1 of such year; (f) Balanced statements of (1) the condition of the Treasury at the end of the last completed fiscal year, (2) the estimated condition of the Treasury at the end of the fiscal year in progress, and (3) the estimated condition of the Treasury at the end of the ensuing fiscal year if the financial proposals contained in the Budget are adopted; (g) All essential facts regarding the bonded and other indebtedness of the Government; and (h) Such other financial statements and data as in his opinion are necessary or desirable in order to make known in all practicable detail the financial condition of the Government".

360 "Section 207. There is hereby created in the Treasury Department a Bureau to be known as the Bureau of the Budget. There shall be in the Bureau a Director and an Assistant Director, who shall be appointed by the President and receive salaries of $\$ 10,000$ and $\$ 7,500$ a year, respectively. The Assistant Director shall perform such duties as the Director may designate, and during the absence or incapacity of the Director or during a vacancy in the office of Director he shall act as Director. The Bureau, under such rules and regulations as the President may prescribe, shall prepare for him the Budget, the alternative Budget, and any supplemental or deficiency estimates, and to this end shall have authority to assemble, correlate, revise, reduce, or increase the estimates of the several departments or establishments".

361 "Section 301. There is created an establishment of the Government to be known as the General Accounting Office, which shall be independent of the executive departments and under the control and direction of the Comptroller General of the United States. The offices of Comptroller of the Treasury and Assistant Comptroller of the Treasury are abolished, to take effect July 1, 1921 [...]".

362 "Section 302. There shall be in the General Accounting Office a Comptroller General of the Unit- 


\subsection{El debate sobre el aumento y redistribución de las bancas en el House. La Permanent Apportionment Act of 1929}

Un debate arduo, que se extendió a lo largo de toda la década de 1920, fue el aumento y la redistribución (reapportionment) de las bancas en el House luego de cada censo. Tal como vimos anteriormente, la Apportionment Act of 1911, siguiendo los resultados del Censo de 1910, estableció que el número de representantes aumentaría de 391 a 435. Hasta ese momento, salvo en 1880, ningún estado había perdido una banca en el House ${ }^{363}$ pues luego de cada censo el número de representantes aumentaba proporcionalmente, precisamente para que ningún estado se viera privado de las bancas que ya poseía. ${ }^{364}$ Esta cuestión volvió a plantearse cuando el 14 Censo, llevado a cabo en 1920, puso de manifiesto que la población no solo había aumentado, sino que una buena cantidad de habitantes había migrado de las zonas rurales a los centros urbanos. Esto obligaba a tomar la decisión de continuar incrementando indefinidamente el número de representantes, o bien de congelarlo en 435 o en algún otro número. Si se decidía lo primero, la cantidad de bancas en esa oportunidad se elevaría a unas 483, por el contrario, si se mantenía su número en 435, 11 estados perderían bancas, las cuales serían redistribuidas en 8 de ellos.

Para evitar esta segunda solución, políticamente conflictiva, a comienzos de 1921, cuando estaba por terminar el 66 Congreso (1919-1921), la Comisión de Censo propuso aumentar los representantes a 483, beneficiando con ello a 25 estados a los cuales se les adjudicaban las nuevas bancas. La propuesta, sin embargo, fue rechazada en el House por una mayoría de 267-76. ${ }^{365}$ En su reemplazo, se dio media sanción a un proyecto que mantenía la cantidad de representantes en los 435 establecidos en 1911, pero se los redistribuía conforme el aumento y la migración poblacional registrada por el Censo de $1920 .^{366}$ Sin embargo, en marzo de 1921, al finalizar el 66 Congreso, el Senado no había aprobado aún esta modificación. Al mes siguiente, cuando se inició el 67 Congreso, la Comisión de Censo del House aprobó un nuevo proyecto,

ed States and an Assistant Comptroller appointed General of the United States, who shall be appointed by the President with the advice and consent of the Senate, and shall receive salaries [...]".

363 Únicamente Maine y New Hampshire habían perdido -una banca cada uno- en 1880.

364 Antes de ello, luego del Censo de 1890, el House había aumentado de 357 a 391.

365 Los argumentos para no aumentar el número de representantes fueron de dos órdenes. En primer lugar, se dijo que una cámara muy numerosa dificultaba los debates. Por el otro lado, se hizo pesar el costo económico de tener que modificar el tamaño del recinto.

366 Se restaban doce bancas a once estados y se las redistribuía entre aquellos que habían tenido mayor aumento poblacional. 
elevando a 460 el número de representantes ${ }^{367}$ pero en el pleno esta propuesta fue rechazada por una mayoría de 146-142 y la cuestión no volvió a ser tratada.

Hacia 1925, el problema no había sido resuelto y ya era claro, por entonces, que la migración de la población de las áreas rurales a las urbanas no había sido un fenómeno meramente temporario producido por la guerra, sino que se trataba de una redistribución permanente. Como resultado de este cambio, ciudades como Los Ángeles y Detroit, cuya población había aumentado sensiblemente, reclamaban una mayor representación. Todo ello generó un debate en el House acerca de si era constitucionalmente obligatorio o no redistribuir las bancas luego de cada Censo. La cuestión fue sometida a votación y, por mayoría de 265-87, se decidió que no lo era. ${ }^{368}$

A pesar de ello, en enero de 1927, Calvin Coolidge insistió en que era necesario sancionar una ley de redistribución de las bancas en el House. Si bien la Comisión de Censo rechazó esta petición, el presidente de la comisión, Edward Hart Fenn, republicano de Connecticut, intentó el 2 de marzo de 1927, un día antes de que concluyera el 69० Congreso (1925-1927), que se aprobara un proyecto de ley de su autoría, autorizando al secretario de Comercio a redistribuir las bancas sobre la base del Censo de 1930. En esa oportunidad, la propuesta fue rechazada por 197-183 votos. Reunido el 70 Congreso (1927-1929), el proyecto de Fenn -con modificaciones- fue sometido nuevamente a votación. Por 186-165 votos, se resolvió enviarlo a comisión y -con nuevas modificaciones- fue aprobado por voto cantado (voice vote) en enero de 1929, casi al final de dicho Congreso. Sin embargo, al mes siguiente, cuando debía ser tratado en el Senado, fue abandonado por sus propios promotores ante un filibuster, que amenazaron con llevar a cabo los senadores de los estados que perderían bancas en el House.

Cuando se reunió el 71 Congreso (1929-1931), habían pasado ya casi diez años desde el Censo de 1920 sin que la composición del House se modificara en función de los cambios poblaciones registrados por dicho censo, de modo tal que era acuciante darle una solución al problema. Herbert Hoover, que por

367 Ello implicaba que Maine y Missouri perdían una banca cada uno.

368 El problema fue planteado en abril de 1926 por Henry E. Barbour, representante republicano de California, en cuya opinión la distribución de las bancas luego de cada censo era constitucionalmente obligatoria. La posición contraria fue sostenida por Bertrand H. Snell, republicano de New York y presidente de la Comisión de Reglamento. Por su lado, Nicholas Longworth, el Speaker, a pesar de que tres de sus predecesores -Joseph W. Kiefer (1881-1883), Thomas B. Reed (1889-1891 y 1895-1899) y David B. Henderson (1899-1903)- habían aplicado la tesis de Barbour, sostuvo que esta era incorrecta y sometió el diferendo a votación. Por una mayoría de 265 a 87, el House decidió por la negativa. 
entonces se estrenaba como presidente, llamó a una sesión especial en abril de 1929 para ponerle fin a este largo conflicto y, en esa oportunidad, ambas cámaras actuaron muy velozmente, sancionando con escasos días de diferencia entre una y otra ${ }^{369}$ la llamada Permanent Apportionment Act of 1929, ${ }^{370}$ que, con las leves modificaciones introducidas en $1940,{ }^{371} 1941^{372}$ y $1996,{ }^{373}$ se mantiene vigente hasta el presente. ${ }^{374}$

Como toda ley que intenta resolver un problema difícil, su texto -bastante oscuro en la parte más importante- es el reflejo de este conflicto. Sus primeros 21 artículos están dedicados a la regulación del censo y recién en el artículo (sección) 22 aparece la cuestión de la composición del House. A este fin, el artículo 22(a) dispuso que, dentro de la primera semana después de concluida la segunda sesión regular del 71 ${ }^{\circ}$ Congreso (1929-1931), ${ }^{375}$ y en cada uno de los cinco congresos siguientes, ${ }^{376}$ el presidente debía informarle al Congreso el número de personas existentes en cada estado ${ }^{377}$ de acuerdo con los resultados del $15^{\circ}$ Censo, ${ }^{378} \mathrm{y}$ de los censos siguientes y de la cantidad de representantes a los que cada estado tuviera derecho, bajo la distribución por entonces existente, ${ }^{379}$ conforme el método que se describía en los incisos siguientes. ${ }^{380}$

Puede verse que esta ley mantuvo en 435 la cantidad de bancas establecida en 1911 sin imponer expresamente que esa cifra debía ser mantenida más allá de 1940, ${ }^{381}$ cuando se llevara a cabo el 16 Censo. Asimismo, estableció en forma

369 En el House fue aprobada el 11 de junio; y en el Senado, el 13 de junio. Hoover la promulgó el 18 de junio.

37046 Status at Large 21.

37154 Status at Large 162.

37255 Statutes at Large 761.

373110 Statutes at Large 1724.

3742 USC § 2 (a).

375 Es decir, a partir de diciembre de 1930.

376 Es decir, hasta la realización del siguiente censo, que tendría lugar en 1940.

377 Quedaban excluidos los indígenas no gravados con impuestos (indians not taxed).

378 Es decir, el Censo de 1930.

379 Es decir, la efectuada por la Ley de 1911.

380 "Section 22(a). On the first day, or within one week thereafter, of the second regular session of the Seventy-first Congress and of each fifth Congress thereafter, the President shall transmit to the Congress a statement showing the whole number of persons in each State, excluding Indians not taxed, as ascertained under the fifteenth and each subsequent decennial census of the population, and the number of Representatives to which each State would be entitled under an apportionment of the then existing number of Representatives made in each of the following manners: [...]".

381 De hecho, se ha mantenido en 435 hasta la actualidad. 
permanente el modo en el que esas bancas se distribuirían automáticamente de allí en adelante, cuidando que todos los estados, sin perjuicio de su población, tuvieran al menos un representante. Para llevar a cabo el reapportionment, la ley preveía tres métodos: (a) el empleado en el último censo; ${ }^{382}$ (b) el de las fracciones mayores; ${ }^{383}$ y (c) el de la igual proporción (equal proportion). ${ }^{384}$ Este último fue el adoptado finalmente en 1941 y es el que rige en la actualidad. ${ }^{385}$ Como resultado de la aplicación de esta ley, en el 73º Congreso (1933-1935), cuyos representantes fueron elegidos en 1932, se produjeron fuertes cambios en la composición del House. ${ }^{386}$

\subsection{La Enmienda XX}

Ya sobre el final de este período, más exactamente el 23 de enero de 1933, fue ratificada la Enmienda XX, que modificó el artículo I, sección 4, cláusula 2 del texto original, poniendo fin a la prolongada extensión que tenían hasta entonces las llamadas lame duck sessions, ${ }^{387}$ es decir, aquellas en las cuales el Congreso continuaba sesionando con sus antiguos miembros, por espacio de cuatro meses, pese a que ya habían sido elegidos los nuevos legisladores.

Esta anomalía tenía una cierta explicación por razones históricas, pero se

382 "Section 2(a)(1) By apportioning the then existing number of Representatives among the several States according to the respective numbers of the several States as ascertained under such census, by the method used in the last preceding apportionment, no State to receive less than one Member".

383 "Section 2(a)(2) By apportioning the then existing number of Representatives among the several States according to the respective numbers of the several States as ascertained under such census, by the method known as the method of major fractions, no State to receive less than one Member".

384 "Section 2(a)(3) By apportioning the then existing number of Representatives among the several States according to the respective numbers of the several States as ascertained under such census, by the method known as the method of equal proportions, no State to receive less than one Member".

385 Conforme a 2 USC § 2(a): "On the first day, or within one week thereafter, of the first regular session of the Eighty second Congress and of each fifth Congress thereafter, the President shall transmit to the Congress a statement showing the whole number of persons in each State, excluding Indians not taxed, as ascertained under the seventeenth and each subsequent decennial census of the population, and the number of Representatives to which each State would be entitled under an apportionment of the then existing number of Representatives by the method known as the method of equal proportions, no State to receive less than one Member".

386 Los cambios fueron los siguientes: 21 estados perdieron en total 27 bancas. De ellos, el más perjudicado fue Missouri, que perdió 3; Georgia, Iowa, Kentucky y Pennsylvania perdieron 2 cada uno. Entre los estados más beneficiados, el gran ganador fue California, que obtuvo 9 bancas adicionales, duplicando prácticamente su número (tenía 11 y llegó a 20), seguido de Michigan con 4, Texas con 3 y New Jersey y New York con 2 cada uno.

387 La expresión lame duck (literalmente, "pato rengo"), se aplica usualmente a aquellas personas que han perdido el poder. 
había convertido en un abuso por parte de aquellos legisladores que no eran reelegidos. Bajo la cláusula constitucional antes mencionada, el Congreso debía reunirse, al menos una vez al año, el primer lunes del mes de diciembre. ${ }^{388}$ Ahora bien, dado que el 1 ${ }^{\circ}$ Congreso (1789-1791) se reunió por primera vez el 4 de marzo de 1789, esta fecha fue tomada como inicio de las sesiones preparatorias; por su parte, las sesiones regulares comenzaban recién en diciembre, nueve meses después. Esta demora, justificable en el siglo XVIII, se fue tornando inadmisible con el correr del tiempo. Se le sumaba a ello que la elección de los senadores y diputados tiene lugar en los años pares, en el mes de noviembre, ${ }^{389}$ esto significaba, en la práctica, que un legislador elegido en noviembre recién tomaba posesión efectiva de la banca cuatro meses después, en marzo del año siguiente. Asimismo, las sesiones regulares recién comenzaban en diciembre de ese año, es decir, trece meses después de haber sido elegidos los nuevos legisladores. Durante ese período de cuatro meses (entre noviembre y marzo del año siguiente), tenían lugar las llamadas lame duck sessions, en las cuales no sesionaban los nuevos legisladores elegidos en la elección anterior, sino que lo hacían muchos de los que debían retirarse. Era frecuente, además, que estos aprovecharan la ocasión para entorpecer las sesiones por medio del filibuster.

Para terminar con esta anomalía, el senador republicano George W. Norris, de Nebraska, ${ }^{390}$ propuso en 1923 una enmienda constitucional para acortar el período que mediaba entre la elección de los legisladores y el inicio de un nuevo Congreso, estableciendo que las sesiones debían comenzar en enero en lugar de marzo. Pese a que la enmienda parecía ser bastante sencilla, en los hechos encontró una resistencia formidable en el House -donde los representantes que no eran reelegidos se veían perjudicados por ella- y su sanción se demoró casi una década.

En febrero de 1923, cuando ya estaba por finalizar el 67 Congreso (1921-

388 "Art. I, s. 4, cl. 2: The Congress shall assemble at least once in every Year, and such Meeting shall be on the first Monday in December, unless they shall by Law appoint a different Day".

389 En los Estados Unidos, el Election Day tiene lugar el martes siguiente al primer lunes del mes de noviembre de los años pares. Ese día, cada cuatro años, son elegidos el presidente y vicepresidente; y cada dos años, los senadores y representantes. Así fue establecido por una ley de 1845 para elegir al presidente y al vicepresidente (Presidential Election Day Act of 1845; 5 Statutes at Large 721), que se mantiene vigente en la actualidad en el 3 USC § 1: "The electors of President and Vice President shall be appointed, in each State, on the Tuesday next after the first Monday in November, in every fourth year succeeding every election of a President and Vice President”. Esta misma disposición fue adoptada también para los senadores (2 USC § 1) y para los representantes (2 USC § 7).

390 El mismo que, siendo miembro del House, había liderado la revuelta contra el Speaker Joseph Cannon en 1910. 
1923), fue aprobada por el Senado por un voto de 63-6. En el House fue aprobada por el Rules Committee, pero su presidente, el republicano Philip Campbell, de Kansas -un lame duck-, se encargó de impedir que llegara al recinto. Al año siguiente, durante el 68 Congreso (1923-1925), el Senado volvió a aprobarla por 63-7, pero el Rules Committee en el House la bloqueó; lo mismo ocurrió en 1926, luego de una votación favorable en el Senado de 72-3. Recién en 1928, durante el 70 Congreso (1927-1929), la Enmienda Norris pudo llegar al recinto del House luego de ser aprobada en el Senado - por cuarta vez- con un voto de 65-6. Si bien en esta ocasión en el House fue aprobada por 209-157 votos, estos no fueron suficientes para alcanzar la mayoría agravada de dos tercios que exige el artículo $\mathrm{V}$ de la Constitución para que una enmienda sea aprobada en el Congreso y pueda ser enviada a las legislaturas estatales para su ratificación. En el 71 Congreso (1929-1931), el Senado la aprobó nuevamente -una quinta vez- por 64-9, pero el House optó por una versión diferente por 290-93. Tampoco pudo ser sancionada en esa oportunidad porque ambas cámaras no lograron acordar el texto. ${ }^{391}$ La Enmienda finalmente pudo ser sancionada en el 72 Congreso (1931-1933), cuando los demócratas recobraron la mayoría en el House. A comienzos de 1932, el Senado la aprobó - por sexta vez- con una mayoría de 63-7 y el House hizo lo suyo con una mayoría 335-56.

Su ratificación en las legislaturas estatales no se demoró y la Enmienda Norris (Lame Duck Amendment) se convirtió en la Enmienda XX el 23 de febrero de $1933 .{ }^{392}$ Con ella fueron modificadas dos fechas importantes en el

391 Recordemos que en los Estados Unidos, en caso de desacuerdo entre el Senado y el House, no prevalece la cámara de origen, como ocurre en el sistema argentino, sino que se designa una comisión bicameral (conference committee) con el objeto de negociar el texto, que elabora el llamado conference report, el cual debe ser aprobado por ambas cámaras sin enmiendas. Esta solución no surge expresamente de la Constitución, pues el artículo I, sección 7, cláusula 2 solo establece que un proyecto, una vez aprobado por ambas cámaras, debe ser enviado al Poder Ejecutivo para que se convierta en ley ("Every Bill which shall have passed the House of Representatives and the Senate, shall, before it become a law, be presented to the President of the United States"). No obstante, es evidente que dicha cláusula no permite enviar al Poder Ejecutivo un proyecto sancionado solamente por una de las cámaras. No me detendré aquí en esta cuestión, pero puede ser consultada, entre otros lugares, en Congressional Research Service (2019). Puede verse también la obra de Bidegain (1950, pp. 626-632).

392 Su texto completo, en lo que aquí interesa, es el siguiente:

"Section 1. The terms of the President and Vice President shall end at noon on the 20th day of January, and the terms of Senators and Representatives at noon on the $3^{\text {rd }}$ day of January, of the years in which such terms would have ended if this article had not been ratified; and the terms of their successors shall then begin.

Section 2. The Congress shall assemble at least once in every year, and such meeting shall begin at noon on the $3 \mathrm{~d}$ day of January, unless they shall by law appoint a different day".

("Sección 1. Los períodos del Presidente y el Vicepresidente terminarán al medio día del veinte de 
calendario político de los Estados Unidos. La fecha de apertura de las sesiones del Congreso fue cambiada del primer lunes de diciembre al 3 de enero. ${ }^{393} \mathrm{Se}$ modificó también la fecha del Inauguration Day, es decir, el día en que toma posesión del cargo el presidente, que fue fijada el 20 de enero. ${ }^{394}$

\subsection{En marcha hacia la crisis}

En marzo de 1929, Herbert Hoover sucedió a Calvin Coolidge en la presidencia. El optimismo expresado por este último en su último mensaje al Congreso ${ }^{395}$ no permitía imaginar -al menos en un análisis superficial- lo que ocurriría menos de un año después. Sin embargo, la orgía especulativa a la que se habían entregado los norteamericanos en los años anteriores tuvo en las finanzas efectos devastadores que irrumpieron en la Bolsa de la Ciudad de New York el jueves 24 de octubre de aquel año y siguieron los días posteriores. ${ }^{396} \mathrm{~A}$ pesar de que muchos creyeron inicialmente que la ola podía ser detenida, ${ }^{397}$ lo cierto es que los nefastos efectos del Jueves Negro se prolongaron durante la década posterior, signada por la Gran Depresión. ${ }^{398}$ A partir de allí, toda la ad-

enero y los períodos de los senadores y representantes al medio día del tres de enero, de los años en que dichos períodos habrían terminado si este artículo no hubiera sido ratificado, y en ese momento principiarán los períodos de sus sucesores. Sección 2. El Congreso se reunirá, cuando menos, una vez cada año y dicho período de sesiones se iniciará al mediodía del tres de enero, a no ser que por medio de una ley fije una fecha diferente").

393 La primera sesión reunida en esa fecha tuvo lugar en 1934, durante el 73॰ Congreso (1935-1937).

394 Hasta ese momento, casi todos los presidentes habían asumido el 4 de marzo. El primer presidente en tomar posesión del cargo el 20 de enero fue Franklin D. Roosevelt, en 1937, al inaugurar su segundo mandato.

395 "Ninguno de los Congresos de los Estados Unidos hasta ahora reunidos para examinar el estado de la Unión -decía el mensaje- se ha encontrado ante una perspectiva tan favorable como la que aparece en los actuales momentos. En el terreno doméstico hay tranquilidad y satisfacción [...] y el más alto récord de años de prosperidad. En el campo exterior hay paz, y esa sinceridad nacida de la comprensión mutua”. El Presidente luego les dijo a los legisladores que ellos y el país podían considerar el presente con satisfacción y anticipar el futuro con optimismo. Ver Galbraith (1992, p. 30).

396 Según explica Galbraith (1992, p. 133), el peor día de la crisis fue el martes 29. Lo califica como la jornada más devastadora de la historia de la Bolsa de New York.

397 El propio Hoover alentó esta creencia diciendo que la crisis sería superada en 60 días (New York Times, 8 de marzo de 1930, como se citó en De Gregorio, 2005, p. 473).

398 Dice Galbraith (1992): "Luego del Gran Crac vino la Gran Depresión, que duró -con cambiante severidad- diez años. En 1933 el Producto Bruto Nacional (producción total de la economía) fue aproximadamente una tercera parte inferior al de 1929. Recién en 1937 el volumen físico de la producción alcanzó los niveles de 1929; pero inmediatamente volvieron a retroceder. Hasta 1941 el valor de la producción en dólares fue menor que el de 1929. Entre 1930 y 1940 solo en una ocasión -1937- bajó durante el año de ocho millones el número de desocupados. En 1933 había en Estados 
ministración de Hoover -quien no atinó a ponerle remedio a la crisis- quedó ensombrecida por los fantasmas del desempleo y la quiebra masiva de bancos y empresas. ${ }^{399}$ El propio presidente vio así demolido su prestigio -ganado como buen administrador durante la época de la guerra- y se convirtió en el símbolo del desastre, ${ }^{400}$ encerrado en su crédito económico-liberal que le impedía adoptar las medidas que recién fueron encaradas por su sucesor.

\section{Conclusión}

Tratándose de una reseña histórica parcial, que espero algún día poder completar hasta la actualidad, no es posible todavía arribar a conclusiones muy definitivas, si es que estas pueden hacerse sobre una institución que está en desarrollo constante.

En ausencia de ellas, diré tan solo que, sin perjuicio de la enorme influencia política ejercida por algunos presidentes notables como Washington, Lincoln y Wilson, el Congreso, durante el siglo y medio que abarca el período aquí considerado, logró emerger y afianzarse como una legislatura estable que nunca interrumpió sus actividades -ni siquiera en plena Guerra Civil-, convirtiéndose en el foro de discusión de los problemas nacionales más trascendentales, en cuyo debate, incluso, desafió a mandatarios poderosos como los mencionados.

No ha estado exento de la pasión ni de los defectos propios de toda institución de su tipo, pero ha contribuido con eficacia a equilibrar el balance poderes.

\section{Bibliografía}

Abraham, H. J. (1985). Justices and Presidents. A Political History of Appointments to the Supreme Court (2 ed.). Oxford University Press.

Angle, P. M. (Ed.). (1991). The Complete Lincoln-Douglas Debates of 1858. The University of Chicago Press.

Unidos casi trece millones de trabajadores sin empleo, es decir, uno por cada cuatro del total de la fuerza de trabajo del país. En 1938 una persona de cada cinco seguía todavía sin empleo” (p. 186).

399 En la primavera de 1930 había cuatro millones de desempleados, cifra que se triplicó en 1933, el peor año de la Depresión, en el que se registró una tasa de desempleo del $25 \%$.

400 Los miles de desempleados que se vieron forzados a abandonar sus hogares pasaron a vivir precariamente en viviendas de cartón y hojalata a las que se llamó hoovervilles. 
Anthony, S. B. (1887-1922). The History of Women Suffrage (Vols. 1-6). National American Suffrage Association.

Baker, George W. (Jr.). (1966). The Wilson Administration and Panama, 1913-1921. Journal of Inter-American Studies, 8(2), 279-293.

Beard, C. A. (1956). An Economic Interpretation of the Constitution of the United States. The Macmillan Co.

Belz, H. (Ed.). (2000). The Webster-Hayne Debate on the Nature of the Union. Selected Documents. Liberty Fund.

Bianchi, A. B. (2008). Historia Constitucional de los Estados Unidos (Tomo I). Cathedra Jurídica.

Bidegain, C. M. (1950). El Congreso de Estados Unidos de América. Derecho y Prácticas Legislativas. Depalma.

Bowen, C. D. (1966). Miracle at Philadelphia. The story of the Constitutional Convention May to September 1787. Little Brown \& Co.

Bueno de Mesquita, B. y Smith, A. (2016). The Spoils of War. Public Affairs Books.

Carey, G. W. (1989). The Federalist. Design for a Constitutional Republic. University of Illinois Press.

Carey, G. y McLean, J. (2001 [1818]). Gideon Edition. Liberty Fund.

Cheathem, M. R. (2018). Andrew Jackson and the Rise of the Democratic Party. University of Tennessee.

Chernow, R. (2005). Alexander Hamilton. Penguin Books.

Congressional Research Service. (21 de mayo de 2019). Conference Committee and Related Procedures: An Introduction. https://fas.org/sgp/crs/misc/96-708.pdf.

Davison, K. E. (1972). The Presidency of Rutherford B. Hayes. Greenwood Press.

De Gregorio, W. A. (2005). The Complete Book of U.S. Presidents (5a ed.). Wings Books.

Dickson, P. y Clancy, P. (Eds.). (1993). The Congress Dictionary. John Wiley and Sons, Inc.

Farrand, M. (1911a). The Records of the Federal Convention of 1787 (Vol. 1). Yale University Press. https://oll.libertyfund.org/title/farrand-the-records-of-the-federal-convention-of-17873vols.

Farrand, M. (1911b). The Records of the Federal Convention of 1787 (Vol. 2). Yale University Press. https://oll.libertyfund.org/title/farrand-the-records-of-the-federal-convention-of-17873vols.

Farrand, M. (1911c). The Records of the Federal Convention of 1787 (Vol. 3, Appendix F). Yale University Press. https://oll.libertyfund.org/title/farrand-the-records-of-the-federal-convention-of-1787-3vols.

Farrand, M. (1913). The Framing of the Constitution of the United States. Yale University Press.

Galbraith, J. K. (1992). The Great Crash 1929. Penguin Books.

Galloway, G. B. (1976). History of the House of Representatives (2a ed.). Thomas Y. Crowell.

Gaustad, E. S. (1968). The Great Awakening in New England. Quadrangle.

Gould, L. L. (1991). The Presidency of Theodore Roosevelt. University Press of Kansas.

Gould, L. L. (2003). Grand Old Party. A History of the Republicans. Random House.

Grant, J. (2011). Mr. Speaker!: The Life and Times of Thomas B. Reed, The Man Who Broke the Filibuster. Simon \& Schuster.

Guide to Congress. (2015). (7 ed.). Congressional Quarterly.

Hasbrouck, P. D. (1972). Party Government in The House of Representatives. Macmillan. 
Haynes, G. H. (1938). The Senate of the United States. Its History and Practice (Vol. 1). Houghton Mifflin Co.

Hazelgrove, W. (2016). Madam President: The Secret Presidency of Edith Wilson. Regnery History. Hecht, M. B. (1972). John Quincy Adams. A Personal History of an Independent Man. Macmillan. Hendricks, N. (2013). Senator Hattie Caraway: An Arkansas Legacy. The History Press.

Holt, M. F. (1999). The Rise and Fall of the American Whig Party: Jacksonian Politics and the Onset of the Civil War. Oxford University Press.

James Madison Writings. (1999). The Library of America, Literary Classics of the United States. Jeffers, P. A. (2000). An Honest President: The Life and Presidencies of Grover Cleveland. Morrow.

Johnson, P. (1997). A History of the American People. Harper Collins.

Jones, C. O. (1970). The Minority Party in Congress. Little Brown \& Co.

Kendrick, B. B. (1969 [1914]). The Journal of the Joint Committee of Fifteen on Reconstruction, 39th Congress, 1865-1867. Negro Universities Press.

Kravitz, W. (1974). Evolution of the Senate's Committee System. The Annals of the American Academy of Political and Social Science, 411(1), 27-38.

Link, A. S. (1954). Woodrow Wilson and the Progressive Era. Harper \& Brothers.

Link, A. S. (1966-1994). The Papers of Woodrow Wilson. Princeton University Press.

Link, A. S. (1982). Woodrow Wilson and a Revolutionary World. University of North Carolina Press.

Lopach, J. J. y Luckowski, J. A. (2018). Jeannette Rankin: A Political Woman. University Press of Colorado.

MacNeil, N. (2011). Forge of Democracy: The House of Representatives.

Mayo, B. (1937). Henry Clay. Spokesman of the New West. Houghton Mifflin.

McCartney, L. (2009). The Teapot Dome Scandal. Random House.

Mee, C. L. (Jr.). (2014). The Ohio Gang: The World of Warren G. Harding. M. Evans \& Company.

Meed, D. (2002). The Mexican War 1846-1848. Osprey Publishing Limited.

Miller, N. (1992). Theodore Roosevelt. A Life. William Morrow.

Morison, S. E., Commager, H. S. y Leuchtenburg, W. E. (1980). The Growth of the American Republic (7 a ed., Vol. I). Oxford University Press.

Patrick, J. J., Piuos, R. M. y Ritchie, D. A. (Eds.). (2001). The Oxford Guide to the United States Government. Oxford University Press.

Perret, G. (1997). Ulysses S. Grant: Soldier and President. Random House.

Purcell, L. E. (2001). Vice Presidents: A Biographical Dictionary. Checkmark Books.

Reeves, T. C. (1991). Gentleman Boss: The Life of Chester Alan Arthur. American Political Bibliography Press.

Riddick, F. M. (1949). The United States Congress. Organization and Procedures. National Capitol Publishers.

Rimini, R. V. (2006). The House. The History of the House of Representatives. Harper Collins.

Rothman, D. J. (1966). Politics and Power. The United States Senate (1861-1901). Harvard University Press.

Schiller, W. J., Stewart, C. y Xiong, B. (2013). U.S. Senate Elections before the 17th Amendment: Political Party Cohesion and Conflict 1871-1913. The Journal of Politics, 75(3), 835-847.

Schumpeter, J. A. (1971). Historia del análisis económico. Ariel.

Singer, A. (1976). Campaign Speeches of American Presidential candidates, 1928-1972. Ungar. 
Sobel, R. (2015). Coolidge: An American Enigma. Regnery History.

Socolofsky, H. y Spetter, A. B. (1987). The Presidency of Benjamin Harrison. University Press of Kansas.

Story, J. (1858). Commentaries on the Constitution of the United States (3a ed., libro 1). Little Brown $\&$ Co.

Thelen, D. P. (1976a). La Follette and the Insurgent Spirit. The University of Wisconsin Press.

Thelen, D. P. (1976b). Robert M. La Follette and the Insurgent Spirit. Little Brow \& Co.

Wilson, W. (2017 [1885]). Congressional Government. A Study in American Politics, Okitos Press.

Wineapple, B. (2020). The Impeachers: The Trial of Andrew Johnson and the Dream of a Just Nation. Random House.

Women in Congress: Statistics and Brief Overview (2021). Congressional Research Service. https:// fas.org/sgp/crs/misc/R43244.pdf.

\section{Anexo I}

Virginia, la más antigua de las colonias, fue fundada por la Virginia Stock Company of London, merced a una carta otorgada por Jacobo (James) I en 1606 y dio lugar a la fundación de Jamestown en 1607, el primer asentamiento inglés permanente en América. Maryland nació a raíz de la carta otorgada a George Calvert en 1632 por el rey Carlos I. Nacida como un refugio para ingleses católicos, su primer asentamiento tuvo lugar en St. Mary’s en 1634, luego llegaron oleadas de protestantes, lo que provocó conflictos entre ambos grupos.

Massachusetts tuvo su origen en el desembarco de los padres peregrinos que arribaron a las costas de Cape Code en 1620 y fundaron Plymouth ese mismo año. En 1629 fue fundada Charlestown y en 1630 desembarcaron allí John Winthrop y otros emprendedores de la Massachusetts Bay Company y fundaron la ciudad de Boston, entre otras.

Connecticut nació por medio de una carta real otorgada por Carlos II en 1662, que unificó los territorios colonizados por Thomas Hooker, que había fundado Hartford en 1636 y por otros puritanos que se habían establecido en Saybrook y New Haven en la misma época. Rhode Island nació como resultado de la disidencia de Roger Williams, un fervoroso adherente de la libertad religiosa, con el Gobierno de Winthrop y los puritanos. Rogers fundó Providence en 1636 y con la reunión de varios asentamientos poblados por librepensadores se federaron en Rhode Island hacia 1644. En 1663 obtuvieron una carta real propia.

New Hampshire fue fundada por varios grupos de puritanos y anglicanos que, entre 1623 y 1640 , se establecieron en tierras otorgadas por Carlos I a John Mason. Estos asentamientos fueron convertidos en colonia real en 1679.

En New York se instaló originalmente la Dutch West Indies Company, que fundó Albany en 1624 y Manhattan en 1626. En 1664, los ingleses se apoderaron de la colonia, expulsaron a los holandeses y la denominaron New York, debido a una concesión de esas tierras que Carlos II le había hecho a su hermano, el duque de York. En 1685, Jacobo II, el otrora duque de York, que había ascendido al trono como consecuencia de la muerte de su hermano, la convirtió en colonia real.

New Jersey se originó en 1665 por medio de una carta otorgada por el entonces duque de 
York (luego Jacobo II), que le otorgó tierras a lord John Berkeley y a George Calvert, quienes denominaron New Jersey a dicha área, dividiéndola en East Jersey y West Jersey. Ambos propietarios vendieron estas parcelas separadamente y volvieron a unirse en una sola colonia en 1702, que hasta 1738 estuvo bajo la autoridad del gobernador de New York.

Pennsylvania fue fundada por William Penn -un cuáquero- mediante una autorización otorgada por el duque de York en 1681. Penn atrajo a muchos de sus pobladores iniciales, tanto ingleses como europeos continentales, prometiéndoles la libertad religiosa y el otorgamiento de tierras, quienes en 1683 fundaron Germantown. Hasta la Revolución, en 1776, Pennsylvania fue una colonia particular.

Delaware fue colonizada originalmente por holandeses y suecos. Los primeros fundaron la ciudad de Lewes en 1631. En 1664, los ingleses tomaron posesión de estos territorios, que fueron incluidos en una concesión otorgada al duque de York, que se los vendió en 1682 a William Penn, pasándose a llamar los Lower Counties. Al igual que Pennsylvania, Delaware continuó siendo una colonia particular hasta 1776. El territorio que hoy ocupan North y South Carolina fue originalmente una extensión de tierras ubicada entre Virginia y Florida, otorgada en 1683 por Carlos II a sir John Colleton y al conde de Shaftesbury. Charleston, en la actual South Carolina, fue fundada en 1670.

South Carolina fue esencialmente una colonia de plantaciones y en North Carolina predominaron las granjas. Ambas se convirtieron en colonias reales en 1729. Georgia, finalmente, fue inicialmente un refugio para los deudores, fundado por James Edward Oglethorpe, un militar inglés y miembro del Parlamento que, junto con otro grupo de filántropos reformistas, intentaba aliviar con ello la dureza de la justicia británica para con los deudores morosos. Fundaron Savannah en 1733 y Georgia obtuvo el estatus de colonia real en 1752 (Guide to Congress, 2015, p. 4).

\section{Anexo II}

1. "[...] the articles of Confederation ought to be so corrected \& enlarged as to accomplish the objects proposed by their institution; namely: 'common defence, security of liberty and general welfare'.

2. [...] the rights of suffrage in the National Legislature ought to be proportioned to the Quotas of contribution, or to the number of free inhabitants, as the one or the other rule may seem best in different cases.

3. [...] the National Legislature ought to consist of two branches.

4. [...] the members of the first branch of the National Legislature ought to be elected by the people of the several States everyfor the term of; to be of the age of years at least, to receive liberal stipends by which they may be compensated for the devotion of their time to public service; to be ineligible to any office established by a particular State, or under the authority of the United States, except those beculiarly belonging to the functions of the first branch, during the term of service, and for the space ofafter its expiration; to be incapable of re-election for the space ofafter the expiration of their term of service, and to be subject to recall. 
5. [...] the members of the second branch of the National Legislature ought to be elected by those of the first, out of a proper number of persons nominated by the individual Legislatures, to be of the age ofyears at least; to hold their offices for a term sufficient to ensure their independency, to receive liberal stipends, by which they may be compensated for the devotion of their time to public service; [21] and to be ineligible to any office established by a particular State, or under the authority of the United States, except those peculiarly belonging to the functions of the second branch, during the term of service, and for the space ofafter the expiration thereof.

6. [...] each branch ought to possess the right of originating Acts; that the National Legislature ought to be impowered to enjoy the Legislative Rights vested in Congress by the Confederation $\&$ moreover to legislate in all cases to which the separate States are incompetent, or in which the harmony of the United States may be interrupted by the exercise of individual Legislation; to negative all laws passed by the several States, contravening in the opinion of the National Legislature the articles of Union; and to call forth the force of the Union against any member of the Union failing to fulfill its duty under the articles thereof.

7. [...] a National Executive be instituted; to be chosen by the National Legislature for the term of years, to receive punctually at stated times, a fixed compensation for the services rendered, in which no increase or diminution shall be made so as to affect the Magistracy, existing at the time of increase or diminution, and to be ineligible a second time; and that besides a general authority to execute the National laws, it ought to enjoy the Executive rights vested in Congress by the Confederation.

8. [...] the Executive and a convenient number of the National Judiciary, ought to compose a council of revision with authority to examine every act of the National Legislature before it shall operate, \& every act of a particular Legislature before a Negative thereon shall be final; and that the dissent of the said Council shall amount to a rejection, unless the Act of the National Legislature be again passed, or that of a particular Legislature be again negatived by of the members of each branch.

9. [...] a National Judiciary be established to consist of one or more supreme tribunals, and of inferior tribunals to be chosen by the National Legislature, to hold their offices during good behaviour; and to receive punctually at stated times fixed compensation for their services, in which no increase or diminution shall be made so as to affect the persons actually in office at the time of such increase or diminution. that the jurisdiction of the inferior tribunals shall be to hear \& determine in the first instance, and of the supreme tribunal to hear and determine in the dernier resort, all piracies $\&$ felonies on the high seas, captures from an enemy; cases in which foreigners or citizens of other States applying to such jurisdictions may be interested, or which respect the collection of the National revenue; impeachments of any National officers, and questions which may involve the national peace and harmony.

10. [...] provision ought to be made for the admission of States lawfully arising within the limits of the United States, whether from a voluntary junction of Government \& Territory or otherwise, with the consent of a number of voices in the National legislature less than the whole. 
11. [...] a Republican Government \& the territory of each State, except in the instance of a voluntary junction of Government \& territory, ought to be guaranteed by the United States to each State.

12. [...] provision ought to be made for the continuance of Congress and their authorities and privileges, until a given day after the reform of the articles of Union shall be adopted, and for the completion of all their engagements.

13. [...] provision ought to be made for the amendment of the Articles of Union whensoever it shall seem necessary, and that the assent of the National Legislature ought not to be required thereto.

14. [...] the Legislative Executive \& Judiciary powers within the several States ought to be bound by oath to support the articles of Union

15. [...] the amendments which shall be offered to the Confederation, by the Convention ought at a proper time, or times, after the approbation of Congress to be submitted to an assembly or assemblies of Representatives, recommended by the several Legislatures to be expressly chosen by the people, to consider \& decide thereon”. Vid. Farrand (1911a, pp. 20-22). También puede verse el texto del Plan en James Madison Writings (1999, pp. 89-91).

\section{Anexo III}

1. "[...] the articles of Confederation ought to be so revised, corrected and enlarged, as to render the federal Constitution adequate to the exigencies of Government, and the preservation of the Union.

2. [...] in addition to the powers vested in the United States in Congress, by the present existing articles of Confederation, they be authorized to pass acts for raising a revenue, by levying a duty or duties on all goods or merchandizes of foreign growth or manufacture, imported into any part of the United States, by Stamps on paper, vellum or parchment, by a postage on all letters or packages passing through the general post-Office, to be applied to such federal purposes as they shall deem proper and expedient; to make rules and regulations for the collection thereof; the same from time to time, to alter and amend in such manner as they shall think proper: to pass Acts for the regulation of trade and commerce as well with foreign nations as with each other: provided that all punishments, fines, forfeitures and penalties to be incurred for contravening such acts rules regulations shall be adjudged by the Common law Judiciary of the State in which any offence contrary to the true intent and meaning of such Acts rules and regulations shall have been committed or perpetrated, with liberty of commencing in the first instance all suits and prosecutions for that purpose in the superior Common law Judiciary in such State, subject nevertheless, for the correction of all errors, both in law and fact in rendering judgment, to an appeal to the Judiciary of the U. States

3. [...] whenever requisitions shall be necessary, instead of the rule for making requisitions mentioned in the articles of Confederation, the United States in Congress be authorized to make such requisitions in proportion to the whole number of white and other free citizens and 
inhabitants of every age sex condition including those bound to servitude for a term of years and three fifths of all other persons not comprehended in the foregoing description, except Indians not paying taxes; that if such requisitions be not complied with, in the time specified therein, to direct the collection thereof in the non complying States for that purpose to devise pass acts directing authorizing the same; provided that none of the powers hereby vested in the United States in Congress shall be exercised without the consent of at least States, in that proportion if the number of Confederated States should hereafter be increased or diminished.

4. [...] the United States in Congress be authorized to elect a federal Executive to consist of persons, to continue in office for the term of years, to receive punctually at stated times a fixed compensation for their services, in which no increase or diminution shall be made so as to affect the persons composing the Executive at the time of such increase or diminution, to be paid out of the federal treasury; to be incapable of holding any other office or appointment during their time of service for years thereafter; to be ineligible a second time, removable by Congress on application by a majority of the Executives of the several States; that the Executives besides their general authority to execute the federal acts ought to appoint all federal officers not otherwise provided for, and to direct all military operations; provided that none of the persons composing the federal Executive shall on any occasion take commission of any troops, so as personally to conduct any enterprise as General, or in other capacity.

5. [...] a federal Judiciary be established to consist of a supreme Tribunal the Judges of which to be appointed by the Executive, and to hold their offices during good behaviour, to receive punctually at stated times a fixed compensation for their services in which no increase or diminution shall be made, so as to affect the persons actually in office at the time of such increase or diminution; that the Judiciary so established shall have authority to hear and determine in the first instance on all impeachments of federal officers, by way of appeal in the dernier resort in all cases touching the rights of Ambassadors, in all cases of captures from an enemy, in all cases of piracies and felonies on the high seas, in all cases in which foreigners may be interested, in the construction of any treaty or treaties, or which may arise on any of the Acts for regulation of trade, or the collection of the federal Revenue: that none of the Judiciary shall during the time they remain in Office be capable of receiving or holding any other office or appointment during their time of service, or for thereafter.

6. [...] all Acts of the United States in Congress made by virtue in pursuance of the powers hereby and by the articles of confederation vested in them, all Treaties made ratified under the authority of the United States shall be the supreme law of the respective States so far forth as those Acts or Treaties shall relate to the said States or their Citizens, that the Judiciary of the several States shall be bound thereby in their decisions, anything in the respective laws of the Individual States to the contrary notwithsting; that if any State, or any body of men in any State shall oppose or prevent the carrying into execution such acts or treaties, the federal Executive shall be authorized to call forth ye power of the Confederated States, or so much thereof as may be necessary to enforce compel an obedience to such Acts, or an Observance of such Treaties.

7. [...] provision be made for the admission of new States into the Union. 
8. [...] the rule for naturalization ought to be the same in every State

9. [...] a Citizen of one State committing an offence in another State of the Union, shall be deemed guilty of the same offence as if it had been committed by a Citizen of the State in which the Offence was committed" (Farrand, 1911a, 242-245).

\section{Anexo IV}

"Resolved that in the original formation of the Legislature of the U.S. the first branch thereof shall consist of sixty-five members, of which number N. Hampshire shall send 3. Massts. 8. Rh. I. 1. Connt. 5. N. Y. 6. N. J. 4. Pena. 8. Del. 1. Maryd. 6. Virga. 10. N. C. 5. S. C. 5. Geo. 3. - But as the present situation of the States may probably alter in the number of their inhabitants, the Legislature of the U.S. shall be authorized from time to time to apportion the number of Reps.; and in case any of the States shall hereafter be divided, or enlarged by, addition of territory, or any two or more States united, or any new States created within the limits of the U. S. the Legislature of the U.S. shall possess authority to regulate the number of Reps, in any of the foregoing cases, upon the principle of their number of inhabitants, according to the provisions hereafter mentioned, namely - provided always that representation ought to be proportioned according to direct taxation; and in order to ascertain the alteration in the direct taxation, which may be required from time to time by the changes in the relative circumstances of the States. Resolved that a Census be taken within six years from the 1st. meeting of the Legislature of the U. S. and once within the term of every 10 years afterwards of all the inhabitants of the U. S. in the manner and according to the ratio recommended by Congress in their Resolution of April 18. 1783. and that the Legislature of the U. S. shall proportion the direct taxation accordingly. Resolved, that all bills for raising or appropriating money, and for fixing the salaries of officers of the Govt. of the U.S. shall originate in the first branch of the Legislature of the U. S. and shall not be altered or amended in $2 \mathrm{~d}$. branch: and that no money shall be drawn from the public Treasury, but in pursuance of appropriations to be originated in the 1 st branch. Resolved that in the $2 \mathrm{~d}$. branch of the Legislature of the U. S. each State shall have an equal vote" (Farrand, 1911a, pp. 13-14).

\section{Anexo V}

Conforme a lo establecido en el artículo VII, eran necesarias 9 ratificaciones para que la Constitución entrara en vigencia. El 6 de diciembre de 1787, dos meses después de firmada la Constitución, la convención de Delaware unánimemente ratificó la Constitución, convirtiéndose en el primero de los estados en hacerlo. Menos de una semana después, el 12 de diciembre, lo hizo Pennsylvania por mayoría de 46 a 23 votos y con gran oposición de los antifederalistas. El 22 de diciembre se sumó New Jersey y poco después, el 2 de enero de 1788, ratificó Georgia. El quinto estado fue Connecticut, que aprobó la Constitución con una mayoría de 128 votos contra 42. En sexto lugar vino Massachusetts, cuya convención se reunió el 9 de enero de 1788, y luego de un acalorado debate y negociaciones de variado tipo, en el que surgió además la necesidad 
de sancionar un Bill of Rights, se obtuvo la ratificación el 6 de febrero por una estrecha mayoría de 187 a 168. John Hancock había sido designado presidente de la Convención, pero se negó a ocupar su puesto hasta que le prometieron apoyo a su candidatura como vicepresidente en la elección nacional, que tendría lugar luego de ratificada la Constitución. Samuel Adams se opuso también hasta que se produjeron algunos acuerdos comerciales para la construcción de buques en los que se hallaba interesado. Siguieron Maryland, el 28 de abril, con una votación 63 a 11, en la que también se propuso un Bill of Rights, y en octavo lugar se produjo la ratificación de South Carolina, el 23 de mayo, con una mayoría de 149 a 46. El noveno estado fue New Hampshire, al que le corresponde el honor de haber dado su voto para la entrada en vigencia de la Constitución. Ello se produjo el 21 de junio por un voto de 57 a 46.

No obstante la entrada en vigencia formal, todavía estaban fuera cuatro estados que reunían el 40 por ciento de toda la población, entre ellos, Virginia -el más poderoso-, sin cuya aprobación no podía hablarse de éxito. Ello tuvo lugar el 23 de junio en una votación dividida 89 a 79, en la cual quedó planteada también la necesidad de incorporar un Bill of Rights. Quedaban todavía New York, North Carolina y Rhode Island, cuyos votos a esa altura ya se daban por descontados. En New York, sin embargo, el debate fue intenso entre el gobernador Clinton, alineado con los antifederalistas, y Alexander Hamilton y John Jay, a favor de la ratificación. El 26 de julio se produjo la ratificación por un escaso margen de 30 a 27 y con gestos de agitación por los antifederalistas, quienes en Albany, capital del estado, llegaron a quemar un ejemplar de la Constitución. Luego ratificó North Carolina el 21 noviembre de 1789. El último de los trece estados originales en ratificar la Constitución fue Rhode Island, que lo hizo en mayo de 1790 mediante una convención convocada ese mismo año.

Ya con anterioridad, el 13 de septiembre de 1788, el Congreso de la Confederación había declarado que la Constitución estaba debidamente ratificada y habían dado comienzo los preparativos para la elección del presidente. Se fijó el primer miércoles de enero de 1789 para la designación de los electores y el primer miércoles de febrero para la elección del presidente. Se estableció, asimismo, que el período presidencial comenzaría el miércoles 4 de marzo. No obstante, recién el 30 de abril de ese año dio comienzo el período presidencial de George Washington. Se decidió también que New York sería la ciudad capital del nuevo Gobierno. Ver, entre muchos otros, Morison et al., (1980, pp. 257-261) y Bowen (1966, pp. 267-310).

\section{Anexo VI}

Brevemente mencionados, los hechos que dieron lugar a la Guerra Civil fueron los siguientes.

Hacia fines de la década de 1850, los estados del sur podían sentirse satisfechos con los resultados obtenidos en el reparto de la esclavitud. Con la Ley Kansas-Nebraska habían abierto una puerta para expandirla hacia el norte y la Corte Suprema -en el caso Strader v. Graham, 51 U.S. 395 (1851) y más especialmente en Dred Scott v. Sandford, 60 U.S. 393 (1859)- había hecho sentir su espíritu sureño.

Sin embargo, en 1860 ocurrió un hecho que desencadenó la tormenta y rompió con este 
frágil esquema. Finalizaba la opaca presidencia de James Buchanan (1857-1861), que no se presentó para una nueva candidatura, y la elección ofrecía un frente político complejo para los esclavistas, pues el Partido Demócrata se dividió en tres facciones, cada una con su candidato. Stephen Douglas, de Illinois, fue nominado por los norteños; John C. Breckinridge, de Kentucky, resultó electo por los sureños; y un grupo remanente que había formado el Constitutional Union Party eligió a John Bell, de Tennessee.

Todos ellos competían con Lincoln, propuesto por el recientemente formado Partido Republicano, quien había saltado a la primera plana política luego de sus debates con Douglas. Si bien en su campaña Lincoln había sido bastante moderado, pues no proponía eliminarla allí donde existía sino tan solo controlar su expansión, los estados del sur igualmente lo veían como una amenaza. Tanto era el temor de que la esclavitud sufriera alguna mengua que South Carolina anunció su propósito de segregarse si Lincoln ganaba. Y así fue. Lincoln ganó la elección con una mayoría del 40 por ciento sobre el segundo, que resultó ser Douglas con el 29 por ciento.

South Carolina entonces cumplió su promesa y el 20 de diciembre de 1860 sancionó su Ordenanza de Secesión. Inmediatamente, este movimiento se esparció como un reguero de pólvora. La siguieron Mississippi (9 de enero de 1861), Florida (10 de enero), Alabama (11 de enero), Georgia (19 de enero), Louisiana (26 de enero), Texas (26 de febrero), Arkansas (6 de mayo), North Carolina (20 de mayo), Virginia (23 de mayo), Tennessee (8 de junio), Missouri (31 de octubre) y Kentucky (20 de noviembre).

Así, un año después de la elección de Lincoln, trece estados habían decidido segregarse formalmente de la Unión y ya formaban un nuevo estado soberano bajo su propia constitución. Sin perder tiempo, los primeros estados segregados comenzaron por elegir un nuevo presidente. La elección recayó en Jefferson Davis, primer y único presidente que tuvo la Confederación. Menos de un mes después, el 11 de marzo de 1861, representantes de los estados de South Carolina, Georgia, Florida, Alabama, Mississippi, Louisiana y Texas sancionaron la Constitución de los Estados Confederados. Su texto no era esencialmente distinto al de la Constitución de 1787, salvo las disposiciones referidas a la esclavitud, que le prohibían expresamente al Congreso dictar leyes que menoscabaran el derecho de propiedad sobre esclavos negros.

Esta situación, ciertamente, no podía mantenerse por mucho tiempo sin caer en una contienda armada. Las hostilidades comenzaron el 11 de abril de 1861, cuando las tropas confederadas exigieron la rendición del Fort Sumpter -una instalación militar del Gobierno federal ubicada en la bahía de Charleston, en South Carolina, la cual, mal defendida, fue tomada por los sureños-, y concluyeron cuatro años después, en abril de 1865 -con un saldo de más de 600000 muertos-, cuando el general Lee se rindió ante el general Grant en Appomattox.

\section{Anexo VII}

Luego del fortalecimiento de los poderes presidenciales durante la Guerra Civil, el mando político del Poder Ejecutivo decayó a niveles que solo se recuperarían hacia el fin del siglo XIX con presidentes fuertes como Theodore Roosevelt y Woodrow Wilson. Así, durante las últimas 
tres décadas del siglo XIX, los ocupantes de la Casa Blanca -dominada preponderantemente por el Partido Republicano- distaron de ser personalidades brillantes.

Ulysses S. Grant (1869-1877), un coloso en el campo de batalla de la Guerra Civil, fue en cambio un presidente mediocre que, obligado a enfrentar los problemas de la Reconstrucción y el ajuste económico, no supo elegir a los asesores apropiados y evitar la corrupción. Apoyándose en la maquinaria republicana, no pudo acabar con el sistema que otorgaba los cargos federales como recompensa a la lealtad política. Además, su inexperiencia en asuntos económicos y su ambición lo convirtieron en fácil presa de aventureros sin escrúpulos. Asimismo, animado por la incorporación final de todos los estados a la Unión, intentó llevar a cabo la reforma del Congreso, pero a la larga no supo mantenerla. Defendió también los derechos de los esclavos libres, pero no pudo evitar la reaparición del racismo en casi todos los estados sureños. En 1872, los disidentes reformistas de su partido organizaron el Liberal Republican Party y eligieron a Horace Greeley como candidato presidencial. Aunque Grant fue reelegido, su segunda administración se vio afectada por diversos casos de soborno y corrupción, en los que se vieron involucrados el vicepresidente, Schuyler Colfax, y el secretario de Guerra, William W. Belknap, entre otros. Todo esto contribuyó al fracaso de su Gobierno, a lo que se le unió la depresión económica de 1873, que dio como resultado una enorme cantidad de desempleados y la pérdida de la mayoría en la Cámara de Representantes, que pasó a estar presidida por los demócratas. Solo tuvo algunos éxitos en política exterior. Sufrió un revés inicial en el Senado, que no aprobó su plan de comprar la isla de Santo Domingo. Sin embargo, Hamilton Fish -como secretario de Estado- pudo zanjar las dificultades existentes con Gran Bretaña tras la firma del Tratado de Washington (1871) y mantuvo la neutralidad de Estados Unidos durante la guerra de los Diez Años que enfrentó a España y Cuba por la independencia de esta. Sobre la vida de Grant puede verse Perret (1997).

Su sucesor, Rutherford B. Hayes (1877-1881), llegó a la presidencia debilitado por la tumultuosa elección de 1866 a la que ya me referí y se vio envuelto también en los problemas de la Reconstrucción, en la necesidad de restaurar el poder de la presidencia y combatir la corrupción política esparcida bajo su antecesor. Bien intencionado en sus objetivos y honesto en su proceder, Hayes se propuso restaurar el poder que la presidencia había perdido con sus dos antecesores (Andrew Johnson y Ulysses Grant), apaciguar a los estados del sur y conformar a sus opositores demócratas, lo que generó un conflicto con su propio partido. Distribuyó cargos entre demócratas sudistas moderados y retiró las últimas tropas federales de los estados del sur. Como medio para combatir la corrupción administrativa, les prohibió a los funcionarios públicos intervenir en campañas políticas y manejar donativos. Esta decisión lo puso en conflicto con el senador Roscoe Conkling, líder republicano que manejaba la aduana de New York como un feudo personal. Al frente de ella se hallaba Chester Arthur, futuro presidente, que fue removido. En política monetaria, Hayes apoyó los esfuerzos de su secretario del Tesoro, John Sherman, para reconvertir los billetes de dólares emitidos durante la Guerra Civil estadounidense en oro. Debió enfrentar también graves disturbios laborales producidos en 1877, los cuales fueron reprimidos con tropas federales y produjeron muertos y heridos. Prefirió no 
presentarse a la reelección y en 1881 se retiró a Fremont (Ohio), donde murió el 17 de enero de 1893. Véase Davison (1972).

A Hayes lo sucedió James A. Garfield (1881), protagonista de una breve presidencia interrumpida por su asesinato, ocurrido a los pocos meses de asumir. Su muerte colocó en el sillón presidencial al vicepresidente, Chester A. Arthur (1881-1885), un personaje directamente asociado a la corrupción política neoyorquina. Elegante en el vestir y dedicado a sus negocios y a la vida cómoda, Arthur prometía lo peor. De todos modos, su desempeño no fue tan malo como se esperaba. Fue hábil en el manejo de sus decisiones. Apoyó tanto la persecución de la corrupción política para castigar a figuras menores como la ley de reforma del servicio civil en la Administración (Pendleton Act) propuesta por los demócratas, luego de perder la elección de 1882. Su imagen, sin embargo, se dañó mucho cuando propuso para la Corte Suprema a su antiguo jefe político, Roscoe Conkling, un viejo líder republicano que había manipulado la corrupción política en New York. Pese a que su pliego fue aprobado por el Senado, Conckling declinó la nominación y prefirió continuar con el lucrativo ejercicio de la profesión de abogado. Véase Reeves (1991).

Luego de Arthur, la presidencia fue ocupada por un demócrata, Grover Cleveland, quien ejerció dos mandatos no consecutivos (1885-1889 y 1893-1897), en medio de los cuales la Casa Blanca fue ocupada otra vez por un republicano, Benjamin Harrison (1889-1893). Cleveland había obtenido reputación de honesto como gobernador de New York y durante sus dos ejercicios intentó restablecer, sin mayor éxito, la autoridad del Ejecutivo. Como consecuencia de ello, sus relaciones con el Congreso no se caracterizaron por la armonía, sino por las constantes fricciones entre los dos poderes, de lo cual da testimonio la gran cantidad de proyectos de ley del Congreso vetados. Véase Jeffers (2000). Harrison -que derrotó a Cleveland en la elección de 1893 y, a su vez, fue derrotado por este en la de 1897 - venía de una familia con una larga tradición cívica, pero agregó poco a su estirpe. Era nieto del presidente William Henry Harrison, que ocupó la Casa Blanca muy brevemente en 1840, pues murió al mes siguiente de haberse hecho cargo, y bisnieto de Benjamin Harrison, signatario de la Declaración de la Independencia. Véase Socolofsky y Spetter (1987).

Esta debilidad ejecutiva, que ya parecía crónica, comenzó a revertirse con William McKinley (1897-1901), bajo cuya presidencia los Estados Unidos libraron con España una breve y exitosa guerra (1898), que les dio como legado el dominio sobre Cuba y Filipinas. Merced a este conflicto, McKinley pudo ejercer los poderes de guerra y contar con el apoyo del Congreso y de la opinión pública en la conducción de la contienda. También se produjo una expansión territorial con la anexión de Hawaii como territorio.

Su asesinato -segundo en la historia norteamericana- dio acceso a Theodore Roosevelt (1901-1909), su vicepresidente. A diferencia de sus predecesores, Roosevelt poseía una vigorosa personalidad que le permitió ejercer una influencia marcada sobre el Congreso. Muy activo tanto en la política exterior como en la doméstica, luchó por controlar el poder de los grandes grupos económicos, fue un precursor en la conservación de los recursos naturales y obtuvo en 1906 el Premio Nobel de la Paz por su mediación en el tratado de paz que concluyó la guerra 
ruso-japonesa. Bajo su administración, además, se iniciaron las obras de construcción del Canal de Panamá. Véanse, entre otros, Miller (1992); Gould (1991).

Su sucesor y heredero político, William Howard Taft (1909-1913), no estaba dotado en cambio del mismo genio. Tuvo, sin embargo, una actuación importante en la aplicación de la legislación antimonopólica, pero su principal objetivo no era la Casa Blanca, sino la presidencia de la Corte Suprema, destino al que finalmente llegó en 1921 de la mano del presidente Warren G. Harding. Naturalmente, en el camino perdió la posibilidad de ser reelegido. Al cabo de su mandato había perdido el apoyo de Roosevelt, su mentor, quien formó una rama disidente entre los republicanos con la cual compitió sin éxito en la carrera presidencial de 1912, junto con el propio Taft y Woodrow Wilson, quien resultó finalmente el ganador.

Así, un nuevo turno en el poder se abrió para el Partido Demócrata. Taft le entregó la presidencia a Wilson (1913-1921), quien se convertiría en uno de los mandatarios más destacados de su país. Este le dio un nuevo empuje a la presidencia y contribuyó a la formación del moderno concepto sobre esta institución. Como profesor universitario, era un estudioso teórico del problema y ya lo había expuesto en dos obras: Congressional Government (1885) y Constitutional Government in the United States (1908). También había propuesto un cambio en las reglas de juego económico a favor de los más débiles en una obra titulada The New Freedom, publicada el mismo año que se hizo cargo de la presidencia. La obra tenía además un subtítulo sugerente: Un llamado a la emancipación de las generosas energías de un pueblo (A call for the emancipation of the generous energies of a people). Llegó al Gobierno en una época de paz y prosperidad, en la cual las condiciones políticas resultaron favorables para el desarrollo de sus ideas sobre el presidente como líder de la acción legislativa, que en la práctica ejerció. Fue el primero de los jefes del Ejecutivo que desarrolló sistemáticamente los poderes legislativos de su función y su influencia quedó marcada en la legislación sobre tarifas, reforma bancaria y represión de los trusts. Luego, la entrada de Estados Unidos en la Primera Guerra Mundial le daría una oportunidad aún más favorable para convertirse en el símbolo de la unidad nacional y depositario de grandes facultades delegadas por el Congreso. De todos modos, el fin de su vida política se vería ensombrecido por la derrota que la oposición republicana le impuso en el Senado al negarse a ratificar el Tratado de Versalles y, con ello, a ingresar en la Sociedad de Naciones, una de sus creaciones más preciadas. El principal biógrafo de Woodrow Wilson es Arthur S. Link, autor de The Papers of Woodrow Wilson (1966-1994), Woodrow Wilson and the Progressive Era (1954) y Woodrow Wilson and a Revolutionary World (1982). 



\section{¿EL RetrocesO de LOS DERECHOS HUMANOS EN EUROPA?}

\section{Laurence R. Helfer}

Duke University School of Law

helfer@law.duke.edu

\section{Erik Voeten}

Georgetown University

ev42@georgetown.edu

Recibido: 28/05/2021

Aceptado: $11 / 10 / 2021$

\section{Resumen}

Jueces y académicos llevan mucho tiempo debatiendo si el Tribunal Europeo de Derechos Humanos (en adelante, TEDH o el Tribunal) puede solo ampliar la protección de los derechos humanos en Europa, pero nunca disminuirlos. Estudios recientes han constatado que las reacciones políticas y las restricciones nacionales han influido en la jurisprudencia del TEDH. Sin embargo, analizar si el TEDH está cambiando hacia una dirección regresiva supone un reto empírico: ¿cómo podemos determinar si el Tribunal está limitando los derechos a lo largo del tiempo si nunca ha revocado expresamente una sentencia anterior en un sentido que favorezca al Gobierno? Para responder a esta pregunta, analizamos todas las opiniones separadas y minoritarias de la Gran Sala del TEDH entre 1998 y 2018. Nos centramos en las opiniones que afirman que la Gran Sala ha revocado tácitamente sentencias anteriores o doctrina establecida para favorecer al Estado demandado, lo que denominamos “disidencias por regresión”. Descubrimos que estas se han vuelto significativamente más comunes en la última década, lo que revela que algunos miembros del TEDH creen que la Gran Sala está revocando cada vez más sentencias anteriores en una dirección regresiva.

Palabras clave: derechos humanos, Tribunal Europeo de Derechos Humanos, disidencias por regresión, derechos protegidos, revocación de sentencias anteriores, democracias establecidas, doctrinas jurídicas anteriores. 


\title{
Walking Back Human Rights in Europe?
}

\begin{abstract}
Judges and scholars have long debated whether the European Court of Human Rights (the ECtHR or the Court) can only expand, never diminish, human rights protections in Europe. Recent studies have found that political backlashes and national-level restrictions have influenced ECtHR case law. However, analysing whether the ECtHR is shifting in a regressive direction faces an empirical challenge: How can we observe whether the Court is limiting rights over time if it has never expressly overturned a prior judgment in a way that favours the government? We gain traction on this question by analysing all separate and minority opinions of the ECtHR Grand Chamber between 1998 and 2018. We focus on opinions as- serting that the Grand Chamber has tacitly overturned prior rulings or settled doctrine in a way that favours the respondent state, which we label as 'walking back dissents'. We find that walking back dissents have become significantly more common in the last decade, revealing that some members of the ECtHR themselves believe that the Grand Chamber is increasingly overturning prior judgments in a regressive direction.
\end{abstract}

Key words: human rights, European Court of Human Rights, walking back dissents, protected rights, overturn prior judgments, established democracies, prior legal doctrines.

\section{Introducción ${ }^{1}$}

Los derechos humanos en Europa son un continuo trabajo en curso. Las libertades individuales protegidas por el Convenio Europeo de Derechos Humanos no están fijadas ni en el texto del tratado ni en la intención de sus redactores. En cambio, el Convenio es reinterpretado sistemáticamente por los 47 jueces del Tribunal Europeo de Derechos Humanos. Aplicando un enfoque interpretativo famoso por su dinamismo y evolución, el Tribunal ha considerado que leyes y prácticas nacionales que anteriormente no planteaban problemas de derechos humanos contravenían el Convenio cuando se reevaluaban con posterioridad a la luz de las tendencias regionales progresistas en materia de legislación, política y opinión pública. Quizás, lo más sorprendente sea que el TEDH no ha dudado en anular explícitamente sus sentencias anteriores para ampliar los derechos protegidos.

1 Agradecemos a los participantes de la Conferencia iCourts 2.0 de la Universidad de Copenhague, el taller Paths of International Law del Graduate Institute of International and Development Studies de Ginebra y el taller de la facultad de Derecho de Duke por sus valiosos comentarios y sugerencias. Emmie Bultemeier y Lauren Hughes han prestado una excelente ayuda en la codificación de los casos. Esta es una traducción al español de: Helfer, L. R. y Voeten, E. (2020). Walking Back Human Rights in Europe? European Journal of International Law, 31(3), 797-827. https://doi.org/10.1093/ejil/chaa071. 
Pero ¿qué sucede si las tendencias europeas se mueven en la otra dirección? Si los Estados reducen la protección de ciertas libertades individuales -en respuesta a la preocupación por el terrorismo o la migración, por ejemplo-, ¿debería el TEDH revisar su jurisprudencia anterior y restringir los derechos humanos en Europa? Como se explica en el apartado 3, los académicos han debatido durante mucho tiempo si el Tribunal puede solo ampliar, y nunca disminuir, los derechos humanos. Durante muchos años, estos desacuerdos nunca se pusieron a prueba en la práctica; las protecciones de los derechos humanos a nivel nacional -y la jurisprudencia del Tribunal que las refleja- se movieron en una sola dirección.

Sin embargo, a partir de mediados de la década de 2000, funcionarios del Ejecutivo, legisladores y jueces de varios países empezaron a criticar al TEDH por llevar la protección de los derechos humanos demasiado lejos. En una serie de temas de gran repercusión y políticamente sensibles -como los derechos de los acusados de delitos, los sospechosos de terrorismo, los solicitantes de asilo y las familias no tradicionales-, el Tribunal interpretó de forma expansiva el Convenio Europeo de Derechos Humanos (en adelante, CEDH o el Convenio $)^{2}$ y limitó la discrecionalidad jurídica y política de los Gobiernos. El descontento con el TEDH pronto pasó de reclamos públicos a acciones concretas: - En la Declaración de Brighton de $2012^{3}$ y en posteriores declaraciones y enmiendas al Convenio, los Estados señalaron de manera colectiva que el TEDH debía concederles una mayor deferencia. ${ }^{4}$

- Varios Estados han reducido las protecciones legales internas, especialmente en el ámbito de la inmigración. ${ }^{5}$

- Algunas democracias consolidadas, que tradicionalmente han apoyado al TEDH, se han negado a ejecutar las sentencias ${ }^{6}$ o las han impugnado abiertamente. ${ }^{7}$

- Algunos políticos y partidos adoptaron posturas escépticas respecto a los derechos humanos internacionales e incluso manifestaron su interés por abandonar el CEDH (Ciacchi, 2017).

2 Convenio Europeo para la Protección de los Derechos Humanos y de las Libertades Fundamentales (CEDH), 4 de noviembre de 1950, 213 UNTS 221, modificado.

3 Conferencia de alto nivel sobre el futuro del Tribunal Europeo de Derechos Humanos, Declaración de Brighton (20 de abril de 2012).

4 Véase, por ejemplo, Comisión Directiva del Consejo de Europa para los Derechos Humanos (2015).

5 Véase, por ejemplo, Kennedy (2019).

6 Véase, por ejemplo, Bates (2015).

7 Véase, por ejemplo, McGoldrick (2011). 
Cuando los Estados cambian colectivamente en una dirección progresista, el TEDH se basa en esas tendencias para revocar explícitamente sus sentencias anteriores y emitir decisiones que "impulsan" a los países rezagados, llevándolos a adoptar reformas más rápidamente, un patrón que hemos documentado en el caso de los derechos LGBT (Helfer y Voeten, 2014, pp. 95-96). ${ }^{8}$ Pero ¿qué ocurre cuando los países se mueven, por término medio, en una dirección regresiva y los Gobiernos se oponen públicamente a ampliar el alcance de la Convención? Si el TEDH se aferra a su enfoque expansionista, corre el riesgo de provocar una reacción que podría reducir su influencia. Como alternativa, podría ajustar su jurisprudencia para seguir las tendencias nacionales restrictivas de los derechos. ${ }^{9}$ Pero este enfoque también implica riesgos. Puede alienar a los grupos que apoyan al Tribunal y limitar la protección de los derechos de aquellos individuos y grupos desfavorecidos que el Tribunal ha identificado que necesitan especialmente su ayuda.

Cualquier análisis sobre si la jurisprudencia del TEDH está cambiando hacia una dirección restrictiva de los derechos se enfrenta a un reto empírico: ¿cómo podemos determinar si el Tribunal está limitando los derechos a lo largo del tiempo si -a diferencia de muchos tribunales supremos o constitucionales nacionales- nunca ha revocado expresamente una sentencia anterior en un sentido que favorezca al Gobierno? Para ello, analizamos sistemáticamente las opiniones minoritarias (separadas) de la Gran Sala del TEDH, el órgano plenario de diecisiete miembros que aborda las cuestiones más importantes en materia de derechos humanos y resuelve las incoherencias de la jurisprudencia anterior (Mowbray, 2007, p. 510). ${ }^{10}$ Detectamos opiniones minoritarias en las que se afirma que la Gran Sala ha revocado sentencias anteriores o doctrina consolidada para favorecer al Gobierno demandado, las cuales son llamadas "disidencias por regresión”. La gran mayoría de estas opiniones minoritarias (85\%) se denominan "disidencias", el resto son opiniones concurrentes que están de acuerdo con el resultado del caso, pero que, sin embargo, acusan a la mayoría de revocar la jurisprudencia o la doctrina anterior. Para facilitar la lec-

8 Donde se concluye que, por término medio, una sentencia del TEDH es responsable de que otros cinco países adopten políticas favorables a los derechos de las personas LGBT en los cinco años inmediatamente posteriores a la sentencia y de que otros ocho países lo hagan durante una década

9 Véase, por ejemplo, Madsen et al. (2018).

10 Las Cámaras del TEDH tienen "formalmente prohibido revocar la sentencia". Véase Schabas (2015, p. 711). Deben renunciar a la competencia a favor de la Gran Sala "cuando la resolución de una cuestión [...] pueda tener un resultado incompatible con una sentencia dictada anteriormente por el Tribunal". Véase CEDH, nota 2 supra, art. 30. 
tura, denominamos a todas las opiniones minoritarias que contienen este tipo de afirmaciones como "disidencias por regresión".

Reconocemos que los jueces del TEDH pueden discrepar razonablemente sobre cómo interpretar decisiones y doctrinas jurídicas anteriores. Lo que la minoría percibe como una anulación tácita de un precedente protector de los derechos, la mayoría puede considerarlo como una aclaración de la jurisprudencia del Tribunal o una adaptación a hechos o circunstancias diferentes. También reconocemos que los juristas que escriben opiniones disidentes pueden tener razones normativas y estratégicas para acusar al TEDH de revocar una sentencia. Por ejemplo, pueden hacerlo para agudizar la mordacidad retórica de su crítica, acentuar sus implicaciones políticas o propiciar nuevos casos de futuros litigantes.

Sin embargo, en el caso de un tribunal en el que se prohíbe la derogación expresa de una sentencia anterior en una dirección restrictiva de los derechos, la mayoría siempre justificará una decisión que logre ese resultado, de hecho, si no de forma nominal, por referencia a las diferentes circunstancias de un caso posterior. Incluso si los jueces disidentes tienen diferentes motivaciones para acusar a la mayoría de anulación tácita, un aumento generalizado de disidencias a lo largo del tiempo proporciona pruebas sugestivas de un grupo de actores especialmente bien informados de que el TEDH está, de hecho, retrocediendo en materia de derechos humanos en Europa, aun si no lo está haciendo abiertamente.

Nuestro conjunto de datos comprende la totalidad de las casi 400 sentencias de la Gran Sala desde 1999 (tras la entrada en vigor del Protocolo No 11) hasta 2018. Durante este período de 20 años, el 83\% de las sentencias incluían al menos una (y a menudo más de una) opinión separada, normalmente una disidencia o una concurrencia total o parcial. Con la ayuda de dos asistentes para realizar la búsqueda, codificamos todas estas opiniones formulando tres preguntas: (i) si la opinión era más o menos favorable al Gobierno que la sentencia mayoritaria; (ii) si la opinión afirmaba que la mayoría había anulado explícita o tácitamente una sentencia anterior del TEDH o había interpretado erróneamente o ignorado la jurisprudencia anterior; y (iii) si la opinión afirmaba que la mayoría aplicaba de forma incoherente principios jurídicos clave, como el margen de apreciación, el instrumento vivo o las doctrinas del consenso europeo.

Encontramos que las disidencias por regresión están en aumento, tanto de forma absoluta como proporcional. Por ejemplo, entre 2012 y 2018, 56 senten- 
cias de la Gran Sala (40\%) fueron acompañadas por una o varias disidencias de reversión. Por el contrario, en el período 1999-2005, esto ocurría solo en el $24 \%$ de las sentencias de la Gran Sala. Ofrecemos una serie de ejemplos cualitativos para ilustrar los argumentos de estas opiniones minoritarias, incluidas las afirmaciones de que la anulación tácita refleja un abandono más amplio del papel histórico del TEDH.

También proporcionamos información sobre los jueces, los países y las cuestiones jurídicas de fondo que se asocian con mayor frecuencia a las disidencias. Consideramos la posibilidad de que los casos de la Gran Sala se hayan vuelto más difíciles o controvertidos con el paso del tiempo y, por lo tanto, sean más propensos a generar disidencias por regresión. Encontramos pruebas -incluso después de controlar estas características de los casos- de que las disidencias por regresión se han vuelto significativamente más probables en el período posterior a Brighton.

El presente artículo se desarrolla de la siguiente manera: en el apartado 2 se describen los métodos dinámicos de interpretación de tratados del TEDH y las opiniones de los jueces y los académicos sobre si el Tribunal puede utilizar estos métodos para contraer derechos, así como para ampliarlos. También se examinan los estudios empíricos existentes sobre cómo responde el TEDH a las presiones de los Estados y la literatura sobre las disidencias judiciales. El apartado 3 explica nuestro diseño de investigación, la recopilación de datos, las expectativas teóricas y los procedimientos de codificación, en tanto que el 4 expone nuestro análisis y resultados. El apartado 5 concluye y considera las implicaciones teóricas y normativas más amplias.

\section{La expansión (¿y contracción?) de los derechos humanos en Europa \\ 2.1. La doctrina del instrumento vivo y la ampliación de derechos}

El Convenio Europeo de Derechos Humanos se adoptó en 1950, pero no fue hasta finales de la década de 1970 cuando el TEDH se enfrentó por primera vez a una práctica -los castigos corporales judiciales a los menores- que en su momento se consideraba inofensiva, pero que se había ido abandonando gradualmente. Al considerar que dicho castigo era degradante, el Tribunal declaró que "el Convenio es un instrumento vivo que debe ser interpretado considerando las condiciones actuales". ${ }^{11}$

11 TEDH, Tyrer c/Reino Unido, Appl. N 5856/72, sentencia de 25 de abril de 1978, párrafo 31. Todas las decisiones del TEDH están disponibles en: http://hudoc.echr.coe.int/. 
Durante las cuatro décadas siguientes, la doctrina del instrumento vivo "se extendió por toda la jurisprudencia de Estrasburgo", permitiéndole al Tribunal "adaptar, con el tiempo, el texto del Convenio a la evolución jurídica, social, ética o científica". ${ }^{12}$ Cuando el TEDH detecta un consenso europeo -o, al menos, una convergencia significativa- en las legislaciones y prácticas nacionales de los Estados miembros en favor de una protección más amplia de un determinado derecho o libertad, es más probable que el Tribunal concluya que un Estado que no ha seguido el ritmo de estas tendencias ha violado el Convenio. ${ }^{13}$

El TEDH aplica este enfoque progresivo incluso cuando ello requiere revocar sentencias anteriores. Aunque reconoce que "la seguridad jurídica, la previsibilidad y la igualdad ante la ley" pesan en contra de "apartarse, sin una buena razón, de los precedentes establecidos en casos anteriores”, también ha sostenido que no "mantener un enfoque dinámico y evolutivo supondría el riesgo de convertirlo en un obstáculo para la reforma o la mejora. ${ }^{14}$

Son numerosos y variados los ejemplos en los que el TEDH ha anulado explícitamente sus propias decisiones anteriores y las de la Comisión Europea de Derechos Humanos (Mowbray, 2009). ${ }^{15}$ Entre ellos se encuentran las sentencias que reconocen los derechos de los objetores de conciencia a negarse a realizar el servicio militar, ${ }^{16}$ de los sindicatos a negociar colectivamente con los empleadores ${ }^{17}$ de los hombres homosexuales a impugnar las leyes que penalizan la actividad homosexual privada ${ }^{18} \mathrm{y}$ de las personas transgénero a contraer matrimonio y a obtener los documentos de identidad adecuados. ${ }^{19}$ El Tribunal también ha revocado sentencias relacionadas con cuestiones de procedimien-

12 TEDH, Magyar Helsinki Bizottság c/Hungary, Appl. N 18030/11, sentencia de la Gran Sala de 11 de agosto de 2016, párrafo 3 (Sicilianos y Raimondi JJ., concurrentes).

13 Véanse, por ejemplo, Dzehtsiarou (2015); Helfer (1993).

14 TEDH, Vilho Eskelinen c/Finlandia, Appl. N 63235/00, sentencia de la Gran Sala de 19 de abril de 2007, párrafo 56.

15 Antes del Protocolo $\mathrm{N}^{\circ}$ 11, la Comisión Europea revisaba las solicitudes y emitía decisiones no vinculantes sobre si el Estado demandado había violado el Convenio. La Comisión o el Estado demandado (pero no el demandante) podían apelar estas decisiones ante el TEDH.

16 TEDH, Bayatyan c/Armenia, Appl. N²3459/03, sentencia de la Gran Sala de 7 de julio de 2011 (anulando la jurisprudencia de la Comisión Europea las décadas de 1970 y 1980).

17 TEDH, Demir y Baykara c/Turquía, Appl. N 34503/97, sentencia de la Gran Sala de 11 de diciembre de 2008 (anulando una sentencia del TEDH de mediados la década de 1970).

18 TEDH, Dudgeon c/Reino Unido, Appl. N 7525/76, sentencia del 22 de octubre de 1981 (revocando la jurisprudencia de la Comisión Europea de las décadas de 1950 y 1960).

19 TEDH, Goodwin c/Reino Unido, Appl. N²8957/95, sentencia de la Gran Sala de 11 de julio de 2002 (anulando múltiples sentencias del TEDH desde la década de 1970 hasta la de 1990). 
to, revocando aquellas que rechazaban la ampliación del derecho a un juicio justo a los procedimientos de requerimiento, ${ }^{20}$ negándose a considerar las violaciones del derecho a un recurso interno efectivo si el Estado violaba otras disposiciones del Convenio ${ }^{21}$ y concluyendo que las medidas cautelares no son jurídicamente vinculantes. ${ }^{22}$ Incluso cuando el TEDH se niega a encontrar una violación del Convenio, a menudo señala que está abierto a volver a examinar la cuestión en el futuro. ${ }^{23}$

\section{2. ¿Puede el TEDH retrotraer los derechos?}

El TEDH no ha dudado en anular explícitamente casos anteriores para ampliar los derechos y las libertades, a menudo haciendo referencia explícita a la evolución legislativa, judicial y social en Europa. Pero ¿qué ocurre si estas tendencias se mueven en una dirección más restrictiva de los derechos?

Existen numerosas pruebas correlativas de que los altos tribunales nacionales responden a los cambios en la opinión pública y al "ambiente político". Los estudios sobre el Tribunal Supremo de Estados Unidos, por ejemplo, revelan que cuando la opinión pública y las políticas -incluidas las relacionadas con las libertades civiles y los derechos de los acusados de delitos- se vuelven más liberales (o conservadoras), las sentencias del Tribunal también tienden a ser más liberales (o conservadoras). ${ }^{24}$ Varios mecanismos pueden explicar esta correlación: (i) los políticos pueden nombrar a jueces más liberales (o más conserva-

20 TEDH, Micallef c/Malta, Appl. N 17056/06, sentencia de la Gran Sala de 15 de octubre de 2009, párrafos 75 y 81 (anulando numerosas sentencias del TEDH de finales de la década de 1990 y de la década de 2000).

21 TEDH, Kudla v. Polonia, App. №30210/96, sentencia de la Gran Sala de 26 de octubre de 2000, párrafos 147-149 (anulando sentencias de principios de la década de 1990 hasta el año 2000 en relación con el derecho a un recurso nacional efectivo).

22 TEDH, Mamatkulov y Askarov c/Turquía, App. № 46827/99 y 46951/99, sentencia de la Gran Sala de 4 de febrero de 2005 (que anula las sentencias del TEDH de principios de la década de 1990 y principios de la de 2000).

23 Véanse, por ejemplo, TEDH, S.H. y otros c/Austria, Appl. N 57813/00, sentencia de la Gran Sala de 3 de noviembre de 2011, párrafo 118 (en el que se afirma que las restricciones a la procreación médicamente asistida es un ámbito "en el que el derecho parece estar en continua evolución y que está sujeto a un desarrollo particularmente dinámico de la ciencia y el derecho [y que, por lo tanto,] debe mantenerse en revisión"); TEDH, Naït-Liman c/Suiza, Appl. N 51357/07, sentencia de la Gran Sala de 15 de marzo de 2018, párrafo 220 (en el que se subraya "el carácter dinámico" de la jurisdicción universal sobre las violaciones de los derechos humanos en los casos civiles, afirmando que "el Tribunal no excluye la posibilidad de que se produzcan evoluciones en el futuro" e invitando a los Estados "a tener en cuenta en sus ordenamientos jurídicos cualquier evolución [pertinente]").

24 Véanse, por ejemplo, Mishler y Sheehan (1993); Friedman (2009). 
dores) de acuerdo con las preferencias políticas del entorno; (ii) a los jueces les puede preocupar que el Tribunal pierda legitimidad si sus decisiones no están en sintonía con la opinión pública; o (iii) los acontecimientos que conforman el estado de ánimo de la opinión pública, como los atentados terroristas u otras amenazas, también pueden afectar los puntos de vista y las opciones interpretativas de los jueces. ${ }^{25}$

En lo que respecta a los tribunales internacionales, hay pruebas fehacientes de que el Tribunal de Justicia de la Unión Europea (TJUE) responde a las señales enviadas por los Estados miembros que expresan su preferencia por una mayor o menor integración europea (Carrubba et al., 2008; Larsson y Naurin, 2016). Del mismo modo, las observaciones de terceros Estados están fuertemente correlacionadas con la dirección y el contenido de las sentencias de los órganos de resolución de conflictos de la Organización Mundial del Comercio (Busch y Reinhardt, 2006). No hay estudios equivalentes sobre el TEDH en los que las observaciones de otros Estados miembros sean menos comunes (Bürli, 2017, p. 9). Sin embargo, hay pruebas de que los Gobiernos más euroescépticos tienden a designar candidatos que favorecen la autolimitación judicial en comparación con los candidatos de los Gobiernos menos euroescépticos (Voeten, 2007).

Aunque es bastante común que los tribunales respondan a su entorno político y social, no conocemos otro sistema jurídico en el que fuertes argumentos normativos limiten la dirección de la respuesta de un tribunal. El auge del terrorismo transnacional suscitó por primera vez un debate sobre si el TEDH puede o debe considerar las tendencias regresivas de la legislación y la política nacionales. Como ha señalado Jeffrey Brauch (2005):

\begin{abstract}
A medida que el mundo se hace más pequeño y la tecnología avanza, el terrorismo representa una amenaza mayor y más inminente. Las naciones están respondiendo con más fuerza y agresividad a esa amenaza. Al hacerlo, el "consenso" del futuro sobre lo que se necesita para luchar contra el terrorismo internacional puede abarcar medidas más estrictas y más violaciones de la intimidad de las personas, quizá las mismas medidas e infracciones que hoy consideramos violaciones de los derechos humanos. Pero bajo un estándar de consenso pueden no constituir violaciones en el futuro. (p. 146)
\end{abstract}

La ampliación de la Convención a Europa del Este en la década de 1990 suscitó preocupaciones similares. La diversidad de las tradiciones jurídicas, so-

25 Véase Epstein y Martin (2010). 
ciales y políticas de estos países llevó a estudiosos como Paolo Carozza (1998) a afirmar que

no solo deberíamos esperar en la práctica, sino estar de acuerdo en principio que la dilución del consenso ocasionada por la integración de un círculo cada vez más amplio de Estados miembros se traduzca en una disminución de las normas ya establecidas. (p. 1231)

Los defensores de una aplicación bidireccional de las doctrinas del instrumento vivo y del consenso europeo presentan una afirmación normativa más general: "No hay ninguna razón de peso para que la protección de los derechos humanos no disminuya si el consenso es el principal determinante de la existencia de un derecho" (Brauch, 2005, p. 146). ${ }^{26}$

Otros estudiosos disienten. Para Alec Stone Sweet, la lógica del "activismo mayoritario" funciona en una única dirección: "Una vez que se ha perdido la autonomía normativa nacional en un ámbito determinado, los Estados nunca la han recuperado. Hasta la fecha, ninguna sentencia del TEDH ha sido anulada" (Stone Sweet y Brunell, 2013, p. 81). Según George Letsas (2013), la interpretación evolutiva "denota un proceso de descubrimiento moral" que requiere "ignorar el consenso e impedir que las preferencias mayoritarias tengan efecto sobre los intereses fundamentales de los individuos" (p. 124). Las tendencias restrictivas de los derechos son irrelevantes para esta "lectura moral" del Convenio, lo que le impide al Tribunal realizar interpretaciones regresivas de los derechos (p. 132).

Los jueces del TEDH están igualmente divididos. El punto de vista del "trinquete unidireccional” fue defendido con más fuerza por el juez Casadevall en una opinión disidente en el caso Gorou c/Grecia:

Una vez que [el Tribunal] ha decidido ampliar los derechos de los individuos [...] no debe [...] revertir su decisión. Los derechos adquiridos en la causa de los derechos humanos son al menos tan valiosos como los derechos adquiridos en otras ramas del derecho y, por tanto, debe prevalecer el principio de no regresión. ${ }^{27}$

26 Véase también O’Mahony y Dzehtsiarou (2013), quienes afirman que "no hay nada en principio que impida que el TEDH se retracte de decisiones anteriores y restrinja el alcance aceptado de una determinada garantía" (p. 339).

27 TEDH, Gorou c/Grecia (N²), Appl. N 12686/03, sentencia de la Gran Sala de 20 de marzo de 2009. 
El expresidente del TEDH, el juez suizo Luzius Wildhaber, no está de acuerdo. Criticando la opinión del juez Casadevall, escribe:

La idea de que se deba aplicar un "trinquete" al proceso interpretativo [...] no tiene ni una base convencional ni de derecho consuetudinario ni una justificación razonada en la jurisprudencia del Tribunal o en la práctica y las reacciones de los Estados a esta jurisprudencia. Las sociedades democráticas pueden, y a veces deben, cambiar sus valores y leyes, especialmente cuando se enfrentan a un terrorismo generalizado y vicioso que pone en peligro la vida. (Wildhaber, 2016, p. 296)

El debate entre jueces y académicos no se ha reflejado (todavía) en la jurisprudencia del Tribunal. En particular, nuestro examen de todas las sentencias de la Gran Sala revela que el TEDH nunca ha revocado expresamente una sentencia anterior en un sentido restrictivo de los derechos. Tampoco conocemos ninguna sentencia mayoritaria que cite el instrumento vivo, el consenso europeo u otra doctrina jurídica para justificar la limitación de un derecho que el Tribunal había ampliado previamente. Lo que sí hemos observado son sentencias recientes en las que los jueces autores de las opiniones minoritarias afirman que la Gran Sala ha revocado tácitamente la jurisprudencia o la doctrina anteriores.

Un ejemplo adecuado es Animal Defenders International c/Reino Unido, un caso de 2013 relativo a una prohibición general de la publicidad política de pago. ${ }^{28}$ Aunque una Sala había estimado una impugnación de una prohibición suiza casi idéntica más de una década antes, ${ }^{29}$ la Gran Sala, por una votación de 9 a 8, concluyó que las restricciones del Reino Unido no violaban el derecho a la libertad de expresión. Los jueces disidentes rechazaron el intento de distinguir los dos casos, acusando a la mayoría de "anular, al menos en lo esencial", la sentencia anterior. ${ }^{30}$ También es ilustrativo el caso Khlaifia c/Italia, ${ }^{31}$ de 2016, que interpreta la prohibición de la expulsión colectiva de extranjeros. En un

28 TEDH, Animal Defenders International c/Reino Unido, Appl. № 48876/08, sentencia de la Gran Sala de 22 de abril de 2013.

29 TEDH, VgT Verein gegen Tierfabriken c/Suiza, Appl. № 24699/94, sentencia de 28 de junio de 2001.

30 TEDH, Animal Defenders International c/Reino Unido, párrafos 1 y 9 (Ziemele, Sajó, Kalaydjieva, Vučinić y De Gaetano JJ., en disidencia); véase también ídem en párrafo 12 (Tulkens con Spielmann y Laffranque JJ., en disidencia), caracterizando la sentencia de la mayoría como "incompatible con [...] la jurisprudencia anterior".

31 TEDH, Khlaifia y otros c/Italia, Appl. N 16483/12, sentencia de la Gran Sala de 15 de diciembre de 2016. 
caso anterior contra Italia, la Gran Sala interpretó la prohibición de forma expansiva, "impidiendo que los Estados puedan expulsar a un determinado número de extranjeros sin examinar sus circunstancias personales". ${ }^{32}$ Sin embargo, en la sentencia posterior, sostuvo que la prohibición "no garantiza el derecho a una entrevista individual en todas las circunstancias", ${ }^{33}$ una conclusión que un juez disidente reprochó como "un grave e injustificado retroceso en la protección de los derechos humanos en materia de expulsión". ${ }^{34}$

Estos votos particulares sugieren que el Tribunal, al menos a los ojos de algunos jueces, podría haber comenzado a retroceder en materia de derechos humanos en Europa. Antes de investigar la frecuencia de los votos particulares y si están aumentando, primero revisamos los estudios sobre si la jurisprudencia del TEDH ha cambiado en los últimos años, y luego discutimos el papel de los votos particulares en general y de los votos particulares en específico.

\subsection{Estudios existentes sobre los cambios en la jurisprudencia del TEDH}

Los académicos están empezando a investigar las decisiones del TEDH antes y después de los acontecimientos descritos en la introducción de este artículo, utilizando enfoques cuantitativos y cualitativos. Mikael Madsen (2018) compara todas las sentencias del TEDH entre 2009 y 2015 y encuentra "un aumento estadísticamente significativo del porcentaje de casos que hacen referencia al margen de apreciación o a la subsidiariedad durante todo el período" ( $\mathrm{p}$. 210). A partir de esto, concluye que el TEDH "proporciona más subsidiariedad en general tras la Declaración de Brighton” (p. 221). Janneke Gerards (2018) ofrece una comparación cualitativa del contexto en el que aparecen estas dos doctrinas en los casos resueltos en los períodos 2012-2013 y 2016-2017. Expresa, al contrario que Madsen, que el Tribunal invoca el margen de apreciación principalmente como un "dispositivo retórico vacío" que no "determina el rigor y los estándares de revisión” (Gerards, 2018, pp. 497, 506).

Başak Çali (2018) sostiene que el Tribunal está aplicando cada vez más un enfoque de geometría variable que otorga mayor deferencia a los Estados que aplican la jurisprudencia del TEDH de buena fe, mientras que desarrolla una "jurisprudencia de mala fe" para los Estados que hacen caso omiso de las nor-

32 TEDH, Hirsi Jamaa y otros c/Italia, Appl. N²7765/09, sentencia de la Gran Sala de 23 de febrero de 2012, párrafo 177.

33 TEDH, Khlaifia y otros c/Italia, párrafo 248.

34 Ibídem, párrafos 12 y 16 (Serghides J., parcialmente en disidencia). 
mas de derechos humanos establecidas (p. 242.). Oddný Arnardóttir (2018) identifica una tendencia diferente. Afirma que el Tribunal posterior a Brighton les está dando un mayor margen de apreciación a los tribunales y parlamentos nacionales que siguen determinados procedimientos de toma de decisiones ( $\mathrm{p}$. 223). Sin embargo, al igual que Çali, Arnardóttir (2018) concluye que el actual Tribunal ha redefinido su relación con las autoridades nacionales otorgando más deferencia "en virtud del principio de proporcionalidad a aquellas autoridades nacionales que muestran la debida diligencia de la Convención aplicando la jurisprudencia y las metodologías analíticas del Tribunal en su país” (p. 223). En consonancia con estas afirmaciones, Øyvind Stiansen y Erik Voeten (2020), luego de analizar todas las sentencias del TEDH hasta mediados de 2016, observan que el Tribunal ha encontrado recientemente menos violaciones por parte de las democracias establecidas, mientras que las tasas de violación contra las no democracias y las nuevas democracias se han mantenido estables.

Los estudios anteriores sugieren que los resultados de los casos han cambiado en los últimos años. Sin embargo, esto no nos indica si el TEDH está de hecho haciendo retroceder los derechos humanos. Incluso si, en promedio, los índices de violación han disminuido con el tiempo, esa tendencia podría reflejar simplemente la maduración del Tribunal. Tal vez los tipos de casos de los que se ocupa ahora la Gran Sala sean más complejos o los demandantes estén presionando al TEDH para que sea aún más progresista, lo que conduce a una menor tasa de conclusiones sobre violaciones. Un Tribunal que es menos propenso a respaldar las peticiones de interpretaciones más amplias de los derechos humanos no es lo mismo que un Tribunal que esté reduciendo las interpretaciones anteriores.

\subsection{El papel de los votos particulares}

Las normas que rigen los votos particulares varían mucho entre los tribunales superiores internacionales y nacionales: desde una prohibición total en un extremo hasta tribunales cuyas sentencias incluyen regularmente múltiples votos particulares en el otro (Dunoff y Pollack, 2017; Kelemen, 2018). Las diferencias en el diseño institucional, la cultura judicial y los antecedentes profesionales de los jueces también influyen en la frecuencia de las opiniones minoritarias en los tribunales, que les permiten a los jueces publicar sus opiniones individuales (Bentsen, 2018). La investigación sobre los votos particulares en los tribunales nacionales es mucho más extensa que los estudios similares sobre los tribunales 
internacionales, pero los estudiosos han identificado un conjunto común de ventajas y desventajas asociadas a esta práctica.

Los beneficios de los votos particulares incluyen la mejora de la calidad del razonamiento de un tribunal, la mejora de la independencia judicial, la transparencia y la responsabilidad, la demostración de la deliberación judicial -incluyendo la revelación a las partes de que sus argumentos han sido cuidadosamente considerados- y el suministro de información a otros jueces, futuros litigantes, grupos de cumplimiento y el público sobre los errores del enfoque de la mayoría, las trayectorias futuras alternativas de la ley o la necesidad de legislación o revisiones de tratados (Vitale, 2014). Las desventajas de las opiniones minoritarias incluyen: reducir la seguridad jurídica y la previsibilidad, erosionar la cooperación profesional, dañar la autoridad y la legitimidad de un tribunal al "socavar la credibilidad del argumento de que la decisión alcanzada se basa únicamente en principios jurídicos sólidos" y (especialmente para los tribunales internacionales) aumentar el riesgo de incumplimiento (Naurin y Stiansen, 2020, p. 964). ${ }^{35}$

El TEDH les ha permitido a los jueces presentar votos particulares desde su creación. Las opiniones concurrentes y disidentes son habituales y se han mantenido relativamente estables a lo largo del tiempo. ${ }^{36}$ Entre 1960 y 1997 -justo antes de la entrada en vigor del Protocolo No 11 - el 42\% de las sentencias de las Salas y el 78\% de las sentencias de la Gran Sala incluían uno o más votos particulares (Wildhaber, 1999, pp. 530-531). Los datos que recogimos para los veinte años siguientes muestran solo un modesto aumento de las sentencias de la Gran Sala con opiniones minoritarias (83\%). Un estudio de 2009 proporciona información adicional para evaluar la división jurisprudencial entre los jueces del TEDH:

Aproximadamente el 25\% de las sentencias de Estrasburgo sobre el fondo son unánimes, el 15\% contiene al menos una opinión disidente y el $60 \%$ contiene al menos una opinión concurrente separada. Esto significa que 85 casos de cada 100 son unánimes en cuanto al resultado, incluso si el razonamiento para ese resultado no es el mismo en la mente de todos los jueces. (White y Boussiakou, 2009, p. 53)

35 Véase también Vitale (2014, p. 92), en el que se analiza la relación entre las opiniones en disidencia y el incumplimiento.

36 Véase, por ejemplo, White y Boussiakou (2009, p. 50), en el que se constata que las sentencias no unánimes oscilaron entre el $69,5 \%$ y el $84,5 \%$ entre 1999 y 2004 , inclusive. 
Estas tasas relativamente altas de concurrencias y disidencias en el TEDH no son sorprendentes. Los estudios sobre los tribunales constitucionales y superiores nacionales revelan que los votos particulares son más frecuentes en los tribunales que conocen de casos complejos y políticamente relevantes y en los tribunales cuyos expedientes se centran en los derechos y las libertades individuales. ${ }^{37}$ Otros estudios constatan que "la probabilidad de desacuerdo crece con el tamaño del panel” (Epstein et al., 2013, p. 267). La Gran Sala de 17 miembros combina estas tres características.

La mayoría de los análisis sobre los votos particulares del TEDH se centran en las pautas de votación de los jueces, como por ejemplo si los jueces nacionales disienten más a menudo que sus colegas cuando el Tribunal falla en contra del Estado que los propuso o nombró. ${ }^{38}$ Algunos estudios investigan las correlaciones entre los índices de los votos particulares y la trayectoria profesional de un juez con algunas pruebas que sugieren que los antiguos académicos escriben votos particulares en mayor proporción que los jueces que anteriormente sirvieron en los tribunales nacionales, y que los antiguos diplomáticos tienden a ser más propensos a disentir a favor del Gobierno demandado. ${ }^{39}$

Fuera de estos temas, los estudiosos han prestado poca atención al papel de los votos particulares en el TEDH.

La aplicación del instrumento vivo y de las doctrinas del consenso europeo a menudo genera divisiones entre los jueces del TEDH sobre el alcance y la rapidez de la evolución del Convenio, incluida la posibilidad de anular la jurisprudencia anterior en una dirección progresiva. Sin embargo, los miembros del Tribunal coinciden en que los derechos humanos pueden ampliarse -y de hecho lo hacen- con el paso del tiempo; el desacuerdo estriba en reconocer o no dicha ampliación en un caso concreto. Por el contrario, los disidentes por regresión acusan a la Gran Sala de anular la jurisprudencia en una dirección restrictiva de los derechos, un movimiento jurisprudencial que el TEDH nunca ha respaldado y que sigue siendo muy discutido. Los disidentes por regresión también acusan a la mayoría -a veces, como mostraremos más adelante, con un lenguaje enérgico e incluso apasionado- de disminuir los derechos mediante el sigilo o el subterfugio.

Por lo tanto, esperamos que los jueces no escriban o se sumen a la ligera

37 Véanse, por ejemplo, Bentsen (2018, p. 194); White y Boussiakou (2009, pp. 50-51).

38 Véanse, por ejemplo, Kuijer (1997); Voeten (2008).

39 Véanse Bruinsma (2008, pp. 36-37); White y Boussiakou (2009, p. 571). 
tales disidencias porque, al hacerlo, se corre el riesgo de socavar la cooperación profesional del TEDH y de disminuir su autoridad y legitimidad. Reconocemos, sin embargo, que la frecuencia y el contenido de los votos particulares, así como las inferencias que pueden extraerse de ellos, dependen en parte de la cultura de disidencia de un tribunal, que puede cambiar con el tiempo. ${ }^{40} \mathrm{El}$ siguiente apartado examina los cambios en el entorno político e institucional del Tribunal que pueden afectar la incidencia de las opiniones minoritarias de la Gran Sala.

\section{Expectativas y datos}

\subsection{Expectativas}

Tenemos conjeturas teóricas e históricas sobre cuándo y por qué los jueces del TEDH anuncian sus disidencias. Dividimos las sentencias de la Gran Sala en tres períodos -de 1999 a 2005, de 2006 a 2011 y de 2012 a 2018- que se corresponden con la forma en la que los Estados miembros, tanto individual como colectivamente, han respondido a las sentencias controvertidas y con la trayectoria más amplia de la jurisprudencia del TEDH. ${ }^{41}$

\subsubsection{Primer período: de 1999 a 2005}

El primer período comienza tras la entrada en vigor del Protocolo № 11 a fines de 1998, el cual transformó el TEDH en un órgano judicial supranacional permanente y a tiempo completo que incluía una Gran Sala para resolver los casos más importantes.

El Protocolo entró en funcionamiento luego de una década trascendental para el sistema regional de derechos humanos. Tras el final de la Guerra Fría, el número de Estados miembros aumentó a medida que los países de Europa Central y Oriental se adhirieron al Convenio, el expediente del TEDH comenzó a engrosarse con nuevos casos y un número creciente de países incorporó el Convenio en su legislación nacional. En respuesta a un "zeitgeist geopolítico gene-

40 Véase, por ejemplo, Greenhouse (2001): "Aunque la cultura de la disidencia que ahora prevalece no es una invención de la Corte de Rehnquist, es un desarrollo sorprendentemente reciente que ilumina no solamente el enfoque de este tribunal hacia su trabajo, sino también la relación cambiante de la Corte Suprema moderna con el país y con el concepto de derecho en sí mismo”.

41 Otros académicos han identificado estos períodos como marcas de diferentes épocas en la evolución del TEDH. Véanse Çali (2018, pp. 247-250); Christoffersen y Madsen (2013, pp. 237-240); Madsen (2016, pp. 167-175). 
ral [que] favorecía los derechos humanos y el neoconstitucionalismo” (Madsen, 2016, p. 166), la Gran Sala calificó audazmente a la Convención como un "instrumento constitucional de orden público europeo” y adoptó una visión amplia de su autoridad como tribunal constitucional regional (Helfer, 2008, p. 138). ${ }^{42}$

El TEDH continuó en esta línea hasta mediados de la década de 2000. El número de sentencias emitidas por las Salas y la Gran Sala aumentó considerablemente, pasando de 177 en 1999 a 1105 en 2005 (Madsen, 2016, p. 160, fig. 3). Muchos casos abordaron controversias de derechos humanos de gran repercusión, como la prohibición de los homosexuales en el ejército, las restricciones a la libertad de expresión y los fallos en los procedimientos penales, civiles y de inmigración nacionales. Esperamos que durante este período sean relativamente pocas las acusaciones de que la mayoría estaba revirtiendo tácitamente su jurisprudencia en una dirección más favorable al Gobierno.

\subsubsection{Segundo período: de 2006 a 2011}

El panorama político e institucional del TEDH comenzó a cambiar a mediados de la década de 2000. Los sucesos ocurridos en el Reino Unido y en Rusia fueron la causa de un creciente descontento con el Tribunal. En el Reino Unido, el Gobierno respondió a un importante atentado terrorista en 2005 adoptando una política de deportación de extranjeros que suponían un riesgo para la seguridad nacional. La jurisprudencia del TEDH obstaculizó este esfuerzo, bloqueando las expulsiones a países en los que las personas se enfrentaban a un riesgo previsible de tortura, maltratos o juicios injustos. ${ }^{43}$ Ese mismo año, el Tribunal dictó la controvertida sentencia Hirst № 2, en la que se declaraba improcedente la prohibición del voto de los presos. ${ }^{44}$ La decisión desencadenó una fuerte reacción por parte de las tres ramas del Gobierno del Reino Unido, que arremetió públicamente contra el TEDH por "ampliar indebidamente el alcance de la interpretación de los derechos del Convenio a expensas de las bien cualificadas autoridades nacionales" (Çali, 2018, p. 249).

Al mismo tiempo, el Tribunal dictó varias sentencias de gran repercusión contra Rusia, incluyendo casos de ejecuciones extrajudiciales en Chechenia, la

42 Citando Loizidou c/Turkey, 310 Eur. Ct. H.R. (ser. A) (1995), en 27.

43 TEDH, Othman (Abu Qatada) c/Reino Unido, Appl. N 8139/09, sentencia de 17 de enero de 2012. Véase también Gearty (2005, p. 29).

44 TEDH, Hirst c/Reino Unido (N²), Appl. N 74025/01, sentencia de la Gran Sala de 6 de octubre de 2005. 
extradición de rebeldes chechenos y los disturbios en la región separatista de Moldavia respaldada por Rusia (Helfer, 2008, p. 157; Madsen, 2016, p. 167). "Casi inmediatamente después, surgieron problemas con el acatamiento ruso y el descontento político” (Madsen, 2016, pp. 167-168). El Gobierno respondió bloqueando la entrada en vigor del Protocolo No 14, que pretendía reducir la acumulación de casos pendientes. Rusia mantuvo al Protocolo como rehén hasta 2010, privando al Tribunal de valiosas herramientas para hacer frente a su crisis de expedientes.

En respuesta a esta evolución, se espera que el TEDH se muestre más prudente a la hora de interpretar los derechos y libertades protegidos entre 2006 y 2011. En comparación con el período anterior, esta tendencia debería reflejarse en un aumento de las sentencias de la Gran Sala acompañadas de votos particulares en los que se afirme que la mayoría anuló implícitamente los precedentes o aplicó erróneamente la doctrina para favorecer a los Gobiernos nacionales.

\subsubsection{Tercer período: 2012 a 2018}

El Consejo de Europa ha adoptado numerosas reformas del sistema regional de derechos humanos desde su fundación en 1950. Todas ellas ampliaron los derechos y libertades protegidos o introdujeron cambios procesales o técnicos para incrementar la competencia del TEDH y su capacidad de revisión de las denuncias. Esta pauta ininterrumpida terminó en 2012 con la Conferencia de Alto Nivel sobre el futuro de la convención, organizada por el Reino Unido en Brighton. Un proyecto de declaración que se filtró ofrecía un plan para debilitar los poderes de revisión del Tribunal (Helfer, 2012). La declaración final fue más mesurada, pero siguió siendo crítica con la trayectoria del TEDH. Los Estados miembros no solo criticaron la calidad de los jueces y las sentencias del Tribunal, sino que también acordaron añadir un párrafo al preámbulo del Convenio en el que se hiciera hincapié en la subsidiariedad y en la doctrina del margen de apreciación (Çali, 2018, p. 250). Los académicos han identificado la Declaración de Brighton como el inicio de una nueva fase en la evolución del TEDH, marcada por "una difusión del discurso crítico en toda Europa" que incluye a los poderes políticos del Gobierno, además de los jueces nacionales. En particular, las críticas proceden de las democracias establecidas, que antes se consideraban los principales defensores del Tribunal (Madsen, 2016, p. 174). ${ }^{45}$

45 Véase también Christoffersen y Madsen (2013, p. 238). 
El tercer período también marcó un cambio en el apoyo institucional disponible para que los jueces redactaran las opiniones minoritarias. Anteriormente, los jueces del TEDH apenas contaban con la ayuda de los abogados de la Secretaría para redactar las opiniones separadas. Sin embargo, en 2012, la Facultad de Derecho de Yale (y posteriormente otras facultades de Derecho universitarias) comenzó a enviar a recién graduados para que se desempeñaran como asistentes de varios miembros individuales del Tribunal. ${ }^{46}$ Estos jóvenes abogados mejoraron la capacidad de esos jueces para redactar opiniones separadas.

En consonancia con esta evolución, observamos, a partir de 2012 y en comparación con los dos períodos anteriores, un aumento del número y del porcentaje de sentencias de la Gran Sala acompañadas de una o más opiniones disidentes que critican a la mayoría por anular tácitamente los precedentes progresistas o por apartarse de las doctrinas que favorecen los derechos individuales.

\subsection{Datos}

Examinamos las 397 sentencias de la Gran Sala no interestatales y no duplicadas entre la creación del nuevo Tribunal en 1998 y finales de 2018. ${ }^{47}$ Nos centramos en la Gran Sala por razones tanto prácticas como de fondo. No es posible codificar sistemáticamente las más de 10000 sentencias dictadas por las Salas del TEDH. Además, la función de la Gran Sala es conocer los casos más importantes y conciliar las incoherencias de las sentencias anteriores. Las sentencias de la Gran Sala son también declaraciones autorizadas del derecho jurisprudencial de Estrasburgo y son citadas con frecuencia por las salas (Lupu y Voeten, 2012).

De las 397 sentencias de la Gran Sala, 331 tenían al menos una (aunque a menudo varias) opiniones concurrentes, disidentes y/o separadas. Estas sentencias dieron lugar a un total de 791 opiniones judiciales: 509 disidentes, 263 concurrentes y 19 separadas. Recogimos el texto de estas opiniones y las identidades de los jueces que las redactaron o firmaron en el sitio web del HUDOC.

46 Centro Schell para los Derechos Humanos Internacionales, Robina Foundation Human Rights Fellows, disponible en: https://bit.ly/3i5XGUo (listado de los recién graduados de la Facultad de Derecho de la Universidad de Yale que han sido secretarios del TEDH a partir de 2012).

47 Eliminamos dos casos interestatales (entre Turquía y Chipre) que no encajan en nuestro marco conceptual. También eliminamos quince sentencias contra Italia, Turquía y el Reino Unido que eran duplicadas y tenían opiniones separadas idénticas (aparte del nombre del demandante). En años posteriores, la Secretaría agrupó estos casos duplicados como una única sentencia. La agrupación de estas opiniones en una única sentencia garantiza la coherencia a lo largo del tiempo. 
Les pedimos a dos asistentes de investigación (AI) que respondieran tres preguntas. ${ }^{48}$ En primer lugar: ¿la opinión separada era más favorable al demandante o al Gobierno demandado en comparación con la opinión mayoritaria? Por ejemplo, les dimos instrucciones a los AI para que codificaran la opinión como más favorable al demandante si la mayoría no encontraba una violación o no declaraba la solicitud admisible, pero un disidente argumentaba que la mayoría debería haber encontrado una violación o que la solicitud debería haber sido declarada admisible. Les hemos solicitado que codifiquen del mismo modo las opiniones concurrentes o separadas que coincidan con el Tribunal en el resultado de un caso, pero que, no obstante, consideren la demanda más favorable al demandante que la mayoría.

En segundo lugar, les preguntamos a los AI si la opinión separada afirma que la mayoría anula la jurisprudencia anterior de una de estas tres maneras: (i) anulando explícitamente sentencias anteriores (ya sea en una dirección progresista o conservadora); (ii) anulando implícita o tácitamente la jurisprudencia anterior; o (iii) interpretando la jurisprudencia anterior de forma demasiado estricta o demasiado amplia, ignorando la jurisprudencia anterior o no aplicándola. ${ }^{49}$

En tercer lugar, les solicitamos a los AI que codificaran si una opinión separada: (i) discrepa de la mayoría sobre la aplicación de una o más doctrinas legales clave y, además, (ii) afirma que la doctrina se había aplicado de forma más amplia o restringida en la jurisprudencia anterior. Estas doctrinas jurídicas clave incluían el margen de apreciación, la doctrina del "instrumento vivo", el análisis del "consenso europeo", la doctrina de la "eficacia" y el principio "in dubio pro persona" o "pro homine".

La Tabla 1 resume nuestra codificación. Identificamos 249 votos particulares en los que se alegaba que la mayoría había actuado de forma inconsistente

48 En un principio, se les pidió a dos AI que codificaran una muestra aleatoria de 33 juicios que contenían 88 opiniones distintas, que se evaluaron y utilizaron para ajustar el libro de códigos y para instruir a los AI. Uno de los evaluadores codificó todas las opiniones, mientras que el otro codificó una submuestra aleatoria de dos tercios de las opiniones.

49 La fiabilidad entre codificadores sobre si la opinión favorecía al Gobierno o al demandante fue excelente: asignaron la misma puntuación en el 97\% de las opiniones. También coincidieron en el $90 \%$ de las ocasiones en las que la opinión argumentaba que se basaba en una jurisprudencia anterior erróneamente decidida o aplicaba erróneamente la doctrina legal anterior. Encontramos más incongruencias en cuanto a si una opinión distinta acusaba a la mayoría de haberse basado en jurisprudencia pasada ( $77 \%$ de coincidencia). Casi todas las incongruencias procedían de nuestra tercera categoría: casos en los que la mayoría interpreta la jurisprudencia anterior de forma demasiado estricta o demasiado amplia, la ignora o no la aplica. Para todas las categorías, comprobamos y recodificamos todos los casos en los que los codificadores no estaban de acuerdo. 
con el precedente. Solo 8 de ellas acusaban a la mayoría de anular explícitamente la jurisprudencia anterior, pero 46 alegaban que el Tribunal lo había hecho implícitamente. Con mucha más frecuencia (195 opiniones), la minoría afirmaba que la mayoría había interpretado erróneamente la jurisprudencia de una manera que favorecía indebidamente al Gobierno o al demandante.

Tabla 1. Codificación de las opiniones separadas que alegan que la mayoría anuló un precedente según si la opinión favoreció al Gobierno o al demandante

\begin{tabular}{l|c|c|c|c}
\hline & \multicolumn{4}{|c}{ Opinión separada: iprogobierno o prodemandante? } \\
\hline & Prodemandante & Progobierno & No claro & Total \\
\hline Sin anulación & 224 & 182 & 94 & 500 \\
Anulación explíita & 3 & 5 & 0 & 8 \\
$\begin{array}{l}\text { Anulación implíita } \\
\begin{array}{l}\text { Anulación por interpre- } \\
\text { tación de la jurispruden- }\end{array}\end{array}$ & 22 & 24 & 0 & 46 \\
$\begin{array}{l}\text { cia anterior } \\
\text { Interpretación errónea }\end{array}$ & 110 & 84 & 1 & 195 \\
$\begin{array}{l}\text { de la jurisprudencia* } \\
\text { Jurisprudencia anterior } \\
\text { errónea }\end{array}$ & 8 & 9 & 0 & 17 \\
\hline Total & $\mathbf{3 8 1}$ & $\mathbf{3 1 3}$ & $\mathbf{9 7}$ & $\mathbf{7 9 1}$ \\
\hline
\end{tabular}

* Las opiniones separadas pueden encajar en varias categorías; para evitar el doble recuento, informamos solo de la categoría que más claramente indica la anulación.

Además, identificamos 57 opiniones en las que se afirmaba que la mayoría había aplicado principios interpretativos clave -como el instrumento vivo y el margen de apreciación- de forma incoherente con aplicaciones anteriores. ${ }^{50}$ Sin embargo, solo 17 de estas 57 opiniones minoritarias no iban acompañadas de una afirmación de que la mayoría del Tribunal había anulado o malinterpretado implícitamente la jurisprudencia anterior. Para evitar la doble contabilización, la Tabla 1 recoge los casos en los que la minoría solo afirmó una interpretación errónea de la doctrina. Por último, 25 de las 791 opiniones

50 Nuestras reglas para codificar la aplicación errónea de la doctrina exigían que una opinión separada argumentara explícitamente que el Tribunal se desviaba de las aplicaciones anteriores de una doctrina, en lugar de limitarse a afirmar, por ejemplo, que el margen de apreciación se aplicaba de forma demasiado amplia o demasiado restringida en el caso al que se adjuntaba la opinión minoritaria. 
afirmaban que la propia jurisprudencia anterior estaba mal resuelta. Dado que estas opiniones no indican, como tales, que el Tribunal esté retrocediendo en materia de derechos, no las incluimos como "disidencias por regresión".

En total, 381 votos particulares eran más favorables al demandante, 313 lo eran al Gobierno y en 97 casos no estaba claro a qué parte favorecía el voto particular. Mientras que el $23 \%$ de las opiniones concurrentes no podían calificarse como favorables a ninguna de las partes, esto solo ocurría con el 6\% de las opiniones disidentes. ${ }^{51}$ Además, pudimos codificar todas las alegaciones de anulación, excepto tres, en función de si el voto particular favorecía al Gobierno o al demandante.

\section{Análisis y resultados}

Como se explica en la introducción, llamamos "disidencias por regresión" a aquellas opiniones minoritarias que afirman que la Gran Sala ha revocado o interpretado erróneamente la jurisprudencia anterior de forma favorable al Gobierno. Los datos también contienen "disidencias de avance", que afirman que el Tribunal ha revocado o interpretado erróneamente la jurisprudencia anterior de forma favorable al demandante. Como se ha señalado anteriormente, el TEDH revoca regularmente sus sentencias anteriores para ampliar los derechos. Por el contrario, las disidencias por regresión afirman que el Tribunal está llevando a cabo una práctica que nunca ha respaldado y que no reconoce formalmente: revocar tácitamente o malinterpretar las interpretaciones para limitar los derechos y libertades protegidos.

Este apartado examina en primer lugar las tendencias generales de las conclusiones sobre violaciones y de las disidencias por regresión. A continuación, analizamos tendencias más matizadas en los datos, incluyendo los jueces autores de estos votos particulares y el tipo de argumentos que plantean, así como los países y las cuestiones jurídicas más frecuentes en los tres períodos de tiempo.

51 Esta categoría incluye los casos en los que el Tribunal debe equilibrar dos derechos en conflicto. Cuando el TEDH "debe pronunciarse sobre un conflicto entre dos derechos que gozan de igual protección en virtud del CEDH, el Tribunal debe ponderar los intereses en conflicto”. Véase Kaboğlu y Orán c/Turquía, App. No 1759/08, 50766/10 y 50782/10, sentencia de 30 de octubre de 2018, párrafo 69. Un ejemplo común se refiere a las personas cuyas actividades se informan en los medios de comunicación, lo que plantea la cuestión de si se ha logrado un equilibrio justo entre el derecho a la privacidad del individuo y el derecho a la libertad de expresión del periódico. El resultado de este tipo de casos puede "variar en función de si fue presentado en virtud del artículo 8 por la persona que fue objeto del artículo de prensa impugnado o en virtud del artículo 10 por el autor del mismo artículo" (ídem.). 


\subsection{Tendencias generales}

Los estudios empíricos existentes se han centrado principalmente en los resultados de las sentencias del TEDH, es decir, si el Tribunal falla a favor del demandante (declarando a su favor al menos una alegación) o del demandado (declarando que no hay violación de los derechos humanos). La Figura 1 documenta un aumento en el número absoluto y relativo de sentencias de la Gran Sala que no declaran ninguna violación del Convenio. ${ }^{52}$ Entre 1999 y 2005, el Gobierno se impuso en el 29\% de las sentencias de la Gran Sala. Esta cifra aumentó al 33\% entre 2006 y 2011 y al 41\% en el período posterior a Brighton (el descenso en el número de casos en 2006-2011 refleja un menor número de sentencias de la Gran Sala en ese período). ${ }^{53}$

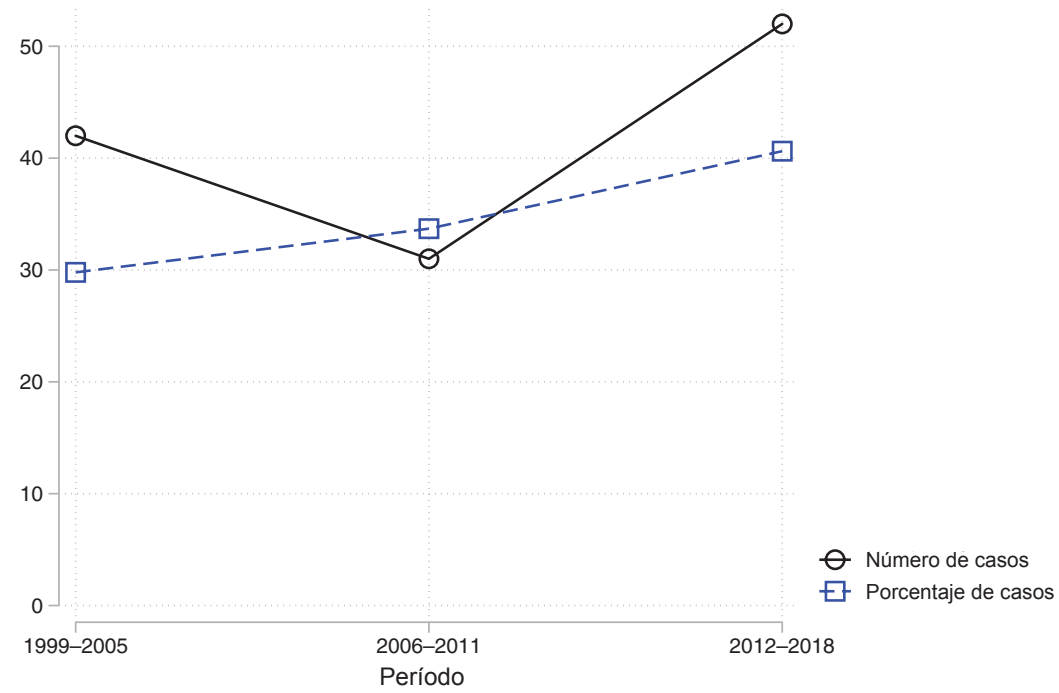

Figura 1. Sentencias de la Gran Sala con conclusiones no violatorias.

52 Un caso declaró la admisibilidad de una solicitud sin llegar a una sentencia sobre el fondo. Lo incluimos con las sentencias favorables a los demandantes. Excluimos 36 sentencias que solo se referían a daños pecuniarios o que anulaban casos porque las partes llegaban a una resolución amistosa. Solo 11 casos se centraron únicamente en cuestiones de admisibilidad (una cuestión que suele tratarse en las decisiones de la Sala). La tendencia básica es sólida al incluir o excluir las decisiones de admisibilidad.

53 Existen patrones similares en las sentencias de las Salas, en las que es menos probable que el Gobierno prevalezca porque muchos casos implican violaciones repetidas. El porcentaje de sentencias por violación disminuyó del 89\% en el período 2006-2011 al 80\% en el período posterior a Brighton. 
La Figura 1 refuerza las conclusiones de estudios anteriores de que el TEDH se ha vuelto más proclive a fallar a favor de los Gobiernos. Sin embargo, esto no indica necesariamente si el Tribunal está retrocediendo en materia de derechos. Los datos de esta figura también son consistentes con un Tribunal que es menos propenso a superar los límites de sus decisiones anteriores, pero que en realidad no da marcha atrás en los precedentes establecidos. El patrón de la figura también podría reflejar la maduración del TEDH. Por ejemplo, es posible que la Gran Sala haya desarrollado previamente jurisprudencia sobre las violaciones más atroces, dejando los casos menos graves que tienen más probabilidades de resultar en sentencias a favor del Gobierno. Por otra parte, los datos podrían subestimar la tendencia favorable al Gobierno. La constatación de una violación no implica necesariamente una victoria para el demandante. Por ejemplo, el Tribunal puede declarar una infracción en una cuestión menor, pero fallar a favor del Estado en las reclamaciones más importantes, o puede fallar a favor del demandante, pero conceder una reparación inadecuada.

La Figura 2 proporciona pruebas directas agregadas de que las disidencias por regresión están aumentando. Además, muestra el porcentaje y el número de sentencias de la Gran Sala con cualquier tipo de voto particular en el que se afirma que la mayoría revocó la jurisprudencia anterior de forma favorable al Gobierno. También muestra claramente que estos votos particulares están aumentando tanto en términos relativos como absolutos. Antes de 2006, el $24 \%$ de las sentencias de la Gran Sala iban acompañadas de un voto particular. Esta cifra aumentó al 30\% entre 2006 y 2011 y al 40\% en el período posterior a $2011 .{ }^{54}$

54 Estos aumentos son estadísticamente significativos al nivel del 95\% según una prueba t. 


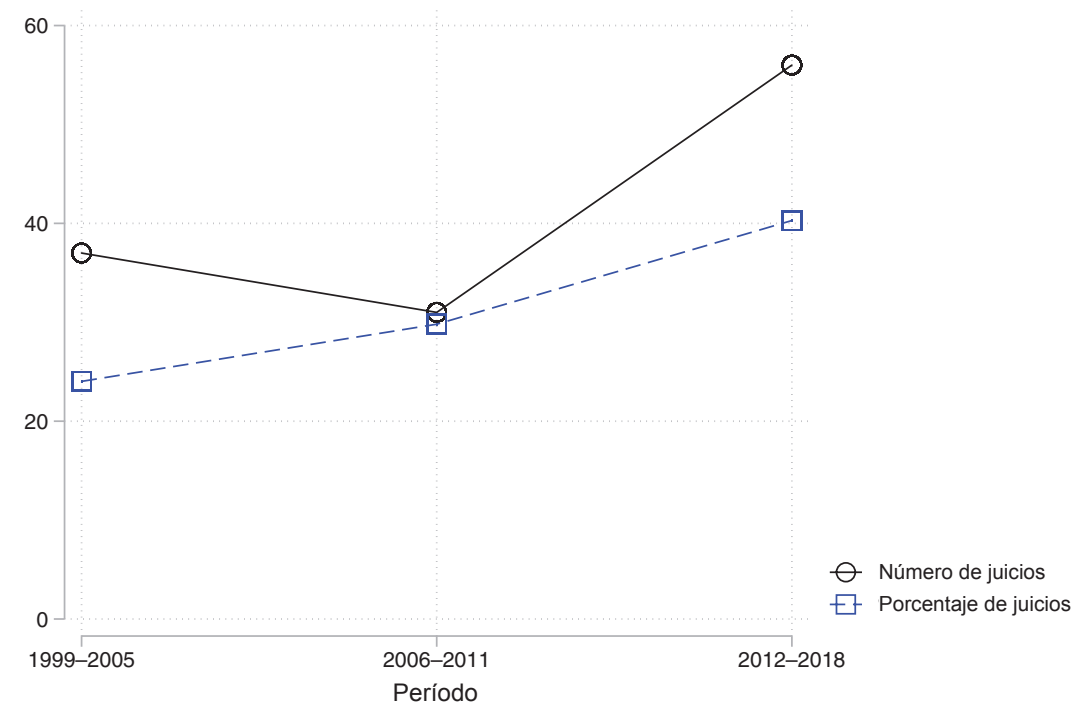

Figura 2. Sentencias con votos particulares que afirman que la Gran Sala revocó la jurisprudencia anterior a favor del Gobierno.

Estos aumentos son consecuentes. Si los jueces hubieran redactado disidencias en la era pos-Brighton al mismo ritmo que antes de 2005, entonces solo 33 (en lugar de 56) sentencias de la Gran Sala habrían ido acompañadas de tal disidencia. Como es lógico, algunos jueces siempre se han quejado de que la Gran Sala es más restringida de lo que la jurisprudencia anterior sugiere que debería ser, sin embargo, tales preocupaciones son mucho más frecuentes en la era posterior a Brighton.

Las pruebas más detalladas de la era posterior a Brighton ayudan a contextualizar esta tendencia. Las 56 opiniones disidentes durante ese período no fueron producto de jueces "lobos solitarios". Solo 19 fueron escritas por un solo juez y 13 fueron firmadas por cinco o más jueces. Por término medio, entre tres y cuatro jueces se sumaron a estas opiniones minoritarias. ${ }^{55}$ Un grupo concreto de jueces es responsable de muchas disidencias por regresión: Tulkens, Rozakis, Sajó, Spielmann y Pinto de Albuquerque escribieron o se unieron a por lo menos 15 de estos votos particulares. Sin embargo, el patrón mostrado en la Figura 1 se mantiene incluso si excluimos los votos particulares que fueron escritos únicamente por estos disidentes seriales.

55 La media es de 3,5 en los períodos posteriores a 2012, de 3,3 en el período 1999-2005 y de 3,1 en el período 2006-2011. 
Resulta interesante que los jueces a veces escriban disidencias por regresión incluso cuando la mayoría falla a favor del demandante. En la era posterior a Brighton, el 36\% de las sentencias de la Gran Sala que declaran al menos una violación del Convenio van acompañadas de este tipo de disidencia (en comparación con el $18 \%$ en los dos períodos anteriores). Normalmente, en estos casos la opinión minoritaria argumenta que el Tribunal debería haber encontrado una violación adicional o debería haber concedido recursos más amplios, como una compensación económica o la reapertura de los procedimientos judiciales. Esta conclusión sugiere que la Figura 1 subestima la reciente tendencia regresiva de la jurisprudencia: hay casos en los que el TEDH constata una violación, pero, sin embargo, es más restrictivo que en el pasado, al menos según la opinión de algunos jueces.

Para obtener un cuadro más completo de la evolución del Tribunal, también examinamos las "disidencias por regresión", es decir, los votos particulares en los que se acusa a la mayoría de revocar la jurisprudencia anterior de forma favorable al demandante. Estas opiniones se adjuntan casi exclusivamente a las sentencias que declaran una o más violaciones del Convenio. Entre 1999 y 2005, el 32\% de las conclusiones sobre violaciones iban acompañadas de un voto particular de este tipo. Esto aumentó al 38\% en el período 2006-2011 y al 53\% en el período 2012-2018. Además, hay indicios de que los votos particulares son cada vez más frecuentes en el conjunto del Tribunal. En la Gran Sala, el $78 \%$, el $73 \%$ y el $90 \%$ de las sentencias en cada uno de los tres períodos, respectivamente, iban acompañadas de al menos un voto particular. Las cifras correspondientes son 37\%, 27\% y $47 \%$ para las sentencias de las Salas más importantes, ${ }^{56}$ y $11 \%$, 9\% y $22 \%$ para todas las sentencias de las Salas en cada período.

El aumento de las disidencias por regresión y de la incidencia de todos los votos particulares es coherente con una conjetura alternativa: que, con el paso del tiempo, el TEDH se está polarizando más ideológicamente con jueces prodemandantes y pro- Gobierno que defienden posiciones opuestas en las opiniones minoritarias. Sin embargo, un análisis más detallado sugiere que hay que ser cautos a la hora de llegar a esta conclusión. En el casi $40 \%$ de los casos de la Gran Sala (41 de 105 sentencias), solamente el juez nacional del Estado

56 El TEDH divide las decisiones en cuatro categorías, siendo el nivel más alto de importancia el de los Informes de Casos o Casos Clave -decisiones seleccionadas para su publicación en el diario oficial del Tribunal-, seguido de los niveles 1, 2 y 3. Véase Tribunal Europeo de Derechos Humanos (s.f.). Los porcentajes citados en el texto corresponden a los informes de casos y a las decisiones de nivel 1. 
demandado firmó el voto particular en el que se acusaba a la mayoría de anular la jurisprudencia a favor del demandante. ${ }^{57} \mathrm{Al}$ igual que todos los jueces del TEDH, los jueces nacionales son independientes y no representan a sus respectivos Gobiernos. Sin embargo, como se ha señalado anteriormente, los estudios han revelado que los jueces nacionales disienten con mucha más frecuencia en los casos en los que se constata una violación del Convenio que los jueces no nacionales. Por lo tanto, es plausible que un voto particular firmado solamente por un juez nacional se considere una prueba débil de que el Tribunal se ha apartado de su jurisprudencia anterior.

Si excluimos los votos particulares "del juez nacional solamente", las disidencias por regresión se presentaron en el 14\%, 16\% y 24\% de todas las sentencias en los tres períodos, respectivamente, y en el 20\%, 27\% y $42 \%$ de las sentencias de violación. Por lo tanto, en aquellas sentencias en las que la Gran Sala considera que existe una violación, hay una tendencia creciente de votos particulares en los que se acusa al Tribunal de haber anulado su jurisprudencia anterior en una dirección progresiva, lo que revela que -al menos para algunos jueces- el TEDH sigue siendo demasiado favorable a la aplicación de algunas cuestiones jurídicas. Los jueces Costa (13), Villiger (10), Wildhaber (9), Turmen (8) y Mahoney (8) se sumaron o redactaron el mayor número de opiniones en las que se acusa al TEDH de haberse desviado de la jurisprudencia anterior hacia una dirección progresista.

\subsection{Ejemplos de disidencias por regresión}

Hasta ahora hemos agrupado los diferentes tipos de disidencias por regresión. Sin embargo, nuestra codificación nos permite extraer información más detallada y tendencias sobre el tipo de afirmaciones realizadas en esas opiniones minoritarias e ilustrarlas con ejemplos concretos.

Los votos particulares en los que se afirma que la mayoría anuló implícita o explícitamente la jurisprudencia anterior a favor del Gobierno han aumenta-

57 Esto incluye 15 sentencias en las que Turquía fue el Estado demandado y cinco en las que lo fue Rusia. Ningún otro Gobierno demandado apareció más de dos veces en esta lista. Como es lógico, no hubo sentencias en las que únicamente el juez nacional argumentara que la mayoría favorecía indebidamente al Estado demandado. Sin embargo, los jueces nacionales, en algunas ocasiones, se unieron e incluso escribieron tales opiniones en nombre de varios jueces. Véase, por ejemplo, TEDH, Moreira Ferreira c/Portugal (N²), Appl. N 19867/12, sentencia de la Gran Sala de 11 de julio de 2017 (Pinto de Albuquerque, Sajó, Tsotsoria, Vehabovi y Kuris, JJ., en disidencia), que se analiza a continuación. 
do significativamente, pasando de dos, en el período 1999-2005, a ocho en el período 2006-2011 y a quince en el período 2012-2018. Estos votos suelen ser bastante contundentes. En el caso Beuze contra Bélgica, por ejemplo, se examinó el derecho de un sospechoso de haber cometido un delito a tener acceso a un abogado mientras estaba bajo custodia policial. Aunque la Gran Sala consideró que se había producido una violación en los hechos presentados, cuatro jueces dedicaron toda una sección de una opinión concurrente conjunto a acusar a la mayoría de "anular" no solo una sentencia anterior, sino toda la línea de jurisprudencia que había generado:

La sentencia Salduz supuso una revolución para los derechos a un juicio justo, al establecer con firmeza que cualquier restricción al derecho de acceso a un abogado debe ser excepcional y susceptible de justificación: "El artículo $6 \S 1$ exige que, por regla general, se facilite el acceso a un abogado desde el primer interrogatorio de un sospechoso por la policía” y que, como se aclaró en Ibrahim y otros, "las restricciones al acceso a la asistencia letrada se permiten solamente en circunstancias excepcionales, deben ser de carácter temporal y deben basarse en una evaluación individual de las circunstancias particulares del caso". La sentencia Beuze representa a este respecto una lamentable contrarrevolución: ha anulado la exigencia "por regla general" -ya repetida en más de un centenar de sentencias ampliamente conocidas como la "jurisprudencia Salduz" - y la ha relativizado drásticamente en detrimento de las garantías procesales. ${ }^{58}$

Algunos votos particulares sostienen que el vuelco tácito del Tribunal en un caso específico significa un retroceso más amplio de su papel histórico, como se ejemplifica en la opinión escrita por los jueces Ziemele, De Gaetano, Laffranque y Keller en Janowiec y otros c/Rusia:

Con esta sentencia, el Tribunal ha perdido la oportunidad de [...] defender la cláusula de los "valores de la Convención" en los principios Šilih. ${ }^{59} \mathrm{Al}$ hacerlo, ha privado a esa cláusula de su efecto humanitario en el caso que nos ocupa y ha debilitado potencialmente su efecto en caso de que se aplique en el futuro. Este enfoque es insostenible si el sistema del Convenio ha de cumplir la función para la que fue concebido: proporcionar un Tribunal que actúe como la "conciencia" de Europa. ${ }^{60}$

58 TEDH, Beuze c/Bélgica, Appl. № 71409/10, sentencia de la Gran Sala de 9 de noviembre de 2018, párrafo 25 (Yudkivska,Vučinić, Turković y Hüseynov, JJ., concurrentes).

59 Los principios Šilih definen el alcance temporal del deber del Estado de investigar las violaciones del derecho a la vida ocurridas en un pasado lejano. Véase Moynihan (2016).

60 TEDH, Janowiec y otros c/Rusia, App. № 55508/07 y 29520/09, sentencia de la Gran Sala de 21 de 
Otro ejemplo interesante es el de Moreira Ferreira c/Portugal (№ 2), que se refiere al rechazo por parte del Tribunal Supremo portugués de una solicitud de reapertura de un procedimiento penal tras una sentencia de la Sala que determinó la violación del artículo 6 (derecho a un juicio justo). La Gran Sala sostuvo, por nueve votos contra ocho, que la decisión del Tribunal Supremo no constituía una violación adicional del artículo 6. En una encarnizada disidencia, los jueces Pinto de Albuquerque, Sajó, Tsotsoria, Vehabović y Kuris argumentaron que el Tribunal estaba retrocediendo en su papel de intérprete autorizado de las normas de derechos humanos en Europa:

[L]a mayoría lo concibe [al TEDH] como un mero órgano consultivo del Tribunal Supremo que, en última instancia, es libre de interpretar las sentencias [del TEDH] como le plazca al Tribunal Supremo, siempre y cuando este exponga algún motivo, cualquier motivo para su interpretación, independientemente del contenido de esos motivos. Aplicando [al TEDH] su propia jurisprudencia [...] habría que concluir que, según la mayoría, [el TEDH] no es un órgano judicial, porque ni siquiera tiene competencia para ordenar una medida individual para reparar una violación del Convenio. ${ }^{61}$

Cabe destacar que esta sentencia también contiene una opinión minoritaria de seis jueces que acusan a la mayoría de hacer exactamente lo contrario: "Anular solapadamente la consolidada jurisprudencia existente" que habría exigido declarar la inadmisibilidad de la solicitud. ${ }^{62}$

Por el contrario, el número de sentencias en las que la minoría afirma que la mayoría ha anulado explícita o implícitamente la jurisprudencia anterior $a$ favor del demandante se ha mantenido prácticamente invariable: de seis, en el período 1999-2005, a trece en el período 2006-2011 y a diez en el período 2012 2018. Algunos de estos votos particulares afirman que el TEDH sigue siendo excesivamente expansivo. Consideremos el caso Del Río Prada c/España, que se refería a las directrices para la imposición de penas a terroristas condenados de la ETA. La disidencia acusa al Tribunal de subterfugio al emitir una sentencia

octubre de 2013, párrafo 34 (Ziemele, De Gaetano, Laffranque y Keller, JJ., parcialmente disidentes).

61 TEDH, Moreira Ferreira c/Portugal (N²), Appl. № 19867/12, sentencia de la Gran Sala de 11 de julio de 2017, párrafo 56 (Pinto de Albuquerque, Sajó, Tsotsoria, Vehabović y Kuris, JJ. en disidencia).

62 Ibíd. párrafo 25 (Raimondi, Nußberger, Gaetano, Keller, Mahoney, Kjølbro y Leary, JJ., en disidencia). Véase también TEDH, Magyar Helsinki Bizottság c/Hungría, Appl. № 18030/11, sentencia de la Gran Sala de 8 de noviembre de 2016, párrafo 30 (Spano y Kjølbro, JJ., en disidencia), afirmando que es "imposible aceptar que la mayoría se limita a 'aclarar' los principios Leander. Por el contrario, que quede claro, hoy la jurisprudencia reiterada del Tribunal [...] ha sido, de hecho, anulada"). 
que en realidad se aparta de la jurisprudencia anterior, pero que "no pretende anular ni apartarse de esa jurisprudencia bien establecida". ${ }^{6}$

Aunque la anulación implícita y explícita ofrece los ejemplos más claros, los votos particulares que alegan la anulación tácita por la aplicación incoherente de la jurisprudencia anterior también acusan a la mayoría de avanzar en una dirección nueva y problemática. Estas afirmaciones suelen ser bastante contundentes. Por ejemplo, como argumentaron los jueces Tulkens, Spielmann y Garlicky en el caso Austin y otros c/Reino Unido:

La posición de la mayoría puede interpretarse en el sentido de que si es necesario imponer una medida coercitiva y restrictiva para un fin legítimo de interés público, la medida no equivale a una privación de libertad. Se trata de una nueva proposición que es eminentemente cuestionable y objetable [...]. ${ }^{64}$

En el caso Regner c/República Checa, un demandante que trabajaba para el Ministerio de Defensa se quejaba de que el procedimiento administrativo para revocar su autorización de seguridad le negaba injustamente el acceso a información clasificada. La opinión disidente del juez Sajó contiene largas secciones en las que se discuten las incoherencias con la jurisprudencia anterior, al igual que la opinión del juez Serghides, que se cita a continuación:

Propongo humildemente que la jurisprudencia no debería haber cambiado de dirección en el presente caso, dando así demasiado rango legal a una restricción absoluta en detrimento de la protección efectiva del derecho de audiencia [...] Hasta ahora hemos sabido que el Convenio prevé algunos derechos absolutos, pero no restricciones absolutas. Una restricción absoluta conduce a la muerte o a la ausencia absoluta de un derecho. ${ }^{65}$

Estos sentimientos no se limitan a las sentencias que no encuentran violaciones. Por ejemplo, en el caso Al-Dulimi y Montana Management Inc. c/Suiza, el Tribunal considera que el Gobierno violó el artículo 6 del Convenio cuando confiscó los bienes del demandante para aplicar una decisión del Comité de Sanciones del Consejo de Seguridad de la ONU. Dos opiniones concurrentes

63 TEDH, Del Río Prada c/España, Appl. N 42750/09, VI Eur. Ct. H.R. 1, 58 sentencia de la Gran Sala de 21 de octubre de 2013 (Mahoney y Vehabovic, JJ., en disidencia).

64 TEDH, Austin y otros c/Reino Unido, Appl. No 39692/09, 40713/09 y 41008/09, sentencia de la Gran Sala de 15 de marzo de 2012, párrafo 3 (Tulkens, Spielmann y Garlicky, JJ., en disidencia).

65 TEDH, Regner c/República Checa, Appl. N 35289/11, sentencia de la Gran Sala de 19 de septiembre de 2017, párrafo 71 (Serghides, J., parcialmente en disidencia). 
alegan que la sentencia de la mayoría es incoherente con sentencias anteriores que abordan posibles conflictos entre el Convenio y las obligaciones de aplicar las resoluciones del Consejo de Seguridad. ${ }^{66}$

Para ser claros, nuestro argumento no es que estas opiniones minoritarias identifiquen correctamente los fallos de la opinión mayoritaria. Tampoco estamos diciendo que la Gran Sala nunca interprete de forma expansiva los derechos y libertades en la era pos-Brighton. Sin embargo, observamos un marcado aumento en las afirmaciones de los jueces de que el TEDH está retrocediendo de su papel tradicional como intérprete progresista de la legislación europea sobre derechos humanos.

\section{3. ¿Geometría variable?}

Como se ha comentado anteriormente, algunos estudios han constatado que el TEDH ha aplicado con mayor frecuencia normas más indulgentes a las democracias establecidas ${ }^{67}$ que a otros tipos de gobiernos (Çali, 2018, p. 242). Algunos miembros del Tribunal también han formulado la misma crítica en opiniones disidentes. Por ejemplo, el juez Pinto de Albuquerque declaró en el caso Hutchinson c/Reino Unido que el "retroceso" de la Gran Sala respecto al caso anterior "no era un hecho aislado", sino el producto de una aplicación sesgada del margen de apreciación, según el cual:

[E]l margen debería ser más amplio para los Estados que se supone que "dan ejemplo a los demás” y más estrecho para los que han de aprender del ejemplo. Evidentemente, esto les deja la puerta abierta de par en par a ciertos Gobiernos para satisfacer su base electoral y proteger sus intereses particulares. En mi humilde opinión, la Convención no se basa en esto. ${ }^{68}$

Nuestros datos proporcionan algunas pruebas que respaldan estas afirmaciones. En el período 1999-2005, Turquía fue el Estado demandado con la mayoría de las sentencias de la Gran Sala acompañadas de disidencias, lo que sugiere que no se le exigieron a Turquía unos niveles de derechos humanos

66 TEDH, Al-Dulimi y Montana Management Inc/c/Suiza, Appl. № 5809/08, sentencia de la Gran Sala de 21 de junio de 2016 (Hajiyev, Albuquerque, Pejchal y Dedov, JJ., concurrente; Keller, J., concurrente).

67 Definido como un país que ha mantenido sistemáticamente una puntuación de Polity de siete o más desde 1988.

68 TEDH, Hutchinson c/Reino Unido, Appl. N 57592/08, sentencia de la Gran Sala de 17 de enero de 2017, párrafo 40 (Pinto de Albuquerque, J., en disidencia). 
suficientemente altos. Por ejemplo, en el caso Sürek c/Turquía (No 1), los jueces Tulkens, Casadevall y Greve argumentaron que el Tribunal se apartó de sus decisiones anteriores, que interpretaban el artículo 10 del CEDH (libertad de expresión) de forma expansiva, al revisar casos que implicaban "declaraciones políticas y críticas a veces virulentas y acerbas contra las acciones de las autoridades turcas". 69

Por el contrario, en el período 2006-2011, los Estados demandados más frecuentes en las sentencias con disidencias por regresión fueron el Reino Unido (siete) y Francia (cinco). En la era posterior a Brighton, el Reino Unido (siete) e Italia (cinco) fueron los más frecuentes en este tipo de casos (y hubo solo una sentencia de este tipo sobre Turquía). En cambio, en el período 1999-2005, apenas el 21\% de las sentencias que implicaban a una democracia establecida iban acompañadas de una disidencia por regresión, frente al 39\% en el período 2006-2011 y el 45\% en el período 2012-2018. No hubo una tendencia similar entre otros tipos de Gobiernos. En resumen, gran parte del aumento de los votos particulares en los que se acusa al Tribunal de dar marcha atrás en la jurisprudencia y las doctrinas jurídicas anteriores procede de sentencias que implican a democracias consolidadas.

\subsection{Cuestiones de fondo}

Los países que han criticado más abiertamente al TEDH están motivados por un conjunto de preocupaciones sustantivas específicas, en particular la jurisprudencia sobre el tratamiento de los detenidos, los inmigrantes y los sospechosos de terrorismo. Estos casos suelen referirse a supuestas violaciones de los derechos a la integridad física (contemplados en los artículos 2, 3 y 5 del $\mathrm{CEDH}$ ) o de los derechos a la intimidad y a la familia (protegidos por el artículo 8 del CEDH).

Las sentencias que plantean estas cuestiones jurídicas son responsables de gran parte del aumento de las disidencias por regresión. En el período posterior a Brighton, 18 de las 56 sentencias de la Gran Sala acusadas de regresión se referían al artículo 8, en comparación con 8 de 37 y 7 de 31 sentencias, respectivamente, en los dos períodos anteriores. Esto no refleja simplemente un aumento en el número total de sentencias del artículo 8. De todas las sentencias de este artículo de la Gran Sala, el 42\% fueron acompañadas de una

69 TEDH, Sürek c/Turquía (N 1), Appl. N²6682/95, sentencia de la Gran Sala de 7 de julio de 1999, párrafo 2 (Tulkens, Casadevall y Greve, JJ., parcialmente en disidencia). 
disidencia por regresión en la era posterior a Brighton (en comparación con el $28 \%$ en el primer período). Las cifras relativas a los derechos de integridad física son similares: 19 disidencias por regresión se referían a los artículos 2, 3 o 5 en el período posterior a Brighton, mientras que el $41 \%$ de todas las sentencias de la Gran Sala relativas a los artículos 2, 3 y 5 fueron acompañadas de una disidencia por regresión en ese período, en comparación con el 35\% y el 28\%, respectivamente, en los períodos anteriores. En conjunto, el porcentaje de sentencias de los artículos 2, 3, 5 y 8 acompañadas de una disidencia por regresión ha aumentado del $25 \%$ al $53 \%$ entre el primer y último período.

No encontramos tendencias similares para otras cuestiones de fondo. Por ejemplo, el número de sentencias de la Gran Sala sobre el artículo 10 (libertad de expresión) que han sido objeto de opiniones disidentes se ha mantenido relativamente constante ( 7,3 y 8 en los tres períodos). El número de casos P1-1 (derechos de propiedad) que atraen tales opiniones tampoco ha aumentado $(6,6$ y 7). En general, el porcentaje de sentencias acompañadas de disidencias por regresión en casos que no invocan los artículos 2, 3, 5 y 8 se ha mantenido constante (35\%) entre el primer y último período de análisis. En resumen, gran parte del aumento de las sentencias que atraen las alegaciones por regresión de derechos se refieren a cuestiones que se han vuelto cada vez más polémicas desde el punto de vista político en las últimas dos décadas en las democracias consolidadas: la integridad física, la intimidad y los derechos de la familia.

\subsection{Análisis de regresión}

Una posible objeción a nuestros resultados es que se deben a cambios en las características observables de los casos. Hemos estimado una serie de modelos de regresión para analizar esta posibilidad. Las unidades de análisis son las sentencias de la Gran Sala. La variable dependiente mide si una sentencia de la Gran Sala va acompañada de una disidencia. El modelo principal 1 (véase la Tabla 2) incluye indicadores para saber si se invocaron los artículos del Convenio mencionados anteriormente, así como un indicador para saber si la sentencia determinó al menos una violación. Como se ha comentado anteriormente, las sentencias que constatan una violación tienen (lógicamente) muchas menos probabilidades de ir acompañadas de una disidencia por regresión, aunque encontramos algunos de estos votos particulares. 
Tabla 2. Análisis de regresión lineal sobre la ocurrencia de disidencias por regresión

\begin{tabular}{|c|c|c|c|}
\hline Variables & Modelo 1 & Modelo 2 & Modelo 3 \\
\hline (1999-2005) & (Categoría de referencia) & & \\
\hline 2006-2011 & $0.06(0.06)$ & $0.07(0.06)$ & $0.05(0.06)$ \\
\hline 2012-2018 & $0.13^{* *}(0.06)$ & $0.15^{* *}(0.06)$ & $0.15^{* *}(0.06)$ \\
\hline Violación & $-0.18^{* * *}(0.05)$ & $-0.18^{* * *}(0.05)$ & $-0.20^{* * *}(0.05)$ \\
\hline Artículo 2 del CEDH & $0.03(0.09)$ & $0.05(0.09)$ & $0.03(0.09)$ \\
\hline Artículo 3 del CEDH & $0.07(0.07)$ & $0.06(0.07)$ & $0.05(0.08)$ \\
\hline Artículo 5 del CEDH & $0.06(0.07)$ & $0.07(0.07)$ & $0.03(0.08)$ \\
\hline Artículo 6 del CEDH & $-0.02(0.05)$ & $-0.01(0.05)$ & $-0.00(0.05)$ \\
\hline Artículo 8 del CEDH & $0.07(0.06)$ & $0.06(0.06)$ & $0.09(0.06)$ \\
\hline Artículo 10 del CEDH & $0.04(0.07)$ & $0.05(0.07)$ & $0.00(0.07)$ \\
\hline P1, Artículo 1 & $-0.02(0.06)$ & $-0.01(0.06)$ & $0.02(0.07)$ \\
\hline Democracia & & $0.06(0.05)$ & $0.05(0.05)$ \\
\hline Prisionero & & & $0.06(0.05)$ \\
\hline Refugiado & & & $-0.08(0.07)$ \\
\hline Informe de caso o caso clave & Categoría de referencia & & \\
\hline Nivel de importancia 1 & & & $-0.14^{* *}(0.06)$ \\
\hline Nivel de importancia 2 & & & $-0.42^{* *}(0.17)$ \\
\hline Nivel de importancia 3 & & & $-0.39^{* *}(0.15)$ \\
\hline Constante & $0.33^{* * *}(0.06)$ & $0.28^{* * *}(0.08)$ & $0.33^{* * *}(0.08)$ \\
\hline Observaciones & 397 & 397 & 366 \\
\hline Coeficiente R2 & 0.06 & 0.07 & 0.11 \\
\hline
\end{tabular}

Errores estándar entre paréntesis.

${ }^{* * *} \mathrm{p}<0.01,{ }^{* *} \mathrm{p}<0.05,{ }^{*} \mathrm{p}<0.1$.

Para evaluar aún más la solidez de los resultados, el modelo 2 incluye una medida para saber si el Estado demandado es una democracia consolidada. Lo definimos como un país que ha recibido una puntuación Polity de siete o superior durante al menos 20 años en $1998 .^{70} \mathrm{El}$ modelo 3 también incluye

70 Esto sigue el enfoque adoptado en Moravcsik (2000). Las democracias consolidadas son: Alemania, Andorra, Austria, Bélgica, Chipre, Dinamarca, España, Finlandia, Francia, Grecia, Irlanda, Is- 
un indicador del nivel de importancia del caso asignado por la Secretaría. La mayoría de las sentencias (78\%) son "casos clave" o "informes de casos". ${ }^{11}$ Esta es la categoría de referencia en el modelo 3. Los coeficientes de los casos de los niveles 1,2 y 3 miden, por tanto, hasta qué punto es menos probable que esas decisiones susciten disidencias. Por último, el modelo 3 incorpora información sobre si el demandante está detenido (preso) o es un refugiado. Esta variable se codificó en función de la aparición de determinados términos (por ejemplo, "detenido" o "asilo") en la descripción de los demandantes. ${ }^{72}$ Sin embargo, esta información solo está disponible para los casos anteriores a 2017.

La Tabla 2 presenta los resultados de un análisis de regresión lineal. (Todos los resultados se mantienen también en una regresión logística, que puede obtenerse de los autores.) La conclusión más importante de la tabla es que la probabilidad de que se produzca una disidencia por regresión ha aumentado entre 13 y 15 puntos porcentuales (según el modelo) en el período posterior a Brighton, en comparación con el período 1999-2005..$^{73}$ Por lo tanto, incluso después de controlar las características de los casos, la probabilidad de una disidencia por regresión ha aumentado significativamente. Esto sugiere que nuestro principal hallazgo descriptivo no se debe a un cambio en las características observables de los tipos de casos que llegan al Tribunal. Aun así, esto no significa que podamos afirmar que hay un efecto causal: podría haber cambios no observables en las características de los casos que no podemos controlar en un análisis estadístico.

Asimismo, esta tabla también revela que, como esperábamos, es mucho más probable que las sentencias por violación vayan acompañadas de una disidencia. Sin embargo, ninguna de las demás características de los casos se correlaciona significativamente con tales disidencias. Nuestro anterior análisis descriptivo demostró que las sentencias relativas a los artículos 2, 3, 5 y 8 del CEDH eran más propensas a atraer disidencias por regresión en el período de 2012 a 2018, pero no en los otros períodos. En un modelo de regresión sobre el período completo de análisis, los coeficientes de regresión sobre estos artículos son positivos, pero no son estadísticamente significativos. ${ }^{74}$ Las únicas excepciones son

landia, Italia, Liechtenstein, Luxemburgo, Malta, Mónaco, Noruega, Países Bajos, Portugal, San Marino, Suecia, Suiza y Reino Unido.

71 Véase la nota 56 supra.

72 Véase Stiansen y Voeten (2020).

73 La diferencia con respecto al período 2006-2011 es de 13 puntos porcentuales.

74 Podrían incluirse efectos de interacción entre los períodos y los artículos para identificar las 
los "informes de casos" o los "casos clave", que tienen más probabilidades de ir acompañados de disidencias por regresión que las sentencias designadas como menos importantes por la Secretaría del Tribunal. Este resultado es coherente con nuestra afirmación de que las disidencias por regresión están asociadas a decisiones que marcan cambios significativos en la jurisprudencia del TEDH.

\section{Conclusión e implicaciones}

Este artículo ha analizado las tendencias generales de la jurisprudencia del TEDH basándose en una revisión y codificación de todos los votos particulares de la Gran Sala entre 1999 y 2018. En los primeros años de estas dos décadas, el TEDH continuó con su larga práctica de interpretar el Convenio como un instrumento vivo que responde a las tendencias de mejora de los derechos en las legislaciones nacionales, incluso anulando las sentencias que no se ajustaban a estos avances. Sin embargo, a partir de mediados de la década de 2000, los Estados miembros, especialmente las democracias establecidas que han sido durante mucho tiempo partidarias incondicionales del TEDH, empezaron a imponer nuevas restricciones a grupos desfavorecidos, especialmente inmigrantes, acusados de delitos y sospechosos de terrorismo. También criticaron públicamente al Tribunal por ampliar demasiado los derechos y las libertades y por no conceder suficiente deferencia a los Gobiernos. Primero de forma vacilante y luego con mayor frecuencia a partir de 2012, la Gran Sala empezó a restringir su interpretación de la Convención, especialmente en casos contra democracias consolidadas.

Lo que el TEDH no ha hecho -al menos no explícitamente- es revocar su jurisprudencia anterior en una dirección restrictiva de los derechos. Tal movimiento representaría una ruptura brusca y controvertida con el instrumento vivo, el consenso europeo y otras doctrinas de expansión de derechos que el Tribunal ha respaldado durante mucho tiempo. En su lugar, la Gran Sala puede conseguir el mismo resultado de forma indirecta, al pretender conciliar sentencias anteriores favorables a los derechos con decisiones posteriores más favorables a los Estados demandados. Sin embargo, para muchos jueces del TEDH, estos esfuerzos son poco convincentes. A modo de protesta por el giro jurisprudencial del Tribunal, estos jueces escriben votos particulares en los que acusan a la mayoría del Tribunal -a veces de forma bastante enérgica

correlaciones cambiantes a lo largo del tiempo. Sin embargo, este tipo de análisis es muy exigente con los datos y daría lugar a estimaciones muy imprecisas. 
y contundente- de anular tácitamente la jurisprudencia anterior o la doctrina establecida en favor de los Gobiernos nacionales.

El aumento de lo que denominamos "disidencias por regresión" revela que algunos miembros del TEDH creen que la Gran Sala está revocando sentencias anteriores en una dirección regresiva. También sugiere que el Tribunal está, de hecho, restringiendo los derechos humanos en Europa. Mostramos que las disidencias por regresión han aumentado tanto en términos absolutos como porcentuales en las últimas dos décadas, siendo el aumento más pronunciado el que se produjo tras la Declaración de Brighton de 2012. También descubrimos que este tipo de disidencias son especialmente comunes en casos contra democracias establecidas y en casos -a menudo presentados por presos, inmigrantes y sospechosos de terrorismo- cuyas protecciones de la Convención han provocado una importante reacción contra el Tribunal.

Existen dos explicaciones posibles para estos resultados. En primer lugar, la Gran Sala puede estar respondiendo a las señales políticas de los Estados miembros de que los jueces de Estrasburgo han sido demasiado agresivos a la hora de interpretar el Convenio, especialmente en los casos que afectan a las democracias de larga data. En segundo lugar, el TEDH puede estar teniendo en cuenta tácitamente el creciente número de Estados miembros que han restringido los derechos de ciertos individuos y grupos minoritarios desfavorecidos, aplicando de hecho las doctrinas del instrumento vivo y del consenso europeo a la inversa.

Sospechamos que ambas tendencias están impulsando el aumento del número de sentencias de la Gran Sala acompañadas de disidencias. Sin embargo, nuestros datos no nos permiten desentrañar estas dos posibles causas ni evaluar su respectiva influencia.

Tampoco excluyen otros factores explicativos, como el nombramiento de jueces que favorecen interpretaciones más restringidas de los derechos humanos. Para desentrañar estos factores, sería necesario, como mínimo, recopilar datos a nivel nacional sobre las tendencias legales progresivas y regresivas en diferentes áreas temáticas, incluyendo aquellas por las que el TEDH ha sido criticado por los Gobiernos y aquellas por las que no. Por ejemplo, los expertos podrían identificar los cambios en los procedimientos nacionales de asilo y examinar si son anteriores o posteriores a los cambios en la jurisprudencia del TEDH.

¿Cuáles son las implicaciones teóricas y normativas más amplias del aumento de las disidencias por regresión? Es bastante habitual que los tribunales constitucionales y superiores nacionales oscilen entre períodos de interpreta- 
ción progresiva y restrictiva, y que algunos derechos se amplíen en una época y se contraigan en otra. Por lo tanto, puede parecer poco llamativo que la Gran Sala retroceda en materia de derechos humanos en Europa, especialmente teniendo en cuenta los importantes cambios recientes en el clima jurídico y político al que se enfrenta el TEDH.

Sin embargo, a diferencia de la mayoría de los tribunales nacionales, el TEDH se ha comprometido desde hace tiempo a ampliar el ámbito y el alcance de los derechos humanos y a respaldar la legitimidad de dichas ampliaciones realizadas por los jueces. Este compromiso es en parte una consecuencia de las normas de competencia y acceso del Tribunal. Dado que los individuos son la fuente de casi todas las reclamaciones, ${ }^{75}$ el TEDH ha desarrollado doctrinas legales que "se centran en los demandantes individuales" e interpretan los derechos de forma expansiva para fomentar la presentación de más casos (Helfer y Slaughter, 1997, pp. 309-312). También opera en paralelo a otro ambicioso proyecto supranacional (la Unión Europea [UE]), con su propio tribunal, famoso por sus propósitos (el TJUE), y con partidarios que defienden una "teoría de la bicicleta” de la integración, según la cual la UE debe expandirse continuamente para evitar la desintegración. ${ }^{76}$ Quizás, lo más importante sea que la visión del TEDH de la Convención como un instrumento vivo ha sido validada (al menos hasta hace poco) por décadas de tendencias jurídicas, políticas y sociales progresistas a nivel nacional y por el compromiso sostenido con el sistema regional de derechos humanos por parte de un número creciente de Estados miembros. De hecho, antes de la Declaración de Brighton de 2012, la totalidad de los numerosos protocolos del Convenio ampliaron la autoridad del TEDH o aumentaron los derechos y libertades que protege (Helfer, 2012).

Estas perspectivas ponen de manifiesto por qué las sentencias de la Gran Sala que hacen retroceder los derechos humanos, incluso tácitamente, son normativas y jurisprudenciales. Lo más evidente es que estas sentencias tienen efectos adversos inmediatos para los miles de individuos vulnerables que buscan una reparación legal en el Tribunal. Pero las sentencias también tienen consecuencias más allá de los litigantes. Cuando el TEDH expone el significado de un determinado derecho o libertad, su interpretación tiene efectos en cadena en los 47 Estados miembros -todos los cuales han incorporado el Convenio a su legislación nacional-y en los poderes judiciales nacionales, en los que

75 Las reclamaciones de grupos, asociaciones y entidades empresariales, así como los casos interestatales, son mucho menos frecuentes.

76 Véase, por ejemplo, Moravcsik (2001, p. 162). 
muchos de sus miembros tienen en cuenta las sentencias del TEDH a la hora de interpretar los derechos o libertades en sus respectivas constituciones. Las sentencias favorables a los Gobiernos que decepcionan a estos actores corren el riesgo de socavar la influencia del Tribunal y su legitimidad.

Al mismo tiempo, el TEDH depende del respaldo político, institucional y financiero de los Estados miembros, especialmente de las democracias establecidas. Cuando ese apoyo disminuye, ya es bastante difícil que el Tribunal haga cumplir a los Estados los compromisos que consintieron expresamente al adherirse al Convenio. Es mucho más peligroso para el TEDH "duplicar" una estrategia de ampliación de derechos y libertades. ${ }^{77}$ Dada la escasez de mecanismos formales a través de los cuales los Estados miembros pueden señalar su apoyo u oposición colectiva a la trayectoria jurisprudencial del TEDH (aparte de las ocasionales conferencias de reforma), no es descabellado que los jueces de Estrasburgo consideren las críticas expresadas por los Gobiernos y tengan en cuenta las tendencias regresivas de las leyes y políticas nacionales.

Equilibrar estas consideraciones contrapuestas es una tarea compleja para cualquier tribunal u órgano de revisión internacional; es aún más difícil para un tribunal de derechos humanos que ha sido alabado como "la joya de la corona del sistema internacional más avanzado del mundo para la protección de las libertades civiles y políticas" (Helfer, 2008, p. 159). Estas cuestiones pueden explicar por qué la Gran Sala ha optado por la anulación tácita y no explícita de las sentencias anteriores (al menos en opinión de algunos de sus miembros) como el enfoque "menos malo" para moverse en un entorno político tenso.

Por un lado, la anulación tácita tiene costes reales. Socava la coherencia y la previsibilidad de la jurisprudencia del TEDH y supone el riesgo de un tratamiento incoherente de los litigantes en situación similar. También genera votos particulares que exponen las fracturas normativas entre los jueces sobre los principios fundamentales. Algunas investigaciones recientes sugieren que las sentencias del TEDH en las que se declara una violación del Convenio y que van acompañadas de una disidencia tienen menos probabilidades de ser aplicadas por el Estado demandado que las sentencias sin dicha disidencia. La lógica en este caso es que las opiniones disidentes "permiten a las partes recalcitrantes argumentar que la decisión del tribunal estaba 'politizada' o no era digna de respeto” (Naurin y Stiansen, 2020, pp. 84-85). No está claro si las disidencias de la marcha atrás tienen efectos similares para los partidarios del Tribunal y 
los grupos de conformidad, disminuyendo su opinión sobre la legitimidad de las sentencias favorables al Gobierno que incluyen esos votos particulares. ${ }^{78}$ Las investigaciones futuras sobre el retroceso en el sistema europeo de derechos humanos podrían investigar si la revocación tácita de las sentencias influye en las estrategias de litigación de los grupos de la sociedad civil que actúan repetidamente ante el TEDH, así como en los esfuerzos de estos grupos para presionar a los Gobiernos con el fin de que nombren a jueces progresistas en el Tribunal. Los académicos también podrían examinar si la revocación tácita anima a los Gobiernos distintos del Estado demandado a reducir la protección de los derechos nacionales, al igual que las sentencias expansivas tienen efectos erga omnes en una dirección progresista (Helfer y Voeten, 2014).

Sin embargo, la revocación tácita también puede tener ventajas. Los estudios sobre los tribunales nacionales e internacionales han revelado que los jueces emiten fallos imprecisos o ambiguos cuando se enfrentan a la incertidumbre política (Staton y Vanberg, 2008). La imprecisión puede "proporcionarles a los funcionarios del Estado una medida de discreción, permitiéndoles la libertad de utilizar los conocimientos locales [...] para alcanzar resultados que los jueces desean, pero que tendrían dificultades para producir sin acceso a mejor información” (Staton y Romero, 2019, p. 477). Las decisiones ambiguas también pueden "atenuar los costes potenciales que los jueces perciben como asociados al incumplimiento" al "dificultar la argumentación de que una orden ha sido realmente incumplida” (p. 478).

En el contexto del TEDH, la ambigüedad puede reducir las presiones de cumplimiento sobre todos los Estados miembros. Por ejemplo, una sentencia de la Gran Sala acompañada de un voto particular que acusa a la mayoría de anular implícitamente una sentencia anterior podría debilitar los efectos erga omnes de ambas sentencias, creando dudas sobre si se aplican a otros países y a circunstancias diferentes y cómo lo hacen. ${ }^{79}$ Los beneficios de la imprecisión también pueden ayudar a explicar por qué observamos un aumento de los vo-

78 Quizás cabe destacar que la lista del blog Observadores de Estrasburgo de las cinco "peores sentencias del TEDH de 2018” incluye dos sentencias de la Gran Sala, ambas con disidencias por regresión. Véanse Poll: Best and Worst ECtHR Judgment of 2018 (2019), que cita al TEDH, Beuze c/ Bélgica, Appl. N 71409/10, sentencia de la Gran Sala de 9 de noviembre de 2018; TEDH, Murtazaliyeva c/Rusia, Appl. N 36658/05, Sentencia de la Gran Sala de 18 de diciembre de 2018. El blog publicó previamente análisis de ambas sentencias de la Gran Sala que criticaban el razonamiento de la mayoría y elogiaban los votos particulares que destacaban las incoherencias con la jurisprudencia anterior del TEDH.

79 El caso de Animal Defenders, comentado anteriormente, que confirmó la prohibición general del Reino Unido sobre la publicidad política pagada a pesar de una sentencia anterior que anulaba una 
tos particulares que acusan a la Gran Sala de revocar tácitamente sentencias o doctrinas anteriores en una dirección favorable a los demandantes: es posible que los jueces del TEDH que forman parte de la mayoría en estos casos se hayan vuelto más circunspectos a la hora de justificar las sentencias progresistas como forma de protegerse de las críticas de los Estados que se oponen a un Tribunal más expansionista.

Una última implicación de nuestras conclusiones se refiere a la reciente oposición nacionalista/populista al sistema multilateral liberal posterior a la Segunda Guerra Mundial, incluidos los tribunales internacionales de derechos humanos y los órganos de revisión. ${ }^{80}$ Las instituciones internacionales que componen este sistema han tendido a ampliar sus competencias con el tiempo. ${ }^{81} \mathrm{Los}$ mecanismos precisos de estas ampliaciones varían, ${ }^{82}$ pero un elemento común que conecta estos diversos ejemplos es que las ampliaciones de autoridad han sido mucho más comunes que las reducciones. Las instituciones internacionales pueden carecer de la flexibilidad y los mecanismos de retroalimentación necesarios para ejecutar correcciones del rumbo que reduzcan su huella legal y política en respuesta a los cambios en el apoyo político y la opinión pública.

El TEDH posterior a Brighton es un ejemplo verosímil de este fenómeno. La anulación tácita que la Gran Sala parece estar utilizando para hacer retroceder los derechos humanos en Europa después de décadas de sentencias dinámicas para mejorarlos -y las controversias que este enfoque ha generado- sugieren la necesidad de reconsiderar si las instituciones internacionales tienen las herramientas adecuadas para reducir -y ampliar- su autoridad a lo largo del tiempo.

\section{Bibliografia}

Arnardóttir, O. M. (2018). The Brighton Aftermath and the Changing Role of the European Court of Human Rights. Journal of International Dispute Settlement, 9(2), 223-239.

Barnett, M. y Finnemore, M. (2004). Rules for the World: International Organizations in Global Politics. Cornell University Press.

prohibición suiza casi idéntica, ofrece un ejemplo adecuado. Véase Animal Defenders International c/ Reino Unido, Appl. N 48876/08, sentencia de la Gran Sala de 22 de abril de 2013.

80 Véanse, por ejemplo, Helfer (2020); Voeten (2020).

81 Véanse, por ejemplo, Helfer (2019); Barnett y Finnemore (2004).

82 Véase, por ejemplo, Bradley y Kelley (2008). 
Bates, E. (15 de diciembre de 2015). The Continued Failure to Implement Hirst v UK. EJIL: Talk! https://bit.ly/3hZ1tmf.

Bentsen, H. L. (2018). Court Leadership, Agenda Transformation, and Judicial Dissent: A European Case of a "Mysterious Demise of Consensual Norms". Journal of Law $\mathcal{E}$ Courts, 6(1), 189.

Bradley, C. y Kelley, J. (2008). The Concept of International Delegation. Law and Contemporary Problems, 76, 1-36.

Brauch, J. A. (2005). The Margin of Appreciation and the Jurisprudence of the European Court of Human Rights: Threat to the Rule of Law. Columbia Journal of European Law, 11, 113.

Bruinsma, J. (2008). The Room at the Top: Separate Opinions in the Grand Chamber of the ECHR (1998- 2006). Ancilla Juris, 32.

Bürli, N. (2017). Third-Party Interventions Before the European Court of Human Rights. Intersentia.

Busch, M. L. y Reinhardt, E. (2006). Three's a Crowd: Third Parties and WTO Dispute Settlement. World Politics, 58(3), 446-477.

Çali, B. (2018). Coping with Crisis: Towards a Variable Geometry in the Jurisprudence the European Court of Human Rights? Wisconsin Journal of International Law, 35(2), 237-276.

Carozza, P. G. (1998). Uses and Misuses of Comparative Law in International Human Rights: Some Reflections on the Jurisprudence of the European Court of Human Rights. Notre Dame Law Review, 73(5), 1217-1238.

Carrubba, C. J., Gabel, M. y Hankla, C. (2008). Judicial Behavior under Political Constraints: Evidence from the European Court of Justice. American Political Science Review, 102(4), 435-452.

Centro Schell para los Derechos Humanos Internacionales. (s.f.). Robina Foundation Human Rights Fellows. https://bit.ly/3i5XGUo.

Ciacchi, A. C. (2017). Political Parties' Programmes: Examples of Governance Against Human Rights? European Journal of Comparative Law and Governance, 4, 105-109.

Comisión Directiva del Consejo de Europa para los Derechos Humanos. (2015). El futuro a largo plazo del sistema del Convenio Europeo de Derechos Humanos.

Christoffersen, J. y Madsen, M. R. (2013). Postscript: Understanding the Past, Present, and Future of the European Court of Human Rights. En Christoffersen, J. y Madsen, M. R. (Eds.), The European Court of Human Rights between Law and Politics (230-249). Oxford.

Dunoff, J. L. y Pollack, M. A. (2017). The Judicial Trilemma. American Journal of International Law, 11(2), 225-276.

Dzehtsiarou, K. (2015). European Consensus and the Legitimacy of the European Court of Human Rights. Cambridge University Press.

Epstein, L., Landes, W. y Posner, R. (2013). The Behavior of Federal Judges: A Theoretical and Empirical Study of Rational Choice. Harvard University Press.

Epstein, L. y Martin, A. D. (2010). Does Public Opinion Influence the Supreme Court? Possibly Yes (But We're Not Sure Why). University of Pennsylvania Journal of Constitutional Law, 13(2), 263.

Friedman, B. (2009). The Will of the People: How Public Opinion Has Influenced the Supreme Court and Shaped the Meaning of the Constitution. Farrar, Straus and Giroux.

Gearty, C. (2005). 11 September 2001, Counter-Terrorism, and the Human Rights Act. Journal of Law and Society, 32(1), 18-33. 
Gerards, J. (2018). Margin of Appreciation and Incrementalism in the Case Law of the European Court of Human Rights. Human Rights Law Review, 18(3), 495-515.

Greenhouse, L. (15 de julio de 2001). Divided They Stand; The High Court and The Triumph of Discord. The New York Times. https://nyti.ms/33Stw1L.

Helfer, L. R. (1993). Consensus, Coherence and the European Convention on Human Rights. Cornell International Law Journal, 26, 133-165.

Helfer, L. R. (2008). Redesigning the European Court of Human Rights: Embeddedness as a Deep Structural Principle of the European Human Rights Regime. European Journal of International Law, 19(1), 125-159.

Helfer, L. R. (2012). The Burdens and Benefits of Brighton. European Society of International Law, 1(1). https://bit.ly/3mHtGS2.

Helfer, L. R. (2019). The ILO at 100: Institutional Innovation in an Era of Populism. AJIL Unbound, 113, 396-401.

Helfer, L. R. (2020). Populism and International Human Rights Institutions: A Survival Guide. En Neuman, G. (Ed.), Human Rights in a Time of Populism: Challenges and Responses. Cambridge University Press.

Helfer, L. R. y Slaughter, A. M. (1997). Toward a Theory of Effective Supranational Adjudication. Yale Law Journal, 107(2), 273-391.

Helfer, L. R. y Voeten, E. (2014). International Courts as Agents of Legal Change: Evidence from LGBT Rights in Europe. International Organization, 68, 77-100.

Kelemen, K. (2018). Judicial Dissent in European Constitutional Courts. Routledge.

Kennedy, R. (22 de febrero de 2019). A "European Race to the Bottom": Human Rights Defenders Criticise Denmark's new immigration bill. Euronews. https://bit.ly/3iXRKOI.

Kuijer, M. (1997). Voting Behavior and National Bias in the European Court of Human Rights and the International Court of Justice. Leiden Journal of International Law, 10(1), 49-67.

Larsson, O. y Naurin, D. (2016). Judicial Independence and Political Uncertainty: How the Risk of Override Affects the Court of Justice of the EU. International Organization, 70(2), $377-408$.

Letsas, G. (2013). The ECHR as a Living Instrument: Its Meaning and Legitimacy. En Føllesdal, A., Peters, B. y Ulfstein, G. (Eds.), Constituting Europe: The European Court of Human Rights in a National, European and Global Context. Cambridge University Press.

Lupu, Y. y Voeten, E. (2012). Precedent in International Courts: A Network Analysis of Case Citations by the European Court of Human Rights. British Journal of Political Science, 42(2), 413-439.

Madsen, M. R. (2016). The Challenging Authority of the European Court of Human Rights: From Cold War Legal Diplomacy to the Brighton Declaration and Backlash. Law and Contemporary Problems, 79, 141-178.

Madsen, M. R. (2018). Rebalancing European Human Rights: Has the Brighton Declaration Engendered a New Deal on Human Rights in Europe? Journal of International Dispute Settlement, 9(2), 199-222.

Madsen, M. R., Cebulak, P. y Wiebusch, M. (2018). Backlash Against International Courts: Explaining the Forms and Patterns of Resistance to International Courts. International Journal of Law in Context, 14(2), 197-220. 
McGoldrick, D. (2011). Religion in the European Public Square and in European Public LifeCrucifixes in the Classroom? Human Rights Law Review, 11(3), 451-502.

Mishler, W. y Sheehan, R. S. (1993). The Supreme Court as a Countermajoritarian Institution? The Impact of Public Opinion on Supreme Court Decisions. American Political Science Review, 87(1), 87-101.

Moravcsik, A. (2000). The Origins of Human Rights Regimes: Democratic Delegation in Postwar Europe. International Organization, 54(2), 217-252.

Moravcsik, A. (2001). Federalism in the European Union: Rhetoric and Reality. En Nicolaidis, K. y Howse, R. (Eds.), The Federal Vision: Legitimacy and Levels of Governance in the United States and the European Union. Oxford Scholarship Online.

Mowbray, A. (2007). An Examination of the Work of the Grand Chamber of the European Court of Human Rights. Public Law, (3), 507-528.

Mowbray, A. (2009). An Examination of the European Court of Human Rights' Approach to Overruling its Previous Case Law. Human Rights Law Review, 9(2), 179-201.

Moynihan, H. (2016). Regulating the Past: The European Court of Human Rights' Approach to the Investigation of Historical Deaths under Article 2 ECHR. British Yearbook of International Law, 86(1), 68-100.

Naurin, D. y Stiansen, Ø. (2020). The Dilemma of Dissent: Split Judicial Decisions and Compliance with Judgments from the International Human Rights Judiciary. Comparative Political Studies, 53(6).

O’Mahony, C. y Dzehtsiarou, K. (2013). Evolutive Interpretation of Rights Provisions: A Comparison of the European Court of Human Rights and the U.S. Supreme Court. Columbia Human Rights Law Review, 44, 309.

Poll: Best and Worst ECtHR Judgment of 2018. (29 de enero de 2019). Strasbourg Observers. https://bit.ly/3kHOjf8.

Schabas, W. A. (2015). The European Convention on Human Rights: A Commentary. Oxford.

Staton, J. K. y Romero, A. (2019). Rational Remedies: The Role of Opinion Clarity in the Inter-American Human Rights System. International Studies Quarterly, 63(3), 477-491.

Staton, J. K. y Vanberg, G. (2008). The Value of Vagueness: Delegation, Defiance, and Judicial Opinions. American Journal of Political Science, 52(3), 504-519.

Stiansen, Ø. y Voeten, E. (2020). Backlash and Judicial Restraint: Evidence from the European Court of Human Rights. International Studies Quarterly, 64(4), 770-784.

Stone Sweet, A. y Brunell, T. L. (2013). Trustee Courts and the Judicialization of International Regimes: The Politics of Majoritarian Activism in the ECHR, the EU, and the WTO. Journal of Law and Courts, 1(1), 61-88.

Tribunal Europeo de Derechos Humanos. (s.f.). HUDOC FAQ: Preguntas frecuentes. https:// bit.ly/3hVFxIN.

Urueña, R. (2018). Double or Nothing? The Inter-American Court of Human Rights in an Increasingly Adverse Context. Wisconsin International Law Journal, 35(2) 398-425.

Vitale, D. (2014). The Value of Dissent in Constitutional Adjudication: A Context-Specific Analysis. Review of Constitional Studies, 19(1), 83-108.

Voeten, E. (2007). The Politics of International Judicial Appointments: Evidence from the European Court of Human Rights. International Organization, 61(4), 669-701. 
Voeten, E. (2008). The Impartiality of International Judges: Evidence from the European Court of Human Rights. American Political Science Review, 102(4), 417-433.

Voeten, E. (2020). Populism and Backlashes against International Courts. Perspectives on Politics, 18(2), 407.

White, R. C. A. y Boussiakou, I. (2009). Separate Opinions in the European Court of Human Rights. Human Rights Law Review, 9(1), 37-60.

Wildhaber, L. (1999). Opinions dissidentes et concordantes de juges individuels à la Cour Européenne des droits de l'homme. En Dupuy, R. J. (Ed.), Droit et justice: Mélanges en l'honneur de Nicolas Valticos (pp. 530-531). Editions A. Pedone.

Wildhaber, L. (2016). The Old Court, the New Court, and Paul Mahoney. Human Rights Law Journal, (36). 



\title{
EL PROBLEMA DE LA DIFICULTAD CONTRAMAYORITARIA DE LA JUSTICIA CONSTITUCIONAL DESDE LA PERSPECTIVA DE LA LEGITIMIDAD DE REFLEXIVIDAD en PIerRe RosanvalloN
}

\section{Fernando D. Álvarez Álvarez}

\author{
Universidad Austral. Universidad Católica Argentina \\ fernando.alvarez3@gmail.com
}

Recibido: 26/08/2021

Aceptado: $12 / 10 / 2021$

\section{Resumen}

El presente estudio aborda el problema de la dificultad contramayoritaria que se les suele imputar a los tribunales que ejercen control de constitucionalidad. Para superar dicha dificultad, se asume la perspectiva de la legitimidad de reflexividad conceptualizada por Pierre Rosanvallon. Con apoyo en las teorizaciones de este autor y enriqueciendo el análisis y la argumentación con diferentes conceptos provenientes del derecho constitucional y de la teoría de la democracia, se propone una hipótesis innovadora: el rol democrático de los tribunales constitucionales y de la reflexividad jurídica en general no remite a fundamentos liberales, sino propiamente democráticos dada la imposibilidad de identificación entre la voluntad del pueblo soberano y la voluntad de los representantes. De este modo, el trabajo pretende dar cuenta, de manera clara y fundada, cómo los tribunales constitucionales pueden cristalizar, en la perspectiva de una democracia compleja, nuevas formas de representación. Si bien la pluralidad necesita ser condensada, simplificada, por los procesos electorales para erigir mayorías gobernantes, como contraparte es imprescindible que existan instancias reflexivas que recompongan la diversidad a través del debate público, poniendo freno a las decisiones mayoritarias, especialmente cuando estas invaden la esfera de los derechos humanos fundamentales. Adicionalmente, puede resultar de especial interés el tratamiento de la cuestión de la temporalidad plural de la democracia, aspecto al que no se le suele prestar atención desde la teoría política y jurídica.

Palabras clave: control judicial de constitucionalidad, dificultad contramayoritaria, legitimidad democrática, legitimidad de reflexividad, democracia constitucional, tribunales constitucionales, democracia. 


\title{
The Problem of the Counter - Majoritarian Difficulty of Constitutional Justice from the Perspective of the Legitimacy of Reflexivity in Pierre Rosanvallon
}

\begin{abstract}
The present study deals with the problem of counter-majoritarian difficulty that usually is attributed to courts of law that apply constitutional review. To overpass such difficulty, it assumes Pierre Rosanvallon's legitimacy of reflexivity perspective. By relying on this author's theorizations and enriching the analysis and argumentation with different Constitutional Law and Democratic Theory concepts, the article proposes an innovative hypothesis: the democratic role of constitutional courts and of legal reflexivity in general does not refer to liberal grounds, but properly democratic ones, because of the impossibility of identification between the sovereign people and the representatives' will. In this way, the article pretends to give an account of how constitutional courts can crystallize, in the perspective of a complex democracy, new forms of representation. Even when the plurality needs to be thicken, simplified, by electoral processes to raise ruling majorities, as a counterpart it is indispensable the existence of reflexive agencies to recompose the diversity through public debate, to put a stop to majoritarian decisions, especially when they invade the sphere of fundamental human rights. Additionally, the matter of democracy's plural temporality can be of especial interest, as an aspect not considered in political and legal theory.
\end{abstract}

Key words: judicial review, counter majoritarian difficulty, democratic legitimacy, legitimacy of reflexivity, constitutional democracy, constitutional courts, democracy.

\section{Introducción}

\subsection{Los problemas en juego}

... when the Supreme Court declares unconstitutional a legislative act or the action of an elected executive, it thwarts the will of representatives of the actual people of the here and now; it exercises control, not in behalf of the prevailing majority, but against it. That, without mystic overtones, is what actually happens. It is an altogether different kettle of fish, and it is the reason the charge can be made that judicial review is undemocratic.

(Bickel, 1986, pp. 16-17) ${ }^{1}$

Tanto en el ámbito político como en cualquier otro de la vida social (en la

1 “... cuando la Suprema Corte declara inconstitucional una ley o el acto de un ejecutivo electo popularmente frustra la voluntad de los representantes del pueblo aquí y ahora; ejerce el control no en favor de la mayoría, sino en su contra. Esto, sin misticismos, es lo que sucede realmente. Es una olla de pescado totalmente diferente y es la razón por la que se puede formular la acusación de que la revisión judicial es antidemocrática" (traducción del autor). 
empresa, en la escuela o en la familia), muchas veces, cuando debemos tomar una decisión como forma de dotar de legitimidad a aquello que se decidirá, convenimos en hacerlo democráticamente. La democracia se ha convertido en un procedimiento de toma de decisiones que se reputan legítimas y que consiste básicamente en decidir por mayoría. Lo democrático expresa, pues, las preferencias mayoritarias. Sin embargo, y como lo examinaremos más adelante, esa mayoría encierra una pretensión de generalidad, pues tiende a identificarse con la voluntad de todos.

Este fenómeno es observable en la propia evolución histórica de la democracia. En efecto, los regímenes democráticos instituidos a finales del siglo XVIII y en la centuria siguiente se fundan en, al menos, dos ficciones (Rosanvallon, 2009, p. 22). La primera consiste en afirmar que la parte vale por el todo, esto es, la mayoría (que es una fracción, aunque sea predominante) es tomada como si valiera por la totalidad. En consecuencia, la improbable unanimidad (que expresaría estrictamente la generalidad) acoge como sucedáneo factible la regla mayoritaria. Así, la voluntad de la mayoría equivale a la voluntad de todos. Por su parte, la segunda ficción consiste en postular que la legitimidad lograda por aplicación de la regla mayoritaria en el momento electoral se prolonga por toda la duración del mandato. Rosanvallon (2009, p. 23) considera a estas como las dos ficciones fundadoras sobre las que se asentó la legitimidad del régimen democrático. La democracia, en suma, obtiene su legitimidad de su identificación con la regla mayoritaria, y esta legitimidad de origen se solapa, confundiéndose, con la de ejercicio, puesto que la unción popular-electoral proyecta automáticamente su efecto legitimador a todo el mandato. Por supuesto que este mismo aparato ficcional se proyecta sobre los productos de los representantes: por ejemplo, la ley, necesariamente votada por mayoría, es la expresión máxima de la voluntad popular.

Sin embargo, nuestros sistemas jurídico-políticos han incorporado otro tipo de institución, cuyos integrantes no son elegidos por el pueblo electoralmente: los tribunales en general y los tribunales constitucionales en particular. Hasta allí la cosa no es tan grave, porque, bien pensado, la gran burocracia estatal, particularmente concentrada en la Administración pública, tampoco es el resultado de elecciones populares y tiene un poder nada desdeñable en las sociedades contemporáneas (incluso, tal vez tengan demasiado poder). Pero hay una diferencia amenazadora: mientras que la Administración se encuentra totalmente sometida a la ley (por lo menos en el mundo del "deber ser"), los 
tribunales constitucionales, ${ }^{2}$ presentada la oportunidad, tienen la facultad de fulminar (con efectos singulares o generales) la decisión legislativa -paradigmático producto de la voluntad popular-, declarándola inconstitucional. ${ }^{3}$ Entonces, surge como un rayo la pregunta insoslayable: ¿cómo puede considerarse legítimo democráticamente que un puñado de jueces no elegidos electoralmente por el pueblo puedan dejar sin efecto la ley (desde no aplicarla al caso concreto a ser derogada, según el sistema de control de constitucionalidad del que se trate), que es la expresión máxima de la soberanía? En esto consiste la denominada dificultad contramayoritaria de la justicia constitucional, que parece ubicar a los tribunales que la integran en la vereda de enfrente de la democracia. Es decir, si todo lo que hemos dicho hasta aquí sobre la democracia la define con certeza y plenitud, la conclusión inevitable es que la jurisdicción constitucional es contramayoritaria y, en ese sentido, antidemocrática.

Precisamente en este trabajo pretendemos echar un poco de luz sobre este problema cada vez más acuciante, teniendo muy particularmente en cuenta para ello los estudios que ha llevado adelante Pierre Rosanvallon, quien ha desarrollado en los últimos años una serie de teorizaciones que conforman una novedosa perspectiva, jalonada de valiosas herramientas, que permiten apreciar con una mirada renovada la democracia y sus mutaciones. Por supuesto que el intentar resolver con mayor felicidad para la justicia constitucional la dificultad contramayoritaria nos conducirá por una serie de cuestiones aún más de fondo, que nos llevará a preguntarnos qué es (o debería ser) la democracia hoy. La tarea es ardua porque implica un viaje desde las ficciones que señala Rosanvallon -que implican ya insostenibles falsificaciones sobre la realidad-para intentar aprehender conceptos y realidades más complejos y, nos animamos a decir, más verdaderos.

2 A los fines de este trabajo, y con el objeto de comprender el más amplio universo de sistemas de control de constitucionalidad judicial posible, vamos a entender por tribunal constitucional a todo aquel habilitado para ejercer control de constitucionalidad, tanto se trate de sistemas de control concentrado como difuso, preventivo o reparador, por vía directa o indirecta, con legitimaciones activas tanto restringidas como amplias y con efecto inter-partes o erga omnes, cuyos integrantes no sean elegidos electoralmente. En síntesis, los elementos decisivos de este concepto de tribunal constitucional son: a) su naturaleza judicial; b) que sus miembros no sean elegidos popularmente; y c) que tengan reconocida -explícita o implícitamente- la facultad de ejercer control de constitucionalidad.

3 La intensidad y extensión de este poder es variable según cuál sea el sistema de control de constitucionalidad imperante en cada Estado. Por supuesto que los tribunales que ejercen control de constitucionalidad pueden declarar la inconstitucionalidad de todos los actos y normas dictados por los poderes estatales, pero la objeción contramayoritaria se hace más patente y acuciante cuando se trata de una ley formal, es decir, dictada por el Parlamento, Congreso o Legislatura, por tratarse de órganos en los que, convencionalmente, se concentra -entre los poderes constituidos- la soberanía popular. 


\subsection{Las nuevas legitimidades de Pierre Rosanvallon}

A lo largo del siglo XX, la concepción procedimental de la democracia que implicaba la automaticidad de la legitimidad como consecuencia de un resultado electoral fue perdiendo paulatinamente credibilidad. La crisis de los partidos políticos, la pérdida de confianza en los dirigentes y en las instituciones políticas, el clientelismo y otros factores corroyeron la representatividad de los electos y la propia noción de que la mayoría electoral era la expresión del pueblo o de la generalidad. ${ }^{4}$ En consecuencia, la legitimidad entendida como una cualidad jurídica, estrictamente procedimental, que es producida de modo perfecto y absoluto por la elección, se desgasta y pierde eficacia. El desencanto y la desconfianza ${ }^{5}$ que resultará de este proceso darán lugar a la aparición de otras formas de legitimidad, que comenzarán a convivir con la de cuño electoral.

Rosanvallon detecta -a partir de la década de 1980- el surgimiento de una nueva era de la legitimidad, que ha dotado a lo que consideramos como democráticamente legítimo de una nueva densidad y hondura. Así, sostiene este autor, son reconocibles tres nuevas formas de legitimidad, que se compadecen con otros tantos nuevos modos de aprehender el imperativo democrático de expresión de la generalidad social:

a. La legitimidad de imparcialidad: consiste básicamente en distanciarse de las posiciones partidistas y de los intereses particulares, de modo que "es legítimo aquello que se muestra como imparcial, desinteresado, y que cumple con la exigencia de unanimidad" (Annunziata, 2012, p. 48). Combina la independencia del poder electoral (variable estructural) con el mantenimiento de la distancia o el equilibrio (variable de comportamiento). Este tipo de legitimi-

4 En rigor, Rosanvallon (2009) sostiene que la democracia encontró sustento en dos formas de legitimidad. Por un lado, encontramos la legitimidad electoral, degradada por las sucesivas crisis de representatividad, y, por otro lado, se encuentra la legitimidad como identificación con la generalidad social, la cual fue forjada a través del poder administrativo, de manera que "la "maquinaria burocrática' constituyera en sí misma una fuerza identificada con la realización del interés general” (p. 24). En esta última especie, los funcionarios eran llamados a volverse "interesados en el desinterés" y a buscar "el acceso a la generalidad mediante las virtudes de una gestión científica". Mientras que a la legitimidad electoral se accedía mediante el voto, a la legitimidad producto de la identificación con la generalidad mediante el poder administrador se accedía por el concurso público. Esta segunda forma de la legitimidad fue debilitada por una retórica neoliberal cuestionadora de la respetabilidad del Estado, que, además, invitó a erigir al mercado como un nuevo mecanismo instituyente del bienestar colectivo (p. 26). En consecuencia, el sistema de la mentada doble legitimidad resultó sustancialmente debilitado, permitiendo el advenimiento de otras formas de legitimidad a partir de 1980.

5 Rosanvallon describe de modo muy interesante este proceso de conformación de una sociedad de la desconfianza en La contrademocracia. La política en la era de la desconfianza (2007), especialmente en pp. 21-42. 
dad define un poder entendido como lugar vacío, de manera que la calidad de generalidad de una institución que goza de legitimidad de imparcialidad está por el hecho de que nadie puede apropiársela; en este sentido, se trata de una generalidad negativa. Es la legitimidad que se les reconoce a las autoridades de control o regulación (Rosanvallon, 2009, p. 28).

b. La legitimidad de reflexividad: aquí se trata de multiplicar los enfoques parciales para lograr una comprensión más plural de las cosas y, por ende, más completa. Es una "generalidad por multiplicación" (Rosanvallon, 2009, p. 28). De esta manera, la tarea a llevar a cabo por la reflexividad consiste en corregir, mediante mecanismos compensadores, la incompletitud de la democracia electoral. Es decir que la legitimidad de reflexividad trata especialmente de corregir los incumplimientos resultantes de la asimilación de la mayoría electoral a la voluntad del cuerpo social tomado en su globalidad. Un tribunal constitucional gozaría de este tipo de legitimidad al hacer pasar por el tamiz de la Constitución las decisiones adoptadas por el partido mayoritario (p. 28). La pluralidad necesita ser condensada, simplificada, por los procesos electorales para erigir mayorías gobernantes. Sin embargo, como contraparte, existen instancias reflexivas que recomponen la diversidad a través del debate público, poniéndoles freno a las decisiones mayoritarias, especialmente cuando estas invaden el "coto vedado" de los derechos.

c. La legitimidad de proximidad: "La proximidad supone [...] una inmersión radical en el mundo de la particularidad, una preocupación por los individuos concretos, una extensión en el campo de atención o [...] un descenso a la generalidad" (Annunziata, 2012, p. 48). En efecto, de lo que se trata aquí es de "tomar en consideración la multiplicidad de situaciones, mediante el reconocimiento de todas las singularidades sociales". Si se la aprecia como cualidad de un comportamiento, es el resultado de "la acción de un poder que no olvida a nadie, que se interesa en los problemas de todos" (Rosanvallon, 2009, p. 28), implica, pues, una cercanía y una empatía que supere la distancia impuesta por la representación tradicional en el vínculo entre gobernantes y gobernados.

En nuestro análisis nos interesa considerar la denominada dificultad contramayoritaria de los jueces desde la perspectiva que ofrece la legitimidad de reflexividad. A continuación, indagaremos un poco más sobre este tipo de legitimidad en el pensamiento de Pierre Rosanvallon. 


\section{La democracia reflexiva}

Estado se llama al más frio de todos los monstruos fríos. Es frio incluso cuando miente; y ésta es la mentira que se desliza de su boca: "Yo, el Estado, soy el pueblo"

(Nietzsche, como se citó en Vita, 2009, p. 214)

Rosanvallon (2009) explica que la concepción electoral representativa de la democracia, puramente procedimental, se estructura a partir de tres presupuestos: a) "la identificación de la opción electoral con la expresión de la voluntad general"; b) "la asimilación de los electores con el pueblo"; c) "la perdurable inscripción de la actividad política y parlamentaria en la continuidad del momento electoral" (p. 183). Esta concepción de la democracia es, para este autor, una versión moderada de lo que denomina la "democracia inmediata".

Vale la pena detenerse en este concepto y en sus implicancias para comprender mejor la tarea correctiva y compensadora que la reflexividad y sus instituciones deberán llevar a cabo sobre esta concepción de la democracia.

La democracia inmediata remite implícitamente a la idea de gobierno popular que se instala con la Revolución Francesa, en la cual el poder constituyente es la expresión más fiel del ideal democrático que, cuando es originario, debe crear un nuevo régimen como si no hubiese habido historia, es decir, es fundacional ex nihilo. El pueblo debe reunirse y, siguiendo su sentido común, tomar todas las decisiones necesarias, catalizando una "'electricidad moral', vector natural de una manifestación unánime”. Así, el poder constituyente expresa una soberanía originaria, extraordinaria, incondicionada, suprema y directa. Tiene la necesidad de producir una ruptura absoluta con el pasado (en el caso, con la herencia monárquica), de manera que solo el presente pueda ser revolucionario, transformándose la voluntad popular en "la versión secularizada del poder divino de crear un orden sin estar sometido a él" (Rosanvallon, 2009, p. 185). En esta inteligencia, la democracia solamente es concebible al cabo de una revolución, en tanto conforma una fuerza insurreccional imparable que opera una desinstitucionalización radical de la política. ${ }^{6}$ Este orden de ideas, que encuentra la explicación de su origen en razones predominantemente históricas, se proyectó hacia adelante traduciéndose en una democracia monista y

6 Esta identificación entre soberanía popular y una radical autoinstitucionalización de lo social reaparecerá con fuerza en el decisionismo de Schmitt y en la perspectiva comunista de un "Estado para todo el pueblo" (Rosanvallon, 2009, pp. 186 y 188). 
unidimensional, que perdurará -instauración de la representación mediantebajo la forma de un hiperelectoralismo (Rosanvallon, 2009, p. 189).

Rosanvallon (2009) va a contrastar la democracia inmediata con lo que él denomina democracia compleja, "basada en la diversificación cruzada de las temporalidades y de los modos de expresión de la vida política” (p. 190). Para ello, reivindicará parte del pensamiento de Condorcet. Mientras que muchos de los contemporáneos del girondino pensaban que el régimen representativo era un sucedáneo práctico de la improbable democracia directa, él revisa el problema y se plantea el camino para conformar una democracia representativa. Para ello es necesario pluralizar los modos en los que se ejerce la soberanía popular, que no puede agotarse en el sufragio ni en las decisiones de los representantes electos en su consecuencia. ${ }^{7}$ Esta visión permite reinterpretar la división de poderes, que deja de ser un reparto más o menos equilibrado de prerrogativas para ser una condición de la profundización de la democracia, convirtiéndose en un canal de la participación de un sujeto necesariamente plural como es el pueblo. Es decir, la multiplicación de las expresiones parciales es la mejor vía para acceder a una aproximación de conjunto. En esta inteligencia, el poder social se torna más efectivo si se pluralizan los medios de involucramiento de las partes del todo social, lo cual requiere multiplicar las instancias funcionales que limitan el poder de las mayorías electorales, aumentando la participación social en el proceso político (Rosanvallon, 2009, p. 192). Lo relevante no es tanto la división de poderes, sino la separación de estos en la medida en que cada uno se transforme en una instancia de control de los demás, ${ }^{8}$ lo que

7 El intelectual francés Marie-Jean-Antoine Nicolas de Caritat, marqués de Condorcet (1743-1794), además de ser un destacado pensador político, era matemático. Combinando ambas disciplinas escribió en 1785 su Ensayo sobre la aplicación del análisis a la probabilidad de las decisiones sometidas a la pluralidad de voces. En esta obra, describe la intransitividad como posible de la mayoría: entre un mismo electorado, y en el curso de una misma elección, es posible que una mayoría prefiera $\mathrm{A}$ antes que $\mathrm{B}$, que otra mayoría prefiera $\mathrm{B}$ antes que $\mathrm{C}$ y que una tercera mayoría prefiera $\mathrm{C}$ antes que $\mathrm{A}$. Las decisiones adoptadas por una mayoría popular siguiendo este modelo de escrutinio serían, pues, incoherentes con respecto a las que adoptaría un individuo racional. A este fenómeno se lo denominó la paradoja Condorcet. Estos estudios parecen señalar la desconfianza que le generaba a este pensador el fundar exclusivamente la democracia en las decisiones de un parlamento o asamblea.

8 Ya Hamilton señalaba, en el $\mathrm{N}^{\circ} 78$ de El Federalista, que los jueces no tienen ni la espada ni la bolsa, y que en ese sentido se trataba del más débil de los poderes del Estado. Sus decisiones incluso han de apoyarse en definitiva "en la ayuda del brazo ejecutivo hasta para que tengan eficacia sus fallos". En este contexto, los jueces están llamados a cumplir primordialmente una función de control, en particular cuando los poderes políticos (que deben encarnar fundamentalmente a la eficacia de la acción de gobierno) se exceden de sus marcos de actuación establecidos en la Constitución, sea en desmedro de los derechos de las personas, sea en las facultades de otro órgano o poder estatal. Inclusive hay autores que sostienen, avanzando aún más en esta dirección, que la Corte Suprema debe cumplir el 
tiende a garantizar que el comando del proceso político esté en manos de la generalidad social.

Una segunda dimensión que hay que atender para lograr la formación de una generalidad de multiplicación es la pluralización de los tiempos de lo político. En efecto, la cuestión de la temporalidad es muy relevante y tiende a desbaratar la idea de que las autoridades electoralmente elegidas implican una reedición permanente de la soberanía popular, como una suerte de reflujo del poder constituyente. Esa visión solo es aceptable si se la acota a momentos excepcionales. Si, en cambio, se la pretende convertir en una regla ordinaria, "la voluntad general no sería más que el capricho de cada momento”, como sostenía Renán (Rosanvallon, 2009, p. 195). De manera que es necesario superar la temporalidad presente para admitir que en la democracia (y, en verdad, en todo régimen político y social) conviven una pluralidad de temporalidades: el tiempo limitado del mandato electoral, el tiempo corto de la opinión, el tiempo largo de la constitución y el tiempo vigilante de la memoria. Todos ellos deberán confrontarse y ajustarse incesantemente, de modo de darle forma al ideal democrático. Así, de este movimiento permanente de reflexión -en sus diversas temporalidades- se arribará a la construcción histórica de la voluntad general. La democracia es, pues, una de las resultantes de esa construcción histórica del pueblo que no se limita a señalar los modos en los que una colectividad se gobierna a sí misma, sino que tiende a la conformación del régimen que posibilita la generación de una identidad común, en la que juegan la realización de valores, la búsqueda de objetivos generales y de largo plazo relativos a la forma que deba tener una sociedad deseada, imbricada con los propósitos, con los sentidos que ella albergue.

Finalmente, Rosanvallon (2009) considera otras dos cuestiones relevantes. Por la primera de ellas se advierte que la necesidad de reflexividad de la democracia no es solamente el resultado de la concurrencia de ciertas condiciones prácticas de una generalidad de multiplicación, sino que la reflexividad resulta una imposición lógica de la vida democrática. Ello es así porque, en contra de lo sostenido por los defensores de la democracia inmediata, es lógicamente impo-

rol de moderador del proceso político. Ello es así porque la funcionalidad del régimen político está ligada al equilibrio de sus poderes, de modo de buscar entre ellos la cooperación y no el bloqueo, amén de evitar la expansión de uno en perjuicio del otro. Con ese objetivo es conveniente que exista un órgano cuya misión sea velar por el correcto funcionamiento de la separación de poderes, aunque permaneciendo al margen de ellos. Este pouvoir neutre -como lo denomina Constant- en las repúblicas modernas coincide frecuentemente con el órgano al que se le ha encomendado el control de constitucionalidad. 
sible autofundar una democracia ex nihilo. Como agudamente señala el profesor del Collège de France, la revolución (y el poder constituyente que engendra) "quiere ser invención y ruptura, pero no se enuncia ni se comprende si no es en la denuncia de un mundo existente y en la referencia a los elementos de una historia" (Rosanvallon, 2009, p. 198). Es decir, no es posible un comienzo absoluto, sino que es necesaria la referencia a lo anterior, de manera de poder tomar una imprescindible distancia que permita advertir al sujeto reflexivo una diferencia, tornando posible de este modo la formación de una identidad o la formulación de un proyecto colectivo. Como afirma Ricoeur, "nunca se asiste al comienzo de la regla, sólo se puede ir de institución en institución" (Rosanvallon, 2009, p. 199, como se citó en Ost, 1999). La imposibilidad de la democracia para autoengendrarse va de la mano de su incapacidad para autocontrolarse. Rosanvallon se refiere, específicamente, a la validación de los mandatos o de los poderes efectuados por las asambleas, los cuales han fracasado en todas las latitudes y que en Francia desaparecieron cuando la Constitución de 1958 le otorgó al Consejo Constitucional la facultad de ser el árbitro final de las elecciones. Empero, creemos que la incapacidad de la democracia, entendida como mera democracia electoral, para controlarse a sí misma es bastante más amplia. En efecto, todo orden político requiere sostener un delicado equilibrio entre un poder eficaz y adecuadas instancias de control que tiendan a evitar y, en su caso, corregir posibles abusos o desviaciones que puedan presentarse. Los controles entre autoridades elegidas electoralmente han sido, y en esto coincidimos con Rosanvallon, de escasísima efectividad. Como muestra, basta mencionar que en 160 años de vivir bajo una Constitución ningún presidente o vicepresidente argentino ha sido destituido por acusación y juzgamiento del Congreso (juicio político), lo cual no habla tanto de la probidad de los gobernantes nacionales, sino más bien de la ausencia de controles políticos eficaces. Es en estos contextos, contar con terceros reflexivos -como los jueces constitucionales- adquiere un altísimo valor social y político, al punto de participar en la ampliación y profundización del sistema representativo, siempre, claro es, en el marco de una democracia compleja que recepte la categoría de la legitimidad de reflexividad.

Por otra parte, no debe perderse de vista que los tribunales constitucionales tienen confiada la misión de proteger los derechos individuales y colectivos, ${ }^{9}$

9 Adopto esta clasificación de los derechos en virtud de que son titularizados por sujetos de derecho individuales (la vida, la libertad, la propiedad) o por sujetos de derecho colectivos (los gremios, los usuarios y consumidores, etc.). El lector argentino está, en general, más familiarizado con la taxonomía de los derechos que propone diferenciar entre los derechos individuales de inspiración liberal, 
de manera de transformarlos en un auténtico coto vedado para las autoridades.

Marcel Gauchet (1995) ha señalado el importante desarrollo de la conciencia de los ciudadanos en torno al rol central que juegan los jueces en la defensa de sus derechos. Así, el Estado garantizador pasó a primer plano sobre el Estado gestor y planificador, apareciendo -paralelamente al desarrollo de este proceso- dos figuras que han pasado a ocupar un primer rango: la prensa y los jueces. Ese dúo de poder informal tiene por misión completar el sistema representativo y ello se aprecia, en el caso de los jueces, por la defensa de la individualidad, de la personalidad ante los abusos de los poderes públicos. Así, la acción judicial (particularmente la de los jueces que actúan en el ámbito del derecho público) se transforma en una pieza central del sistema representativo (en el sentido simbólico del término), pues es el factor clave que nos permite gobernarnos a nosotros mismos a través de otros hombres que nos gobiernan. De esta manera, los jueces son los guardianes del principio de composición del cuerpo social. Tienen por función mantenerlo inalterado, esto es, preservar las condiciones que hacen a su poder soberano, igual a sí mismo en todos los instantes del tiempo. Si el juez se le opone al pueblo, es con el fin de evitarle ponerse en contradicción consigo mismo (Gauchet, 1995).

A continuación, pasaremos a examinar las instituciones de la legitimidad de reflexividad de mayor relevancia: los tribunales constitucionales.

\section{Los tribunales constitucionales como instituciones de la legitimidad de reflexividad 3.1. El control de constitucionalidad como mutación de la democracia electoral}

Si el siglo XIX fue el siglo del Poder Legislativo (encarnado en parlamentos y congresos), el XX y los albores del XXI han sido los de la justicia constitucional. En efecto, así como las jefaturas de Gobierno y de Estado y las asambleas parlamentarias formaban parte del elenco estable de las constituciones clásicas, a partir de 1945 las constituciones de casi todo el mundo fueron incorporando la jurisdicción constitucional, ${ }^{10}$ que básicamente implica que un órgano imparcial

reconocidos en la Constitución de 1853/1960 (artículos 14, 17, 18, 19), los derechos sociales introducidos en la reforma de 1957 (artículo 14 bis o nuevo) y los derechos colectivos o de incidencia colectiva, incorporados en la reforma de 1994 (artículos 41 y 42, por ejemplo).

10 Es cierto que hay varias y notables excepciones. El sistema de control judicial de las leyes comienza a funcionar en los Estados Unidos en 1803, a partir de la sentencia de la Suprema Corte federal en el célebre caso Marbury v. Madison. Sin embargo, debe tenerse presente que la Constitución federal de 1787 no le otorgaba tal prerrogativa en forma expresa a la Suprema Corte de Justicia, que se "autorreconoció" pretorianamente dicha prerrogativa. 
e independiente, cuyos miembros no son elegidos popularmente, pueda dejar sin efecto (sea inter partes, sea erga omnes) o rectificar -conforme a las distintas modalidades y efectos vigentes, según cuál sea el sistema imperante en cada ordenamiento jurídico- una decisión proveniente de cualquier autoridad pública, incluso de leyes sancionadas por los parlamentos. A esto se lo denomina control de constitucionalidad.

El éxito de la jurisdicción constitucional no deja de ser sorprendente en cuanto propone una forma de legitimidad diferente a la derivada de la tradición democrática clásica, que entroniza como principio legitimador a la soberanía popular y que se vuelve operativa mediante el sufragio. Así, a) el pueblo elige a sus representantes mediante el voto; b) por medio de este procedimiento electoral se determina la voluntad mayoritaria del pueblo; c) mediante la votación de las leyes los elegidos expresan y traducen esta voluntad mayoritaria; d) por el control judicial de constitucionalidad los magistrados enjuician las leyes que expresan y traducen la voluntad mayoritaria del pueblo. Los tres primeros elementos ( $\mathrm{a}, \mathrm{b}, \mathrm{c})$ desarrollan la definición clásica de democracia. El cuarto elemento $(\mathrm{d})$ es extraño, ajeno a aquella definición. Se presenta como una ruptura, como una discontinuidad que configura más bien una encrucijada que nos permite acceder a una conformación política más compleja -también más contradictoria- que persigue hacer cohabitar bajo el mismo régimen los principios de la soberanía popular y los de la vigencia de los derechos humanos. Estos últimos, en la medida en que son reconocidos por los textos constitucionales, se convierten en un freno, en un límite a la voluntad expresada por los elegidos, aun cuando representen a una mayoría abrumadora.

La proliferación y el creciente activismo de los tribunales constitucionales han venido gestando una formidable mutación de las concepciones vigentes sobre la democracia, que obliga a plantearse revisiones y renovaciones urgentes de la filosofía política y jurídica. No obstante ser para algunos una "piedra de escándalo", en cuanto elemento disruptivo en el sentido ya señalado más arriba, el control de constitucionalidad llevado a cabo por las cortes o tribunales constitucionales es celebrado con un fuerte apoyo público (lo cual puede apreciarse globalmente, más allá de los sistemas considerados en su particularidad) y los tribunales que lo llevan a cabo son percibidos como exponentes de la más legítima institucionalidad democrática (Rosanvallon, 2009, p. 202).

En definitiva, los tribunales constitucionales se han convertido en la más destacada institución de la reflexividad, proponiendo una superación de las concepciones inmediatas y procesalistas de la democracia para permitir aden- 
trarnos en una versión más compleja y complicada de esta, que no se agote en la voluntad mayoritaria expresada electoralmente y el proceso decisional derivado de ello, sino que instale decididamente la efectiva vigencia de los derechos humanos como un principio legitimador de la misma envergadura que la soberanía popular. De este modo, nos adentramos en el concepto de democracia compleja de Rosanvallon y de lo que el constitucionalista francés Dominique Rousseau denomina democracia continua.

En esta inteligencia, y luego de describir sucintamente los dos grandes modelos de control de constitucionalidad: el liberal, con su énfasis en poner un límite al poder estatal, y el europeo-continental (kelseniano), enfocado en crear un legislador negativo que garantice la intangibilidad del sistema jerarquizado de fuentes, Rosanvallon se aboca a desarrollar lo que denomina la concepción democrático-reflexiva del control de constitucionalidad. Así, sostiene que, a las finalidades del control, además de comprender las ya mencionadas, debe añadírseles la de incrementar indirectamente el poder del ciudadano sobre las instituciones $\mathrm{o}$, al decir de Dominique Rousseau, poner en funcionamiento "un régimen alternativo y complementario de enunciación de la voluntad general" (como se citó en Rosanvallon, 2009, p. 204). Rosanvallon (2009) rastrea la búsqueda del fortalecimiento del poder ciudadano en la tradición norteamericana, en algunos elementos de la democracia jeffersoniana, preocupada por "la tiranía de las legislaturas" (p. 204, citando una carta de Jefferson a Madison). ${ }^{11}$ Sostiene que "en esta perspectiva, la judicial review podía ser asimilada a un poder popular de resistencia" y que Jefferson "apelaba a la adopción de una declaración de derechos, entendiéndola como un medio para 'garantizar el pueblo contra el gobierno federal”' (Rosanvallon, 2009, p. 204). En esta inteligencia, el mejor método para evitar que un Gobierno se convierta en opresivo consistiría en fortalecer el poder de los ciudadanos, de manera que la regla de derecho pueda ser en el marco de lo recién expuesto como equivalente a un mecanismo de democracia directa. En este orden de ideas, vuelven a aparecer las consideraciones de Gauchet (1995) cuando justifica que el juez puede limitar la fuerza de las mayorías, de manera que el pueblo no se contradiga a sí mismo.

11 También encuentra antecedentes en la Francia de la primavera de 1793. En efecto, en ese momento aparecieron concepciones semejantes a la jeffersoniana, en las que se postulaba que un jury nacional podría funcionar como "un medio para preservar al pueblo de la opresión del cuerpo legislativo" (Rosanvallon, 2009, p. 205). 


\subsection{Control de constitucionalidad y reflexividad}

De lo expuesto hasta aquí se concluye que los tribunales constitucionales son terceros, respecto a las autoridades elegidas por vía de sufragio, que ejercen una función de representación social y política, fruto de una mutación de la democracia basada en la transformación del vínculo entre derecho (control de constitucionalidad) y principio mayoritario (democracia electoral). Esta funcionalidad de los tribunales constitucionales viene a ratificar la idea de Rosanvallon sobre la existencia de una democracia compleja compuesta por varias dimensiones del pueblo. Particularmente confirma la existencia del pueblo-principio. ${ }^{12}$ Esta noción se encuentra fundada en la igualdad, en cuanto elemento que incluye a todos en la sociedad. Darle vida al pueblo-principio es asegurar el reconocimiento para todos de los bienes públicos que conforman el aspecto más estructural del bien común: los derechos humanos. Estos derechos constituyen la ciudadanía individual en tanto lazo de pertenencia a la comunidad, y reconocen la humanidad del sujeto en cuanto titular de una singularidad irreductible. Esta concepción del pueblo se encarna en el sujeto de derecho, que ya no refiere a un hombre meramente formal o ficcional, sino al "hombre más concreto que existe" (Rosanvallon, 2009, p. 194). En este orden de ideas, los tribunales constitucionales ejercen la función central de encarnar al pueblo-principio recordándoles a las autoridades popularmente elegidas que el soberano no se reduce a su expresión electoral mayoritaria, reeditando así, constantemente, la oposición del pueblo de los votos y el pueblo de los principios.

Otra cuestión que debe destacarse son las diferentes temporalidades en jue-

12 Las otras dos dimensiones son el pueblo-electoral y el pueblo-sociedad. El primero se expresa de manera inmediata a través de la conformación de una mayoría y de una minoría al cabo de una elección. A pesar de que los resultados de una elección dividen, correspondería considerar esta variante electoral del pueblo como constitutiva de la generalidad social, en tanto implica el reconocimiento de una igualdad radical manifestada en que todos pueden concurrir a las urnas a elegir a los candidatos de su preferencia. Es decir que, como dice Rosanvallon (2009, p. 193), el procedimiento que fundamenta al pueblo electoral tiende a unificar. Por otro lado, la cifra electoral posee una contundencia que permite cerrar toda controversia. El pueblo-social, por su parte, está conformado por la sucesión ininterrumpida de todas las minorías, es la sumatoria de las protestas, de las denuncias de situaciones vividas como la alteración de un orden justo, "manifestación sensible de lo que hace o deshace la posibilidad de un mundo en común. Es un pueblo cuya unidad está dada por ser una fuerza vital que se expresa en esa contradicción en movimiento que llamamos sociedad (Rosanvallon, 2009, p. 193). La faramalla de las cuestiones que constituyen el lazo colectivo nos permite entenderla como una generalidad social, que se expresa en el ámbito de lo que Rosanvallon denomina la "contrademocracia”, continente que es resultado de un conjunto de prácticas de control, de obstrucción y de enjuiciamiento, a través de las cuales la sociedad ejerce su poder de corrección y de presión. En consecuencia, junto al pueblo-electoral emergen las figuras de un pueblo-vigilante, de un pueblo-veto y de un pueblo-juez (Rosanvallon, 2007). 
go en los distintos pueblos. El pueblo-electoral está dominado por la inmediatez, por el corto plazo, mientras que el pueblo-principio inscribe generalmente su actuación en el largo plazo. No se trata de ser un mero árbitro en la faz agonal de la política (aunque, en ocasiones, deberá serlo), sino de participar en "la determinación y el fortalecimiento del ser-juntos” (Rosanvallon, 2009, p. 206). Por otra parte, al operar permanentemente a través de los derechos y principios fundamentales (constitucionales), los tribunales que ejercen control de constitucionalidad cumplen una función política de control y vigilancia de la memoria colectiva, haciendo presente los principios organizativos de la vida social y trayendo a la actualidad las promesa que la colectividad se hizo alguna vez a sí misma. Rosanvallon (2009), con todo, no coloca las distintas temporalidades en conflicto, sino que pretende integrar y armonizar los tiempos cortos del poder ejecutivo y del parlamento y los ciclos largos que impone el derecho constitucional y sus operadores más eminentes a través de una tarea permanente de reflexión que contribuya a la deliberación democrática y, más específicamente, a la formación de una voluntad común que permita superar el culto del presente y de la decisión inmediata (Rosanvallon, 2009, p. 211).

La armonización de las dos temporalidades y de los dos pueblos que se manifiestan a través de ellas les permite a los tribunales constitucionales dotar de mayor profundidad a la vida democrática, cumpliendo el rol de un tercero reflexivo productor de sentido. De este modo, los tribunales constitucionales participan en la ampliación y profundización del sistema representativo, facilitando la multiplicación de los distintos modos de representación.

Concluyendo este apartado, digamos, pues, que los tribunales constitucionales permiten corregir las desviaciones del sistema representativo (trayendo a los actuales representantes del pueblo-electorado los enunciados anteriores de la voluntad general, especialmente los consagrados en ese pacto e instrumento de gobierno a largo plazo que es la constitución) al tempo que desarrollan su funcionalidad democrática, enriqueciendo la deliberación política, permitiéndonos acceder a una profundización del sentido del con-vivir y del ser-juntos. De este modo, el control de constitucionalidad permite la alternancia de dos maneras de comprender y construir la voluntad general en las democracias: por una parte, la lógica del número, de las mayorías, que hace prevalecer la opinión inmediatamente predominante; por la otra, la lógica de la razón, que implica alargar la mirada gracias a la reflexividad, en la que la voluntad popular se construye a partir del razonamiento y del ejercicio de la memoria en torno a los compromisos que el pueblo asumió consigo mismo. La combinación dinámica 
de estos dos pueblos es tan indispensable como diferentes y complementarios son ellos entre sí, propendiendo a la reducción de la brecha entre las preferencias de hoy y las finalidades y significaciones de siempre, tornando así menos visible la demarcación entre la democracia como procedimiento y la democracia como contenido.

\subsection{La dificultad contramayoritaria}

Aquí retornamos a la pregunta con la que hemos comenzado este trabajo y que, de alguna manera, lo atraviesa íntegramente: ¿es democrático que un grupo de jueces no elegidos popularmente puedan imponer sus decisiones a los representantes del pueblo, esto es, contra el parlamento o congreso, o contra el Poder Ejecutivo?

Este es un debate que se originó hace más de doscientos años en los Estados Unidos y que, desde la década de 1960, se lo ha venido conociendo como la dificultad contramayoritaria de los jueces (refiriéndose a los que ejercen control de constitucionalidad), tal la denominación que introdujo Alexander M. Bickel (1986) en su ya clásico The Least Dangerous Branch de 1962. En los últimos cincuenta años, la cuestión ha merecido ser estudiada por varios de los constitucionalistas y politólogos más eminentes de los Estados Unidos y, más recientemente, se ha convertido en una cuestión clave de la teoría política y jurídica en Europa y en América Latina, toda vez que, como ya hemos tenido oportunidad de referir, la jurisdicción constitucional es hoy un fenómeno global.

En general, los objetores de la jurisdicción constitucional consideran -como bien reseña Rosanvallon (2009)- que

la defensa de la razón constitucional en el fondo no hace más que reactualizar las viejas prevenciones liberales contra el poder del número y que las antiguas figuras aristocráticas y de exigencia de capacidades previas [capacitaires] han adoptado hoy la máscara de los jueces constitucionales. (p. 226)

Al decir de Carlos Nino (1997), el control de constitucionalidad judicial implica el ejercicio de un cierto elitismo epistémico que se lleva mal con la democracia. El propio Bickel (1986) sostiene que los jueces constitucionales invocan al pueblo para justificar la revisión judicial cuando, en realidad, lo que hacen es justificar una frustración de "la voluntad de aquellos que efectivamente representa[ban] la mayoría prevaleciente" (p. 16). La revisión judicial representa "el poder aplicar y dar forma a la Constitución, en cuestiones de 
la mayor importancia, contra los deseos de las mayorías legislativas que son, a su vez, incapaces de torcer la decisión judicial” (Bickel, 1986, p. 17). Si la democracia implica que los ciudadanos puedan conducirse según sus propios juicios (y, por añadidura, de los representantes que libremente eligen), ese derecho resulta gravemente afectado por las intervenciones de la Corte Suprema (Waldron, 1993), en tanto máxima expresión de la jurisdicción constitucional en el sistema jurídico-político norteamericano, de manera que dicho tribunal es percibido por los objetores y sus seguidores como una institución contramayoritaria y, en consecuencia, antidemocrática.

Rosanvallon (2009, p. 227) se pregunta si, en atención a la dificultad contramayoritaria, resultaría necesario dotar a los tribunales constitucionales de una legitimidad directamente electoral. Luego de pasar revista a los disímiles antecedentes de la jurisdicción constitucional en los Estados Unidos y en Francia, el profesor del Collège de France distingue entre dos tipos de elecciones de jueces: la "pura elección o elección de confianza", como procedimiento de consagración popular de una autoridad, que tiene como finalidad explícita la confianza de los electores en una persona y, a fin de cuentas, en una institución; y una "elección partidaria", que necesariamente conlleva una confrontación de intereses o ideas, en la que de lo que se trata es de elegir entre personas que compiten o, en su caso, de escoger entre puntos de vista antagónicos. Con buen criterio, Rosanvallon (2009) sostiene que la elección partidaria de los jueces atenta contra la misión y la funcionalidad de los tribunales constitucionales, en tanto suprime de hecho la dimensión de generalidad que le es consustancial. En efecto, "una corte constitucional debe encarnar estructuralmente una capacidad de reflexividad e imparcialidad que quedaría destruida por la inscripción en un orden partidario" (Rosanvallon, 2009, p. 237). ${ }^{13}$ Por su parte, la pura elección o la elección de confianza implica un mecanismo en el que generalmente hay un solo candidato (no hay competencia), que es nominado con anterioridad (existen varios procedimientos al respecto) generalmente sobre la base de sus aptitudes y competencias. En un segundo paso se realiza la elección que, en rigor, es una confirmación..$^{14}$ Es cierto que estos mecanismos

\section{Cursivas en el original.}

14 En la mayoría de los estados que integran los Estados Unidos se utiliza un sistema similar al descrito, denominado Merit Plan. En el ámbito federal, el mecanismo es totalmente distinto: los jueces son elegidos por el presidente con el acuerdo del Senado, que, cuando se trata de ministros de la Suprema Corte, requiere una mayoría calificada. En la Argentina existe un sistema prácticamente idéntico al imperante para la designación de jueces federales en los Estados Unidos (los jueces federales inferiores son designados por el presidente con acuerdo del Senado con base en una terna elevada 
tienen una fuerte carga utópica y que su funcionamiento en la realidad tiende a ser colonizado por cuestiones políticas más bien coyunturales. Ello conduce a la conclusión poco auspiciosa, desde la lógica del sufragio como factor que otorga legitimidad, de que la distinción fáctica entre los dos tipos de elecciones es muchas veces harto difícil. De allí que Rosanvallon (2009) concluya que en materia de tribunales constitucionales no se debe intentar legitimarlos por el recurso al voto, sino que más bien "resulta decisivo argumentar la importancia que reviste la no elección para esas funciones" (p. 237).

Es por este orden de razones que parece preferible no intentar legitimar los tribunales constitucionales -en tanto instituciones de la reflexividad- mediante la vía de la "democratización por sufragio", es decir, aceptando como paradigma democrático verdadero o superior la lógica de la elección, sino que la justificación debe provenir de la propia lógica de la reflexividad, esto es, de la instauración de instituciones que puedan garantizar el interés general más allá de las diferencias del plano electoral. La conocida distinción entre la faz agonal y la faz arquitectónica de la política se ajusta sin dificultad a la democracia contemporánea. Es dable referirse así a una faz agonal de la democracia caracterizada por la competencia entre personas y programas diferenciados, y a una democracia arquitectónica, que permite elevar la mirada por sobre las coyunturas y conflictividades cotidianas que se encuentran al cuidado de las instituciones reflexivas o imparciales. La democracia actual es, así, necesariamente dual. La clave no es confundir una con la otra, sino, por el contrario, profundizar las condiciones de legitimidad propias de cada una de estas esferas del universo democrático (Rosanvallon, 2009, p. 239).

Finalmente, es oportuno hacer mención a una de las críticas que suelen

por el Consejo de la Magistratura al cabo de un concurso público). En el año 2003 se dictaron dos decretos del Poder Ejecutivo, los 222 y 588, que limitaron la discrecionalidad del presidente en la designación de los jueces de la Corte Suprema, en el primer caso, y de los jueces federales inferiores, en el segundo. El mecanismo se iniciaba con la postulación de un candidato a cubrir la vacante. El Ministerio de Justicia podía recibir apoyos o rechazos a la postulación, que podía provenir tanto de personas físicas como jurídicas. Se celebraba una audiencia pública a efectos de que el postulante pudiese dar razón de su candidatura y, especialmente, de los rechazos o críticas que se le habían formulado. Luego, el Ministerio de Justicia elaboraba un informe en el que daba cuenta del procedimiento. Lo que surgiese de dicho informe no era vinculante para el Poder Ejecutivo. La iniciativa, inaugurada con la postulación de Eugenio Zaffaroni como magistrado de la Corte Suprema, fue recibida con buenas expectativas, las cuales fueron defraudadas ante los recortes de información que se advertían en el informe del Ministerio. El sistema se desacreditó y prácticamente nunca se utilizó en las designaciones de los jueces federales de cámara y de $1^{\text {a }}$ instancia, so pretexto de mediar razones de urgencia para concretar los nombramientos. El procedimiento reseñado no constituía un mecanismo de elección, pero sí de nominación que, de haber sido bien implementado, podría equivaler a una elección de confianza. 
formulársele recurrentemente a la justicia constitucional: el riesgo de tornar posible "el Gobierno de los jueces", desplazando a las autoridades elegidas por el voto popular. En primer lugar, señalemos que tal hipótesis no se ha verificado jamás en toda la historia del constitucionalismo, sino que, más bien, la amenaza más palpable es la opuesta: que las presiones de los poderes estatales que se conforman electoralmente neutralicen la tarea de reflexividad de los tribunales constitucionales. Por otro lado, la posibilidad de actuación de los tribunales se encuentra limitada: normalmente, la interpretación de los tribunales tiene que ajustarse a un texto; hay una actitud prudencial característica de los jueces constitucionales que es la autorrestricción (self-restraint), por la que se expresa una cierta deferencia por el obrar de los poderes electivos, todo lo cual conduce a sancionar un acto o una norma con su inconstitucionalidad cuando se verifica una incompatibilidad inconciliable entre esta y la Constitución; luego, hay cuestiones que generalmente son irrevisables en tanto actos de naturaleza política (v.gr. declaración de guerra, estado de sitio, etc.); en algunos sistemas el control de la norma es anterior a su sanción (previo), mientras que en otros es posterior; en algunos el efecto es derogatorio, mientras que en otros es solamente para el caso concreto; etc.); los criterios de designación son estrictamente de competencia o idoneidad técnica; en tanto instituciones reflexivas, su proceder está fuertemente orientado por criterios éticos avalados en un fuerte prestigio social, todo lo cual genera confianza (al estilo de las "instituciones invisibles" de Arrow) o autoridad. ${ }^{15}$

\section{A modo de conclusión}

"The question is", said Alice, "whether you can make words mean so many different things".

"The question is", said Humpty Dumpty, "wich is to be the master-that's all".

(Lewis Carroll, Througt the Looking-Glass and what Alice found there)

15 Es interesante traer a colación la distinción que realizaban los romanos entre autorictas y potestas. Mientras que la primera es el saber socialmente reconocido, la segunda es el poder socialmente reconocido. Desde esta perspectiva podría pensarse que el juez constitucional, a través de su razonamiento, no está en sentido último haciendo ejercicio de un "poder", sino de un "saber" que se le ha reconocido. A lo sumo, puede pensarse que si el juez tiene poder -que efectivamente lo tiene-, este se legitima por su "saber". Es decir que la potestad y la autoridad, en los sentidos apuntados, responden a ámbitos distintos y a fuentes de legitimidad también diferentes. El gobernante no gobierna en virtud de su conocimiento o sabiduría, sino porque se le reconoce un poder que se legitima por la elección popular o en el consenso. En cambio, el juez constitucional no es elegido popularmente, sino que es designado por su saber. 
We are under a Constitution, but the Constitution is what the judges say it is.

(Charles Evans Hughes -1862-1948-, Chief Justice de la Suprema Corte de los Estados Unidos entre 1930 y 1941)

Luego de haber recorrido los aspectos más sustanciales del tratamiento que Pierre Rosanvallon hace de la legitimidad de reflexividad en general y de su aplicación en particular a la función que desempeñan en la democracia los tribunales constitucionales, finalizaremos esta exploración con algunas reflexiones personales que pretenderemos vertebrar con las del eminente pensador francés.

Está claro que Rosanvallon lleva adelante una explicación que gira permanentemente en torno al reconocimiento, diferenciación y complementariedad entre visiones dualistas de la democracia: la democracia electoral y la democracia reflexiva; la democracia del número y la democracia de la razón; la democracia de la lucha por el poder y la democracia que vela por la realización de un proyecto común, del ser-juntos. En suma, la democracia como régimen político y la democracia como forma de sociedad. Se acepta, al menos en el desarrollo que hemos recorrido, que electoralmente los elegidos por el voto representan a los votantes, es decir, a los gobernados. Esta es una legitimidad que se presenta como naturalizada y que se enuncia como verdadera. Claramente, el esfuerzo argumentativo de Rosanvallon está orientado a dar cuenta de la existencia de una legitimidad complementaria a la electoral (la de reflexividad).

Sin embargo, debemos preguntarnos: ¿es realmente equiparable la voluntad de los ciudadanos con la voluntad de sus representantes elegidos por sufragio? Si existiese una identificación perfecta entre ambas voluntades, el Legislador sería, entonces, la encarnación del soberano, de modo que trastocar la ley mediante el control de constitucionalidad que ejercen los tribunales constitucionales implicaría un atentado contra la soberanía popular, de manera que solamente podrían salvar la legitimidad de esos tribunales explicaciones como las que procura Rosanvallon (2009). Empero, también es posible sostener que existen diferencias entre la voluntad de los representantes y las de los representados. De hecho, los fenómenos que dan cuenta de la crisis de representatividad tienden a verificar la existencia de esa distancia (y que el propio Rosanvallon (2007) plasma tan brillante y persuasivamente con su concepto de contrademocracia). Ya Juan Jacobo Rousseau (2001a; 2001b) sostenía, en su crítica a la representación, que los gobernantes pasaban a constituir un cuerpo intermedio que desarrollaba un "yo particular" enfrentado al "yo común" del pueblo, manifestando su esfuerzo constante por adueñarse de la soberanía. En este sentido, precisamente lo que el constitucionalismo viene a decir es que vivir bajo una constitución 
encierra la pretensión de que los representantes políticos se sometan a reglas y a principios de decisión definidos por otros, distintos de ellos mismos, concretamente por el pueblo soberano, que es el autor de la constitución. Esta, pues, es la expresión del pueblo, mientras que la ley es la expresión de los representantes. La segunda está subordinada a la primera, de manera que para que una ley sea democráticamente válida debe someterse al designio del pueblo contenido en la constitución.

Se presentan, entonces, dos esferas bien diferenciadas: la de los ciudadanos, conformada por los derechos y los principios organizativos de los poderes estatales, y la de los representantes, que deben procurar respetar y llevar adelante lo que les mandan sus representados. Para que esta distinción tenga sentido es fundamental que las dos esferas cuenten con su expresión institucional. Si alguno de los dos se quedase sin voz, sin poder pronunciar el derecho, quedaría sojuzgado a merced del otro y nos hallaríamos frente a una democracia parcial, falsificada. En esta inteligencia, los tribunales constitucionales son los órganos de la esfera ciudadana o, más específicamente, se encuentran en la intersección de las dos esferas, vigilando (desde la imparcialidad y la reflexividad, al decir de Rosanvallon) la vigencia de los derechos de las personas involucrados en medio de las decisiones de los órganos políticos de representación electoral. El control de constitucionalidad es una función imprescindible para garantizar la supremacía de la constitución en tanto garantía del ser-juntos, y encuentra su legitimidad democrática en su misión de asegurar la tutela de los derechos y libertades. El respeto de estos derechos es una precondición de un régimen democrático y, además, los órganos que llevan a cabo esta garantía (los tribunales constitucionales) resultan en sí mismos una instancia necesaria de las democracias contemporáneas.

Conforme nos lo ha demostrado Rosanvallon, el origen de los poderes no es el único criterio distintivo de la democracia, por los menos en una concepción de la democracia que quiera ser más compleja y satisfactoria. Por supuesto que las mayorías tienen derecho a tomar decisiones mediante los órganos representativos elegidos por el voto, pero, como hemos visto a lo largo de todo este trabajo, hay otros criterios de legitimidad -además del electoral- que permiten controlar el modo en el que ese poder mayoritario se ejerce (lo que suele denominarse "legitimidad de ejercicio"). Si esto no fuera así, estaríamos hablando de una democracia sometida a un único control: el que el elector puede llevar a cabo de una elección a otra (v.gr. censurando a sus elegidos, el "voto castigo"). Es por ello que la justicia constitucional aparece como esa instancia de control permanente que impide que las mayorías puedan llevarse por delante todo 
(incluso las decisiones superiores preexistentes, constitucionales). En la medida en que los gobernados puedan ejercer este control continuo y eficaz sobre los gobernantes a través de los jueces constitucionales, estos se legitimarán democráticamente..$^{16}$

En consecuencia, y como primera conclusión, debemos consignar que las dos cuestiones principales que tienden a legitimar a los tribunales constitucionales como instituciones reflexivas son, por un lado, sus funciones de garantes de los derechos y libertades y, por otro lado, transformarse en la instancia de control de los poderes electorales en nombre y en favor de los gobernados. El individuo emancipado, que debe ser el sujeto de la democracia, logra a través de la justicia constitucional el medio para que le sea reconocido ese estatus que se traduce operativamente en su condición de sujeto de derecho, titular de libertades y controlador de aquellos a los que elige como representantes.

Es evidente que la democracia moderna ha sufrido muchos e importantes cambios desde fines del siglo XVIII hasta la actualidad: la expansión del sufragio, la democracia de partidos, las tecnocracias de antes y de ahora, la encarnación de la desconfianza en la contrademocracia, etc. Está también claro que el advenimiento y desarrollo de la justicia constitucional presupone un concepto de democracia que ya no puede ser definido simplemente como el gobierno del pueblo por el propio pueblo (electoral), sino como gobierno de una voluntad general formada, en parte, bajo la influencia que el pueblo ejerce a través de los representados, y en parte por las decisiones de los jueces constitucionales. Esta nueva mutación de la democracia reconoce el poder de la mayoría, pero también designa una suerte de reino de los principios y valores democráticos en el que residen las libertades y derechos de cada uno. Ese reino no es otro que el reino de la constitución, del cual los tribunales constitucionales son operadores imprescindibles. En otros términos, para que la democracia sea considerada legítima, ya no basta con que se hallen representadas las mayorías del momento presente, no basta con la inmediatez; la democracia para ser legítima debe ser una democracia constitucional con todas las implicancias que venimos considerando.

¿Cómo conciliar regla de la mayoría con constitución y, por tanto, con tutela de los derechos y control sobre el poder, garantizados por esa instancia de reflexividad

16 Sin embargo, el control no se limita al que se pueden ejercer entre sí las instituciones del Estado. Como bien enseña Rosanvallon (2007), hay un control que es el que se ejerce desde la democracia de los poderes indirectos diseminados en el cuerpo social, la democracia de la desconfianza organizada frente a la democracia de la legitimidad electoral: la contrademocracia. 
que son los tribunales constitucionales? La principal condición de posibilidad creemos que es el empoderamiento del ciudadano y de la sociedad. En esa línea, la justicia constitucional tiene varias e importantes funciones que desempeñar: el control de los poderes elegidos electoralmente; la tutela de los derechos humanos, especialmente de aquellos que tienden a realizar la democracia en todas sus dimensiones y acepciones, tales como la libertad de expresión, los derechos de reunión, asociación, manifestación y a la información; el acceso a la justicia; promover a través de sus decisiones el desarrollo de canales participativos y deliberativos; entre otras.

La democracia, en suma, ya no es unidimensional ni puede reducirse a simple aritmética. En cambio, se ha vuelto más y más compleja y tiende a transformarse en un sistema jurídicamente sujeto a reglas de creciente exigencia en el que se destaca la justicia constitucional como exponente de la legitimidad de reflexividad, ${ }^{17}$ la que, evitando los eventuales atropellos de las mayorías circunstanciales sobre las minorías y los individuos y asegurando el respeto de los derechos, permite el despliegue de la autonomía de cada ciudadano, asentada en su humana dignidad, fundamento de toda forma civilizada del con-vivir.

\section{Bibliografía}

Álvarez Álvarez, F.D. (2003). Legitimidad democrática y control judicial de constitucionalidad. Díkaion, Revista de Fundamentación Jurídica, (17)12, 147-177.

Annunziata, R. (2012). Hacia un nuevo modelo de lazo representativo. La representación de proximidad en las campañas electorales de 2009 y 2011 en Argentina. En Cheresky, I. y Annunziata, R. (Comps.), Sin programa, sin promesas. Liderazgo y procesos electorales en Argentina (pp. 45-87). Prometeo.

Bickel, A. (1986). The Least Dangerous Branch (2a ed.). Yale University Press.

Gauchet, M. (1995). La Révolution des pouvoirs. La souveraineté, le peuple et la répresentation. 1789. 1799. Gallimard.

Hughes, C. E. (1971). La Suprema Corte de los Estados Unidos (2a ed.). Fondo de Cultura Económica. Madison, H. J. (1966). The Federalist Papers. Doubleday.

Nino, C. S. (1997). La Constitución de la Democracia Deliberativa. Gedisa.

Rosanvallon, P. (2007). La contrademocracia. La política en la era de la desconfianza. Manantial.

17 La legitimidad de reflexividad formulada por Rosanvallon (2009), como he intentado demostrarlo en el presente estudio, es un componente imprescindible de una concepción robusta de la democracia. Con anterioridad, he examinado otros nueve argumentos que procuran conciliar democracia con magistratura constitucional (Álvarez Álvarez, 2003). 
Rosanvallon, P. (2009). La legitimidad democrática. Imparcialidad, reflexividad, proximidad. Manantial. Rousseau, J. J. (2001a). Discurso sobre el origen y los fundamentos de la desigualdad entre los hombres. El Ateneo.

Rousseau, J. J. (2001b). El contrato social. El Ateneo.

Vita, L. (2009). La crítica de Nietzsche al Estado moderno. Lecciones y Ensayos, 86, 213-233.

Waldron, J. (1993). A Right-Based Critique of Constitutional Rights. Oxford Journal of Legal Studies, 13(1), 18-51. 


\title{
LOS LÍMTTES DE LA CAUSALLDAD PROBABILISTICA EN DERECHO
}

\section{Ignacio N. Cofone}

\author{
Universidad McGill \\ ignacio.cofone@mcgill.ca
}

Recibido: 10/06/2021

Aceptado: 23/07/2021

\section{Resumen}

El criterio que se debe utilizar para evaluar causalidad continúa siendo controvertido. El análisis económico del derecho propone el uso de la causalidad probabilística como criterio rector, lo cual sugiere la eliminación de criterios de causalidad binarios. Esto lleva a explicaciones que violan nuestras intuiciones, que no explican la toma de decisiones judicial y que se consideran injustas. Este artículo propone que ni la causalidad binaria ni la probabilística pueden brindar una respuesta satisfactoria para todos los supuestos. La causalidad probabilística funciona para los enunciados causales generales (tipos de enunciados en los que está involucrada la formulación de reglas), mientras que los criterios binarios funcionan mejor para los enunciados causales singulares (tipos de enunciados que generalmente abordan los tribunales).

Palabras clave: causalidad, responsabilidad, causalidad probabilística, derecho de responsabilidad civil, eficiencia.

\section{The Limits of Probabilistic Causality in Law}

\begin{abstract}
There is still controversy regarding what criterion to use to evaluate causality. The law \& economics literature proposes the use of probabilistic causality as a superior criterion, suggesting the elimination of binary causality criteria. This led to explanations that violate our intuitions, fail to explain judicial decision-making, and are considered unjust. This paper proposes that neither binary nor probabilistic causality can provide a satisfactory answer for all scenarios. Probabilistic causality works well for general causal claims (types of claims centrally involved in rulemaking) while binary criteria perform better for single causal claims (types of claims commonly addressed by courts).
\end{abstract}

Key words: causation, responsibility, probabilistic causality, tort law, efficiency. 


\section{Introducción ${ }^{1}$}

La causalidad es un asunto clave para las ciencias naturales y sociales, y se ha recibido un trato preponderante en la mayoría de estas ciencias desde Hume (Mackie, 1974). En los últimos años, además, los filósofos y estadísticos le han prestado tal especial atención que, de manera independiente, crearon criterios nuevos (Rizzo, 1996; Salmon, 1980; Spector, 2011). Este artículo se enfoca en la aplicación de estos criterios al derecho.

En la responsabilidad jurídica en particular, la causalidad se consideró fundamental para lo que se denomina "la columna vertebral del derecho de responsabilidad civil” (Schultz, 2001, p. 467), una afirmación que bien podría parafrasearse para aplicarla a cualquier otro tipo de responsabilidad jurídica.

Como es sabido, el criterio que los tribunales utilizan para evaluar la causalidad en la mayoría de los ordenamientos jurídicos es (con algunos ajustes) la prueba de "equivalencia de las condiciones" o el criterio sine qua non. ${ }^{2} \mathrm{El}$ análisis económico del derecho propone la sustitución de esta regla por la causalidad probabilística, criterio que Shavell (1980) y Rizzo y Arnold (1980) diseñaron originalmente para los casos de incertidumbre, en los cuales se sugiere la ampliación del criterio a todos los casos de responsabilidad civil (Ben-Shahar, 2000; King, 1981; Young et al., 2004).

La doctrina lo ha considerado como un signo de falta de poder explicativo de análisis económico del derecho y como un grave defecto de su enfoque metodológico (Coleman, 1992; Geistfeld, 2006; Stapleton, 2008). Para enfrentar estas críticas, el presente artículo analiza algunos argumentos nuevos para ayudar a elegir el mejor criterio de causalidad para la atribución de responsabilidad con un enfoque en análisis económico del derecho (es decir, el criterio más consistente, explicativo y eficiente).

Para ello, el artículo comienza con una revisión de los conceptos de causalidad. Introduce los problemas principales que se presentan con la aplicación de la causalidad probabilística, que, como señala la literatura en derecho y en filosofía -además de algunos inconvenientes desde el punto de vista del len-

1 Esta es una traducción al español de: Cofone, I. N. (2015). The Limits of Probabilistic Causality in Law. Global Jurist, 15(1), 29. https://www.doi.org/10.1515/gj-2014-0012.

Le agradezco a Jennifer Arlen, Pierre Bentata, Pierre Garello, Diego Papayannis, Mario Rizzo, Eduardo Stordeur, Dina Waked y a los participantes de la Conferencia Law \& Boundaries (Sciences Po, 2014) y al Taller EMLE Workshop in Law and Economics (Hamburg University, 2013) por sus útiles comentarios. Todos los errores me pertenecen.

2 El significado literal de la frase en latín es "sin la cual no". 
guaje $^{3}$ que no se tratan en este artículo-, ${ }^{4}$ son tres. Luego, demuestra que la aplicación del criterio puede generar resultados contrarios a la lógica cuando se identifican causas. Asimismo, afirma que el criterio no describe la manera en la que los tribunales abordan realmente la causalidad. Por otro lado, argumenta que esta aplicación generalizada puede crear costos artificialmente altos y llevar a resultados que se consideran ampliamente injustos o parciales. Luego, aborda el problema de la incertidumbre causal, que es el posible principal contraargumento a esta afirmación.

Por último, introduce una distinción que separa al conjunto de situaciones en las cuales la causalidad probabilística presenta todos estos problemas de un conjunto de casos en los cuales puede ser adecuada. Propone que estos problemas existen debido a la falta de distinción entre los enunciados causales generales (que se utilizan principalmente para la creación de normas) y los enunciados causales singulares (que se utilizan en general para la aplicación de normas). Estos enunciados difieren en su estructura y exigen un tratamiento distinto para sus relaciones causales. Asimismo, sugiere un criterio alternativo para los casos que no encuadran en el conjunto mencionado.

\section{Causalidad}

\subsection{Causas y responsabilidad}

La estructura de la responsabilidad se puede apreciar en un caso muy simple: Jack y Jill. Jack y Jill subieron la montaña para ir a buscar un balde de agua. Jack se cayó y se rompió la coronilla y después Jill se cayó rodando.

En muchos ordenamientos jurídicos, y en particular en el derecho anglosajón, la responsabilidad jurídica se estructura con la verificación de la existencia de tres elementos: daño, causa e incumplimiento del deber (negligencia). ${ }^{5}$ Es decir, A (en nuestro ejemplo, Jack) es responsable cuando causa, de manera negligente o deliberada, un daño a B (Jill).

En la mayoría de los casos, se necesitan los tres elementos de la responsabilidad para que alguien sea responsable. Sin embargo, en la responsabilidad

3 Shavell (2004, p. 250), por ejemplo, considera que el criterio sine qua non es el significado del concepto de causa como se utiliza en el lenguaje ordinario.

4 Esta sería una discusión sobre las expresiones analíticas o un pseudo problema. Si bien ha habido algunas dudas sobre la distinción desde Quine, todavía parece ser relevante para las discusiones filosóficas (Russell, 2008).

5 Algunas culturas jurídicas denominan este último criterio como "el factor de atribución", que se puede expresar mediante la responsabilidad objetiva o negligencia. 
objetiva es suficiente la existencia de la causa y el daño (no es necesario el incumplimiento del deber), y en la responsabilidad por conducta riesgosa ${ }^{6}$ es suficiente el mero incumplimiento de deber (y no se exige el daño). En los ordenamientos jurídicos contemporáneos no hay un tipo de responsabilidad que exija daño y negligencia, pero no exige ningún tipo de causalidad entre estos dos factores $^{7}$ (Alexander, 1987; Shavell, 1998).

Por ende, la existencia de una causa es necesaria, pero no es condición suficiente para la responsabilidad por daños. Como dice Posner (1986), "la causalidad define el conjunto de posibles demandados” (p. 174). Esta condición es de tipo fáctica. Si bien una afirmación de que el demandado le ocasionó daños al demandante es una cuestión de hecho (provocó o no efectivamente el daño), la afirmación de que el demandado sea responsable por los daños que el demandante sufrió es una cuestión de derecho (los valores involucrados que definen si el demandado debe pagar por dichos daños, que se saque al posible demandado del conjunto). La diferencia entre la causalidad y la responsabilidad se puede apreciar en que no es posible deducir afirmaciones normativas a partir de afirmaciones fácticas, se necesita otro elemento (normativo) además de la causalidad para llenar el vacío (Cooter, 1987). Al mismo tiempo, ese elemento normativo no es suficiente sin una afirmación fáctica (Coderch y Fernández Crende 2006; Fumerton y Kress, 2001). Uno puede producir la causa fáctica de un resultado y no ser responsable porque no se incumplió un deber.

Desde esta perspectiva, para poder seleccionar las mejores reglas para responder a los interrogantes de la causa, es fundamental distinguir la causalidad de la responsabilidad (Wright, 1987). En el lenguaje jurídico, a veces se altera el orden de los elementos y se analiza primero quién incumplió el deber y, únicamente después de ese análisis, se consideran las posibles causas dentro de dicho alcance del incumplimiento de deber. Un análisis apresurado de estas sentencias podría dar la impresión de que la causalidad implica la responsabilidad, pero esta conclusión sería errónea. En esas sentencias, la causalidad implicó la

6 Todavía se considera parte del derecho de responsabilidad civil y no una cuestión regulatoria.

7 En este caso, asumo que las omisiones son hechos y que, por ende, pueden ser causas. La responsabilidad por omisión sería un caso en el que no se necesita una causa si no se adopta la metafísica para considerar que las omisiones tengan el potencial para ser causas. Sin embargo, en el lenguaje habitual, las omisiones se denominan "causas" y se puede ver que la mayoría de la doctrina jurídica no está de acuerdo con esta presunción (Schaffer, 2004). Como resulta evidente, en la responsabilidad por conducta riesgosa, dado que no hay daño, no puede haber una causa del daño, pero las diferencias relevantes entre este tipo de responsabilidad y la responsabilidad estándar se dan no por la ausencia de causa, sino por la ausencia de daño. 
responsabilidad únicamente porque se habían comprobado previamente otros dos elementos.

En nuestro ejemplo, para responder si Jack era responsable de la caída de Jill, la primera pregunta que se debe hacer es si la caída de Jack fue la causa de la caída de Jill, y para dar esa respuesta dependerá de lo que uno entienda por "causalidad".

\subsection{Conceptos de causalidad}

Los criterios de causalidad determinísticos o binarios consideran que un hecho $(E)$ es la causa de un resultado $(R)$ si (y solo si) se cumple una determinada condición.

La condición que se debe cumplir en las explicaciones más básicas de los criterios es que, para que $R$ ocurra, $E$ es: (i) necesario (condición sine qua non); o (ii) suficiente (causa causans). La primera condición se puede expresar como (E $\rightarrow R)$ si-y-solo-si $(\neg \exists R \mid-E),{ }^{8}$ y la segunda se puede expresar como $(E \rightarrow R)$ si-y-solo-si $(\exists R \mid E){ }^{9}$

En las explicaciones más complejas, $E$ es la causa de $R$ si es un elemento necesario de un conjunto suficiente de condiciones para ese E (NESS). Es decir, hay un determinado grupo de condiciones $(S)$ que puede producir con suficiencia $R$, y un $E$ identificado como causa que es un elemento necesario de ese grupo. NESS se podría representar como $(E \rightarrow R)$ si-y-solo-si $[(E \in S) \wedge(\neg \exists S \mid \neg E)]$ $\wedge(\exists R \mid S) .^{10}$

Por otro lado, la causalidad probabilística define $E$ como una causa de $R$ si (y solo si) E aumenta la probabilidad de $R \cdot{ }^{11} \mathrm{~A}$ su vez, esto se puede representar como $(E \rightarrow R)$ si-y-solo-si $[P(R \mid E)>P(R \mid \neg E)]$ o alternativamente como $(E \rightarrow R)$ si-ysolo-si $[P(R \mid E)>P(R)]^{12}$

8 Se lee: $E$ causa $R$ si y solo si, cuando no $E$, necesariamente no $R$. Ver Lewis (1973).

9 Se lee: $E$ causa $R$, si y solo si cuando $E$, necesariamente $R$. Formalmente, si $E$ es condición suficiente de $R$, entonces $R$ es una condición necesaria de $E$ (Von Wright, 1971; 1975).

10 Se lee: $E$ causa $R$ si y solo si $E$ es un elemento de $S$, y cuando no $E$ es necesario que no $S$, y cuando $S$ es necesario que $R$.

11 Se lee: $E$ causa $R$ si y solo si la probabilidad de $R$ dado $E$ es mayor que la probabilidad de $R$ dado no E. Ver Skyrms (1980) y Eells (1991). Calabresi (1975) lo denomina "nexo causal" para distinguirlo de los criterios de causalidad clásicos (binarios).

12 Se lee: $E$ causa $R$ si y solo si la probabilidad del $R$ dado $E$ es mayor que la probabilidad de $R$. Ver Suppes (1970) y Cartwright (1979). Ver también Salmon (1980). 
Tradicionalmente, los ordenamientos jurídicos atribuyen la causalidad con los criterios de necesidad, como la prueba de la "equivalencia de las condiciones”, que también se conoce como el criterio sine qua non (Coleman, 1992, p. 270). Esto genera varios problemas, ya que el criterio sine qua non no siempre explica adecuadamente las relaciones causales subyacentes o la manera en la que los tribunales las utilizan. Esta regla se encuadra dentro del exceso de atribución de causalidad en algunos casos en los que la cadena causal es extensa, y dentro de la falta de atribución de causalidad cuando existen múltiples causas presentes (Hart y Honoré, 1985). Esto se puede explicar a partir de los siguientes ejemplos: "el abuelo culpable" es un ejemplo de la sobredeterminación denominada "causalidad exagerada", mientras que "los dos cazadores" y "los viajeros del desierto" son ejemplos de la subdeterminación denominada "causalidad múltiple" y "prelación”, respectivamente.

Estos ejemplos también se pueden utilizar para evaluar otros criterios. Además de ser habituales en la literatura de filosofía sobre causalidad, a veces podría parecer que incurren en un argumento circular. Si ya conocemos el resultado del experimento, ¿por qué probamos diferentes criterios (equivalencia de las condiciones, causalidad probabilística)? El motivo es que los modelos de causalidad son útiles cuando pueden explicar una relación causal que es exógena al modelo. Por ende, probar nuestros modelos causales con estos ejemplos que tienen un resultado claro nos ayuda a saber cuál es el modelo de causalidad adecuado para cada situación. A su vez, esto será útil para identificar causas en casos más complejos cuando nuestra intuición no sea suficiente.

El abuelo culpable. Una persona asesina a su vecino. Con el criterio sine qua non, su abuelo hubiese sido considerado la causa de la muerte porque es un elemento necesario, ya que si no hubiese sido por él, el asesino no hubiese existido. Sin embargo, esta conclusión viola nuestras intuiciones y, en este ejemplo, no funciona como quisiéramos. La mayoría de la gente estaría de acuerdo con que el abuelo no fue culpable del delito y no se lo consideraría culpable en la mayoría de los tribunales.

Los dos cazadores. Dos cazadores están en la búsqueda de una presa y, por error y en simultáneo, le disparan a un tercer cazador y lo matan. Si uno de los dos no hubiese disparado, el tercer cazador hubiese fallecido de todas formas por el disparo del otro. ${ }^{13}$ Como ninguno de ellos es un elemento necesario de

13 Esta es una modificación simplificada de Summers v. Tice, adaptado al ejemplo que proporcionó 
su muerte conforme al criterio sine qua non, ninguno sería considerado como causa de la muerte, incluso cuando la mayoría de la gente consideraría que ambos la provocaron.

El viajero del desierto. Un hombre que viaja por el desierto es perseguido por dos enemigos. El primer enemigo envenena su botella de agua. El segundo hace un agujero en la botella. El viajero muere de sed. Nuevamente, con el criterio sine qua non, ellos no serían la causa, ya que ninguno es elemento necesario, incluso si, por intuición, uno dijera que el primer enemigo intentó asesinar al viajero y el segundo efectivamente le provocó la muerte (Mackie, 1974).

Debido a estos problemas, los tribunales a veces incorporan una separación entre la causalidad fáctica (que se considera sine qua non) y la causalidad denominada "normativa" (Robertson, 1997; Wright, 1985b). En general, en los sistemas de derecho anglosajón, la causalidad normativa consiste en el criterio de la causalidad próxima; y en los sistemas de derecho continental, el criterio de la causalidad adecuada. ${ }^{14}$

El análisis económico del derecho sugiere la sustitución de esta regla con la causalidad probabilística (Ben-Shahar, 2000). Esto conlleva una nueva manera de responder a los interrogantes causales en derecho, que se aparta de los criterios de necesidad como sine qua non, pero también del criterio de causalidad de todo o nada (determinista) en general.

Esta manera de pensar el interrogante causal tiene una determinada familiaridad (la incorporación de probabilidades), pero difiere sustancialmente de la antigua teoría "más probable que improbable", que se basa en los criterios

Mackie (1974). En Summers, solo uno de los cazadores hirió al tercero, pero no se sabe cuál de los dos fue.

14 La tensión está en que si bien los criterios de causalidad fáctica son descriptivos, los criterios denominados "de causalidad normativa" involucran políticas públicas (Coleman, 1992; Honoré, 1983; Rizzo, 1987; Robinson, 1982). En la causalidad normativa existe un tipo de avance en la siguiente pregunta: iqueremos que $D$ sea responsable de $R$ ? Si uno acepta que es posible verificar o inferir la causalidad, entonces el valor de verdad (o su ausencia) de la causalidad no puede modificarse por las consecuencias morales o jurídicas que se puedan derivar de ella (Edgerton, 1924; Green, 1929; Kelman, 1987; Malone, 1956; Moore, 1985, 1987; Thomson, 1987a). Esto es particularmente claro cuando se toma en cuenta que la causalidad no es en sí misma una condición suficiente para la responsabilidad. En este sentido, la causalidad normativa se encuentra analíticamente entre la causalidad (fáctica) y el incumplimiento de deber. Por lo tanto, esta dualidad entre la causalidad fáctica y la causalidad normativa parece ser, de alguna forma, artificial (Becht y Miller, 1961). Dado que todas las limitaciones impuestas en la causalidad denominada "normativa" también se imponen en la etapa de incumplimiento de deber (Miceli y Segerson, 2007), la dualidad también parece innecesaria (Becht y Miller, 1961). Los criterios no siempre serán útiles, salvo que tengan una dirección clara (Ver Beale, 1920; McLaughlin, 1925; Smith, 1911; Terry, 1915). 
deterministas ${ }^{15}$ (Gold, 1986; Levmore, 1990; Rosenberg, 1984) y de la doctrina de la predictibilidad, que no aborda los interrogantes causales. ${ }^{16}$

El motivo principal detrás del uso de la causalidad probabilística en análisis económico del derecho, en especial en su permutación de responsabilidad proporcional, es que, en palabras de Shavell (1985), para "hacer que las partes reduzcan los riesgos de accidente de manera adecuada, en general deberían enfrentarse a que la responsabilidad 'esperada' o sin contar la probabilidad es igual al aumento de las pérdidas previstas que generan” (pp. 587-588).

La causalidad probabilística es un criterio atractivo en parte porque se relaciona estrechamente con la eficiencia. Si uno quiere disuadir las acciones peligrosas en la medida en que son perjudiciales para la sociedad, sancionarlas en la proporción en que (puedan) ocasionar daños es simple y directo. Al haberse tomado de la metodología económica, ${ }^{17}$ el criterio asegura la compatibilidad con un análisis basado en la eficiencia, dado que se alinea con el enfoque metodológico general que se utiliza en análisis económico del derecho.

El criterio es superior a los criterios antiguos de causalidad próxima y adecuada no solo porque presenta ventajas desde un punto de vista de la eficiencia (que es la preocupación principal del derecho y de la economía), sino también porque es más claro desde el punto de vista conceptual, ya que tiene una definición más restringida. También es una buena regla para descartar los factores

15 Si bien el uso de las probabilidades en la causalidad probabilística define la causa, el uso de las probabilidades en la teoría "más probable que improbable" es meramente epistémica (Parascandola, 1996) y no hace que el interrogante sea menos fáctico (Wright, 1985b). El primero (E es la causa de $R$ porque aumenta sus probabilidades en un porcentaje $X$ ) define la causa de acuerdo al aumento de las probabilidades, y el segundo ( $E$ era la causa más probable de $R$ ) es una estimación de la causa, que se define de manera determinista, es decir, una suposición informada de la causa de hecho. Esto nos dirige a diferencias operativas. Por ejemplo, en "los dos cazadores", si descubriéramos que solo una bala llegó al cuerpo y si supiéramos de qué cazador provino, parecería que ambos cazadores aumentaron la probabilidad marginal previa al daño en más de un $50 \%$, pero solo uno de ellos es la causa más probable que improbable del daño.

16 Si bien la causalidad probabilística define el nexo causal en función de una evaluación de: si E aumentó las probabilidades de $R$ y en qué medida, la predictibilidad es el elemento que evalúa si el autor del hecho ilícito civil, con la información disponible, podría haber predicho razonablemente que $R$ se inferiría de hecho del E (Calabresi, 1975, pp. 87-88). La teoría de la predictibilidad no intenta definir la causalidad, sino que se utiliza de manera independiente del establecimiento de la causalidad para explicar en qué medida las partes tenían conocimiento del nexo causal o deberían haberlo tenido (Moore, 2000) para establecer un nivel razonable de cuidado. Si bien algunos operadores jurídicos utilizan la predictibilidad como una herramienta común para decidir si alguien es responsable o no, la causalidad probabilística, en su formato matemático, no ha tenido éxito en los tribunales (Dewees et al., 1996; Wright, 1985b), salvo en casos de acciones colectivas, como se explica a continuación.

17 Ver Rizzo (1996). 
coincidentes del conjunto de causas posibles (Calabresi, 1975), que es una función relevante para las reglas que abordan el interrogante causal.

Al mismo tiempo, crea problemas graves. La mayoría de ellos no están presentes en los criterios antiguos, lo que puede llevar a reconsiderar qué tan prudente es su uso.

\section{Algunos casos de Gettier para la causalidad 3.1. Presentación del problema}

La gran dificultad que uno encuentra al identificar causas con cualquier criterio es distinguirlas sistemáticamente de las meras condiciones (Lipton, 1992) sin caer un una sobredeterminación (identificar condiciones como causas) o subdeterminación (identificar causas como condiciones). ${ }^{18}$

Como ya se explicó, el criterio sine qua non enfrenta ambos problemas. La causalidad probabilística resuelve la subdeterminación a través del problema de causalidad múltiple (ya que ambos hechos son generadores de probabilidades). Sin embargo, cae dentro del problema de la sobredeterminación a través de la causalidad exagerada y convierte a la prelación de un problema de subdeterminación en un problema de sobredeterminación (Menzies, 1996).

Esto se puede ver en los ejemplos utilizados. En "los dos cazadores", ambos aumentaron marginalmente la probabilidad de muerte de la persona y, por ende, no hay problema para identificarlos a ambos como causa de la muerte, incluso si, sin ellos, la muerte hubiese ocurrido de todos modos. Sin embargo, "el abuelo culpable", con el criterio de la causalidad probabilística, igual se consideraría una causa de la muerte provocada por su nieto, ya que aumentó marginalmente su probabilidad. De forma similar, en "el viajero del desierto", dado que ambos enemigos aumentaron las probabilidades marginales de la muerte del viajero, ambos se identifican como causa con este criterio.

Al identificar los problemas de sobredeterminación y subdeterminación de manera más precisa, algunas publicaciones sobre el tema en filosofía usan dos contraejemplos principales (superposición y prelación causal) para demostrar que la causalidad probabilística a veces lleva a resultados contrarios a la lógica.

18 Todo problema de sobredeterminación se puede atenuar con el uso de un umbral de incumplimiento de deber adecuado que filtre estas condiciones que el criterio identifica como causas. Sin embargo, es mejor utilizar un concepto de causalidad que no caiga en ese error, en particular debido a la dificultad de crear un estándar de incumplimiento de deber que pueda dividir las acciones deseables de las indeseables que generan daños y, a su vez, filtrar aquellos hechos que no lo generan. 
Más adelante se mencionará una teoría sobre cómo agrupar y tratar dichas situaciones.

\subsection{Contraejemplos}

Superposición. La superposición involucra casos en los que existe un E que eleva las probabilidad de $R$ cuando, en los hechos, no es la causa porque $R$ es igualmente ocasionado por otro $E$. Esto se puede ver en un caso de cuento de hadas elaborado por Schaffer (2000):

\section{De principe a rana}

Merlín hace un hechizo con una probabilidad de 0,5 de convertir al rey y al príncipe en ranas. Morgana hace un hechizo (independiente en términos probabilísticos) con una probabilidad de 0,5 de convertir al príncipe y a la reina en ranas, y [...] el rey y el príncipe se convierten en ranas, pero la reina no. (p. 40)

En este cuento, es claro que el hechizo de Morgana no tuvo éxito, ya que convertiría tanto al príncipe como a la reina en ranas, y la reina no se convirtió en rana. Como por definición los hechizos fallidos no tienen consecuencias, el hechizo de Morgana no puede ser la causa de que el príncipe se haya convertido en rana (Schaffer, 2000, p. 40). Sin embargo, también es claro que el hechizo de Morgana aumentó las probabilidades de que el príncipe se convierta en rana: $P($ Rana $\mid$ Hechizo $)>P($ Rana $\mid \neg$ Hechizo $)$. Por ende,

la estructura general que este cuento de hadas demuestra (dado que el punto de los cuentos de hadas es revelar estructuras mediante las abstracción clara de los detalles contingentes) es que puede haber un aumento de las probabilidades directo y preciso que genere causalidad siempre que los efectos proyectados de las múltiples fuentes de posibilidades se superpongan parcialmente. (Schaffer, 2000, p. 40)

La misma estructura se puede explicar con una modificación de "los dos cazadores", que se denominará "los dos cazadores 2":

Los dos cazadores 2. Los dos cazadores están en búsqueda de una presa y piensan que un tercer cazador es una presa. Ambos cazadores en simultáneo le disparan. La primera bala falla y la segunda lo mata.

Es claro que dispararle a alguien aumenta su probabilidad de muerte: P(Muerte $\backslash$ disparar $)>P($ Muerte $\mid$ _disparar $)$. Sin embargo, a pesar de que el primer cazador le disparó al tercero y así aumentó las probabilidades de que muriera, 
su bala falló y la mayoría de la gente estaría de acuerdo con que no provocó la muerte de su colega.

Prelación. Los casos de prelación causal pueden ser de dos tipos. Puede haber un factor que aumente la probabilidad y que no sea la cusa (como en el caso de la superposición) porque un $E$ distinto ocasionó el $R$ antes, o puede haber una causa que reduzca efectivamente la probabilidad porque evitaría un $E$ distinto que ocasionaría el $R$ (Hitchcock, 2010).

Un ejemplo del primero es el caso del "viajero del desierto". El hombre que envenena la botella de agua del viajero aumenta la probabilidad de su muerte: $P($ Muerte $\mid$ Veneno $)>P($ Muerte $\mid \neg V e n e n o)$. Sin embargo, no provoca la muerte del viajero porque el segundo hombre la previno al vaciar la botella.

Tanto en prelación causal ("el viajero del desierto") como en superposición ("de príncipe a rana"), hay un $E_{1}$ que eleva la probabilidad de $R$, pero no es la causa y existe un $E_{2}$, que es la causa de $R$. La diferencia entre ellos es que, en la superposición, $E_{1}$ y $E_{2}$ son independientes, mientras que en la prelación causal $E_{1}$ no es la causa debido a $E_{2}$.

Para tomar un ejemplo del segundo tipo de prelación causal, usemos una variación del "viajero del desierto", que se denominará "el viajero del desierto 2":

El viajero del desierto 2 . Un hombre que viajaba por el desierto es perseguido por dos enemigos. El primer enemigo cambia su botella de agua por una con un veneno fuerte $(0,75$ de probabilidad de muerte). El segundo enemigo, sin saber esto, cambia su botella de agua por una con un veneno suave $(0,5$ de probabilidad de muerte). El viajero muere.

En este caso, el criterio sine qua non presenta el mismo problema que antes, ya que ninguno de los enemigos son elementos necesarios de la muerte aun cuando el segundo sí provocó su muerte en los hechos.

Sin embargo, las explicaciones probabilísticas de la causalidad presentan el problema opuesto. El segundo enemigo cambió el veneno fuerte por uno suave: $P($ Muerte $\mid$ Veneno $)=0,5$ y $($ Muerte $\mid \neg$ Veneno $)=0,75$, respectivamente. Por ende, el segundo enemigo disminuyó las probabilidades de que muera: $P($ Muerte $/$ Veneno $)<P($ Muerte $\mid \neg V e n e n o)$. Sin embargo, el resultado intuitivo es que el segundo enemigo en realidad provocó la muerte del viajero.

$R$ inexistente. Con respecto a los factores elevadores de probabilidades que no tienen una causa fáctica, existen también casos de $R$ que (en lugar de suceder debido a un $E$ diferente, como en la prelación causal) no se produce. En este supuesto, es más claro que el factor elevador de probabilidades no puede ser la causa de $R$, ya que $R$ no se produce porque no hay causa. 
Un $E$ puede aumentar las probabilidades de $R$ y luego no producirlo fácticamente (Wright, 1988). Esta afirmación fáctica es evidente: una persona puede fumar y no desarrollar cáncer, puede conducir descuidadamente y no estar involucrada en un accidente y puede correr con tijeras en la mano sin terminar sangrando. Si $R$ no se produce, no existe en el mundo, y si $R$ no existe, no hay causa. Si $R$ no tiene causa, $E$ no puede haber sido la causa de $R$.

Por ende, si uno define la causa de $R$ en la medida en que $E$ aumenta marginalmente su probabilidad, uno debe concluir que $E$ es y no es la causa de $R$, lo que viola el segundo principio de la lógica. ${ }^{19} \mathrm{El}$ problema es más grave que los anteriores, dado que en este caso la aplicación de la causalidad probabilística no solo tendría resultados contraintuitivos, sino directamente contradictorios. ${ }^{20}$

\subsection{Balance}

$\mathrm{Al}$ igual que con los contraejemplos de Gettier -que demuestran que a pesar de la verificación de los requisitos de la explicación clásica del conocimiento, hay casos en los cuales diríamos que no hay conocimiento-, estos contraejemplos presentan casos en los cuales, a pesar de la verificación de los requisitos de la causalidad probabilística, diríamos que no hay causalidad (o a la inversa). Demuestran que una determinada explicación teórica de causalidad no puede explicar nuestras intuiciones. Ante esto, se podrían plantear dos objeciones.

La primera objeción posible es atacar algún ejemplo en particular, como cambiar la definición de "hecho". Sin embargo (como con los contraejemplos de Gettier), esto no es suficiente para lidiar con ellos porque los contraejemplos siguen un patrón. La causalidad probabilística en esta explicación clásica no puede lidiar con la prelación y la superposición. Por ende, incluso si fuera posible atacar un ejemplo particular, se pueden extraer otros ejemplos dado que el patrón persiste. Salvo que se pueda encontrar una manera general de lidiar con estos contraejemplos, la explicación de la causalidad que atacan enfrenta un problema.

$19 X$ no puede ser $Y$ y no ser $Y$ al mismo tiempo.

20 Bunge (1973) formuló una crítica más general: "La mayoría de las siete objeciones anteriores al análisis de Humean de la causalidad se han debatido en muchas publicaciones filosóficas sobre la causalidad, que Suppes eligió ignorar, en gran parte. (Estar exclusivamente interesado por las publicaciones no hará que le saques ventaja al bibliotecario, pero ignorarlas por completo puede hacer que descubras el Mediterráneo o que te lo pierdas). Si bien vale la pena leer este estudio, solo porque reconstruye una teoría filosófica en términos exactos que es tan importante como falsa” (p. 2). Ver también Otte (1981), quien argumenta que este criterio no distingue entre causas genuinas y falsas y entre causas directas e indirectas, y no logra funcionar como un criterio de causalidad para los mundos deterministas y no deterministas. 
La segunda objeción posible es afirmar que si definimos la causalidad en términos probabilísticos, los contraejemplos no son tales, ya que con esta definición de la causalidad uno podría llegar a una conclusión opuesta. Como en otros argumentos circulares, esto es cierto, independientemente de lo poco instructivo que es; el punto de los contraejemplos es demostrar que una definición de la causalidad no puede lidiar con nuestras explicaciones habituales.

\section{Poder descriptivo}

Una de las principales ventajas que el análisis económico del derecho afirma tener, en comparación con los paradigmas que le compiten, es su habilidad para predecir las consecuencias legales sin importar sus anomalías (Landes y Posner, 1987; Posner, 1986). Al mismo tiempo, es evidente que la causalidad (fáctica) no se puede considerar una de dichas anomalías, ya que es el elemento crucial del derecho de responsabilidad civil en particular y de la responsabilidad en general (Krecke, 1996; Wright, 1987). Por lo tanto, el análisis económico del derecho debería proveer una explicación factible de la causalidad fáctica.

Las primeras explicaciones del análisis económico del derecho de responsabilidad civil consideraban que las causas no cumplían un rol importante para la eficiencia ${ }^{21}$ (Ben-Shahar, 2000; Thomson, 1987b), lo cual generó las críticas mencionadas. Académicos jurídicos consideran que no presentar una explicación para la causalidad fáctica es un defecto metodológico y una falta de capacidad para explicar y predecir las decisiones legales reales (Coleman, 1992; Geistfeld, 2006; Stapleton, 2008).

El primer avance en este tema lo hicieron Shavell (1980) y Rizzo y Arnold (1980), quienes formaron un criterio de causalidad basado en el modelo de Brown (1973) (Cooter, 1987), mediante el cual se logra una respuesta positiva a la pregunta de si corresponde incorporar la causalidad, pero se la vincula con un criterio débil, más cercano al aumento del riesgo que a la causalidad fáctica. Las críticas persistieron.

Landes y Posner (1983), en particular, intentaron demostrar que la causalidad fáctica se puede descartar por completo del análisis económico del derecho y sustituirse con una explicación de la vinculación probabilística que estaba implícita en la regla de Hand, sin perder el poder de explicar las decisiones

21 Ver Coase (1960), Calabresi (1970), Brown (1973) y Landes y Posner (1981). Para obtener una interpretación diferente de la explicación de Landes y Posner sobre causalidad, en la cual afirman que utilizan la causalidad ex post, ver Wright (1985a). 
en cuanto a la responsabilidad civil que emiten los tribunales. Para hacerlo, presentaron una nueva interpretación de Weeks v. McNulty, que a menudo se utiliza para respaldar el criterio.

Sin embargo, los casos de subdeterminación que se explicaron con anterioridad demuestran que es probable que este argumento sea incorrecto. La regla de Hand, o cualquier otro criterio de incumplimiento de deber, puede restringir la causalidad y, por ende, limitar los casos de sobredeterminación, pero los resultados contrarios a la lógica que se producen con la subdeterminación no pueden resolverse con los criterios que limitan la causalidad. Este es el motivo por el cual Landes y Posner necesitaron incorporar las evaluaciones de causas (fácticas) ex post al analizar los casos, como lo demuestra Wright (1985a).

En Weeks v. McNulty, McNulty no instaló una escalera de emergencia en un edificio. Cuando se produjo un incendio con Weeks dentro del edificio, este no intentó salir y murió. En esta causa, el tribunal determinó que a pesar de que McNulty había actuado de manera negligente, no provocó la muerte de Weeks y, por ende, no era responsable. Landes y Posner (1983) llegaron a la conclusión de que la sentencia del tribunal era eficiente.

El caso implica un problema de prelación que, como ya se analizó, la causalidad probabilística no puede resolver. $E_{1}$ (no instalar escaleras de emergencia) podría haber sido la causa del daño si no hubiese sido por $E_{2}$ (no intentar salir del edificio), que provocó la muerte de Weeks y se anticipó a E1 y lo convirtió en algo irrelevante.

Una sentencia basada en la causalidad probabilística concluiría que no instalar escaleras de emergencia en un edificio aumenta marginalmente el riesgo y, por ende, sería una causa de la muerte de Weeks. Combinado con la negligencia de McNulty, esto llevaría a la responsabilidad. Landes y Posner (1983) considerarían que esta sentencia es ineficiente y no hubiesen podido predecir la decisión del tribunal. También alegan en su artículo que "la probabilidad de su muerte era independiente de si se había producido una violación o no" (Landes y Posner, 1983, p. 115), pero es solo cierto desde una perspectiva ex post. El resultado de un análisis probabilístico ex ante hubiese sido distinto (Wright, 1985a).

Para predecir (o describir) la decisión del tribunal, se necesita un criterio que pueda enfrentar casos de prelación, como aquellos que se sugieren en la sección final de este artículo. Si el análisis económico del derecho se apartase del minimalismo causal sin abandonar su enfoque en las medidas preventivas y, a su vez, conservase las consideraciones de eficiencia, aumentaría su poder predictivo y explicativo. 


\section{Problemas operativos \\ 5.1. Costos administrativos}

Los costos administrativos que las diferentes normas jurídicas generan para el ordenamiento jurídico (y en particular los costos de la información) juegan un rol fundamental en la determinación de la eficiencia de las normas (Posner, 1986). Estos costos incluyen principalmente la incidencia que una norma tiene en la cantidad de juicios y en los gastos por juicio. El cambio de un criterio determinista a uno probabilístico para la causalidad afecta ambos aspectos.

La aplicación general de la causalidad probabilística con responsabilidad proporcional aumentaría la cantidad de juicios que se inician, ya que las (potenciales) partes que no obtendrían un resarcimiento con otros criterios podrían obtenerlo con la causalidad probabilística (Shavell, 1985, 1998).

El supuesto hipotético en el cual la causalidad probabilística se aplica de forma generalizada convertiría la afirmación de que solamente aumentaría el número de casos en una subestimación. Si la regla se implementara de esa forma, todas las actividades que suponen un aumento del riesgo de daño, ya que se considerarían causas del daño, se llevarían a juicio y prácticamente todas las actividades humanas conllevarían un aumento del riesgo de daño. Claramente, esto sería, si no absurdo, demasiado costoso. El caso de Alfredo y Beto ilustra este punto.

Alfredo y Beto. Alfredo retrocedió con su auto para salir de la entrada de su casa sin mirar hacia atrás. Beto hizo lo mismo al día siguiente y, desafortunadamente, un niño estaba jugando en la entrada. El auto de Beto le rompió las piernas al niño (Thomson, 1987b).

Tanto Alfredo como Beto tuvieron un comportamiento negligente y riesgoso. El motivo por el cual Beto lesionó al niño y Alfredo no fue mera suerte, ya que ninguno de los dos tuvo control sobre la ubicación del niño. Ambos actuaron de manera inoportuna. Por ende, puede resultar deseable también sancionar a Alfredo junto con Beto. Sin embargo, sería difícil para el ordenamiento jurídico tener la capacidad de sancionar a todos los Alfredos e, incluso si fuese posible, es evidente que sería significativamente más costoso. Al mismo tiempo, determinar que solo Beto es responsable, como sucedería en la mayoría de los ordenamientos jurídicos, parecería disuadir tanto a Alfredo como a Beto.

Respecto a los costos de cada juicio, la causalidad probabilística con responsabilidad proporcional afecta los costos de la información y los costos administrativos. La causalidad probabilística implica un proceso de toma de decisiones más complejo, que aumenta los costos relacionados con la adquisición de in- 
formación relevante necesaria (Kaye y Aickin, 1984). A su vez, esto afectaría los costos administrativos. Debido a la complejidad de su estimación, los criterios imposibilitarían que las partes prevean el resultado más probable respecto a la causalidad y, por lo tanto, aumentaría las asimetrías de la información entre las partes. Esto significa que reduciría la probabilidad de que se llegue a un acuerdo. Por los mismos motivos, aumentaría la cantidad de juicios, lo que incrementaría la cantidad de demandantes en cada acción por responsabilidad civil e introduciría la magnitud de la causalidad como un asunto sujeto a objeción. Todos estos factores elevarían los costos administrativos por juicio (Shavell, 1985).

Por lo tanto, la causalidad probabilística incurre en costos más altos que las reglas deterministas (Shavell, 1985). Si el criterio presenta ventajas de eficiencia superiores a los criterios de causalidad determinista para algunos casos únicamente, pero no en todos, su aplicación general aumentaría innecesariamente los costos de todos los demás. ${ }^{22}$

\section{2. (In)justicia}

Objetivos del derecho de responsabilidad civil. El criterio elegido de causalidad solo puede ser "mejor" o "peor" que el resto en función de cuánto ayuda a lograr objetivos sociales previamente establecidos (Calabresi, 1975, p. 73).

Si bien existe un consenso general en análisis económico del derecho sobre la maximización del bienestar social como objetivo, ${ }^{23}$ no existe dicho consenso en la doctrina o entre operadores jurídicos. La mayoría de los teóricos y operadores jurídicos posicionan nociones de justicia e imparcialidad en un nivel superior a la eficiencia y, cuando se enfrentan a un intercambio, están predispuestos a sacrificar parte de la eficiencia a favor de una solución que consideran justa o imparcial24 (Wright, 1992). El foco de muchos académicos parece no

22 El mismo Shavell (2004) afirmó que "para que el nivel de cuidado sea óptimo, las partes no deben ser responsables cuando no son las causas de las pérdidas" (p. 250) por responsabilidad objetiva, y que "los incentivos óptimos se mantienen incluso si se escapan de la responsabilidad, si no generan pérdidas" (p. 251) por negligencia, ya que de otra forma las partes tomarán medidas excesivas de precaución, en cuyo supuesto la causa significa una causa sine qua non.

23 Incluso en las publicaciones de análisis económico del derecho algunos autores afirmaron que el derecho de responsabilidad civil tiene otros objetivos, además de la eficiencia y la maximización del bienestar social (Ver Borgo, 1979; Burrows, 1999; Cooter, 1987; Epstein, 1973, 1974, 1987).

24 Por ejemplo, Sanders et al. (2014) demuestra que la mayoría de las personas consideran algún tipo de justicia correctiva en la que el resarcimiento del daño predomina como elemento central del derecho de responsabilidad civil. Esto no significa que en análisis económico del derecho se debe 
ser la disuasión (teoría de la eficiencia), sino el resarcimiento de la víctima o el castigo del autor del acto ilícito (teoría de la justicia correctiva) (Dewees et al., 1996; Kelman, 1987; Perry, 1992; Schwartz, 1987; Weinrib, 1992).

Una discusión fructífera sobre este tema no implica determinar cuál es la perspectiva normativa que se debería adoptar, ya que esto en cierto sentido es una cuestión de preferencias, sino cuáles son los mejores instrumentos para lograr cada una de ellas (Dewees et al., 1996, p. 9). En este sentido, es preferible presentar herramientas que puedan prestar atención a una diversidad de funciones (Calabresi, 1975). ${ }^{25}$

Esto presenta otro problema para la responsabilidad proporcional, ya que, como afirma Shavell (1985, p. 605), en muchos casos se considera contradictoria al principio de imparcialidad (o justicia). ${ }^{26}$

La posibilidad de que la gente sea sancionada por resultados cuyas probabilidades aumentaron marginalmente, pero que de hecho no provocaron, es contrario a las perspectivas del derecho de responsabilidad civil y derecho penal no basadas exclusivamente en la disuasión. ${ }^{27}$ La mayor parte de la doctrina consideraría que la idea de que alguien sea sancionado por un resultado que en realidad dicha persona no ocasionó, sino que lo ocasionó alguien o algo más, es injusta y rechazable, sin perjuicio de la optimización social del nivel de disuasión que lograría (Shavell, 1998). ${ }^{28}$

Si en el ejemplo de "los dos cazadores" se hubiese descubierto que uno de los dos provocó la lesión mientras que el otro falló, sin dudas la mayoría de los operadores jurídicos haría pagar al primer cazador por la indemnización correspondiente (Thomson, 1987b). Sin perjuicio de las limitaciones en la des-

abandonar la teoría de la eficiencia y sustituir su objetivo con otro, sino que si uno quiere que una propuesta sea exitosa, se debe reconocer esta diversidad de objetivos y evaluar su compatibilidad con los otros objetivos que establecen los operadores jurídicos.

25 Para ver una opinión interesante sobre cómo incorporar las consideraciones morales al análisis económico del derecho, ver Shavell (2004, pp. 635-646).

26 Shavell (1985) sostiene que existe otra regla que, de hecho, viola el principio de imparcialidad. Su afirmación es normativa en el sentido de que menciona la existencia de una norma moral particular. Las afirmaciones de este artículo, que es más limitado que el suyo, describen las opiniones morales generalizadas.

27 Ver Rizzo y Arnold (1980) para obtener una posición parcialmente diferente. Para ver una crítica a dicha opinión, ver Kaye y Aickin (1984) y Robinson (1982).

28 Para algunos, la responsabilidad basada en el criterio del riesgo es una violación directa de los principios de justicia (Robinson, 1985; Weinrib, 1983). Para otros, el no ser sancionado por el resultado que alguien no produjo en los hechos es un elemento fundamental de la libertad de acción (Thomson, 1984). 
cripción fáctica, la mayoría de nosotros consideraría que dicho resultado es imparcial y adecuado como consecuencia legal. Declarar que una persona es responsable por un resultado que no ocasionó en función de la creación de un incremento marginal del riesgo para aumentar la función del bienestar social es, en una medida relevante, utilizarlo como un instrumento para el bienestar social y, por ende, tratarlo con interés y respeto distintos (Dworkin, 1977). ${ }^{29}$

Aquellos que están de acuerdo con Posner (1981) en que el concepto básico de justicia correctiva incluido en Aristóteles ${ }^{30}$ no solo es compatible, sino también necesario en toda teoría económica del derecho, deberían tomar esta conclusión. Lo mismo aplica a aquellos que coinciden con Cooter (1987) en que el derecho de responsabilidad civil debería ser una unión entre la libertad y la eficiencia.

Si la utilidad obtenida por la población a partir de la satisfacción de estándares morales generalizadas no se da por sentada y la justicia correctiva se incorpora en el modelo de la responsabilidad civil -como Polinsky y Shavell (2000) hicieron con la imparcialidad para la seguridad pública-, cambiaría la función de bienestar social producida por criterios de causalidad diferentes. Estos criterios, que producen resultados que la población considera justos, en dicho caso mejorarían el bienestar.

Error. La minimización de errores se relaciona con los principios de justicia en todos los tipos de responsabilidad jurídica (Shavell, 1985, p. 605). Este principio no solo está estrechamente vinculado con la eficiencia (Young et al., 2004), sino también con la justicia correctiva; la gente se suele oponer moralmente a la penalización de los inocentes.

Como lo demostró formalmente Kaye (1982), la teoría de más probable que improbable, junto con la causalidad determinista, es superior a la causalidad probabilística desde la perspectiva de la minimización de los errores y, en particular, a la causalidad probabilística con responsabilidad proporcional (Kaye,

29 Las diferencias entre el derecho de responsabilidad civil y el derecho penal -con respecto a que las sanciones del derecho de responsabilidad civil son pecuniarias y no involucran la libertad de acción y que los demandados en los casos de responsabilidad civil en muchos casos son empresas y no personas físicas (Shavell, 1985)- no son relevantes en lo que respecta a la moral porque la pregunta subyacente es metaética. Si la imparcialidad tiene algún valor en sí mismo, entonces sería incoherente afirmar que tiene una importancia mayor o menor según la gravedad de las sanciones. Esto sería compatible si la imparcialidad tuviese un valor instrumental para algún otro valor susceptible de ser alterado por la gravedad de estas sanciones. Sin perjuicio de que el derecho penal muchas veces involucra sanciones pecuniarias y no la prisión, el derecho de responsabilidad civil muchas veces involucra a personas físicas y no a empresas.

30 Es decir, la eliminación de las ganancias y pérdidas ilícitas. 
1982; Shavell, 1985). Estos criterios disminuyen marginalmente el error en principio porque son más simples de analizar.

Si esto es correcto y la causalidad probabilística aumenta marginalmente el error (es decir que aumenta la cantidad de personas que son sancionadas incluso sin aumentar el riesgo y de personas que no son sancionadas incluso si aumentan el riesgo), sus resultados no solo serán menos eficientes que lo que uno supone en primer lugar (Young et al., 2004), sino que también presentarían nuevas incompatibilidades con las nociones generalizadas de "justicia" e "imparcialidad".

Si se considera que una persona es culpable en función del aumento del riesgo, es porque el aumento del bienestar puede ser moralmente atractivo para aquellos que siguen algunos tipos de análisis utilitarios, incluso si quienes sostienen la metaética deontológica y algunos utilitaristas de la norma lo rechazarían (teorías de justicia correctiva). Sin embargo, si alguien es considerado culpable sin serlo realmente, y sin que esto aumente el bienestar social, la regla no sería moralmente atractiva para nadie.

\section{Reducir la incertidumbre causal}

\subsection{Problemas de información}

La pregunta que se deriva de estas preocupaciones sería, si se exilia la causalidad probabilística del derecho, cómo se pueden resolver los problemas de la incertidumbre causal, que son los problemas para los cuales se diseñó originalmente el criterio.

La incertidumbre es un problema desafiante para aquellas ramas del derecho que implican la determinación de la responsabilidad. En particular, esto se ha convertido en un problema con la inclusión de nuevos tipos de responsabilidad (como el daño ambiental y la mala praxis médica), en los que es particularmente difícil determinar el origen del daño. No obstante lo antedicho, el problema de la incertidumbre no es exclusivo de la causalidad. La incertidumbre del daño y del nivel de cuidado ejercido pueden presentar problemas igual de desafiantes (Kahan, 1989).

No debería sobrestimarse la frecuencia de los problemas de la incertidumbre causal. Los estudios empíricos han demostrado que de entre todos los litigios que resolvió la Cour de Cassation francesa entre 1956 y 2010 sobre accidentes ambientales, que son aquellos en los cuales es más relevante la incertidumbre causal (Gold, 1986; Young et al., 2004), en el 78\% no se consideró que la incer- 
tidumbre causal sea un problema esencial (Bentata, 2013). Para aquellos en los que sí se consideró como tal, los tribunales pudieron obtener información de las autoridades reguladoras, lo que redujo en términos significativos la incertidumbre (Bentata, 2013).

Los artículos principales sobre causalidad probabilística propusieron el criterio (y en especial la responsabilidad por participación en el mercado como una herramienta basada en dicho criterio) como una solución para este problema (Rizzo y Arnold, 1980, 1986; Shavell, 1980, 1985). En función de lo que se ha dicho hasta ahora, debería ser posible distinguir estas situaciones en las cuales la causalidad probabilística es una solución para la incertidumbre causal de aquellas en las que esta, lejos de ser un argumento a su favor, es un problema para su aplicación.

Lo primero que se debe considerar es que en un mundo de información imperfecta a veces es difícil o imposible evaluar la medida en la cual E aumentó la probabilidad de $R$. Cuando el juez no conoce la causa de $R$, en la mayoría de los casos no conocerá los factores que aumentaron marginalmente el riesgo de su ocurrencia y mucho menos en qué medida cada factor aumentó el riesgo. Es más fácil evaluar las afirmaciones causales singulares que las afirmaciones causales generales (Lipton, 1992) y es más fácil evaluar las afirmaciones causales que los aumentos del riesgo.

Esto lleva a considerar que la causalidad probabilística solo constituye una regla más precisa que las reglas de la causa adecuada y próxima cuando se toman una serie de presunciones sobre la información que el agente tiene al momento de la toma de decisiones. Es decir que el juez tiene una estimación precisa de cuán probable es que $E$ aumente la probabilidad de $R$. Esta información va de la mano con la información sobre cuán probable es que $E$ sea la causa de $R$. Esto sugiere que la causalidad probabilística solo funcionaría en supuestos con altos niveles de información y, en general, es más fácil tener estimaciones precisas sobre las relaciones causales que estimaciones precisas sobre los aumentos de la probabilidad marginal.

Si ese es el caso, no es claro qué queda como el beneficio principal del modelo probabilístico para la incertidumbre causal. En las palabras de Shavell (1985),

en el contexto de la mayoría de los hechos ilícitos civiles, sin embargo, no habrá una ventaja real de responsabilidad proporcional, ya que la probabilidad de la incertidumbre sobre la causalidad es, sin dudas, baja. Por ende, es bastante entendible que el enfoque general del derecho haya sido adoptar un enfoque de a todo o nada basado en un criterio de probabilidad umbral. (p. 107) 
El problema se hace más evidente cuando se considera que la causalidad probabilística requiere una toma de decisiones central, mientras que las explicaciones deterministas de la causalidad no. La responsabilidad civil proporciona un sistema para evaluar riesgos de manera dispersa. Cada agente, utilizando su propia información privada sobre sus niveles de precaución y probabilidades de accidente estimadas, adopta un nivel de cuidado, y si el riesgo se materializa (con o sin que sea necesario el incumplimiento del deber, según el tipo de responsabilidad), el agente será responsable. Por ende, el agente (si es racional) adoptará un nivel de cuidado que minimice sus costos privados y, en el proceso, los costos sociales. La causalidad probabilística puede hacer lo mismo solo si uno asume que el juez tiene la misma información o más información sobre el funcionamiento de los agentes, y que la autoridad central no tiene costos de supervisión o, si los tiene, son bajos para adquirir dicha información.

Esto se puede ilustrar con un caso paradigmático de la incertidumbre causal.

\subsection{Reconsideración de Sindell}

Los casos de exposición masiva presentan dos tipos de problemas de incertidumbre causal. El primero es si alguno de los fabricantes de un determinado producto (o los demandados en general) había sido la causa del daño del demandante. El segundo, una vez que se responda al primero de manera positiva, es cuál de los muchos fabricantes le provocó daños al demandante y en qué medida (Rosenberg, 1984). ${ }^{31}$

La responsabilidad por participación de mercado parece ser igual a la causalidad probabilística con responsabilidad proporcional solo con la presunción de que el aumento marginal del riesgo de daño generado por cada compañía es directamente proporcional a su presencia en el mercado, es decir, cuando la incertidumbre causal proporciona principalmente el segundo problema mencionado: un problema de correspondencia (Levmore, 1990). Solo en ese momento el aumento marginal del riesgo que las víctimas recibieron será igual a la participación del mercado de la empresa. Para que esto suceda, es necesario que todas las empresas hayan tenido niveles de negligencia equivalentes y niveles de actividad proporcionales a su participación en el mercado o que estas variables sean compensables entre ellas.

31 Si bien el segundo problema es específico de los casos de exposición masiva, el primero existió en la responsabilidad jurídica antes que estos casos. Por ejemplo, este es el caso de mala praxis médica debido a prolongados períodos de latencia (Gold, 1986). 
La presunción antes mencionada era la presunción subyacente (razonable ${ }^{32}$ ) en Sindell v. Abbott Laboratories, ${ }^{33}$ y también es una presunción (razonable) en daños recurrentes entre las partes (Levmore, 1990).

Estos casos presentaron incertidumbre en la identidad de los autores del acto ilícito, pero necesariamente bajo, ya que (se presume que) su aumento marginal en el riesgo de daño de todo el conjunto de demandantes es proporcional a su participación del mercado ${ }^{34}$ (u otra variable utilizada para la asignación).

Si la presunción es inaplicable y la incertidumbre sobre la identidad del autor del acto ilícito en consecuencia es alta, lo que se debe reducir en ese tipo de incertidumbre es la investigación fáctica; en el caso de dietilestilbestrol (DES), las estadísticas epidemiológicas -(Gold, 1986; Rosenberg, 1984)-, que funcionan con los criterios de causalidad determinísticos.

En el caso Sindell, las estadísticas epidemiológicas resolvieron el primer problema y ayudaron a informar que el medicamento DES producía cáncer. Lo que la responsabilidad por participación de mercado hizo por las hijas DES fue resolver el problema de correspondencia para aliviarlas de la imposible carga de la prueba de demostrar cuál de todos los fabricantes les había ocasionado daños de manera grupal e individual.

En los sistemas de asignación de responsabilidad, como la responsabilidad por participación de mercado, la relajación del requisito causal (determinista) es mucho más sutil que en otras aplicaciones de la causalidad probabilística con responsabilidad proporcional. Esto es así porque, a pesar de que el demandante no necesita demostrar un nexo causal (determinista) entre su daño y el accionar de cada uno de los demandados, igualmente debe probar la existencia de un nexo causal determinista entre su daño y los demandantes como grupo (Geistfeld, 2006).

Si el razonamiento detrás de una aplicación de responsabilidad por participación de mercado (o los sistemas de asignación con una variable similar) es que, al enfrentarse a la incertidumbre causal alta, es eficiente dividir la responsabilidad de esa manera porque es probable que las empresas hayan generado daño en dicha proporción, por lo que la regla se puede interpretar de la misma

32 En los casos DES, esta presunción es razonable porque todos los demandantes participaban en la misma actividad (Robinson, 1982).

33 En el caso, mujeres embarazadas utilizaban medicamentos basados en dietilestilbestrol (DES, por sus siglas en inglés) para prevenir abortos espontáneos, lo que provocó que sus hijas (posteriormente conocidas como "las hijas DES") desarrollaran cáncer veinte años más tarde (Sindell v. Abbott Laboratories).

34 Esto, a su vez, depende de cómo uno defina el mercado relevante. 
manera desde el punto de vista de la causalidad probabilística con responsabilidad proporcional y desde una variación de la regla "más probable que improbable”, que revierte la carga de la prueba como una respuesta clásica para el problema de la información asimétrica entre los fabricantes y los consumidores con respecto al riesgo de los productos (Marino, 1991).

En resumen, la responsabilidad por participación de mercado parece ser una regla eficiente para resolver solo determinado tipo de incertidumbre por sobre la causalidad (singular) y, en aquellos casos en los que resulta útil, se basa en explicaciones de la causalidad determinista y no en las explicaciones probabilísticas.

Esto puede explicar el éxito de los criterios para aquellos casos que proponen Shavell (1980) y Rizzo y Arnold (1980) y la reticencia simultánea de los tribunales a utilizarla para cualquier otro caso. ${ }^{35}$ Esto puede servir como una formulación más clara de un espacio de muestra para la causalidad probabilística.

\section{Marco para la solución}

\subsection{Enunciados causales generales y singulares}

Cuando alguien dice que $E$ ocasionó $R$, la afirmación puede significar dos cosas diferentes. Si la afirmación describe la relación causal concreta entre un E particular y un $R$ particular en un tiempo y lugar específicos (como "fumar hizo que Juan tenga cáncer"), se trata de un enunciado causal singular. Si la afirmación describe la relación entre una categoría de E (como "fumar causa cáncer"), se trata de un enunciado causal general.

Las preguntas causales son preguntas de por qué (Hausman, 2009) y el porqué de los hechos singulares es diferente en su estructura del porqué de los grupos de hechos. Por ejemplo, uno podría decir que la gente tiende a cambiar de trabajo para ganar más dinero, para hacer tareas que disfrutan más o para trabajar más cerca de sus hogares. Pero si uno se pregunta por qué Juan Perez cambió de trabajo, sabríamos que estas podrían o no ser las causas de su cambio en particular (Lipton, 1992). La respuesta a "¿por qué Perez cambió de trabajo?" exige un tipo de información diferente que la respuesta a "ipor qué la gente cambia de trabajo?".

La distinción entre los enunciados causales singulares y generales está bien establecida en la literatura sobre causalidad (Bunge, 2009; Eells, 1991; Good, 1961a, 1961b; Hellner, 2000; Hitchcock 1995; Mackie, 1965; Moore, 1987;

35 Para revisar los casos en los que se rechazó este tipo de prueba, ver Wright $(1988,2008)$. 
Sober, 1985; Von Wright, 1971, 1975, Woodward, 1984, 2003; Wright, 1985b, 1988; Yablo, 2002) y está implícita en estadística, que trata con enunciados causales generales. ${ }^{36}$ En análisis económico del derecho, Borgo (1979) lo menciona, aunque no lo desarrolla.

La relevancia de esta distinción para la manera en que el análisis económico del derecho trata la causalidad se puede ver si nos remontamos al ejemplo de "Jack y Jill" y pensamos las respuestas que uno podría obtener si nos preguntamos si Jack era la causa de la caída de Jill. Las respuestas que se podrían escuchar serían, por ejemplo: "sí, porque Jack le agarró el brazo a Jill para evitar lesionarse y accidentalmente la tiró para abajo", "sí, porque Jill intentó agarrarlo a Jack en la caída pero se cayó abajo de él", "sí, porque Jill se desmaya cuando ve sangre", o "no, fueron dos hechos independientes", etc. Probablemente no se escuchará la explicación de que "Jack causó al caída de Jill porque, hablando en términos estadísticos, existe una relación positiva entre las caídas de los hermanos senderistas", y los operadores jurídicos tampoco la considerarían factible.

El motivo es que cuando uno pregunta si Jack fue la causa de la caída de Jill, se trata de un enunciado causal singular y no de un enunciado causal general. Cuando los abogados preguntan sobre la causa de algo, cuando preguntan el porqué de algo, están buscando un hecho que explique el fenómeno y que sirva como fundamento para la responsabilidad (Moore 2009; Schultz, 2001). Por ende, responder la pregunta utilizando las relaciones causales entre tipos de hechos es una respuesta a una pregunta diferente. Las relaciones funcionales, como las que se utilizan en la causalidad probabilística, son descripciones matemáticas de las generalizaciones causales (Cooter, 1987).

Todos los contraejemplos provistos con anterioridad para la causalidad probabilística implican enunciados causales singulares. Esto no es una coincidencia. A diferencia de las relaciones causales generales, las relaciones causales singulares son binarias. Existen dos valores: la causalidad presente y la causalidad ausente, ya sea que $E$ sea la causa de $R$ o no, tertium non datur (principio del tercero excluido). En "Jack y Jill", las únicas respuestas posibles a la pregunta de la causalidad son "Jack causó la caída de Jill” y "Jack no causó la caída de Jill”. Es por esta cualidad binaria que, como señala Rizzo (1996), es difícil tomar relaciones causales singulares en las funciones (Hellner, 2000). ${ }^{37}$

36 Ver Salmon (1980) para obtener un ejemplo claro de esto.

37 Desde el punto de vista formal, Kaye y Aickin (1984) y Kruskal (1986) explican que no es sensible tomar productos marginales, que necesitan los derivados parciales cuando uno no trata con una función exenta de problemas. 
Por ende, parece razonable afirmar que la causalidad probabilística se debería utilizar para enunciados causales generales y un criterio de causalidad distinto es necesario para los enunciados causales singulares (Hitchcock, 2010). ${ }^{38}$ Esto evita confusiones entre la causa de un resultado y (la causa del) aumento del riesgo de un resultado (Moore, 1985; 1987), que es solo el potencial de ser la causa de un hecho singular y no la causa en sí misma. Como explican Rizzo (1987) y Papineau (1985), en enunciados causales singulares "un aumento en la probabilidad (frecuencia) de un resultado puede ser prueba de la causalidad [pero] no es el fenómeno causal en sí mismo" (Rizzo, 1987, p. 403). ${ }^{39}$

El alcance para el uso de la causalidad probabilística de alguna forma está implícito en el uso intuitivo del término "causa" en el lenguaje cotidiano, y tanto los tribunales como la doctrina parecen insistir en que la causalidad en el derecho debería basarse en principios del sentido común que se relacionen intrínsecamente con el lenguaje (Hart y Honoré, 1985). En el contexto de una apuesta, por ejemplo, la probabilidad ex ante de un E se debería considerar información útil para apostar a un $R$, pero nunca para resolver la apuesta (Wright, 2011). ${ }^{40}$

Dado que la causalidad para hechos singulares se verifica necesariamente ex post, y ex ante solo se puede predecir, las teorías de la responsabilidad civil y penal son estructuralmente retrospectivas (Alexander, 1987; Coleman, 1992; Miceli, 1996). Aunque el razonamiento ex ante es útil para políticas dirigidas a la disuasión, su incorporación en el derecho debe ocurrir teniendo en consideración la estructura retrospectiva de la responsabilidad para evitar resultados indeseables, como aquellos que se analizaron en las últimas tres secciones (Coleman, 1992).

En resumen, la causalidad probabilística describe el comportamiento promedio y no individual (Holland, 1986). El derecho necesita modelos de causalidad que describan adecuadamente a ambos.

38 Las primeras evaluaciones de causalidad en economía se basaban en el concepto de Feigl de "predictibilidad de acuerdo con un conjunto de leyes" (Granger, 1987, p. 381), y la idea de Feigl era explicar fenómenos generales y no singulares (Hausman, 2009).

39 Las relaciones causales típicas entre hechos son útiles para identificar relaciones causales entre hechos singulares (Rizzo y Arnold, 1980), pero la epistemología y la metafísica son cosas diferentes. La afirmación no contradice el hecho de que los tipos de relaciones causales sean diferentes (Hart y Honoré, 1985; Moore, 1985).

40 "Si se afirma que X fue la causa de Y, se debe hacer algo para prever y responder la objeción 'Sí: X en este caso estuvo seguido de Y como en la mayoría de los casos, pero ¿cuál fue la causa en este caso?” (Hart y Honoré, 1985, p. 49). 


\subsection{Creación y aplicación de normas}

Por ende, ¿es la causalidad probabilística siempre inadecuada para el derecho?

Al utilizar la distinción delineada, es posible ver que muchos de los problemas que existen en cómo el análisis económico del derecho trata la causalidad están creados por las confusiones sobre cómo opera la causalidad en el derecho. Los operadores jurídicos a veces se enfrentan con evaluaciones causales generales y a veces con evaluaciones causales singulares; la manera de tratarla debería ser diferente según el tipo de información necesaria para cada una.

En términos generales, los operadores jurídicos se enfrentan a dos tareas estructuralmente diferentes al hacer evaluaciones causales: la creación de la norma, que en general exige el uso de enunciados causales generales, y la aplicación de la norma, que exige el uso de enunciados causales singulares. ${ }^{41}$

En el primer caso, el órgano crea una norma que puede aplicarse en el futuro, una tarea que en general requiere información sobre la relación entre los tipos de hechos. Cuando se debate si desalentar fumar, uno de los asuntos clave es si, en general, fumar es perjudicial para la salud. Cuando se debate si hacer obligatorios los extintores y las escaleras de emergencia, una de las preocupaciones principales es si, en general, ayudan a prevenir las muertes en incendios.

En el segundo tipo de tarea, el órgano (a menudo un juez) aplica la norma a una situación particular que implica enunciados causales sobre hechos particulares. La responsabilidad, como ya se dijo, es retrospectiva. Lo que el juez quiere saber es si Jack efectivamente provocó la caída de Jill.

Esto puede explicar el predominio de la prueba particularista en los juicios.

La prueba particularista es necesaria para la explicación causal (determinar lo que pasó de verdad), ya que solo la prueba particularista puede establecer o refutar la instanciación de los elementos abstractos en una posible generalización causal aplicable y su derecho causal subyacente. [...] Las probabilidades causales ex ante, que son probabilidades basadas en clases no particularizadas, son necesarias para la predicción causal (proyectar lo que sucederá), pero no son útiles para la explicación causal. (Wright, 1988)

Como las sentencias ex ante son necesariamente abstractas y se basan en

41 Esto parece estar implícito en Calabresi (1975) cuando afirma que "los objetivos de disuasión exigen un nexo causal [causalidad probabilística] y pueden ser tan fundamentales en el derecho de responsabilidad civil para hacer que el requisito sea casi un requisito previo absoluto de la responsabilidad. Dada la determinación individual de la responsabilidad, la disuasión del mercado puede agregar una causa sine qua non como un requisito previo útil y, de hecho, casi fundamental” (p. 90). 
enunciados causales generales, proporcionan poca información sobre cuál de los elementos abstractos de una generalización causal se materializó en un enunciado causal singular en la sentencia (Wright, 1988). Este rol es el de las explicaciones causales singulares.

Por lo tanto, la causalidad probabilística es adecuada para la creación de normas, pero no para su aplicación. Las sentencias judiciales, en general, exigen la evaluación de relaciones causales singulares (Hart y Honoré, 1985), ${ }^{42}$ lo que podría explicar por qué rara vez se cita a Hume (prácticamente el creador de las explicaciones modernas de la causalidad) en la literatura de causalidad en derecho (Schultz, 2001).

\subsection{Un modelo responsivo de causalidad}

Si la causalidad sine qua non y la causalidad probabilística son criterios inadecuados para enunciados causales singulares, resta responder la pregunta de qué criterio se debería utilizar para esos casos. El candidato obvio es el criterio de la suficiencia, que se describió con anterioridad. Sin embargo, este presenta sus propias dificultades. Al igual que las explicaciones probabilísticas, convierte a la prelación en un problema de sobredeterminación, ${ }^{43}$ a la vez que presenta problemas de subdeterminación. ${ }^{44}$

En el conjunto de criterios de causalidad determinados existe más de un único criterio factible que involucra alguna combinación entre condiciones suficientes y necesarias y que aborda las preguntas de causalidad mejor que los criterios sine qua non y causa causans. Por ejemplo, condición insuficiente pero parte necesaria de una condición no necesaria pero suficiente (INUS) (Mackie, 1965, 1974), elemento necesario de un set de condiciones suficiente (NESS)

42 En los países en los que prevalece el derecho creado por los jueces (al menos cuantitativamente) por sobre el derecho conformado por normas, puede ser difícil trazar la distinción. Sin embargo, gran parte de la doctrina en las jurisdicciones del derecho anglosajón considerarían inadecuado que un tribunal tomara una decisión determinada (es decir, sobre la culpabilidad de Jack) que ignore los hechos del caso, lo cual incluye la relación causal entre los individuos. En todo caso, la distinción igual estaría presente; ocasionalmente se les daría más importancia a los enunciados causales generales y menos a los enunciados causales singulares.

43 En "el viajero del desierto", el criterio de la suficiencia consideraría que ambos enemigos son causas de la muerte del viajero, incluso si solo el segundo provocó efectivamente su muerte, ya que ninguno de ellos fue suficiente para lograr el resultado.

44 Ver, por ejemplo, el siguiente caso:

La máquina de golosinas. Una máquina de golosinas en la universidad expide las golosinas seleccionadas cuando se inserta una moneda. Sin embargo, como muchas máquinas en las universidades, a 
(Hart y Honoré, 1985; Wright, 1985a, 1985b, 1987, 1988, 2011), la teoría de la influencia de Lewis (Lewis, 2000) y 3-set mínimo-máximo (MMTS) (Spector, 2011). No busco defender ninguno de estos criterios como superior al resto.

Estos criterios resuelven los problemas principales de sine qua non y causa causans y, a su vez, mantienen una explicación no normativa de la causalidad (Fumerton y Kress, 2001). Al mismo tiempo, dado que son deterministas, no presentan los problemas que surgen de la aplicación de criterios probabilísticos a enunciados causales singulares. Esto podría derivarse del hecho de que la prueba fue originalmente diseñada por disciplinas normativas como el derecho.

Los problemas que estos criterios presentan aparecen cuando se analizan enunciados causales generales (Fumerton y Kress, 2001). Este es el caso, por ejemplo, del problema del subconjunto NESS (Kelman, 1987).

Las explicaciones de la causalidad determinista combinadas presentan, para la toma de decisiones judiciales, costos administrativos comparativamente bajos y son más compatibles con las teorías de justicia correctiva que los enfoques probabilísticos. Resuelven múltiples problemas de prelación y causalidad (Wright, 1988), los problemas de sinergia causa ${ }^{45}$ y pueden describir y predecir el comportamiento de los tribunales de mejor manera que las explicaciones probabilísticas de la causalidad y los criterios de necesidad y suficiencia. ${ }^{46}$

\subsection{Impacto en la eficiencia}

Falta evaluar si el NESS podría llegar a los mismos resultados de eficiencia que la causalidad probabilística, una pregunta clave para el análisis económico del derecho.

veces no expide las golosinas, incluso cuando uno inserta el dinero. La mayoría estaría de acuerdo en que, cuando la máquina expide la golosina, la inserción de la moneda es la causa. Pero una prueba de suficiencia pura no daría dicho resultado, ya que el hecho de que la golosina no siempre sea el resultado de insertar una moneda demuestra que insertar dinero no es suficiente para obtener una golosina (Mackie, 1974).

45 Ver, por ejemplo, el siguiente caso:

Los envenenadores de agua. Cinco hombres, de manera independiente, envenenan con mercurio los mismos mil vasos de agua, los cuales beben mil personas. Cuatro unidades de mercurio serían inofensivas para aquellos que beben agua, pero cinco unidades provocan daños graves.

Este es un caso de subdeterminación tanto para los criterios de necesidad pura como de suficiencia pura, pero el NESS (como sería la causalidad probabilística) identifica a todos los hombres como causas conjuntas de los daños. Si bien ninguno de ellos es necesario o suficiente para los daños, todos son elementos necesarios del conjunto de condiciones precedentes reales que fue necesario para que se produjeran los daños (Wright, 1985b).

46 Por ejemplo, el NESS sería capaz de predecir la decisión de Weeks v. McNulty. 
El argumento central a favor de la causalidad probabilística es que el costo del cuidado solo se puede justificar al hacer referencia a los Estados del mundo en los que dicho costo reduce las consecuencias perjudiciales y, por ende, se compensa (Shavell, 2007, pp. 118-121).

Si tanto el criterio de incumplimiento de deber (sea la regla de Hand, el teorema de Grady, el estándar de hombre razonable, etc.) como el criterio de la causalidad probabilística tienen el objetivo de la eficiencia, entonces pueden ser: (i) complementarios si se necesitan mutuamente para funcionar; o (ii) redundantes si no se necesitan. Si son complementarios, una explicación probabilística de la causalidad será necesaria para lograr resultados eficientes. Si son redundantes, el criterio de causalidad probabilística se puede sustituir con otro sin tener que alterar el modelo de responsabilidad civil y sin pérdida de la eficiencia.

El principio básico detrás de la regla de Hand (marginal) es que se deberían prohibir las acciones cuando su costo social marginal es mayor que su beneficio social marginal (United States et al. v. Carroll Towing Co., Inc., et al.). Es decir, cuando los beneficios de la acción (compuestos principalmente por la anulación del costo de precaución) son menores que el costo previsto de la acción (compuesto principalmente por la probabilidad de la ocurrencia del daño y la pérdida generada por el daño): $B<P L$.

De esta manera, la regla -uno de los posibles criterios normativos, el que se aplica de manera más extendida en análisis económico del derecho- se utiliza para definir cuándo se debería prohibir y cuándo permitir una determinada acción (incumplimiento del deber). Es un parámetro normativo para establecer si debería permitirse un $E$ que efectivamente cause $R$ una vez que la causalidad está establecida.

Tanto la regla de Hand como los criterios de causalidad probabilística buscan prohibir acciones en la medida en que disminuyen el bienestar social. Al mismo tiempo, la causalidad probabilística puede funcionar con otros criterios de incumplimiento de deber, y la regla de Hand puede funcionar con otros criterios de causalidad, ya que da por sentado la causalidad.

Si las partes potenciales saben eso (ex ante), en el caso de producir efectivamente un daño con su comportamiento, los tribunales los declararán culpables (ex post) por el daño ocasionado y tendrán incentivos (ex ante) para comportarse de manera eficiente. Esto significa que si se presume un nivel adecuado de implementación en un sistema de responsabilidad consecuente con la causalidad, un posible generador de daños tiene una responsabilidad prevista más 
alta cuando es negligente que su costo de tener precaución al no ser negligente (Singh, 2002). Esto lo demostraron formalmente Van Wijck y Winters (2001) para los modelos unilaterales y Singh (2007) para los modelos bilaterales. Lejos de confundir las perspectivas ex ante y ex post, esto se deriva del entendimiento de su relación y del entendimiento de los mecanismos detrás de los sistemas positivos del derecho de responsabilidad civil consecuente con la causalidad.

El motivo por el cual la denominada causalidad ex post ${ }^{47}$ puede funcionar desde el punto de vista de la disuasión es el siguiente: como lo que importa para los incentivos es lo que se espera que hagan los operadores jurídicos (Kahan, 1989) y se espera (presuntamente) que los operadores jurídicos sigan las normas jurídicas, es posible predecir los resultados jurídicos. De esa forma, una sanción ex post por generar daño altera los incentivos futuros (ex ante), de manera que los posibles (futuros) generadores de daño tienen incentivos para evitar producirlos. Las normas jurídicas retrospectivas también tienen efectos futuros (Alexander, 1987).

En este sentido, existe un tipo de proceso empresarial en los sistemas consecuentes con la causalidad que establecen incentivos para que la gente descubra, de forma privada, los costos y beneficios de las actividades que la autoridad que toma las decisiones (el juez) hubiese descubierto en sistemas alternativos (Alexander, 1987).

\section{Conclusión}

Este artículo propone una distinción ausente en derecho y economía, pero presente en otras disciplinas. La distinción haría que las evaluaciones de causalidad se entiendan mejor y, por ende, se adapten mejor a la responsabilidad jurídica. Se lograrían resultados beneficiosos al tratar los enunciados causales generales con explicaciones probabilísticas de causalidad y los enunciados causales singulares con explicaciones deterministas de causalidad.

Desde un punto de vista descriptivo, la distinción llevaría a una explicación de la causalidad fáctica y de la responsabilidad consecuente con la causalidad dentro del análisis de eficiencia, que aumentaría el poder explicativo del análisis económico del derecho de la responsabilidad tanto para intuiciones causales como para el comportamiento de los tribunales.

Desde el punto de vista normativo, aumentaría el atractivo de las teorías de

47 Si la causalidad es una afirmación sintética, la "causalidad ex post" es tautológica. 
la responsabilidad basadas en la eficiencia al mejorar su compatibilidad con otras perspectivas del derecho sin necesidad de modificar sus modelos formales, por ende, estaría un paso más cerca de formar parte de políticas públicas.

De esta forma, el artículo intenta definir la medida en la cual un enfoque cuantitativo hacia la causalidad puede mejorar el análisis jurídico. A un nivel más general, este es un paso hacia la determinación del límite de los métodos cuantitativos en derecho.

\section{Bibliografía}

Alexander, L. A. (1987). Causation and Corrective Justice. Does Tort Law Make Sense? Law and Philosophy, 6(1), 1-23.

Beale, J. (1920). The Proximate Consequence of an Act. Harvard Law Review, 33(5), 633-658.

Becht, A. C. y Miller, F. W. (1961). The Test of Factual Causation in Negligence and Strict Liability Cases. Washington University Studies.

Ben-Shahar, O. (2000). Causation and Foreseeability. En Bouckaer, B. y De Geest, G. (Eds.), Encyclopedia of Law and Economics. Edward Elgar.

Bentata, P. (2013). Environmental Regulation and Civil Liability Under Causal Uncertainty: An Empirical Study of the French Legal System. Review of Law E Economics, 9(2): 239-263.

Borgo, J. (1979). Causal Paradigms in Tort Law. Journal of Legal Studies, 8(3), 419-455.

Brown, J. (1973). Toward an Economic Theory of Liability. Journal of Legal Studies, 2(2), 323-349.

Bunge, M. (1973). A Probabilistic Theory of Causality by P. Suppes. The British Journal of Philosophy of Science, 24(4), 409-410.

Bunge, M. (2009). Causality and Modern Science (4a ed.). Transaction Publishers.

Burrows, P. (1999). A Deferential Role for Efficiency Theory in Analysing Causation-Based Tort Law. European Journal of Law and Economics, 8, 29-49.

Calabresi, G. (1970). The Costs of Accidents. A Legal and Economic Analysis. Yale University Press. Calabresi, G. (1975). Concerning Cause and the Law of Torts: An Essay for Harry Kalven, Jr. The University of Chicago Law Review, 43(1), 69-108.

Cartwright, N. (1979). Causal Laws and Effective Strategies. Nous, 13, 419-437.

Coase, R. (1960). The Problem of Social Cost. Journal of Law and Economics, 3, 1-44.

Coderch, P. S. y Fernández Crende, A. (2006). Causalidad y Responsabilidad. InDret, (artículo 329). Coleman, J. L. (1992). Risks and Wrongs. Cambridge University Press.

Cooter, R. (1987). Torts as the Union of Liberty and Efficiency: An Essay on Causation. Chicago-Kent Law Review, 63, 523-552.

Dewees, D., Duff, D. y Trebilcock, M. (1996). Exploring the Domain of Accident Law. Oxford University Press.

Dworkin, R. (1977). Taking Rights Seriously. Harvard University Press.

Edgerton, H. W. (1924). Legal Cause. University of Pennsylvania Law Review, 72, 211-243. 
Eells, E. (1991). Probabilistic Causality. Cambridge University Press.

Epstein, R. A. (1973). A Theory of Strict Liability. Journal of Legal Studies, 2, 151-204.

Epstein, R. A. (1974). Defenses and Subsequent Pleas in a Theory of Strict Liability. Journal of Legal Studies, 3, 185-201.

Epstein, R. A. (1987). Causation-in Context: An Afterword. Chicago-Kent Law Review, 63, 653-682.

Fumerton, R. y Kress, K. (2001). Causation and the Law: Preemption, Lawful Sufficiency, and Causal Sufficiency. Law Eु Contemporary Problems, 64(4), 83-105.

Geistfeld, M. (2006). The Doctrinal Unity of Alternative Liability and Market-Share Liability. University of Pennsylvania Law Review, 155, 447-501.

Gold, S. (1986). Causation in Toxic Torts: Burdens of Proof, Standards of Persuasion, and Statistical Evidence. Yale Law Journal, 96(2), 376-402.

Good, I. J. (1961a). A Causal Calculus I. British Journal for the Philosophy of Science, 11(44), 305-318. Good, I. J. (1961b). A Causal Calculus II. British Journal for the Philosophy of Science, 12(45), 43-51.

Granger, C. (1987). Causal Inference. En Eatwell, J., Milgate, M. y Newman, P. (Eds.), The New Palgrave: A Dictionary of Economics. The McMillan Press Limited.

Green, L. (1929). Are There Dependable Rules of Causation? University of Pennsylvania Law Review and American Law Register, 77(5), 601-628.

Hart, H. L. A. y Honoré, T. (1985). Causation in the Law (2 ed.). Oxford Clarendon Press.

Hausman, D. M. (2009). Laws, Causation and Economic Methodology. En Kincaid, H. y Ross, D. (Eds.), The Oxford Handbook of Philosophy of Economics. Oxford University Press.

Hellner, J. (2000). Causality and Causation in Law. Scandinavian Studies in Law, 40, 111-134.

Hitchcock, C. (1995). The Mishap at Reichenbach Fall: Singular Vs. General Causation. Philosophical Studies, 78, 257-291.

Hitchcock, C. (2010). Probabilistic Causation. En Zalta, E. N. (Ed.), The Stanford Encyclopedia of Philosophy. http://plato.stanford.edu/archives/win2011/entries/causation- probabilistic.

Holland, P. W. (1986). Statistics and Causal Inference. Journal of the American Statistical Association, 81(396), 945-960.

Honoré, T. (1983). Causation and Remoteness of Damages. En Tunc, A, (Ed.), International Encyclopedia of Comparative Law (Vol. XI: 1).

Kahan, M. (1989). Causation and Incentives to Take Care Under the Negligence Rule. Journal of Legal Studies, 18, 427-447.

Kaye, D. (1982). The Limits of the Preponderance of the Evidence Standard: Justifiably Naked Statistical Evidence and Multiple Causation. American Bar Foundation Research Journal, 7(2), 487-516.

Kaye, D. y Aickin, M. (1984). A Comment on Causal Apportionment. Journal of Legal Studies, 13, 191-208.

Kelman, M. (1987). The Necessary Myth of Objective Causation Judgments in Liberal Political Theory. Chicago-Kent Law Review, (63), 579-638.

King, J. H. (1981). Causation, Valuation, and Chance in Personal Injury Torts Involving Preexisting Conditions and Future Consequences. Yale Law Journal, 90, 1376-1396.

Krecke, E. (1996). The Nihilism of the Economic Analysis of Law. Journal Des Economistes Et Des Etudes Humaines, 3, 19-37.

Kruskal, W. (1986). Terms of Reference: Singular Confusion About Multiple Causation. Journal of Legal Studies, 15(2), 427-436. 
Landes, W. M. y Posner, R. A. (1981). The Positive Economic Theory of Tort Law. Georgia Law Review, 15, 851-924.

Landes, W. M. y Posner, R. A. (1983). Causation in Tort Law: An Economic Approach. Journal of Legal Studies, 12, 109-134.

Landes, W. M. y Posner, R. A. (1987). The Economic Structure of Tort Law. Harvard University Press.

Levmore, S. (1990). Probabilistic Recoveries, Restitution, and Recurring Wrongs. Journal of Legal Studies, 19, 691-726.

Lewis, D. (1973). Causation. Journal of Philosophy, 70, 556-567.

Lewis, D. (2000). Causation as Influence. Journal of Philosophy, 97, 182-197.

Lipton, P. (1992). Causation Outside the Law. En Gross, H. y Harrison, R. (Eds.), Jurisprudence: Cambridge Essays (pp. 127-148). Oxford University Press.

Mackie, J. L. (1965). Causes and Conditions. American Philosophical Quarterly, 2(4), 245-264.

Mackie, J. L. (1974). The Cement of the Universe: A Study of Causation. Oxford Clarendon Press.

Malone, W. S. (1956). Ruminations on Cause-in Fact. Stanford Law Review, 9(1), 60-69.

Marino, A. M. (1991). Market Share Liability and Economic Efficiency. Southern Economic Journal, 57(3), 667-675.

McCloskey, D. (2005). The Trouble with Mathematics and Statistics in Economics. History of Economic Ideas, 13(3), 85-102.

McLaughlin, J. A. (1925). Proximate Cause. Harvard Law Review, 39(2), 149-199.

Menzies, P. (1996). Probabilistic Causation and the Pre-Emption Problem. Mind. New Series, 105(417), 85-117.

Miceli, T. J. (1996). Cause in Fact, Proximate Cause, and the Hand Rule: Extending Grady's Positive Economic Theory of Negligence. International Review of Law and Economics, 16(4), 473-482.

Miceli, T. J. y Segerson, K. (2007). Punishing the Innocent Along with the Guilty: The Economics of Individual Versus Group Punishment. Journal of Legal Studies, 36(1), 81-106.

Moore, M. (1985). Causation and the Excuses. California Law Review, 73(4), 1091-1149.

Moore, M. (1987). Thomson's Preliminaries About Causation and Rights. Chicago-Kent Law Review, 63, 497-521.

Moore, M. (2000). The Metaphysics of Causal Intervention. California Law Review, 88(3), 827-877.

Moore, M. (2009). Causation and Responsibility: An Essay in Law, Morals and Metaphysics. Oxford University Press.

Otte, R. (1981). A Critique of Suppes' Theory of Probabilistic Causality. Synthese, 48(2), 167-189.

Papineau, D. (1985). Probabilities and Causes. Journal of Philosophy, 82(2), 57-74.

Parascandola, M. (1996). Evidence and Association: Epistemic Confusion in Toxic Tort Law. Philosophy of Science, 63, 168-176.

Perry, S. R. (1992). The Moral Foundations of Tort Law. Iowa Law Review, 77, 449-514.

Polinsky, A. M. y Shavell, S. (2000). The Fairness of Sanctions: Some Implications for Optimal Enforcement Policy. American Law and Economics Review, 2, 223-237.

Posner, R. A. (1981). The Concept of Corrective Justice in Recent Theories of Tort Law. Journal of Legal Studies, 10(1), 187-206.

Posner, R. A. (1986). Economic Analysis of Law. Little, Brown \& Company.

Rizzo, M. J. (1987). Foreword: Fundamentals of Causation. Chicago-Kent Law Review, 63, 397-406.

Rizzo, M. J. (1996). The Genetic-Causal Tradition and Modern Economic Theory. Kyklos, 49(3), 273-317. 
Rizzo, M. J. y Arnold, F. S. (1980). Causal Apportionment in Tort Law: An Economic Theory. Columbia Law Review, 85, 1399-1429.

Rizzo, M. J. y Arnold, F. S. (1986). Causal Apportionment: Reply to the Critics. Journal of Legal Studies, 15, 219-226.

Robertson, D. W. (1997). The Common Sense of Cause in Fact. Texas Law Review, 75, 1765-1800.

Robinson, G. O. (1982). Multiple Causation in Tort Law: Reflections on the DES Cases. Virginia Law Review, 68(4), 713-770.

Robinson, G. O. (1985). Probabilistic Causality and Compensation for Tortious Risk. Journal of Legal Studies, 14, 779-798.

Rosenberg, D. (1984). The Causal Connection in Mass Exposure Cases: A "Public Law" Vision of the Tort System. Harvard Law Review, 97, 849-929.

Russell, G. (2008). Truth in Virtue of Meaning: A Defense oftheAnalytic/Synthetic Distinction. Oxford University Press.

Salmon, W. C (1980). Probabilistic Causality. Pacific Philosophical Quarterly, 61, 50-74.

Sanders, J., Kugler, M. B., Darley, J. M. y Solan, L. M. (2014). Must Torts Be Wrongs? An Empirical Perspective. Wake Forest Law Review, 49, 1-235.

Schaffer, J. (2000). Overlappings: Probability-Raising Without Causation. Australasian Journal of Philosophy, 78(1), 40-46.

Schaffer, J. (2004). Causes Need Not Be Physically Connected to Their Effects: The Case for Negative Causation. En Hitchcock, C. (Ed.), Contemporary Debates in Philosophy of Science (pp. 197-216). Blackwell.

Schultz, M. (2001). Further Ruminations on Cause-in-Fact. Scandinavian Studies in Law, 41, 467-501.

Schwartz, A. (1987). Causation in Private Tort Law: A Comment on Kelman. Chicago-Kent Law Review, 63, 639-652.

Shavell, S. (1980). An Analysis of Causation and the Scope of Liability in the Law of Torts. Journal of Legal Studies, 9, 463-516.

Shavell, S. (1985). Uncertainty Over Causation and the Determination of Civil Liability. Journal of Law and Economics, 28, 587-609.

Shavell, S. (1998). Causation and Tort Liability. En Newman, P. (Ed.), The New Palgrave Dictionary of Economics and the Law. McMillan Reference Limited.

Shavell, S. (2004). Foundations of Economic Analysis of Law. The Belknap Press of Harvard University Press.

Singh, R. (2002). Causation, Economic Efficiency and the Law of Torts. Centre for Development Economics (working paper No. 102).

Singh, R. (2007). 'Causation-Consistent' Liability, Economic Efficiency and the Law of Torts. International Review of Law and Economics, 27, 179-203.

Skyrms, B. (1980). Causal Necessity. Yale University Press.

Smith, J. (1911). Legal Cause in Actions of Tort. Harvard Law Review, 25, 303-327.

Sober, E. (1985). Two Concepts of Cause. En Asquith, P. y Kitcher, P. (Ed.), PSA 1984 (Vol. II, pp. 405-424). Philosophy of Science Association.

Spector, H. (2011). The MMTS Analysis of Causation. En Goldberg, R. (Ed.), Perspectives on Causation. Hart Publishing.

Stapleton, J. (2008). Choosing What We Mean with "Causation" in the Law. Missouri Law Review, 73(2), 433-480. 
Suppes, P. (1970). A Probabilistic Theory of Causality. North-Holland Publishing.

Terry, H. T. (1915). Proximate Consequences in the Law of Torts. Harvard Law Review, 28(1), 10-33.

Thomson, J. J. (1984). Remarks on Causation and Liability. Philosophy Ë Public Affairs, 13(101), $127-133$.

Thomson, J. J. (1987a). Causality and Rights: Some Preliminaries. Chicago-Kent Law Review, 63, 471-496.

Thomson, J. J. (1987b). The Decline of Cause. Georgetown Law Review, 76, 137-150.

Van Wijck, P. V. y Winters, J. K. (2001). The Principle of Full Compensation in Tort Law. European Journal of Law and Economics, 11(3), 319-332.

Von Wright, G. H. (1971). Explanation and Understanding. Cornell University Press.

Von Wright, G. H. (1975). Causality and Determinism. Columbia University Press.

Weinrib, E. J. (1983). Toward a Moral Theory of Negligence Law. Law EO Philosophy, 2, 37-48.

Weinrib, E. J. (1992). Corrective Justice. Iowa Law Review, 77, 403-425.

Woodward, J. (1984). A Theory of Singular Causal Explanation. Erkenntnis, 21, 231-262.

Woodward, J. (2003). Making Things Happen: A Theory of Causal Explanation. Oxford University Press.

Wright, R. W. (1985a). Actual Causation Vs. Probabilistic Linkage: The Bane of Economic Analysis. Journal of Legal Studies, 14, 435-456.

Wright, R. W. (1985b). Causation in Tort Law. California Law Review, 73, 1735.

Wright, R. W. (1987). The Efficient Theory of Causation and Responsibility: Unscientific Formalism and False Semantics. Chicago-Kent Law Review, 63, 553-578.

Wright, R. W. (1988). Causation, Responsibility, Risk, Probability, Naked Statistics, and Proof:

Pruning the Bramble Bush by Clarifying the Concepts. Iowa Law Review, 73, 1001-1077.

Wright, R. W. (1992). Substantive Corrective Justice. Iowa Law Review, 77, 625-711.

Wright, R. W. (1995). The Standard of Care in Negligence Law. En Owen, D. (Ed.), Philosophical Foundations of Tort Law. Oxford Clarendon Press.

Wright, R. W. (2008). Liability for Possible Wrongs: Causation, Statistical Probability and the Burden of Proof. Loyola of Los Angeles Law Review, 41, 1295-1344.

Wright, R. W. (2011). Proving Causation: Probability Vs. Belief. En Goldberg, R. (Ed.), Perspectives on Causation. Hart Publishing.

Yablo, S. (2002). De Facto Dependence. Journal of Philosophy, 99(3), 130-148.

Young, R., Faure, M. y Fenn, P. (2004). Causality and Causation in Tort Law. International Review of Law and Economics, 24, 507-523.

\section{Jurisprudencia citada}

Supreme Court of California, Sindell v. Abbott Laboratories, 26 Cal. 3d 588.

Supreme Court of California, 1948. Summers v. Tice, 33 Cal. 2d 80, 199 P.2d 1.

Supreme Court of Tennessee, 1898. Weeks v. McNulty, 101 Tenn. 495, 48 S.W. 809.

United States Circuit Court of Appeals, Second Circuit, United States et al. v. Carroll Towing Co., Inc., et al., 159 F.2d 169. 



\title{
ASOCIACIONES CIVILES, TUTELA INDIVIDUAL HOMOGÉNEA Y LAS FACULTADES REGLAMENTARIAS DE LA CoRTE SuPREMA de JuSticia dE la NacióN
}

\section{Adriel Fernández Santander}

\author{
Departamento de Derecho Procesal, Facultad de Derecho, Universidad Austral \\ afernandezsantander@austral.edu.ar
}

Recibido: 26/08/2021

Aceptado: 29/09/2021

\section{Resumen}

La reforma constitucional de 1994 introdujo cambios en la regulación del amparo en la Argentina, entre las que se destaca el empoderamiento otorgado a las asociaciones civiles para litigar en defensa de derechos colectivos. Sin una normativa legal adecuada, la Corte Suprema de Justicia de la Nación generó mecanismos procesales, mediante su actividad jurisdiccional y haciendo uso de sus facultades regulatorias, para que estas personas jurídicas impulsen acciones judiciales de tutela individual homogénea para derechos completamente divisibles e independientes. En este trabajo se relevan los hitos más importantes del camino recorrido por la Corte y se realiza un análisis crítico de este a la luz del ordenamiento jurídico vigente.

Palabras clave: acción de clase, proceso colectivo, tutela individual homogénea, derecho procesal civil, facultades regulatorias judiciales, asociaciones civiles.

\section{Nonprofit Corporations, Class Actions and Argentine Supreme Court of Justice's Regulatory Powers}

\footnotetext{
Abstract

The 1994 amendment of the Argentine Constitution passed some important changes that entitled nonprofit organizations to sue in defense of other rights with a collective impact.

Without a proper statute law, the Argentine Supreme Court designed a sui generis type of judicial process providing these corporations with the standing to sue without being the real owner of a divisible and independent claim. This paper is a description of the landmarks in
} 
the path of the Argentine Supreme Court in this field and an analysis under the parameters of the Argentine legal system.

Key words: class action, collective action, civil litigation law, judiciary regulatory powers, nonprofit corporations.

\section{Introducción ${ }^{1}$}

La Corte Suprema de Justicia de la Nación (en adelante, CSJN, la Corte, entre otros), en ejercicio de sus facultades jurisdiccionales y reglamentarias, es la precursora de los procesos de tutela individual homogénea en la Argentina.

El mundo de lo que se conoce como "justicia colectiva" ${ }^{2}$ es sumamente atractivo, quizás porque puede parecer mágico cómo con una sola resolución judicial se le pone fin al actuar ilícito de grandes entidades y se reparan los daños provocados a una multitud. Tan es así que hasta en el cine se han producido películas cuya trama gira alrededor de una acción de clase, a las que se ha referido la doctrina nacional para explicar los primeros y resonantes casos resueltos a través de esta vía.

Si bien tomó fuerza desde la reforma constitucional de 1994, la regulación de los procesos colectivos es una discusión de larga data en diversos ámbitos en nuestro país, con resultados disímiles en las distintas jurisdicciones. En algunas de ellas no existe ningún tipo de normativa; en otras, la praxis tribunalicia se rige por precedentes jurisprudenciales, mientras que algunas no cuentan con experiencia en la materia.

Como sucede en la mayoría de los asuntos jurídicos de la Argentina, resulta sumamente relevante el desarrollo que la CSJN ha generado sobre a este cauce procesal. El camino iniciado en 2006 por el fallo Mendoza $a^{3}$ y continuado en 2009 en la causa Halabi ${ }^{4}$ tuvo destacados complementos hasta el día de hoy, conformando un conjunto digno de ser estudiado.

De los cuantiosos aspectos a abordar a la hora de referirse a este tipo de

1 Agradezco los valiosos aportes a este trabajo del Dr. Gustavo Calvinho, director del Departamento de Derecho Procesal de la Universidad Austral.

2 Existen diversas explicaciones doctrinarias respecto a la terminología a emplear en la materia, las cuales se encuentran resumidamente expuestas en Lorenzetti (2017, pp. 11-13).

3 CSJN, Mendoza, Beatriz Silvia y otros c/Estado Nacional y otros s/daños y perjuicios (daños derivados de la contaminación ambiental del Río Matanza - Riachuelo), 20/06/2006, Fallos: 329:2316.

4 CSJN, Halabi, Ernesto c/Poder Ejecutivo Nacional - ley 25.873 - dto. 1563/04 s/amparo ley 16.986, 24/02/2009, Fallos: 332:111, Nro. Interno: H.270. XLII. 
procesos, quiero hacer foco en determinar qué elemento faculta a entablar una acción judicial para promover la defensa de un derecho que no es propio. ${ }^{5}$

A continuación, habré de referirme a lo actuado por la Corte, con una mirada crítica, a la luz de las normas vigentes en el ordenamiento jurídico argentino y haciendo especial hincapié en el respeto por los principios de la forma republicana de gobierno consagrada en la Constitución Nacional ${ }^{6}$ (en adelante, $\mathrm{CN}$ ), en especial la división de poderes.

Del universo que compone lo que se conoce como "justicia colectiva", solo abordaré el mundo de aquellos supuestos tratados por la Corte relativos a la tutela individual homogénea, sin desconocer que existe otro tipo de realidades susceptibles de protección. Para ser más específico, el punto concreto al que dirigiré mi atención es el modo en el que la CSJN reconoce la legitimación extraordinaria, especialmente a las asociaciones civiles en este tipo de litigios.

Este estudio se divide en dos partes. En la primera abordaré el marco normativo vigente y la elaboración jurisprudencial de la Corte. Procuraré brindar un enfoque que dé cuenta del desarrollo histórico de los conceptos relevantes en la materia, incluidas algunas iniciativas significativas que no han llegado a concretarse. En segundo término, me referiré de manera crítica al tratamiento que la judicatura le ha otorgado a la legitimación extraordinaria de las asociaciones civiles en procesos de tutela individual homogénea por no respetar las pautas constitucionales vigentes para la regulación procesal, las cuales son salvaguarda de las garantías procesales de las partes involucradas en esta clase de litigios.

Podré verificar de primera mano a lo largo del presente estudio el pensamiento formulado, quizás a modo de advertencia, por Alvarado Velloso (2010), quien afirma que

algunos jueces con vocación de protagonismo mediático han comenzado a intervenir en toda suerte de asuntos, propios de la competencia constitucional exclusiva de otros Poderes del Estado, interfiriendo con ello en la tarea de gobernar al asumir el cumplimiento de funciones que son privativas de otras autoridades. Y, de tal forma, han abandonado el juicioso acatamiento de la ley para entrar al

5 Cfr. Briseño Sierra (1966, p. 263): "[A]hí donde el titular del derecho obra por sí, siendo hábil, no debe hablarse de legitimación sino de titularidad. La legitimación sólo tiene lugar cuando es menester de un órgano o de una persona que exprese eficazmente su voluntad en el ejercicio de los derechos ajenos, cuyo titular es inhábil".

6 "Artículo 1\%.- La Nación Argentina adopta para su gobierno la forma representativa republicana federal, según la establece la presente Constitución”. 
campo del cogobierno y, aun más, ingresando a un terreno muy peligroso: el de una suerte de increíble desgobierno, ya imposible de controlar. (p. 1212)

\section{La legitimación extraordinaria de las asociaciones civiles en los supuestos de tutela individual homogénea \\ 2.1. Precisiones conceptuales}

El título de la primera parte de este trabajo requiere de algunas precisiones en cuanto al significado de las palabras allí mencionadas.

\subsubsection{Legitimación extraordinaria}

El desarrollo de la legitimación como figura relevante en un litigio judicial surge de la distinción entre dos derechos: el pretendido en un proceso y el derecho autónomo de acción.

Tradicionalmente, los sistemas jurídicos solo admitían el ejercicio del derecho a accionar a quien afirmaba ser titular, al mismo tiempo, del derecho subjetivo reclamado en el marco de un litigio judicial. Este tipo de legitimación, conocida como "ordinaria", proviene de la pretendida titularidad de un derecho subjetivo cuya tutela se exige en juicio. Se advierte así la trascendencia de la frase retórica de Couture (2010 [1950], p. 158) en la que pregunta: "¿Qué significado tendría ser titular de derechos si no se tuviera junto a ellos aptitud jurídica para defenderlos en juicio?".

Por ello, en el ámbito de un proceso jurisdiccional, lo habitual es que el magistrado pueda conceder lo solicitado a quien justifica su carácter de parte actora, con fundamento en una relación jurídica sustancial previa. ${ }^{7}$

En un sentido similar a la pregunta del maestro uruguayo, puedo cuestionarme acerca del fundamento por el cual se posee la aptitud de defender derechos en juicio sin afirmar ser el titular de estos.

Más recientemente, las normas procesales han permitido disociar los derechos de pretender y accionar en cabezas diferentes, admitiendo que alguien litigue por un derecho ajeno. Esta es, sin más, la noción de "legitimación extraordinaria”.

En palabras de Montero Aroca et al. (2001), célebre procesalista español contemporáneo, la existencia misma del concepto procura 
distinguir entre partes materiales y partes procesales, y respecto de estas segundas la legitimación resuelve la cuestión de quién puede pedir en juicio la actuación del derecho objetivo en el caso concreto y contra quién puede pedirse. [...] La legitimación adquiere entidad cuando se admite que la misma puede existir sin derecho subjetivo. (p. 82)

Esta idea también es abordada por Palacio (2017), quien explica que la legislación procesal

contempla diversos casos de legitimación anómala o extraordinaria, a los cuales caracteriza el hecho de que resultan habilitadas para intervenir en el proceso, como partes legítimas, personas ajenas a la relación jurídica sustancial que en aquél se controvierte. $(\S 81)$

Sin esta separación entre titularidad de la relación jurídica material y la posibilidad de pretender en el plano procesal, solo cabría hablar de titularidad de un derecho como puerta de acceso para promover su defensa en juicio.

Refiriéndose al ámbito específico de este estudio, Salgado (2011) nos advierte:

la distinción entre la legitimación tradicional u ordinaria y la extraordinaria radica en su disociación entre la titularidad material del derecho sustancial y la habilitación legal para disponer de él. En la ordinaria, no existirán diferencias entre quien se presenta como su titular en el plano material y quien se encuentra habilitado para su ejercicio. En la extraordinaria, en cambio, al no existir un sujeto materialmente predeterminado a disponer de los derechos colectivos -sean difusos o individuales homogéneos-, se recurre a una habilitación normativa que autoriza a determinados sujetos, y no a otros, a activar el resguardo de la prerrogativa. (pp. 146-147)

¿Cuáles serán los motivos que justifican y permiten esta facultad especial? Existen razones de política legislativa que fundamentan los extremos por los que un juez puede dictar una sentencia que incidirá sobre los derechos de alguien que no inició ni impulsó un proceso, promovido por otro sujeto en calidad de parte actora sin afirmar su titularidad.

A diferencia de la legitimación ordinaria, estos supuestos extraordinarios son habilitados no por detentar un derecho subjetivo cuya defensa se pretende en juicio, sino por una norma que permite esta posibilidad y torna eficaz la tutela jurisdiccional al operarse de esta manera. ${ }^{8}$ 


\subsubsection{Tutela individual homogénea}

El concepto con el que se titula este apartado está en íntima relación con lo explicado en el punto anterior, porque, tanto para la doctrina como para la jurisprudencia, la tutela individual homogénea se vincula inexorablemente con el concepto de "legitimación extraordinaria".

Salgado (2011, p. 1) la define como la "posibilidad de dar respuesta, con valor de cosa juzgada, a un número plural de reclamos en un solo proceso judicial, aunque éstos, en teoría, podrían ser postulados o defendidos en tantos litigios como personas integren el conjunto".

Según lo expresado por Giannini (2015)

El típico ejemplo es el de los daños y perjuicios ocasionados masivamente en razón de productos en mal estado, catástrofes, explosiones, etc. [...] Pero las hipótesis no se limitan exclusivamente a los supuestos de mass tort litigation. Existe una variadísima gama de pretensiones en las que resulta materialmente viable la diferencia de trato entre los distintos sujetos de la clase. Por ejemplo: a) pretensiones de hacer -v.gr., remover personas indebidamente colocadas en un registro o prohibir la utilización de la información volcada un una base de datos más allá de los fines específicos para los que fue voluntariamente aportada (hábeas data, otorgar a determinados sujetos los beneficios de las prestaciones médicas basadas en la seguridad social, entregar alimentos o insumos educativos a niños de una región necesitada, construir viviendas, entregar medicamentos para enfermos de determinadas características, etc.-; b) acciones de cesación de actividades indebidas -v.gr., interdicción de descuentos o rebajas salariales. (§ 544 Quinquies)

La peculiaridad de esta figura, frente a otras en las que se admite la configuración plural de alguna de las partes,

es que los integrantes del grupo no tendrán necesidad de comparecer al proceso desde un comienzo [...] e incluso podrán sumarse personas [...] cuando el proceso haya culminado. Un tercero, legitimado extraordinario, propondrá un litigio representativo y actuará en defensa de los derechos de todos los integrantes del grupo, ausentes o presentes en el reclamo. (Giannini, 2015, §544 Quinquies)

Más adelante ahondaré en las características que la jurisprudencia de la CSJN y la doctrina han otorgado a este supuesto de tutela.

\subsubsection{Asociaciones civiles}

Dentro del catálogo de personas jurídicas privadas se incluye en el inciso b) del 
artículo 148 del Código Civil y Comercial de la Nación (en adelante, CCCN) ${ }^{9}$ a las asociaciones civiles.

Esta misma norma, entre los artículos 168 y 186, regula los aspectos específicos de estas.

Tobías (2018) define a la asociación civil como

persona jurídica privada que se forma con la unión estable de una pluralidad de personas (independiente en su existencia del cambio de miembros), que tiene una constitución corporativa y un nombre colectivo, cuyo objeto no debe ser contrario al interés general o al bien común, no puede perseguir el lucro como fin principal para sí, ni tener por fin el lucro para sus miembros o terceros. (Capítulo XXI, Sección 1a)

La importancia para los supuestos de legitimación extraordinaria que trataré en este trabajo es, como bien lo expresa Salgado (2011), que

la asociación actuará en nombre de una clase o grupo de personas, circunstancia que podrá ser coincidente o no con la nómina de personas vinculadas a ella. Es decir, no actuará por mandato de sus socios sino por una autodesignación como legitimada; luego se podrá observar que la clase representada en el proceso estará conformada por algunos de los asociados y por terceros ajenos a la entidad, y podrá ocurrir que determinados socios no se encuentren comprendidos en la clase de que se trata. (pp. 166-167)

Cuando exponga sobre la regulación del artículo 43 de la CN, de la inclusión allí de esta clase de personas jurídicas y lo interpretado por la CSJN en cuanto al alcance de la cláusula, resultará clara la importancia del análisis de esta figura.

\subsubsection{Recapitulación}

Luego del desarrollo de los conceptos antes detallados, procuraré realizar una breve síntesis conjunta, que es oportuna para comprender con precisión el objeto específico del presente estudio.

De todas las alternativas posibles en las que un sujeto se presenta en un juicio relativo a un derecho ajeno, solo habré de referirme a los supuestos en los que esa legitimación extraordinaria es ejercida por una asociación civil que se

Ley 26994 de Código Civil y Comercial de la Nación, BO 08/10/2014. 
designa a sí misma para tutelar derechos completamente divisibles e independientes, sin mediar ningún tipo de acuerdo previo con sus titulares (Salgado, 2011, p. 1) o, como se explicará más adelante, sin una ley que así lo prevea.

La importancia de este estudio radica en que es un verdadero desafío justificar que una asociación plantee una pretensión procesal en virtud de una relación jurídica en la que no es parte y sin que se le haya conferido un mandato contractual o representación legal que le otorgue dicha facultad. Fallar en ese cometido afectaría, entre otros, el derecho de defensa de quienes podrían estar legitimados y desconocen una pretendida representación, de quienes resulten parte demandada en un proceso o de aquellos que, sin intervenir en este, puedan ser alcanzados por los efectos derivados en él (Lorenzetti, 2017, pp. 206-207).

Por ello, como afirma Lorenzzeti (2017, p. 206), "[1]a legitimación para obrar, que es de obligado análisis en todo juicio a fin de evitar soluciones nulas, cobra mayor trascendencia en los planteos colectivos".

En el mismo sentido, Verbic (2017, pp. 301-302) sostiene que "[l]a legitimación para promover la tutela judicial colectiva de derechos reviste fundamental importancia, a punto tal de haber sido considerada por autorizada doctrina como el verdadero talón de Aquiles de cualquier sistema de protección de este tipo".

Por cierto, los dos autores antes citados son promotores de este tipo de procesos y advierten este riesgo que traigo a colación.

\section{Fisonomía argentina de la tutela individual homogénea: jurisprudencia, acordadas, normas vigentes e iniciativas legislativas}

La reforma constitucional de 1994 elevó el estatus de la regulación de la acción de amparo e introdujo novedades y modificaciones a esta. ${ }^{10}$

A los efectos del presente estudio, cabe destacar que el artículo 43 de la CN otorgó de manera genérica una legitimación activa al afectado, al defensor del pueblo y a las asociaciones civiles registradas para promover procesos en defensa de derechos de incidencia colectiva, sin una determinación precisa de los extremos de dicha participación.

Textualmente, la $\mathrm{CN}$ dispone en los primeros dos párrafos de la norma citada lo siguiente:

10 Un excelente análisis y resumen de la regulación histórica del amparo y cómo fue plasmado en el artículo 43 de la CN puede encontrarse en Gelli (2018a, pp. 786-824). 
Toda persona puede interponer acción expedita y rápida de amparo, siempre que no exista otro medio judicial más idóneo, contra todo acto u omisión de autoridades públicas o de particulares, que en forma actual o inminente lesione, restrinja, altere o amenace, con arbitrariedad o ilegalidad manifiesta, derechos y garantías reconocidos por esta Constitución, un tratado o una ley. En el caso, el juez podrá declarar la inconstitucionalidad de la norma en que se funde el acto u omisión lesiva.

Podrán interponer esta acción contra cualquier forma de discriminación y en lo relativo a los derechos que protegen al ambiente, a la competencia, al usuario y al consumidor, así como a los derechos de incidencia colectiva en general, el afectado, el defensor del pueblo y las asociaciones que propendan a esos fines, registradas conforme a la ley, la que determinará los requisitos y formas de su organización [...].

Si bien la norma no lo plantea de manera expresa, existe una conceptualización tripartita de los bienes sobre los que pueden recaer los derechos que pueden protegerse a través de una acción de amparo, la cual fue adoptada por la jurisprudencia y valorada positivamente por la doctrina mayoritaria.

A continuación, abordaré los aspectos más relevantes hoy de la defensa de uno de esos bienes -los derechos individuales homogéneos-, impulsada por asociaciones civiles. Entre ellos, tiene un lugar preponderante la tarea realizada por la CSJN a través de su jurisprudencia y del dictado de dos acordadas, imprimiendo una pretendida operatividad a las disposiciones genéricas del artículo 43 de la $\mathrm{CN}$, sin contar con una reglamentación clara y completa de todos los institutos procesales en juego. También resulta apropiado relevar la normativa vigente y los proyectos de legislación discutidos en torno a la materia.

Cabe aclarar que, como recorte metodológico, solo describiré el desarrollo de la jurisprudencia a partir del año 2009, momento en el que los fallos de la CSJN receptaron el concepto "derechos individuales homogéneos". No desconozco, sin embargo, un importante desarrollo previo a dicha fecha, del cual existen innumerables reseñas. ${ }^{11}$

Sobre esta etapa, afirma Salgado (2011):

en líneas generales, se les ha reconocido su legitimación sobre la base de lo normado por el art. 43, párr. $2^{\circ}$, de la Const. Nacional. Entendemos que, en esos precedentes en que aquella aptitud para demandar les fue desconocida, en realidad se verificaba una deficiencia en su representación adecuada, o bien una

11 Ver Lorenzetti (2017, pp. 44-60) y Salgado (2011, pp. 169-177). 
ausencia de caso o controversia [...] por el no reconocimiento de los derechos individuales homogéneos como un caso susceptible de ser resuelto por los tribunales. (p. 177)

\subsection{Derechos individuales, colectivos e individuales homogéneos. El caso Halabi (2009) ${ }^{12}$}

En la instancia del recurso extraordinario interpuesto y concedido en el caso Halabi, se discutía únicamente el alcance erga omnes que la sentencia apelada le había otorgado a la decisión del litigio. ${ }^{13}$ Por ello, el alto tribunal expresó

para la dilucidación de este aspecto, según los propios términos en que ha sido formulado el cuestionamiento, es necesario determinar cuál es la naturaleza jurídica del derecho cuya salvaguarda se procuró mediante la acción deducida, quiénes son los sujetos habilitados para articularla, bajo qué condiciones puede resultar admisible y cuáles son los efectos que derivan de la resolución que en definitiva se dicte. ${ }^{14}$

La CSJN condensa en los considerandos 10 a 13 del paradigmático Halabi su interpretación en torno a lo que entiende por "derechos de incidencia colectiva” en el marco del artículo 43 de la CN. Según la postura adoptada por la Corte, la heterogeneidad de la naturaleza de los derechos en juego en cuanto a la legitimación procesal para su defensa permite "delimitar con precisión tres categorías de derechos: individuales, de incidencia colectiva que tienen por objeto bienes colectivos, y de incidencia colectiva referentes a intereses individuales homogéneos". ${ }^{15}$

Recuerda Gozaíni (2018, p. 311) que "[e]sta triple categorización de los derechos se encuentra en el Código Modelo para Iberoamérica, aprobado en el año 2002 por la Asamblea del Instituto Iberoamericano de Derecho Procesal".

El caso en análisis se detiene inicialmente a recordar que la regla tradicional en materia de legitimación es que su tutela jurisdiccional está en cabeza del titular de un derecho que recae sobre un bien jurídico individual. Esa afirmación, según la Corte,

12 Recomiendo el análisis del caso presente, entre otros, en Dalla Vía (2009) y en Sagüés (2009).

13 Cfr. Halabi, considerando 7.

14 Ídem, considerando 8.

15 Ídem, considerando 9. 
no cambia por la circunstancia de que existan numerosas personas involucradas, toda vez que se trata de obligaciones con pluralidad de sujetos activos o pasivos, o supuestos en los que aparece un litisconsorcio activo o pasivo derivado de la pluralidad de sujetos acreedores o deudores, o bien una representación plural. ${ }^{16}$

Este tipo de legitimación ordinaria es el que se protegió, según el alto tribunal, en sus precedentes Siri ${ }^{17}$ y $\mathrm{Kot}^{18}$, cuya salvaguarda se encuentra proporcionada por el párrafo primero del artículo 43 de la CN. Asimismo, concluye en que la acción de amparo "está destinada a obtener la protección de derechos divisibles, no homogéneos y se caracteriza por la búsqueda de la reparación de un daño esencialmente individual y propio de cada uno de los afectados". ${ }^{19}$

La novedad surge al desarrollar los alcances de los dos tipos de derechos de incidencia colectiva enunciados: a) los que tienen por objeto bienes colectivos; y b) los referentes a bienes individuales homogéneos.

Sobre la primera categoría, entiende que se procura "la tutela de un bien colectivo, lo que ocurre cuando éste pertenece a toda la comunidad, siendo indivisible y no admitiendo exclusión alguna", ${ }^{20}$ lo cual fundamenta la legitimación extraordinaria de los sujetos enumerados en la cláusula constitucional. En esta clase de supuestos, si bien no hay directamente derechos subjetivos en juego, recuerda Lorenzetti $(2017$, p. 22) que "la lesión a este tipo de bienes puede tener una repercusión sobre el patrimonio individual".

Como consecuencia de lo anterior, para promover este tipo de acciones, el mismo autor sostiene que

la pretensión debe ser focalizada en la incidencia colectiva del derecho. Ello es así porque la lesión a este tipo de bienes puede tener una repercusión sobre el patrimonio individual, como sucede en el caso del daño ambiental, pero esta última acción corresponde a su titular y resulta concurrente con la primera. (Lorenzetti, 2017, p. 22)

Queda delimitada una clara línea que diferencia al amparo para procurar la tutela de bienes enteramente individuales de los supuestos en los que está en juego uno colectivo.

16 Ídem, considerando 10.

17 Siri, Ángel s/interpone recurso de hábeas corpus, 27/12/1957, Fallos: 239:461.

18 Kot, Samuel S.R.L. s/recurso de hábeas corpus, 05/09/1958, Fallos: 241:291.

19 Ídem.

20 Ídem, considerando 11. 
Esto último no sucede, según la CSJN, para el segundo tipo de derecho de incidencia colectiva: el relativo a bienes individuales homogéneos. En los considerandos 12 y 13 se esbozan los lineamientos esenciales para procurar su tutela.

Según la Corte, existe una particularidad especial en "el caso de los derechos personales o patrimoniales derivados de afectaciones al ambiente y a la competencia, de los derechos de los usuarios y consumidores como de los derechos de sujetos discriminados". ${ }^{21}$ Se explica que se estaría ante supuestos similares a los abordados en el considerando 10 del fallo -derechos individuales enteramente divisibles-, pero con "un hecho, único o continuado, que provoca la lesión a todos ellos y por lo tanto es identificable una causa fáctica homogénea”. ${ }^{22}$

En este importante precedente se encuentra que esta situación común que produce el daño es la que justifica la celebración de un solo proceso para la determinación de responsabilidades con efectos expansivos del caso juzgado a quienes no intervinieron en calidad de parte, particularizando en un momento posterior la cuantía de la reparación para cada uno de los afectados.

El considerando 13 sintetiza lo anteriormente reseñado y enuncia una especie de protonorma para plantear procesos de tutela individual homogénea, motivo por el cual se transcribe íntegramente

Que la procedencia de este tipo de acciones requiere la verificación de una causa fáctica común, una pretensión procesal enfocada en el aspecto colectivo de los efectos de ese hecho y la constatación de que el ejercicio individual no aparece plenamente justificado. Sin perjuicio de lo cual, también procederá cuando, pese a tratarse de derechos individuales, exista un fuerte interés estatal en su protección, sea por su trascendencia social o en virtud de las particulares características de los sectores afectados.

El primer elemento es la existencia de un hecho único o complejo que causa una lesión a una pluralidad relevante de derechos individuales.

El segundo elemento consiste en que la pretensión debe estar concentrada en los efectos comunes y no en lo que cada individuo puede peticionar, como ocurre en los casos en que hay hechos que dañan a dos o más personas y que pueden motivar acciones de la primera categoría. De tal manera, la existencia de causa o controversia, en estos supuestos, no se relaciona con el daño diferenciado que cada sujeto sufra en su esfera, sino con los elementos homogéneos que tiene esa pluralidad de sujetos al estar afectados por un mismo hecho.

21 Ídem, considerando 12.

22 Ídem. 


\begin{abstract}
Como tercer elemento es exigible que el interés individual considerado aisladamente, no justifique la promoción de una demanda, con lo cual podría verse afectado el acceso a la justicia. Sin perjuicio de ello, como se anticipó, la acción resultará de todos modos procedente en aquellos supuestos en los que cobran preeminencia otros aspectos referidos a materias tales como el ambiente, el consumo o la salud o afectan a grupos que tradicionalmente han sido postergados, o en su caso, débilmente protegidos. En esas circunstancias, la naturaleza de esos derechos excede el interés de cada parte, y al mismo tiempo, pone en evidencia la presencia de un fuerte interés estatal para su protección, entendido como el de la sociedad en su conjunto. En tal sentido, los arts. 41, 42 y 43, párr. 2, CN., brindan una pauta en la línea expuesta. ${ }^{23}$
\end{abstract}

Se establecen así los requisitos de procedencia para este tipo de acciones, los cuales son empleados por primera vez para dar un alcance especial al planteo que el actor, Dr. Halabi, ${ }^{24}$ había incoado en defensa únicamente de sus propios derechos. ${ }^{25}$

Como ya se ha mencionado, del amplio espectro detallado por la CSJN en este precedente, solo me encuentro abordando los supuestos relativos a intereses individuales homogéneos, en los que principalmente existe una multiplicidad de sujetos titulares de un derecho enteramente individual que se encuentran afectados por una causa común. ${ }^{26}$

En abstracto, cada uno podría accionar en solitario contra quien lesiona a todos al no verificarse los supuestos del litisconsorcio necesario ${ }^{27} \mathrm{y}$, teóricamente, podría existir multiplicidad de procesos con distintos actores e idénticas pre-

23 Ídem, considerando 13.

24 Cfr. Ídem, considerando 14.

25 Según surge de la lectura del fallo, en el considerando 1. Asimismo, habría sido la Sala II de la Cámara Nacional de Apelaciones en lo Contencioso Administrativo Federal la que introdujo la pretensión colectiva. Según se relata en el considerando 4, "estimó que la legitimación del actor no excluia la incidencia colectiva de la afectación a la luz del $2^{\circ}$ párrafo del art. 43 de la Constitución Nacional por lo que la sentencia dictada en tales condiciones debía aprovechar a todos los usuarios que no han participado en el juicio" (en cursiva figura lo transcripto por la Corte del fallo de la Cámara).

26 Además de los derechos relativos a bienes individuales homogéneos, quiero traer a colación unas pocas líneas que condensan muy bien las diferencias entre los conceptos que a continuación se expondrán. Estas figuran en la primera edición de Lorenzetti (2010, p. 19): "Derechos sobre bienes jurídicos individuales: [en los que] el interés es individual, la legitimación también, y cada interés es diverso de otros; cada titular inicia una acción y obtiene sentencia en un proceso bilateral [...]. Es el modelo tradicional del litigio singular [...]. Derechos sobre bienes jurídicos colectivos: [en los cuales] el bien afectado es colectivo, el titular del interés es el grupo y no un individuo particular".

27 Regulado en el artículo 89 del Código Procesal Civil y Comercial de la Nación (en adelante, CPCCN), el cual establece: "Art. 89.- Cuando la sentencia no pudiere pronunciarse útilmente más que con relación a varias partes, éstas habrán de demandar o ser demandadas en un mismo proceso. Si así no sucediere, el juez de oficio o a solicitud de cualquiera de las partes ordenará, antes de 
tensiones y partes demandadas, pero, por diversos motivos, se opta por unificar los procesos en un solo expediente. ${ }^{28}$

Resulta sumamente apropiado para este estudio reseñar el presente caso porque si bien la acción es deducida por un particular en interés propio -el afectado-, la CSJN admite la posibilidad de que también el Defensor del Pueblo y las asociaciones, ambos mencionados en el artículo 43 de la CN, puedan deducir pretensiones colectivas similares a las planteadas en este precedente. ${ }^{29}$

Cabe concluir este apartado con lo mencionado por la CSJN respecto a la inexistencia de una norma que regule los procesos colectivos:

debe existir una ley que determine cuándo se da una pluralidad relevante de individuos que permita ejercer dichas acciones, cómo se define la clase homogénea, si la legitimación corresponde exclusivamente a un integrante de la clase o también a organismos públicos o asociaciones, cómo tramitan estos procesos, cuáles son los efectos expansivos de la sentencia a dictar y cómo se hacen efectivos. ${ }^{30}$

Sin embargo, no considera que este déficit sea un obstáculo -aunque sí un claro retardo en las obligaciones del Poder Legislativo que debe ser subsanado cuanto antes-, porque la cláusula constitucional en análisis "es claramente operativa y es obligación de los jueces darle eficacia, cuando se aporta nítida evidencia sobre la afectación de un derecho fundamental y del acceso a la justicia de su titular". 31

Entonces, según explica Lorenzetti (2017, p. 128), "[1]a fuente de los procesos colectivos puede ubicarse en el bloque de constitucionalidad [...]”, siendo el amparo una garantía reconocida por la Constitución Nacional y la Convención Americana sobre Derechos Humanos, lo cual transforma a las disposiciones que lo consagran sendas normas operativas que, ante la falta de desarrollo legislativo por parte del Congreso, pueden ser integradas - no solo interpretadas y aplicadas- según lo que el juez considere oportuno para cada caso. ${ }^{32}$

dictar la providencia de apertura a prueba, la integración de la litis dentro de un plazo que señalará, quedando en suspenso el desarrollo del proceso mientras se cita al litigante o litigantes omitidos".

28 No habré de referirme a los supuestos de legitimación pasiva colectiva que si bien son tratados por la doctrina, no han tenido repercusión en la jurisprudencia de la Corte Suprema de Justicia de la Nación y no son conducentes a los efectos del presente estudio.

29 Cfr. Halabi, considerando 19 in fine.

30 Cfr. Ídem, considerando 12.

31 Ídem.

32 Ver Lorenzetti (2017, p. 79): “Conviene aclarar que cuando se habla de operatividad de las normas declarativas de derecho, se está aludiendo a la posibilidad de que éstas sean autoejecutorias, que 
Por lo tanto, la existencia de derechos sobre bienes individuales homogéneos habilitaría a los magistrados a brindarles una tutela que surge directamente de las normas constitucionales y convencionales, supliendo la discreción de los magistrados a la inexistencia de leyes procesales. ${ }^{33}$

A partir de las apreciaciones realizadas por la Corte, resulta de vital importancia lo manifestado por ella en el considerando 20 del fallo. A continuación se transcribe en su totalidad por entender que allí se plasmó el nuevo paradigma procesal que luego fue desarrollando la CSJN hasta llegar a su configuración actual

\begin{abstract}
Ante la ya advertida ausencia de pautas adjetivas mínimas que regulen la materia, se torna indispensable formular algunas precisiones, con el objeto de que ante la utilización que en lo sucesivo se haga de la figura de la "acción colectiva" que se ha delineado en el presente fallo se resguarde el derecho de la defensa en juicio, de modo de evitar que alguien pueda verse afectado por una sentencia dictada en un proceso en el que no ha tenido la posibilidad efectiva de participar. Es por ello que esta Corte entiende que la admisión formal de toda acción colectiva requiere la verificación de ciertos recaudos elementales que hacen a su viabilidad tales como la precisa identificación del grupo o colectivo afectado, la idoneidad de quien pretenda asumir su representación y la existencia de un planteo que involucre, por sobre los aspectos individuales, cuestiones de hecho y de derecho que sean comunes y homogéneas a todo el colectivo. Es esencial, asimismo, que se arbitre en cada caso un procedimiento apto para garantizar la adecuada notificación de todas aquellas personas que pudieran tener un interés en el resultado del litigio, de manera de asegurarles tanto la alternativa de optar por quedar fuera del pleito como la de comparecer en él como parte o contraparte. Es menester, por lo demás, que se implementen adecuadas medidas de publicidad orientadas a evitar la multiplicación o superposición de procesos colectivos con un mismo objeto a fin de aventar el peligro de que se dicten sentencias disímiles o contradictorias sobre idénticos puntos.
\end{abstract}

Como puede observarse, el alto tribunal establece pautas procesales genéricas para un litigio colectivo, las cuales serán aplicadas luego por la decisión discrecional del juez que intervenga en cada supuesto de tutela individual homogénea. A los efectos del presente estudio, resulta de especial interés que el requisito de "idoneidad de quien pretenda asumir su representación" sea elevado por la Corte al estatus de presupuesto de admisibilidad que, de no verificarse,

habiliten expresamente el uso y goce del derecho declarado".

33 Cfr. Lorenzetti (2017, p. 83). 
podría presumirse que le cabría al magistrado la posibilidad de rechazo in limine de la demanda promovida. ${ }^{34}$

La CSJN, en muchas ocasiones, se muestra con una preocupación por la inexistencia de una ley procesal específica que le permita a la justicia tramitar expedientes relativos a la materia. Sin embargo, en los hechos, siempre encuentra algún justificativo o excusa para intervenir a pesar de este déficit. Por ejemplo, como más adelante se comentará, en el año 2016 la Corte dictó la Acordada 12, creando un Reglamento relativo a diversos aspectos de tramitación de la mayoría de los procesos colectivos. En el punto IV, en sintonía con el considerando 9 de Halabi, dispone que este "tendrá vigencia hasta tanto el Poder Legislativo Nacional sancione una ley que regule este tipo de procesos".

Puede verse cómo, por un lado, el alto tribunal admite la necesidad de una norma legal para tramitar procesos colectivos, pero, por el otro, genera sus propias disposiciones por considerarse habilitada para suplir esta carencia de manera pretoriana. ${ }^{35}$

\subsection{Desarrollo jurisprudencial y acordadas dictadas por la CSJN}

\subsubsection{PADEC (2013) $)^{36}$}

Ante una excepción de falta de legitimación activa declarada procedente por las instancias inferiores, en este precedente la Corte aplicó por vez primera ${ }^{37}$ lo reglado en Halabi para una acción incoada por una asociación civil, revocó el

34 Tal como lo prevé el artículo 337 del CPCCN: "Los jueces podrán rechazar de oficio las demandas que no se ajusten a las reglas establecidas, expresando el defecto que contengan [...]".

35 Cfr. Halabi, considerando 15.

36 CSJN, PADEC c/Swiss Medical S.A. s/nulidad de cláusulas contractuales, 21/08/2013, Nro. Interno: P.361.XLIII, Id SAIJ: FA13000127. Se recomienda la lectura de la reseña realizada en Ylarri (2014).

37 El precedente será citado en diversas oportunidades por la Corte. Por la masividad de sus efectos, haré referencia al caso CEPIS, en el cual se sintetizó PADEC en los siguientes términos: "Es menester recordar que, en recientes precedentes, esta Corte reconoció que, de acuerdo a las disposiciones del artículo 43 de la Constitución Nacional, las asociaciones de usuarios y consumidores se encuentran legitimadas para iniciar acciones colectivas relativas a derechos de incidencia colectiva referentes a intereses individuales homogéneos, incluso de naturaleza patrimonial, en la medida en que demuestren: la existencia de un hecho único susceptible de ocasionar una lesión a una pluralidad de sujetos; que la pretensión este concentrada en los 'efectos comunes' para toda la clase involucrada; y que de no reconocerse la legitimación procesal podría comprometerse seriamente el acceso a la justicia de los integrantes del colectivo cuya representación se pretende asumir" (CSJN, Centro de Estudios para la Promoción de la Igualdad y la Solidaridad y otros c/Ministerio de Energía y Minería s/amparo colectivo, 18/06/2016, Nro. Interno: FLP 8399/2016/CS1, Id SAIJ: FA16000098, considerando 10). 
fallo y remitió el expediente al tribunal de primera instancia para que se sustancie el proceso según las expresas instrucciones que se brindan en este. ${ }^{38}$

No constan en el fallo las razones aducidas por la demandada para plantear la excepción mencionada, pero sí los motivos por los que el juez de primera instancia y la cámara de apelaciones hicieron lugar a esta. En general, se entendió que la asociación civil PADEC no podía impulsar válidamente el proceso por no tratarse de un supuesto de tutela individual homogénea. ${ }^{39}$

La pretensión de la actora, que se presentaba en defensa de derechos ajenos, resultaba ser la declaración de nulidad de una cláusula del contrato de adhesión mediante el cual la demandada, una empresa de medicina prepaga, podía modificar de manera unilateral el canon mensual abonado por terceros, los afiliados a dicha empresa, que no intervinieron en este juicio. De esta manera, se dejarían sin efecto los aumentos ya fijados y cancelados, devolviéndose así las sumas indebidamente percibidas.

Retomando lo dicho en Halabi, la Corte encuentra que se verifican los requisitos establecidos en dicho precedente para admitir el proceso colectivo y reconocer la legitimación extraordinaria, revirtiendo así lo dispuesto por el tribunal inferior. ${ }^{40}$ Es explícito el reconocimiento a las asociaciones civiles para promover acciones de tutela individual homogénea que surge del considerando 12, en el que expresa:

en cuanto a los sujetos habilitados para demandar en defensa de derechos como los involucrados en el sub lite, es perfectamente aceptable dentro del esquema de nuestro ordenamiento que determinadas asociaciones deduzcan, en los términos del ya citado segundo párrafo del artículo 43, una acción colectiva con análogas características y efectos a la existente en el derecho norteamericano. ${ }^{41}$

38 Cfr. PADEC, considerando 12 y parte resolutiva de la sentencia.

39 Cfr. Ídem, considerando. 2, el que textualmente manifiesta: "Que para decidir como lo hizo, el tribunal a quo consideró que el derecho invocado por la actora no constituía un derecho de incidencia colectiva. Por el contrario, entendió que los intereses involucrados en el caso eran patrimoniales y divisibles, que podían resultar contradictorios o confusos, y que su homogeneidad era solo aparente. Agregó que no surgía del expediente que todos los afiliados hubieran avalado la promoción de la demanda, y consideró cuanto menos riesgoso dejar librada su defensa a una asociación de consumidores. Al respecto, entendió que la afectación de derechos subjetivos proyectada a un grupo determinado de personas no necesariamente conllevaba a un derecho de incidencia colectiva, sino más bien a una sumatoria de derechos subjetivos y que, en estos casos, correspondía ser extremadamente cauto, puesto que se corría el riesgo de sustituir la voluntad del interesado a quien le correspondía en forma exclusiva el ejercicio y tutela de sus derechos. En consecuencia, concluyó que el carácter divisible y no homogéneo de los intereses en juego determinaba la falta de legitimación de la actora para demandar la nulidad de las cláusulas contractuales impugnadas”. Ver también considerando 7.

40 Cfr. Ídem, considerandos 11 y 12.

41 Cfr. considerando 19 in fine del fallo Halabi. 
Entre sus argumentos, resulta de especial interés para la CSJN que el objeto social de la entidad es idóneo para impulsar la tutela pretendida ${ }^{42}$ según los requisitos previstos en el considerando 20 de Halabi.

Es llamativo que, solo al concluir con su análisis, la CSJN trae a colación que en la legislación vigente -Ley 24240 de defensa del consumidor- se habilita a las asociaciones civiles de consumidores a realizar planteos colectivos. ${ }^{43}$ En otras palabras, la legitimación extraordinaria de este tipo de entidades está amparada, según la Corte, de manera principal en el artículo 43 de la CN y en el caso Halabi, aunque también existen normas de rango infraconstitucional que así lo prevén.

\subsubsection{Acordada 32/2014, Reglamento de Registro Público de Procesos Colectivos ${ }^{44}$}

En una primera lectura, parece ser bastante tangencial la importancia de esta acordada dictada por la CSJN para el objeto de este estudio.

A 5 años de que Halabi viera la luz, la Corte creó un Registro Público de Procesos Colectivos para evitar la tramitación de causas con igual o similar objeto ante diversos órganos judiciales. ${ }^{45}$

Es cierto que la finalidad perseguida parecería loable, ya que procuraba evitar el dictado de sentencias contradictorias sobre los mismos asuntos litigiosos. Sin embargo, quizás fue solo un resultado lógico del devenir de la jurisprudencia de la Corte hasta el momento y una consecuencia esperable de la falta de acatamiento por parte de los tribunales inferiores a los precedentes por ella elaborados.

Por lo tanto, con el dictado de la acordada solo se dio cierto orden y registración al trámite de procesos colectivos que, luego de Halabi y PADEC, se multiplicaban dentro de los distintos fueros del Poder Judicial de la Nación, con el peligro del dictado de resoluciones judiciales contrapuestas ya mencionado. ${ }^{46}$

Analizando las disposiciones específicas del Reglamento, este cobra una especial relevancia respecto a la legitimación extraordinaria de las asociaciones, porque la norma establece que el juzgado interviniente debe pronunciarse

42 Cfr. PADEC, considerando 13.

43 Cfr. Ídem, considerandos 15 y 16.

44 CSJN, Acordada 32/2014, 01/10/2014, AR/LCON/6CE4.

45 Esta novedad fue anunciada por la Corte en Municipalidad de Berazategui c/Cablevisión S. A. s/amparo, 23/09/2014, Nro. Interno: M. 1145. XLIX., considerando 7 in fine, Id SAIJ: FA14000143.

Ver Acordada 32/2014, considerando 1. 
sobre la idoneidad del representante del colectivo involucrado en el caso correspondiente.

¿Bajo qué criterios? En el punto 1 del Reglamento, la Corte dispone que deben acatarse las "definiciones" que surgen de Halabi y PADEC para los supuestos de tutela de intereses individuales homogéneos. ${ }^{47}$ Hasta el momento del dictado de la acordada, podría decirse que la idoneidad para accionar en este tipo de procesos alegando legitimación extraordinaria está condicionado por la relación entre el objeto estatutario de la asociación civil y la naturaleza de la pretensión.

\subsubsection{DEFEINDER (2014) ${ }^{48}$}

El proceso judicial en materia de derecho del consumidor que desemboca en este fallo de la CSJN es impulsado por una asociación civil que si bien cuenta con una inscripción genérica para funcionar como persona jurídica, no se halla incorporada en el Registro Nacional de Asociaciones de Consumidores (ReNAC). ${ }^{49}$ Es decir, solo cumple con los recaudos del Código Civil vigente hasta 2015 relativos a las asociaciones civiles y la normativa local específica para cualquier persona jurídica. Ante la demanda incoada, se interpone en el caso la excepción de falta de legitimación activa.

La Ley de Defensa del Consumidor establece como requisito de legitimación para las asociaciones de consumidores solicitar y obtener autorización para funcionar. ${ }^{50} \mathrm{Si}$ esta es otorgada, las entidades pasan a ser parte del ReNAC.

Ante esta circunstancia, la Corte interpreta que la registración "conforme a la ley" ordenada por el artículo 43 de la $\mathrm{CN}$ es indispensable para poseer la legitimación extraordinaria que otorga dicha cláusula constitucional.

En general, ese recaudo se acredita cumpliendo con lo previsto en la legislación de fondo y en la normativa sobre personas jurídicas de la jurisdicción local

47 "1. En el Registro se inscribirán ordenadamente todos los procesos colectivos, tanto los que tengan por objeto bienes colectivos como los que promuevan la tutela de intereses individuales homogéneos con arreglo a las concordes definiciones dadas por esta Corte en los precedentes 'Halabi' (Fallos: 332:111) y P.361.XLIII 'PADEC c/Swiss Medical S.A. s/nulidad de cláusulas contractuales', sentencia del 21 de agosto de 2013”.

48 CSJN, Asociación Civil DEFEINDER c/Telefónica de Argentina S.A. s/proceso de conocimiento, 27/11/2014, Nro. Interno: A.803. XLVI.

49 Registro creado por el Decreto 1798/1994, reglamentario de la Ley 24240, BO 18/10/1994.

50 Cfr. artículos 55 y siguientes de la Ley 24240 de Defensa al Consumidor, BO 15/10/1993, norma que será comentada más adelante en este trabajo. 
en la que se constituyera una asociación civil. De manera particular, en caso de existir una ley especial que imponga requisitos especiales de registración, estos son insoslayables para pretender en un proceso colectivo.

Dicho razonamiento, aplicado a este caso que versa sobre los derechos de usuarios y consumidores, impone la obligación de estar incluido en el ReNAC. ${ }^{51}$

\subsubsection{SUTPLA (2015) ${ }^{52}$}

La CSJN desconoció la legitimación extraordinaria a una asociación sindical patrocinadora de un grupo de personas privadas de la libertad que solo acreditaba en el expediente haber iniciado los trámites necesarios para obtener la personaría gremial, sin obtener la incorporación como entidad gremial según la Ley $23551^{53}$ al momento de promover la demanda.

Con mayor precisión, la Corte delimita en este precedente el momento específico desde el cual una asociación -sindical en este caso- puede ser parte en un proceso de tutela individual homogénea. Este es la incorporación por parte de la autoridad competente en el registro general o especial, en caso de existir. Por tanto, la mera iniciación de los trámites correspondientes no habilita a presentarse en juicio.

\subsubsection{Acordada 12/2016, Reglamento de Actuación en Procesos Colectivos ${ }^{54}$}

En esta norma, la Corte ratifica la Acordada 32 dictada en 2014, aporta mayores precisiones e incorpora elementos del amplio desarrollo jurisprudencial del bienio transcurrido entre ambas disposiciones.

51 Bien se explica en el dictamen de la Procuración General de la Nación que "[l]a resolución 1139/97 de la Secretaria de Industria, Comercio y Minería acotó la obligatoriedad de la inscripción en el Registro Nacional mencionado sólo a aquellas asociaciones de consumidores que funcionaran en el ámbito nacional y que acreditasen su actuación efectiva en más de una jurisdicción, ya sea provincial o de la Ciudad Autónoma de Buenos Aires. Las restantes asociaciones que tuvieran sede y desarrollaran sus actividades únicamente en ámbitos locales, debían, conforme esa resolución, inscribirse en los registros creados en cada jurisdicción” (apartado IV, página 5 del dictamen).

52 CSJN, Sindicato Único de Trabajadores Privados de la Libertad Ambulatoria c/Estado Nacional - Ministerio de Justicia y Derechos Humanos de la Nación y otros s/amparo, 10/11/2015, Nro. Interno: CSJ 841/2013 (49-S) /CS1. Se recomienda el comentario presente en Rodríguez Mancini (2016).

53 Ley 23551 de Asociaciones Sindicales, BO 22/04/1988.

54 CSJN, Acordada 12/2016, 05/04/2016, AR/LCON/75EC. Además del artículo de Salgado (2016), que será citado un poco más adelante, se recomienda el comentario a la acordada presente en Verbic y Sucunza (2016). 
Así como en 2014 la obligación registral pesaba sobre "el tribunal de radicación de la causa" ${ }^{55}$ la disposición en análisis dispone el deber de acatar las nuevas medidas a "los tribunales y las partes". ${ }^{56}$ Esta intervención de la Corte produce un verdadero cambio de paradigma al generar normas que inciden sobre los derechos procesales de los sujetos que intervienen en juicio.

La regulación más relevante a los efectos del presente estudio se encuentra en el punto II, en el cual se establece que la parte actora debe, "[e]n los términos del artículo 330 del Código Civil y Comercial de la Nación, [...] b) justificar la adecuada representación del colectivo; [e] c) indicar, de corresponder, los datos de la inscripción en el Registro Nacional de Asociaciones de Consumidores; $[\ldots] "$.

Se admite, de esta manera, que no siempre corresponde la inscripción en un registro especial de asociaciones para hallarse legitimado de manera extraordinaria, es decir, solo será exigible en caso de existir uno.

\subsubsection{Asociación Sepa Defenderse (2018) ${ }^{57}$}

Se suscita un conflicto negativo de competencia que, con sus matices, llega a la CSJN, la cual resuelve que resulta inoficioso pronunciarse sobre la cuestión planteada porque la Asociación de Consumidores que promueve el expediente fue excluida del ReNAC durante su tramitación.

A lo reglado en DEFEINDER se le suma una interpretación adicional sobre el tiempo durante el cual la asociación civil debe encontrarse registrada "conforme a la ley". Este recaudo no debe observarse solo al incoar el proceso, sino también durante toda su tramitación.

\subsection{Estándar judicial en materia de legitimación extraordinaria de asociaciones civiles}

Reseñé los aspectos más relevantes de lo actuado por la CSJN a lo largo de casi diez años, desde Halabi en 2009 hasta Asociación Sepa Defenderse en 2018, dos acordadas mediante.

En lo que respecta a la legitimación extraordinaria de asociaciones civiles para intervenir en supuestos de tutela individual homogénea, puedo afirmar

\footnotetext{
55 Ídem, punto 3.

56 Ídem, punto I.

57 CSJN, Asociación Sepa Defenderse c/Secretaría de Energía de la Nación y otros s/amparo colectivo, 26/12/2018, La Ley, AR/JUR/79291/2018.
} 
que el acervo producido por la Corte genera una regla que podría enunciarse del siguiente modo:

La legitimación extraordinaria concedida por el artículo $43 \mathrm{CN}$ a las asociaciones civiles para la tutela de derechos individuales homogéneos en el marco de procesos colectivos se encuentra permitida ("Halabi") y, en cada caso, el juez que interviene debe verificar que a) la asociación sea un adecuado representante del colectivo, al ser su objeto estatutario idóneo a tal fin ("PADEC", "Acordada 32/2014" y "Acordada 12/2016”); b) cuente con la necesaria autorización legal de la autoridad pública competente para funcionar ("DEFEINDER"), no siendo suficiente la mera presentación del trámite para obtenerla ("SUTPLA"); c) contar con una inscripción especial en razón de la materia, en caso de que una ley determine dicha necesidad ("DEFEINDER" y "Acordada 12/2016"); y d) conservar durante todo el proceso los requisitos legales necesarios para incoarlo ("Sepa Defenderse").

\subsection{Facultades legislativas de la CSJN según el propio tribunal}

La propia Corte, en los fallos relativos a la materia, así como en las acordadas comentadas anteriormente, reconoce la imperiosa necesidad del dictado de normas legales para la regulación de los procesos colectivos.

A modo de ejemplo, conviene recordar lo dicho -y ya citado anteriormente- por la CSJN en el considerando 12 de Halabi. De manera paulatina, se fueron generando lineamientos jurisprudenciales que marcaban un norte para la interposición de acciones colectivas y la respuesta de la judicatura ante estas.

El punto cúlmine de esta tarea se alcanzó con el dictado de dos acordadas, en cuyos considerandos se citan tres normas en las que, según la propia CSJN, se le otorgan las atribuciones necesarias para emitir este tipo de disposiciones. A continuación, haré referencia a estas, transcribiendo lo que allí se establece.

En primer lugar, la Ley 48 (1863), que en su artículo 18 indica que "[1]a Corte Suprema podrá establecer los reglamentos necesarios para la ordenada tramitación de los pleitos, con tal que no sean repugnantes a las prescripciones de la Ley de Procedimientos".

Segundo, el artículo 10 de la Ley 4055 (1902) dispone que "[l]a Suprema Corte ejercerá superintendencia sobre las Cámaras Federales, Jueces de Sección, Jueces Letrados de Territorios Nacionales y demás funcionarios de la Justicia Federal, debiendo dictar los reglamentos convenientes para procurar la mejor administración de justicia”.

Tercero, la ley de reforma del Código Procesal Civil y Comercial de la Na- 
ción, obrada por Ley 25488 (2001), que en su artículo 4, párrafo $2^{\circ}$ establece que "[l]a Corte Suprema de Justicia de la Nación queda facultada para dictar las medidas reglamentarias y todas las que considere adecuadas para el mejor cumplimiento de las normas y fines de esta reforma".

En el considerando 10 de la Acordada 12/2016 la Corte menciona que, ante la falta de una norma emanada por el Congreso de la Nación,

resulta indispensable fijar reglas orientadas a ordenar la tramitación de este tipo de procesos a fin de evitar circunstancias que pueden conllevar a situaciones de gravedad institucional, hasta tanto el Poder Legislativo Nacional sancione una ley que regule su procedimiento.

Por tal motivo, la citada norma tiene vigencia hasta este último momento citado, ${ }^{58}$ el cual no ha sucedido hasta ahora.

Sin lugar a dudas, la CSJN reconoce que se encuentra ejerciendo facultades regulatorias exclusivas del legislador, aunque realiza cierto esfuerzo por justificar dicha intromisión. Ante esta situación, Salgado (2016) sostiene que "la omisión imperturbable del Poder Legislativo es lo que legitima, antes que autoriza, a la Corte a avanzar en el desarrollo del proceso colectivo" (p. 4), por lo que "[e]l silencio será un nuevo elemento que legitimará el obrar futuro de la Corte en este campo, avanzando en [su] regulación integral [...]” (p. 5).

En apoyo de este rol legislativo, Azar-Baud (2016) defiende el dictado de este tipo de normativa como herramienta idónea para

vigorizar el rol del juez como un director y/o saneador del proceso colectivo, con amplias facultades y obligaciones, [...] aplicado a un proceso complejo y sensible, donde los paradigmas han cambiado y se vuelve necesario de dotar al proceso civil de características dispositivas mixtas, tomando rasgos del inquisitivo sin perder el eje del dispositivo. (p. 3)

Si bien en esta primera parte del trabajo me encuentro realizando una tarea de índole mayormente descriptiva, quiero adelantar mi desacuerdo con la opinión de ambos autores, sobre el cual me explayaré más adelante.

El camino recorrido por la Corte va por un plano inclinado, de menor a mayor, el cual culmina con el dictado de normas procesales para tramitar procesos colectivos, lo cual perfila así un rol activista en la materia. ${ }^{59}$

58 Cfr. Acordada 12/2016, Punto IV.

59 Cfr. Salgado (2011, pp. 131-141). 


\subsection{Legislación nacional vigente y proyectos normativos}

Luego de lo recorrido, llega el turno de analizar lo que sucede en el plano normativo formal en cuanto a la recepción de las herramientas legales, vigentes y sin haber sido aprobadas aún, para promover supuestos de tutela individual homogénea.

\subsubsection{Código Civil y Comercial de la Nación}

Estas nociones teóricas y sus antecedentes jurisprudenciales han encontrado resistencia para ser incorporadas en la normativa legal vigente.

En la génesis del Código Civil y Comercial de la Nación, su comisión redactora introdujo en el anteproyecto diversas disposiciones, receptando la clasificación de derechos en simplemente individuales, individuales homogéneos y colectivos. El artículo 14 disponía

Derechos individuales y de incidencia colectiva. En este Código se reconocen: a) derechos individuales; b) derechos individuales, que pueden ser ejercidos mediante una acción colectiva, si existe una pluralidad de afectados individuales, con daños comunes pero divisibles o diferenciados, generados por una causa común, según lo dispuesto en el Libro Tercero, Título V, Capítulo 1; c) derechos de incidencia colectiva, que son indivisibles y de uso común. El afectado, el Defensor del Pueblo, las asociaciones registradas y otros sujetos que dispongan leyes especiales, tienen legitimación para el ejercicio de derechos que protegen al ambiente, a la competencia, al usuario y al consumidor, así como a los derechos de incidencia colectiva en general. La ley no ampara el ejercicio abusivo de los derechos individuales cuando puede afectar gravemente al ambiente y a los derechos de incidencia colectiva en general.

Asimismo, la iniciativa incluyó una sección en la cual se creaba un marco regulatorio para los "Daños a los derechos de incidencia colectiva". Allí, entre los artículos 1746 y 1748 se receptaban de manera condensada la doctrina de los precedentes de la CSJN en la materia. ${ }^{60}$

60 "Artículo 1746.- Daño a derechos individuales homogéneos. Hay daños a derechos individuales homogéneos cuando media una pluralidad de damnificados individuales con daños comunes pero divisibles o diferenciados, generados en forma indirecta por la lesión a un derecho colectivo o provenientes de una causa común, fáctica o jurídica. Pueden demandar la reparación de esta clase de daños: a) el afectado individual o agrupado que demuestre un interés propio; b) el Defensor del Pueblo de la Nación, de las provincias y de la Ciudad Autónoma de Buenos Aires, según corresponda; c) las organizaciones no gubernamentales de defensa de intereses colectivos, en los términos del artículo 43 de la Constitución Nacional". 
Finalmente, el proyecto que efectivamente elevó el Poder Ejecutivo al Congreso -el cual dio origen a la norma hoy vigente- no contiene siquiera el término "acción colectiva"; su artículo 14 fue modificado, ${ }^{61}$ eliminando los derechos individuales homogéneos, y la sección mencionada en el párrafo anterior fue suprimida.

Aparentemente, este revés legislativo no generó ningún tipo de cambio en la praxis tribunalicia y la CSJN continuó con la línea jurisprudencial iniciada en Halabi para los supuestos de tutela de intereses individuales homogéneos. ${ }^{62}$ Según la interpretación de Lorenzetti (2017, p. 25), esta supresión no afecta los derechos homogéneos por ser, en esencia, derechos individuales que sí se encuentran expresamente receptados en el nuevo Código. ${ }^{63}$

"Artículo 1747.- Presupuestos de admisibilidad. Para el reconocimiento de la legitimación en los procesos en los que se reclama el resarcimiento de daños a derechos de incidencia colectiva o individuales homogéneos, se debe exigir que el legitimado cuente con aptitudes suficientes para garantizar una adecuada defensa de los intereses colectivos. Entre otros requisitos, el juez debe tener en cuenta: a) la experiencia, antecedentes y solvencia económica del legitimado para la protección de este tipo de intereses; b) la coincidencia entre los intereses de los miembros del grupo, categoría o clase y el objeto de la demanda. Para la admisibilidad de los procesos en los que se reclama la reparación de daños a derechos individuales homogéneos es requisito necesario que el enjuiciamiento concentrado del conflicto constituya una vía más eficiente y funcional que el trámite individual, para lo cual el juez debe tener en consideración aspectos tales como el predominio de las cuestiones comunes sobre las particulares o la imposibilidad o grave dificultad de constituir un litisconsorcio entre los afectados".

"Artículo 1748.- Alcances de la sentencia. Cosa juzgada. En los procesos colectivos referidos a derechos individuales homogéneos, la sentencia hace cosa juzgada y tiene efecto erga omnes, excepto que la acción sea rechazada. Este efecto no alcanza a las acciones individuales fundadas en la misma causa. Si la pretensión colectiva es acogida, los damnificados pueden solicitar la liquidación y la ejecución de la sentencia a título personal ante el juez de su domicilio. La sentencia que rechaza la acción colectiva no impide la posibilidad de promover o continuar las acciones individuales por los perjuicios ocasionados a cada damnificado".

61 "Artículo 14.- Derechos individuales y de incidencia colectiva. En este Código se reconocen: a) derechos individuales; b) derechos de incidencia colectiva. La ley no ampara el ejercicio abusivo de los derechos individuales cuando pueda afectar al ambiente y a los derechos de incidencia colectiva en general".

62 Ver Lorenzetti (2014, p. 75). En la nota al pie No 80, el autor de esta obra, ministro de la Corte Suprema de Justicia de la Nación y protagonista principal en la redacción del anteproyecto del Código Civil y Comercial de la Nación, plantea al pasar y sin dar mayores precisiones que "[e]n el proyecto elaborado por la Comisión se incluía una tercera categoría: b) Derechos individuales, que pueden ser ejercidos mediante una acción colectiva, si existe una pluralidad de afectados individuales, con daños comunes pero divisibles o diferenciados, generados por una causa común, según lo dispuesto en el Libro Tercero, Título V, Capítulo 1, pero ello fue suprimido por el Poder Ejecutivo nacional”.

63 En el mismo sentido, afirma Catalano (2015) que "nada impide que se considere a los intereses individuales homogéneos como integrantes de la categoría de derechos de incidencia colectiva que nombra la norma, junto a los derechos difusos o propiamente colectivos. Esta télesis del art. 14 se revela como la única salida para seguir avanzando en un ámbito que no admite vuelta atrás, so riesgo de quedar a espaldas de la realidad social, donde las cuestiones de discriminación, competencia, 


\subsubsection{Normas legales con alguna referencia a procesos colectivos específicos}

Si bien en el CPCCN la regulación vinculada a la legitimación activa no ha sufrido cambios, sí existen normas procesales de gran importancia para el objeto del presente estudio en diversos ámbitos.

\subsubsection{Derechos de los usuarios y consumidores}

La propia reforma constitucional de 1994, la cual ya fue comentada por su importancia en materia del proceso de amparo, sostuvo el protagonismo que la Ley 24240 les otorgó a las asociaciones de consumidores y usuarios al incorporar el nuevo artículo 42 de la CN. ${ }^{64}$

Al tiempo que la "Ley de Leyes" contiene disposiciones pertinentes, lo propio sucede con normas supraconstitucionales que poseen preceptos procesales para la tutela colectiva de derechos, algunas de las cuales serán detalladas a continuación.

La principal que conviene analizar es la citada Ley de Defensa del Consumidor (en adelante, LCD), en vigencia desde 1993. En sus capítulos XIII y XIV regula la legitimación extraordinaria de un tipo específico de asociaciones civiles, las de usuarios y consumidores.

En el artículo 52 se reconoce entre los legitimados procesales en la defensa de los intereses de usuarios y consumidores a las asociaciones. En lo atinente al presente estudio, dicha cláusula establece

Acciones Judiciales. Sin perjuicio de lo dispuesto en esta ley, el consumidor y usuario podrán iniciar acciones judiciales cuando sus intereses resulten afectados o amenazados.

acceso a la información y defensa de los derechos de usuarios y consumidores, por mencionar las más sobresalientes, se plantean con habitualidad".

64 "Artículo 42.- Los consumidores y usuarios de bienes y servicios tienen derecho, en la relación de consumo, a la protección de su salud, seguridad e intereses económicos; a una información adecuada y veraz; a la libertad de elección, y a condiciones de trato equitativo y digno.

Las autoridades proveerán a la protección de esos derechos, a la educación para el consumo, a la defensa de la competencia contra toda forma de distorsión de los mercados, al control de los monopolios naturales y legales, al de la calidad y eficiencia de los servicios públicos, y a la constitución de asociaciones de consumidores y de usuarios.

La legislación establecerá procedimientos eficaces para la prevención y solución de conflictos, y los marcos regulatorios de los servicios públicos de competencia nacional, previendo la necesaria participación de las asociaciones de consumidores y usuarios y de las provincias interesadas, en los organismos de control”. 
La acción corresponderá al consumidor o usuario por su propio derecho, a las asociaciones de consumidores o usuarios autorizadas en los términos del artículo 56 de esta ley, a la autoridad de aplicación nacional o local, al Defensor del Pueblo y al Ministerio Público Fiscal. Dicho Ministerio, cuando no intervenga en el proceso como parte, actuará obligatoriamente como fiscal de la ley.

En las causas judiciales que tramiten en defensa de intereses de incidencia colectiva, las asociaciones de consumidores y usuarios que lo requieran estarán habilitadas como litisconsortes de cualquiera de los demás legitimados por el presente artículo, previa evaluación del juez competente sobre la legitimación de éstas.

Resolverá si es procedente o no, teniendo en cuenta si existe su respectiva acreditación para tal fin de acuerdo a la normativa vigente [...].

El Decreto Reglamentario admite que esta posibilidad de accionar en cabeza de una asociación de consumidores no necesita de ningún tipo de reconocimiento por parte del particular afectado o titular de la relación jurídica sustancial (el usuario o consumidor individual) en caso de que se esté promoviendo la protección de algún interés general.

Más adelante, el artículo 55 reconoce de manera más clara dicha legitimación, supeditada a la obtención de la correspondiente autorización para funcionar por parte de la autoridad pública competente en la materia

Legitimación. Las asociaciones de consumidores y usuarios constituidas como personas jurídicas reconocidas por la autoridad de aplicación, están legitimadas para accionar cuando resulten objetivamente afectados o amenazados intereses de los consumidores o usuarios, sin perjuicio de la intervención de éstos prevista en el segundo párrafo del artículo 58 de esta ley.

Las acciones judiciales iniciadas en defensa de intereses de incidencia colectiva cuentan con el beneficio de justicia gratuita.

Los requisitos para obtener dicho reconocimiento se encuentran en los artículos 56 y 57 de la ley, en su Decreto Reglamentario 1798/1994 y en las resoluciones y disposiciones que norman el ReNAC.

Esta normativa regula la legitimación extraordinaria colectiva de las asociaciones de usuarios y consumidores, pero lo más importante es que define los 
alcances de dicha intervención procesal en el artículo $54^{65}$ desde la reforma introducida en 2008 por la Ley 26361. ${ }^{66}$

A pesar de existir algunas nociones que dan un marco general en la normativa para el desarrollo de procesos de tutela individual homogénea en materia de usuarios y consumidores, Picasso y Vázquez (2013) afirman que

la disposición en análisis despeja toda duda en cuanto a la existencia de acciones colectivas en la materia, regulando algunos aspectos de particular relevancia en este tipo de procesos. Sin perjuicio de ello, no debe dejar de señalarse que esta norma no constituye un procedimiento completo y acabado en la materia, sino que se refiere a algunos aspectos de las acciones colectivas, a saber: a) el procedimiento para arribar a un acuerdo o transacción y sus efectos; b) el alcance de la cosa juzgada en este tipo de litigios; y c) el procedimiento para la determinación de la indemnización que corresponda a cada uno de los consumidores, en caso de que el juicio tenga contenido patrimonial. (p. 676)

Como puede percibirse, existe una diferencia sustancial entre el desarrollo jurisprudencial de la tutela individual homogénea y la que ofrecen los derechos de los usuarios y consumidores, al existir en este último caso normas procesales con algún grado de mayor especificidad.

65 "Articulo 54.- Acciones de incidencia colectiva. Para arribar a un acuerdo conciliatorio o transacción, deberá correrse vista previa al Ministerio Público Fiscal, salvo que éste sea el propio actor de la acción de incidencia colectiva, con el objeto de que se expida respecto de la adecuada consideración de los intereses de los consumidores o usuarios afectados. La homologación requerirá de auto fundado. El acuerdo deberá dejar a salvo la posibilidad de que los consumidores o usuarios individuales que así lo deseen puedan apartarse de la solución general adoptada para el caso.

La sentencia que haga lugar a la pretensión hará cosa juzgada para el demandado y para todos los consumidores o usuarios que se encuentren en similares condiciones, excepto de aquellos que manifiesten su voluntad en contrario previo a la sentencia en los términos y condiciones que el magistrado disponga.

Si la cuestión tuviese contenido patrimonial establecerá las pautas para la reparación económica o el procedimiento para su determinación sobre la base del principio de reparación integral. Si se trata de la restitución de sumas de dinero se hará por los mismos medios que fueron percibidas; de no ser ello posible, mediante sistemas que permitan que los afectados puedan acceder a la reparación y, si no pudieran ser individualizados, el juez fijará la manera en que el resarcimiento sea instrumentado, en la forma que más beneficie al grupo afectado. Si se trata de daños diferenciados para cada consumidor o usuario, de ser factible se establecerán grupos o clases de cada uno de ellos y, por vía incidental, podrán éstos estimar y demandar la indemnización particular que les corresponda”.

Ley 26361, BO 07/04/2008. 


\subsubsection{Asociaciones sindicales}

Especial y breve mención merece la Ley de Asociaciones Sindicales, previa a la última reforma constitucional argentina del siglo XX. En ella se otorga de manera genérica a los gremios la legitimación para "[d]efender y representar ante el Estado y los empleadores los intereses individuales y colectivos de los trabajadores". ${ }^{67}$

Esta norma concede dicha posibilidad siempre que la entidad obtenga la inscripción con personería gremial prevista en los artículos 25 y siguientes de la ley. ${ }^{68}$

Asimismo, a diferencia de lo que podría suceder con la LDC, existe más bien un reconocimiento con escasas precisiones procesales para la tutela individual homogénea de los derechos de los trabajadores.

\subsubsection{Propuestas normativas}

Lo sostenido por la CSJN en el considerando 9 de Halabi, ya mencionado previamente, tuvo su eco en la labor legislativa de integrantes de ambas cámaras del Honorable Congreso de la Nación, ${ }^{69}$ sin haber obtenido resultados exitosos hasta ahora.

Asimismo, el 22 de diciembre de 2017, el Poder Ejecutivo Nacional hizo públicas sus intenciones de emplear sus facultades para presentar iniciativas legislativas a tratar por el Poder Legislativo. Así fue cómo el Ministerio de Justicia y Derechos Humanos de la Nación creó la Comisión Redactora del Anteproyecto de Ley de Procesos Colectivos en el ámbito del programa Justicia 2020, ${ }^{70}$ a la cual le encomendó "desarrollar un marco normativo que ordene el tratamiento de las cuestiones de afectación masiva a través de reglas que aporten a los justiciables accesibilidad, previsibilidad, coherencia en las decisiones y eficacia en el cumplimiento de los decisorios". ${ }^{71}$

Si bien el trabajo no concluyó de manera definitiva, se hizo público un borrador en la página web del Ministerio de Justicia y Derechos Humanos en mayo de 2018, ${ }^{72}$ el cual fue ampliamente comentado y valorado por la más

\section{Artículo 31, inciso a).}

68 Cfr. Salgado (2011, p. 168).

69 Pueden encontrarse numerables referencias a los proyectos de ley presentados en Dirección de Servicios Legislativos del Honorable Congreso de la Nación (2019, pp. 3-4).

70 Cfr. Resolución del Ministerio de Justicia y Derechos Humanos de la Nación (2017).

71 Ídem.

72 El link en el cual fue publicado (https://www.argentina.gob.ar/justicia/foro/topic/ley-de-proce- 
destacada doctrina especializada en la materia. ${ }^{73}$ Sin embargo, nunca vio oficialmente la luz ni discurrió el trámite legislativo ordinario.

Vale la pena también tener siempre presente, como referencia internacionalmente conocida, el Código Modelo de Procesos Colectivos para Iberoamérica, elaborado por el Instituto Iberoamericano de Derecho Procesal ${ }^{74}$ y publicado en el año 2004. ${ }^{75}$

\section{Síntesis parcial}

Hace poco más de diez años, la Corte comenzó a recorrer un camino en el cual otorgó legitimación extraordinaria de las asociaciones civiles en los supuestos de tutela individual homogénea. Luego de lo descripto a lo largo de los apartados anteriores, en este procuraré realizar en pocas líneas una valoración global del mencionado proceso en la praxis de la justicia nacional y federal.

La CSJN procuró impulsar la visión tripartita de los derechos -simplemente individuales, colectivos e individuales homogéneos- receptada desde el Código Modelo de Procesos Colectivos para Iberoamérica. A pesar del esfuerzo realizado, no logró permear en la legislación formal vigente y sufrió un duro revés al aprobarse el Código Civil y Comercial de la Nación, en el cual se suprimió la triple categorización antes mencionada.

Esta circunstancia no se constituyó en un obstáculo para que la Corte realizara el amplio desarrollo descripto durante esta sección que aquí concluyo. Si bien es cierto que contó con la vaga referencia presente en el artículo 43 de la $\mathrm{CN}$ a los derechos de incidencia colectiva, una pretendida operatividad de la legitimación extraordinaria en favor de las asociaciones civiles allí mencionada y alguna normativa infraconstitucional, la realidad es que careció de "pautas adjetivas mínimas que regulen la materia”, como ella misma reconoció en el ya citado considerando 20 de Halabi.

Al abrir la puerta de la tutela individual homogénea en 2009, creó de mane-

sos-colectivos) ya no se encuentra activo para su consulta.

73 Entre ellos, Camps (2019); Catalano (2018); Giannini (2018); Halabi y Díaz Cisneros (2019); Verbic (2018); entre otros.

74 Según la presentación institucional que figura en su página web, "[e]l Instituto Iberoamericano de Derecho Procesal se fundó en Montevideo, en las Primeras Jornadas Latinoamericanas de Derecho Procesal, realizadas en 1957, en homenaje a la Memoria de Eduardo J. Couture. [...] El Ministerio de Relaciones Exteriores de la República Oriental del Uruguay resolvió en el 2010 otorgarle personería jurídica" (http://www.iibdp.org/es/presentacion-institucional/).

75 Ver el resumen explicativo del Código Modelo en Lorenzetti (2017, pp. 118-121). 
ra paulatina un marco propicio para que una nueva clase de expedientes judiciales proliferara. Con casos de los más variados, la Corte encontró un campo fértil para elaborar un acervo jurisprudencial que terminó de adquirir un verdadero carácter vinculante con el dictado de las Acordadas 32/2014 y 12/2016.

El aparente vacío legislativo en la materia fue el espacio que la CSJN se propuso ocupar y lo hizo generando verdaderas normas procedimentales con un impacto contundente en los procesos civiles de la justicia nacional y federal de nuestro país.

De esta manera, con un impulso en solitario por parte de la Corte como cabeza del Poder Judicial de la Nación, las asociaciones civiles lograron adquirir un poder del que carecían hasta el momento: el de la legitimación extraordinaria en acciones de clase, a través del cual pueden constituirse en parte actora pretendiendo la defensa de derechos enteramente individuales y ajenos en un proceso judicial.

\section{Los alcances de la facultad reglamentaria de la CSJN}

En la primera parte, desarrollé el modo en el cual la Corte generó un nuevo camino procesal y focalicé la atención del presente estudio en la legitimación extraordinaria reconocida para asociaciones civiles en supuestos de tutela individual homogénea.

Al tiempo que la sección anterior fue de índole mayormente descriptiva, en esta etapa procuraré realizar un análisis crítico sobre el obrar de la CSJN a la luz de las cláusulas normativas vigentes.

\subsection{Límites constitucionales, convencionales y legales}

\subsubsection{La garantía del debido proceso y el derecho de instar ante las autoridades} Indica el artículo 18 de la $\mathrm{CN}$ :

Ningún habitante de la Nación puede ser penado sin juicio previo fundado en ley anterior al hecho del proceso, ni juzgado por comisiones especiales, o sacado de los jueces designados por la ley antes del hecho de la causa. [...] Es inviolable la defensa en juicio de la persona y de los derechos [...].

Una lectura cuidadosa de esta norma vinculada al derecho de petición plasmado en el artículo 14 de la $\mathrm{CN}$ permite sostener que dichas cláusulas habilitan a las partes procesales a exigir que los órganos judiciales intervinientes se ciñan 
a las normas sustantivas y adjetivas vigentes al momento del hecho que genera la disputa puesta a consideración de estos últimos.

Si bien podría afirmarse que la redacción de la citada disposición extiende una garantía únicamente para los procesos de índole penal, resulta sumamente iluminador el artículo 8, inciso 1 de la Convención Americana sobre Derechos Humanos, con jerarquía constitucional en la Argentina en virtud del artículo 75 , inciso 22, párrafo 2 . De allí se infiere que la garantía del debido proceso es aplicable en favor de toda persona "para la determinación de sus derechos y obligaciones de orden civil, laboral, fiscal o de cualquier otro carácter” . 76 Por lo tanto, rige ante la tramitación de todo expediente jurisdiccional en cualquier materia. $^{77}$

Por su parte, el artículo 14 de la $\mathrm{CN}$ reconoce el derecho de peticionar ante las autoridades "conforme a las leyes que reglamenten su ejercicio". La acción procesal a través de la instancia judicial es una de las formas posibles de ejercer esta facultad ${ }^{78}$ y esta se debe regir por las pautas legales que norman el proceso.

Para algunas materias específicas, la propia Constitución Nacional prevé expresamente la necesidad de una regulación legal de los procesos. Así lo establece, por ejemplo, el artículo 42 de la $\mathrm{CN}$ para los casos de derechos de los consumidores y usuarios:

[...] La legislación establecerá procedimientos eficaces para la prevención y solución de conflictos, y los marcos regulatorios de los servicios públicos de competencia nacional, previendo la necesaria participación de las asociaciones de consumidores y usuarios y de las provincias interesadas, en los organismos de control.

76 En similar sentido, ver artículo 14, inciso 1 del Pacto Internacional de Derechos Civiles y Políticos.

77 Así lo reconoce la Corte Interamericana de Derechos Humanos, por ejemplo, en su precedente Pollo Rivera y otros vs. Perú, sentencia del 21 de octubre de 2016 (fondo, reparaciones y costas). Allí, en su párrafo 209, el mencionado organismo internacional sostiene: "Este Tribunal ha señalado que la aplicación de las garantías contenidas en el artículo 8 de la Convención Americana, si bien se titula 'Garantías Judiciales', no se limita a los recursos judiciales en sentido estricto, sino al conjunto de requisitos que deben observarse en las instancias procesales a efectos de que las personas estén en condiciones de defender adecuadamente sus derechos ante cualquier tipo de acto del Estado que pueda afectarlos. Es decir, cualquier actuación u omisión de los órganos estatales dentro de un proceso, sea administrativo sancionatorio o jurisdiccional, debe respetar el debido proceso legal. Además, de acuerdo a lo dispuesto en el artículo 8.1 de la Convención, es claro que, en la determinación de los derechos y obligaciones de las personas, de orden penal, civil, laboral, fiscal o de cualquier otro carácter, se deben observar 'las debidas garantías' que aseguren, según el procedimiento de que se trate, el derecho al debido proceso".

78 En este sentido, ver lo explicado en Alvarado Velloso (2009, pp. 55-66); Briseño Sierra (como se citó en Calvinho, 2013, p. 21); Couture (2010 [1948], pp. 9-26). 
Nunca está de más recordar que esta garantía de legalidad, exigida para la regulación de los derechos constitucionales, requiere que las normas dictadas provengan del poder legislativo y cumplan con los requisitos que los ordenamientos jurídicos prevén para su entrada en vigencia (promulgación, publicación, entre otros), o, al menos y de manera excepcional, surjan de los procesos de delegación legislativa expresamente presentes en la normativa constitucional interna. ${ }^{79}$

Por lo tanto, nuestra Constitución y los tratados internacionales con jerarquía constitucional imponen la obligación de que no cualquier norma ni órgano estatal regulen los derechos de las partes procesales, sino solo los que han recibido de manera expresa la atribución de dictar leyes en sentido formal.

\subsubsection{Reglamentos y acordadas del Poder Judicial de la Nación}

Resulta de vital importancia detenerse en una facultad normativa otorgada por la propia Constitución Nacional a la Corte. Me refiero a la atribución que se le reconoce para dictar su reglamento interior en el artículo $113,{ }^{80}$ sin conceder allí ningún tipo de atribución para generar normas que puedan incidir regulando los derechos de los particulares en el marco de un proceso judicial, lo cual es materia reservada a los poderes legislativos, como ya expliqué anteriormente.

Es una potestad que puede compararse a la que detentan las cabezas de los otros poderes del Estado. Por un lado, la del Poder Ejecutivo Nacional de dictar decretos autónomos, contemplada en el artículo 99, inciso 1 de la $\mathrm{CN},{ }^{81} \mathrm{y}$, por el otro, con la de cada cámara del Honorable Congreso de la Nación de dictar su propio reglamento, prevista en el artículo 66 de la $\mathrm{CN} .{ }^{82}$

Sobre este punto, sostiene Sacristán (2020):

el artículo 113 coloca directamente en cabeza de la Corte Suprema -por "delegación” del Constituyente, si se quiere, o, mejor dicho, por "creación” de este- una competencia reglamentaria de fuente textual constitucional enderezada primigeniamente al plano intrapoder, internamente interorgánico, sin perjuicio de eventuales efectos o beneficios hacia terceros. (pp. 512-513)

79 Ver lo dicho por la Corte Interamericana de Derechos Humanos en Opinión Consultiva OC-6/86. La expresión "leyes" en el artículo 30 de la Convención Americana sobre Derechos Humanos. Solicitada por el Gobierno de la República Oriental del Uruguay, 09/05/1986.

80 "Artículo 113: La Corte Suprema dictará su reglamento interior y nombrará a sus empleados".

81 Cfr. Sacristán (2020, pp. 499-530 y 502-510).

82 Cfr. Gelli (2018b, p. 567). 
Respecto a las disposiciones legales en análisis, explica Salgado (2016, p. 4): "Las facultades conferidas son aquellas inherentes a todo poder público para su existencia y conservación, recursos propios para mantener y hacer práctica su autoridad, y toda la independencia necesaria para su organización interna”.

Por lo tanto, según el mismo autor, las normas que dicte la Corte en consecuencia poseen la virtualidad de ser

reglamentarias a efectos del mejoramiento del servicio de justicia, mas siempre están supeditadas a las leyes procesales y, obviamente, al bloque de constitucionalidad. Indefectiblemente su alcance ha quedado delimitado a las previsiones del art. $113 \mathrm{CN}$, que faculta a la Corte a dictar "su reglamento interior" lo que implica su organización, gobierno y funcionamiento. Salgado $(2016, \text { p. } 4)^{83}$

No solo la Constitución Nacional le reconoce cierta facultad regulatoria a la Corte Suprema. Sobre este punto conviene detenerse en el análisis de las tres normas de rango legal citadas ${ }^{84}$ por la CSJN en los considerandos de algunas de sus acordadas ${ }^{85}$ como fundamento de la atribución para el dictado de estas. Palacio (2017) explica
A fin de facilitar el mejor funcionamiento de la administración de justicia, y frente a la imposibilidad de prever los múltiples problemas de orden práctico que la actividad procesal puede suscitar, las leyes suelen conferir a los órganos judiciales superiores la facultad de dictar normas generales, destinadas a com- plementar o integrar los textos legales relativos a determinados aspectos de la organización judicial y a la regulación de los procedimientos. (§ 30)

Asimismo, sobre esta atribución reglamentaria reconoce claros límites para su ejercicio y sostiene que posee "una limitación sustancialmente análoga a la que el art. 99 inc. $2^{\circ} \mathrm{CN}$ impone al Poder Ejecutivo en lo que respecta a la reglamentación de las leyes nacionales" (\$33).

Para Sacristán (2020, p. 522), la actividad reglamentaria de la CSJN puede ser más amplia respetando siempre una serie de límites, entre los que se

83 Cabe destacar que el autor que realiza esta consideración sostiene la necesidad de contar con una ley que regule los supuestos de tutela individual homogénea -sobre todo ante la necesidad de clarificar cuestiones no tratadas-, pero no descalifica el proceder de la CSJN.

84 Fueron mencionadas en la primera parte del trabajo las leyes 48 (1863), 4055 (1902) y 25488 (2001).

85 Las pioneras fueron la Acordada 28/2004, de autorización de Amigos del Tribunal, y la Acordada 4/2007, del reglamento sobre los escritos de interposición de los recursos extraordinarios y de queja. Esta misma línea argumentativa fue seguida por las acordadas 32/2014 y 12/2016. 
destacan no invadir materias reservadas al Poder Legislativo y no contrariar la legislación vigente.

De cualquier manera, puedo sostener que no existe disposición normativa alguna que habilite a la Corte a dictar legislación general que regule los derechos de las partes en el marco de un proceso.

\subsubsection{Delegación legislativa}

En las diversas acordadas en las que la Corte actúa ejerciendo facultades exclusivas del legislador, da a entender que es el propio Congreso de la Nación el que ha obrado una especie de delegación legislativa de dichas atribuciones en cabeza del Poder Judicial. Sin embargo, esa posibilidad regulada en el artículo 76 de la CN solo se admite entre el Poder Legislativo y el Poder Ejecutivo, según lo establecido por la mencionada norma incorporada en el año 1994

Se prohíbe la delegación legislativa en el Poder Ejecutivo, salvo en materias determinadas de administración o de emergencia pública, con plazo fijado para su ejercicio y dentro de las bases de la delegación que el Congreso establezca [...].

Sagüés (2018) sostiene que admitir una delegación legislativa en cabeza de un órgano judicial resulta improcedente de acuerdo con la regulación actual de dicha figura

si se tiene en cuenta que la Constitución Nacional no la menciona (con lo que podría entenderse que no la autoriza, atento el principio de corrección funcional), y que la reforma de 1994 restringió la delegación legislativa sobre el Poder Ejecutivo, en el nuevo art. 76. (pto. IV)

No solo resulta inviable esta alternativa debido a los argumentos que expone este autor, sino también porque la propia Ley $26122^{86}$ solo regula el trámite de las normas emanadas del Poder Ejecutivo Nacional en virtud de un supuesto de delegación por parte del Congreso.

Por lo tanto, si bien es cierto que el Legislativo facultó al Judicial con ciertas atribuciones reglamentarias, lo hizo solo para materias determinadas y específicas sin permitirle innovar respecto a la legislación procesal ni regular los

86 Ley 26122 de régimen legal de los decretos de necesidad y urgencia, de delegación legislativa y de promulgación parcial de leyes, BO 28/07/2006. 
derechos de las partes en un litigio, lo cual no está expresamente habilitado por la Constitución Nacional.

\section{Tutela individual homogénea: inconsistencias con el ordenamiento jurídico argentino}

A continuación, expondré cuáles son los puntos de la normativa vigente cuya aplicación se pone en crisis por la Corte en los supuestos de tutela individual homogénea promovidos por asociaciones civiles.

\subsection{Legitimación extraordinaria regulada por un órgano incompetente}

En los casos relevados en este trabajo, las asociaciones civiles se presentan en juicio en defensa de un derecho del cual no son titulares, como ya se explicó anteriormente. Así lo admitió la Corte en su acervo jurisprudencial y, de manera más concreta, en sus acordadas 32/2014 y 12/2016.

Específicamente, en el Reglamento de Registro Público de Procesos Colectivos (Acordada 32/2014), lo dicho en el párrafo anterior se concreta en el punto 3 de la norma al atribuirle facultades al órgano judicial que interviene, mediante las que "reconoce la idoneidad del representante y establece el procedimiento para garantizar la adecuada notificación de todas aquellas personas que pudieran tener un interés en el resultado del litigio".

Por su parte, el Reglamento de Actuación en Procesos Colectivos (Acordada 12/2016) le impone al actor la obligación de "justificar la adecuada representación del colectivo" al presentar la demanda.

Sin embargo, este accionar es inconstitucional porque el Poder Judicial de la Nación no cuenta con las atribuciones suficientes para modificar o crear normas procesales que incidan de manera directa en los derechos de las partes procesales, siendo esta una facultad propia del Honorable Congreso de la Nación que, excepcionalmente, puede ser ejercida por el Poder Ejecutivo.

\subsection{Modificación de los requisitos para interponer una demanda}

En el punto II de la Acordada 12/2016, la CSJN expresamente amplía los requisitos para la interposición de una demanda, previstos en el artículo 330 del CPCCN, ${ }^{87}$ circunstancia que ya fue expuesta al comentar el reglamento dictado por la Corte.

87 Ley 17454 de Código Procesal Civil y Comercial de la Nación, BO 07/11/1967. 


\begin{abstract}
Al explicar Palacio (2017) cuál es el alcance de las normas de alcance general dictadas por el alto tribunal, expresa:
\end{abstract}

los reglamentos judiciales no pueden alterar y menos contrariar los requisitos de lugar, tiempo y forma que las leyes imponen a los actos procesales, debiendo limitarse a regular los aspectos secundarios o estrictamente materiales de tales requisitos. No cabría, así, por vía reglamentaria, imponer al actor la carga de incluir, en el escrito de demanda, enunciaciones que hagan al fondo de ésta y no se encuentren contempladas por el art. 330 del Código Procesal de la Nación ni tampoco suprimir alguno de los requisitos exigidos por dicha norma. Pero el reglamento puede exigir, v.gr., que en el escrito respectivo se utilice exclusivamente tinta negra o que los abogados y procuradores que lo suscriben indiquen el tomo y el folio o el número de la matrícula de su inscripción. (\$ 33)

Por lo tanto, si bien la Corte cuenta con cierto poder reglamentario, excede en este caso los límites previstos para su correcto empleo.

\title{
6.3. Tercero interesado \\ El artículo 90 del CPCCN habilita a cualquier persona a
}

intervenir en un juicio pendiente en calidad de parte, cualquiera fuere la etapa o la instancia en que éste se encontrare, quien: 1) Acredite sumariamente que la sentencia pudiere afectar su interés propio. 2) Según las normas del derecho sustancial, hubiese estado legitimado para demandar o ser demandado en el juicio.

Por su parte, el artículo 91 del CPCCN indica:

En el caso del inciso 1. del artículo anterior, la actuación del interviniente será accesoria y subordinada a la de la parte a quien apoyare, no pudiendo alegar ni probar lo que estuviese prohibido a ésta.

En el caso del inciso 2. del mismo artículo, el interviniente actuará como litisconsorte de la parte principal y tendrá sus mismas facultades procesales.

\section{Explica Palacio (2017):}

La intervención de terceros tiene lugar cuando, durante el desarrollo del proceso, y sea en forma espontánea o provocada, se incorporan a él personas distintas a las partes originarias con el objeto de hacer valer derechos o intereses propios, aunque vinculados a la causa o al objeto de la pretensión. (§ 338) 
Resulta paradójico que, al tiempo de que los contornos impuestos por la CSJN a la tutela individual homogénea abren una puerta a las asociaciones civiles -sin contar con recaudos legales claros-, se ha negado la posibilidad de participar en un proceso ya iniciado a sujetos que sí sostienen ser titulares del derecho en disputa, a pesar de lo dispuesto en el inciso $2^{\circ 88}$ de la norma procesal citada en el párrafo anterior.

Así sucedió, por ejemplo, en un expediente que arribó a la Corte mediante recurso de queja, el cual fue resuelto en diciembre de $2014 .{ }^{89}$

En la causa, el alto tribunal negó la procedencia de la solicitud de un grupo de 2641 personas que procuraban adquirir la calidad de parte actora junto con las 25 que habían dado inicio a un proceso vinculado con la prestación de un servicio público domiciliario, entre las que se encontraba representada la Asociación Todos por el Agua. Sorprendentemente, a pesar de no admitirlos como demandantes, mantuvo vigente para ellos la medida cautelar dictada en favor del conjunto más pequeño con anterioridad a su intervención.

La Corte sostuvo que la jurisdicción provincial no estaba respetando los parámetros por ella delineados para los procesos colectivos al darles participación a todos los integrantes de un colectivo que ya se encontraba representado por quienes propiciaron la acción judicial, en especial la asociación civil antes mencionada, la cual, incluso, había celebrado un acuerdo transaccional con la contraparte para darle solución al pleito.

Esta decisión pone de relieve cómo se violentan los derechos procesales previstos en los artículos 90 y 91 del CPCCN, pero se intenta enmendar el error admitiendo la extensión de una tutela cautelar a un conjunto de individuos que no revisten la calidad de parte en el litigio. Quizás, de este modo, la lesión a la garantía del debido proceso no resulta ser tan obvia por sus efectos para

88 Allí se regula la denominada por la doctrina como "intervención adhesiva autónoma o litisconsorcial”. Palacio (2017, §344) sostiene que, en ella, "el ingreso del tercero en el proceso pendiente tiene por objeto hacer valer un derecho propio frente a alguna de las partes originarias, adhiriendo a la calidad (actora o demandada) asumida por la otra u otras".

89 CSJN, Kersich, Juan Gabriel y otros c/Aguas Bonaerenses S.A. y otros s/amparo, 02/12/2014, Nro. Interno: CSJ 42/2013 (49-K). Cabe aclarar que las normas procesales aplicadas en este expediente fueron las que rigen en el territorio de la provincia de Buenos Aires que, en cuanto al instituto de la intervención de terceros, resulta idéntica al CPCCN. Asimismo, la Corte entendió que se encontraba frente a un caso de protección de uno de los componentes del bien colectivo ambiente, el agua potable, sin visualizar que la pretensión se enfocaba claramente en un típico supuesto de tutela individual homogénea, como lo es la provisión del servicio público domiciliario de agua potable. Sin embargo, como bien surge del considerando 9 del fallo, la Corte sostiene que las reglas que deben aplicarse en un proceso colectivo son las que surgen del artículo 43 y de las pautas previstas en su 
con los actores excluidos, pero no puede afirmarse lo mismo para con la parte demandada.

Desde la entrada en vigencia de la Acordada 12/2016, esta virtual desaparición de la figura del tercero interesado quedó plasmada de manera implícita. Al resolver el juez la inscripción de un proceso de estas características, queda identificada la composición del colectivo ${ }^{90}$ y se deben "determinar los medios más idóneos para hacer saber a los demás integrantes del colectivo la existencia del proceso, a fin de asegurar la adecuada defensa de sus intereses". ${ }^{91}$

Sin embargo, según el Reglamento, la promoción de la acción compete solo a quien presente la demanda y justifique su calidad de representante adecuado. Por lo que si el juez arriba a la conclusión de que debe registrar el proceso, ninguno de los integrantes del colectivo representado podrá adquirir la calidad de parte, como sí ocurriría en un proceso tradicional con cualquier tercero interesado admitido en función de la normativa vigente del Código Procesal Civil y Comercial de la Nación.

Este resultado insólito al que arriba la Corte parece contrario a la lógica de otros casos previstos en el derecho vigente, en los que existe algún tipo de legitimación extraordinaria.

Solo a modo de ejemplo habré de referirme al supuesto de nulidad absoluta de un matrimonio y a los sujetos que se hayan habilitado para impulsar el proceso. En el artículo 424 del CCCN se reconoce esta facultad a los cónyuges y también se legitima de manera extraordinaria a las mismas personas que podrían haberse opuesto a la celebración de las nupcias. Resultaría sumamente ilógico y contrario a las normas vigentes que, luego de presentada la demanda por cualquiera de las personas mencionadas en el artículo $411 \mathrm{CCCN}$, se rechazara la participación de cualquiera de los cónyuges que desea intervenir en calidad de parte.

\subsection{Representación procesal: ¿adecuada?}

Si bien la participación prevista por la Constitución Nacional para las asociaciones civiles en supuestos de tutela individual homogénea es en calidad de legitimadas extraordinarias, tanto la doctrina como la jurisprudencia de la CSJN

propia jurisprudencia.

90 Cfr. Reglamento de Actuación en Procesos Colectivos, puntos V.1 y VIII.1.

91 Ídem, punto VIII.2. 
emplean una terminología que puede generar cierta confusión con el instituto de la representación procesal.

Tanto la Acordada 32/2014 como la 12/2016 se refieren a que quien acciona debe ser representante idóneo o adecuado del colectivo involucrado en un caso, sin aportar mayores precisiones respecto a los requisitos o cualidades que permiten adjetivar de esta manera a quien presenta la demanda, dejando más bien el análisis en la apreciación discresional del órgano judicial interviniente.

La discusión respecto a qué se entiende por "representación adecuada" es ajena al objeto del presente estudio, sin perjuicio de que el concepto es relevante en el marco de los procesos de tutela individual homogénea.

Según Gozaíni (2018),

Cada cual tiene una mirada distinta. Algunos quieren proteger los derechos sin mirar quién los representa; otros abren la puerta cuando la "clase" que se presenta tiene un portavoz adecuado; también están los que piden condiciones institucionales de organización y respaldo para actuar en un proceso colectivo, y obran asimismo en este cuadro, superficial y ejemplificativo, los que usan criterios espejados con la representación convencional en los que la protección se dispensa siempre y cuando el representado haya acordado al representante una expresa voluntad de delegación. (pp. 683-684) 92 $^{92}$

Quizás por su similitud terminológica y utilización que suele recibir, conviene hacer un breve repaso sobre el concepto de "representación procesal". Afirma Alvarado Velloso (2009) que

el representante debe acreditar cabalmente su calidad de tal a fin de que el proceso pueda desarrollarse con el objeto de lograr la eficaz heterocomposición del litigio. Si esto no ocurre, la parte contraria puede exigir la vigencia del requisito de marras mediante la excepción de falta de personería y, aún más, debe ser suplible de oficio por el juez (o el árbitro) en razón de que si no se comprueba adecuadamente la representación cuya existencia se afirma, la sentencia que se dicte como culminación del proceso será inútil pues no resultará vinculante para la parte procesal cuya representación no se acreditó. (pp. 581-582)

Si en lugar de un supuesto de legitimación extraordinaria la tutela individual homogénea fuera ejercida mediante el instituto de la representación pro-

92 Esta figura es también analizada de manera exhaustiva en la obra de Gozaíni (2018, pp. 725 y 799 ). Al hablar de la importancia de este concepto, explica Salgado (2011, pp. 211-212) que: "Una vez superado el escalafón de la legitimación extraordinaria, y establecidos los sujetos que se encuentran 
cesal, la representación adecuada se acreditaría cumpliendo con lo dispuesto en los artículos 46 y 47 del CPCCN, que establecen

\begin{abstract}
Artículo 46.- La persona que se presente en juicio por un derecho que no sea propio, aunque le competa ejercerlo en virtud de una representación legal, deberá acompañar con su primer escrito los documentos que acrediten el carácter que inviste [...].
\end{abstract}

Artículo 47.- Los procuradores o apoderados acreditarán su personalidad desde la primera gestión que hagan en nombre de sus poderdantes, con la pertinente escritura de poder [...].

En consonancia con lo ya mencionado, las asociaciones civiles carecen de una representación legal otorgada de manera clara y precisa y, en los casos reseñados, tampoco cuentan con un poder extendido por los verdaderos titulares de los derechos litigiosos.

Ante lo expuesto, podría plantearse en estos supuestos de tutela individual homogénea la excepción prevista en el inciso 2 del artículo 347 del CPCCN, en el que se indica que "[s]ólo se admitirán como previas las siguientes excepciones: [...] 2) Falta de personería en el demandante, en el demandado o sus representantes, por carecer de capacidad civil para estar en juicio o de representación suficiente [...]."

Afirmar lo contrario implicaría admitir que una entidad sin representación

autorizados legalmente para poder estar en el proceso en nombre de la clase y obtener así la tutela de sus derechos [...], la representación adecuada viene a resolver un problema central: la situación de los miembros de la clase ausentes del litigio y el respeto de su garantía a un debido proceso.

Es decir, ¿cómo garantizaremos la inviolabilidad de los derechos de aquellas personas que, sin haber comparecido personalmente al litigio, podrán verse afectadas por la sentencia de mérito que se dicte en él?

El esquema de razonamiento para dar respuesta a esos interrogantes es el siguiente: debe controlarse que aquel que se designe como legitimado extraordinario, a efectos de instar una tutela colectiva, se encuentre en condiciones de defender o gestionar los intereses de todos los miembros ausentes de la clase, tal y como si aquéllos hubieran estado presentes en el litigio, o que su actuación permita afirmar que, de haber ejercido éstos -los ausentes- su defensa de modo personal, no podrían haberlo hecho de una menor manera que su representante.

De esa suerte, si ello ocurre, todos los integrantes de la clase, notificados o no, presentes o ausentes, podrán verse vinculados por la eficacia de la cosa juzgada de ese proceso. Por ello se ha dicho que legitimación y representación adecuada se encuentran en una relación simbiótica.

Se trata de un prerrequisito que debería ser exigido en resguardo del debido proceso en todo litigio colectivo, sin el cual se corre el riesgo de fracasar y recorrer el camino del proceso sin lograr utilidad ninguna a su término. Los elementos a evaluar son que el representante pueda ejercer una tutela vigorosa de los derechos de los miembros ausentes y que no existan intereses contrapuestos con los integrantes del grupo". 
suficiente ejerce la defensa de derechos que no le son propios. Incluso, cabría preguntarse si reconocerles esta participación a las asociaciones civiles contrariando la normativa procesal haría también extensiva las obligaciones y responsabilidades previstas entre los artículos $49^{93}$ y $52^{94}$ del CPCCN.

\section{Síntesis parcial}

Al finalizar esta segunda parte, pude comprobar que la Corte cuenta con atribuciones para el dictado de normas conferidas por la propia Constitución Nacional o por leyes dictadas por el Congreso, cuyo límite está dado por las materias concretas contempladas al otorgar dicha facultad y por los derechos de las partes procesales, que solo pueden ser regulados por una ley formal.

Asimismo, y a la luz de lo expresado en el párrafo anterior, arribo a la conclusión de que la CSJN se excede en el ejercicio de esas facultades reglamentarias e invade las que son propias y exclusivas del legislador, porque ha generado un nuevo cauce procesal que contraría o modifica el derecho positivo vigente. La consecuencia de esta transgresión normativa es que, al tiempo que vuelve operativa según pautas discresionales una legitimación extraordinaria en favor de las asociaciones civiles, restringe la posibilidad de quien procura la defensa de sus propios derechos.

Siendo coherentes con la legislación vigente expuesta, a lo sumo podría encuadrarse a la participación de las asociaciones civiles como una mera gestión procesal en los términos del artículo 48 del CPCCN, ${ }^{95}$ con las consecuentes limitaciones que dicho instituto procesal prevé.

En todo caso, queda una vez más en evidencia la inexorable necesidad de disposiciones legales claras y precisas para que una asociación civil impulse un

93 "Artículo 49.- Presentado el poder y admitida su personería, el apoderado asume todas las responsabilidades que las leyes le imponen y sus actos obligan al poderdante como si él personalmente los practicare".

94 "Artículo 52.- Sin perjuicio de la responsabilidad civil o criminal por el ejercicio del mandato, el mandatario deberá abonar a su poderdante las costas causadas por su exclusiva culpa o negligencia, cuando éstas fueran declaradas judicialmente. El juez podrá, de acuerdo con las circunstancias, establecer la responsabilidad solidaria del mandatario con el letrado patrocinante".

95 "Artículo 48.- Cuando deban realizarse actos procesales urgentes y existan hechos o circunstancias que impidan la actuación de la parte que ha de cumplirlos, podrá ser admitida la comparecencia en juicio de quien no tuviere representación conferida. Si dentro de los CUARENTA (40) días hábiles, contados desde la primera presentación del gestor, no fueren acompañados los instrumentos que acrediten la personalidad o la parte no ratificase la gestión, será nulo todo lo actuado por el gestor y éste deberá satisfacer el importe de las costas, sin perjuicio de su responsabilidad por el daño que hubiere producido [...]". 
proceso de tutela individual homogénea de manera respetuosa con el ordenamiento jurídico argentino.

\section{Conclusión}

En diferentes momentos a lo largo del presente estudio ha quedado en evidencia el perfil activista que la CSJN adoptó en el campo de los procesos colectivos, especialmente en los relativos a supuestos de tutela individual homogénea, al haberles otorgado legitimación extraordinaria a asociaciones civiles.

La propia Corte es quien reconoce la necesidad de la existencia de legislación formal que regule la materia analizada a lo largo de estas páginas. Ya en el considerando 12 de Halabi, la Corte lo expresó así

$[\mathrm{N}]_{\mathrm{o}}$ hay en nuestro derecho una ley que reglamente el ejercicio efectivo de las denominadas acciones de clase en el ámbito específico que es objeto de esta litis. Este aspecto resulta de gran importancia porque debe existir una ley que determine cuándo se da una pluralidad relevante de individuos que permita ejercer dichas acciones, cómo se define la clase homogénea, si la legitimación corresponde exclusivamente a un integrante de la clase o también a organismos públicos o asociaciones, cómo tramitan estos procesos, cuáles son los efectos expansivos de la sentencia a dictar y cómo se hacen efectivos.

Sin embargo, puedo afirmar que se desdice con sus actos intentando justificar el dictado de fallos y normas en contra de lo dispuesto por el ordenamiento jurídico argentino con una supuesta mora inconstitucional ${ }^{96}$ del legislador que no reglamenta, principalmente, al artículo 43 de la $\mathrm{CN}$ según cómo debería ser a la luz de la interpretación del alto tribunal.

Resulta de gran interés la opinión de Sagüés (2013) sobre este punto, quien, comentando Halabi, sostiene:

La Corte (voto mayoritario) señala que la acción de clase es un imperativo constitucional, y que el silencio legislativo al regularla importa inconstitucionalidad por omisión. Sin embargo, la lectura de las actas de la convención reformadora de 1994 no evidencia esa voluntad del constituyente, por lo que no existe una directriz constitucional clara a cumplir obligadamente por el legislador, requi-

96 CSJN, Halabi, considerando 12: "Frente a esa falta de regulación -la que, por lo demás, constituye una mora que el legislador debe solucionar cuanto antes sea posible, para facilitar el acceso a la justicia que la Ley Suprema ha instituido-, cabe señalar que la referida disposición constitucional es claramente operativa y es obligación de los jueces darle eficacia [...]". 
sito indispensable para que se perfile la referida inconstitucionalidad omisiva. (cap. XII, § 7.2)

Además de la supuesta operatividad de la mencionada cláusula constitucional, este "pequeño desliz" de arrogarse funciones legislativas también es justificado por la Corte debido a los importantes beneficios que teóricamente se obtendrían gracias a la tramitación de procesos colectivos.

Para los casos de tutela individual homogénea, la CSJN puso el foco en la inviabilidad económica de afrontar un proceso judicial en solitario por cada uno de los potenciales demandantes en este tipo de casos, por resultar, en muchas ocasiones, mayor el costo de la tramitación del expediente que el potencial beneficio en caso de obtener una sentencia favorable. Así lo expresó, entre otros, en el considerando 13 de Halabi al afirmar que "es exigible que el interés individual considerado aisladamente, no justifique la promoción de una demanda, con lo cual podría verse afectado el acceso a la justicia”.

La doctrina también ha realizado esfuerzos para avalar este camino procesal. Con una finalidad pedagógica, Salgado distingue en dos categorías los fundamentos ${ }^{97}$ del apoyo a la tutela individual homogénea en: 1) motivos de orden práctico y de ajuste del sistema procesal; e 2) implicancias políticas, sociales y económicas.

Dado el grado de avance del presente trabajo, para no introducir un nuevo elemento cuyo desarrollo implicaría un esfuerzo que me apartaría del eje central, solo haré mención a las referidas ventajas pragmáticas, sin desconocer que existen muchas otras.

Entre ellas podemos encontrar la economía de insumos materiales y humanos al condensar innumerables procesos en un solo expediente judicial, la posibilidad de llevar adelante reclamos de pequeña cuantía -impracticables en un sistema tradicional- y el consecuente desincentivo de realizar las prácticas antijurídicas masivas que motivarán a aquellos a litigar, la posibilidad de brindar herramientas al servicio de administración de justicia para evitar su colapso, entre otras. ${ }^{98}$

A pesar de los aparentes aspectos positivos enunciados, la conveniencia de estas ventajas no cambia el hecho de que nuestro andamiaje constitucional pre-

97 Cfr. Salgado (2011, pp. 8-23). Para comprender ventajas y riesgos posibles, se recomienda también la lectura de los trabajos de Cazaux (2019) y de Maqueda Fourcade (2018).

98 Además de Salgado (2011), sugiero la lectura sobre las ventajas del proceso colectivo en Verbic (2017, pp. 264-284). 
vé que la regulación de alcance general de los derechos sea dictada por los poderes legislativos nacional y provinciales, según corresponda, salvo los supuestos expresamente establecidos que habilitan a los poderes ejecutivos federal y locales a dictar normas de naturaleza semejante. Nuevamente, reitero que el proceso civil, como concreción del derecho de peticionar ante las autoridades, no debe ser regulado por cualquier ente gubernamental so pretexto de aparentes ventajas, sino únicamente por quienes están expresamente empoderados a tal fin.

Por ello, si bien son innumerables los beneficios hipotéticos que se plantean, lo cierto es que la Corte no se encuentra facultada para poder generar válidamente las normas procesales que regulen este tipo de cauce colectivo, por lo cual debería respetar el ejercicio de quienes sí poseen las atribuciones constitucionales necesarias para ello. ${ }^{99}$

En rigor de verdad, la Constitución Nacional solo le otorga a la CSJN atribuciones reglamentarias en torno a su funcionamiento interno, y las posibilidades en cuanto a la regulación de derechos solo están previstas de manera particular para las causas en las que interviene.

Sostiene Calvinho (2013):

a primer golpe de vista, el activismo judicial puede parecer atractivo si atendemos sólo a la meta -o sea, si asumimos una postura exclusivamente finalistapues sus resultados se obtienen merced a un intervencionismo judicial en el método. (p. 15)

Lo paradójico de este supuesto de activismo es que no se limita a una intervención en el proceso ejerciendo el rol que les corresponde a las partes, sino que ha desplazado los límites de sus avances de manera más feroz porque también se entromete en las atribuciones específicas del legislador.

A modo de crítica, afirma Jiménez (2010, p. 130) que "[e]l juez liberal y garantista se limita modestamente a pretender hacer efectivo el derecho positivo

99 Resulta muy interesante la opinión de Dalla Vía (2009) al comentar Halabi, quien afirma que: "No nos parece, en cambio, tan adecuado que un mecanismo procesal tan complejo en cuanto a su funcionamiento se haya adoptado por vía pretoriana, considerándola como una suerte de garantía implícita entre las formas de amparo colectivo. [...] El caso actual es distinto, ya que aquí la Corte crea un mecanismo procesal más que un derecho sustancial, aun cuando considera en los fundamentos de la sentencia que el amparo colectivo del art. $43 \mathrm{CN}$ contiene de modo implícito el mecanismo procesal adoptado. Nos parece que la situación se asemeja más al caso 'Sejean', de 1985, que a la de los casos 'Siri' (1957) y 'Kot' (1958). Efectivamente, en 'Sejean' la Corte creó el divorcio vincular, a pesar de que la Ley de Divorcios vigente solamente autorizaba la separación personal de los cónyuges”. 
entre los ciudadanos, a aplicar la ley" valiéndose de los elementos aportados por las partes procesales.

En este estudio he podido vislumbrar un activismo que va mucho más allá de los supuestos por los que, como afirma Alvarado Velloso (2010, p. 1212), "se elimina la idea de proceso como método de discusión y se lo utiliza como medio de investigación”.

He aquí, probablemente, la mencionada corriente procesal en su estado más puro, por la cual el Poder Judicial, más allá de la intensidad con la que interviene en el marco del proceso, no solo se aparta de las disposiciones legales vigentes, sino que también las reemplaza por otras de creación propia. En otras palabras, no contentos con limitarse a la "modesta" tarea de aplicar la ley entre las partes, no aplica normas imperantes, las deroga y/o crea otras nuevas.

La mera excusa de alcanzar supuestos beneficios no habilita una intromisión ilegítima, que quiebra con las disposiciones constitucionales que prevén la necesidad de leyes formales para la regulación del proceso judicial. Admitir lo contrario es permitir un desplazamiento inválido de los límites de la división de poderes, lo cual afecta principios republicanos básicos que resguardan los mecanismos previstos para la salvaguarda de garantías fundamentales. Como bien recuerda Gelli (2018a, p. 33), "[e]n el sistema de la república democrática, la separación de poderes fue dispuesta para controlar el poder, posibilitar la libertad y garantizar los derechos de las personas".

Existen innumerables ejemplos de derecho comparado y legislación provincial vigente que dan muestras de que los procesos de tutela individual homogénea pertenecen al ámbito de las atribuciones de los poderes legislativos. ${ }^{100}$

La propia Corte, desde Halabi, recuerda esas experiencias normativas comparadas entre los incisos 17 y 18 del fallo. Respecto a los ejemplos de jurisdicciones locales, según explica Salgado (2011)

\begin{abstract}
Algunos Estados provinciales han regulado mecanismos de tutela colectiva, entre los cuales se destacan los derechos individuales homogéneos. El común denominador, aun cuando existan esfuerzos más meritorios que otros, es que resultan incompletos o internamente discordantes. [...] Un primer grupo de regulaciones, más avanzadas, son aquellas que específicamente se han ocupado de hablar de los derechos individuales homogéneos como una categoría de tener un mecanismo de tutela específico. [...] En una línea menos rigurosa, encontramos regulaciones provinciales que se han ocupado de regular procesos colectivos orientados a la defensa de los derechos de los consumidores o usuarios -sin
\end{abstract}

100 Sobre la experiencia internacional, se recomiendan las siguientes lecturas: Bianchi (2001; 2002, pp. 93-130); González Campaña (2018, p. 38); Lorenzetti (2017, pp. 107-118); Salgado (2019); Verbic 
especificar la divisibilidad o indivisibilidad de su objeto- que, según cuál sea la interpretación que de ellos hagan los operadores, podrían permitir la tramitación de pretensiones individuales homogéneas". (pp. 240-241) 101

Los representantes del pueblo que se dan cita en el Congreso de la Nación no han logrado todavía encontrar una fórmula que pueda hacer realidad este nuevo camino jurisdiccional. Sin embargo, mientras que para algunos esta aparente carencia normativa resulta ser una omisión inconstitucional, para los que creemos en la forma republicana de gobierno es, sin más, el libre juego de la división de poderes en un Estado democrático que no puede ser soslayado por la judicatura.

Quienes sostienen las banderas del activismo judicial, quizás con intenciones loables mal encauzadas, ven solo un formalismo inútil en quienes velan por la división de poderes. Quizás convenga reflexionar en torno a lo afirmado por Calvinho (2012), quien sostiene

Una democracia evolucionada, abonada con el aporte del constitucionalismo moderno, la división de funciones del poder y su intercontrol -pilares del republicanismo-, el sometimiento del poder a la ley -que surge del Estado de derecho- y la preocupación social por fortalecer sus instituciones, brinda una plataforma que coadyuva a la realización plena del ser humano. (p. 69)

Así, defender una operatividad automática del artículo 43 de la $\mathrm{CN}$, sin legislación proveniente de las autoridades envestidas constitucionalmente y dejando en manos de la discrecionalidad judicial los derechos de las partes en un litigio, equivale a no respetar el proceso como garantía inherente al ser humano, lo cual lesiona derechos como el de peticionar ante las autoridades, el de acceso a la justicia y el de defensa en juicio. ${ }^{102}$

Sin lugar a dudas, vale la pena una discusión legislativa seria para procurar un sistema de tutela individual homogénea.

Lo que es seguro, tal cual afirma Alvarado Velloso (2010), es que

(2017, pp. 239-263); entre otros.

101 En Giannini y Verbic (2017, pp. 123-888) se analiza la situación de la Ciudad Autónoma de Buenos Aires y de 18 provincias en cuanto al grado de desarrollo de supuestos de justicia colectiva. En caso de proceder a su lectura, debe tenerse en cuenta que para la provincia del Chaco correspondería una actualización a la descripción allí realizada porque su Legislatura aprobó la Ley 3325-B de Juicios Civiles y Comerciales por Jurados, BO 03/02/2021, que, entre otros, regula diversos supuestos de procesos colectivos. Lo propio sucede en la Ciudad Autónoma de Buenos Aires, que aprobó la Ley 6407 del Código Procesal para la Justicia en las Relaciones de Consumo en el ámbito de la Ciudad Autónoma de Buenos Aires, BO 19/03/2021.

102 Cfr. Calvinho (2013, p. 17). 
los jueces no pueden aspirar a equipararse a los comisarios de policía -por buenos y justicieros que éstos pudieren ser- en aras de lograr una eficiencia que no encuentran respetando la Constitución. No es eso lo que precisamente juraron cuando fueron investidos de sus cargos. (p. 1212)

A ellos, y a todos los que deseen aproximarse al mundo de la justicia colectiva, vale la pena recordarles, con palabras del mismo autor, "que el proceso es garantía de los derechos individuales y, en especial, del de la libertad que, aun cuando implícito, es el máximo valor de la norma fundamental" (Alvarado Velloso, 2010, p. 1212).

\section{Bibliografía}

Alvarado Velloso, A. (2009). Sistema procesal. Garantía de libertad (Tomo I). Rubinzal- Culzoni. Alvarado Velloso, A. (2010). El garantismo procesal. La Ley, 2010-F, 1212.

Azar-Baud, M. J. (25 de abril de 2016). El arte de evitar el escándalo jurídico. La Ley, 3.

Bianchi, A. B. (2001). Las acciones de clase. Una solución a los problemas procesales de la legitimación colectiva a gran escala. Ábaco.

Bianchi, A. B. (2002). Control de constitucionalidad. (2a ed., Tomo II). Ábaco.

Briseño Sierra, H. (1966). Excepciones Procesales. Revista de la Facultad de México, XVI(63-64), 255-351.

Calvinho, G. (2012). El proceso con derechos humanos. Método de debate y garantía frente al poder. Universidad del Rosario.

Calvinho, G. (2013). La procedimentalización posmoderna. Revista del Instituto Colombiano de Derecho Procesal, (39), 11-31.

Camps, C. E. (2019). El anteproyecto de Ley de Procesos Colectivos de Justicia 2020 frente a la eficacia. La Ley, RDAmb 57, 22/03/2019, 15, AR/DOC/3803/2018.

Catalano, M. (17 de junio de 2015). Los derechos colectivos en el título preliminar del nuevo Código Civil y Comercial de la Nación. La Ley, 49, AR/DOC/4701/2015.

Catalano, M. (2018). El anteproyecto de ley de procesos colectivos. Justicia 2020. La Ley, 2018C, 1244, AR/DOC/1335/2018.

Cazaux, D. H. (2019). Análisis económico de los procesos colectivos en la Argentina. La Ley, SJA 22/05/2019, AR/DOC/3878/2018.

Couture, E. J. (2010 [1948]). Obras (5ª ed., Tomo II). Estudios de Derecho Procesal Civil (Vol. 1). La Constitución y el Proceso Civil. La Ley.

Couture, E. J. (2010 [1950]). Obras (5a ed., Tomo II). Estudios de Derecho Procesal Civil (Vol. 3). El juez, las partes y el proceso. La Ley.

Dalla Vía, A. R. (2009). El activismo de la Corte Suprema puesto en defensa de la privacidad. Jurisprudencia Argentina, 2009-II, 509, 0003/014388. 
Dirección de Servicios Legislativos del Honorable Congreso de la Nación. (2019). Dossier legislativo. Derechos de incidencia colectiva, VII (167).

Gelli, M. A. (2018a). Constitución de la Nación Argentina. Comentada y concordada (5a ed., Tomo I). Thomson Reuters La Ley.

Gelli, M. A. (2018b). Constitución de la Nación Argentina. Comentada y concordada (5ª ed., Tomo II). Thomson Reuters La Ley.

Giannini, L. J. (2018). Análisis crítico del Anteproyecto de Ley de Procesos Colectivos del Ministerio de Justicia de la Nación. La Ley, 2018-D, 526, AR/DOC/1425/2018.

Giannini, L. J. y Verbic, F. (Dirs.). (2017). Los procesos colectivos y acciones de clase en el derecho público argentino. Rubinzal-Culzoni.

González Campaña, G. (7 de febrero de 2018). Las acciones de clase en Estados Unidos y los procesos colectivos de Argentina: dos modelos antagónicos. La Ley, 38, AR/DOC/4370/2017.

Gozaíni, O. A. (2018). Legitimación, capacidad y representación en juicio. Problemas de articulación del Código Civil y Comercial de la Nación con los Códigos Procesales en lo Civil y Comercial. Rubinzal-Culzoni.

Halabi, E. y Díaz Cisneros, A. P. (12 de junio de 2019). Diez años del fallo "Halabi”. Diez años de acciones de clase. La Ley, 3, AR/DOC/1263/2019.

Jiménez, M. E. (2010). Poderes instructorios del juez. Medidas para mejor proveer. Activismo judicial versus garantismo. Nuevas tendencias y recaudos. CSJN. LLC, 130.

Lorenzetti, R. L. (2010). Justicia colectiva. Rubinzal-Culzoni.

Lorenzetti, R. L. (Dir. gral.). (2014). Código Civil y Comercial Explicado. Doctrina - Jurisprudencia. Título preliminar. Rubinzal-Culzoni.

Lorenzetti, R. L. (2017). Justicia colectiva (2a ed.). Rubinzal-Culzoni.

Maqueda Fourcade, S. (2018). Economía de los procesos colectivos. El sistema de procesos colectivos como solución estatal a las "fallas" del mercado de procesos individuales. La Ley, 2018-B, 1051, AR/DOC/733/2018.

Montero Aroca, J., Gómez Colomer, J. L. y Montón Redondo, A. (2001). El nuevo proceso civil, Ley 1/2000. Tirant Lo Blanch.

Morello, A. M., Sosa, G. L. y Berizonce, R. O. (2015). Códigos Procesales en lo Civil y Comercial de la Provincia de Buenos Aires y de la Nación (4a ed., Tomo V). Abeledo Perrot.

Palacio, L. E. (2017). Derecho Procesal Civil (4a ed.). Abeledo Perrot.

Picasso, S. y Vázquez, R. A. (Dirs.) (2013). Ley de Defensa del Consumidor comentada y anotada (Tomo I Parte General). La Ley.

Rodríguez Mancini, J. (2016). Derechos de incidencia colectiva (según el art. 14 del Anteproyecto de CCC) y relaciones laborales. La Ley, 227, AR/DOC/352/2016.

Sacristán, E. (2020). La Corte Suprema como titular de poder reglamentario. Revista Jurídica Austral, 1(2), 499-530. https://doi.org/10.26422/RJA.2020.0102.sac.

Sagüés, N. P. (2009). La creación judicial del "amparo-acción de clase" como proceso constitucional. Jurisprudencia Argentina, 2009-II-627, 0003/014385.

Sagüés, N. P. (12 de septiembre de 2018). El trámite del amparo colectivo nacional y los roles nomogenéticos de la Corte Suprema. Jurisprudencia Argentina, 80, AR/DOC/3413/2018, pto. IV Sagüés, N. P. y Sagüés, M. S. (2013). Dinámica actual del derecho procesal constitucional. En Vigo, R. L. y Gattinoni de Mujía, M. (Dirs.), Tratado de Derecho Judicial (Tomo I Teoría General), Abeledo Perrot. 
Salgado, J. M. (2011). Tutela individual homogénea. Astrea.

Salgado, J. M. (25 de abril de 2016). La Corte legisla sobre los procesos colectivos. La Ley, 4.

Salgado, J. M. (2019). Conflicto masivo y proceso (Ponencia general). Congreso Nacional de Derecho Procesal, San Juan, Argentina.

Tobías, J. W. (2018). Tratado de Derecho Civil. Parte General. La Ley.

Verbic, F. (2017). Manual de introducción a los procesos colectivos y las acciones de clase. En Fandiño, M. y González, L. (Dirs.), Diálogo multidisciplinario sobre la nueva Justicia Civil en Latinoamérica (pp. 219-379). Centro de Estudios de Justicia de las Américas.

Verbic, F. (2018). El anteproyecto de Ley de Procesos Colectivos impulsado por el Ministerio de Justicia. La Ley, 2018-C, 1236, AR/DOC/1336/2018.

Verbic, F. y Sucunza, M. A. (18 de mayo de 2016). Postulación de pretensiones colectivas a la luz de la reciente acordada de la Corte Suprema. La Ley, 1, AR/DOC/1275/2016.

Ylarri, J. S. (2014). La legitimación de las asociaciones de consumidores y usuarios en las acciones de clase: el precedente PADEC. Revista de Derecho Administrativo, 2014-92, 355-363, AR/DOC/4899/2014.

\section{Legislación citada}

\section{Normas nacionales}

Decreto 1798/1994, reglamentario de la Ley 24240, BO 18/10/1994.

Ley 17454 de Código Procesal Civil y Comercial de la Nación, BO 07/11/1967.

Ley 23551 de Asociaciones Sindicales, BO 22/04/1988.

Ley 26122 de régimen legal de los decretos de necesidad y urgencia, de delegación legislativa y de promulgación parcial de leyes, $\mathrm{BO}$ 28/07/2006.

Ley 26994 de Código Civil y Comercial de la Nación, BO 08/10/2014.

Resolución del Ministerio de Justicia y Derechos Humanos de la Nación 2017-1026-APN-MJ de Creación de la Comisión Redactora del Anteproyecto de Ley de Procesos Colectivos, BO 22/12/2017.

\section{Normas provinciales}

\section{Ciudad Autónoma de Buenos Aires}

Ley 6407 del Código Procesal para la Justicia en las Relaciones de Consumo en el ámbito de la Ciudad Autónoma de Buenos Aires, BO 19/03/2021.

\section{Provincia del Chacho}

Ley 3325-B de Juicios Civiles y Comerciales por Jurados, BO 03/02/2021, que, entre otros, regula diversos supuestos de procesos colectivos. 


\section{Jurisprudencia citada}

\section{Corte Interamericana de Derechos Humanos}

Opinión Consultiva OC-6/86. La expresión 'leyes' en el artículo 30 de la Convención Americana sobre Derechos Humanos. Solicitada por el Gobierno de la República Oriental del Uruguay, 09/05/1986, Serie A, $\mathrm{N}^{\circ} 6$.

Pollo Rivera y otros vs. Perú, (fondo, reparaciones y costas), 21/10/2016, Serie C, Nº 319.

\section{Corte Suprema de Justicia de la Nación}

Acordada 12/2016, 05/04/2016, AR/LCON/75EC.

Acordada 32/2014, 1/10/2014, AR/LCON/6CE4.

Asociación Civil DEFEINDER c/Telefónica de Argentina S.A. s/proceso de conocimiento, 27/11/2014, Nro. Interno: A.803. XLVI.

Asociación Sepa Defenderse c/Secretaría de Energía de la Nación y otros s/amparo colectivo, 26/12/2018, La Ley, AR/JUR/79291/2018.

Centro de Estudios para la Promoción de la Igualdad y la Solidaridad y otros c/Ministerio de Energía y Minería s/amparo colectivo, 18/6/2016, Nro. Interno: FLP 8399/2016/CS1, Id SAIJ: FA16000098.

Halabi, Ernesto c/Poder Ejecutivo Nacional - ley 25.873 - dto. 1563/04 s/amparo ley 16.986, 24/02/2009, Fallos: 332:111, Nro. Interno: H.270. XLII.

Kersich, Juan Gabriel y otros c/Aguas Bonaerenses S.A. y otros s/amparo, 02/12/2014, Nro. Interno: CSJ 42/2013 (49-K).

Kot, Samuel S.R.L. s/recurso de hábeas corpus, 05/09/1958, Fallos: 241:291

Mendoza, Beatriz Silvia y otros c/Estado Nacional y otros s/daños y perjuicios (daños derivados de la contaminación ambiental del Río Matanza - Riachuelo), 20/06/2006, Fallos: 329:2316.

Municipalidad de Berazategui c/Cablevisión S. A. s/amparo, 23/09/2014, Nro. Interno: M. 1145. XLIX., Id SAIJ: FA14000143.

PADEC c/Swiss Medical S.A. s nulidad de cláusulas contractuales, 21/08/2013, Nro. Interno: P.361. XLIII, Id SAIJ: FA13000127.

Sindicato Único de Trabajadores Privados de la Libertad Ambulatoria c/Estado Nacional - Ministerio de Justicia y Derechos Humanos de la Nación y otros s/amparo, 10/11/2015, Nro. Interno: CSJ $841 / 2013$ (49-S) /CS1.

Siri, Ángel s/interpone recurso de hábeas corpus, 27/12/1957, Fallos: 239:461. 



\title{
LA DISCRIMINACIÓN POR RAZONES GREMIALES COMO DIFERENCIA FUNCIONAL Y SU IMPACTO EN EL SISTEMA JURÍDICO SINDICAL ARGENTINO
}

\section{Leonardo J. Ambesi}

\author{
Departamento de Derecho del Trabajo, Facultad de Derecho, Universidad Austral \\ lambesi@austral.edu.ar
}

Recibido: 07/09/2021

Aceptado: 10/11/2021

\section{Resumen}

La Ley 23592 sanciona con la nulidad, entre otros supuestos, los actos discriminatorios realizados por motivos de opinión gremial. A partir de su consolidación jurisprudencial, se ha interpretado con carácter amplio el alcance de esta norma, incluyendo las distintas manifestaciones de la actividad sindical así como los diferentes sujetos que las llevan a cabo.

En la práctica, ello ha significado la prevalencia del ordenamiento antidiscriminatorio por sobre el de la Ley 23551 de Asociaciones Sindicales, elaborándose un sistema particular que impone una vía procesal y pautas probatorias propias que, en caso de despido, derivan en la reinstalación del afectado a su puesto de trabajo. Como resultado de esta tendencia, en el máximo nivel judicial se ha intentado deslindar los campos de aplicación de ambas normas, así como la defensa que el empleador puede oponer en cada caso, sin que al momento se haya alcanzado este objetivo en plenitud.

En el marco antes citado, el presente trabajo pretende analizar el problema con apoyo en las nociones básicas de la teoría de los sistemas complejos de Luhmann, a fin de poner en evidencia la naturaleza funcional de un asunto, que ha derivado, a través de sucesivas diferenciaciones, en la creación de un régimen autónomo de protección contra la discriminación sindical en su sentido más amplio.

Palabras clave: sistema, discriminación, opinión, actividad, sindical, función. 


\title{
Discrimination Based on Union Activity as a Functional Difference and its Impact on the Argentine Union Legal System
}

\begin{abstract}
Law 23592 nullifies discriminatory acts based on reasons of union support or opinion. Since its jurisprudential consolidation, the scope of this rule has been interpreted broadly, including extensive manifestations of union activity as well as the different participants that carry them out. In the practice, this results in the prevalence of the Anti-discrimination Law 23592 over the Trade Union Law 23551, developing a peculiar system with its own procedure and rules of evidence that, in the event of dismissal, may lead to the reinstatement of the affected person into the workplace.

As result of this court trend, there have been attempts at the highest judicial level to establish the boundaries of both rules, as well as the defenses that the employer can oppose in each case, purpose that at the moment hasn't been fully achieved.

The present work attempts to analyze the problem with the support of the basic notions of Luhmann's theory of complex systems, in order to highlight the functional nature of the issue, which has derived in the creation of an autonomous system of protection against union discrimination in its broadest sense.
\end{abstract}

Key words: system, discrimination, opinion, activity, union, function.

\section{Introducción}

Hace una década, la Corte Suprema de Justicia de la Nación determinó la plena vigencia de la Ley 23592 antidiscriminatoria en el ámbito de las relaciones laborales. La confirmación de la tendencia jurisprudencial favorable que se había desarrollado en este sentido consolidó la existencia de reclamos en los que la alegación de un obrar discriminatorio por razones sindicales, esencialmente en casos de despido, tiene allí su argumento principal o concurrente. Esta particularidad contiene un doble componente: el primero, de raíz subjetiva, al ser invocada por quienes -debido a variadas circunstancias- no se encuentran expresamente tutelados por la Ley 23551 de asociaciones sindicales; el segundo, de índole objetiva, al recurrirse a la noción de "opinión gremial" contenida en la norma citada al inicio, que se ha expandido hasta comprender distintas situaciones de actividad sindical.

Dicha proyección de la Ley 23592 ha dado lugar a múltiples debates. Desde los efectos retroactivos que derivan de la calificación de nulidad atribuida a la conducta discriminatoria, con el lógico regreso a la situación anterior (para el despido, ello implica, como principio, la reinstalación del trabajador), pasando por el motivo imputado (aquí la opinión o actividad de naturaleza gremial), 
siguiendo por la exigencia que se le requiere al pretensor para acreditar la existencia de su actividad y el alcance del acto censurado (indicios verosímiles) hasta llegar al modo de asignar y apreciar la prueba que pueden producir las partes (carga probatoria).

Junto a estas temáticas, sin embargo, aparece otra que no ha recibido idéntica difusión, como es de la funcionalidad que presenta el citado conglomerado jurídico-jurisprudencial, que ha provocado, entre otras consecuencias, la pérdida de protagonismo en el tema de la Ley 23551, que en varias de estas controversias ha quedado subordinada como simple vehículo procesal de la norma anterior.

Para destacar la importancia que posee esta situación, se ha estimado conveniente apelar a la metodología descriptiva desarrollada por Niklas Luhmann respecto a los sistemas complejos, especialmente los jurídicos. La adopción de algunas de las herramientas conceptuales planteadas por Luhmann permite una mejor comprensión de las dificultades internas que se evidencian en un sistema concreto ante el despliegue de otro que ofrece un mayor nivel de efectividad frente a las aspiraciones de los involucrados.

Como paso previo a transitar el recorrido jurisprudencial que ha seguido el proceso en estudio, el camino propuesto obliga a detenerse en una teoría que, irónicamente, hace de la diferencia su nudo central, la cual se utilizará aquí para comprender el ascenso de un sistema jurídico que justamente sanciona la distinción peyorativa, asumiéndola como discriminación.

Corresponde efectuarle al lector dos advertencias antes de emprender esta marcha. En la primera de ellas se advierte que no se trata aquí de asumir una determinada postura antropológica del pensamiento luhmanniano (la que ha merecido serías y fundadas críticas), tampoco aceptar sin reservas todas sus conclusiones vinculadas al sistema jurídico (que también ha tenido sus objeciones, algunas de las cuales se mencionarán a lo largo de este trabajo), sino de emplear algunos de sus lineamientos básicos para describir lo sucedido con ambos sistemas jurídicos. ${ }^{1}$ En segundo lugar, se previene que, salvo en lo inevitable, las referencias constitucionales y/o de otros niveles normativos serán mínimas. En esta aproximación, lo que importa es la funcionalidad sistémica y cómo, desde ella, se pueden alumbrar los fenómenos jurídicos en juego. Se apartan, sin des-

1 Sobre las críticas a este aspecto, ver Miranda Rebeco (2012). Sin embargo, para contradecir esta atribución al pensamiento del autor, podemos citar sus clases sobre el amor; ver Luhmann (2012). A juicio de este humilde lector, a pesar de estar en clave sistémica, su ocupación del tema ya lo redime de su potencial ahumanidad. 
merecerlos por cierto, otros acercamientos a la cuestión planteada, sea desde el derecho constitucional, el derecho internacional de los derechos humanos, la perspectiva hermenéutica o la teoría de la decisión, por citar algunos de ellos. Aquí interesa observar el diseño de cada conjunto normativo en el tema propuesto, para luego detenerse en el proceso de expansión indicado al inicio.

\section{Los sistemas sociales y jurídicos complejos}

A la hora de ingresar en las concepciones de Luhmann sobre los sistemas hay que recordar que, para el citado autor, el carácter complejo de la sociedad moderna proviene de haber superado los parámetros anteriores de la organización jerárquica y de la circulación centro/periferia para sustentarse en la denominada "diferenciación funcional" que, a su criterio, es lo que tiene primacía (Luhmann, 2007b, pp. 118 y 763). El constructivismo se manifiesta en este pensamiento, por ello, se le otorga significación al concepto "función", alejado de la idea de "sustancia", y más bien asentado en el terreno de la "capacidad" para ordenar posibilidades, algo que ya realiza el ser humano como sistema individual (Luhmann, 2010, pp. 147-149).

Esta apelación a la función como aptitud ordenativa se revela en el conocido paradigma sobre el que se elaboró esta teoría, conformado por la diferencia entre "sistema" y "entorno". En sus palabras, "los sistemas se constituyen y se mantienen mediante la creación y la conservación de la diferencia con el entorno, y utilizan sus límites para regular dicha diferencia” (Luhmann, 1998b, p. 40).

La mentada frontera, de carácter externo, no impide la existencia de relaciones entre dichos contextos; por el contrario, entre ambos se desarrolla un proceso de intercambio de comunicaciones que varía en cada caso. Lo destacable es que el sistema social no mantiene una relación jerárquica con el entorno. Una vez recibida la comunicación, es procesada en su interior de manera independiente. En esto, los sistemas se autoorganizan, crean sus propias estructuras de conexión; son autónomos y, a la vez, autopoiéticos, es decir, producen las operaciones que son necesarias para producir más operaciones, sirviéndose para ello de su propia red (Luhmann, 2007a, p. 118). ${ }^{2}$

La autonomía supone la existencia de un sistema operativamente cerrado.

2 Es conocida la influencia en el tema de la autopoiesis de Maturana y Varela, aunque Luhmann y el primero de los autores aludidos no dejaron de señalar sus discrepancias en el empleo de la acepción. Ver al respecto Nafarrate (2009). 
No resulta posible para Luhmann la noción de una autonomía relativa: los sistemas producen sus propios procedimientos, operaciones y estructuras bajo un determinado código que los define. En general, esta codificación es única y alude a un par binario de valores contrapuestos (para el sistema jurídico, "conforme a derecho/no conforme a derecho"), aunque en algunos casos (como la política o la economía) ha admitido la presencia de medios primarios y secundarios, al entenderlos como resultado de la evolución social (Baxter, 2013).

Ahora bien, así como se manifiesta el sistema hacia el exterior mediante su diferencia con el entorno, en su aspecto interno se observa también la aparición de diferenciaciones, que replican en el interior aquella distinción primera, provocando un aumento de la complejidad del sistema, pero permitiendo al mismo tiempo nuevas formas de reducción de esa misma complejidad. Cada unidad efectúa selecciones de posibilidades a su nivel y repite en sí misma la formación del sistema global; en palabras de Luhmann (1998b), "multiplica su propia realidad” (p. 184). La construcción de la diferencia se encuentra ligada a la de la identidad: desde su distinción con el entorno, un observador puede visualizar los rasgos que confieren al sistema su unidad como tal, pero ello es algo que el propio sistema también percibe y sobre lo cual reflexiona para sí (Corsi et al., 2006, pp. 118-121). ${ }^{3}$

La reducción de la complejidad es otro de los temas fundamentales. En las sociedades modernas, los sistemas sociales se ocupan de gestionar esa tarea mediante la faena de reducir lo complejo creando algo más complejo. Luhmann, maestro de paradojas, pone de relieve en este esquema uno de los dilemas que deben resolver los sistemas: el que designa como "doble contingencia", es decir, "aquello que puede ser como es (fue, será), pero puede ser de otro modo. El concepto designa, por lo tanto, lo dado (experimentado, esperado, pensado, imaginado) a la luz de un posible estado diferente" (Luhmann, 1998b, pp. 115116). Para superar la doble contingencia, hay que trabajar en términos de expectativas -favorables y/o desfavorables-, de riesgos y, sobre todo, de selecciones, articuladas por los sistemas como mecanismo de gestión de la incertidumbre.

En el derecho, la doble contingencia obliga a pensar alternativas tanto a quienes comparecen en un litigio como a quienes deben resolverlo, porque la solución dentro de los distintos mecanismos internos del sistema admite la eventualidad de que exprese en uno u otro sentido. Esto no supone un proce-

3 No es casual que los autores -en particular Elena Esposito-, al relevar el vocablo, tomaran en cuenta la entrada del estudio sobre los sistemas sociales, realizado por Luhmann (1990), titulado "Identität - was oder wie" (p. 121). 
dimiento anárquico, sino más bien una red jurídicamente ordenada de otras posibilidades (Luhmann, 2019, p. 142).

Por eso, la doble contingencia remite al par "confianza/desconfianza" como factor de tolerancia a esa incertidumbre que se origina en las relaciones con el sistema. Este es un problema de reducción de complejidad y, para ello, el sistema "[...] sustituye la certeza externa por la certeza interna, y al hacerlo eleva la tolerancia de la incertidumbre en las relaciones externas" (Luhmann, 2005, p. 45).

Hasta ahora se han reseñado algunos conceptos elementales de la teoría convocada: "sistema y entorno", "diferenciación funcional", "complejidad", "doble contingencia” y "confianza”. El interrogante que sigue a esto es cómo reacciona un sistema determinado frente a un cambio en el entorno. La respuesta de Luhmann (1998b, pp. 173-176, 183) consiste en advertir que los cambios en el entorno provocan adaptaciones al sistema e implican cambios en el entorno de otros sistemas; al mismo tiempo, se abren nuevas formaciones de sistema, con renovadas diferencias y limitaciones. En estos movimientos, también hay lugar para la llamada "interpenetración", esto es, "[...] cuando ambos sistemas se posibilitan mutuamente aportar al otro su propia complejidad preconstituida" (p. 202).

La parte final (y no menos importante) de este segmento se dedica a completar lo dicho sobre la complejidad de los sistemas jurídicos complejos. Para el catedrático de Bielefeld, todos son conceptos que remiten a la reducción de complejidad por conducto de la doble contingencia. En este punto, el derecho deberá operar también en una paradoja ("conforme a derecho"/"no conforme a derecho") en la que la complejidad se reduce a partir de la programación de una fórmula (v.gr., la "justicia" u otra) que no necesita fundamentarse por sí misma y que se hace relevante para todas las decisiones que se adoptan al respecto (Luhmann, 2005, pp. 284-285).

Como se anticipó, el esfuerzo del sistema jurídico se concentra en gestionar las incertidumbres externas mediante el grado de confianza que genera desde la esfera interna. Por ello,

la estructura de un sistema puede aumentar la tolerancia a la incertidumbre por la manera en la que clasifica las certidumbres; es más, solo alcanzará una complejidad sistémica típicamente superior si prevé más certidumbres y, al mismo tiempo, más incertidumbres. De ahí que la certidumbre no pueda ser concebida solo como lo contrario de la incertidumbre, sino también como una incertidumbre estructurada. (Luhmann, 2019, p. 135) 
La descripción precedente, vinculada al cariz autopoiético del sistema jurídico, transmite otro interrogante: ¿qué sucede cuando el sistema ya no puede resolver los problemas que produce? La respuesta es contundente: estos "[...] tienen que ser transferidos al sistema que está mejor preparado y especializado para resolverlos" (Luhmann, 1998a, p. 93).

Ahora, con la asistencia de estos elementos conceptuales y metodológicos de nuestra "caja de herramientas", ha llegado el momento de avanzar en la consideración de lo sucedido en el tema planteado.

\section{La discriminación y el sistema de la ley de asociaciones sindicales}

En una rápida mirada, puede notarse que el modelo establecido en 1988 por la Ley 23551, tomado en su versión original, se asemeja bastante a las nociones de "sistema autónomo", "autorreferente" y "autopoiético" de Luhmann. Contiene un código binario principal, como es el de "libertad sindical/no libertad sindical”, en los términos en los que el propio sistema decide (ver su título preliminar, artículos 1 a 3), del cual se desprende un conjunto de subcódigos, operaciones, procedimientos y estructuras que, a partir de esa matriz, se despliegan para absorber las cargas de expectativas que allí depositan los interesados. Estos grados de confianza se administran a partir de sucesivas diferenciaciones internas. De esta manera, la Ley 23551 replica en su interior variadas diferenciaciones funcionales. Comienza por la más básica, "trabajador/afiliado", pasando luego a la de "afiliado/delegado" así como a la de "delegado/autoridad sindical”. En materia de representación, la dupla es bien evidente al asignarles determinados derechos a los sindicatos, según sean reconocidos como "más representativos" frente a aquellos que no lo son, denominando a los primeros "con personería gremial" y a los otros "inscriptos" (artículos 23, 25-28 y 31). Los trabajadores, volviendo a los primeros niveles distintivos, tienen en este ordenamiento un conjunto de derechos que se les reconoce por su condición de tales, entre los que se cuentan los de "reunirse y desarrollar actividades sindicales" y "peticionar ante las autoridades y empleadores" (artículo 4, inciso c).

La técnica no es ajena al derecho, y menos al derecho colectivo del trabajo, que bien puede verse como un producto de recurrentes desgajamientos desde las ramas jurídicas públicas y privadas, y particularmente desde el propio derecho individual laboral (Simon, 2012a, p. 4).

Es curioso, pero la impronta organicista de la ley, que remite prácticamente la totalidad de la vida gremial al sindicato, ha dejado en este artículo, junto a 
otras garantías (constituir libremente entidades, afiliarse, no afiliarse, desafiliarse, participar en la vida interna de las organizaciones) un espacio a la acción y a la expresión que no se encuentra mediado y, por lo tanto, resguarda la posibilidad del activismo.

¿Qué sucede con la discriminación? El sistema de la Ley 23551 contiene una norma relativa al tema, al establecer en su artículo 7:

Las asociaciones sindicales no podrán establecer diferencias por razones ideológicas, políticas, sociales, de credo, nacionalidad, raza o sexo, debiendo abstenerse de dar un trato discriminatorio a sus afiliados. Lo dispuesto regirá también respecto de la relación entre una asociación de grado superior y otra de grado inferior.

El dispositivo, además de su relevancia, posee una estructura que opera a distintos niveles; comprende las situaciones de tratamiento organización/individuo, por una parte, y, por otra, en forma convergente las de organización/ organización. Sin embargo, se observa una carencia evidente, como es la posible conducta y consecuente tutela que se tenga respecto a los trabajadores no afiliados. Por supuesto, tampoco se contemplan otras discriminaciones que se produzcan fuera del continente plasmado por la estructura sindical.

Una explicación del tema la encontramos en López (1998, p. 122), para quien la norma en cuestión funge como una derivación en clave de igualdad de la garantía constitucional de "organización sindical libre y democrática" del artículo 14 bis de la Constitución Nacional (CN), esto es, una inserción del principio de igualdad destinado a todo los habitantes del país dentro de la entidad gremial. ${ }^{4}$ Esta proyección no es exclusiva del régimen sindical, por cuanto también se predicaba similar fundamento para el sistema de la Ley 20744 de Contrato de Trabajo, que ya contenía expresas disposiciones que le prohibían al empleador la discriminación, entre otras causales por motivaciones gremiales, y le ordenaban la dispensa de un trato igualitario a los trabajadores (artículos 17 y 81; López et al., 1987, p. 227).

Más allá de lo expuesto, hay que recordar que la ley cuenta con un procedimiento, como es el del amparo sindical, que legitima a todo trabajador o asociación sindical que "[...] fuere impedido u obstaculizado en el ejercicio regular de los derechos de la libertad sindical garantizados por la presente ley [...]", para "[...] recabar el amparo de estos derechos ante el tribunal judicial competente

4 La versión actualizada por Julio C. Simon (2012, pp. 222-223) se mantiene sin cambios en este punto. 
[...] a fin de que éste disponga, si correspondiere, el cese inmediato del comportamiento antisindical" (artículo 47).

La textura del articulado refuerza, sin dudas, el sentido autopoiético que se viene afirmando. Los derechos comprometidos deben obedecer a un "ejercicio regular" y ser de la "libertad sindical" definida y comprendida por la ley. A su vez, el "cese inmediato" refiere a un detenimiento certero de una conducta u omisión que merezca ser calificada de "antisindical", lo cual permite contener en su interior los comportamientos discriminatorios por razones gremiales, cualquiera sea el sujeto que los lleve a cabo.

La doctrina contemporánea interpretó la presencia de esta vía específica de manera integrada y, lo que es más interesante para el presente análisis, desde una perspectiva sistémica. Así, para Rodríguez Mancini (1992)

\begin{abstract}
[...] entre la acción del artículo 47 y el resto de los dispositivos con los cuales se configura el sistema de organización sindical y de protección de los derechos de la libertad sindical se puede establecer la misma relación jurídico procesal que la que existe entre la acción de amparo [...] y las acciones comunes que son resueltas por las vías ordinarias ante los jueces competentes [...] porque es coherente con el sistema y la naturaleza de una acción de esta especie, a que no existan otros procedimientos propios para tramitar la cuestión. (p. 299)
\end{abstract}

Ahora bien, esta visión desde el "sistema" no le había impedido al citado autor reflejar, a poco tiempo de vigencia de la ley sindical, algunas de las cuestiones controvertidas que su contenido presentaba -a su criterio- desde el punto de vista constitucional. En dicha aproximación, Rodríguez Mancini acompañó su trabajo con un ejemplar de la presentación del informe realizado por Nicolás Valticos, enviado por la Organización Internacional del Trabajo (OIT) en mayo de 1984 a la República Argentina con motivo de la elaboración de una nueva ley en la materia. Si bien no se trató del texto que estamos analizando, no está de más señalar que uno de los tópicos en los que hizo hincapié el experto era el de asegurar "[...] una protección más eficaz contra los actos de discriminación antisindical a todos los trabajadores" (Rodríguez Mancini, 1988, p. 1217). El tema de la discriminación del trabajador en la afiliación, por otra parte, ya había sido considerado en la doctrina (Fernández Madrid, 1985).

Dichos antecedentes acreditan que la problemática referida al alcance del amparo sindical y su eventual conexión con las conductas discriminatorias ya tenía su tiempo y habitaba en lo que podríamos afirmar el "entorno" del sistema. Otra voz poderosa como la de Vázquez Vialard (1989), que toma la idea 
desarrollada por J. López (1987) sobre la extensión de la protección del despido arbitrario, reflexionó por esa época a partir de la potencial eficacia que tendría el amparo sindical como tutela sindical genérica. Apeló para ello a otro dispositivo del sistema jurídico sindical que sanciona como práctica desleal, imputable a los empleadores o a las asociaciones que los representen, la conducta tendiente a "practicar trato discriminatorio, cualquiera sea su forma, en razón del ejercicio de los derechos sindicales tutelados por este régimen" (artículo 53, inciso j). Según el jurista, dado que la ley les garantiza a los trabajadores reunirse y desarrollar actividades sindicales, ante una medida adoptada por el empleador para impedir el goce de tales derechos, se permitiría el inicio de una acción dirigida a que el juez disponga el cese de dichas obstrucciones, con base en este artículo; así, "el trabajador afectado [...] previa comprobación en juicio contencioso, tiene derecho a que el juez disponga el cese inmediato y la 'reinstalación' de las condiciones de trabajo anteriormente vigentes (statu quo ante)" (Vázquez Vialard, 1989, p. 11).

En suma, el diseño de la Ley 23551 de asociaciones sindicales, desde su versión original, contiene en su interior una serie de diferenciaciones funcionales producidas por su propio código de lo que entiende el sistema por "libertad sindical", que se replica de manera constante brindándole la identidad (y unidad) que necesita para continuar operando. Esta identidad hace que las dos acciones antes descriptas, amparo sindical y querella por práctica desleal, más que como procedimientos se erijan como validadores del propio sistema. En otras palabras, no puede haber legitimación activa para el amparo sindical por una eventual conducta discriminatoria que no sea como consecuencia del "ejercicio regular" de los derechos de libertad sindical protegidos por la ley, ni práctica desleal que no se vincule con la discriminación en el ejercicio de aquellos derechos sindicales que no sean los "tutelados por este régimen". La autoproducción luhmanniana se muestra así en todo su esplendor.

\section{La entrada en vigencia de la ley antidiscriminatoria en el ámbito laboral y sus consecuencias para la discriminación por motivos gremiales}

Desde la perspectiva del sistema cerrado, la valoración formulada respecto a la Ley 23592, destinada a sancionar comportamientos discriminatorios, no suscitó mayor controversia. Es probable que, al ser una norma coetánea de la ley sindical (se publicó en el Boletín Oficial el 05/09/1988, cinco meses después de la Ley 23551), haya sido considerada desde el inicio como un régimen dirigi- 
do específicamente a un conjunto de fenómenos poco observados en el sistema sindical. Su lenguaje parece confirmarlo:

Art. $1^{\circ}$.- Quien arbitrariamente impida, obstruya, restrinja o de algún modo menoscabe el pleno ejercicio sobre bases igualitarias de los derechos y garantías fundamentales reconocidos en la Constitución Nacional, será obligado, a pedido del damnificado, a dejar sin efecto el acto discriminatorio o cesar en su realización y a reparar el daño moral y material ocasionados.

A los efectos del presente artículo se considerarán particularmente los actos u omisiones discriminatorios determinados por motivos tales como raza, religión, nacionalidad, ideología, opinión política o gremial, sexo, posición económica, condición social o caracteres físicos.

Como puede observarse, se habla de "bases igualitarias", de "motivos" y, fundamentalmente, de "opinión" en clave política o sindical, un aspecto este último que se desgrana luego en el combate a los tópicos discriminatorios más universales. ${ }^{5}$

Finalmente, si bien la reforma constitucional de 1994 incorporó la figura del amparo (artículo 43), situó a nivel constitucional un conjunto de convenciones, pactos y tratados internacionales sobre derechos humanos, en los cuales se menciona el Convenio 87 de la OIT sobre Libertad Sindical, y fortaleció la idea tendiente a considerar a los demás convenios de esa organización como fuente supralegal (entre ellos, el Convenio 111 sobre la discriminación en el empleo y la ocupación, ratificado por Argentina mediante Ley 11677 de 1968), lo cual no aparentaba una amenaza concreta a los postulados congénitos de la Ley 23551. A modo de ejemplo, merece citarse una sentencia pionera de la Cámara Nacional de Apelaciones del Trabajo en esta época, en la que el elemento de "opinión" (de tipo política) fue excluyente para resolver la nulidad de un despido. ${ }^{6}$

La presión del "entorno", sin embargo, vendría con el giro neoconstitucional de la jurisprudencia.

5 Se contempla especialmente la elevación del máximo previsto en la escala penal cuando la actividad sea cometida por persecución u odio a una raza, religión o nacionalidad, con el objeto de destruir todo o parte de un grupo por tales razones, incluyendo un tipo penal para quienes participen de una organización o realicen propaganda de superioridad sobre tales aspectos, o incitaren a la persecución y al odio por causa de ello (artículos 2 y 3 ).

6 Cámara Nacional de Apelaciones del Trabajo, Sala X, 29/06/2001, Stafforini, Marcelo c/Estado Nacional. 
En la crítica que le formulan Van der Kerchove y Ost (1988) al paradigma de Luhmann se advierte, entre otras observaciones, el reproche dedicado a la pretensión de completa autonomía del sistema jurídico. En sus palabras, aun cuando los sistemas -bajo su propio control- posean la capacidad de modificar las informaciones que tratan e incluso sus reglas de funcionamiento, tal cualidad es parcial, en tanto ello supone un salto cualitativo hacia una mayor complejidad:

Dicho de otro modo, los únicos cambios que afectan a la organización misma -y no únicamente a los diferentes estados del sistema, que no son otra cosa que las fases de un programa constante- deben producirse desde el exterior del sistema. (Van der Kerchove y Ost, 1988, pp. 139-140)

Aquí, esa exterioridad tuvo como punto de partida la entrada del derecho del trabajo argentino en la corriente del neoconstitucionalismo, con el dictado por parte de la Corte Suprema de Justicia de la Nación de los precedentes Vizzoti y Aquino en el año 2004, que reivindicaron la primacía operativa de los principios constitucionales y asignaron la calificación del trabajador como sujeto de "preferente" o "especial" tutela constitucional (Ambesi, 2017). Cuatro años más tarde, cuando el alto tribunal emitió la sentencia Asociación Trabajadores del Estado (conocida también como ATE I), en la que declaró la inconstitucionalidad de los recaudos previstos en la Ley 23551 para la postulación y elección de delegados -restringida a los sindicatos con personería gremial-, el sistema jurídico sindical recibió la comunicación como una interpelación a su código cerrado. ${ }^{?}$

A casi veinte años del movimiento inicial, puede decirse que los citados pronunciamientos no fueron los únicos ni los más relevantes en la producción del cambio. Entiéndase bien: lo anterior no significa restarle importancia a la hora de presentarlos como hitos jurisprudenciales en la materia, lo que aquí interesa es verlos desde otro vértice, desde el cual los fallos operaron como inputs más allá de lo expresado en sus argumentos. En otras palabras, importa verlos en el desborde funcional que provocaron en el sistema de la Ley 23551.

Es evidente que la reacción al cambio del entorno no fue concordante con la velocidad impresa a la transformación encarada. Basta ver algunos de los fallos paradigmáticos dictados por la Cámara Nacional de Apelaciones del Trabajo en este período para comprobar que "opinión" y "acción" sindical se fundían

7 Se trata aquí de los Fallos: 327:3677 del 14/09/2004; 327:3753 del 21/09/2004; y 331:2499 del $11 / 11 / 2008$. 
en un solo movimiento comunicativo, impactando en la calificación del despido como discriminatorio. ${ }^{8}$

Dos años después del precedente ATE, la Corte Suprema de Justicia de la Nación emitió el fallo Álvarez c/Cencosud, en el que se estableció la aplicación de la Ley 23592 antidiscriminatoria a las relaciones laborales, validando por mayoría la reinstalación en su puesto de trabajo de quienes habían sido despedidos (en el caso intentaban formalizar la creación de una asociación sindical destinada a la defensa de sus intereses profesionales).

El voto mayoritario dice más por lo que omite del régimen sindical que por lo que afirma. Salvo la referencia al Pacto Federal del Trabajo, aprobado por la Ley 25212, que tipifica y sanciona las decisiones empleadoras que impliquen una discriminación -entre otros, por motivos gremiales-, no hay alusión más cercana a la ley de asociaciones sindicales. Se exhibe, eso sí, un amplio despliegue de instrumentos, jurisprudencia y opiniones calificados del derecho internacional, así como un correlativo detalle de fallos dictados por la Corte Suprema en materia de condiciones de trabajo, pero la sentencia no acude a ningún dispositivo de la Ley 23551, ni siquiera para completar la fundamentación. Esto es así porque se estaba consolidando la estructuración de un sistema basado en la gestión de expectativas generadas en torno a otro código binario: el del respeto al principio de igualdad. La definición se implanta de manera evidente en el considerando 11:

... nada hay de objetable a la aplicación en esta causa de la Ley 23592, que reglamenta directamente un principio constitucional de la magnitud del art. 16 de la Constitución Nacional.

La posición minoritaria, encarnada en la disidencia parcial efectuada por otros tres jueces del Colegiado, apunta al nudo de esta cuestión. En primer lugar, porque además de discrepar en cuanto a la reinstalación que supone la declaración de nulidad del despido discriminatorio, hace una referencia concreta a la ley sindical cuando se mencionan los supuestos en los cuales el ordenamiento legal ha clausurado temporalmente la posibilidad de la extinción del vínculo sin causa para los representantes gremiales (artículos 48/50 de la Ley

8 Cfr., entre otros, Cámara Nacional de Apelaciones del Trabajo, Sala VI, 20/03/2004, Balaguer, Catalina c/Pepsico de Argentina S.R.L.; Sala IX, 31/05/2005, Greppi, Laura c/Telefónica de Argentina S.A.; Sala V, 14/06/2006, Parra Vera, Máxima c/San Timoteo S.A. El Boletín Temático de Jurisprudencia de la Cámara Nacional de Apelaciones del Trabajo, publicado en el año 2012, da buena cuenta de las diferentes opiniones y evaluaciones formuladas en esa época. 
23551, ver considerando 14). En segundo término, porque destaca el propio rasgo funcional de la Ley 23592, al advertir en su considerando 16 que

... en razón de su carácter general y trasversal a todas las ramas del derecho, requiere de una aplicación apropiada que no distorsione el equilibrio de derechos al que responde cada sector del ordenamiento jurídico, sea público o privado.

Visto con los ojos de la actualidad, la turbulencia sistémica provocada por Álvarez aparece de similar o superior magnitud a la de otros fallos de la época. Con la entrada de la Ley 23592 a pleno en la órbita sindical, se inaugura un nuevo período sistémico de diferenciación funcional. El par que puede denominarse "trabajadores con actividad sindical no discriminados/trabajadores con actividad sindical discriminados", derivado de una norma que involucra otros supuestos en juego, ingresa en el ámbito gremial con sus propios códigos para forjar su estructura de reducción de complejidad y canalizar a través de él sus operaciones decisorias. Estas resoluciones, sin perjuicio de disponer el cese y/o nulidad del acto controvertido, pueden adicionar reparaciones por los daños ocasionados de acuerdo a lo previsto en el texto aplicado. La Corte Suprema se ocupó especialmente de advertir sobre el tratamiento que debía dársele al reclamo por daño moral (caso Bichi), como también de ratificar la vigencia de la reinstalación en el empleo provocada por la nulidad del despido discriminatorio (caso Cejas c/Fate).

La solución de un problema conduce a otro, y en esto queda en primer plano el vértice probatorio. La vinculación entre lo que se denuncia como conducta discriminatoria y lo que se acredita no deja de ser un requisito común a todo pleito. Hay que notar que la Corte Suprema revocó, al tiempo de sentar su doctrina en Álvarez y ante la falencia de esta conexión, una sentencia que había admitido la reinstalación de una trabajadora con base en el carácter discriminatorio del despido, señalando en la causa Pellejero que ni del fallo atacado ni de la demanda incoada se explicaban los hechos y circunstancias en los que se habrían puesto de relieve los extremos discriminatorios ni lo elementos arrimados al juicio que favorecían tal ponderación.

Pero el problema seguía abierto y llamaba a ser resuelto, por lo que el máximo tribunal fijó en el año 2011, a través del precedente Pellicori, las pautas procesales para los litigios de esta índole:

... resultará suficiente, para la parte que afirma dicho motivo, con la acreditación de hechos que, prima facie evaluados, resulten idóneos para inducir su 


\begin{abstract}
existencia, caso en el cual corresponderá al demandado a quien se reprocha la comisión del trato impugnado, la prueba de que éste tuvo como causa un motivo objetivo y razonable ajeno a toda discriminación. La evaluación de uno y otro extremo, naturalmente, es cometido propio de los jueces de la causa, a ser cumplido de conformidad con las reglas de la sana crítica [...] La doctrina del Tribunal, por ende, no supone la eximición de prueba a la parte que tilda de discriminatorio un actor pues, de ser esto controvertido, pesa sobre aquella la carga de acreditar los hechos de los que verosímilmente se siga la configuración el motivo debatido. Tampoco implica, de producirse esa convicción, una inversión de la carga probatoria ya que, ciertamente, en este supuesto, al demandado le corresponderá probar el hecho que justifique descartar el prima facie acreditado. (considerando $11^{\circ}$ )
\end{abstract}

Frente a este diagrama, la doctrina anticipó el próximo debate en torno a la discriminación, especialmente con relación a la profundidad de la actividad sindical. Como se pregunta Guibourg (2015), a los fines de habilitar la rotación de la carga probatoria

¿qué clase o intensidad de activismo sindical ha de considerarse suficiente? El representante y el candidato están amparados por la Ley 23551; al parecer, quien hace gestiones sindicales ante el empleador o promueve la constitución de un nuevo sindicato, está incluido en lo que pudiera llamarse 'vulnerabilidad discriminatoria' ¿Qué otras circunstancias implican esa vulnerabilidad? He aquí un continuo de intensidades en el que sería conveniente fijar un límite reconocible. (p. 489)

La nueva dificultad, entonces, radica en el reconocimiento por parte del juzgador de esa profundidad en la discriminación sindical; constituye el modo de arranque que lleva a poner en marcha la operación rotatoria antes indicada. La diferenciación interna del sistema aquí pasa a ser "intenso/no intenso". De allí la idea que sostiene E. Álvarez (2012) consistente en denominar a los indicios requeridos por el precedente Pellicori como "humo de discriminación", sosteniendo con ello que la Corte no se ha apartado de la "... estricta jurisdiccionalidad que presupone la corroboración judicial de la ilicitud” (p. 73).

Ambas reflexiones favorecen el presente estudio, en tanto reflejan otros aspectos del problema de funcionalidad que se postula y se ha encauzado por dotar preeminencia a la ley antidiscriminatoria como sistema idóneo frente al de la ley sindical, de cuyo sendero procesal se ha apropiado. Es que si la intensidad de la actividad gremial pasible de discriminación se reconoce a partir de la constatación de este fumus boni iuris específico, no resulta necesario transitar un 
proceso de pleno debate y prueba para resolver su protección. Sea que se trate de una acción de amparo general, del particular amparo sindical del artículo 47 de la Ley 23551 o de cualquier otro trámite tutelar expedito, el objetivo estaría cumplido.

Así es como ha sucedido muchas veces en la práctica. Ello revela que el sistema de la Ley 23592 montó su estructura y cooptó al mismo tiempo la vía breve contenida en el sistema de la Ley 23551. La interpenetración sistémica condujo a gestionar una expectativa creciente, como es la de resolver estas situaciones derivadas de la libertad sindical que excedieron hace tiempo la mera "opinión" del texto originario de la primera de las normas y el mero "cese" del comportamiento antisindical de la segunda de ellas. A base de sucesivas diferenciaciones funcionales, se ha pergeñado un nuevo sistema.

La hiperfuncionalidad de la Ley 23592 para gestionar los grados de confianza y expectativa en la resolución de controversias basadas en la discriminación sindical para aquellos sujetos no tutelados especialmente por la Ley 23551 puso de manifiesto la necesidad de avanzar en un deslinde de sistemas y mecanismos probatorios para evitar distorsiones, tanto en lo referido al tándem activo subjetivo/objetivo (a quién se protege y cuál es el comportamiento de resguardo) como en lo vinculado al destinatario pasivo de la pretensión, principalmente el empleador, dado que la consecuencia de la nulidad del despido discriminatorio trae consigo el restablecimiento de la condición anterior. La misma hiperfuncionalidad detectada llevó al alto tribunal a dejar sin efecto una medida cautelar de reinstalación con el fundamento de que anticipaba la solución de fondo (caso Laurenzo).

En este sentido, la Corte Suprema de Justicia de la Nación delineó un camino decisorio jurisdiccional con bifurcaciones dedicadas a habilitar y deshabilitar cada uno de los pasos hermenéuticos implicados en la discriminación y su particular subtipo sindical. Desde esta perspectiva, el precedente Varela c/Disco, del año 2018, puede ser considerado como un manual del usuario, elaborado con directrices para acoplar y desacoplar sistemas que son entornos de otros.

Las llaves de este mecanismo se encuentran en el considerando $9^{\circ}$, que se afirma en un razonamiento jurídico-judicial que amerita la siguiente partición.

Validación del estándar probatorio ante el problema intersistémico: para la Corte, lo dicho en Pellicori resulta de plena aplicación a la causa, en la que se discute si un despido ha sido motivado por razones sindicales, en el marco de la Ley 23551, o por razones de opinión gremial conforme la Ley 23592. Por ello, quien alega la existencia de un motivo discriminatorio debe acreditar en 
principio o verosímilmente que se encontraba llevando a cabo una actividad protegida por las normas que invoca.

Primera distinción: para el máximo tribunal, “... no cualquier actividad u opinión en el ámbito laboral es de carácter sindical o gremial [...] quien invoca un despido discriminatorio en los términos de la ley 23.551 debe mostrar verosímilmente que realizaba una actividad sindical específicamente protegida por dicha ley”. El requerimiento parece genérico, pero no lo es. Ya ubica el supuesto en el sistema jurídico sindical y la exigencia que continúa profundiza los límites del campo de acción: "Más aún, el interesado debe acreditar de modo verosímil que estaba ejerciendo una actividad protegida en dicha ley de modo regular. El art. 47 de la referida ley 23.551 así lo exige expresamente”.

Se observa un rescate metodológico de aquel concepto ya analizado en este trabajo. La diferenciación "ejercicio de modo regular/ejercicio de modo irregular" recobra protagonismo y se apela a la textura originaria del amparo sindical para demarcar la geografía tuitiva. La hermenéutica final sobre este aspecto trata de clausurar dicho espacio:

No toda actividad sindical constituye el ejercicio regular de un derecho sindical y, dado el lenguaje utilizado, no puede entenderse que la norma otorgue la protección que concede a quien no ejerce uno de sus derechos sindicales.

Sin embargo, aquí surge otra duda. Si el amparo sindical se concentra en quienes ejercitan "de modo regular" sus derechos sindicales, además de los ya tutelados por su situación (representante gremial, candidato, dirigente), queda otro conjunto de sujetos que también pueden invocar dicho ejercicio regular, apelando a los postulados de libertad sindical contenidos en la propia ley. La salida a esta discusión remite, nuevamente, a una ponderación de la "intensidad" con la que se ejerció el derecho sindical y el contexto en el cual se realizó. En otras palabras, a un discernimiento probatorio por parte del operador judicial.

Segunda distinción: el pronunciamiento se enfoca luego en el sistema antidiscriminatorio. Afirma que "En el caso de la ley 23.592, el interesado debe acreditar de modo verosímil que el tipo de actividad desarrollada cuenta como una opinión gremial a los fines de dicha ley y que la actividad satisface los requisitos más generales del ejercicio de la libertad de expresión”.

Como en el supuesto anterior, se practica una remisión expresa al texto de la ley, intentando fijar el límite en la noción de "opinión", pero anudándola a otro derecho fundamental antes que al ejercicio de los derechos sindicales. 
En este desnivel de relevancias parece más importante lo que el sujeto a tutelar "manifiesta" que lo que "hace" en concreto con su libertad sindical.

La frontera entre ambos comportamientos remite, de nuevo, a cuestiones fácticas.

Tercera distinción: finalmente, este segmento del fallo se expide en relación con la calidad de respuestas que puede brindar el empleador imputado por la discriminación de su despido, una vez acreditada la verosimilitud de la conducta, cuando la decisión extintiva es incausada:

... en la medida en que nuestro régimen constitucional y laboral no ha vedado el supuesto de despido sin causa y, por lo tanto, el empleador puede rescindir el vínculo laboral sin justificación alguna, es suficiente para evitar las consecuencias que las leyes 23551 y 23592 determinen en caso de despidos discriminatorios que el empleador acredite que el trato dispensado al trabajador en cuestión no obedeció al motivo discriminatorio reprochado.

Conforme a lo que se adelantó al inicio, la visión encarada en el presente es de carácter funcional. Desde ese esquema, sorprende que luego de invertir esfuerzos dialécticos en deslindar un sistema de otro, la conclusión sea que ambos resultan idóneos para sustanciar un reclamo por despido discriminatorio y que la reacción del empleador no estaría tanto en la naturaleza y el modo de ejercicio de los derechos, sino en la causalidad del despido. Es más, la fórmula concluye expresando: "Bastará que demuestre que el distracto se dispuso por cualquier otro motivo, de la naturaleza que fuere. La única limitación es que la rescisión no responda a los móviles discriminatorios proscriptos".

Resta el caso del distracto con expresión de la causal resolutiva. Para este supuesto, se emplea un mecanismo similar al anterior con un matiz final:

... Si la desvinculación se ha producido con invocación de causa, es suficiente para el empleador acreditar que dicha causa razonablemente se ha configurado. Por último, sea que se trate de la parte que alega el motivo discriminatorio o de aquella que niega su existencia, para la acreditación de los extremos mencionados y para la evaluación de la prueba deben emplearse los medios habituales.

¿Hay en esta última parte del considerando una disminución de la entidad probatoria que posee el material indiciario? ¿O es solamente una ratificación de las distintas modalidades de prueba que pueden utilizarse para ello?

La suma de estas disquisiciones revela que el objetivo pretendido en Varela no se habría cumplido en su totalidad, y a pesar de haberse transmitido cierta 
idea de cierre jurisprudencial, la aparición tres años más tarde del fallo Fontana indica la vigencia del debate.

A los fines del análisis en curso, este último precedente registra tres posiciones significativas:

La ratificación del estándar fijado en Varela por el voto mayoritario. Luego de reiterar el canon probatorio establecido en Pellicori y Sisnero, la sentencia reivindica la posibilidad que tiene la empleadora para alejarse de la imputación por discriminación gremial del despido, reiterando en el final del considerando $5^{\circ}$ : "Bastará que [el empleador] demuestre que el distracto se dispuso por cualquier motivo, de la naturaleza que fuere. La única limitación es que la rescisión no responda a los móviles discriminatorios proscriptos”. Dicha reivindicación se refleja el considerando $6^{\circ}$ :

\begin{abstract}
... si bien el cuestionamiento a la calidad de activista de la actora no supera el marco de una discrepancia valorativa, asiste razón a la recurrente en cuanto reprocha al fallo de cámara la absoluta falta de tratamiento de su planteo relativo a que la decisión de despedir había obedecido a graves problemas económicos de la empresa, debidamente acreditados en el expediente [...] lo cual configura prima facie una causa seria y objetiva ajena a toda discriminación, en los términos de la doctrina precedentemente reseñada.
\end{abstract}

La variación sobre el estándar fijado en Varela por el voto minoritario concurrente. Mediante una opinión propia, uno de los jueces del alto tribunal (Maqueda) adhiere a la solución anterior, aunque sus fundamentos presentan un matiz distinto. Y es que en el considerando $5^{\circ}$ de este voto se omite, a diferencia de la mayoría, la reiteración de lo dicho en el precedente citado en cuanto a la capacidad extensa que tiene a su disposición el empleador para desvirtuar la motivación atribuida al despido. En palabras sencillas, aquí no hay un "bastará..." y eso es importante para visualizar que la adaptación extensiva de la capacidad argumentativa y probatoria intentada en el año 2018 puede restringirse.

La disidencia que omite el estándar fijado en Varela. El fallo comentado registra una disidencia individual (Rosatti), en la que se aprecian dos elementos reveladores. El primero de ellos es la ausencia de mención del precedente Varela, sobre el que se sustentaron los anteriores votos (el mayoritario en forma total). El segundo aspecto (conectado con el anterior) se refiere a la reivindicación del precedente Pellicori en su versión original, para desestimar la tacha de arbitrariedad de la sentencia inferior, en la parte inicial del segundo párrafo del considerando $4^{\circ}$ : 
... el cuestionamiento a la calidad de actividad de la actora no supera el marco de una discrepancia con la valoración de la prueba realizada por el a quo, y el planteo referente a la omisión de considerar constancias de la causa carece de la debida autosuficiencia, en tanto el recurrente no individualiza cuáles son concretamente los elementos de juicio que lograron demostrar la crisis económica invocada y en qué medida resultaron idóneos para hacer caer los indicios de discriminación que el a quo tuvo en cuenta.

A diferencia de los otros votos, aquí se conecta el obrar gremial de la activista con la aplicación de la regla de rotación de la carga probatoria, a lo que se suman otras circunstancias fácticas de apreciación. ${ }^{9}$

\section{Conclusiones}

Dentro de la extensa producción científica de Luhmann se ha resaltado la necesidad de factorizar o descomponer el continente de un problema -incluyendo sus límites- para obtener una perspectiva que le permita considerar el todo. En cierto sentido, se trata de dividir, de aislar la cuestión de estudio para luego reformular el examen en su integralidad. ${ }^{10}$

Algo de ello se ha intentado aquí. El cercenamiento (cuando ha sido posible) de todo otro material jurídico no imprescindible ha sido de provecho para extraer la cuestión de la diferencia funcional como un módulo impulsor del problema central que se ha presentado.

En el presente, la Ley 23592 resulta, en la visión delineada, el sistema jurídico que mejor absorbe la carga de expectativas y gestiona la incertidumbre de quienes demandan el bloqueo de los comportamientos discriminatorios por motivos sindicales, antes que restringir los planteos dentro del sistema de la Ley 23551 por vía exclusiva del amparo especial.

Las ventajas son numerosas: una amplísima legitimación activa, que alcanza a los propios representantes sindicales y anida a los activistas, militantes y a todo aquel que realice una tarea o formule una manifestación de naturaleza gremial; un conjunto pasivo indeterminado, que alcanza por supuesto a los empleadores; un objeto de protección igualmente extenso, al otorgarse a la acepción "opinión gremial" un contenido tanto del "decir" como del "obrar",

9 “... la actora fue despedida dos veces, la primera al culminar el conflicto gremial de 2013, y la segunda, en octubre de 2014, desvinculación que dio lugar a estas actuaciones".

10 En uno de sus ensayos más conocidos, escrito poco antes de su magnum opus sobre la teoría de los sistemas, Luhmann (2009) inicia su análisis con este comentario epistemológico. 
un comportamiento imputado que puede revestir diversas modalidades (incluso mobbing, acoso, violencia laboral) y un procedimiento flexible, porque la Ley 23592 puede anclarse -según el caso- en las vías del ampro general o del artículo 47 de la Ley 23551, entre otros rituales.

Ante dicho panorama, la ley de asociaciones sindicales adolece de una patente incapacidad. Si bien mucho se ha hablado de la apertura del modelo sindical, lo que se trata de advertir en el presente trabajo es, antes que ello, un agotamiento funcional del sistema para hacerles frente a estas controversias. Los debates y posiciones enarboladas respecto a las inconstitucionalidades de la Ley 23551 (de las que se ha participado) se han enfocado en las dificultades más evidentes del ordenamiento, de cara tanto a las observaciones internacionales como a la evolución judicial que ha seguido. Empero, despejado este panorama, o, mejor dicho, efectuado el trabajo de descomposición, lo que emerge es una situación de déficit funcional por la insuficiente idoneidad de este régimen jurídico para producir operaciones antidiscriminatorias que lleguen a todos quienes se lo requieran.

Para el analista del derecho, la teoría sistémica (en particular la de Luhmann) resulta cruel en determinada medida, más aún si la dinámica adaptativa impone hablar de obsolescencia funcional, ya que la mirada tradicional prefiere posarse en la seguridad jurídica que ofrecen las instituciones para no ingresar en terreno desconocido. El institucionalismo, sin embargo, no es de por sí reprochable para la perspectiva apuntada. Lo que es la sociedad moderna no tolera, y por lo cual busca salidas particularizadas y eficientes, es el inmovilismo normativo totalizador. En esto, la ley antidiscriminatoria se ha ganado su lugar protagónico.

Se habló anteriormente de ventajas funcionales y no pueden soslayarse, a esta altura, algunas desventajas en ese campo. La primera de ellas es que, a tamaña amplitud, se reacciona con una renovada diferenciación. Como ya se explicó, los conceptos de "ejercicio regular" y "derechos reconocidos" vuelven a tomar un puesto de contención a la dispersión originada desde la propia Ley 23592. En segundo lugar, sigue pendiente otra diferenciación en la órbita probatoria: entre lo que se demanda, lo que se responde y lo que se prueba continúa existiendo un vacío conceptual que la teoría de los indicios no alcanza a cubrir con fuerza de clausura. Persiste, entonces, un margen de apreciación en el juez que aún no ha sido delimitado.

Finalmente, resta la construcción de una arquitectura de respuesta al gran interrogante, relativo a la vigencia de la reinstalación como consecuencia de la 
nulidad del despido discriminatorio por opinión gremial. La jurisprudencia ha sido inflexible en este tema, aunque la materia requiere hacer otra diferenciación a partir de casos en los que el remedio previsto puede terminar ocasionando una nueva revictimización, pues no toda reposición en el empleo se mantiene inocua.

Esto significaría, funcionalmente, la realización de una nueva partición interna dentro de la Ley 23592, y quizás la emergencia de un nuevo sistema que atienda esta complejidad.

\section{Bibliografía}

Álvarez, E. (2012). El acto discriminatorio bajo la forma del despido. En Asociación Argentina de Derecho del Trabajo y de la Seguridad Social, Anuario 2011 Despido discriminatorio (Año II, N², pp. 69-96). Rubinzal Culzoni.

Ambesi, L. (2017). Constitución, ley y derecho del trabajo. El sistema jurídico laboral en la teoría y en la práctica. La Ley.

Baxter, H. (2013). Niklas Luhmann's Theory of Autopoietic Legal Systemas. Annual Review of Law and Social Science, 9, 167-184.

Corsi, G., Esposito, E. y Baraldi, C. (2006). GLU. Glosario sobre la teoría social de Niklas Luhmann (Trad. M. Romero Pérez, C. Villalobos). Universidad Iberoamericana.

Guibourg, R. (2015). Vulnerabilidad discriminatoria. Derecho del Trabajo, (3), 487-494.

Fernández Madrid, J. C. (1985). Bases para una ley de organización sindical. Derecho del Trabajo, A, 735.

López, J. (1998). Libertad sindical. En Derecho Colectivo del Trabajo. La Ley.

López, J., Centeno, N. y Fernández Madrid, J. C. (1987). Ley de contrato de trabajo comentada (2a ed.). Ediciones Contabilidad Moderna.

Luhmann N. (1990). Identität - was oder wie? En Soziologische Aufklärung 5: Konstruktivistische Perspektiven. VS Verlag für Sozialwissenschaften.

Luhmann, N. (1998a). Complejidad y modernidad: de la unidad a la diferencia. Trotta.

Luhmann, N. (1998b). Sistema sociales. Lineamientos para una teoría general (2a ed.). Anthropos Editorial/Universidad Iberoamericana/CEJA, Pontificia Universidad Javeriana.

Luhmann, N. (2005). El derecho de la sociedad (2a ed.). Herder/Universidad Iberoamericana.

Luhmann, N. (2007a). Introducción a la teoría de los sistemas. Lecciones publicadas por Javier Torres Nafarrate. Universidad Iberoamericana/Instituto Tecnológico y de Estudios Superiores de Occidente.

Luhmann, N. (2007b). La sociedad de la sociedad (Trad. J. Torres Nafarrate). Herder/Universidad Iberoamericana.

Luhmann, N. (2009). ¿Cómo es posible el orden social? (Trad. P. Morande Court). Herder/ Universidad Iberoamericana. 
Luhmann, N. (2010). Los derechos fundamentales como institución. Aportación a la sociología politica. Universidad Iberoamericana.

Luhmann, N. (2012). El amor. El amor como pasión. Curso dictado durante el semestre de verano de 1969 (Trad. F. Martín y S. Villegas). Prometeo libros.

Luhmann, N. (2019). Contingencia y derecho. La teoría del derecho en un contexto interdisciplinario. Trotta.

Miranda Rebeco, P. (2012). La precomprensión de lo humano en la sociología de Luhmann. Raíces antropológicas del antihumanismo teórico luhmanniano. Ediciones Universidad Alberto Hurtado.

Nafarrate, J. T. (2009). Introducción. En Maturana R. H., La realidad: ¿objetiva o construida? I Fundamentos biológicos de la realidad (2 ed., pp. 3-63). Anthropos/Universidad Iberoamericana/ITESO/Universidad Jesuita de Guadalajara.

Rodríguez Mancini, J. (1988). Cuestiones constitucionales de la nueva ley sindical. Derecho del Trabajo, B, 1213-1227.

Rodríguez Mancini, J. (1992). Acción de tutela por conductas antisindicales. Trabajo y Seguridad Social, 297-302.

Rottleuthner, H. (1989). A purified Sociology of Law: Niklas Luhmann on the Autonomy of the Legal System. Law Eु Society Review, 23(5), 779-798.

Simon, J. C. (2012a). Introducción al derecho colectivo del trabajo. En Simon, J. C. (Dir.), Tratado de Derecho Colectivo del Trabajo (Tomo I, pp. 3-10). La Ley.

Simon, J. C. (Dir.). (2012b). Tratado de Derecho Colectivo del Trabajo (Tomo I). La Ley.

Van der Kerchove, M. y Ost, F. (1988). El sistema juridico entre orden y desorden. Universidad Complutense.

Vázquez Vialard, A. (1989). La estabilidad absoluta del trabajador víctima de una práctica antisindical. Derecho del Trabajo, A, 1-13.

\section{Jurisprudencia citada}

\section{Corte Suprema de Justicia de la Nación}

Álvarez, Maximiliano y otros c/Cencosud S.A. s/acción de amparo, 07/12/2010, Fallos: 333:2306.

Bichi, Luis Ángel y otros c/Centro de Comisarios Navales s/acción de amparo, 15/12/2015.

Cejas, Adrián Enrique c/Fate S.A. s/juicio sumarísimo, 26/03/2013.

Fontana, Edith Fabiana c/Cibie Argentina S.A. s/juicio sumarisimo, 08/04/2021, Fallos: 344:527.

Laurenzo, Juan Manuel c/Unión Platense s/amparo, 04/06/2020, Fallos: 343:341.

Pellejero, María Mabel s/amparo s/apelación, 07/12/2010, Fallos: 333:2296.

Pellicori, Liliana Silvia c/Colegio Público de Abogados de la Capital Federal s/amparo, 15/11/2011, Fallos: 334:1387.

Sisnero, Mirtha Graciela y otros c/Taldelva S.R.L. y otros s/amparo, 20/05/2014, Fallos: 337:611.

Varela, José Gilberto c/Disco S.A. s/amparo sindical, 04/09/2018, Fallos: 341:1106. 

ANÁLISIS, CRÓNICAS Y COMENTARIOS 



\section{¿HAY UNA RESPUESTA CORRECTA PARA CADA CASO JURÍDICO? DWORKIN VERSUS FINNIS}

\section{Rodolfo L. Vigo}

Universidad Austral

RVigo@austral.edu.ar

\section{Resumen}

La repuesta jurídica correcta para cada caso propuesta por Ronald Dworkin supone una confianza extraordinaria en la razón práctica jurídica, y entre los que polemizaron con ella está el representante más difundido del iusnaturalismo clásico: John Finnis, que si bien afirma la existencia de esa razón valorativa, se limita a reconocerle la doble función de: i) descartar respuestas inadmisibles por suprimir "bienes humanos básicos"; y ii) ofrecer alternativas igualmente razonables e inconmensurables que le corresponde al juez optar entre ellas. Esas posiciones y sus argumentos respectivos mantienen plena actualidad en torno a las posibilidades que ofrece la razón práctica jurídica.

Palabras clave: respuesta correcta, razón práctica, discrecionalidad judicial, bienes humanos básicos, razonabilidad.

\section{Propósito}

Es conocida la propuesta de Ronald Dworkin que en cada caso jurídico es posible encontrar la "respuesta correcta" (one right answer), la cual generó un amplio debate que tiene muchas aristas y en el que intervinieron autores adscriptos a distintas escuelas iusfilosóficas. Sin embargo, esa polémica no tuvo demasiado interés en las filas de aquellos que se inspiran en Aristóteles y en Tomás de Aquino. Una destacada excepción fue John Finnis, que, en coherencia con las tesis centrales de su visión del derecho, rechaza aquella alternativa. Más allá de aquella disputa puntual, estimamos que hay preguntas y proyecciones implicadas en esta que mantienen permanente actualidad en torno a las posibilidades de la razón práctica y a las características que exhibe el trabajo judicial. 


\section{Las propuestas dworkinianas}

Es cierto que la right thesis no siempre luce suficientemente clara, ${ }^{1}$ e incluso no hay coincidencia sobre si se mantuvo inalterable a lo largo del tiempo. ${ }^{2}$ Es que el estilo del profesor norteamericano suele dejar en penumbras o en interrogantes supuestos filosóficos importantes, especialmente aquellos vinculados a la cuestión antropológica y gnoseológica. De todas maneras, recordemos que la tesis en cuestión se dirige a contradecir el discrecionalismo judicial que le atribuye a Hart. Este asimila el derecho a un sistema de reglas, las cuales suponen "casos fáciles" subsumibles en ellas, pero la "textura abierta" del lenguaje supone que van aparecer casos que se asimilen a los previstos o estimar que son diferentes a estos y, en consecuencia, en esos supuestos fácticos (casos difíciles= hard cases) el juez crea -como un legislador intersticio- el derecho determinando que la conducta en cuestión está prohibida o permitida jurídicamente. ${ }^{3}$ Dworkin considera que una visión normativista (the model of rules) conlleva esa consecuencia, dado que una norma se aplica a "todo o nada", de ese modo, frente a un hecho caben solo dos alternativas: que esté o no esté contemplado en la norma, y en esta última posibilidad la respuesta la crea la autoridad discrecionalmente en un sentido "fuerte", dado que no hay solución jurídica prevista.

Nuestro interés no es la referida polémica, sino cómo defiende Dworkin su propuesta de la respuesta correcta. $\mathrm{Al}$ respecto, nos parece ${ }^{4}$ que podemos identificar hasta seis argumentos principales contra la creación judicial del derecho: (i) el lingüístico: los abogados se dirigen al juez como si a él siempre le compitiera descubrir y aplicar derechos existentes, y el juez, a su vez, habla como si el derecho fuera un sistema de atribución de las facultades sin fisuras en el que espera ser descubierta, y no inventada, una solución para cada caso; (ii) el democrático: defender esa creación judicial del derecho contradice el diseño institucional de división de los poderes, en tanto dicha función está encomendada a funcionarios que han sido elegidos por la comunidad a tales fines; (iii) el axiológico: se violenta el principio de irrectroactividad del derecho, lo cual afecta la justicia y la seguridad del derecho permitiendo que ex post facto el juez invente soluciones jurídicas; (iv) la norma positiva: Dworkin, polemizando con Raz, reconoce que pueden existir sistemas jurídicos que contengan una regla que estipule la discre-

1 Cfr. Moore (2000, p. 266).

2 Jules Coleman (1995) estima que Dworkin (1986), en Law's Empire, la abandona; sin embargo, se confirma en On Gaps in the Law (Dworkin como se citó en Amselek y MacCormick, 1991, p. 84).

3 Cfr. Hart (1994, p. 154).

4 Cfr. Vigo (2019, pp. 125-158). 
cionalidad judicial para casos difíciles, pero, sin valorar la hipótesis, destaca que en el common law no se da una regla de ese tipo; (v) el lógico: si dos proposiciones jurídicas son contradictorias (una reconoce un derecho y la otra lo niega), la falsedad de una implica la verdad de la otra y no cabe atribuirle verdad a ambas; ${ }^{5}$ y (vi) la responsabilidad política: pesa sobre los funcionarios políticos -legisladores y jueces- la obligación moral y política de tomar sus decisiones de manera que "las pueden justificar dentro del marco de una teoría política que justifique las otras decisiones que se propone tomar" (Dworkin, 1984, p. 22).

En definitiva, la propuesta dworkiniana confía en que se encuentre la respuesta correcta para cada caso por medio de una teoría de la adjudicación que implicará, al mismo tiempo, una "explicación" del derecho explícito de la sociedad y una "justificación moral" de ese derecho. El esfuerzo que supone semejante teoría omnicomprensiva del derecho, que abarcará coherentemente al conjunto de principios que están implícitos o que son presupuestos por el derecho explícito, requiere la presencia de una juez filósofo dotado de una habilidad, erudición, paciencia y perspicacia sobrehumana, que Dworkin llamará "Hércules": "Es posible que el derecho -advierte el profesor norteamericanono sea un sistema sin lagunas, pero el demandante tiene derecho a pedir que Hércules lo trate como si fuera" (Dworkin, 1984, p. 190). La teoría hercúlea de adjudicación es una construcción de un esquema de principios abstractos y concretos que identifica la moralidad presupuesta en las leyes e instituciones de la comunidad, e implica la justificación coherente del ordenamiento vertical y horizontal de las decisiones jurídicas. Esta teoría permite obtener la respuesta correcta al caso difícil sin necesidad de reconocer en el juez un poder de creación jurídica retroactiva, y ella cuenta con una dimensión "descriptiva" en cuanto permite conocer la totalidad del derecho vigente y el modo como se opera en la adjudicación de derechos, pero también la teoría tiene una dimensión "prescriptiva" en cuanto armoniza al derecho con los principios de moralidad objetiva y justifica la solución que Hércules adopta.

\section{La propuesta finnisiana ${ }^{6}$}

Empecemos con un texto del profesor oxoniense que de algún modo sintetiza su posición respecto al tema bajo estudio:

$5 \quad$ Cfr. Vigo (2019, p. 135); Dworkin (1985, pp. 119 y ss.).

6 Cfr. Vigo (2019, pp. 281-315). 
Una teoría de la ley natural en la tradición clásica no pretende que la razón natural pueda identificar la única respuesta correcta a las innumerables cuestiones que surgen para el juez cuando las fuentes son poco claras [...] En la visión clásica, expresada por Tomás de Aquino con una clara deuda a Aristóteles, existen muchas de equivocarse y de hacer el mal; pero en muchas -quizás casi todas- de las situaciones de la vida personal y social existen muchas opciones correctas (i.e. no-equivocadas) incompatibles. (Finnis, 1990, p. 151)

Aclara que el rechazo de la rigth thesis no implica "comprometerse con ningún tipo de escepticismo sobre la objetividad de los bienes humanos o sobre los juicios correctos acerca de lo bueno y de lo malo" (Finnis, 1990, p. 151).

Conviene precisar a continuación que la remisión que formula el profesor oxoniense sobre el conocimiento conlleva la distinción entre el saber y verdad teórica, por un lado, y, por el otro, el saber y verdad práctica. ${ }^{7}$ En efecto, mientras que respecto a la verdad teórica funciona la correspondencia entre el entendimiento y la cosa con la que se adecua, la verdad práctica no consiste en conocer por conocer, sino conocer para obrar, pues el interés cognoscitivo se dirige a lo que queremos hacer y que aún no existe, y así en Aquinas leemos:

Lo que es en sí práctico es acerca de qué cosa hacer [...]. No es acerca de lo que es el caso, tampoco acerca de lo que será el caso. Es acerca de lo que es para hacer, debe ser hecho -una prescripción y no, en cuanto tal, una predicción-. (Finnis, 1998, p. 38)

El hombre, al reflexionar sobre qué hacer, recurre -al margen del acierto o error en sus conclusiones- a "una serie de principios prácticos básicos que muestran las formas básicas de realización humana plena como bienes que se han de perseguir y realizar" (Finnis, 2000, p. 57). Esos principios, que son los también llamados "más generales" (communissima) de la ley natural, al expresar "las formas básicas del bien humano" (Finnis, 2000, p. 63), constituyen "el sus-

7 "La verdad del entendimiento especulativo se obtiene por la conformidad del entendimiento con la cosa conocida; y como el entendimiento no puede conformarse infaliblemente con las cosas contingentes sino tan solo con las necesarias, por eso ningún hábito especulativo de las cosas contingentes es virtud intelectual, sino que ésta versa únicamente sobre lo necesario. En cambio, la verdad del entendimiento práctico se obtiene por la conformidad con el apetito recto; conformidad que no tiene lugar en las cosas necesarias, que no dependen de la voluntad humana, sino tan solo en las cosas contingentes, que pueden ser hechas por nosotros, bien se trate de lo agible interior, bien se trate de lo factible exterior. Por eso, la virtud del entendimiento práctico no se da más que sobre las cosas contingentes: el arte sobre lo factible, y la prudencia sobre lo agible" (Tomás de Aquino, Suma Teológica, I-II, a.57, a.5, ad.3). 
trato valorativo de todos los juicios morales" (p. 91). Todo ser humano con uso de razón y experiencia suficiente aprehende por evidencia esos bienes básicos comprendiéndolos "como oportunidades o fines deseables y potencialmente realizables y, por ende, como que-han-de-ser-buscados y realizados en la propia acción, acción a la cual uno ya está encomendado a dirigirse por este mismo acto de comprensión práctica" (Finnis, 2000, p. 78). Esos bienes humanos básicos y premorales constituyen lo "dado" para el ser humano, pero luego, ya con el ejercicio pleno de la razón y la libertad, corresponde definir un plan de vida o una moral conforme a la cual dirigir la vida, y así "cada uno de nosotros puede razonablemente elegir tratar uno o algunos de los valores como de mayor importancia en su vida" (Finnis, 2000, p. 124). Finnis (2000) define en Ley natural y derechos naturales nueve exigencias que expresan "el método de la ley natural para elaborar la 'ley natural' (moral) a partir de los primeros principios de la ley natural (pre-morales)" (p. 134).

Las precisiones precedentes responden a que está muy extendida la crítica injustificada que se le hace al iusnaturalismo porque postula una noción de verdad práctica sujeta a la teoría de la correspondencia, cuando esta es solo propia de la verdad teórica.

Ahora sí tratemos los argumentos que avalan ese rechazo a la tesis jurídica de la única respuesta correcta, y si bien algunos son explícitamente aducidos por Finnis, otros son simplemente derivados y coherentes con su filosofía jurídica.

\subsection{Los "absolutos morales"}

Finnis (1988) ha defendido los "absolutos morales", y ello supone la descalificación moral de ciertas opciones que supone suprimir bienes humanos básicos. De manera que, sin perjuicio de que la razón práctica no puede indicarme cuál es la opción correcta, ella sí puede descartar alternativas por ser clara y evidentemente irracionales. Por poner un ejemplo: torturar siempre merece un reproche moral o jurídico justificado racionalmente, al margen de que se la practique y del aval eventual de la sociedad.

\subsection{La dimensión técnica}

El derecho, según Finnis, cuenta con una dimensión técnica, de adecuación o de ajuste (fit), y otra dimensión moral, rectitud o justificación (soundness), y ello supone que en la determinación del derecho caben alternativas dentro de 
los márgenes que dejan la razón o la corrección moral. El derecho comparado confirma que el derecho es un orden cultural-técnico y que, definido este, solo cabe a la sociedad ajustarse a sus exigencias particulares.

\subsection{Lo sociológico}

Aunque puede comprenderse el presente argumento en el anterior, nos gustaría particularizar con Tomás de Aquino que el derecho debe adecuarse a las costumbres y al tono moral de la sociedad, pues la situación del gobernante se asemeja a la de un padre que debe orientar y educar a sus hijos teniendo en cuenta sus características personales, especialmente la edad. ${ }^{8}$ No hay que olvidar la vieja enseñanza moral que lo mejor es enemigo de lo bueno, de ahí que el saber prudencial discierne lo bueno concreto y posible.

\subsection{La libertad}

Si la razón práctica estuviera en condiciones de indicar la mejor respuesta moral en cada caso, la consecuencia antropológica sería un debilitamiento o supresión de la libre elección. Esa pretensión no solo es ficticia, sino que conllevaría graves consecuencias en la realidad humana personal e institucional, llegando a absurdos, tales como el suprimir las elecciones del gobernante -dado que tenemos un método racional para saber cuál es el mejor candidato- o también eliminar los tribunales por la existencia de mecanismos que esclarezcan la respuesta jurídica inobjetablemente correcta.

\subsection{Las virtudes}

La ética tradicional ha insistido en la integralidad del ser humano, pues él no es solo razón y voluntad, también cuenta con los apetitos sensibles que pueden perturbar las buenas elecciones, aunque también ellos están en condiciones de ayudarlas. Las virtudes ${ }^{9}$ operan coordinadamente en orden a la verdad práctica, y por esa vía la prudencia necesita de una voluntad recta y también que la fortaleza y la templanza colaboren en encontrar la conducta que provea un bien. ${ }^{10}$

8 Tomás de Aquino (Suma Teológica, I-II, q.95, a.3).

9 "Por eso dice el Filósofo en el Libro III de la Ética (cap. 6, 1.IX, cap. 4) que el hombre virtuoso es la medida de los otros hombres" (Tomás de Aquino, In II Sent. d.14.q.3, a.3, ad.3).

10 Acerca de la presencia y necesidad de las emociones en la vida moral, cfr. Finnis (1998, p. 75). 


\subsection{La inconmensurabilidad de los bienes}

Si bien Finnis ha brindado diferentes nóminas de los bienes humanos básicos premorales, siempre ha defendido que ellos son inconmensurables, en tanto no existe un baremo estricto para jerarquizarlos y, consecuentemente, tampoco son conmensurables las morales que cada ser humano define para dirigir su vida. La clave que importa es que ellas aporten al "florecimiento" humano, al margen del espacio que se le reconozca a cada uno de los bienes humanos básicos.

\subsection{El plano fronético o prudencial}

Cabe advertir en sintonía con la gnoseología clásica que el saber práctico admite distintos niveles de mayor o menor generalidad, y, de ese modo, en el nivel más cercano a la conducta concreta y contingente se acentúa el riesgo de error. Es relativamente fácil reconocer la verdad de que no puedo matar al otro, sin embargo, está la excepción del supuesto de legítima defensa, y aquí, frente al caso concreto, seguramente aparecen muchísimas dudas y se potencia el riesgo de errar en el juicio práctico.

\subsection{El silogismo prudencial ${ }^{11}$}

Desde Aristóteles sabemos que corresponde distinguir entre razonamientos necesarios o apodícticos y razonamientos dialécticos o retóricos, pues estos parten de premisas verosímiles o plausibles ${ }^{12}$ y en el supuesto del razonamiento judicial hay premisas fácticas cuya certeza habitualmente no es absoluta o inequívoca, a lo que cabe agregar eventualmente la presencia de premisas jurídicas razonables discutibles. Dado que hay una regla del silogismo que impone que la conclusión sigue a la premisa más débil, cabe admitir que la debilidad de la premisa fáctica (eventualmente también de la premisa jurídica) se trasmitirá a la conclusión de aquel discurso judicial.

\section{Conclusión}

Quizás resulta innecesario agregar que suscribimos a la alternativa finnisiana, y de ahí que nos hemos animado, más que a reseñar taxativamente sus planteos al

11 Cfr. Vigo (2015, pp. 69-108).

12 Aristóteles se encarga de precisar: premisas (endoxa) aceptadas por todos, o por la mayoría, o por los sabios (Tópicos, 100b21-3). 
respecto, a procurar explicitar o completar lo que se puede racionalmente aducir en favor de que habitualmente no hay una respuesta jurídica correcta para los casos jurídicos, sino que la razón práctica prudencial puede excluir algunas respuestas y, además, brindar el margen para escoger de entre las respuestas jurídicas correctas. Subrayamos "habitualmente" atentos a que es posible identificar casos en los que solo cabe una respuesta jurídica, sin embargo, ellos exceden los interrogantes jurídicos que constituyen la normalidad del derecho y que requieren de la atención de un juez para que lo "diga" (iuris dictio) autoritativamente.

Ejemplifiquemos la matriz sintetizada precedentemente. Parece evidente que la razón práctica deja un amplio margen sobre qué derechos le asisten al empleado respecto al empleador que ha decidido no pagarle la totalidad de su sueldo devengado, sin que ni siquiera pueda invocar para ello ninguna causa justificatoria racional. Por supuesto que frente a esa hipótesis corresponde distinguir la magnitud del incumplimiento, pues serán distintas las respuestas jurídicas disponibles para el empleado según no se haya abonado la totalidad del sueldo, la mitad de este o menos del uno por ciento. En el caso más grave, la razón no tolerará que se le conceda al trabajador el derecho de matar al empleador, pero sería posible racionalmente que se le atribuya el derecho de mantener automáticamente la relación laboral con más alguna reparación económica complementaria. Para el supuesto de la retención del cincuenta por ciento del sueldo, nos podemos imaginar que se conceda el derecho de rescindir la relación laboral con una suma indemnizatoria. Y finalmente, frente al caso del no pago de una reducidísima parte del sueldo, puede contemplarse el derecho de una inmediata conciliación o algo similar.

Es obvio que caben muchas más y mejores alternativas a las propuestas, pero nuestro propósito central es mostrar que la razón práctica puede no solo identificar caminos inviables o intolerables, sino reconocer fácilmente magnitudes de irracionalidades con respuestas jurídicas racionales frente a esas hipótesis diferentes. Frente al extendido escepticismo genérico respecto a la razón en el terreno axiológico o moral, una mirada más atenta y concreta puede comprobar ciertas posibilidades cognoscitivas de esa razón práctica. Precisamente, la determinación autoritativa escogerá prudencial y válidamente dentro de los márgenes que deja la razón práctica.

En definitiva, pensamos que hemos mostrado -en sintonía con Dworkin y Finnis- las diferencias entre la razón teórica y la razón práctica, aunque el primero, asumiendo un ultrarracionalismo constructivista, confía en que se puede encontrar la respuesta jurídica correcta para los casos judiciales, mientras que 
Finnis, en coincidencia con el realismo jurídico clásico, defiende que la razón está en condiciones de descartar opciones jurídicas e indicar márgenes para que la autoridad judicial escoja entre ellas.

\section{Bibliografía}

Amselek, P. y MacCormick, N. (Eds.). (1991). Controversies about Law's Ontology. Edinburgh University Press.

Coleman, J. L. (1995). Truth and Objetivity in Law. Legal Theory, 1(1), 33-68.

Dworkin, R. (1984). Los derechos en serio. Ariel.

Dworkin, R. (1985). Is There Really No Right Answer in Hard Cases? En A Matter of Principle. Harvard University Press.

Dworkin, R. (1986). Law's Empire. Harvard University Press.

Finnis, J. (1988). Moral Absolutes. Catholic University of America Press.

Finnis, J. (1990). Natural Law and Legal Reasoning. Cleveland State Law Review, 38(1).

Finnis, J. (1998). Aquinas. Oxford University Press.

Finnis, J. (2000). Ley natural y derechos naturales. Abeledo Perrot.

Hart, H. L. (1994). The Concept of Law. Clarendon Press.

Moore, M. (2000). Educating Oneself in Public. Oxford University Press.

Vigo, R. L. (2015). Interpretación (argumentación) juridica en el Estado de Derecho Constitucional. Rubinzal-Culzoni.

Vigo, R. L. (2019). Perspectiva iusfilosóficas contemporáneas (3a ed.). Abeledo Perrot. 



\title{
LA EDUCACIÓN ES EL CAMINO
}

\section{Noelia Gutiérrez Herrera}

\author{
Ministerio Público Fiscal, Ciudad Autónoma de Buenos Aires \\ gutierrez.herrera.noelia@gmail.com
}

\section{María Laura Barbado}

Cámara Federal de Apelaciones de Tucumán, Poder Judicial de la Nación

marialaurabarbado@gmail.com

\section{Resumen}

Este trabajo analiza el derecho a la educación desde los aspectos filosóficos, jurídico y sociológico en tanto herramienta para la formación integral del ser humano, considerado individualmente y como miembro de una comunidad. Se abordan temas como los dilemas de la democracia, los conceptos de "libertad" y "verdad" y la regulación normativa del derecho a la educación en Argentina y en los tratados internacionales. Se efectúan propuestas para la mejor formación del ciudadano como parte de la sociedad y como actor en la democracia participativa.

Palabras clave: derecho a la educación, ciudadanía, democracia participativa, libertad, verdad, ética.

\section{Education is the way}

\begin{abstract}
This article analyzes the right to education from the philosophical, legal and sociological aspects as a tool for the integral formation of the human being, considered individually and as a member of a community. Issues such as the dilemmas of democracy, the concepts of freedom and truth and the normative regulation of the right to education in Argentina and in international deals. Proposals are made for the better training of citizens as part of society and as an actor in participatory democracy.
\end{abstract}

Key words: right to education, citizenship, participatory democracy, freedom, truth, ethics. 
La educación no cambia el mundo, cambia a las personas que van a cambiar el mundo.

Paulo Freire

\section{Introducción}

El propósito del presente análisis es invitar a pensar sobre el derecho a la educación, no solo desde una concepción estrictamente jurídica, sino también como parte del comportamiento político y social de los cuales el Estado, organizaciones, personas jurídicas y ciudadanos somos protagonistas.

Proponemos una mirada filosófica y a la vez cotidiana de la educación, tanto del derecho a educar como del derecho a aprender, siendo este último un derecho fundamental para el desarrollo del ser humano en tanto individuo y en su calidad de ciudadano.

Planteamos ver en qué medida podemos modificar nosotros mismos nuestro parecer según el rol que nos toca cumplir a cada uno, ya sea como docentes, políticos, profesionales, madres, padres, ciudadanos en general.

Para ello, abordaremos diferentes tópicos, tales como algunos dilemas de la democracia, la vida en sociedad, la libertad y la verdad, para luego focalizarnos en el derecho a la educación y su regulación normativa en nuestro país.

No olvidamos que las mejoras a nivel educativo son una enorme deuda social. Aceptarla implica demostrar qué país queremos, qué tipo de democracia merecemos y en qué sociedad deseamos realmente vivir.

Si invertimos más tiempo y recursos en educación, mayor será nuestra aspiración a crecer como sociedad. Ello implica que predominen el debate y el intercambio de opiniones, respetando las distintas posturas. Es allí donde lograremos una sociedad más madura, en la que prevalezcan el diálogo y la construcción, mas no la discusión.

En definitiva, si queremos ver algún cambio en la sociedad donde vivimos, ese cambio debería empezar por nosotros mismos. ${ }^{1}$ Por esto, al final del artículo acercamos propuestas que implicarían mejoras para nuestra educación como ciudadanos.

1 Adaptación de la frase célebre de Mahatma Gandhi "Si quieres cambiar al mundo, cámbiate a ti mismo". 


\section{Dilemas de la democracia}

Una nota periodística (Marconiz, 2021) da cuenta de un suceso acaecido en la provincia de Jujuy, donde un grupo de personas se concentró en un predio -en el que se encontraba ubicada una cancha de fútbol barrial-para impedir la construcción de una escuela y exigir que la obra fuera ubicada en otro lugar bajo la consigna “cancha sí, escuela no". Tal situación de tensión se produjo durante la firma de un acta para la construcción del edificio de la Escuela Secundaria No 39, en Campo Verde. En la ceremonia también se había anticipado el desarrollo de un polideportivo que sería administrado por el Centro Vecinal del barrio. Cabe destacar que, según testimonios, en esta zona hay una sola escuela secundaria pública.

Dicho ejemplo pone en juego dos estados de cosas que consideramos valiosas: por un lado, la educación, por otro, la posibilidad de hacer deportes. ¿Cuál de los dos platillos pesará más en la balanza?

Muchas veces nos encontramos con situaciones como las aquí descriptas, en las que están en pugna posturas conflictivas en las que se invoca, incluso en muchos casos, unos derechos humanos para vulnerar otros derechos humanos. En ese sentido, se ha sostenido que el problema reside en que si hoy hacemos pagar a otros un costo muy alto para defender lo que amamos, mañana otros pueden hacérnoslos pagar a nosotros para defender lo que ellos aman con igual o mayor fervor (Guibourg, 2012, p. 4).

Ahora bien, es sabido que la vida en democracia es el ámbito propicio para la diversidad y la tolerancia, lo que, a su vez, debería implicar la pacífica convivencia entre quienes piensan de modos diferentes, creen en cosas diferentes y actúan según diferentes valores.

Pareciera, sin embargo, que hay determinadas cosas para las cuales no existe consenso y para las que la sociedad se halla dividida, prácticamente partida en dos. En esos casos, unos ciudadanos pretenden defender con fervor sus creencias e intereses a costa de imponérselas a otros de cualquier modo. En cuestiones que son de la más diversa índole, muchas veces triunfa quien aplica métodos más virulentos, y otras veces no es suficiente lo que opina la mayoría (no siempre legítimamente conformada). Incluso, en algunos casos, la minoría es tan amplia que quienes la componen se sienten insatisfechos o no escuchados, lo cual genera malestar y desencanto, que se vuelca a la sociedad de un modo más o menos conflictivo según la discusión de turno.

Piénsese, por ejemplo, en cuestiones tan polémicas como el aborto, el matrimonio entre personas del mismo sexo, la ley de identidad de género, la muerte 
asistida. $\mathrm{O}$ en otras cuestiones diarias como piquetes, huelgas, infracciones de tránsito y, actualmente, disputas de todo tipo acerca de las medidas para enfrentar la pandemia. Llevado al ámbito de la justicia, la marcada división entre iuspositivistas e iusnaturalistas, formalistas y aformalistas, garantistas y quienes no lo son repercute en el modo en que se resuelven las contiendas judiciales y en el sentido en que se conforma la jurisprudencia.

Esta dicotomía se presenta en el caso que comentamos: ise puede impedir la construcción de una escuela? ¿Es más importante defender el espacio recreativo o brindar acceso a un nuevo colegio? O, en otra línea de pensamiento, si la escuela y la cancha son necesarias para el desarrollo de los niños y adolescentes, para su salud física y mental, no deberíamos tener necesidad de optar.

\section{Sobre las convicciones personales y la vida en sociedad}

Permanentemente lidiamos con cuestiones relativas a la moral y a la ley. Nos preguntamos si está bien o mal hacer huelga, vender mercadería en las calles, defender una cancha de fútbol en vez de la creación de una escuela, tomar clases presenciales o virtuales, cerrar o abrir bares en épocas de pandemia, e inmediatamente nos planteamos qué debería regularse al respecto y qué debería hacer el Estado o, en su caso, si no debería hacer nada. Sostiene Michel Sandel (2011, p. 4) que esas cuestiones no se refieren solo a cómo deberían tratarse los individuos entre sí, sino a qué debería hacer la ley y cómo debería organizarse la sociedad. Se refieren a la justicia y al modo de concebirla.

Pero en las sociedades pluralistas hay distintas maneras de concebir la justicia. ¿Quién puede definir qué es la justicia? ¿Qué es lo moralmente correcto? ¿Debe el Estado intervenir y regular conductas según criterios morales? ¿O, por el contrario, debe mantenerse neutral?

Entonces nos encontramos con que esas distintas concepciones de la justicia, la moral, el derecho, la verdad, el Estado liberal o paternalista nos entrampan en un juego de posiciones opuestas en el que cada uno puede pensar lo que quiere y defender su posición sin reparar en los demás. Esto nos lleva a una situación tal de permisivismo y relativismo que pareciera que lo importante es la discusión en sí misma y la defensa de la postura adoptada más que lograr un acuerdo en el que, sin renunciar a las propias convicciones, podamos convivir armónicamente en sociedad.

Este dilema nos introduce en una de las grandes cuestiones de la filosofía política: 
Una sociedad justa, iha de perseguir el fomento de la virtud de sus ciudadanos? ¿O no debería más bien la ley ser neutral entre concepciones contrapuestas de la virtud, de modo que los ciudadanos tengan la libertad de escoger por sí mismos la mejor manera de vivir? (Sandel, 2011, pp. 6-7)

A su vez, esta cuestión separa el pensamiento político antiguo del moderno. Aristóteles enseñaba que la justicia consiste en dar a cada uno lo que se merece. Y para determinar quién merece qué, hemos de determinar qué virtudes son dignas de recibir honores y recompensas. Según Aristóteles, no podemos hacernos una idea de cómo es una constitución justa sin haber reflexionado antes sobre la manera más deseable de vivir. Para él, la ley no puede ser neutral en lo que se refiere a las características de una vida buena. Por el contrario, los filósofos políticos modernos -desde Immanuel Kant en el siglo XVIII a John Rawls en el XX-sostienen que los principios de la justicia que definen nuestros derechos no deberían fundamentarse en ninguna concepción particular de la virtud o de cuál es la forma de vivir más deseable. Muy al contrario, una sociedad justa respeta la libertad de cada uno de escoger su propia concepción de la vida buena. En consecuencia, las teorías antiguas de la justicia parten de la virtud, mientras que las modernas parten de la libertad (Sandel, 2011, pp. 6-7).

Podría pensarse que a la sociedad en la que vivimos no le interesan los grandes temas filosóficos como la justicia, el derecho, la moral, la libertad. Que estos temas quedan relegados para su estudio en los ámbitos académicos mientras que a los ciudadanos les interesa la seguridad, el aumento de precios, los accidentes de tránsitos, las huelgas de los maestros, en fin, los problemas cotidianos. Pero a poco de analizar se advierte que existen en nuestra vida diaria variadas muestras de situaciones que generan antagonismo y que, en su esencia, implican la necesidad de considerarlas en términos de justicia, de derecho, de ejercicio de la libertad.

\section{Libertad}

Pareciera que el problema radica en el ejercido de la libertad y en lo que cada uno considera como la verdad que orienta sus acciones para la vida.

Respecto a lo primero, Erick Fromm (1986, p. 33) explica que en el concepto freudiano de las relaciones humanas el individuo aparece plenamente dotado con todos sus impulsos de carácter biológico, que deben ser satisfechos. Con este fin, entra en relación con otros "objetos". Así, los otros individuos constituyen siempre un medio para el fin propio, nunca un fin en sí mismo. 
Por el contrario, Fromm considera que lo central es la conexión del individuo con el mundo y no la satisfacción o frustración de una u otra necesidad per se. La sociedad no ejerce solamente una función de represión -aunque no deja de tenerla-, sino que posee también una función creadora. Al ser ello así, el hombre se encuentra en sociedad proyectando sus deseos, su voluntad y su libertad en interferencia con los deseos, voluntades y libertades de otros hombres (Fromm, 1986, p. 34).

Una mentalidad muy extendida en Occidente implica que cada uno es libre de elegir lo que quiera siempre que los demás no se vean perjudicados: aunque alguien se equivoque, es preferible dejarlo en el error antes que mostrarle una opinión o una elección diferente de la propia.

Yepes considera que en el hecho de poner a la libertad de elección como valor primero se advierten algunas deficiencias. Entre ellas, se confunde libertad con espontaneidad, lo cual es muestra de analfabetismo (Yepes y Aranguren, 2009, pp. 126-127). Si solo hay espontaneidad, si no existe un acuerdo previo acerca de qué cosas son perjudiciales, es imposible establecer los límites de lo tolerable y lo intolerable.

Si a la libertad la analizamos en los términos antes referidos, podremos advertir que muchos de los actos que generan desorden y desagrado en nuestra sociedad son más productos de la espontaneidad que del verdadero ejercicio de la libertad de opción.

En el ejemplo que citamos al comienzo, parece un mero acto espontáneo oponerse a la creación de una nueva escuela. En efecto, no debería tratarse de la educación sobre el deporte, o viceversa, pues incluso debemos considerar que la escuela es tan importante como un espacio deportivo.

Acciones como la relatada degradan el concepto de "libertad". La cuestión no debería reducirse al solo ejercicio de la espontaneidad (mal llamada "libertad") de un grupo de reclamantes, ya que ello priva a los demás (sus propios hijos y los padres a favor de la educación) del bien que merecen y del derecho que gozan los seres humanos a recibir educación.

En ese sentido, en la sociedad actual no basta con respetar el principio de libertad, tal como lo formuló Kant, como único derecho originario que corresponde a cada hombre como elemento integrante de la humanidad (Vigo, 2008, p. 118).

La idea de que la libertad de uno termina donde empieza la del otro resulta individualista. Ello no quiere decir que sea errónea, sino que para poder convivir hace falta algo más que simplemente ejercer mi libertad sin dañar a otro. Probablemente, la filosofía kantiana, motivada por los males de su tiempo, 
no llegó a abrazar completamente la visión del hombre como un ser que debe contribuir con la sociedad en la que vive para poder gozar verdaderamente de su libertad.

En esa línea de pensamiento, la idea de "individuo aislado" no es más que una abstracción racionalista. El principio de no hacer daño a otros es un criterio necesario, pero no es el único. Encerrar a la gente en ese egoísmo constitutivo es empobrecerla. La tolerancia entendida como permisivismo pretende excluir cualquier forma de reproche hacia conductas distintas a las que nosotros practicamos. Esto se llama political correctness (corrección política). Consiste en no reprocharle a nadie su conducta y evitar cualquier signo que pueda ser interpretado como discriminatorio (Yepes y Aranguren, 2009, pp. 132-133).

Pero, aparentemente, estos males sociales no son nuevos:

En el año 400 A.C. Platón trazó el cuadro sombrío de la democracia desquiciada de su propio tiempo. 'La ciudad -escribe- rebosa ahora libertad y cada cual puede hacer de ella lo que se le antoje. La libertad consiste, pues, sobre todo, en sentirse libre de toda clase de deberes, no en someterse por sí mismo a ciertas normas interiores. Cada cual organiza su vida como mejor le place [...]. Esta emancipación del individuo perjudica al hombre tanto como el sistema de la coacción y de la exagerada disciplina que oprime al individuo [...]. El espíritu de la tolerancia impera aquí sobre la justicia. La moral de la sociedad no reconoce pequeñeces, no se establece ninguna cultura del espíritu como condición previa para la actuación política. Donde primero se manifiestan los síntomas de la anarquía es en el campo de la educación'. (Jaeger, 1957)

El relato es elocuente y parece la descripción exacta de una parte de nuestra realidad actual. A su vez, nos brinda una prueba de que los excesos en el ejercicio de la libertad sin el correlato de ciertos deberes y la falta de anclaje en la educación generan daños en cualquier sociedad.

\section{Verdad}

Hay otra cuestión que incide en los conflictos sociales desde la antigüedad y que se relaciona con lo que cada uno considera como la verdad que orienta sus acciones para la vida.

Aristóteles había definido a la verdad como la adecuación del intelecto a la realidad. Pero esa sencillez de la definición no resulta aplicable en todos los casos. De hecho, hay verdades relativas, ya que lo que es verdad en un sistema de pensamiento puede no serlo en otro (Guibourg, 2004, p. 70). 
En efecto, lo que es verdad para los cristianos no lo es para los judíos o los musulmanes. Lo verdadero para los burgueses no lo era para los proletarios. Siguiendo ese criterio, puede considerarse lo sostenido por Marx y Engels (2000, pp. 25-26) acerca de que la historia de toda la sociedad no ha sido sino la historia de la lucha de clases. "Hombres libres y esclavos, patricios y plebeyos, nobles y siervos, maestros, jurados y compañeros, en una palabra, opresores y oprimidos, en lucha constante...”. ¿Acaso esas luchas no se basaban en los principios que cada clase quería sostener? Y, siendo ello así, ¿no implicaba la consideración por cada clase de que sus principios eran válidos, verdaderos, respecto a los de sus adversarios?

Siguiendo el ejemplo citado como estudio, podemos considerar que aquellos vecinos que se oponen a la construcción de una escuela secundaria sostienen como "su" verdad que es mejor la permanencia de la cancha que la creación de la escuela.

Más allá de que el tema de la verdad es de profunda envergadura, puede entenderse, en líneas generales, que en nuestros tiempos existen, además, numerosos problemas al respecto, uno de ellos es la confusión entre "verdad" y "opinión"; el otro es el relativismo. ${ }^{2}$

A ello se suma que, en la actualidad, nos encontramos atravesados por los medios de comunicación y las redes sociales en los que prevalece la opinión sin un análisis profundo de los temas debatidos.

Naturalmente, el hombre tiende a optar, a posicionarse a favor de unos o de otros, a sostener un plan de vida diferente del de los demás, a creer en una religión determinada o no creer en nada, a estar a favor o en contra del aborto, a pertenecer a uno $\mathrm{u}$ otro partido político.

Es propia del ser humano la capacidad para pensar, para expresar sus ideas y para disentir, ello es lo que determina la identidad del hombre. Ocurre que no es la diferencia de pensamiento la que nos perjudica como sociedad, sino el exceso y las pasiones que deslegitiman los reclamos de quienes no piensan de igual modo.

2 "El relativismo invita a construir para mi vida una 'verdad' que no sea un problema, que no me comprometa, que no me exija, que sea tan maleable como para ajustarse a mis deseos, que abarque todo lo que yo quiera introducir en mi cotidianeidad y, sobre todo, que renuncie a su pretensión de definitividad porque quién sabe si lo que hoy me agrada y me conviene me agradará o convendrá mañana” (Sánchez, 2020, pp. 908-909). 


\section{Ponernos de acuerdo: la clave está en la educación}

Vivimos en una época de profunda polarización, en la que se ha olvidado el concepto de bien común y en la cual mucha gente solo escucha opiniones que refuerzan lo que ya creen. Se ingresa en un círculo vicioso en el que no se quiere escuchar al otro a pesar de que ello podría agregar elementos nuevos a los propios análisis y así mejorar el razonamiento y, por ende, las decisiones y el consecuente accionar.

Pero más que intentar dilucidar quién tiene la razón o centrarnos en firmes posturas antagónicas y/o tratar de descubrir una única verdad podemos empezar por respetar al otro, reconocer que tiene ideas diferentes, ello como punto de partida para el debate democrático y para el logro de resultados comunes que sean valiosos para todos aquellos que integramos una sociedad.

Aun para autores como Kant (2008, pp. 36-37), que enseñaba que nadie me puede obligar a ser feliz según su propio criterio, sino que cada cual debe buscar su felicidad por el camino que se le ocurra, hay un límite al ejercicio de la libertad que es no perjudicar la libertad de los demás, para lograr así que su libertad coexista con la de los otros según una posible ley universal, es decir, con el derecho de los demás.

En similar sentido, otros autores liberales reconocen que los ciudadanos, como seres autónomos que son, deciden por sí mismos, pero se comprometen también a respetar los primeros principios de justicia que hayan acordado. Se conocen las reglas y se aceptan como razonables. Hay un respeto mutuo de unos por otros.

Con ello queremos significar que aun para los más acérrimos defensores del ejercicio de la libertad en su máxima extensión se deduce que hay un cierto contenido mínimo de valoraciones y de cuestiones sobre las que debemos ponernos de acuerdo no en términos de convencer al otro, sino en términos de respetar las convicciones de los demás como medio para no dañarnos mutuamente y poder convivir en forma pacífica.

Podemos tener cada uno un proyecto de vida, considerar nuestra libertad como esencial y la verdad en la que creemos como la única válida, pero no por ello renunciar al entendimiento con los otros, a la tolerancia y al respeto hacia los demás.

Para lograr ese cometido, los filósofos, en líneas generales, concluyen que tenemos que generar debates y ponernos de acuerdo sobre los temas que originan conflicto en la comunidad. Pero esas discusiones raramente se logran.

En sociedades como la nuestra, pareciera que lo que prevalece es la opinión 
en los medios de comunicación y redes sociales, la crítica y la pelea. Sin embargo, al analizar la cuestión se advierte que tales disputas parecen estériles sin que de ellas se arribe a conclusiones prácticas y superadoras.

Esto demuestra que como sociedad nos debemos al menos dos cosas: debates serios para arribar a posibles soluciones y preparación de los ciudadanos para la democracia participativa.

Creemos que es la educación la que nos permite ampliar el horizonte y concebir planes de vida propios, reconociendo el derecho de los demás a un plan de vida diferente y la consiguiente obligación de respetarlo, a la vez que supone la posibilidad de prevenir problemas que se presentan en la convivencia diaria por falta de esta.

No tenemos dudas de que solamente a través de la educación pueden inculcarse valores, entre ellos, el respeto al prójimo y la tolerancia, para de ese modo formar ciudadanos comprometidos y preparados para vivir en democracia.

Entendemos que estar capacitados para situaciones diarias, como, por ejemplo, esperar el turno de cada uno o -como cotidianamente se suele decir- "no colarse en la fila", son principios y valores que se aprenden desde niños en el seno familiar.

Por ello, cuando hablamos de educación no solo nos estamos refiriendo a la que se imparte en las escuelas. También debemos mencionar el rol esencial que cumple la familia ${ }^{3}$ como institución básica que existe en nuestra sociedad y en la cual, sobre todo en los primeros años de vida, el aprendizaje y la transmisión de valores parece darse en forma más marcada. Es durante la niñez cuando aparece el desarrollo del potencial, que más adelante servirá para alcanzar la autonomía y construcción de un pensamiento crítico.

Es en la familia donde surgen los primeros conceptos, hábitos y costumbres, que luego se transmiten de generación en generación, esas pautas y reglas, tales como esperar el turno para hablar, escuchar al otro, ayudar, colaborar, ordenar son las que luego dan sentido a los valores y principios que se practicarán, primero en el grupo primario familiar, luego en el jardín, en la escuela, con los amigos y así hasta llegar a relacionarnos con el resto de la sociedad. Por ello, la educación es importante no solo desde un punto de vista formal. También es fundamental la formación familiar, porque, junto con aquella, contribuye al desarrollo integral del ser humano.

3 El artículo 75, inciso 19 de la Constitución Nacional expresamente contempla: “... la participación de la familia y la sociedad, la promoción de los valores democráticos y la igualdad de oportunidades y posibilidades sin discriminación alguna...”. 
Confucio enseñaba, 500 años a. C., que:

\begin{abstract}
Quienes deseaban tener ordenada su vida nacional regulaban primero su vida familiar; los que deseaban regular su vida familiar cultivaban primero sus vidas personales; los que deseaban cultivar sus vidas personales enderezaban primero sus corazones; quienes deseaban enderezar sus corazones hacían primero sinceras sus voluntades; y quienes deseaban hacer sinceras sus voluntades llegaban primero a la comprensión; la comprensión proviene de la exploración del conocimiento de las cosas. Cuando se gana el conocimiento se logra la comprensión; cuando se gana la comprensión la voluntad es sincera; cuando la voluntad es sincera el corazón se endereza; cuando el corazón se endereza se cultiva la vida personal; cuando la vida personal se cultiva, se regula la vida familiar; cuando ello ocurre la vida nacional es ordenada, y cuando la vida nacional es ordenada, el mundo está en paz. Desde el emperador hasta el hombre común, el cultivo de la vida personal es el cimiento para todo. Es imposible que cuando los cimientos no están en orden se halle en orden la superestructura. Jamás ha habido un árbol de tronco delgado cuyas ramas superiores sean pesadas y fuertes.
\end{abstract}

Si una sociedad justa requiere un intenso sentimiento comunitario, tendrá que encontrar una forma de cultivar en los ciudadanos una preocupación por el conjunto, una dedicación al bien común. No puede ser indiferente a las actitudes y disposiciones que los ciudadanos llevan consigo a la vida pública. Debe encontrar una manera de apartarse de las nociones puramente privatizadas de la vida buena y cultivar la virtud cívica (Sandel, 2011, pp. 165).

\title{
7. Sobre el derecho a la educación en la Argentina. Breve referencia al marco normativo
}

Todo ser humano tiene un derecho elemental a educarse. El mínimo y el máximo de esa educación está dado por factores diversos, como ser la propia capacidad, la propia pretensión, los medios de los que individual y socialmente dispone y las políticas que la constitución le impone al Estado (Bidart Campos, 2000, p. 40).

El derecho a la educación, como todos los derechos humanos, le impone tres tipos o niveles de obligaciones al Estado: respetar, proteger y cumplir. Esta última, a su vez, implica la obligación de facilitar y de proveer. La obligación de respetar exige que el Estado evite las medidas que obstaculizan o impiden el disfrute del derecho a la educación. La obligación de proteger le impone al Estado adoptar medidas que eviten que el derecho a la educación sea entorpecido por terceros. La obligación de cumplir exige tanto que el Estado adopte medidas 
positivas que les permitan a los individuos y comunidades disfrutar del derecho a la educación y les preste asistencia como la obligación misma de cumplir con dicho derecho (Calogero, 2002, pp. 146-147).

En otro orden de ideas, María Angélica Gelli (2015) sostiene que:

La educación formal, la impartida en los niveles y con las modalidades establecidas por el Estado siempre se nutre, en su organización, funcionamiento y métodos, en objetivos presupuestos. La finalidad expresa o implícita de la educación indica el ideario, los valores metapolíticos y metajurídicos que emergen de la sociedad y condicionan la política arquitectónica. Esa finalidad se origina de una cosmovisión del mundo, de la persona humana y de las relaciones sociales. Claro que puede suceder que esos idearios declarados se sustituyan, en los hechos, por otros diferentes y en contradicción con aquellos. (pp. 11-12)

En nuestro país, para el ejercicio del derecho a la educación se prevé una serie de principios tales como: gratuidad, equidad, solidaridad, igualdad de oportunidades y posibilidades sin discriminación alguna y promoción de los valores éticos y democráticos, libertad de cátedra o libertad académica para enseñar y aprender.

Desde el año 1853, el derecho a la educación en Argentina se encuentra constitucionalmente consagrado como un derecho individual de enseñar y aprender. Incluso podemos decir que se encuentra contemplado en el preámbulo dentro del propósito de promover el bienestar general. Fue conservado en las sucesivas reformas y replicado en las constituciones provinciales, en cumplimiento de la encomienda dispuesta en la propia carta magna en la cual se garantiza el sistema representativo, republicano y federal de gobierno y, entre otras cuestiones, especialmente la educación primaria para la población en sus respectivos territorios.

La Ley 1420 de Educación Común, del año 1884, se convirtió en la base normativa fundamental del sistema educativo nacional. Esta norma consagró la instrucción primaria obligatoria, gratuita y gradual, la formación de maestros, el financiamiento de las escuelas públicas y el control de la educación, la creación de un Consejo Nacional de Educación y de consejos escolares, cuyo deber era inspeccionar la calidad, higiene y cumplimiento de las leyes en las escuelas.

En el año 1905, con el dictado de la Ley 4874 (denominada Ley Láinez) se habilitaba a las provincias a crear y dirigir establecimientos de nivel primario de acuerdo con los lineamientos de la Ley 1420.

Cabe mencionar que en la reforma constitucional de 1949 (derogada en el 
año 1957) se incluyó una serie de derechos como los de la cultura, el trabajador (entre los que se menciona el derecho a la capacitación), la educación, la creación de escuelas primarias, secundarias, universitarias y académicas, y se previó además el otorgamiento de becas.

En la última reforma constitucional (año 1994) se establecen -en el artículo 75 , incisos 18 y 19- las disposiciones que deben leerse en conjunto y que ligan las políticas y organización educativa con el progreso de la ilustración, distribuyendo, en cabeza del Congreso Nacional, dictar los planes de instrucción general y universitaria y, en las provincias, la estructura y organización de los demás ciclos o grados de enseñanza.

El mencionado inciso 19 consagra la adopción de políticas públicas en materia de educación bajo los principios de gratuidad y equidad y establece de modo definitivo la responsabilidad indelegable del Estado, la participación de la familia y la sociedad, la promoción de valores democráticos y la igualdad de oportunidades y posibilidades sin discriminación alguna en materia educativa.

No podemos dejar de citar el inciso 22 introducido en la reforma constitucional de 1994, que les asigna jerarquía constitucional a diversos tratados internacionales referidos, entre otros, al derecho en análisis. Podemos mencionar la Convención Americana sobre Derechos Humanos - Pacto de San José de Costa Rica (artículo 30 ap. a y b); el Pacto Internacional de Derechos Económicos, Sociales y Culturales (artículos 10.1, 13, 14 y 15); la Declaración Universal de los Derechos Humanos (artículo 26). También se han incorporado con rango constitucional obligaciones del Estado relativas a sujetos de especial protección en materia educativa en la Convención Internacional sobre la Eliminación de Todas las Formas de Discriminación Racial (artículo 5 v) y 6); la Convención sobre la Eliminación de Todas las Formas de Discriminación contra la Mujer (artículo 10); la Convención contra la Tortura y otros Tratos o Penas Crueles Inhumanos o Degradantes (artículo 10); la Convención sobre los Derechos del Niño (artículos 28, 29 y 30); y la Convención sobre los Derechos de las Personas con Discapacidad (artículo 24).

A nivel nacional, la Ley Federal de Educación 24195 destaca, como dato de relevancia, que la educación es un servicio público que puede ser gestionado por el sector público y por el privado. Esta equiparación entre educación pública y privada posibilita el derecho a las familias a elegir la educación de los hijos.

Por su parte, la Ley 24521 regula el nivel de Educación Superior, estableciendo en su artículo 1 que el Estado nacional, las provincias y la Ciudad Autónoma de Buenos Aires tienen la responsabilidad principal e indelegable sobre 
la educación superior, en tanto la educación y el conocimiento "son un bien público y un derecho humano personal y social en el marco de lo establecido por la ley 26206". ${ }^{4}$

La Ley 26206 de Educación Nacional hace referencia al desarrollo de políticas de promoción de la igualdad educativa, destinadas a enfrentar situaciones de injusticia, marginación, estigmatización y otras formas de discriminación; la necesidad de asegurar condiciones para la inclusión, el reconocimiento, la integración y el logro educativo, además de asignar recursos presupuestarios con el objeto de garantizar la igualdad de oportunidades y resultados educativos para los sectores más desfavorecidos de la sociedad.

A este plexo normativo se le agrega la Ley 26061 de Protección Integral de los Derechos de los Niños, Niñas y Adolescentes. Esta norma también reconoce que las niñas, niños y adolescentes con capacidades especiales tienen todos los derechos y garantías consagrados y reconocidos en ella, además de los inherentes a su condición específica. Garantiza, entre varios postulados, el acceso a la educación y la obligación de expedir la certificación o diploma correspondiente.

Por su parte, la Ley 26075 regula el financiamiento educativo, y la Ley 26150 contempla la educación sexual integral.

De la reseña efectuada se vislumbra que ya en la Constitución histórica de 1853 la educación, si bien no fue considera como derecho fundamental, ocupó un lugar preponderante como libertad de educar y aprender, que lo vincula como un derecho civil y político, poniendo en cabeza del Estado la responsabilidad para garantizar el desarrollo y promoción de la educación en todo el país.

El elenco de normas citadas produjo cambios significativos en el reconocimiento de la educación como derecho fundamental, con principios, deberes y obligaciones para los Estados nacional y provinciales y es garantía para todos los ciudadanos.

\section{Propuestas de cambio}

La educación cívica como parte integrante de todos los planes de estudio Desde los orígenes de la escuela pública, en los países democráticos se había establecido una instrucción cívica destinada a enseñar no solo los conocimientos sobre el sistema político de cada nación, sino también una formación básica acerca de normas de urbanidad y convivencia social.

4 Artículo sustituido por el artículo 1 de la Ley 27204, BO 11/11/2015. 
En nuestro país, la materia ocupa un lugar residual con muy poca carga horaria y escaso contenido en aquellos establecimientos educativos, generalmente secundarios, en donde se la dicta bajo las denominaciones de: "Instrucción Cívica", "Educación Cívica" "Derecho", "Formación Ciudadana” o "Ciudadanos".

La educación cívica implica la formación de los miembros de una comunidad humana en una conciencia viva de pertenencia a esta, en todo un conjunto de habilidades y aptitudes para participar en su dinámica y en el compromiso de mejorarla desde una sana visión crítica hasta una auténtica implicación personal (Jordán, 2003).

La formación de aptitudes para participar en la dinámica social implica la enseñanza de hábitos, de valores y de actitudes positivas para la convivencia con los semejantes. Incluye el aprendizaje de conceptos como "justicia", "dignidad", "respeto" y todo lo que tenga relación con una amplia formación en valores que puedan volcarse a la vida en comunidad.

Ahora bien, podría pensarse que el Estado deja de ser neutral si incorpora la educación cívica obligatoria en los planes de estudio. Sin embargo, a poco de analizar se advierte que no por ello el Estado asumiría un rol paternalista, ya que no se obliga a que las personas adopten el plan de vida de otro ni se impone desde el Estado un plan de vida determinado (Bobbio et al., 1994). ${ }^{5}$

Por el contrario, si se educa en el respeto mutuo y la tolerancia, es posible que muchas situaciones hoy conflictivas puedan evitarse en el futuro. En ese orden de pensamiento, podríamos incluso revertir la tasa de accidentes de tránsito, ya que no puede olvidarse que en nuestro país la mayoría de los accidentes ocurren por "no respetar" señales de tránsito, semáforos, preferencia del peatón en cruces peatonales, circulación por la banquina y en rotondas, entre otros.

Así, Carlos Nino (2014, p. 239) resaltaba que la enseñanza de la Constitución se toma con ligereza en todas las escuelas e incluso en los ámbitos universitarios. Que buena parte de la gente, aun con cierto grado de educación, cree que un presidente puede sancionar una ley. No se conocen las funciones de los cuerpos legislativos ni se enseñan pautas básicas del código penal ni normas impositivas ni de tránsito.

5 Bobbio et al. (1994) enseñan que en el lenguaje común el paternalismo indica una política social tendiente al bienestar de los ciudadanos y del pueblo, que excluye la participación de estos: es una política autoritaria y benévola al mismo tiempo, una actitud asistencial ejercida desde arriba. Sin embargo, no parece que la obligatoriedad de la enseñanza de la educación cívica sea una actitud paternalista, por el contrario, les permitiría a los ciudadanos mejorar su participación en el bienestar de la sociedad y, por ende, en el propio, lo que les posibilitaría un comportamiento típico de adultos. 
Todo esto puede ser modificado y mejorado mediante la enseñanza de la educación cívica en escuelas públicas y privadas en todos los niveles educativos.

La educación cívica obligatoria no solo no le haría daño a nadie, sino que, por el contrario, es un inmenso valor al que todos deberíamos poder acceder.

Así, pues, es importante destacar que hay normas intersubjetivas necesarias para la vida cívica que deben promoverse para materializar la autonomía personal que el liberalismo ensalza. Una de las formas de promover tales normas es a través del proceso educativo. Es inevitable recurrir a ese proceso para promover virtudes en los individuos que les permitan alzar su plenitud personal (Nino, 2014, pp. 233-235).

Con ello queremos transmitir que el dictado de materias como "Educación Cívica", "Ciudadanos" o "Derecho", junto con aquellas como Filosofía, Sociología, Historia e incluso Antropología, contribuyen como herramientas necesarias para la formación de ciudadanos que fortalezcan el sistema democrático de gobierno en la medida en que puedan ejercer y respetar sus derechos. Si algo nos demuestra la historia es que en épocas de Gobiernos autoritarios o totalitarios lo primero que se suprimen son este tipo de materias como parte del plan sistemático para silenciar a la sociedad.

Es la educación la que nos permite ampliar nuestras perspectivas, ser capaces de valorar los aportes del otro, acceder a la dimensión de la dignidad humana y a la comprensión de su esencia y ser, en definitiva, verdaderamente libres en tanto conocedores de las opciones disponibles y de las consecuencias que traen aparejadas las decisiones voluntarias.

Parece imposible pensar en una sociedad avanzada en la que no prevalezca el respeto mutuo. Es curioso cómo nos quejamos de muchos males de la vida cotidiana, desde el que estaciona en doble fila hasta el que circula por la banquina en una ruta infringiendo toda norma de tránsito. Sin dudas, son todas muestras de falta de respeto hacía la propia vida y la de los demás. Pero ¿hasta qué punto conocemos realmente esos valores? ¿Hasta qué punto se puede percibir lo que la propia vida implica, lo que es la dignidad, el derecho de los demás a ser respetados en sus vidas y en sus bienes, o el hecho de que las convicciones propias no son suficientes para ofender a los que no las comparten?

Es sabido que no todas las personas que conviven en nuestra sociedad tienen la posibilidad de acceder al conocimiento ni a la información necesarios para llegar a comprender tales valores y su magnitud. También es cierto que muchas otras sí los tienen y que es preciso que comiencen a ponerlos en práctica para mejorar la sociedad en la que vivimos. 
La enseñanza de ética profesional en las universidades

Sería deseable que la educación integral se completara con la enseñanza de la ética en las universidades.

Referimos a la ética como un conjunto de valores y principios a partir de los cuales los seres humanos actuamos y decidimos. También nos ayuda a desarrollar capacidad reflexiva y de discernimiento para manifestarnos de una $\mathrm{u}$ otra manera.

Los planes de estudio en nuestro país -y en varios países de Latinoamérica- parecen agotarse con la transmisión de conocimientos científicos olvidando la formación de la conducta. El ingreso a la universidad, sobre todo a las universidades públicas, parece librarnos al estudio de una carrera de la que no conocemos las condiciones de su ejercicio. ${ }^{6}$

En la mayoría de las universidades se olvida la necesidad de brindar una preparación integral al futuro profesional. Así, por ejemplo, se enseñan leyes en vez de derecho, se enseñan teorías en vez de preparar al alumno para pensar que el derecho es un instrumento para ordenar el conflicto y hacer justicia. Sobre todo en las carreras universitarias que tienen una función de servicio social (destacándose, entre ellas, la abogacía y la medicina), la formación ética no debería ser dejada de lado porque implica también el mejoramiento de la persona en sí misma y no solo la mera destreza para la aplicación automática de conocimientos.

No debemos olvidar que el origen de las profesiones se encuentra en la necesidad de satisfacer de la mejor manera posible los requerimientos que en el hombre y la vida social fueron apareciendo. La génesis de las profesiones tiene ese enclave ético en tanto que con ellas se buscó satisfacer requerimientos humanamente valiosos (Vigo, 2007, pp. 41-42).

Es que también muchos problemas de la vida moderna podrían evitarse si se forjaran ciudadanos más responsables dedicados a cumplir con la finalidad de sus carreras y aspirar a la excelencia más que a conducirse como burócratas con total desapego de la función social de sus profesiones y empleos.

En definitiva, las propuestas de las que hablamos pueden no ser novedosas o revolucionarias, de hecho, formaron parte de los planes de estudio e incluso existen en la actualidad en los programas académicos de varias escuelas y uni-

6 Escribía la poeta peruana Blanca Varela (1986) en el poema "Curriculum vitae”: "Digamos que ganaste la carrera y que el premio era otra carrera. Que no bebiste el vino de la victoria sino tu propia sal. Que jamás escuchaste vítores sino ladridos de perros. Y que tu propia sombra fue tu única y desleal competidora" (p. 164). 
versidades. Lo importante es que contribuyen en buena medida al debate sobre el tipo de educación necesaria para la democracia participativa.

En esa línea de pensamiento, debemos recordar que:

\begin{abstract}
Así como no se aprenden la biología, las matemáticas, a leer o escribir por el solo hecho de estar en el mundo, tampoco se aprende a vivir en democracia y respetar los derechos humanos por el solo hecho de vivir en una sociedad democrática y en una cultura respetuosa de los derechos humanos. Nadie puede negar que esta es una condición necesaria, pero todos sabemos también que no es una condición suficiente. Se requiere intencionar deliberadamente este aprendizaje. (Magendzo, 1994, p. 142)
\end{abstract}

Entendemos que con estos aportes se lograría completar y mejorar el sistema educativo para la formación de ciudadanos como seres humanos integrales (completos libres y comprometidos) y como partes de una sociedad que requiere-imperiosamente- respeto, tolerancia, empatía y cooperación.

\title{
9. Conclusión
}

Este análisis se inició con la referencia a un artículo periodístico que daba cuenta de una disputa que llevó el lema "cancha sí, escuela no". Una disputa como cualquiera de las que acaecen a diario en nuestro país.

Fue simplemente un disparador que motivó la necesidad de reflexionar sobre el derecho a la educación no solo desde una perspectiva jurídica y filosófica, sino también como parte del comportamiento político y social de los cuales el Estado, organizaciones, personas jurídicas y ciudadanos somos protagonistas.

Entendemos que el respeto por el otro es fundamental y es base de la tolerancia. A su vez, el ejercicio de la libertad no puede concebirse solo en términos de espontaneidad, sino que también requiere su coherencia con los distintos proyectos de vida y con la vida social en común.

Ello no significa de ningún modo sostener que el Estado deba imponernos propósitos de vida ni decirnos de qué forma podemos ser más felices. Tampoco implica que tengan que inculcarse determinados valores o ideales. Sí, en cambio, pensamos que solo en una sociedad basada en el respeto mutuo y la tolerancia es posible que los planes de vida y la autonomía personal puedan concretarse. Caso contrario, la falta de respeto y de educación incidirán hasta en la continuidad de la vida misma, sin la cual el proyecto personal quedará truncado. 
La idea de que la libertad de uno termina donde empieza la del otro resulta individualista e insuficiente para la época que nos toca vivir. Ello no quiere decir que sea errónea, sino que para poder convivir hace falta un poco más que solamente ejercer mi libertad sin dañar a otro. La historia nos ha demostrado que hombres y mujeres debemos contribuir con la sociedad de la que formamos parte para poder gozar -verdaderamente- de nuestra libertad.

Para ello, y como lo analizamos más arriba, es importante poner al derecho a la educación en el lugar prioritario que le correspondió, desde el pensamiento filosófico antiguo, y en el que fue incorporado por nuestros constituyentes.

La educación es, por un lado, una obligación ineludible del Estado y, por el otro, una formación que no solo se imparte en las escuelas, sino que la familia cumple en ella un rol esencial.

Si queremos vivir en una sociedad justa, debemos encontrar una forma de cultivar en los ciudadanos su preocupación por el conjunto y la voluntad de trabajar por el bien común. Creemos que una manera de lograr tal cometido es incluir a la educación cívica como parte esencial en los planes de estudio de todos los niveles. Esta propuesta debería complementarse con la enseñanza de la ética profesional en las universidades.

Como quedó demostrado, la educación es un derecho reconocido constitucionalmente tanto en el ámbito federal como en el provincial. Este derecho es notablemente enriquecido con las leyes nacionales y con las disposiciones específicas que surgen de los tratados internacionales.

Queremos destacar que, tal y como lo postula la Ley 24521, la educación es una responsabilidad principal e indelegable del Estado en tanto es un bien público y un derecho humano personal y social.

En consecuencia, estamos convencidas de que cumplir dicha obligación desde el Estado y desde el rol que cada uno ocupa en la sociedad implica demostrar qué país queremos, qué tipo de democracia merecemos y en qué sociedad deseamos realmente vivir.

Anhelamos que la educación nos permita superar las disputas, las confrontaciones vacías, el conflicto y la violencia en pos del crecimiento, la tolerancia y el respeto. 


\section{Bibliografía}

Atienza, M. (2003). Entrevista a Ricardo Guibourg. DOXA. Cuadernos de Filosofía del derecho, (26), 893-917. https://doi.org/10.14198/DOXA2003.26.36.

Bidart Campos, G. (2000). Manual de la Constitución reformada (Tomo I). Ediar.

Bobbio, N., Mateucci, N. y Pasquino, G. (1994). Diccionario de politica. Siglo XXI.

Calogero, P. (2002). Constitución Nacional comentada, anotada y concordada junto a los tratados internacionales y la jurisprudencia de organismos internacionales de Control. Ediciones Jurídicas Cuyo.

Frankl, V. E. (1978) Psicoanálisis y existencialismo. Fondo de Cultura Económica.

Fromm, E. (1986). El miedo a la libertad. Paidós.

Gelli, M. A. (2015). Educación y cultura, espejos de la política argentina. Comunicación de la académica María Angélica Gelli, en sesión privada de la Academia Nacional de Ciencias Morales y Políticas, el 25 de noviembre de 2015. https://www.ancmyp.org.ar/user/files/ Gelli-D-15.pdf.

Guibourg, R. (2004). La construcción del pensamiento: decisiones metodológicas ( $1^{\mathrm{a}} \mathrm{ed}$.). Colihue.

Guibourg, R. (23 de marzo de 2012). Cómo no Torturar. La Ley.

Jaeger, W. (1957). Paideia, libro III, cap. IX, (La República II). Fondo de Cultura Económica.

Jordán, J. A. (2003). Concepto y objeto de la educación cívica. Estudios sobre educación, (4).

Kant, I. (2008). Teoría y praxis. Prometeo Libros.

Magendzo, A. (1994). Formación de profesores para una educación para la vida democrática y el respeto de los derechos humanos. En Educación en Derechos Humanos: Apuntes para una nueva práctica (pp. 139-146). Corporación Nacional de Reparación y Reconciliación. http://www.piie.cl/biblioteca/publicaciones/libros/L-1994-053.pdf.

Marconiz, C. (9 de marzo de 2021). Impedir la construcción de una escuela es un crimen. El Tribuno. https://www.eltribuno.com/jujuy/nota/2021-3-9-1-0-0-impedir-la-construccionde-una-escuela-es-un-crimen.

Marx, C. y Engels, F. (2000). Manifiesto Comunista. El Aleph.

Nino, C. (2014). Un Pais al margen de la ley (4a ed.). Ariel.

Pérez Luño, A. E. (2005). Derechos humanos, Estado de Derecho y Constitución (9a ed.). Tecnos.

Sánchez, A. M. (2020). La enseñanza de la ética en tiempos de relativismo. Revista Jurídica Austral, 1(2), 907-928. https://doi.org/10.26422/RJA.2020.0102.sanc.

Sandel, M. J. (2011). Justicia iHacemos lo que debemos? Penguin Random House.

Varela, B. (1986). Canto Villano. Poesía reunida 1949-1983. Fondo de Cultura Económica.

Vigo, R. L. (2007). Ética y responsabilidad judicial (1ª ed.). Rubinzal Culzoni.

Vigo, R. L. (2008). Visión crítica de la historia de la filosofía del derecho. Rubinzal Culzoni.

Yepes, R. y Aranguren, J. (2009). Fundamentos de antropología. Un ideal de la excelencia humana.

Ediciones Universidad de Navarra. 


\title{
AUTONOMÍA MUNIIIPAL EN EL FALLO
}

\section{Municipaldoad de Esperanza C/Provincia de Santa FE. Corte Suprema de Justicia de Santa Fe}

\section{Agustín López Olocco}

Universidad Nacional de Córdoba

agustin.lopez.olocco@mi.unc.edu.ar

\section{Resumen}

El presente trabajo consiste en una explicación del leading case de la Corte Suprema de Justicia de la Provincia de Santa Fe, Municipalidad de Esperanza c/Provincia de Santa Fe s/Recurso contencioso administrativo, de fecha 25 de abril de 2006. Se pretende elaborar un análisis preciso y minucioso desde una mirada crítica del rol de los jueces en la aplicación del artículo 123 de la Constitución Nacional. Se busca resaltar la importancia del respeto de la autonomía municipal desde un enfoque con clave en la supremacía constitucional. Este análisis fue elaborado en el marco del II Seminario de Derecho Municipal del Centro de Investigaciones Jurídicas y Sociales de la Universidad Nacional de Córdoba. A su vez, el método de estudio se basa en el modelo jurídico multidimensional propuesto por el jurista cordobés Fernando Martínez Paz (2005).

Palabras clave: poder de policía, medioambiente, exención tributaria, poder fiscal, autonomía municipal.

\section{Municipal Autonomy in the Leading Case Municipalidad de Esperanza c/Provincia de Santa Fe. Corte Suprema de Justicia de la Provincia de Santa Fe}

\begin{abstract}
This work consists of an explanation of the leading case of the Corte Suprema de Justicia de la Provincia de Santa Fe, Municipalidad de Esperanza c/Provincia de Santa Fe s/Recurso contencioso administrativo, dated April 25, 2006. It is intended to elaborate a precise and meticulous analysis from a critical perspective of the role of judges in the application of article 123 of the National Constitution (hereinafter: CN). It seeks to highlight the importance of respect for municipal autonomy from an approach with a key to constitutional supremacy.
\end{abstract}


It is made within the framework of the II Municipal Law Seminar of the Centro de Investigaciones Juridicas y Sociales of the U. N. C. In turn, the study method is based on the multidimensional legal model proposed by the lawyer Fernando Martínez Paz (2005).

Key words: police power, environment, tax exemption, fiscal power, municipal autonomy.

\section{Introducción}

En las sesiones del II Seminario de Derecho Municipal del Centro de Investigaciones Jurídicas y Sociales de la Universidad Nacional de Córdoba, se llevó a cabo una serie de debates en torno a cierta jurisprudencia específica. Esta versó sobre algunos de los fallos más importantes de los máximos tribunales de justicia de tres provincias argentinas: Buenos Aires, Santa Fe y Mendoza.

El tema objeto de análisis fue la autonomía municipal, y las tres provincias mencionadas fueron elegidas por una particular razón. Guillermo Barrera Buteler (2010a) entiende que sus constituciones provinciales son inconstitucionales en lo que refiere a la autonomía de los municipios. Ello es así porque estas no consagraron normativamente la naturaleza jurídica del municipio como lo manda el artículo 123 de la Constitución Nacional (en adelante, CN). De tal modo, el objetivo principal de estas jornadas fue estudiar el rol que tuvieron los jueces en la corrección de esta falencia.

Uno de los fallos objeto de estudio fue Municipalidad de Esperanza c/Provincia de Santa Fe (2006). Allí, la Corte Suprema de Justicia de la Provincia de Santa Fe estaba compuesta por los señores ministros Roberto Héctor Falistocco, María Angélica Gastaldi, Mario Luis Netri, Eduardo Guillermo Spuler (según su voto) y Rodolfo Luis Vigo, con la presidencia de Rafael Francisco Gutiérrez.

La Municipalidad de Esperanza entendía que ciertos decretos y leyes provinciales se estaban inmiscuyendo en potestades propias del municipio. Estas facultades giraban en torno a su poder tributario, poder de policía sanitario, de higiene urbana y medioambiental e incluso sobre planificación urbana y servicios públicos.

La intromisión alegada como ilegítima era la intención de la provincia de Santa Fe de regular y prestar el servicio público de provisión de agua potable y desagües. En este sentido, la provincia impuso una exención tributaria municipal, licitó y adjudicó la prestación del servicio y limitó la posibilidad del municipio de ejercer control sobre la actividad.

Lo resuelto por este fallo fue contrario a la pretensión de la Municipalidad de Esperanza, por lo que la Corte entendió que la autonomía municipal no era 
vulnerada en el caso concreto. Corresponde determinar el grado de acierto de la decisión (con su consiguiente impacto institucional) a partir de la descripción y estudio de los fundamentos empleados por las tres partes: la actora, la demandada y los jueces.

\section{Vía de acceso a la Corte}

La Ley 11330 regula el Recurso Contencioso Administrativo previsto en el artículo 93, inciso 2 de la Constitución de la Provincia de Santa Fe (en adelante, CP). Esta, en su artículo 35, se reserva una modalidad específica cuando el sujeto impugnante es un municipio o una comuna. Dicho artículo posee un trámite judicial especial y rápido, ya que es resuelto directamente por la Corte Suprema de Justicia cuando el Poder Ejecutivo provincial no hubiera dictado resolución dentro de los treinta días.

Sin embargo, este instituto procesal se encuentra reservado "contra los actos del Poder Ejecutivo de la Provincia que invadan ilegalmente la esfera de atribuciones de los Municipios y Comunas o desconozcan sus potestades o vulneren los derechos o intereses legítimos que el ordenamiento jurídico les reconoce" (artículo 35, Ley 11330). A pesar de que su redacción carece de comas, es un instrumento altamente novedoso que no se encuentra regulado en todas las provincias de Argentina.

La Municipalidad de Esperanza interpone el mentado recurso ante la Corte contra el Decreto 2141/1995 de la provincia de Santa Fe en $1998^{1}$ (Expediente 00306). Este es el que puso fin a un proceso licitatorio adjudicándole a Aguas Provinciales de Santa Fe S.A. la prestación de los servicios públicos de provisión de agua potable y desagüe. Empero, se reclamó la inconstitucionalidad de muchos artículos de la Ley 11220, en la que la Legislatura reglamentó cómo debía prestarse tal servicio en todo el territorio provincial.

La vía optada posibilitó un acceso rápido al máximo tribunal provincial, pero este resolvió en ocho años desde la primera presentación judicial. Ello demuestra, prima facie, la dificultad extrema que existe a la hora de hacer valer los derechos en el Poder Judicial.

El primer argumento esgrimido por la provincia para repeler esta acción fue la de sostener que la vía procesal no era la correcta. Ello por entender que el

1 Es menester resaltar que desde el primer reclamo administrativo, el 14 de septiembre de 1995, se interpusieron debidamente tres pronto despacho (11/12/1995, 09/12/1996, 01/12/1997), frente a lo cual el Poder Ejecutivo provincial guardó silencio absoluto. 
decreto de adjudicación de una licitación solo puede ser impugnado por aquellos que formaron parte del procedimiento. En alusión a esto, expresa que la Municipalidad debió iniciar una acción de inconstitucionalidad contra la Ley 11220. A pesar de ello, el recurso fue admitido formalmente por la Corte con el argumento de que el decreto del Poder Ejecutivo objeto de impugnación torna aplicable ciertos artículos de la Ley 11220 pretendidamente inconstitucionales por vulnerar facultades del municipio.

No obstante, el municipio sostiene que estas normas no garantizan ningún régimen municipal, por lo que es indistinto que se lo considere como una entidad autárquica o autónoma. Quizás, el municipio optó por esta alternativa argumental dadas las reiteradas interpretaciones de la Corte contrarias a la autonomía de los municipios.

\section{Poder tributario municipal}

El primer agravio expresado por la Municipalidad de Esperanza es el relativo al inciso n del artículo 70 de la Ley 11220, al que reputa como inconstitucional. Este refiere a los deberes y atribuciones de los prestadores del servicio:

Cumplimentando las disposiciones aplicables, utilizar la vía pública y el subsuelo para la obtención de fuentes de agua, la instalación de cañerías, conductos y otras obras o construcciones afectadas al servicio, sin cargo o gravamen alguno, de naturaleza provincial, municipal o comunal. Esto no incluye los costos vinculados a inspección de obra inherentes al poder de policía urbano y hasta el monto que efectivamente irrogue la inspección para el municipio o comuna que la realice.

De tal modo, se encuentra el municipio imposibilitado de cobrar la tasa de ocupación de dominio público. Lo único que puede percibir la municipalidad en concepto de tasa son los gastos que irrogue en inspeccionar tales obras. Ahora bien, ¿cómo es el régimen aplicable al poder tributario de un municipio de Santa Fe?

El artículo 123 de la CN expresa que las provincias deben asegurar la autonomía municipal y reglar el contenido y alcance de los cinco aspectos que enumera. Dos de estos aspectos son el económico y el financiero, que refieren a la potestad de los municipios de procurarse sus propios recursos y de administrarlos sin injerencia de ningún otro poder. Esto es, 
el reconocimiento con jerarquía constitucional de una capacidad de los municipios para decidir por sí mismos, sobre la cuantía de los recursos que han de obtener para atender a las necesidades públicas municipales, efectuando una libre, racional, armónica y organizada distribución de sus gastos. (Pidoux, 2020, p. 1)

De esto se desprende la indubitable potestad tributaria -propia del poder de imperio- que ostentan los municipios de toda la República Argentina. Sin embargo, si bien las provincias están obligadas a asegurar tal estatus, pueden reglamentarlo de manera diversa entre sus pares. En el caso que nos acoge, debemos ahondar en la regulación optada por la provincia de Santa Fe.

En primer lugar, la Constitución de Santa Fe, en su artículo 107, inciso 3, expresa que la ley debe proveer recursos financieros suficientes para gestionar los intereses locales del municipio, y continúa: "Pueden crear, recaudar y disponer libremente de recursos propios provenientes de las tasas y demás contribuciones que establezcan en su jurisdicción”. Ello implica que en la regulación provincial del "alcance y contenido" de este aspecto mínimamente se ha concedido a los municipios el poder de crear y recaudar tasas. A su vez, el artículo citado habla de "demás contribuciones", pero no corresponde ahondar en este asunto por cuestiones de extensión y relevancia.

Por otra parte, la Ley Orgánica Municipal de Santa Fe 2756 (en adelante, LOM) incorpora en su articulado una serie de normas dignas de análisis. En su artículo 2 se enuncia que los municipios: "Forman sus rentas, pudiendo establecer impuestos, tasas derechos o contribuciones, sobre los ramos y materias que se determinen, administran libremente sus bienes". A continuación, el artículo 39 enumera una serie de potestades de los concejos municipales, entre las que se encuentra crear impuestos (inciso 16) y fijar un presupuesto anual de gastos con cálculo de recursos (inciso 17).

Dado que es evidente que los municipios argentinos, incluidos los santafesinos, poseen poder tributario con raigambre constitucional, el debate del fallo comienza a centrarse en la potestad de la provincia de eximir transjurisdiccionalmente.

La Municipalidad de Esperanza, en su acción judicial, expresa que el artículo 70, inciso n de la Ley 11220 no se adecúa a los preceptos constitucionales en esta materia. En este orden de ideas, señala que el artículo 55, inciso 16 de la CP marca como potestad de la Legislatura conceder estímulos o privilegios, pero estos deben ser por tiempo indeterminado, con fines industriales y de carácter general, lo que en el caso concreto esto no se evidencia. Por otro lado, remarca que el artículo 55, inciso 22 de la CP tampoco regula esta situación, ya que habla de subsidios, no de exenciones. 
Frente a tales alegaciones, si bien la provincia no niega la potestad tributaria del municipio, tampoco la reconoce absolutamente, ignorando toda la normativa citada precedentemente. Menciona que la situación jurídica se enmarca verdaderamente en el artículo 55, inciso 27 de la $\mathrm{CP}$, que reza:

En general, ejercer la potestad legislativa en cuanto se considere necesario o conveniente para la organización y funcionamiento de los poderes públicos y para la consecución de los fines de esta Constitución, en ejercicio de los poderes no delegados al gobierno federal, sin otras limitaciones que las emergentes de dicha Constitución o de la Nacional.

La Corte, por su parte, acoge la tesis propuesta por la provincia. Entiende que el artículo 55, inciso 27 de la CP autoriza a la provincia a realizar tal exención municipal. Nada más alejado de la realidad, porque si tal precepto constitucional habilitara a realizar sin límites todo aquello que se considere "necesario", no tendría sentido redactar una constitución con división de poderes y asignación de potestades. En efecto, este artículo debe ser usado para llevar adelante las competencias propias, no las ajenas. El límite de esta facultad legislativa está dado por la propia Constitución de la Provincia de Santa Fe, por lo que mal podría entenderse que se puede realizar tal exención municipal cuando en el inciso 16 del mismo artículo se detallan las condiciones, las cuales no pueden eludirse.

Es curioso que la Corte, seguidamente, exponga una serie de fallos de la Corte Suprema de Justicia de la Nación referidos al artículo 75, inciso 18 de la CN, la mentada "cláusula del progreso". Estos son: Municipalidad de la Plata, Telefónica Argentina S.A. c/Municipalidad de General Pico; Gas Natural Ban S.A. c/ Municipalidad de Campana; Litoral Gas S.A. c/Municipalidad de Villa Constitución. Tales pronunciamientos son irrelevantes, ya que la normativa en cuestión no es la cláusula del progreso nacional. El hecho de que la nación realice exenciones provinciales en nada tiene relación con que la provincia realice exenciones municipales, porque las normas aplicables son diferentes.

Finalmente, la Corte manifiesta que el Municipio no acreditó venir cobrando la tasa con significativa trascendencia. Al respecto, cabe decir que es absurdo sostener que, con el correr del tiempo, el poder tributario de un municipio se pierde por su no uso. La Municipalidad de Esperanza no acreditó tal extremo porque era evidentemente innecesario. Ante tales posturas, Fazio (2010) se proclama férreo defensor de los intereses locales: "La posibilidad de imponer tributos deviene de un poder propio y no de una graciosa delegación efectuada 
en su favor por otros niveles de gobierno. Admitir lo contrario implicaría reducir el municipio a un mero administrador de fondos ajenos" (p. 345).

\section{Poder de policía sanitario, de higiene urbana y medioambiental}

El poder de policía es la facultad estatal de reglamentar los derechos y garantías constitucionales de los ciudadanos (Ávalos et al., 2016). Su carácter es eminentemente local (artículos 121 y 123 de la CN), por lo que su ejercicio le compete como regla a provincias y municipios. Se evidencian tres formas de su función: la reglamentaria, la preventiva o de control y la represiva. Además, María Angélica Gelli (2004) entiende que facilita la convivencia social, la libertad y el bienestar general.

En el Estado federal argentino, de gran extensión, existe una multiplicidad de conflictos de jurisdicción constantes, más aún en materias como la contaminación ambiental y salubridad, en las que los límites territoriales se convierten en meras ficciones jurídicas.

Frente a esta dificultad, se dictó el artículo 41 de la $\mathrm{CN}$, que asegura el derecho constitucional a un medioambiente sano. A su vez, se impone el deber a las "autoridades" de proteger este derecho, aunque sin hacer referencia a su procedencia nacional, provincial o municipal, lo que parece indicar una concurrencia necesaria entre estas. La nación dicta una ley de presupuestos mínimos, mientras que las provincias deben complementarla.

Al no hacer mención a los municipios, comienzan a forzarse interpretaciones. Un ejemplo de ello es que la Municipalidad de Esperanza, en el fallo en cuestión, entiende que la mención de la palabra "aquéllas", en la expresión "sin que aquéllas alteren las jurisdicciones locales", hace referencia a las provincias que no deberían inmiscuirse en los intereses locales del municipio. Sin embargo, esto es incorrecto, ya que el vocablo alude a las normas que dicte la nación, y "jurisdicciones locales" comprende tanto provincias como municipios sin asignar preeminencia a ninguno de estos. El inconveniente surge, entonces, para determinar cuándo debe actuar el municipio y cuándo la provincia. Es inteligible que existe en materia de poder de policía medioambiental una concurrencia de funciones, es decir, que los tres órdenes de gobierno tienen potestades para reglamentar, controlar y sancionar. Se requiere una acción conjunta entre todos estos actores para armonizar funciones e instituciones a partir de una concertación y coordinación que permita alcanzar los objetivos sin que los conflictos entre estados menoscaben los derechos de los habitantes. 
La Municipalidad de Esperanza pretende determinar cómo se debe llevar a cabo en su territorio la prestación del servicio de agua y saneamiento, realizar un control preventivo sobre el actuar del prestador y sancionar el incumplimiento de tales normas dictadas por su Gobierno local. Encuentra algunas dificultades para esto en la Ley 11220, la que parece limitar las potestades del municipio en este sentido. En su artículo 20, asigna el poder de policía al Ente Regulador de Servicios Sanitarios de la provincia. Aunque los artículos 25 y 54 otorguen cierta participación a los municipios, entiende que no son suficientes, ya que el artículo 100 dispone que el Ente Regulador "podrá obligar a las autoridades locales a permitir la ejecución de los planes de mejoras y desarrollo" frente a la oposición de los municipios o comunas. Finalmente, el artículo 118 absorbe para los organismos provinciales todas las competencias de contralor y sancionatorias medioambientales.

El Municipio manifiesta que dicha normativa le imposibilita cumplir con las prerrogativas de la LOM contenidas en los artículos 39, incisos 52, 53 y 62 ; y 41 , inciso 24 , todos estos relativos a la preservación de la higiene general, desinfección de agua, salud y bienestar general del municipio. Asimismo, asevera que sus posibilidades de planificación urbanística y arquitectónica se encuentran disminuidas. Ello lo prueba por medio de una informativa -contenida en fojas 311/314 - practicada por un profesional arquitecto y especialista en gestión urbana. En su dictamen se marcó como imprescindible la necesidad de que el municipio ostente competencia y jurisdicción sobre los servicios mencionados, así como también que es imprescindible la presencia del municipio en la planificación por su calidad de receptor de las necesidades primarias de los vecinos.

La Corte no identificó en estos argumentos un menoscabo de los intereses locales. Así, enmarcó la situación jurídica en el artículo 72, inciso 5 de la CP, que estipula: "Provee, dentro de los mismos límites, a la organización, prestación y fiscalización de los servicios públicos", en referencia a las potestades del gobernador de la provincia. De tal modo, la Municipalidad de Esperanza se quedó sin la posibilidad de: combatir eficazmente el surgimiento de enfermedades; controlar la calidad de las aguas que beben; planificar el crecimiento demográfico de la ciudad; fijar nuevos barrios, parques industriales y reordenar la ciudad; determinar la calidad del aire que respiran; decidir la utilización del suelo y el grado de contaminación; e imponer sanciones.

Indubitablemente, este pronunciamiento no soluciona la problemática en cuestión. El municipio no puede gestionar sus intereses locales y la provincia 
no es alentada a concertar ni descentralizar funciones. Con cita al fallo Obras Sanitarias Mendoza S.A. c/Municipalidad de Rivadavia (2003) de la Suprema Corte de Justicia de Mendoza, la máxima autoridad judicial santafesina sentencia que el servicio público de agua potable y desagüe le compete a la provincia de Santa Fe por ser materia no delegada en la nación (artículo 121 de la CN). No debe sorprender que la Corte decida traer a colación un fallo de otra de las tres provincias argentinas que no reconocen la autonomía del municipio, como lo es la provincia de Mendoza.

Etcheverry (2006) entiende que hay una serie de servicios públicos eminentemente municipales, entre los que se pueden mencionar la provisión de agua potable y cloacas. Por esto, los intereses locales fueron dejados de lado en el fallo objeto de análisis. Un marcado desconocimiento territorial fue el imperante allí, ya que la provincia de Santa Fe tiene $133007 \mathrm{~km}^{2}$, de los cuales 289 $\mathrm{km}^{2}$ son de Esperanza. Frente a una comunidad que en un momento histórico determinado pretende ejercer un rol más activo, la provincia debería ceder y los jueces tendrían que alentar este actuar. Es insólito que un estado de tales dimensiones pretenda ejercer funciones que no puede y se mantenga sin intenciones de descentralizar al aparato burocrático-estatal.

Además, no se puede dejar de mencionar que el municipio es la entidad más próxima a los problemas locales, por lo que ostenta una posición privilegiada en su solución. Los servicios públicos son de las más importantes razones de la génesis del municipio (Bonifacino, 2010) porque procuran satisfacer las necesidades colectivas de la comunidad, motivo esencial de su existencia. Es por tal motivo que su participación debe acrecentarse no solo en Santa Fe, sino en toda la República Argentina.

\section{Antecedentes del servicio de provisión de agua potable y saneamiento}

Una de las defensas más fuertes esgrimidas por la provincia de Santa Fe es la relativa a los antecedentes históricos nacionales y provinciales sobre la regulación jurídica del servicio objeto de análisis. Argumenta que la normativa impugnada en nada innova la situación jurídica previa, en la que el municipio tampoco ostentaba las potestades que pretende. De tal modo, hace uso de la teoría de los actos propios, cuya aplicación implicaría que si Esperanza consintió la situación con anterioridad, no se encontraría en posición de reclamar. La Corte parece acoger este posicionamiento, pero sin ahondar demasiado.

El servicio público analizado comienza a ser responsabilidad del Gobierno 
nacional en el año 1892. Allí, mediante la Ley 2927 se creó la Comisión de Obras de Salubridad. Seguidamente, en pos de una mayor tecnificación, se creó el organismo denominado Obras Sanitarias de la Nación (OSN) a través de la Ley nacional 8889 de fecha 18 de julio de 1912. En el año 1949, se le impuso el carácter de empresa a OSN, pero bajo las directrices de la Subsecretaría de Recursos Hídricos del Ministerio de Obras y Servicios Públicos (Ley 13577).

Durante todos esos años, las provincias reclamaban su lugar en la participación de esta prestación, hasta que las presiones efectuadas comenzaron a dar frutos. En 1970, a través de la Ley 18586, se facultó al Poder Ejecutivo Nacional a transferir a las provincias los organismos y funciones nacionales que se prestaran en ellas. Sin embargo, recién diez años después se efectuó la mentada transferencia - por medio del Decreto 258/1980- de diversos servicios como el prestado por OSN.

Santa Fe, para poder prestar este servicio, creó la Dirección Provincial de Obras Sanitarias (DiPOS) hacia fines de 1980 con el dictado de la Ley 8711. Cabe resaltar que el capítulo XIII de esta norma excluye completamente a los municipios, asignando "potestad exclusiva a la Provincia en la materia". Luego, con la finalidad de privatizar la prestación del servicio, se comenzó a llevar a cabo un proceso licitatorio de este, que empezó con los decretos 3666/1994 y 3927/1994. Licitación que culminó con la adjudicación a la empresa Aguas Provinciales de Santa Fe S.A. al dictarse el Decreto 2141/1995, el que fue impugnado en el fallo objeto de análisis.

Es interesante remarcar que el trato que las provincias le exigían a la nación argentina hasta la década de 1980 es el mismo que les exigen los municipios a sus respectivas provincias desde tal fecha. Es insólito pensar que el servicio de agua y saneamiento puede prestarse para todo el país por un organismo que tiene sede en Buenos Aires. Las distancias existentes evidencian esta dificultad, haciendo nacer la necesidad de un federalismo de concertación que descentralice funciones. También es inaudito pretender que las provincias argentinas de gran tamaño puedan prestar el servicio, con todo lo que conlleva. Lo que es dificultoso comprender es por qué las provincias practican el mismo actuar que la nación tiene (o tuvo, en este caso) para con ellas, hacia sus municipios. Durante décadas, las provincias forzaron a la nación a delegar funciones, pero ahora son los municipios quienes batallan desde hace años contra sus provincias por los mismos motivos. 


\section{Supremacía constitucional y autonomía municipal}

La Constitución Nacional es el cuerpo normativo que le da unidad a todo el sistema jurídico de un país, representa un centro aglutinador de todo el derecho vigente y futuro. Así ha querido ser demarcado por su artículo 31, cuando expresa que esta es la "ley suprema de la Nación; y las autoridades de cada provincia están obligadas a conformarse a ella”.

En este sentido se ha pronunciado Del Rosario Rodríguez (2011):

La Constitución es suprema por los valores y principios fundamentales que alberga, por esta razón es que debe contener una fuerza normativa lo suficientemente eficaz que permita el funcionamiento estructural del sistema jurídico y, de esta manera, no existan elementos que se antepongan a ella. (p. 102)

Los jueces han sido instituidos como garantes de esta supremacía constitucional a través del control de constitucionalidad que están obligados a practicar. El deber judicial de preservar la supremacía de una Constitución rígida data del precedente Marbury v. Madison" (1803) de la Suprema Corte de los Estados Unidos.

Es evidente la importancia supina del control de constitucionalidad en el Estado de derecho constitucional. Gelli (2011, p. 1), en este sentido, expresa que se funda en "razones de política institucional y constituyente, en la preservación de la estructura del Estado y en la distribución de poder prevista en la Constitución”. Ahora bien, no surge de manera evidente que los jueces de la República Argentina sean verdaderos custodios de la Constitución. Ello, a la luz de las sistemáticas violaciones a esta, ya sea por particulares o por los estados mismos que conviven en este país.

El fallo que ha sido analizado cuidadosamente en este ensayo demuestra que los jueces que componían la Corte Suprema de Justicia de la Provincia de Santa Fe en el año 2006 no se esforzaron lo suficiente en defender al federalismo de concertación argentino. Se limitaron a tomar una decisión sin soluciones a una problemática con ocho años de antigüedad. Lo cierto es que el artículo 123 de la $\mathrm{CN}$ se vio vulnerado.

El ámbito de competencias no puede ser jamás una decisión discrecional del Estado, sino que se deben respetar un mínimo de atribuciones necesarias, por lo que tal reglamentación no puede desvirtuar o retacear indebidamente los fines propios del municipio (Barrera Buteler, 2010b). Sin un poder judicial fuerte, los habitantes se encuentran altamente desprotegidos. Es por ello que los jueces deben corregir los abusos a las constituciones. Esta desprotección es 
irremediable, ya que la instancia judicial es la última línea de defensa que las personas tienen.

\section{Conclusiones}

En los párrafos que anteceden se describieron los argumentos volcados en el fa1lo. Este presenta ciertas incoherencias, ya que lo resuelto no resuelve el problema. Además, la Corte reconoce expresamente la autonomía del municipio con cita de los fallos Rivademar y Municipalidad de Rosario. Sin embargo, en ambos, la Corte Suprema de Justicia de la Nación revocó el pronunciamiento de la Corte santafesina por entenderlo contrario a la autonomía municipal. Luego de varios años, y a pesar de los esfuerzos de la Corte nacional, los jueces santafesinos continúan vulnerando los Estados municipales.

El municipio es un estado, al igual que las provincias y la nación. Como tal, ostenta potestades y poderes propios e independientes de inmisiones ilegítimas. El constituyente nacional y provincial lo dispone así en este país, cuya extensión requiere una descentralización contraria a una concentración de poder. Una interpretación armónica de la CN lleva a la aplicación del principio de subsidiariedad del federalismo. Barrera Buteler (2008) lo explica claramente:

En virtud de este principio, la autoridad central debe permitir que cada comunidad local resuelva por sí todas aquellas cuestiones que hacen a su vida interna y no afecten a otra comunidad ni al conjunto de la federación y sólo deberá intervenir, subsidiariamente, cuando la entidad local no pueda hacerlo. (p. 6)

A la Municipalidad de Esperanza se le vedó la posibilidad de gestionar sus intereses locales. No pudo cobrar una tasa de suma importancia, ya que por medio de ella se arreglan las calles, se gestionan semáforos, se barren las veredas, se ilumina la vía pública y se ejercen diversos controles. Todos servicios necesarios para el funcionamiento del municipio y que son utilizados por la provincia y la empresa prestadora del servicio.

Además, el poder de decisión sobre el uso del suelo se quebrantó de manera patente. Una herramienta instrumental del federalismo es la concurrencia de funciones. Esta es impuesta por los constituyentes en diversas oportunidades para fomentar el diálogo entre los diversos órdenes de estado. Sin embargo, en la práctica esto no ocurre de tal modo e implica una lucha (muchas veces judicial) constante en determinar quién es el competente en cada caso. Más que fomentar la unión, este tipo de normas han generado conflicto permanente. 
Cabe preguntarse si la dirigencia de todo el territorio nacional argentino está a la altura de tales debates.

Las decisiones de los jueces, en particular de las máximas cortes provinciales, se encuentran altamente influenciadas por lo signos partidarios imperantes en la escena política del momento. Durante los años atinentes al fallo analizado -desde 1991 hasta 2007- fueron gobernadores de la provincia Carlos Reutemann (1991-1995; 1999-2003) y Jorge Obeid (1995-1999; 2003-2007), ambos por el Partido Justicialista. En simultáneo, en la Municipalidad de Esperanza el signo político era opuesto. Hasta el año 1995 fue intendente Carlos Fascendini y, a continuación, Rafael De Pace fue el titular del Ejecutivo municipal hasta 2007, ambos afiliados a la Unión Cívica Radical y al Partido Socialista. Esto lleva a concluir la alineación entre los jueces de la Corte y los gobernadores de provincia en desmedro de las autonomías municipales cuando el intendente no comparte banderas partidarias.

Parte del articulado de la Ley 11220 le impide a la Municipalidad de Esperanza gobernar sus propios intereses, por lo que se convierte en derecho opuesto a la constitución (artículo 123 de la CN), ergo, es derecho inválido (Sagüés, 2016). Lastimosamente, los jueces del fallo no defendieron los estandartes federales de la Constitución Nacional.

\section{Bibliografía}

Ávalos, E., Buteler, A y Massimino, L. (2016). Derecho Administrativo 1 (2 ed.). Alveroni Ediciones. Barrera Buteler, G. E. (2008). Estado unitario y formas federativas. En Barrera Buteler, G. E. (Dir.), Cuadernos de estudio: Derecho Público Provincial y Municipal, Cátedra "B". Facultad de Derecho, Universidad Nacional de Córdoba.

Barrera Buteler, G. E. (2010a). Marco normativo del Municipio. En Barrera Buteler, G. E. y Zarza Mensaque, A. (Dirs.), Introducción al Derecho Municipal (pp. 123-163). Advocatus.

Barrera Buteler, G. E. (2010b). El Municipio. En Barrera Buteler, G. E. y Zarza Mensaque, A. (Dirs.), Introducción al Derecho Municipal (pp. 7-33). Advocatus.

Bonifacino, N. (2010). Servicios Públicos. En Barrera Buteler, G. E. y Zarza Mensaque, A. (Dirs.), Introducción al Derecho Municipal (pp. 286-309). Advocatus.

Del Rosario Rodríguez, M. F. (2011). La supremacía constitucional: Naturaleza y alcances. Dikaion, Revista de actualidad jurídica, 20(1), 97-117.

Etcheverry, G. (2006). Aproximación al estudio del servicio público municipal como fenómeno multidimensional. En Bonifacino, N., Derecho Municipal Profundizado, Cuadernos de Estudio: Una propuesta para profundizar el estudio y análisis del Derecho Municipal a través del 
modelo juridico multidimensional (pp. 477-502). Facultad de Derecho y Ciencias Sociales, Universidad Nacional de Córdoba.

Fazio, J. (2010). Régimen económico-financiero municipal. En Barrera Buteler, G. E. y Zarza Mensaque, A. (Dirs.), Introducción al Derecho Municipal (pp. 337-364). Advocatus.

Gelli, M. A. (2004). Constitución de la Nación Argentina comentada y concordada (2a ed.). La Ley.

Gelli, M. A. (2011). El debido proceso adjetivo en el control de constitucionalidad y convencionalidad. En Sagüés, N. P. (Dir.), Jurisprudencia Argentina. Suplemento Especial Derecho Procesal Constitucional. Abeledo Perrot.

Martínez Paz, F. (2005). Introducción al derecho (2a ed.). Editorial Ábaco de Rodolfo Depalma.

Pidoux, V. (2020). Análisis del Poder Tributario Municipal en la Provincia de Córdoba y las limitaciones del Derecho Federal e Intrafederal. Revista de Estudios Jurídicos y Sociales, (1). https:// ar.ijeditores.com/pop.php?option=articulo\& Hash=423f4fe815338d52c125eb7944542582.

Sagüés, N. P. (2016). Manual de derecho constitucional (2a ed.). Astrea.

\section{Legislación citada}

Decreto del Poder Ejecutivo Nacional 258/1980, Organismos Nacionales. República Argentina, 13/02/1980.

Decreto Ejecutivo 2141/1995, Adjudicación del servicio de agua potable y saneamiento a Aguas Provinciales de Santa Fe S.A. Provincia de Santa Fe.

Decreto Ejecutivo 3666/1994, Comisión y Pliego del servicio público de agua potable y saneamiento. Provincia de Santa Fe.

Decreto Ejecutivo 3927/1994, Licitación pública del servicio de agua potable y saneamiento. Provincia de Santa Fe.

Ley Nacional 2927, Comisión de Obras de Salubridad. República Argentina, 30/12/1892

Ley Nacional 8889, Reorganización de la Dirección General de Obras de Salubridad. República Argentina, 18/07/1912.

Ley Nacional 13577, Obras Sanitarias de la Nación. República Argentina, BO 02/11/1949.

Ley Nacional 18586, Transferencia de Organismos Nacionales. BO 26/02/1970.

Ley Provincial 2756, Orgánica de Municipalidades. Provincia de Santa Fe, BO 21/05/1986.

Ley Provincial 8711, Dirección Provincial de Obras Sanitarias. Provincia de Santa Fe, BO 19/12/1980.

Ley Provincial 11220, Transformación del sector público de agua potable, desagües cloacales y saneamiento. Provincia de Santa Fe, BO 12/12/1994.

Ley Provincial 11330, Recurso Contencioso Administrativo. Provincia de Santa Fe, BO 26/12/1995.

Constitución de la Provincia de Santa Fe, 14/04/1962.

Ley 24430, Constitución Nacional, Ordena su publicación, 03/01/1995.

\section{Jurisprudencia citada}

Gas Natural Ban S.A. c/Municipalidad de Campana (Pcia. de Buenos Aires) s/acción meramente declarativa (2003). Corte Suprema de Justicia de la Nación, https://sjconsulta.csjn.gov. ar/sjconsulta/documentos/verUnicoDocumentoLink.html?idAnalisis $=541555$ \& cache $=1610915510077$. 
Litoral Gas S.A. c/Municipalidad de Villa Constitución s/acción meramente declarativa (2004). Corte Suprema de Justicia de la Nación, https://sjconsulta.csjn.gov.ar/sjconsulta/documentos/ verUnicoDocumentoLink.html?idAnalisis=560427\& cache=1610915653492.

Marbury v. Madison (1803). Suprema Corte de los Estados Unidos.

Municipalidad de Esperanza c/Provincia de Santa Fe s/recurso contencioso administrativo (2006). Corte Suprema de Justicia de la Provincia de Santa Fe, http://bdj.justiciasantafe.gov.ar/index. php?pg=bus $\& \mathrm{~m}=$ busqueda $\& \mathrm{c}=$ busqueda $\& \mathrm{a}=$ get $\& \mathrm{id}=21361$.

Municipalidad de la Ciudad de Rosario c/Provincia de Santa Fe (1991). Corte Suprema de Justicia de la Nación, http://www.saij.gob.ar/corte-suprema-justicia-nacion-federal-ciudad-autonoma-buenos-aires-municipalidad-ciudad-rosario-santa-fe-provincia-inconstitucionalidad-cobro-australes-fa91000263-1991-06-04/123456789-362-0001-9ots-eupmocsollaf.

Municipalidad de La Plata c/Provincia de Buenos Aires s/inconstitucionalidad del decreto-ley 9111 (2002). Corte Suprema de Justicia de la Nación, https://sjconsulta.csjn.gov.ar/sjconsulta/ documentos/verUnicoDocumentoLink.html?idAnalisis=520631\& cache=1610915250990.

Obras Sanitarias Mendoza S.A. c/Municipalidad de Rivadavia s/acción de inconstitucionalidad (2003). Suprema Corte de Justicia de la Provincia de Mendoza, http://www2.jus.mendoza.gov.ar/ jurisprudencia/consultar/fallo.php?fallo=03199126\& ta=sc.

Rivademar, Ángela D. B. Martínez Galván c/Municipalidad de Rosario (1989). Corte Suprema de Justicia de la Nación, 21 de marzo de 1989. En Bonifacino, N. (2006). Derecho Municipal Profundizado, Cuadernos de Estudio: Una propuesta para profundizar el estudio y análisis del Derecho Municipal a través del modelo jurídico multidimensional. Facultad de Derecho, Universidad Nacional de Córdoba.

Telefónica Argentina S.A. c/Municipalidad de General Pico s/acción meramente declarativa (1997). Corte Suprema de Justicia de la Nación, https://sjconsulta.csjn.gov.ar/sjconsulta/documentos/verUnicoDocumentoLink.html?idAnalisis=380532\& cache=1610915393279. 

ReCENSIONES 



\section{UNA DEFENSA DEL LIBERALISMO CONSERVADOR}

\section{Francisco José Contreras}

Madrid: Unión Editorial/Centro Diego de Covarrubias, 2018, 172 páginas.

Hace unos años, leí con interés, provecho y deleite un libro de Francisco Contreras: Liberalismo, catolicismo y ley natural (Madrid, Encuentro, 2013). Lo disfruté, lo recomendé y lo cité en un breve artículo sobre el pensamiento de Joseph Ratzinger acerca del rule of law. Ahora he vuelto a disfrutar este nuevo volumen, más breve y más fácil de leer, pero de un contenido enormemente valioso. Efectivamente, su desarrollo de las tesis central es que el desenvolvimiento y el éxito de la economía de mercado exige un sustrato moral en la sociedad en la que tiene vigencia, que los orígenes -en especial anglosajones- de la idea liberal son indiscutiblemente cristianos, que para que el liberalismo funcione es necesario que cuente con un trasfondo conservador en las ideas políticas, el valor de las ideas republicanas para la armonía y prosperidad de las naciones, los desastres que conlleva el populismo socialista para el bienestar de las sociedades políticas y varias más está realizado de un modo sólido, convincente y esclarecedor.

Seguidor consecuente del recientemente fallecido Roger Scruton (19442020), Contreras -que no solo escribe libros valiosos, sino que también participa activamente en la vida política de su país- muestra con rigor cómo una sociedad en la que no se tenga una vigencia efectiva de una tradición moral objetiva no tiene posibilidades de prosperidad, auténtico progreso y libertad. Y en lo que respecta a la moral sexual, destaca que la deriva permisivista creciente es el camino más seguro para desarticular y, en definitiva, destruir a la institución familiar, que ha sido por milenios el punto de anclaje de toda sociedad armónica y razonable. En este punto destaca la diferencia que existe entre el liberalismo clásico y el libertarianismo, para el cual toda norma categórica e inexcepcionable es meramente opresiva y destructora de la libertad humana, que es o bien absoluta o lisa y llanamente no existe.

Pero lo que merece mayor atención es su denuncia acerca del "gen autofágico" y destructivo que llevan ínsitas inexorablemente casi todas las formas del liberalismo: el que radica en la concepción de la autonomía, primero como un 
principio de carácter absoluto y, por lo tanto, ilimitado, y en segundo lugar como el núcleo central y decisivo de toda ética posible. La presencia de ese gen maligno es todavía débil en las primeras versiones del liberalismo, toda vez que esa presencia se veía compensada por las vivencias religiosas y la inexcusable referencia a la ley natural, muy clara en Locke, Montesquieu y los iusnaturalistas modernos. Esa referencia se desarticula en Kant, quien, a pesar de exaltar esa centralidad de la autonomía, intenta ponerle un límite meramente formal con la remisión al principio de universalidad (por medio del "imperativo categórico”), que limitaría de algún modo la absolutidad completa del principio de autonomía.

Pero los continuadores de Kant -comenzando por John Stuart Mill- decidieron suprimir el límite que suponía el "test de universabilidad" y proponer una autonomía total e ilimitada, propia del "sujeto empírico", que para el filósofo de Königsberg era incapaz de formular deberes morales. De este modo, utilitaristas, positivistas, empiristas, partidarios de la filosofía lingüística, posmodernos nihilistas y varios más propusieron una ética centrada en la autolegislación humana, aunque varios de ellos, para evitar caer en la ficción de una ética en la que cada uno podría hacer lo que le viniera en gana, le agregaron un principio indemostrado e indemostrable desde una perspectiva autonomista, según el cual la acción autónoma de cada sujeto tendría un límite: no podía causar daño a otros. Por supuesto que se trataba de un daño fundamentalmente físico y causado a sujetos individuales, ya que la concepción de un bien común y fundamentalmente espiritual había desaparecido, para esas corrientes de pensamiento, del horizonte del conocimiento práctico-moral humano.

Ahora bien, las consecuencias prácticas de esa concepción de una ética sin deberes, normas, valores, bienes o facultades objetivas, es decir, sin baremos impersonales e invariables de bondad o maldad moral, son detallada y rigurosamente analizadas en el libro de Contreras bajo el título "liberalismo autofágico". En esta forma de liberalismo, devenido en liberacionismo progresista, se ha abandonado la cultura del trabajo y del esfuerzo, del sacrificio por la familia y las sociedades, tanto las infrapolíticas cuanto la política, y se ha abocado al consumo, el placer y la pereza, con el resultado de que no resulta posible la economía de mercado (que es la única que produce riqueza), ni la ciencia rigurosa, ni la democracia republicana, ni la educación de calidad, ni la seguridad pública ni nada de lo que hace posible la vida buena de los seres humanos en sociedad.

En rigor, todo esto ha sucedido -sostiene el profesor español- porque se ha 
dejado de lado, a través de una evolución maligna del pensamiento occidental, la matriz conservadora que hacía posible el funcionamiento de un liberalismo próspero, participativo, de seres humanos emprendedores, con libertades públicas y gobierno limitado. Y todo esto se debe principalmente al ya mencionado "gen autodestructivo" del liberalismo, para el cual todo curso de acción ha de ser decidido por la autonomía completa del individuo consumidor y gozador, y el abandono de todos los parámetros que servían hasta la segunda posguerra para la determinación de los perfiles de la vida buena realizada en común. Pero además de ese "gen autonómico" pareciera que hay otro, que es el que consiste en la difuminación de todos los bienes comunes, es decir, de todos aquellos bienes humanos que solo se logran en un esfuerzo mancomunado y se disfrutan participándose a través de la justicia distributiva. Es lo que MacIntyre denominó "la privatización del bien humano" y que consiste en que solo existirían bienes particulares que se reparten conforme a los criterios arbitrarios generados por la voluntad autonómica de los individuos. El resultado de todo esto es la anomia social, la lucha de todos contra todos preconizada por Hobbes y la miseria material y cultural que se difunde por los países que han abrazado el liberacionismo consumista.

La solución que propone Contreras es el "liberalismo perfeccionista", que se integra con una revalorización de la naturaleza humana (y de los bienes humanos que corresponden a sus dimensiones centrales) como criterio de perfección, la reconstrucción de la familia heterosexual y procreativa, la reformulación de la economía de mercado y la vida política republicana, y, sobre todo, la revivificación de una vida ética de bienes y virtudes y no meramente de derechos individuales basados en la autonomía.

En definitiva, se trata de un libro corto (Borges siempre elogiaba la brevedad en la literatura), valiente, bien escrito, desafiante de las modas contemporáneas (Thibon definía la moda como "esa tiranía de lo efímero que se ejerce sobre los desertores de la eternidad") y sensato. Realmente vale la pena leerlo detenidamente para conocer las causas reales de nuestra crisis actual y el camino razonable y realista para superarla. Y respecto al nombre sugerido por el autor a su propuesta: "liberalismo conservador", considero que quizá sería más oportuno sustituirlo por el de "conservatismo republicano", ya que el de "liberalismo" genera, en razón del "gen autonómico" y de las peripecias de la historia reciente del término, bastantes reacciones contrarias que sería necesario evitar. Además, la expresión "conservatismo" remite a la genial y memorable frase de Edmund Burke: "La civilización es siempre sabia, solo el individuo es necio", 
que convendría grabar a fuego en la mente de nuestros contemporáneos en sustitución del necio prejuicio autonómico-progresista tan difundido y admirado en nuestros días.

\section{Carlos I. Massini-Correas}

Universidad de Mendoza. Universidad Austral carlos.massini@um.edu.ar 


\section{PRINCIPIO DE SUBSIDIARIEDAD Y MARGEN NACIONAL DE APRECIACIÓN. ARTICULACIÓN DEL SISTEMA INTERAMERICANO DE PROTECCIÓN DE DERECHOS HUMANOS CON LOS REGIMENES NACIONALES}

\section{Alfonso Santiago}

Buenos Aires: Astrea, 2020, 264 páginas.

“-... Sólo puedes exigir a cada uno lo que cada uno puede hacer [...] La autoridad reposa, ante todo, sobre la razón. Si ordenas al pueblo que se arroje al mar, el pueblo hará la revolución. Yo tengo derecho a exigir obediencia porque mis órdenes son razonables".

Fragmento del diálogo entre el rey del asteroide 325 y el Principito.

De Saint-Exupéry (2019, p. 65).

De un tiempo a esta parte se han evidenciado nuevos desafíos en el Sistema Interamericano de Derechos Humanos (SIDH). Quizás, uno de los puntos más sensibles sea la coordinación de las relaciones de los Estados parte con los organismos internacionales creados en los acuerdos constitutivos de dicho Sistema. En este marco, Alfonso Santiago, en Principio de subsidiariedad y margen nacional de apreciación. Articulación del sistema interamericano de protección de derechos humanos con los regimenes nacionales, ofrece una respuesta "fuera del molde" a muchas de las preguntas que asedian a los operadores jurídicos frente al avance del Derecho Internacional de los Derechos Humanos (DIDDHH).

¿Cómo se armoniza el DIDDHH con los ordenamientos jurídicos nacionales? ¿Qué debe primar en caso de conflicto insalvable entre normas constitucionales y convencionales? ¿Quién tiene la última palabra en materia de derechos humanos? ¿Qué valor tienen las decisiones de la Corte Interamericana (Corte IDH)? ¿Puede subsistir la doctrina del control de convencionalidad? ¿Cuál es, en definitiva, el fundamento del "nuevo orden internacional"? ¿Cuáles son sus límites? Santiago afronta estos interrogantes a partir de un principio transversal 
a los sistemas de derechos humanos: el principio de subsidiariedad, y de lo que él describe como su "corolario": la doctrina del margen nacional de apreciación.

El trabajo condensa años de investigación: el autor fue uno de los primeros en explorar esta temática que hoy interpela a iusfilósofos, internacionalistas y constitucionalistas por igual ${ }^{1}$ y a la que aún rodea un halo de misterio en la región. Ya en 2013 Santiago ponía la lupa en la cuestión, en la comunicación que presentó ante el Instituto de Política Constitucional de la Academia Nacional de Ciencias Morales y Políticas, titulada "El principio de subsidiariedad en el Derecho Internacional de los Derechos Humanos". Sus credenciales en la materia se aprecian en la profundidad del estudio, en su actualización, en la original metodología con la que desarrolla los puntos cruciales y en el logrado complemento entre teoría jurídica y práctica jurisprudencial. La solidez del trabajo fue refrendada por pares en un formato de evaluación bajo el sistema "doble ciego", que no abunda en la publicación de libros y que le imprime a este un sello de calidad.

El desarrollo comienza con el surgimiento y la evolución del DIDDHH. El planteo es razonable: únicamente un repaso por la historia y por los sujetos involucrados desde el origen brindan el contexto adecuado para la justificación del principio de subsidiariedad como núcleo de los sistemas de protección de derechos humanos. Santiago va afinando el foco paulatinamente: del sistema universal (capítulo I) pasa al interamericano (capítulo II) para, finalmente, adentrarse en el derecho argentino, en su particular recepción constitucional del DIDDHH y en la relación de la Corte IDH con el máximo tribunal local (capítulo III).

La empresa se lleva adelante desde un enfoque primordialmente histórico, aspecto en el cual Santiago es una voz autorizada si se considera que ha encabezado un estudio colectivo con motivo de los cuarenta años de la Corte IDH, el cual no registra antecedentes en la región (Santiago y Bellocchio, 2018). Pero además este aporte se enriquece con una mirada iusfilosófica. El autor no evade las reflexiones acerca de la dignidad humana como fundamento del DIDD$\mathrm{HH}$ y del "carácter supremo" de ese principio, en la medida en que "apunta a tutelar lo que de universal y permanente se puede reconocer en la persona humana" (p. 11). A partir de esa premisa, se hace cargo de los debates que provocan tanto el proceso expansivo del DIDDHH como el papel de los órganos internacionales y el problema de la legitimidad democrática en la definición

1 En los últimos años, la doctrina argentina ha puesto la atención sobre el tema con notable énfasis. Entre otras, merece destacarse la obra conjunta El margen nacional de apreciación: Aportes a la soberanía jurídica de los Estados, que fue prologada por el propio Santiago (Díaz Solimine y Díaz Solimine, 2020). 
de los contenidos fundamentales de esos derechos. Sobre esto, explica cómo la jurisprudencia de los tribunales internacionales (y también locales) ha procurado ampliar los contenidos obligatorios e indisponibles, más allá de los textos de los tratados y las inevitables controversias que estas posturas aparejan. Aquí cobran especial relevancia las advertencias que el autor formula, en línea con Benedicto XVI, sobre el riesgo que entraña la desnaturalización de los derechos humanos, siempre que se funden en una moral relativista, así como la amenaza que supone una excesiva "inflación" cuantitativa de "pseudo-derechos" que conlleve su desvalorización (p. 21).

Más adelante, vuelve sobre el fenómeno de la expansividad del DIDDHH, al considerar el establecimiento del tribunal regional como uno de los hitos del SIDH. A pesar del balance positivo al que arriba sobre su desempeño, indica con agudeza que para alcanzar una "plena madurez institucional”, el tribunal debe aceptar la necesidad de "consensuar [...] con otros actores, entre ellos, los Estados parte que le dieron vida” (pp. 52-53). La aplicación de estas ideas al escenario jurídico argentino lo lleva, por ejemplo, a reconocer que existe un proceso dialógico activo en dirección "descendente", que no tiene correlato en sentido "ascendente".

El capítulo IV reúne el corazón de la investigación. Santiago argumenta a favor de la vigencia del principio de subsidiariedad en el derecho internacional como un criterio "iluminador" para "articular, coordinar y armonizar las normativas y jurisdicciones nacionales con las internacionales en materia de protección de los derechos humanos" (p. 89). Se adentra en las raíces de aquel principio y, con acierto, las remonta a la antigüedad grecorromana y al pensamiento de Santo Tomás, para luego mostrar su desarrollo indiscutible en el más reciente Magisterio Social de la Iglesia. Destaca también el fundamento del principio de subsidiariedad: la protección de la persona humana, de los "grupos intermedios" y, desde la perspectiva internacional, de los "Estados nacionales" (p. 91). Se refiere, finalmente, a las manifestaciones que la subsidiariedad posee en el derecho internacional positivo, tanto en el sistema universal como en el interamericano y el europeo. Incluso, en este último caso, el autor anticipa una inminente reforma a la Convención Europea de Derechos Humanos (p. 141) (la adopción del Protocolo No 15, que efectivamente entraría en vigor el 1 de agosto de 2021, con posterioridad a la publicación del libro). ${ }^{2}$ Esa reforma adicionó una referencia explícita al principio de subsidiariedad y al margen de apreciación en el Preámbulo

2 Cfr. artículo $1^{\circ}$ del Protocol No. 15 amending the Convention for the Protection of Human Rights and Fundamental Freedoms, Strasbourg, 24/06/2013. Le agradecemos este dato al profesor Alfredo M. Vítolo. 
de aquella Convención, lo que evidencia que el tópico desarrollado en la obra también tiene absoluta relevancia del otro lado del Océano.

Santiago se detiene en el principio de subsidiariedad en su doble dimensión. Por un lado, presenta una dimensión sustantiva, que determina que el DIDDHH no sustituye el derecho local, sino que lo completa y refuerza, con respeto por la diversidad y el contexto concreto de cada comunidad. Por otro lado, encara la dimensión procesal del principio de subsidiariedad, criterio organizador por el que se reconoce prioridad a las autoridades domésticas para garantizar la vigencia de los derechos humanos y solo ulteriormente se admite la supervisión de los tribunales internacionales. El capítulo culmina con un recorrido de las decisiones de la Corte IDH, más cercanas en el tiempo, en las que se ha recogido el principio de subsidiariedad. Tal comprensión le permite caracterizar la novedosa (y compleja) relación entre el SIDH y los Estados parte. Fijada la semblanza de ese vínculo, se anima a esbozar pautas de interconexión normativas, procesales, axiológicas e institucionales que podrían afianzar el nexo entre el sistema regional y los domésticos (capítulo V).

La obra de Santiago no representa una cerrazón hacia el DIDDHH. Por el contrario, él se esfuerza en señalar que la indiferencia de los tribunales internacionales respecto a principios basales, como el de subsidiariedad, y la utilización estratégica del sistema regional para zanjar debates aún abiertos en el ordenamiento interno minan el prestigio del tribunal y menoscaban la autoridad jurídica de sus decisiones. De este modo, su propuesta constituye un llamado de atención sobre la extensión de las obligaciones asumidas por los Estados -tanto a nivel internacional como nacional-, con el fin de garantizar la efectividad del sistema, el cumplimiento de las decisiones de sus órganos y la permanencia de los Estados que lo conforman. Precisamente, Santiago se empeña en "tender puentes" y no en construir murallas: su posición es indudablemente dialógica.

Uno de aquellos puentes que él encuentra para facilitar la interconexión del sistema nacional con el internacional es el margen nacional de apreciación, a cuya exploración dedica buena parte del libro. El capítulo VI proporciona un análisis teórico de esta doctrina jurídica, criterio jurisprudencial y técnica hermenéutica, en el que se exploran sus fundamentos y se sustenta rigurosamente su compatibilidad con el respeto al contenido esencial de los derechos humanos. $^{3}$

Santiago ve en el margen nacional de apreciación un mecanismo no traumá-

3 La pacífica y necesaria concatenación entre el principio de subsidiariedad y el margen nacional de apreciación, trazada con solvencia por Santiago, permite ahuyentar las preocupaciones de quienes 
tico para solucionar el binomio universalismo-particularismo. Justamente, su aplicación exige el respeto de un espacio de maniobra -"un cierto grado de libertad" (p. 137) - a los Estados parte y, en paralelo, la "modestia" de los órganos de tratados (p. 151). En este sentido, se destaca la mirada realista del derecho, en tanto -sin desconocer aquello que es necesario- el académico asume las contingencias y diferencias propias del obrar humano y de su cultura. Una vez más, en este capítulo, la teoría se potencia con un formidable análisis jurisprudencial y comparativo, que contrasta las decisiones de la Corte Europea de los Derechos Humanos con las provenientes de la Comisión Interamericana y de la Corte IDH en cuestiones análogas.

La investigación se completa con un "Apéndice documental", que añade datos estadísticos y gráficos ilustrativos del funcionamiento de la Corte IDH (Anexo I) y una reproducción de la Declaración sobre el Sistema Interamericano de Derechos Humanos de 2019, firmada por Argentina, Brasil, Chile, Colombia y Paraguay (Anexo II). Dicha declaración constituye un verdadero llamado de atención de esos países en orden al reconocimiento de un margen nacional de apreciación, por ende, es prueba irrefutable de la relevancia jurídica y política de la temática en la región. Como se ha apuntado, hay allí una demostración del interés de los Estados parte en la subsistencia del SIDH, pues los suscriptores han manifestado inquietudes legítimas que traslucen la voluntad de mejorar su funcionamiento (Paúl, 2020, pp. 70-71, 80).

Asimismo, la obra reseñada presenta una construcción sólida del DIDDHH sobre los cimientos del principio de subsidiariedad. Se trata de un libro de consulta obligada para especialistas avezados, pero también de interés para la enseñanza universitaria de la materia. Cabe añadir que el patrimonio jurisprudencial que recoge Santiago resulta sin duda valioso para el profesional que, con frecuencia, ve inundada su cotidianidad con pretensiones formuladas en clave de derechos humanos.

Principio de subsidiariedad y margen nacional de apreciación... es un novedoso abordaje del SIDH, aunque sus conclusiones pueden extenderse a cualquier sistema de protección de los derechos humanos. El autor proporciona herramientas no solo para comprender el solapamiento de órdenes jurídicos, sino también para desarticular obstáculos procedimentales, competenciales y hermenéuticos que se interponen en la protección de los derechos humanos. Allí abrevarán quienes, preocupados como el autor por el desenlace de las tenden- 
cias internacionalistas, transhumanistas y gnosticistas, pretendan alzar su voz para que el sistema conserve su esencia.

Por lo demás, sus postulados acerca del funcionamiento institucional del SIDH y del resguardo de la autonomía de los Estados renuevan los incansables debates que suscita el DIDDHH. Las reflexiones a las que arriba al respecto se alinean -y deben complementarse- con una verdad subyacente, a la que Santiago alude en diversas oportunidades: la del fundamento de los derechos humanos (Glendon, 1999) y sus correlativos deberes, a menudo olvidados (Quintana, 2017).

Con espíritu conciliador, Alfonso Santiago llama a la prudencia de los organismos locales e internacionales y ofrece un camino a transitar para evitar que el sistema pierda el rumbo. Después de todo, no debe pedírsele al DIDDHH más de lo que puede ofrecer.

Florencia Ratti

Pontificia Universidad Católica Argentina

florenciaratti@uca.edu.ar

Sofía Calderone

Pontificia Universidad Católica Argentina

sofiacalderone@uca.edu.ar

\section{Bibliografía}

De Saint-Exupéry, A. (2019). El Principito (Trad. P. Gómez Carrizo). Biblok.

Díaz Solimine, O. L. (Dir.) y Díaz Solimine, I. L. (Coord.). (2020). El margen nacional de apreciación: Aportes a la soberanía jurídica de los Estados. Astrea.

Glendon, M. A. (1999). Foundations of Human Rights: The Unfinished Business. American Journal of Jurisprudence, 44(1). https://scholarship.law.nd.edu/ajj/vol44/iss1/1.

Nash Rojas, C. (2018). La doctrina del margen de apreciación y su nula recepción en la jurisprudencia de la Corte Interamericana de Derechos Humanos. CDI-Anuario Colombiano de Derecho Internacional, (11), 71-100. https://doi.org/10.12804/revistas.urosario.edu.co/ acdi/a.6539. 
Paúl, A. (2020). ¿Una paradoja interamericana? Chile, un Estado que cumple las sentencias del Sistema Interamericano de Derechos Humanos, pero que impulsa su reforma. Revista de Investigações Constitucionais, 7(1), 59-85. https://doi.org/10.5380/rinc.v7i1.70231.

Quintana, E. M. (2017). Dignidad y deberes humanos. Prudentia Iuris, (83), 73-94.

Santiago, A. (2013). El principio de subsidiariedad en el Derecho Internacional de los Derechos Humanos (comunicación presentada en la sesión privada del Instituto de Política Constitucional). Academia Nacional de Ciencias Morales y Políticas. https://www.ancmyp.org.ar/user/files/02-Santiago13.pdf.

Santiago, A. y Bellocchio, L. (Dirs.). (2018). Historia de la Corte Interamericana de Derechos Humanos. La Ley. 



\section{CONTRA EL GOBIERNO DE LOS JUECES}

\section{Jeremy Waldron}

Buenos Aires: Siglo XXI, 2018, 254 páginas

Jeremy Waldron, neozelandés y ampliamente reconocido en el plano académico internacional por sus contribuciones al derecho constitucional y a la teoría política, realiza una elegante crítica sobre el control judicial de la constitucionalidad. Lo que no es sorprendente viniendo de Waldron, que a fin de cuentas es, en sus palabras, "enemigo declarado del control judicial" (p. 45). Su obra constituye un aporte significativo al tipo de posturas que consideran que el poder de los jueces no necesariamente debe ser aceptado a la hora de decidir qué es o no constitucional en una democracia. Tener la última palabra en la interpretación de la constitución del Estado y revisar las leyes ${ }^{1}$ emanadas de un poder netamente democrático como el Parlamento, cuanto menos, genera sospecha.

La obra se estructura en cinco partes, cuyo objeto es criticar el control judicial fuerte ${ }^{2}$ de las leyes, en el cual existe una excesiva intromisión judicial en la actividad política parlamentaria y argumentar por qué se deben buscar otras alternativas institucionales cuando se interpretan las constituciones.

En la primera parte de la obra se empieza analizando el significado de una palabra determinante, como lo es "constitucionalismo". Palabra que, sin lugar a dudas, es muy relevante en el derecho constitucional y la teoría política. Así, critica la idea de constitucionalismo para aproximarse al sentido que puede tener como concepto. Describe cómo "constitucionalismo" puede usarse de distintas maneras en el ámbito académico, incluso, haciendo énfasis en el componente "ismo" que contiene la idea, ya que existen otras palabras como liberalismo o socialismo, es decir, interpretándose como una suerte de ideología, lo cual resulta interesante debido a que no suele ser planteado el concepto de esa manera.

\footnotetext{
1 No se incluye en el objeto de la obra la revisión judicial sobre actos jurídicos provenientes del Ejecutivo o administración.

2 No se incluye en su crítica el control judicial débil.
} 
Se realiza un repaso de los fundamentos que se suelen señalar del constitucionalismo, desmenuzando los diversos sentidos que desde las revoluciones liberales del siglo XVIII se le han atribuido. Sobremanera, resalta el sentido de control que implica el constitucionalismo, lo cual ha sido una nota esencial y siempre reafirmada por los grandes pensadores. Controlar el poder, en efecto, es una propiedad del constitucionalismo que suele ser alegada por los constitucionalistas cuando se invoca a debate esa palabra. Diseñar límites al poder público es el telos o "razón de ser del constitucionalismo" (Sartori, 2005, p. 213). Basta indicar que constitucionalismo, en su origen, surge como oposición al absolutismo del poder que tiende a abusar y corromper. En esencia, el descontrol del poder es lo que suscitó el constitucionalismo como necesidad institucional para garantizar los derechos fundamentales. Tal rasgo de control resulta indisociable de la definición de "constitucionalismo", pese a denominaciones que ahora se puedan encontrar de "constitucionalismo autoritario". ${ }^{3}$

En la segunda parte, la obra se adentra en los argumentos contra el control judicial fuerte y que sostienen la afirmación de que es "inapropiado como última instancia dentro del proceso de toma de decisiones en una sociedad libre y democrática" (p. 56). La vulnerabilidad del control judicial fuerte se puede destacar, según nuestra interpretación, de la ilegitimidad democrática sobre la cual descansa, que privilegia el voto mayoritario de un pequeño grupo de jueces no elegidos democráticamente y que no les rinden cuentas a los depositarios de la soberanía popular.

El control judicial que se critica es un control matizado sobre ciertas condiciones sociales: 1) instituciones democráticas, cuyo poder legislativo sea elegido mediante sufragio universal; 2) instituciones judiciales, comprometidas con el mantenimiento del Estado de derecho; 3) compromiso de la sociedad y los agentes públicos con la idea de los derechos individuales y de las minorías; y 4) desacuerdos legítimos sobre los derechos de parte de la sociedad. Con base en estas condiciones, se aborda el aspecto decisorio institucional del control judicial.

Asimismo, se consideran también las virtudes de la decisión tomada por el poder legislativo y los factores clave que influyen en el razonamiento para crear una ley. Especialmente se realiza una comparación entre el sistema constitucional de los Estados Unidos y el sistema del Reino Unido. Por un lado, se destaca la labor activista de la Corte Suprema norteamericana y, por el otro, la

Ver Tushnet (2015). 
supremacía legislativa del Parlamento en el Reino Unido. Pero ¿por qué un ciudadano debe aceptar la decisión de una corte o de un parlamento? En el caso legislativo, la aceptación de la decisión es considerablemente superior en valores democráticos al caso judicial. Esto es un rasgo trascendental en el momento de aceptar una decisión desde la perspectiva de la legitimidad democrática. Los legisladores rinden cuentas periódicamente ante los electores, situación que no ocurre por parte de los jueces.

Por si el argumento no fuera suficiente, es menester destacar que si bien se argumenta que los jueces que conforman una Corte toman decisiones con base en argumentos, algo así como una aristocracia de la "razón", como bien señala el autor, "en definitiva todo se reduce a contar cabezas" porque, por ejemplo "en la Corte Suprema de los Estados Unidos, cinco votos vencen a cuatro, independientemente de los argumentos esgrimidos por los jueces" (p. 106). Este es un factor clave para entender la crítica que se propone, ya que los jueces deciden bajo el criterio del mayoritarismo. De manera que la famosa tiranía de la mayoría que suele argumentarse para sustentar los poderes activistas de los jueces que limitan la labor legislativa se vuelve muy dudosa. En efecto, los tribunales también pueden actuar de manera tiránica. A veces, hasta más tiránicos que un parlamento. ${ }^{4}$

El tercer capítulo se refiere a la "supremacía judicial", que se define como "la tendencia de cualquier arreglo institucional que permite que esas cuestiones vitales [esto es, cuestiones que afectan a toda la población] y divisivas sean resueltas por tribunales" (p. 132). Tal supremacía judicial se establece en sistemas en los que persiste un control judicial fuerte. Asimismo, la idea de supremacía judicial se relaciona con la idea de soberanía judicial. Waldron, cuando trata este punto, refiere elementos fundamentales acerca de la soberanía y el poder constituyente. Principalmente, resalta que los tribunales con su control judicial pueden atribuirse el lugar supremo del poder constituyente cuando consideran solamente su propia idea de constitución, como una especie de propietario, sin considerar las demás ramas del poder o "sociedad abierta de intérpretes constitucionales", 5 a los cuales sus decisiones afectan. Es decir, el monopolio de la

4 Por ejemplo, el caso de la Sala Constitucional del Tribunal Supremo de Justicia de Venezuela es un supuesto muy pertinente para explicar cuán tiranos pueden ser los jueces (esto, pese a que escapa de las condiciones sociales sobre las cuales el autor fundamenta su crítica). En Venezuela, la Sala Constitucional desconoció al Parlamento como hacedor de la ley, vaciando de contenido la mayor parte de sus competencias para herir gravemente la democracia y la Constitución.

Ver Häberle (2008). 
interpretación de la constitución es, sin dudas, una situación alarmante en el diseño institucional de un ambiente democrático.

La cuarta parte se refiere a las razones del porqué en los tribunales deciden "mayorías exiguas". Es casi una costumbre universal que los tribunales colegiados deban decidir mediante el criterio de las mayorías en cualquier tipo de asunto, trátese de derecho público o derecho privado. Entonces, los defensores del control judicial alegan que se oponen al mayoritarismo, pero es un argumento de escasa fuerza, desenmascarado por el autor: en la práctica, las decisiones judiciales dependen de un "conteo de cabezas" (p. 158). Así, quienes están a favor del control judicial "[e]n realidad se oponen al mayoritarismo democrático, no al mayoritarismo como tal” (p. 155). En otras palabras, el control judicial tiene un problema o dificultad contrademocrática más que lo que Bickel (1986) en su momento calificó como "contramayoritaria".

Ahora bien, habiendo entendido que los jueces deciden también bajo el criterio de la mayoría, con acuerdos y desacuerdos, por consiguiente, también existe deliberación. Tratando la génesis del tipo de mayoría que generalmente se requiere para tomar decisiones en un órgano judicial colegiado, se indica que es un tipo de mayoría "exigua”. Eso, por cuanto, generalmente, la mayoría requerida no es calificada o por unanimidad para dirimir los desacuerdos. Este es un elemento interesante, ya que ampliar el tipo de mayoría requerida en un tribunal para tomar una decisión podría hacer que no se tome a la ligera la dignidad de la ley. Asimismo, los desacuerdos naturales de todo ser racional exigirían mayor calidad argumentativa para ser dirimidos.

Finalmente, en la quinta parte, el autor ofrece "modelos de diálogo entre jueces y legisladores", algo parecido a una alternativa sobre cómo lidiar con el ego judicial y legislativo. Sobre todo el primero, que es objeto de su crítica. Se destacan seis posibilidades de diálogo entre jueces y legisladores dentro de múltiples supuestos. Los modelos de diálogo que se analizan son: 1) modelo Lord Devlin; 2) modelo de diálogo paralelo; 3) modelo neozelandés; 4) modelo británico; 5) modelo canadiense; y 6) el camino que no se tomó en City of Boerne c/Flores. Acerca de todos estos modelos se resaltan los diseños institucionales empleados para cada país y en lo que contribuyen al sentido del diálogo.

De acuerdo con el análisis de Waldron, en aquellos sistemas en los que existe supremacía judicial tiende a haber menos diálogo que en los sistemas en los que hay supremacía legislativa. Los jueces tienen más probabilidad de ser escuchados en un sistema en el que el parlamento sea soberano que la probabilidad que tienen los legisladores de ser escuchados en un sistema en el que los jueces 
tengan la última palabra. Estas son las críticas que realiza el autor en contra del control judicial fuerte o gobierno de los jueces.

Cada palabra escrita en esta obra es merecedora de una seria reflexión. La mayor parte de los sistemas constitucionales en América Latina son preponderantes a tener un control judicial fuerte, en el cual los jueces tienen la última palabra sobre cuestiones trascendentales para la sociedad, como el aborto, la eutanasia o el matrimonio entre personas del mismo sexo. Considerar posiciones como la de Waldron al momento de reformar o crear nuevas constituciones en la región es una forma de enriquecer el debate constitucional. Especialmente enriquecedor para el constitucionalismo de la región sería pensar sobre diseños institucionales que contribuyan a democratizar más el ejercicio del poder. Los cambios constitucionales recientes se han preocupado más por reconocer ampliamente los derechos que por diseñar nuevas instituciones. ${ }^{6}$ Por tanto, la obra del autor constituye una crítica respetable sobre el control judicial fuerte de las leyes, cuyo significado no debe pasar desapercibido en un momento de reflexión constitucional.

\section{Angello Javier Peña Barrios}

Universidad de Los Andes

angellojavierpb@gmail.com

\section{Bibliografía}

Bickel, A. (1986). The Least Dangerous Branch (2 ${ }^{\mathrm{a}}$ ed.). Yale University Press.

Gargarella, R. (2013). Latin American Constitutionalism, 1810-2010. The Engine Room of the Constitution. Oxford University Press.

Häberle, P. (2008). La sociedad abierta de los intérpretes constitucionales: una contribución para la interpretación pluralista y 'procesal' de la constitución. Academia, Revista sobre enseñanza del Derecho, 6(11), 29-61.

Sartori, G. (2005). Ingeniería constitucional comparada. Fondo de Cultura Económica.

Tushnet, M. (2015). Authoritarian Constitutionalism. Cornell Law Review, 100(391), 393-460.

Ver Gargarella (2013). 

SOBRE LOS AUTORES 


\section{Fernando D. Álvarez Álvarez}

Abogado graduado con Diploma de Honor (UBA). Magíster en Derecho Administrativo (Universidad Austral). Premio al mejor promedio de la X Promoción de esa carrera y Premio Editorial La Ley a la mejor tesis. Diploma Superior en Ciencias Políticas y Sociología (FLACSO). Ha publicado numerosos trabajos sobre temas de derecho constitucional y administrativo, ciencia política y sociología, capítulos de libros en publicaciones nacionales y extranjeras y el volumen Sociología de la Comunidad Local (Aproximaciones Teóricas y Estudios de Casos) en coautoría (2016). A lo largo de más de veinticinco años se ha desempeñado como profesor adjunto, asociado y titular en diversas universidades públicas y privadas argentinas, tanto en carreras de grado como de posgrado. Actualmente es profesor pro titular de la Pontificia Universidad Católica Argentina, donde enseña Teoría y Derecho Constitucional e Historia de las Ideas Políticas en la Facultad de Ciencias Sociales. Asimismo, es profesor adjunto de Sociología de la Organización en la Facultad de Ciencias Económicas de la Universidad de Buenos Aires y en asignaturas de derecho electoral, teoría política y constitucional en las maestrías en Comunicación Política (Universidad Austral) y en la de Ciencias Políticas (Universidad Nacional de La Plata). Es investigador principal de CICLOP (Centro de Investigaciones en Comunidad Local y Participación), asociado al CONICET. Ha sido varias veces funcionario público del Gobierno Nacional, consultor del Programa para el Desarrollo de Naciones Unidas, presidente del Consejo Electoral de UNASUR durante el ejercicio de la Presidencia Pro Témpore de la Argentina y asesor de organizaciones privadas, organismos públicos y de partidos políticos.

Correo electrónico: fernando.alvarez3@gmail.com

ORCID: https://orcid.org/0000-0002-3900-1399

\section{Leonardo J. Ambesi}

Abogado (UBA), MDA y doctor en Derecho (Universidad Austral). Miembro del Instituto de Derecho del Trabajo y Seguridad Social de la Academia Nacional de Derecho y Ciencias Sociales de Buenos Aires. Director del Departamento de Derecho del Trabajo, Facultad de Derecho (Universidad Austral). Asimismo, es juez de la Sala X de la Cámara Nacional de Apelaciones del Trabajo. Correo electrónico: lambesi@austral.edu.ar

\section{María Laura Barbado}

Abogada y procuradora (Universidad Nacional de Tucumán). Magíster en Derecho Judicial (Maestría en Formación Aspirantes a Magistrados de la Nación, Escuela Judicial del Consejo de la Magistratura de la Nación). Egresada de la Maestría en Derecho Procesal con orientación civil (UNT). Diplomada en Teoría General del Derecho y Argumentación Jurídica (Universidad Austral). Diplomada en Derecho Administrativo (Universidad de la Coruña, España). Experiencia laboral: secretaria judicial/relatora del Poder Judicial de la Nación, prosecretaria de Cámara efectiva a cargo de superintendencia, Poder Judicial de la Nación, entre otros. Es autora de diversas publicaciones en revistas jurídicas y congresos nacionales e internacionales. Coautora de la obra colectiva Una mirada procesal de los derechos de incidencia colectiva (Buenos Aires, La Ley, 2012) y de Estudio del Amparo Nacional y en la Provincia de Tucumán (Ediciones del Rectorado de la Universidad Nacional de Tucumán, 2006). Es docente de la Cátedra A de Filosofía del Derecho de la Facultad de Derecho y Ciencias Sociales (UNT), docente de la Fundación "Lograr", avalada por Ministerio de Justicia de la Nación e Investigadora categorizada nivel 5 por CIUNT.

Correo electrónico: marialaurabarbado@gmail.com

ORCID: https://orcid.org/0000-0002-0519-8007

\section{Alberto B. Bianchi}

Abogado (UCA). Doctor en Derecho (UBA) con tesis recomendada al Premio Facultad. Miembro titular de la Academia Nacional de Derecho y Ciencias Sociales de Buenos Aires. Miembro titular de la Academia Nacional de Ciencias de Buenos Aires. Premio Academia Nacional de Derecho y Ciencias Sociales de Buenos Aires (1991). Premio Academia Nacional de Derecho y Ciencias 
Sociales de Córdoba (2012). Premio Konex en el área Derecho Constitucional (2016). Profesor de Derecho Constitucional Profundizado (Universidad Austral), (UCA). Autor de 19 libros y más de 400 artículos sobre temas de derecho administrativo y derecho constitucional.

Correo electrónico: ab@bgcv.com.ar

\section{Sofía Calderone}

Abogada (UCA) graduada con diploma de honor. Doctoranda en Ciencias Jurídicas (UCA). Diplomada en Derecho Constitucional Profundizado y Especializado (Universidad Austral). Diplomada en Derecho Procesal Constitucional (Universidad Austral). Prosecretaria del Centro de Derecho Constitucional, Facultad de Derecho (UCA). Secretaria de redacción de FORUM: Revista del Centro de Derecho Constitucional de la Facultad de Derecho de la Pontificia Universidad Católica Argentina. Adjunta a la cátedra de Derechos Humanos (UCA). Asistente en la cátedra de Formación del Pensamiento Jurídico Político (UCA).

Correo electrónico: sofiacalderone@uca.edu.ar

\section{Ignacio N. Cofone}

Profesor adjunto en McGill University Faculty of Law. Affiliated Fellow en Yale Law School Information Society Project.

Correo electrónico: ignacio.cofone@mcgill.ca

\section{Adriel Fernández Santander}

Abogado (2013) y magíster en Derecho (2021), ambos títulos por la Universidad Austral (Buenos Aires). Abogado de matrícula en la provincia de San Juan desde el año 2016. Profesor ayudante diplomado de la materia Derecho Procesal Civil en grado y Coordinador de la Carrera de Abogacía de la Universidad Austral (Buenos Aires).

Correo electrónico: afernandezsantander@austral.edu.ar

ORCID: https://orcid.org/0000-0003-2709-0520

\section{Noelia Gutiérrez Herrera}

Abogada y procuradora (Universidad Nacional de Tucumán). Magister en Derecho Administrativo (Universidad Austral). Diplomada en Contratos del Estado e Infraestructura Pública (Universidad Austral). Diplomada en Derecho Administrativo (Universidad de la Coruña, España). Es secretaria de Primera Instancia en la Secretaría Judicial del Ministerio Público Fiscal de la Ciudad Autónoma de Buenos Aires. Fue jefa del Departamento de Asuntos Jurídicos del Ministerio Público Fiscal (CABA), prosecretaria administrativa en el Juzgado Contencioso Administrativo y Tributario $\mathrm{N}^{\circ} 10$ (CABA) y jefa de Despacho Relator y otros cargos en la Procuración General de la Nación. Es autora de diversas publicaciones en revistas jurídicas. Ha recibido el premio "Naciones Unidas" a la mejor presentación de un caso de derechos humanos (Facultad de Derecho y Ciencias Sociales, UNT).

Correo electrónico: gutierrez.herrera.noelia@gmail.com

ORCID: https://orcid.org/0000-0003-1539-5028

\section{Laurence R. Helfer}

Harry R. Chadwick, profesor de Derecho, Facultad de Derecho de la Universidad de Duke (Estados Unidos). Profesor invitado permanente, iCourts: Centro de Excelencia para Tribunales Internacionales, Universidad de Copenhague (Dinamarca).

Correo electrónico: helfer@law.duke.edu

\section{Agustín López Olocco}

Estudiante del último año de la carrera de Abogacía (Universidad Nacional de Córdoba) y del Profesorado en Ciencias Jurídicas. Se desempeña en la ciudad de Córdoba como meritorio en el Juzgado 
de Primera Instancia Civil y Comercial de $48^{\circ}$ Nominación del Poder Judicial de la Provincia de Córdoba. Ha sido pasante de la Inspección de Personas Jurídicas de la Provincia de Córdoba. Es también becario de pregrado del Centro de Investigaciones Jurídicas y Sociales de la UNC e investigador de Proyecto FORMAR de la SeCyT (UNC) para el período 2020-2022. Asimismo, es ayudante de cátedra de las asignaturas Derecho Público Provincial y Municipal y Derecho Tributario (UNC). Correo electrónico: agustin.lopez.olocco@mi.unc.edu.ar ORCID: https://orcid.org/0000-0001-5376-2955

\section{Carlos I. Massini-Correas}

Abogado, doctor en Ciencias Jurídicas y Sociales y doctor en Filosofía. Catedrático de Filosofía Jurídica en la Universidad de Mendoza (Argentina), donde dirige el Instituto de Filosofía Práctica. En el nivel de posgrado, es profesor de los doctorados de la Universidad Austral de Buenos Aires, de la Universidad Panamericana de México y de la Universidad de Los Andes de Santiago de Chile. Se desempeñó como investigador principal del Consejo Nacional de Investigaciones Científicas (CONICET), como director del Doctorado en Derecho de la Universidad Católica de Santa Fe y como secretario académico de la Universidad de Mendoza. Tiene publicados 30 libros y más de 200 artículos en América y en Europa sobre temas de filosofía del derecho, filosofía política, ética y bioética. Entre los últimos libros publicados cabe destacar: Alternativas de la ética contemporánea. Constructivismo y realismo ético (Rialp, 2019); Jurisprudencia analítica y derecho natural. Análisis del pensamiento filosófico de John Finnis (Marcial Pons, 2019) y Dignidad humana, derechos humanos y derecho a la vida (UNAM, 2020). Ha sido Visiting Scholar en las universidades de Münster, París, Navarra, La Coruña, Notre Dame-Indiana, Panamericana de México, De los Andes de Santiago de Chile, entre otras. Correo electrónico: carlos.massini@um.edu.ar

\section{Angello Javier Peña Barrios.}

Abogado Summa Cum Laude (Universidad de Los Andes, Venezuela). Investigador adscrito al Grupo de Investigación Robert Von Möhl de la Universidad de Los Andes. Maestrante en Ciencias Políticas por la Universidad de Los Andes.

Correo electrónico: angellojavierpb@gmail.com

Orcid: https://orcid.org/0000-0003-2381-0324

\section{Florencia Ratti}

Doctora en Ciencias Jurídicas (summa cum laude, Universidad Católica Argentina-CONICET). Diplomada en Derecho Constitucional Profundizado (Universidad Austral) y abogada (Medalla de Oro, UCA). Becaria posdoctoral del CONICET. Profesora de Derechos Humanos y Análisis de Jurisprudencia (UCA). Jefa de trabajos prácticos de Taller de Doctrina y Jurisprudencia (Universidad Nacional de Lomas de Zamora). Ex-Fulbright Visiting Scholar en Boston College Law School (Boston, MA). Ex-Visiting Scholar en Osgoode Hall Law School (York University, TO). Secretaria del Centro de Derecho Constitucional de la Facultad de Derecho de la UCA.

Correo electrónico: florenciaratti@uca.edu.ar

\section{Rodolfo Luis Vigo}

Abogado (Universidad Nacional del Litoral). Doctor en Ciencias Jurídicas y Sociales (Universidad Nacional del Litoral). Licenciado en Ciencias Políticas (Universidad Nacional de Rosario). Exjuez de la Cámara de Apelaciones en lo Civil y Comercial de la ciudad de Santa Fe (1984-1988). Exministro de la Corte Suprema de Justicia de la Provincia de Santa Fe (1988-2007). Presidente de la Junta Federal de Cortes y Superiores Tribunales de Justicia de las Provincias Argentinas (desde su fundación en 1994 hasta 1997). Premio Konex en 1998 en el rubro "Jueces", otorgado a los cinco jueces argentinos más destacados de los últimos diez años. Miembro de la Academia Nacional de Derecho y Ciencias Sociales de Buenos Aires y de Córdoba. Catedrático de Filosofía del Derecho y de Introducción al Derecho (Universidad Nacional del Litoral). Profesor de posgrado en la Uni- 
versidad Católica de Santa Fe, en la Pontificia Universidad Católica Argentina (sedes Buenos Aires y Rosario), en la Universidad Austral y en la Universidad Nacional del Litoral. Autor de números libros, capítulos de libros y artículos vinculados a la filosofía del derecho.

Correo electrónico: RVigo@austral.edu.ar

\section{Erik Voeten}

Peter F. Krogh, profesor de Geopolítica y Justicia en Asuntos Mundiales, Escuela de Servicio Exterior Edmund A. Walsh, Universidad de Georgetown (Estados Unidos).

Correo electrónico: ev42@georgetown.edu 

NORMAS EDITORIALES 


\section{Temática y alcance}

La Revista Jurídica Austral es una publicación semestral de la Facultad de Derecho de la Universidad Austral que tiene por fin primordial difundir investigaciones científicas originales e inéditas de todas las ramas del derecho, nacional y comparado, con el propósito de realizar aportes significativos al desarrollo de las distintas disciplinas jurídicas, proporcionando criterios de análisis e interpretación del derecho válidos y útiles para sus lectores.

Sus destinatarios son, fundamentalmente, académicos, investigadores, profesores, alumnos universitarios, miembros de los tres poderes del Estado (en cualquiera de sus niveles), centros de investigación, organismos púbicos y privados y operadores del derecho en general.

\section{Selección de artículos}

Los trabajos serán recibidos y examinados por el Consejo Editorial, que corroborará su pertinencia en relación a la temática y alcance de la RJA, analizando, además, la originalidad, importancia, calidad académica e interés científico. El Consejo Editorial decidirá la aceptación o rechazo de los artículos recibidos, comunicando su decisión a los remitentes. El rechazo podrá ser sometido a reconsideración del mismo órgano dentro del plazo de diez días de comunicado al autor.

Se aceptan artículos y contribuciones de toda la comunidad científica nacional e internacional, sin cargos por procesamiento de artículos (APC) ni de ningún otro tipo. Asimismo, no se exige cargo alguno de envío (submission fee).

\section{Detección de plagio}

El Consejo Editorial de la Revista Jurídica Austral y el director ejecutivo realizan un estricto control de todos los manuscritos recibidos para verificar si presentan plagio. Este primer análisis permite detectar todas aquellas conductas inapropiadas o reprochables desde el punto de vista ético, sin perjuicio de los controles posteriores y particularizados que realicen los árbitros revisores. En caso de detectarse prácticas de plagio o autoplagio, los artículos serán rechazados y devueltos al autor, mediante decisión expresa y fundada que identifique la infracción cometida.

\section{Sistema de revisión por pares (peers revievwers)}

Con el propósito de garantizar la calidad científica de las publicaciones, la Revista Jurídica Austral adopta el sistema de revisión por pares o peers revievwers en la modalidad doble ciego, de esta manera, el anonimato recíproco entre autores y revisores permite lograr una mayor objetividad en el análisis de los artículos, obteniendo un control de calidad del contenido más eficiente y con mejores estándares de transparencia editorial e institucional.

Este proceso de revisión se realizará de la siguiente manera:

1. Los artículos serán recibidos y examinados por el Consejo Editorial, que corroborará su pertinencia en relación a la temática y alcance de la RJA, analizando, además, la originalidad, importancia, calidad académica e interés científico. El Consejo Editorial decidirá la aceptación o rechazo de los artículos recibidos, comunicando su decisión a los remitentes. El rechazo podrá ser sometido a reconsideración del mismo órgano dentro del plazo de 10 días de comunicado al autor.

2. El proceso de arbitraje solo se iniciará si los artículos recibidos cumplen las directrices para autores, las cuales pueden consultarse en este mismo portal.

3. Los artículos serán evaluados bajo la modalidad doble ciego, para lo cual serán remitidos a dos árbitros externos previamente seleccionados por el Consejo Editorial, sin revelar la identidad de los autores. Los pares revisores, por su parte, tampoco conocerán la identidad de aquellos. El Consejo Editorial eliminará del texto y del archivo los nombres de los autores para preservar el anonimato.

4. Los árbitros solicitados, previa aceptación del arbitraje, deberán evaluar los artículos conforme a 
las normas de publicación y guardar confidencialidad respecto a todo lo referido a su intervención. Asimismo, para expedirse tendrán un plazo máximo de 15 días desde su aceptación como árbitros.

5. Los árbitros externos expedirán un informe al Consejo Editorial sobre el tratamiento de los artículos con las siguientes variantes en cuanto al contenido: a) aconsejando la publicación sin modificaciones; b) aconsejando la publicación con mejoras; c) rechazando la publicación. El dictamen será comunicado al autor, garantizando el anonimato del árbitro.

6. En caso de que se trate de un artículo aprobado con sujeción a cambios, el autor contará con un plazo de 15 días para el envío de la nueva versión, en cuyo caso deberá informar los cambios realizados o justificar cuando haya decidido no realizarlos. Por su parte, en caso de que corresponda, el árbitro deberá verificar las correcciones en un plazo de 15 días.

7. En caso de desacuerdo entre los árbitros, el Consejo Editorial de la RJA podrá requerir la designación de un tercer árbitro, cuya opinión permitirá sumar mejores fundamentos a la decisión que finalmente deba adoptarse.

8. El Consejo Editorial tomará la decisión de si finalmente publicará el artículo.

9. En todos los casos, se publicará la fecha de recepción del artículo y la fecha de su aceptación.

10. Los autores recibirán un ejemplar de la revista impresa.

Las recensiones de obras bibliográficas, análisis, comentarios y notas que se publicarán en las secciones correspondientes no serán sometidas al proceso de revisión por pares, sin perjuicio del control previo y estricto que llevará a cabo el Consejo Editorial de la RJA, pudiendo, según los casos, remitir a un árbitro externo dichos contenidos cuando la profundidad, extensión y complejidad de estos lo justificara.

\section{Ética y buenas prácticas editoriales}

La Revista Jurídica Austral adhiere al Código de conducta y buenas prácticas editoriales del Committee on Publicación Ethics (COPE), foro de discusión para editores de publicaciones científicas arbitradas (www.publicationethics.org.uk), cuyo objetivo primordial es promover la integridad de las investigaciones académicas y sus publicaciones.

\section{Política de secciones}

Las ediciones de la Revista Jurídica Austral se componen de tres secciones:

a) Artículos de investigación

b) Análisis, crónicas y comentarios

c) Recensiones

\section{Derechos de autor}

Los autores remitirán las investigaciones o recensiones haciendo constar que previamente no han sido publicadas por ningún medio gráfico o digital, garantizando a la Universidad Austral el derecho a la primera publicación. Asimismo, manifestarán que no han sido cedidos los derechos de autor a cualquier otra institución o persona física y/o jurídica. La licencia de uso se ejercerá conforme a los siguientes términos y condiciones:

USOS PERMITIDOS. El AUTOR, por el solo hecho de enviar su ARTÍCULO, RECENSIÓN, ANÁLISIS, CRÓNICAS O COMENTARIOS para su publicación en la RJA, cede a la UNIVERSIDAD AUS. TRAL los derechos de autor en forma no exclusiva, confiriendo una licencia gratuita para ejercer por medios impresos y/o digitales los derechos de reproducción, distribución, publicación, comunicación pública, puesta a disposición, transmisión y/o depósito de aquellos en el Repositorio Institucional o en otros sitios de confianza que permitan su preservación digital. La UNIVERSIDAD AUSTRAL, por medio del Consejo Editorial, queda también autorizada para realizar las modificaciones formales y técnicas necesarias para el ejercicio de las facultades aquí conferidas, como así también para asignarle a los artículos el destino que les corresponda en la sección que considere adecuada, pudiendo explotar comercialmente las obras enviadas 
mediante la venta de los ejemplares de forma individual y/o como parte de una compilación. Cada una de estas formas de explotación podrá ser llevada a cabo por la licenciataria mediante cualquiera de las modalidades de explotación conocidas, incluyendo el uso de medios impresos y/o digitales.

DERECHOS MORALES. La presente licencia no transfiere derechos morales, los cuales permanecen en cabeza del AUTOR de conformidad con las normas de derecho de autor.

BUENAS PRÁCTICAS EDITORIALES. El AUTOR declara y reconoce bajo juramento, el cual se entiende prestado por el solo hecho de darse de alta con la creación de su usuario y contraseña que permite ingresar al sistema OJS de la RJA, ser autor del ARTÍCULO, RECENSIÓN, ANÁLISIS, CRÓNICAS O COMENTARIOS enviados y titular de los derechos de autor que aquí se licencian; que sobre estos derechos no se han contraído compromisos ni gravámenes de ninguna especie a favor de terceros que resulten incompatibles con la cesión o que puedan atentar contra los derechos de la UNIVERSIDAD AUSTRAL; que la obra es original, inédita y fue creada sin infringir derechos de terceros; que las imágenes, citas y/o transcripciones que incorpora se encuentran debidamente referenciadas y fueron autorizadas por su titular o están amparados por una excepción o limitación al derecho de autor; y que no contiene declaraciones difamatorias contra terceros ni contrarias al ordenamiento jurídico. Asimismo, declara, tal como resulta del primer párrafo de este título, que los manuscritos enviados para su publicación en la RJA no han sido difundidos previamente por ningún medio gráfico o digital, como así también que no han sido cedidos los derechos de autor a cualquier otra institución o persona física y/o jurídica. El autor, en caso de autorizar la publicación de su obra a otras editoriales o medios de divulgación científica o académica posterior a la primera publicación garantizada, se compromete a exigir que se haga constar que ha sido previamente publicada por la RJA, aclarándose expresamente y por escrito el título, año de publicación, número de volumen, paginación, DOI y demás datos que permitan su identificación.

EXTRATERRITORIALIDAD Y DURACIÓN. La presente licencia se rige por la legislación de la República Argentina y es válida en todo el territorio nacional y en todos los demás países, por el tiempo máximo de protección que la legislación en materia de derechos de autor le confiera a la obra.

Esta revista y sus artículos se publican bajo la licencia Creative Commons Atribución-NoComercial-SinDerivadas 4.0 Internacional (CC BY-NC-ND 4.0), la cual permite al usuario descargar, compartir, copiar y redistribuir el material en cualquier medio o formato, siempre y cuando dé crédito de manera adecuada, brinde un enlace a la licencia e indique si se han realizado cambios. No autoriza el uso del contenido con propósitos comerciales y/o que se pueda remezclar o transformar el material, sin permisos para distribuir el material si fuera modificado.

\section{Directrices para autores}

Los trabajos deberán ajustarse a las directrices que a continuación se detallan sin excepción. Aquellos que no se ajusten a las recomendaciones editoriales serán devueltos para su adecuación antes de ser considerados por el Consejo Editorial para su revisión.

Los originales deberán estar concluidos cuando se entreguen para publicar; no se podrán introducir modificaciones que no estén debidamente justificadas y autorizadas por el Consejo Editorial. Se recomienda a los autores la lectura y revisión crítica del texto, en particular su redacción, sintaxis y ortografía en nombres, siglas y datos bibliográficos.

\section{Instrucciones generales}

Se aceptan trabajos en versión electrónica en formato Microsoft Word (no se aceptarán archivos en formato PDF).

Los artículos deben ser originales e inéditos y escritos en español. Deberán enviarse sin consignar el nombre o la firma del autor o autores, anonimizando el manuscrito de modo tal que se preserve su identidad en todo el proceso de revisión. 
Asimismo, deberán adjuntarse los datos personales del autor o autores, pertenencia institucional, un breve currículum que no exceda las diez líneas, dirección de correo electrónico y perfil ORCID.

Los trabajos se recibirán por medio del sistema Open Journal System, al cual se accede a través de este portal. El envío debe contener todos los requisitos que solicita el sistema.

Para asegurar la integridad de las evaluaciones anónimas por pares de los envíos, se hará todo lo posible para impedir que los autores conozcan la identidad de los revisores y viceversa. Para ello, se deben comprobar que se han seguido los siguientes pasos relacionados con el texto y con las propiedades del archivo:

* Los autores del documento han borrado sus nombres del texto y han evitado autorreferenciarse.

* En el caso de los documentos de Microsoft Office, también deberá quitarse la identificación del autor de las propiedades del archivo haciendo clic en las opciones que se indican a continuación. Empezar con Archivo en el menú principal de la aplicación de Microsoft: Archivo > Guardar como > Herramientas (u Opciones en Mac) > Seguridad > Eliminar información personal de las propiedades del archivo al guardar > Guardar.

\section{Artículos}

Se publicarán artículos de investigación originales e inéditos, de todas las ramas del derecho, nacional y comparado, los cuales deben ofrecer aportes significativos al desarrollo de las distintas disciplinas jurídicas, proporcionando criterios de análisis e interpretación del derecho que resulten válidos y útiles para los lectores.

Deberán incluir un resumen de entre 200 y 300 palabras y de 4 a 8 palabras clave, todo tanto en español como en inglés.

Extensión: de 20 a 40 páginas, es decir, entre 9000 y 18000 palabras (tomando como referencia 450 palabras por página, aproximadamente).

A modo de orientación, se sugiere que los artículos sigan la siguiente estructura:

- Introducción

- Desarrollo

- Conclusiones

- Bibliografía

- Legislación y jurisprudencia citadas

- Anexos y/o apéndices

Análisis, crónicas y comentarios

Se publicarán análisis, crónicas y comentarios vinculados con la temática y alcance de la RJA y que el Consejo Editorial considere relevantes debido a que ofrecen aportes significativos o novedades para el ámbito de la investigación y divulgación jurídica. Asimismo, se incluirán reseñas de actividades académicas relacionadas con el campo del derecho que resulten de importancia para su difusión. Se aceptarán trabajos en cualquier idioma. En caso de que incluyan citas y referencias, deberán seguir las normas que se detallan más adelante. Asimismo, deberán incluir un resumen en español de entre 100 y 200 palabras y de 4 a 8 palabras clave.

Deberán incluir un resumen en español de entre 100 y 200 palabras y de 4 a 8 palabras clave.

Extensión: hasta 15 páginas (6700 caracteres en total aproximadamente).

\section{Recensiones}

Se publicarán recensiones de obras bibliográficas publicadas recientemente vinculadas con el campo del derecho. En ellas deberán consignarse los datos bibliográficos del libro que se revise: autor/es, año de publicación, título del libro, ciudad de publicación, editorial y número de páginas total del libro. En caso de que se reseñe un capítulo concreto dentro de un libro, es preciso añadir el título del capítulo y las páginas de inicio y fin de este. 
Extensión: hasta 4 páginas (1800 caracteres en total aproximadamente).

\section{Estilo}

Los trabajos enviados deberán seguir el estilo de la RJA, que a continuación se detalla:

* Formato

Tamaño A4 con márgenes de $2,5 \mathrm{~cm}$ en cada extremo.

*Tipografía

Título: Times New Roman, negrita, cuerpo 14 puntos, interlineado 1,5.

Texto: Times New Roman, cuerpo 12 puntos, interlineado 1,5.

Citas textuales de más de 40 palabras: Times New Roman, cuerpo 10 puntos, interlineado a 1,5.

Notas al pie: Times New Roman, cuerpo 10 puntos, interlineado a 1,5.

Subtítulos (en todas sus jerarquías): Times New Roman, negrita, cuerpo 12 puntos, interlineado a 1,5.

Estilo de numeración: correlativa en números arábigos (no utilizar números romanos).

*Alineación

Todo el texto y los títulos deben estar alineados a la izquierda, sin utilizar sangrías ni tabulaciones.

No dejar espacios entre párrafos.

Las citas textuales de más de 40 palabras deben colocarse en párrafo aparte con una sangría de 1,5 para todo el párrafo.

* Se deben respetar los signos diacríticos propios de cada idioma (diéresis, acentos ortográficos, etc.), incluso en las mayúsculas. Las frases no deben comenzarse con abreviaciones ni gerundios.

* Todas las imágenes (fotos, tablas, ilustraciones, gráficos, etc.) deben citarse en el texto, por ejemplo: (Gráfico 1) (Tabla 4).

${ }^{*}$ Los fragmentos, frases o palabras que se transcriban en idioma extranjero deben ponerse en letra cursiva. Se exceptúan los nombres geográficos, los nombres de entidades, organismos, instituciones, corporaciones, etc.; los nombres de acuerdos, pactos o tratados, etcétera.

* Las llamadas de las notas al pie se indican en números arábigos consecutivos en superíndice y, cuando corresponda, luego de los signos de puntuación, por ejemplo: ${ }^{3}$

* En el cuerpo del trabajo no deben emplearse ni subrayados ni negritas. En caso de que sea necesario enfatizar una palabra, se hará entre comillas dobles.

* Abreviaciones

Se deja un espacio después de todo signo de puntuación: A. L. Jiménez y no A.L. Jiménez.

Los acrónimos deben escribirse totalmente con mayúsculas y sin puntuación, por ejemplo: UBA (por Universidad de Buenos Aires).

* Tablas, cuadros y gráficos

Pueden ser realizados con Excel o Power Point, según sea necesario, y ser pegados en el archivo Word como imagen. Además, deberá enviarse el archivo original donde se realizaron para poder corregirlos, si fuera necesario.

* Ilustraciones, mapas, fotografías, dibujos

Deberán ser pegados en el archivo Word y además enviados por separado en alguno de los siguientes formatos: JPG, TIF, PNG, AI, PS en alta resolución.

\section{Citas y bibliografía}

Para las citas y las referencias bibliográficas, la RJA sigue el estilo de las normas APA (American Psychological Association) 7a edición. Se recomienda seguir los siguientes ejemplos:

Citas

Las referencias a autores deben estar insertas en el texto y no en nota al pie: (Bianchi, 2005). 
Si la cita tiene dos autores, se colocan los dos apellidos: (Marcus y Perry, 1985).

Si la cita tiene tres o más autores, se coloca el primer apellido y “et al.”: (Álvarez et al., 2015).

Si la cita es textual y tiene menos de 40 palabras, se coloca entre comillas sin cursiva. Se sugiere seguir alguno de estos dos ejemplos:

Las opiniones consultivas cumplen, pues, una función trascendente en el desarrollo de los principios de derecho internacional de los derechos humanos, ya que, como señala Buergenthal (1985, p. 18), "parecen prestarse más fácilmente que los casos contenciosos a la articulación de principios legales generales”.

Las opiniones consultivas cumplen, pues, una función trascendente en el desarrollo de los principios de derecho internacional de los derechos humanos, ya que, como señala Buergenthal (1985), "parecen prestarse más fácilmente que los casos contenciosos a la articulación de principios legales generales” (p. 18).

Si tiene 40 palabras o más, se coloca en párrafo aparte con una sangría de 1,5, sin comillas ni cursiva:

Luego de arrogarse la atribución de no aplicar las leyes anticonstitucionales, la Corte Suprema la ejercitó con tanta moderación que transcurrió más de medio siglo sin que otra ley del Congreso fuera rechazada por el tribunal. Ello aconteció en 1857, en otro caso famoso, el de Dred Scott v. Sanford. (Bidegain, 1994, p. 127)

Si una cita textual extraída de un trabajo publicado en formato digital no tiene identificado el número de página, se debe identificar el número de párrafo:

Nótese que un gobierno podría -en una ley procesal, que puede sancionar por mayoría simple-agrupar todos los jueces que le molestan y asignarlos a una sala a la que le atribuya competencia marginal, y dejar jueces más favorables en una sala temática a la que le asigne centralidad y mayor chance de intervención. (Arballo, 2014, párr. 9)

Las citas textuales en idioma extranjero se ponen entre comillas y sin cursiva.

Se recomienda a los autores evitar la autorreferencialidad, es decir, citarse a sí mismo en el cuerpo del texto.

\section{Bibliografía}

Se ordena en orden alfabético de autores y en orden cronológico cuando se citen varios trabajos del mismo autor. Si hubiera trabajos del mismo autor con la misma fecha, se identificarán agregando una letra minúscula, por ejemplo: 2006a, 2006b.

Se recomienda seguir el siguiente estilo:

* Libro impreso

Apellido, N. (año). Título del trabajo. Editorial.

* Libro en línea

Apellido, N. y Apellido, N. (año). Título del libro. Editorial. https://doi.org.

Apellido, N. y Apellido, N. (año). Título del libro. Editorial. https://www.url.com.

* Libro con editor, coordinador, director

Apellido, N. (Ed.) (año). Título del libro. Editorial.

Apellido, N. y Apellido, N. (Coords.) (año). Título del libro. Editorial.

* Capítulo de libro

Apellido, N. (año). Título del capítulo o entrada. En Apellido, N. (Ed.), Título del libro (pp. inicio-fin del capítulo). Editorial. 
Apellido, N. (año). Título del capítulo o entrada. En Apellido, N. (Ed.), Título del libro (xx ed., Vol. xx, pp. inicio-fin del capítulo). Editorial.

* Artículo en revista

Apellido, N. (año). Título del artículo. Nombre de la revista, volumen(número), número de las páginas xx-xx.

Apellido, N. (año). Título del artículo. Nombre de la revista, volumen(número), número de las páginas xx-xx. https://doi.org.

Apellido, N. (año). Título del artículo. Nombre de la revista, volumen(número), número de las páginas xx-xx. https://www.url.com.

* Trabajos sin identificación del autor

Título del trabajo. (año). Fuente.

* Artículo en periódico

Apellido, N. (día, mes, año). Título del artículo. Nombre del periódico, número de página.

Apellido, N. (día, mes, año). Título del artículo. Nombre del periódico. https://www.url.com.

* Artículo en periódico sin identificación del autor

Título del artículo. (día, mes, año). Nombre del periódico, número de página.

Título del artículo. (día, mes, año). Nombre del periódico. https://www.url.com.

${ }^{*}$ Diccionarios o enciclopedias

Apellido Autor o Editor, N. (Ed., cuando es editor). (Año). Nombre del diccionario o enciclopedia (xx ed., Vol. xx). Ciudad: Editorial.

* Tesis y doctorados

Apellido, N. (año). Título de la tesis (Tesis de pregrado, maestría o doctoral). Nombre de la institución, Ciudad.

Apellido, N. (año). Título de la tesis (Tesis de pregrado, maestría o doctoral). Nombre de la institución, Ciudad. https://www.url.com.

* Referencia a páginas webs

Apellido, N. (s.f.). Nombre de la página. https://www.url.com.

Apellido, N. (s.f.). Título del artículo. Nombre de la página. https://www.url.com.

Nombre de la página o institución. (s.f.). Título del artículo. https://www.url.com.

* Ponencias y conferencias

Apellido, N. (año). Título de la ponencia o conferencia. Nombre de las jornadas o simposio donde se presentó. Ciudad, País, fecha.

* Informes de instituciones

Nombre completo de la institución. (año). Título del informe. Editorial.

Nombre completo de la institución. (año). Título del informe. https://www.url.com.

\section{Citas de legislación y jurisprudencia}

Las referencias a la legislación y jurisprudencia citadas se colocarán en nota al pie (cuando sean citadas en el texto) o luego de la bibliografía, de acuerdo a la siguiente clasificación:

Legislación

* Normas internacionales (pactos, convenios, declaraciones)

* Normativa comunitaria

* Leyes ratificatorias de tratados internacionales

* Constituciones

* Códigos

* Leyes

${ }^{*}$ Decretos 
* Resoluciones

* Disposiciones

Estilo a seguir:

Constitución de la Nación Argentina.

Constitución de la Nación Argentina, artículo 75, inciso 2 (o 75.2.).

Leyes

Ley 11723.

Ley 11723 de Propiedad Intelectual, BO 30/09/1933.

Ley 11723 de Propiedad Intelectual, BO 30/09/1933, artículo 5.

Decretos

Decreto 245/2002.

Decreto 245/2002, BO 28/11/2002, artículo 5.

Resoluciones

Resolución 2030/2015.

Resolución 2030/2015, BO 12/06/2015, artículo 1.

Disposiciones

Disposición 306/2015.

Disposición 306/2015, BO 28/05/2015.

Jurisprudencia

* Corte Suprema (nacional, federal, provincial, internacional)

* Tribunales internacionales

* Tribunales del sistema interamericano

Estilo a seguir:

Corte Suprema de Justicia de la Nación, Fernández Arias c/Poggio, 19/09/1960, Fallos 247:646.

Suprema Corte de Justicia de Buenos Aires, Vasena Marengo, José Francisco y otra c/Rodríguez, Jorge Mario y otra, 28/09/2004.

Cámara Federal de Casación Penal: Di Plácido, Jorge Alberto, 22/05/2014, [FBB/7963/2013/CFC1, Registro 864/14].

Suprema Corte de los Estados Unidos, Wood v. Milyard, 566 U.S. 463 (2012).

Suprema Corte de Carolina del Norte, Bayard v. Singleton, 1 N.C. 5 (1787).

Sentencia del Tribunal Constitucional, 83/2016, 28 de abril. [España].

Corte Interamericana de Derechos Humanos, Caso Almonacid Arellano y otros vs. Chile, Excepciones

Preliminares, Fondo, Reparaciones y Costas, 26/09/2006, Serie C, N 154.

Fallos: 329:2316. 


9

Aứ:TTRARAL

DERECHO 